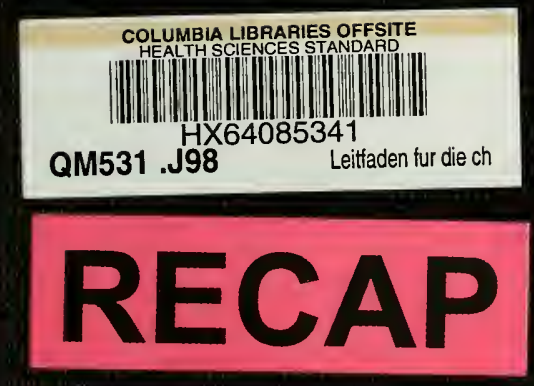




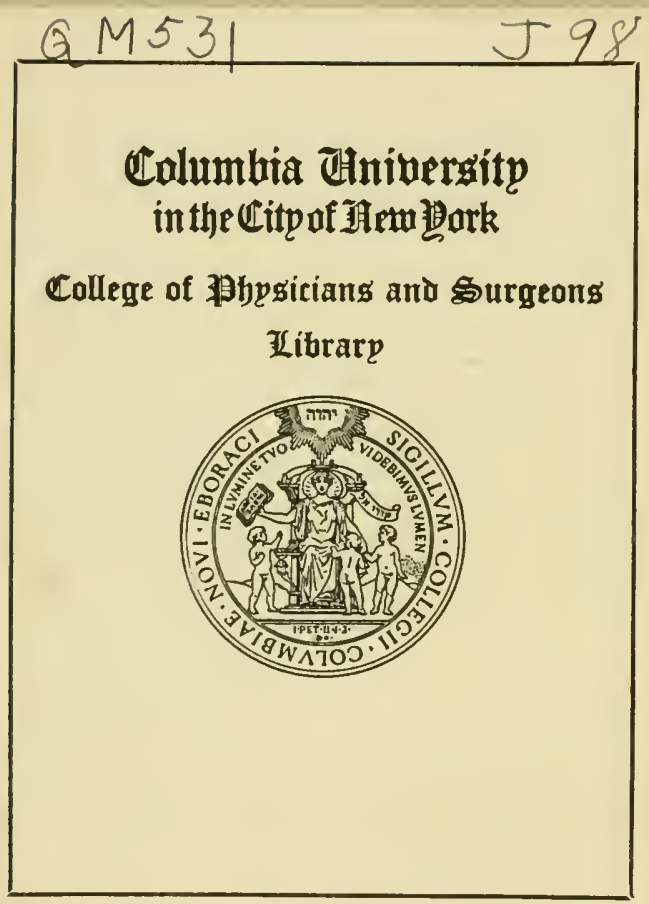





Digitized by the Internet Archive in 2010 with funding from

Open Knowledge Commons (for the Medical Heritage Library project) 


\title{
Leitfaden
}

lür die

\section{chirurgische Anatomie}

\author{
ron
}

\section{Dr. E. Juvara}

Subdirector und Assistent am Institut für practische Anatomie und für Chirurgie und erster Assistent der ehirurgischen Abtheilungen im Coltza-Spitale zu Bukarest.

Mit 183 Abbildungen im Text.

Berlin 1899.

Verlag von August Hirschwald.

NW. Unter den Linden 68. 
Alle liechle rorbelialtem.

$$
\begin{aligned}
& \text { QM5 } 31 \\
& \text { J98 }
\end{aligned}
$$




\section{Vorwort.}

An der medieinischen Fakultät in Paris sieht das Programm für den praktisehen Theil aus der Anatomie ror, dass der Candidat eine "Aufsuchung." vornehme, d. h. extempore irgend ein Gebilde: Muskel, Sehne, Arterie, Terv etc. freilegen soll. Durch diese Operation zeigt der Candidat gewissermaassen der Jury die Summe seiner anatomischen Kenntnisse und auch die Gründlichkeit derselben; denn, um ein Gebilde freizulegen, muss die Schnittführung und Aufsuchung am richtigen Orte geschehen und dann muss das Gebilde ohne Zögern herausgehoben und gezeigt werden.

In den letzten Jahren hielt Professor Poirier im Amphitheater der Schule für praktische Medicin vor einem mehrere hundert Hörer umfassenden Auditorium eine Reihe ron Torlesungen aus der praktischen Anatomie. In diesen klassischen Vorlesungen, die täglich während zweier Stunden gehalten wurden, machte er einen Auszug aus der praktischen Anatomie mit besonderer Berücksichtigung desjenigen Theiles, aus welchem der Candidat beim Examen gefragt werden und dessen er sich in seiner praktischen Carriere öfter bedienen wird. Das Studium jeder Region war mit der Freilegung der wichtigen Gebilde, die in dieser enthalten waren, rerbunden; denn der Professor suchte durch eine genaue Beschreibung und präcise Technik, so gleichzeitig auf Gehör und Gesicht wirkend, dem Gedächtnisse der Hörer die Beziehungen der Gebilde so tief als mögtich einzuprägen. -

Mehrere Jahre nacheinander wohnte ich regelmässig diesen Vorlesungen bei, den gleichen in jedem Jahre, und jedesmal lernte ich vieles rom rerehrten Meister und wiederholte ungezählte Nale mit ihm rerschiedene Freilegungen der Gebilde.

Völlig' überzeugt von der Wichtigkeit der „Freilegungen"., welche nicht nur bestimmt sind die Anatomie dem Gedächtnisse einzuprägen, sondern anch viel zur chirurgisehen Ausbildung beizutragen, indem sie Gelegenheit 
Eeben, so oft als moglich die rersehiedensten Operationen zu wichlerholen, habe jelı mich antschlossen, diese Tortesumgen aus der Anatomie zu schreiben mach den Mluster derjenigen, die ich semeinsan mit meinem Collegen Fritean in framzösischer spratehe verölfentlicht habe, bloss bestrebt etwas ansführlicher zu sein, indem ich die kapitel der Anatomic weitläufiger hehandelte und die Zahl der Operationen rargrösserte.

Ohe Anspruch eines Lehrbuches der Inatomic wendet sich dieses sehr unvollständige Handbuch nicht an Infänger, sondern an Solche, welche

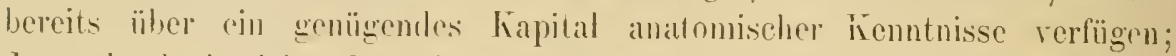
dennech alaube ich, dass die Sudirenden einige Alschnitte der Nuatomie finden werden, in denen sir ihre bereits erworbenen Kemntnisse genauer präicisiren oder sogar vervollständigen kömuen.

Mit Rïeksicht aul' dic Studirenden, die die ehirurgische Technik einüben, habe ich versucht, grïsseren Raum der Buschreibung derjenigen Arterien zu geben, an welehen die l'nterhindungen gewöhn!lich ansgefïhrt werden.

Im ein Gobilde aufzulinten wicht P'rolessor Poiricr fortwährend scinen Hörern folgende Rathschläge, welche ich, ta ich sie hunderte Male gehört und mich ihrer bedient habe, anch hier anführen will.

Wemn man rerlangt, dass \%. B. die Arteria brachialis freigelegt werde, so sammolt man in cincm Augenblicke, noch bevor man die Instrumente crlasst, die anatomischen Kienntnisss, wetche man üher dieses Gebilde besitzt und rergegenwärtige sich, wo es gelagert ist, wo es anfüngt, wo es aufhört, womit es in Bezichung steht u. s. w., - denn oft habe ich Gelegenheit gehabt zu bcobachten, lass Hörer: olnne viel zu überlegen, ein anderes als das rerlangte Gebilde aufsuchten und zeigten, - man tastet darauf die rordere und imnere Fläche des Oberarms ab dort, wo eben die Arterie sich befindet und rersueht dureh eine aufmerksame Palpation, wenn es möglich ist das gesuchte Gebilde oder seinen Ort längs des Suleus brachialis, derjenigen Furche, in welcher die Arterie liegt, anfunfinden.

Durch dic anfmerksamste Untersuchung wird man nicht die Arteria brachialis fühlen kömen, wohl aber den Nervus medianus; den Begleiter der Arteric. Wem man num don Nerr fühlt, hat man anch schon die Arterie gefunden, denn die Arterie liegt neben dem Nerr. Dann erst nimmt man das Bistouri zur Hand und schneidet cin. Mlan macht genügend lange Incisionen, geht systematiseh ror, marht das Operationsfeld deutlich dureh Einlegung ron stumpten Haken unter genauer Controlke der Augen, wohl die Gicbilde beachtend, die jenen anvertraut sind, wenn man vermeiden will, lass durch etwaige Unachtsamkeit oder sogar Boshaftigkeit des Assistenten gerade dasjenige Gebilde, welches man sucht, abgezogen und verborgen sei untre einem der stumpfen Haken. Man untersucht den Boden des Schnittes 
und führt die Finger nur dann ein, wenn absolute Nohbwendigkeit rorhanden ist, denn obwohl der Finger das beste Instrument ist, vertratic man sich demselben nicht an, bevor man mit dem Auge Controlle gë̈bt hat. Nan hüte sich vor unregelmässiger Schnittührung und davor, Venen zu verletzen, denn das ausströmende Blut verunreinigt und überschwemmt sogar die Schnittwunde und rerbirgt das Gebilde, das man sucht. Ein wenig Aufmerksamkeit und dieser Unfall, der auf den Examinator einen unangenehmen Eindruck macht, wird rermieden.

Wenn es sich ereignet, dass man bei der Operation, obwohl diese gut ausgeführt ist, das gesuchte Gebilde nicht findet, damn zieht man die stumpfen Haken wieder heraus und untersucht ron nenem das Operationsfeld, denn es kann geschehen, dass unter einem von diesen das gesuchte Gebilde sich befindet. Wenn man es trotz aufmerksamer Controlle nicht finden kann, kann man wohl sagen, dass das Gebilde sich nicht an seiner normalen Stelle befindet und man es hier mit einer Anomalie zu thun habe. Denn, wenn man am richtigen Orte genau untersucht hat, so hat sich nur das fehlende Gebilde in der Stelle geirrt. Man sucht dann dort, wo es sich bei Positionsanomalien gewöhnlich findet und man wird es auch finden.

Um endlich zusammenzufassen, sammelt man, wenn man ein Gebilde auffinden will, zuerst die anatomischen Kenntnisse, palpirt dann, schneidet ein und sucht systematisch das rerlargte Gebilde. Ian bewabre die ganze Zeit die nöthige Ruhe, das ist die Bedingung mit der Zeit ein guter Chirurg zu werden.

Ich habe dieses Buch mit 183, theils schematischen, theils nach der Natur getreuen Abbildungen ausgestattet. (Einige beziehen sich auf die Anatomie, andere auf die Operationstechnik.)

Ich ergreife noch diese Gelegenheit, um den Herren Dr. Jo sef Schneyer und Dr. Bernhard Schwalb für die freundliche Unterstützmng bei der Uebersetzung dieser Arbeit meinen verbindlichsten Dank auszusprechen. 



\section{Inhalts-Verzeichniss.}

Region der Schulter.

\section{Ohere Extremität.}

Digitaluntersuchung . . . . . . . . . . . . . . . . 1

Interlinea acromio-clavicularis . . . . . . . . . . . . . 1

Processus coracoides und dessen Aufsuchung . . . . . . . . . 1

Ligamenta coraco-clavicularia . . . . . . . . . . . . . 3

Ligamentum trapezoidum . . . . . . . . . . . . . .

Ligamentum conoideum . . . . . . . . . . . . . . . 3

Vena cephalica . . . . . . . . . . . . . . . . 4

Musculus subclavius . . . . . . . . . . . . . . . . 4

Arterie, Vene und Nervus subclavius . . . . . . . . . . . 5

Die Nuskeln am Processus coracoides . . . . . . . . . . . 5

Pectoralis minor . . . . . . . . . . . . . . . . . . 6

Ligamentum acromio-coracoideum . . . . . . . . . . . .

Articulatio scapulo-humeralis . . . . . . . . . . . . . 8

Das periarticuläre Mnskelbündel . . . . . . . . . . . . S

Sulcus bicipitalis und der lange Bicepskiopf . . . . . . . . . ?

Die Sehne des langen Bicepskopfes. . . . . . . . . . . . 10

Region der Achselhöhle.

Gestaltung . . . . . . . . . . . . . . 10

Inhalt der Achselhöhle.

Arteria axillaris . . . . . . . . . . . . . . . . . 12

Die Stränge des Plexus brachialis . . . . . . . . . . . . 13

Vena axillaris . . . . . . . . . . . . . . . . . 13

Musculus coraco-brachialis, Nervus musculo-cutanens . . . . . . 14

Ligamentum suspensorium der Achselhöhle . . . . . . . . . 14

Die Axillardrüsen . . . . . . . . . . . . . . . . 15

Nervus costo-brachialis . . . . . . . . . . . . . . . 15

Arteria und Nerrus circumflexus . . . . . . . . . . . . 15

Oberarm.

Hintere Fläche, Quadriceps hmmeri . . . . . . . . . . . . 16

Aenssere Fläche, Nervus radialis . . . . . . . . . . . . 17

Innere Fläche, Arteria lnumeralis, Nerrus medianus . . . . . . . 18

Nervus musculo-cutaneus und die Anastomose mit dem Medianus . . . 19

Vena basilica . . . . . . . . . . . . . . . . 20

Tervus brachii cutaneus internus . . . . . . . . . . . . . 20

Jerrus cubitalis . . . . . . . . . . . . . . . 21 
liegion des Fllbogens.

Vordere Fläche

Der innere Schenkel der T. bicipitalis

Vena medio-basilica.

Arteria humeralis

Tervus medianus.

Der äussere Schentiel der $\mathrm{V}$. bicipitalis . . . . . . . . . 2.)

Tena medio-cephalica

Nervus radialis

Die Sehne des Biceps

Die Aponemrose des Biceps . . . . . . . . . . . . . . 26

Vella mediana .

Die Supra-epitrochlealdrïsen

IIintere Fläche des Ellbogens

Epitrochlea

Epicondylus

Linea articularis

Capsula articularis

Jigamentum laterale internum

Tervus culitalis

Musenlus anconaens und sein Nerr.

liegion des Vorderarmes.

Vordere Fläche

Arteria radialis und der Hautast des Nerrus radialis . . . . . . . 33

Arteria radialis

Torderer Ast des Nerrus radialis

Die Mnskelmasse an der Epitrochlea

Pronator teres

Palmaris breris

Palmaris longus

Flexor superficialis

Mnsculus cubitalis internus . . . . . . . . . . . . . . 40

Arteria cubitalis und Nerrus cubitalis . . . . . . . . . . 41

Yerrus medianus.

Flexor profundus .

Supinator longus.

Pronator cuadratus

Radialis primus.

Radiali. secundus

Region der ll andwurzel.

Digritaluntersuchnng .

Leussere Fläche der Handwurzel.

Tabalisqrube

Abductor longus und Extensor pollicis brevis.

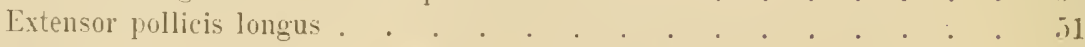

Tena cephalica des Daumens, Jerius und Arteria radialis . . . . . 52

selmen der Radialismuskeln 
Selinen des Extensor communis.

Sehne des Extensor digiti minimi proprius . . . . . . . . . 56

Dorsalast des Nerrus cubitalis . . . . . . . . . . . . . 57

Linea articularis radio-carpea und Ligamentum triangulare . . . . . 5 -

Region der Hand.

Palma manus . . . . . . . . . . . . . . . . . . 61

Hohlhand . . . . . . . . . . . . . . . . . . . . . . . .

Fascia palmaris superficialis . . . . . . . . . . . . . . 62

Areus palmaris superficialis . . . . . . . . . . . . . . . . . 63

Anastomose des Medianus mit dem Cubitalis . . . . . . . . . 64

Sehnen der Beuger . . . . . . . . . . . . . . . . . . . . . . . . . . . . . . . 65

Synovialscheiden der Palma manus . . . . . . . . . . . . . 66

Aeussere Synovialscheide . . . . . . . . . . . . . . 66

Innere Synorialscheide . . . . . . . . . . . . . . . 66

Nervus medianus . . . . . . . . . . . . . . . . . . . 67

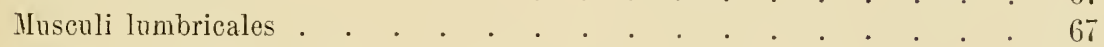

Erster Lumbricalis . . . . . . . . . . . . . . . 68

Zweiter Lumbricalis . . . . . . . . . . . . . . . 68

Dritter Lumbricalis . . . . . . . . . . . . . . . . . . . . . . . . . 68

Vierter Lumbricalis . . . . . . . . . . . . . . . . 68

Areus palmaris profundus oder radialis . . . . . . . . . . 68

Thenar . . . . . . . . . . . . . . . . . 69

Erste Schichte . . . . . . . . . . . . . . . . 69

Zweite Schichte . . . . . . . . . . . . . . . . . . . . . . 69

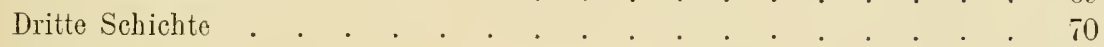

Antithenar . . . . . . . . . . . . . . . . 72

Oberflächliche Schichte . . . . . . . . . . . . . 72

Zweite Schichte . . . . . . . . . . . . . . . . . . . . . . 72

Dritte Schichte . . . . . . . . . . . . . . . 73

Musculi interossei . . . . . . . . . . . . . . . . . . . . . . . . . . . . . . . . . . . . . .

Interossei dorsales . . . . . . . . . . . . . . . . . . . . . . . . . . . . . . . . . .

Interossei palmares . . . . . . . . . . . . . . . . . . . . . 74

Die Finger.

Gestaltung . . . . . . . . . . . . . . . . 74

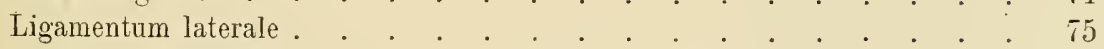

Sehnen der Beuger . . . . . . . . . . . . . . . . . . . . . . . . . . . . . . . . . . . .

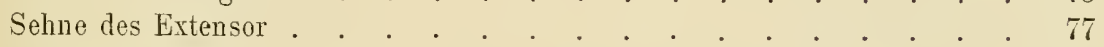

Nervi collaterales . . . . . . . . . . . . . . . . . . . . . 78

Collaterales dorsales . . . . . . . . . . . . . . 78

Region der Inguinalbeuge.

Untere Extremität.

Gestaltung

Spina iliaca anterior superior

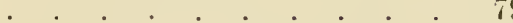

. . . . . . . . . 79

Ponpart'sches Band . . . . . . . . . . . . . . 80

Ligamentum ileo-pectineum . . . . . . . . . . . . . . 81

Region der Hüfte.

Oberes Ende des Femur . . . . . . . . . . . . . . 82 
Trorlianter major .

Trochanter minor

Digitaluntersuchung

Irticulatio roxo-femuralis

Digitaluntersuchumg des Gelenlies

Revion ler Glutacen .

Aufeinanderfolge der Schichteu.

Glutaeus maximus

Nichtmuslulïse fibröse Partie

'Tensor fasciae

Glutaens medius.

Musenus prriformis

Arteria glutara.

Glutacus minimus

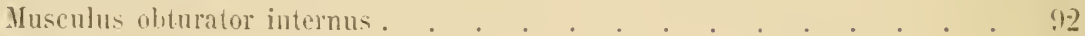

Musculun uemellus superior . . . . . . . . . . . . . . . . 92

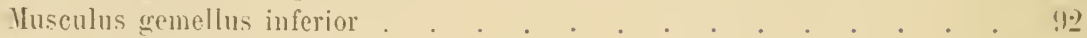

Jerros ischiadicus major . . . . . . . . . . 9.2

Nerrus ischiadirus minor . . . . . . . . $! 9$

Arteria ischiarlica . . . . . . . . . . . . . . . . . . . . .

l'acliet des Verven. ler Arteria und Vena pudenda interna . . . . . 9:3

Foramen ischiadicum majus. . . . . . . . . . . . . . . 9:3

Foramen ischiadicum minus . . . . . . . . . . . . . . 93

Ligamentum sacro-ischiadicum majus . . . . . . . . . . . . 95

Ligamentum sacro-jschiarlicum mims . . . . . . . . . . . 95

Region des Obersehenkels.

Tordere liäche

Das Scarpa'srhe Dreieck . . . . . . . . . . . . . . 996

Die Aufeinanderfolge der Schichten . . . . . . . . . . . 9 . . . . . .

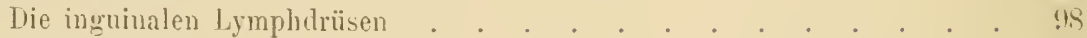

Die cruralen lymphdrïsen . . . . . . . . . . . . . . 95

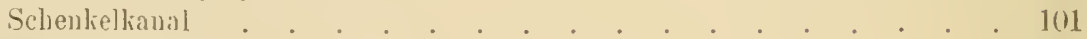

Nervus cruralis. . . . . . . . . . . . . . . . . . . . . . . . . . . . . . .

Mnsculus ilio-psoas . . . . . . . . . . . . . . . . 101

Musculus pectinens . . . . . . . . . . . . . . . 102

Arteria femoralis . . . . . . . . . . . . . . 103

Yena femoralis . . . . . . . . . . . . . 104

Jerrus saphemus. . . . . . . . . . . . . . . . 10.)

Terrus accessurius saphenus internus . . . . . . . . . . . 10;

Tervus crumalis . . . . . . . . . . . . . . . 108

Vena saphena interna . . . . . . . . . . . . . . . 109

Verrus femoro-glutaeus . . . . . . . . . . . . 111

Insculus quadriceps femoris . . . . . . . . . . . . . 111

Musrulus rectus anterior . . . . . . . . . . . . . . . . 111

Vastus extemus. . . . . . . . . . . . . . 112

Tastus internus . . . . . . . . . . . . . . 112

Musculus cruralis . . . . . . . . . . . . . . 112

Adductoren . . . . . . . . . . . . . . . . . . . . . . . . . . .

Adductor medins . . . . . . . . . . . . . . . 113 
Adductor brevis

Adductor magnus

Musculus rectus internns . . . . . . . . . . . . 115

Canalis sub-pubiens . . . . . . . . . . . . . . 116

Hintere Fläche des Oberschenkels . . . . . . . . . . . 116

Inskelmasse des Sitzbeins . . . . . . . . . . . . . 117

Insculus biceps cruralis . . . . . . . . . . . . 118

Semitendinosus . . . . . . . . . . . . . . . . 118

Semimembranosus . . . . . . . . . . . . . . 118

Region des Knies.

Digitaluntersuchung . . . . . . . . . . . . . . . . 120

Bursa serosa prae-patellaris . . . . . . . . . . . . . 121

Ligamentum patellare . . . . . . . . . . . . . . 129

Das liniegelenk . . . . . . . . . . . . . . . . 123

Aripae patellares . . . . . . . . . . . . . . . . . 124

Ligamenta cruciata . . . . . . . . . . . . . . . . . . . . . . . . . . . . . . .

Tena saphena und Nerrns saphenus internus . . . . . . . . . 127

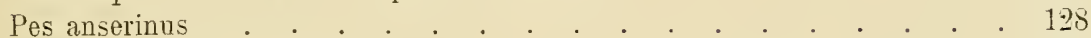

Sehne des Rectus internus . . . . . . . . . . . . . 128

Sehne des Semitendinosus . . . . . . . . . . . . . 129

Der subpatellare Nervenfaden . . . . . . . . . . . . . 129

Ligamentum laterale internum . . . . . . . . . . . . . 129

Sehne des Biceps . . . . . . . . . . . . . . 131

Ligamentnm Maessias . . . . . . . . . . . . . . . 131

Ligamentum laterale externum . . . . . . . . . . . . . 131

Kniekehle.

Digitaluntersuchung . . . . . . . . . . . . . . 132

Gestaltung . . . . . . . . . . . . . . 132

Inhalt der línieliehle.

Der grosse Tervus ischiadicus . . . . . . . . . . . . . 136

Terrus popliteus internus . . . . . . . . . . . . . . 136

Nervus ischiadicus popliteus externus . . . . . . . . . . 137

Arteria poplitea . . . . . . . . . . . . . . 138

Vena poplitea . . . . . . . . . . . . . . . . . . . . . . . . . . . . . . 14

Tena saphena externa . . . . . . . . . . . . . 112

Tervus saphenus-externus . . . . . . . . . . . . . 142

Region des Unterschenkels.

Gestaltung . . . . . . . . . . 143

Torderer Rann . . . . . . . . . . . . . . . . 143

Digitaluntersuchung . . . . . . . . . . . . . . . . 144

Tibialis anticns . . . . . . . . . . . 145

Extensor communis . . . . . . . . . . . . . 146

Extensor proprius hallucis . . . . . . . . . . . . 116

Peronens anterior . . . . . . . . . . . . . 147

Packet der Gefässe und des Nerrus tibialis anticus . . . . . . . 14i

Arteria tibialis antica . . . . . . . . . . . . 140

Tervus tibialis anticus . . . . . . . . . . . . 118

deusserer Raum . . , , , . , . . . . , , 150 
Permenes longus lateralis

peroneus brevis

Nerrus musculo-cutaneus

IIntere Fläche des Unterschenliels.

Digitaluntersuchung .

Die hintern lluskeln des Ĺnterschenliels . . . . . . . . . . 15i:

limg des soleus

Bursa serosa supra-calcanea

Dic tiefliegende Fläiche

Flexor proprius lallucis

Flexor communis .

Tibialis posticus . . . . . . . . . . . . . . . 15!

Arteria tibialis postica . . . . . . . . . . . . . . . 160

Arteria peronca . . . . . . . . . . . . . . 161

Nerrus tibialis posticus . . . . . . . . . . . . . . . L6il

Fus usurzol.

Digitaluntersuchung .

liegio anterior.

Nerrus musculo-cutaneus . . . . . . . . . . . . 16i3

Die Sehnen der Extensoren und des Tibialis anticus . . . . . . . 16ii.

Die Scheide des Extensor communis . . . . . . . . . . . 165

Die Scheide des Extensor proprius . . . . . . . . . . . . 166

Die Scheile des Tibialis anticus . . . . . . . . . . . . 166

liegio posterior.

Tena und Nerrus saphenus externus . . . . . . . . . . . 16i

Die Sehmen der Peronei laterales . . . . . . . . . . . . 16i

Die Sehne des Peroneus breris . . . . . . . . . . . 16i

Die Sehne des Peroneus longus . . . . . . . . . . . . 16is

Dic Srnovialscheide ler Sehne der l'eronei . . . . . . . . . 16s

Der äussere Bandapparat . . . . . . . . . . . . 11

kegio malleolaris interna.

Vena und Nervus saphenus internus . . . . . . . . . . . 172

Sulcus retro-mallcolaris interuus . . . . . . . . . . . . 172

Die Sehnen des Tibialis posticus und des llexor communis . . . . . 172

Die sehne des Flexor jroprius . . . . . . . . . . . . . 174

Die Gefässe und her Nerrus tibialis posticus . . . . . . . . . 174

Der innere Bandapparat . . . . . . . . . . . . . . 175

Der Fuss.

Dorsalfläche. Digitaluntersuchung . . . . . . . . . . . . 177

Musculus dorsalis pedis . . . . . . . . . . . . . . . . . . . . . . . . .

Arteria dorsalis pedis und Nerrus tibialis posticus . . . . . . . 178

Bursa serosa der Sehne des Extensor proprius . . . . . . . . 180

Ligamentum in Y. Chopart scher Schlïssel . . . . . . . . . 181

Canalis internssetis talo-calcaneus . . . . . . . . . . . . 183

Acusserer liand des Fusses. Digitaluntersuchunщ . . . . . . . . 183

Terrus saphenus externus . . . . . . . . . . . . . . 183

Innerer Rand des Fusses. Digitaluntersuchmng . . . . . . . . 184 
Die Fussolile.

Grestaltung

Fascia plantaris

Mittlerer Raum . . . . . . . . . . . . . . 185

Die Sehne des Flexor communis longus . . . . . . . . . . 186

Caro quadrata . . . . . . . . . . . . . . . 186

Musculi lumbricales . . . . . . . . . . . . . . . . . . . . . . . . . . . . . . 185

Adductor obliquus . . . . . . . . . . . . . . . . . . . . . . . . . . . . . . . . . . . . .

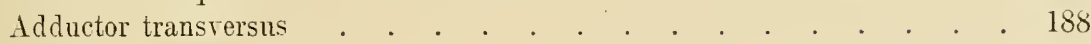

Musculi interossei . . . . . . . . . . . . . . . . 189

Ligamentum calcaneo-cuboideum . . . . . . . . . . . . 189

Innerer Muslielraum . . . . . . . . . . . . . . . 189

Abductor hallucis . . . . . . . . . . . . . . . . . . . . . . . . . . . . . . 189

Flexor breris . . . . . . . . . . . . . . . . . . 190

Packet der Gefässe und des Nervus plantaris internus . . . . . . 190

Aeusserer Muskelraum . . . . . . . . . . . . . . . 191

Abductor der Kleinzehe . . . . . . . . . . . . . . . 191

Flexor proprins breris der Kleinzehe . . . . . . . . . . . 191

Das Packet der Gefässe und des Nerrus plantaris externus . . . . . 192

\section{Der Kopf.}

Das Gesiclit. Regio supra-orbitalis.

Nerrus ophthalmicus . . . . . . . . . . . . 193

Nervus frontalis . . . . . . . . . . . . . . . 193

Der Muskel der Brane . . . . . . . . . . . . . . . 194

Sinus frontalis . . . . . . . . . . . . . . . 194

Canalis frontalis . . . . . . . . . . . . . . . . . . . . . . . . . . . . . . . . . .

Ligamentum palpebrale internum . . . . . . . . . . . . 194

Regio orbitalis.

Ligamentum palpebrale internum . . . . . . . . . . . . 195

Der Thränensack . . . . . . . . . . . . . . . . . 196

Horner'sche Muskel . . . . . . . . . . . . . . 196

Die Sehne und die Trochlea des Obliquns major . . . . . . . . 196

Die Thränendrüse . . . . . . . . . . . . . . . 197

Die Muskeln der Orbita . . . . . . . . . . . . . . . . . . . . . . . . . . . . . . . 197

Musculus levator palpebrae . . . . . . . . . . . . . . 197

Die M. recti. Rectus superior . . . . . . . . . . . . . 197

Rectus internus . . . . . . . . . . . . . . . . 198

Rectus externus . . . . . . . . . . . . . . . . . . . . . . . . . . . . . . . . . . . . 198

Rectus inferior . . . . . . . . . . . . . . . . . 198

Obliquus minor . . . . . . . . . . . . . . . . 198

Capsula bulbi tenoni . . . . . . . . . . . . . . . 199

Regio nasalis.

Nervus naso-lobularis . . . . . . . . . . . . . 199

Regio-infraorbitalis.

Musculus levator com. labii superioris alaeque nasi . . . . . . . 200

Musculus levator proprins labii superioris . . . . . . . . . . 200

Husculus caninus . . . . . . . . . . . . . 901 
Zygomaticus major

'Lygomaticus minor

Nervus infraorbitalis

Regio parotideo-masseteriea.

Ductus Stenonianus

Tervus und Arteria buccalis

Arteria und Vena facialis

Regio prae-auricularis.

Arteria temporalis superficialis

lena temporalis

Nervus auriculo-temporalis

liegio pterygo-maxillaris.

l'terygoidens externus oder superior

P'terygoideus internns

Ligamentum spheno-maxillare

Arteria maxillaris interna

Nerrus maxillaris inferior

lianglion oticum

Verrus maxillaris superior

Venae maxillares internae

Regio mentalis.

Musculus triangularis labiorum .

Jusculus quadratus menti

Musculus lerator menti

Nerrus dentalis inferior

Caritas buccalis.

Die Mundhöhle

Die Nun'sche Drüse

Flandulae sublinguale:

liegio parotidea.

Digitaluntersuchung.

Arteria carotis exterua

Nerrus facialis

Ligamentum stylo-maxillare

liegio mastoidea.

Musculus auricularis posterior

Crista supra-meatica .

Intrum petrosum

Glandula lymphatica praemastoirlea

liegio submastoideo-occipitalis.

Nerrus spinalis

Arteria occipitalis

Nerrus vecipitalis

Regio inframaxillaris.

Glandula submaxillaris

Arteria facialis 
Nervus lingualis

Nerrus mylo-hyoideus

Nervus hypoglossus

Arteria lingualis .

Nervus hypoglossus

Regio supra-hyoidea.

Glandulae lymphaticae supra-hyoideae . . . . . . . . . . 226

Der vordere Biventerkopf

226

Musculi genio-hyoidei

226

Tordere Fläche.

Der Hals.

Digitaluntersuchung . . . . . . . . . . . . . . . 22 -

Membrana hyo-thyreoidea . . . . . . . . . . . . . . 299

Arteria thyreoidea superior . . . . . . . . . . . . . . 229

Nervus laryngeus superior . . . . . . . . . . . . . . . . . . 229

Arteria laryugea superior . . . . . . . . . . . . . . . . 229

Musenli sublyoidei . . . . . . . . . . . . . . . . 230

Musculus und Membrana crico-thyreoidea. Nerrus laryngeus externus . . 231

Glandula thyreoidea . . . . . . . . . . . . . . . . 232

Nerrus laryngens inferior oder recurrens . . . . . . . . . . 293

Regio carotidea.

IInsculus sterno-mastoidens . . . . . . . . . . . . . . 234

Plexus cervicalis superficialis . . . . . . . . . . . . . 236

Vena jugularis externa . . . . . . . . . . . . . . . . . . . . . . . . . . . . . . .

Vena jugularis antero-lateralis . . . . . . . . . . . . . . 297

Gefäss- und Nervenpacket . . . . . . . . . . . . . . 238

Arteria carotis commnnis dextra und sinistra . . . . . . . . . 239

Vena jugularis interna . . . . . . . . . . . . . . . . 239

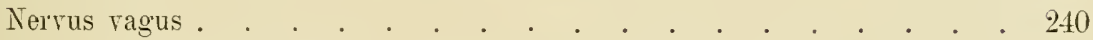

Nervus glosso-pharyngeus . . . . . . . . . . . . 240

Nerrus spinalis . . . . . . . . . . . . . . . . . 240

Hypoglossus . . . . . . . . . . . . . . . . . . 240

Nervus sympathicus cervicalis . . . . . . . . . . . . 243

Regio supra-clavicularis.

Gestaltung . . . . . . . . . . . . . . . 244

Scalenus anticus . . . . . . . . . . . . . . . . 244

Scalemus medius. . . . . . . . . . . . . . . 244

Scalenus posticus . . . . . . . . . . . . . . . . . 245

Angulus interscalenicus . . . . . . . . . . . . . . . . . 245

Plexus brachialis . . . . . . . . . . . . . . . 245

Arteria subclavia dextra . . . . . . . . . . . . . 248

Arteria subclavia sinistra . . . . . . . . . . . . . . 249

Tena subclavia . . . . . . . . . . . . . . . 249

Regio scaleno-vertebralis.

Gestaltung

Regio sterno-clavioularis.

Digitaluntersuchung . . . . . . . . . . . . . . 254 
sternaler Intheil der Selme. Sterno-cleido-mastoisleus

Fordere $\mathbb{W}$ and.

bere Thorix.

Arteria manmaria interua

Vorilese IV and.

\section{loas Abiloment.}

Der Nabelring

Linea alba

Rectus abdominis

Musculus byriformis abdominis

Regio canalis inguinalis.

Arteria epigastrica

Arteria iliaca externa

Foreae inguinales $26 i^{-}$

Forea inguinalis interna .

Forea inguinalis media

Forea ingualis externa

liegio hypogastriea.

Der Urachus

Die Harnblase

Regio serotalis

Caritas abdominalis.

Itie Gallenblase

Iliatus Winslowii .

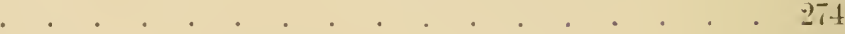

Regio pylorica. Pylorus . . . . . . . . . . . . . 27i

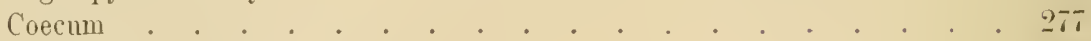

Duodenum. Recessus dnodenales . . . . . . . . . . . . 20̄o

Colon iliacum . . . . . . . . . . . . . . 280

Colon pelrinum . . . . . . . . . . . . . . . . 280

Die Nieren . . . . . . . . . . . . . . . . 281

Uterus . . . . . . . . . . . . . . . . . . . . 284

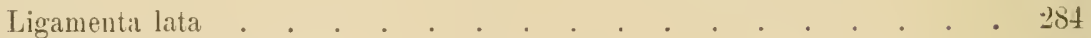

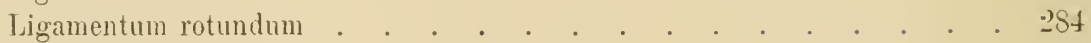

Arteria ovarica . . . . . . . . . . . . . . . . 285

Arteria uterina . . . . . . . . . . . . . . . . . . . . 286

Arteria iliaca communis . . . . . . . . . . . . . . 28s

Arteria hypogastrica . . . . . . . . . . . . . . . 289

Arteria ischiatical. . . . . . . . . . . . . . 29) 


\section{Obere Extremität.}

\section{Schultergegend.}

Digitaluntersuchung. Untersucht man die Schultergegend, so fühlt man an der oberen und vorderen Seite das Schlüsselbein. Sein äusseres verdicktes Ende ist oberhalb der Acromialebene gelegen. Der äussere Rand des Acromion ist leicht zu begrenzen; vorne begrenzt er sich durch die Acromialspitze, hinten durch das Tuberculum acromiale. Drückt man unter dem Acromialwinkel die Weichtheile nieder, so fühlt man eine vom Kopfe des Humerus gebildete resistente Fläche. Vor der Acromialspitze und dem äusseren Ende des Schlüsselbeines fühlt der tastende Finger den Kopf des Humerus als einen runden Körper, welcher sich zwischen ihnen bewegt, sobald mit dem Arme Rotationsbewegungen gemacht werden.

Acromio-clavicular-Zwischenlinie. Das äussere Ende der Clavicula ist mit dem Acromion durch eine fibröse Brücke verbunden, welche an der oberen Fläche durch das Ligamentum acromio-claviculare superius verdickt ist. Die Richtung der Gelenklinie ist schief nach unten innen und vorne gerichtet, da die Clavicula auf dem Acromion liegt.

Um die Spitze eines Bistouri in die Gelenklinie einzustechen, muss man vorher durch den Finger ihren Ort markiren. Längs dem Nagel dieses Fingers wird die Spitze eines Bistouri eingestochen, indem man die Klinge nach unten und innen richtet.

Der Processus coracoides hat die Form eines durch eine solide Basis auf dem oberen Rande des Schulterblattes festsitzenden Hakens. Von vorne nach hinten gerichtet schaut er mit der unteren concaven Schulterfläche nach unten und aussen gegen den Humeruskopf (Fig. 1-2).

Auffindumg des Processus coracoides. An mageren Leichen erkennt man leicht den Processus coracoides, der sich reliefartig unter der Haut abhebt. An fetten Leichen oder wenn die Schulter geschwollen ist, kann die Auffindung einigen Schwierigkeiten begegnen. Folgt man mit der Fingerspitze vou aussen nach innen der resistenten Fläche vor dem Schlüsselbeine, die vom Humeruskopfe gebildet wird, so fühlt der Finger in einem gegebenen Momente eine Vertiefung, welche durch einen knöchernen Vorsprung, dem Processus coracoides, begrenzt ist. Ein anderes Auffindungs- 


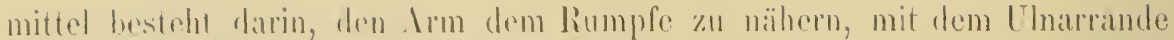

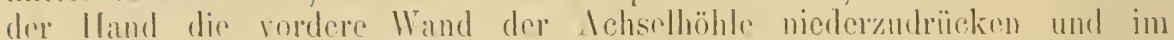
oberen Theile der auf diese ITeise gebildeten kiurehe fühlen die Finger-

Fig. 1.

Tulsereulum majus

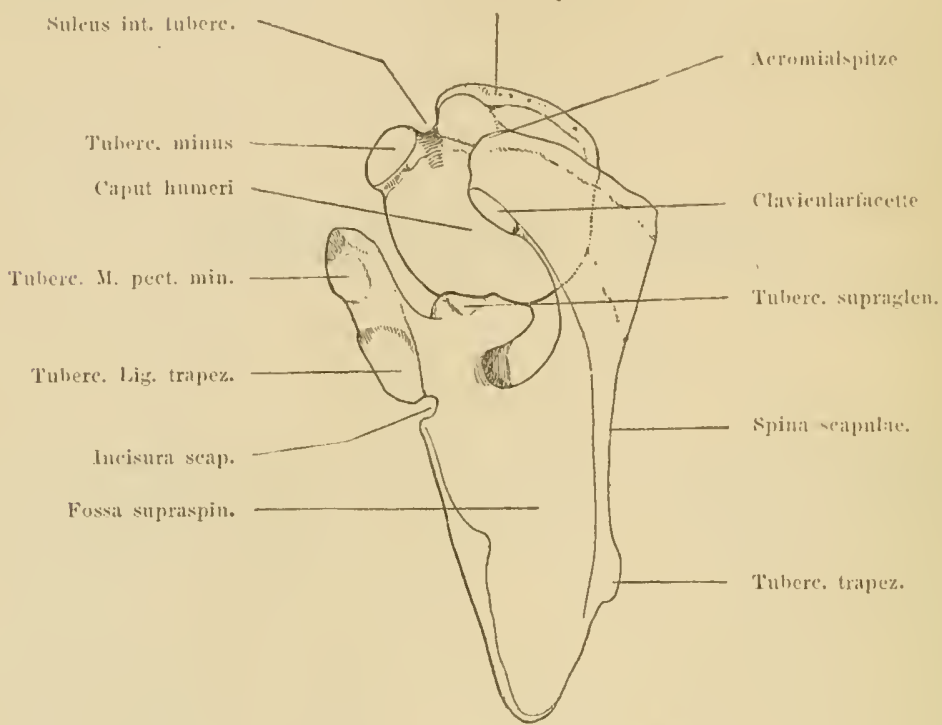

Beziehungen zwischen Itumeruskopf, Caritas glenoidalis, Acromion u. Processus coracoides.

Fig. 2.

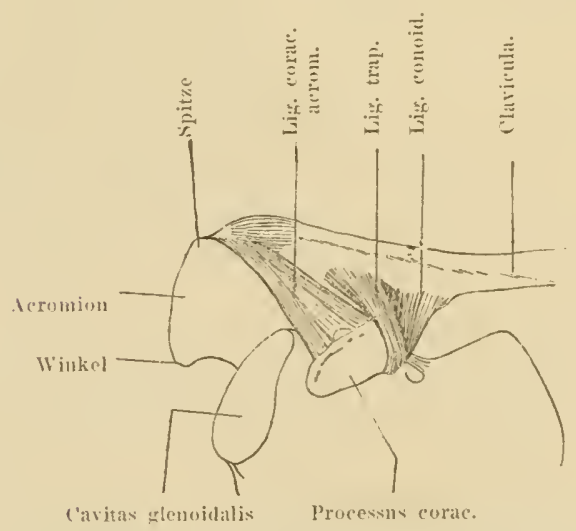

Das rechte Coraco-claviculargelenk. Das erhobene und nach rückwärts gedrehte Schliisselbein legt die Ligamenta coraco-clavicularia frei.

spitzen die Spitze des Processus coracoides. Man möge diese Untersuchung recht oft rornehmen, denn der Processus coracoides ist ein wichtiger Führer bei der Stellung riner genauen Diagnose einer der Varietiten der IlumerusLuxationen. 
Coraco-C'lavicular-Ligamente. Das Schlüsselbein ist mit dem Processus coracoides durch zwei kräftige Bänder, Ligamentum trapezoidum und Ligamentum conoidum, fest verbunden (Fig. 2).

Das Ligamentum trapezoidum ist horizontal zwischen den Rauhigkeiten der unteren Fläche des äusseren Clavicularendes einerseits und dem inneren Rande und der oberen. Fläche der hinteren Hälfte des Processus coracoides andererseits gespannt.

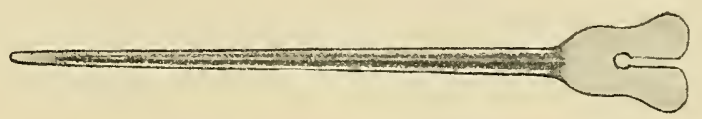

Eine feste Hohlsonde nach Nélaton.

Das Ligamentum conoidem hat die Form eines Dreieckes; mit seiner Basis inserirt es sich an dem Tuberculum conoidenm des Schlüsselbeines, mit der Spitze haftet es am Tuberculum, welches auf der Basis des Processus coracoides sich befindet. Ein Schleimbeutel befindet sich am Ligamentum trapezoidum, ein zweiter zwischen Ligamentum conoideum einerseits, zwischen Ligamentum coracoideum und Ligamentum trapezoideum andererseits.

Fig. 3.

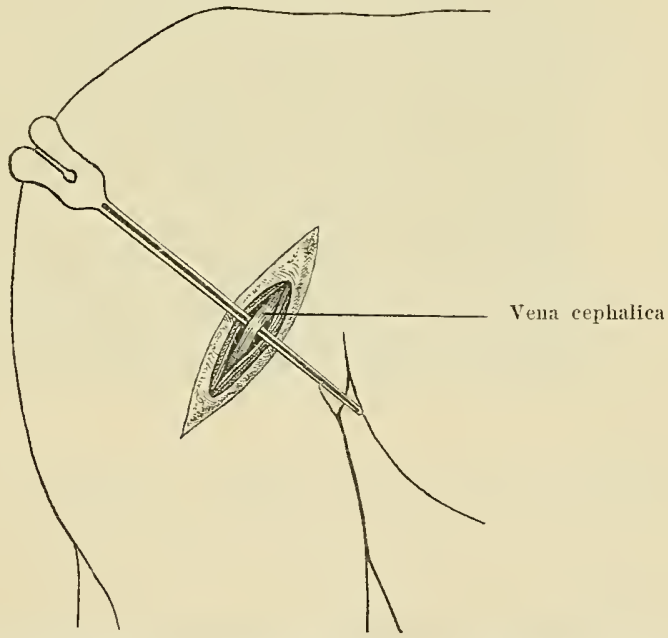

Das Aufsuchen der Vena cephalica im Interstitium deltoideo-pectorale. Die Vene ist auf eine Hohlsonde gehoben.

Techuik zur Auffindung der Gebilde. Man sucht den vorderen Rand der Clavicula und den Processus coracoides auf. Ian löst dann den Deltoides von der Clavieula in einer Länge der äusseren Hälfte dieses Randes ab, und desarticulirt das Schlüsselbein rom Acromion. Ein Gichilfe zieht die Clavicula nach oben und in dem so eröffneten coraco-clavicularen Raume werden jene beiden Ligamente präparirt. Nan durchschneidet zuerst 
das liganentum trapeznideum, dann sicht man, dass der Humerus sich schr leicht nach innen rersehiebt. Sehneidet man dann das ligamentum conoideum durch, so entfernt sich sofort das Schlüsselbein rom Processus ('oracoirles.

Vella cephlalica. Viese beginnt in der Ellbogengegend, wo sie durch Vereinigung Ier Yena neelio-cephalica und der Tena mediana entsteht; zuerst anf der Aponeurose liegend, verliuft sie dann längs des änsseren landes des Biceps. Im Niveau des Sulcus deltoideo-pectoralis komnt sie unter der Aponeurose zu liegen, folgt dieser und nü̈ndet oberhalb des oberen Ramles des Peetoralis minor in die Vena subclavia ein oder in das Endstiick der Tena axillaris. Ein Vene, die oberhalb der Clavicula verläuft, rerbindet die Vena cephaliea mil der V'ena jugularis externa.

Techuik zur Auffindnum d. G. Ein Gehilfe hält den Arm in Abduetionsstellung; man erkennt an der vorderen gespannten Wand der Achselhöhle den Suleus deltoideo-pectoralis. Führt man längs der Furche cinen Schnitt, so findet man mit der Hohlsonde und Pincette im Interstitium museulare die Vene, welche in Form eines blauen Bandes erscheint. Neben dieser lingt die Arteria deltoideo-pectoralis, ein Ast der Arteria acromio-thoracica.

Musculus subclavius. Ein spindelförmiger, zwisehen dem Schlüsselbeine und alem línorpel der ersten Rippe gespannter Muskel; er entsteht auf der Clavicula und an deu beiden Rändern der Sulelaricularfurche. Die Muskelfasern vereinigen sich zu einer Sehne, die an der vorderen Fläehe des ersten Rippenknorpels sieh anheftet. Diese Selne folgt dem unteren Rande des Mnslielkörpers. Der Inseulus subelavius befindet sich in einen Blatte der Clavi-coraco-axillar- $A$ poneurose.

Ter'hnik zur Auffindung d. (*. Man führt einen Hantschnitt längs des vorderen Raudes der Clavicula rom Sternum bis zum Acromion und tremnt ron ihr das Clavicularbindel des Mnsculus pectoralis maior ab. Der untere Rand des Schnites wirl abgezogen, und man erkennt durch die Dicke der Aponeurose den Mnskelkörper des Musculus subclavius. Wird mit der Hohlsonde las aponeurotische Blättchen, das ihn bedeckt, abgezogen, so folgt man der Sehne lis zur Insertionsstelle am Rippenknorpel. Darauf durchschneidet man quer diese Sehne und präparirt seine tiefe Sehichte.

Nicht selten findet man zwischen dieser und dem Ligamentum costoclariculare einen Sehleimbeutel. Wenn ein Gehilfe die Schulter nach oben drückt, so erweitert sich der Costo-elavieularraum und in seinem inneren Winkel sieht man das ligamentum rosto-claviculare.

Das subrlaviculare (iefäiss- und Yervenpacket. Zwischen dem den Musculus subelarins tragenden Theil der Clarieula und der ersten Rippe, welehe ron den obersten Zacken des Musculus serratus magnus bedeckt ist, zieht von der Supraclaviculargegend in die Aelıselhöhle das subelariculare Gefäss- und Nervenpacket.

Die Arteria subelavia liegt in der Mitte.

Die Vena subelaria liegt innen und etwas ror der Arterie. Die Stränge des Plexus brachialis findet man gemeinsam anssen und hinter der Arterie (Fig. 4).

Terhnik zur Auffindung d. (4. Legt man der Länge nach unter dem Rü̈ken der Leiche einen IJolzkril, so treten die Schultern nach rüekwärts und das schlüsselbein nähert sich der ersten Rippe. Sucht man den 
vorderen Rand der Clavieula und bezeichnet mit der Nagelspitze die Mitte, so entspricht diesem Punkte in der Tiefe die Arteria subclavia. Längs dieses Randes wird ein 6-8 cm langer Einschnitt gemacht und das Clavicularbündel des Musculus pectoralis major von der Clavicula losgelöst, darauf der untere Rand des Schnittes abgezogen. Nit der Hohlsonde wird längs des Musculus subclavius die Aponeurosis clavi-coraco-axillaris durchtrennt und mit der Sondenspitze das Fett behutsam nach abwärts gedrückt. Nun erblickt man den Nerv des Musculus pectoralis major von der Dicke eines vertical nach abwärts gerichteten Zündhölzchens; zieht man mit der Hohlsonde den Nerv beiseite, so findet man die Arteria subclavia, an ihrer Innenseite die Vena subclavia und aussen die Stränge des

Fig. 4.

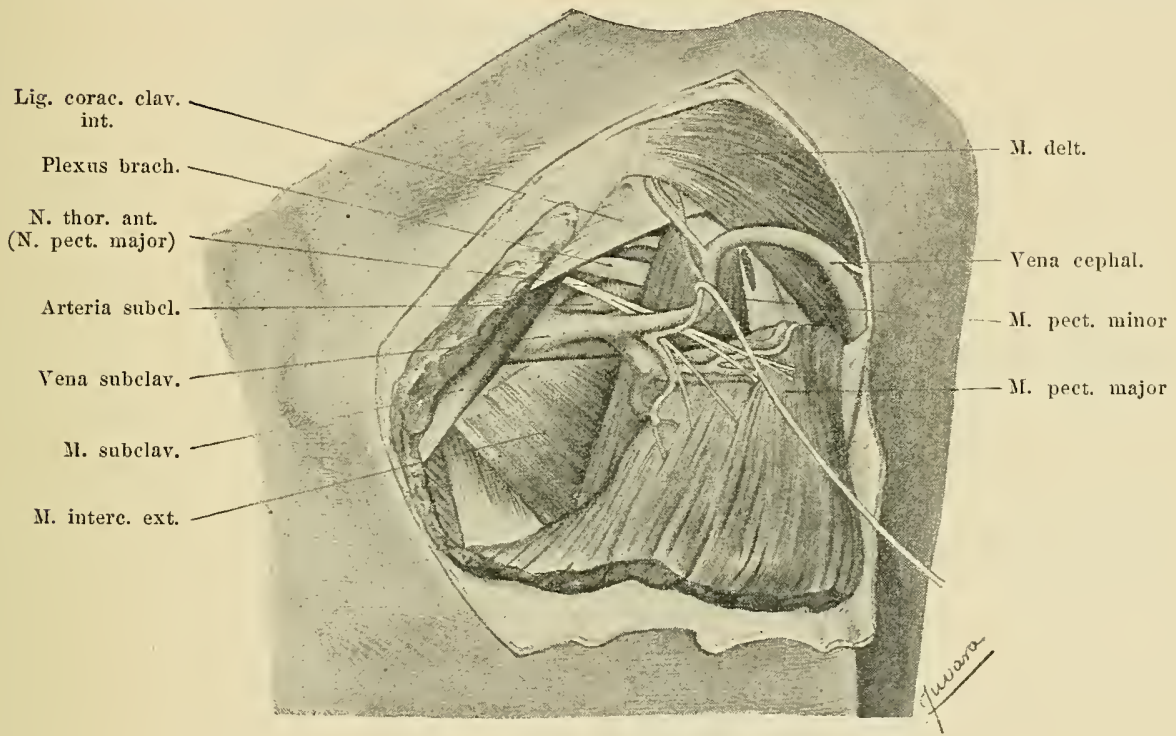

Regio subclavicularis. Der Museulus pectoralis major wurde an seiner Insertion an der Clavicula durchschnitten und nach unten gezogen. Die Vena cephalica ist mit einem Haken abgezogen.

Plexus brachialis. Oftmals deckt die breite Vena subclavia die Arterie, damn muss man hinter dem Nerv des Pectoralis major zuerst die Vene von den nervösen Strängen frei machen und in dem so geschaffenen Zwischenraume sucht man die Arterie.

Bei dieser Operation muss man stets vorsichtig verfahren und das Feld genügend beleuchten. Ian muss darauf achten, unter Controle des Auges zu arbeiten und nicht blindlings vom Tastgefühle des Fingers sich leiten zu lassen. Es giebt nichts Leichteres, als im äusseren Winkel des Schnittes die Stränge des Plexus brachialis, in Innern die Vena subclavia aufzufinden (Fig. 5).

Die Muskehn des Processus coracoides. Es giebt deren drei: 1. der Mns- 
culus pectoralis minor, 2. Jer liurze líopf des Musculus biceps, 3. der Musculus coracobrachialis.

Der Husculus pectnralis minor inserirt sich am inneren Rande und an der oberen Flaiclue Jes Processus coracoides. Oftmals fiudet sich ein Schleimbeutel unter der tiefen Flïche seiner Sehne.

Der kurze liopf des Musculus biceps und der Musculus coracobrachialis inseriren sich an der Spitze des Processus coracoides, der liceps an ier :usseren, der M. coraco-brachialis an der inneren Fläche desselben. Anfangs sind die beiden Muskelliörjer vereint, weiter unten theilen sie sich, indem der Musculus coracobrachialis nach hinten und an die Innenseite des Musculus biceps zu liegen liommt.

Techunik zur Auffindung d. G. Musculus hiceps mud ('oraco-brachialis. Man sucht den P'rocessus coracoides anf und macht eine lange Incision ron der Spitze des Processus coracoides bis zur innem Oberarmfläche und

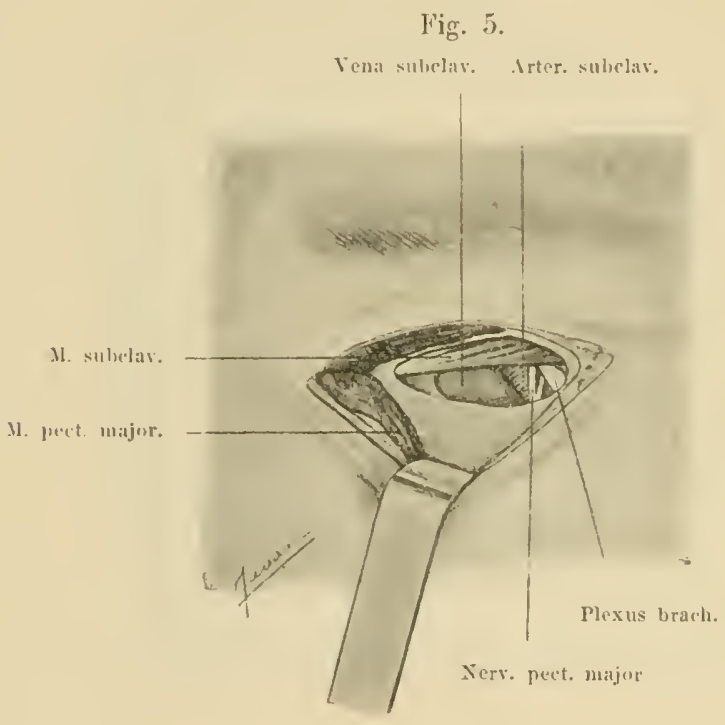

Das rechte subclaviculare Gefïss- und Nervenbündel. Ein stumpfer Haken zieht den Musculus subclavius nach oben, ein zweiter den Schnitt des Pectoralis major.

durchschneidet rertical den Körper des Musenlus pectoralis major. Entfernt man nun die beirlen hïnder ron cinander, so findet man in der Tiefe den «emeinsamen Nuskelkörper des Biceps und Coraco-brachialis. Mit der Hohlsonde sucht man das Interstitimm auf, welches den Musculus coraco-brachialis ron dem kurzen liopfe des Musenlus bieeps seheidet.

Dev Teprus musculo-rutaneus zicht zwischen den beiden Bündeln des Musculus coraco-brachialis. Durehsehmeidet man den Kiörper des Nusculus biceps und M. coraco-brachialis transversal, so findet man unter seiner tiefen Lage einen Schleimbeutel, weleher ihn von M. subscapularis scheidet.

Musculus pectoralis minor. Nach $\Lambda$ uffindung des Processus coracoides macht man einen schiefen Einschnitt ron der Spitze des Proc. coracoides Lis zum rierten Rippenkïrper. Unter der ticfen Sehichte des Nusculus jee- 
toralis major findet man den II. pectoralis minor. Zieht man den oberen Rand des Schnittes ab, so findet man unmittelbar oberhalb des obern Randes des M. pectoralis minor den von der Arteria axillaris abgehenden Stamm der Arteria acromio-thoracica, welchen eine Nerrenschlinge, die Anastomose der Nervi des II. pectoralis major und II. pectoralis minor; umgiebt. Man durchschneidet die Sehne dieses Muskels etwas unterhalb des Proc. coracoides und präparirt seine tiefe Lage, man findet oft einen Schleimbeutel zwischen Sehne und Proc. coracoides. -

Das Ligamentum coraco-acromiale ron dreiechiger Form inserirt sich mit der Basis am äusseren Rande des Proc. coracoides und mit seiner Spitze an der Spitze und an der untern Fläche des Acromion. - Es besteht ans zree Bündeln. Der änssere

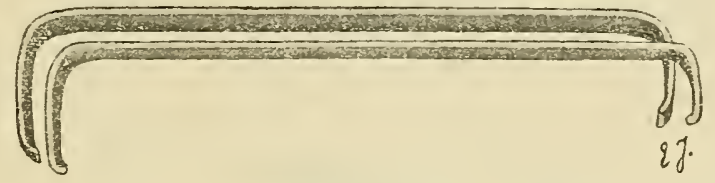

Zwei stumpfe Haken nach Prof. Farabeuf.

Rand des Ligamentum coraco-acromiale setzt sich unter der tiefen Lage des Musculns deltoidens in die Aponeurosis subdeltoidea fort; seine untere Fläche entspricht dem obern Rande des M. subscapularis und der rom M. supra-spinosus bedeckten Gelenlikapsel. Das Ligamentum coraco-acromiale bildet mit dem Proc. coracoideus und dem Acromion, die Acromio-coracoidalmölbung, in welcher der Humeruskopf sich berregt.

Techuik zur Anffindmig d. G. Nan sucht den Processus coracoideus und die Spitze des Acromion auf. Bei einem zarten Individuum fühIt man im Coraco-acromialraume unmittelbar vor der Claricula die solid geformte

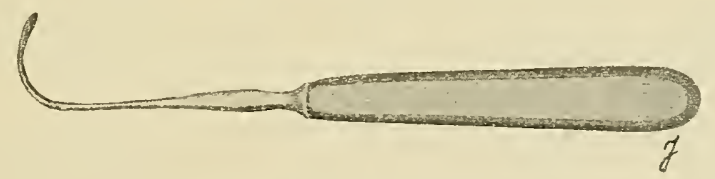

Ein Haken nach Cooper.

Fläche des genannten Ligaments und mit der Fingerspitze kamn man seinen äusseren Rand greifen. Wird ein tiefer Einschnitt rom Acromion zum Proc. coracoideus gemacht, der II. deltoideus durchschnitten und entfernt, so erblickt man unter demselben das Ligamentum coraco-acromiale. Führt man längs des äusseren Randes einen Schnitt, so eröffnet man den serösen Subdeltoidalbentel, welcher durch Reibung des Humeruskopfes in der Acromiocoracoidalwölbung entsteht. Die Entzündung dieses serösen Beutels führt den Namen Arthritis peri-scapularis.

Das Humero-scapular-Gelenk. Die Gelenkkapsel ist eine fibröse Hülle ron der Form eines gestutzten Conus, inserirt sich innen am Rande der Caritas glenoidalis und 
am Glabrum glenoidale, aussen am Collum anatomicum und an der inncrn fiäche des chirurgischen Ilalses des IHumerus, Fig. 6. Diese hapsel ist an ihrer oberen vordern und untern Seite durch drei diclie fibrïse Büudel, ligamente, rerstärlit:

A. Das Ligamentum rol'aro-humerale inserirt sich imnen am äusseren Rande nud an der Basis des Proc. coracoides, aussen verbreitert sich dasselbe und heftet sich am grossen IIöelier des Oberarmes an, mit einigen mehr vorderen Fasern inserirt es sich am lileinen Ilöcker und an der fibrösen Brücke, unter welcher die Bicepssehne hindurchgeht. Der vordere Rand dieses Bandes ist frei, während der hintere sich in die Gelenlikapsel fortsetzt.

B. Ligamentum supra-g]eno supra-humerale. Es inserirt sich innen am ïusseren Rande der Basis des Coracoidalfortsatzes und aussen am anatomischen Halse und im Grunde einer kleinen IHöhle, welche nahe an Halse des IImmeruskopfes sich befindet. Es liegt unterhalb des Ligamentum coraco-humerale.

Fig. 6.

Lig. coraco-hum. Proc. corac.

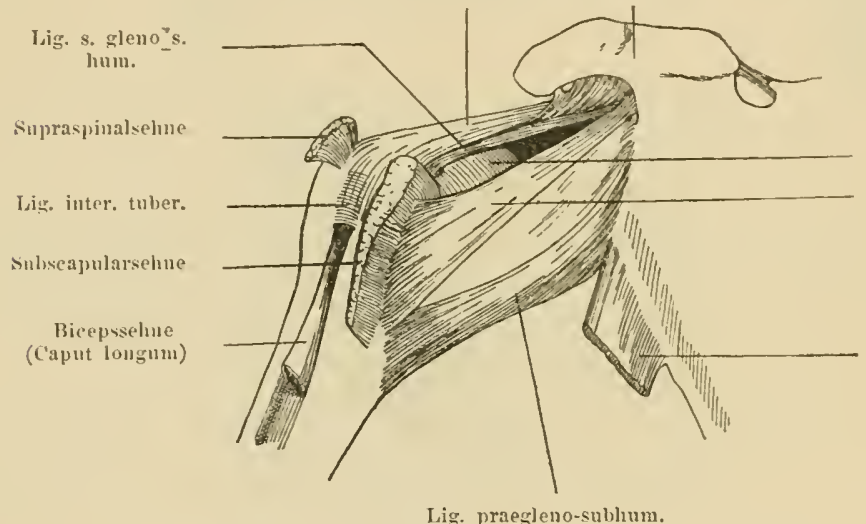

Caput humeri

Lig. s, gleno-praeiัเกแ.

Lange Tricejss seline.

Die rordere Fläche des rechten Scapulo-humeralgelenkes. - Durch einen oben vom Ligamentum supragleno-suprahumerale, unten rom Ligamentum supragleno-prachumerale begrenzten Abschnitt sieht man den Gelenkkopf des Humerus.

C. Ligamentum supra-gieno prae-humerale. Es hat die Form eines dreieckigen Bandes, das schief nach unten und aussen gerichtet ist. Es beginnt am untern Rande der Caritas glenoidalis und am Glenoidalwulste, wird nach aussen breiter und inserirt sich am innern Drittel der rorderen Fläche des kleinen Höckers unterlıalb der Ansatzstelle der Subscapularselme. Sein oberer Rand begrenzt mit den rorderen Rande des Ligamentum supra-gleno supra-humerale die Wtitbrecht'sche Lücke, durclı welche die Sehne des Musculus subscapularis in das Gelenk eindringt und eine Synovialtasche hervortritt.

D. Ligamentum prae-gleno sub-lumerale. Es hat die Form eines Bandes, das von nach hinten und aussen gedrehten Bündeln gebildet wird. Es inserirt sich innen am vordern und untern Rande der Cavitas glenoidalis aussen an der innern Fläche des chirurgischen Humerushalses 5-6 mm unterhalb des Kopfes.

Die periarticuläre Muskelhiille. Die Kapsel des Scapulo-humeralgelenkes ist ringsum ron einer Muskel- und Sehnenhïlle umgeben, welche rorne ron Musculus subscapularis, oben rom M. supra-spinosus, hinten rom M. subspinosus und M. teres minor 
gebildet wird. Gegen den untern Theil wird die Hülle durch den langen Bicepsliopf und den M. teres major vervollständigt (Fig. 7).

Teclnik zur Auffindung d. G. Nan sucht den Kopf des Humerus auf und macht einen hufeisenförmigen Einschnitt, der von dem Humeruskopfe ummittelbar ausserhalb des Proc. coracoides beginnt, dem äusseren Rande des Acromion folgt und an der hintern Fläche des Humerus endigt. Der II. deltoides wird durchschnitten und die Bursa subdeltoidea eröffnet. Wenn man nun den so geschaffenen Hautmuskellappen nach abwärts zieht, so wird der Humeruskopf frei und man erblickt: vorne den M. subscapularis halb sehnig, halb musculös, oben den II. supraspinosus, hinten den MI. subspinosus und den Teres minor, in seiner unteren Hälfte fleischig. Nlan schneidet tief in den periarticularen Yuskelconus ein und eröffnet die Gelenkkapsel. Wird der Humeruskopf nach aussen luxirt, so sieht man rings um die Pfanne den Glenoidalwulst und in der Tiefe der Cavitas glenoidalis die centrale Stelle, welche dem Tuberculum Assaky entspricht.

Fig. 7.

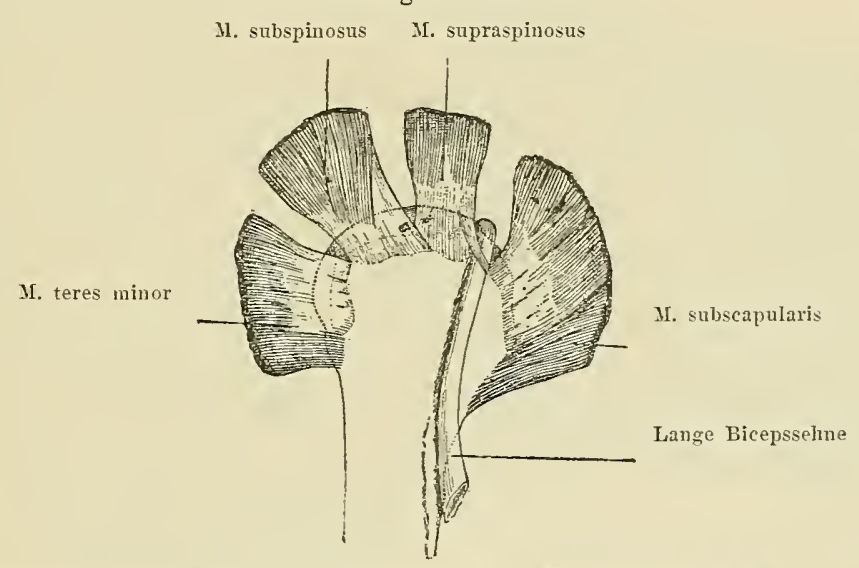

Das obere Ende des Humerus. Die Insertionen der Muskeln am grossen und kleinen Trochanter.

Sulcus bicipitalis und der lange Kopf des Biceps. Die Bicipitalfurche ist auf der obern Hällte der vordern Fläche des Humeruskopfes gelagert; breit und wenig tief in ihrem untern Theile wird sie enger und tiefer zwischen beiden Höckern und endet im Niveau des Collum anatomicum. Auf dem äussern und rauhen Rande inserirt sich die lamellenförmige Sehne des M. pectoralis major. Auf dem innern treniger erhobenen Rande inserirt sich der Teres major. Am Grunde der Furche auf einer Reibe von Rauhigkeiten, schief rom äussern gegen den innern Rand gerichtet, inserirt sich die Sehne des M. latissimus dorsi.

Die Sehne des langen Bicepskopfes liegt in der Bicipitalfurehe unterhalb der Sehne des Musculus pectoralis major. Die Sehne des Biceps dringt unter einer fibrösen, zwischen den Höckern gespannten Brücke in das Scapulo-humeralgelenk, umgiebt den Humeruskopf und inserirt sich am Supra-glenoidalhöcker und an dem Glenoidalwulste.

Technik zur Auffindung d. G. Man fühlt durch Palpation durch die 
Wrechtheile hindureh die Bicipitalfurche. Drüelit man die Fingerbecre an diese an und werden dem $A$ rme Rotationsbewegungen crtheilt, so fülılt man unter dem Finger den äusseren Rand der Furche. Ë̈n Schnitt wird längs des Sulcus deltoiden-pretoralis gematht, die Sohne des Muse. peetoralis major durehschnitten und in der Tiefe des Schnittes erscheint die Bieipitalschine. biese wird aus der Furehe herausgehoben und his zor Insertion an der

Fig. S.

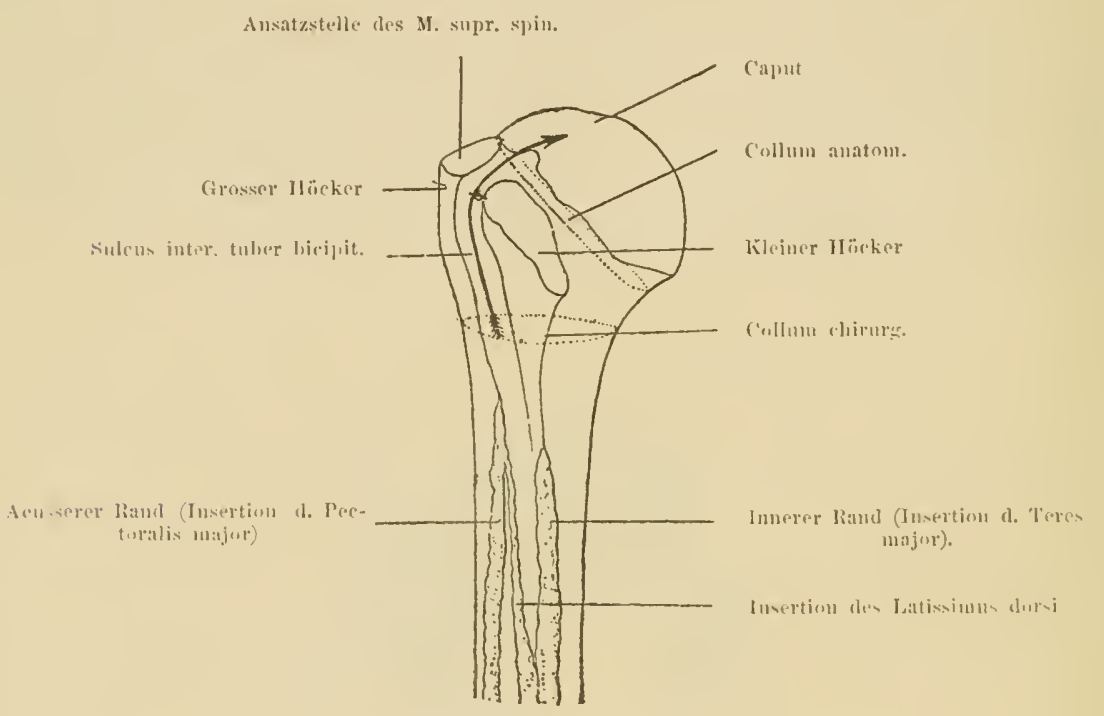

Das obere Ende des Ifumerus.

Scapula rerfolgt. Wird die Biejpitalsehne herausgehoben, so findet man darunter die Selme des M. latissimus dorsi. Wird auch diese vertieal durchsehnitten, so erblickt man in der Tiefe den Schlembentel, weleher sie ron der Sehne des Teres major seheidet. Wird dam auch diese Selme durchschnitten, so eröffnet man unter seiner tiefen Fläche cinen Schleimbental, welcher diese vom Humerus scheidet.

\section{Region der Achselhöhle.}

Die Achselhöhle lat bei einer leichten Abduction des Oberarmes die Form einer dreiecligen mit der Basis nach unten gerichteten Ilohlpyramide (Fig. 9).

Die rordere Wand ist muskulös und wird gebildet: aus der Haut, dem M. pect. major und dem N. pect. minor. Letzterer ist ron der Clavi-coraco-axillar-Aponeurose eingehüllt.

Die hintere Wand wird gebildet imnen und oben rom Schulterblatte, das rom M. subscapularis bekieidet ist, aussen und unten rom Teres major, der an der rorderen liäche rom Fö̈per nul der Sehme des M. Iatissimus dorsi bedeclit wirl. Die den 
M. latissimus dorsi bekleidende Fascie vereinigt sich mit der des M. subscapularis. In derNähe des anatomischen Halses und im Nireau der Interstitien, welche den T'eres major rom M. subseapularis scheiden, ist die Faseie mit einer durch einen Wall begrenzten, concar nach oben gerichteten Lücke rersehen, durch welche aus der Achselhöhle die Arteria circumflexa und der Nervus circumflexus, für den M. deltoides bestimmt, austreten. - Die innere Wand wird von derThoraxwand gebildet, die rom M. serratus magnus überkleidet wird. Der Muskel ist mit einer dïnnen zellig faserigen Fascie bedeckt.

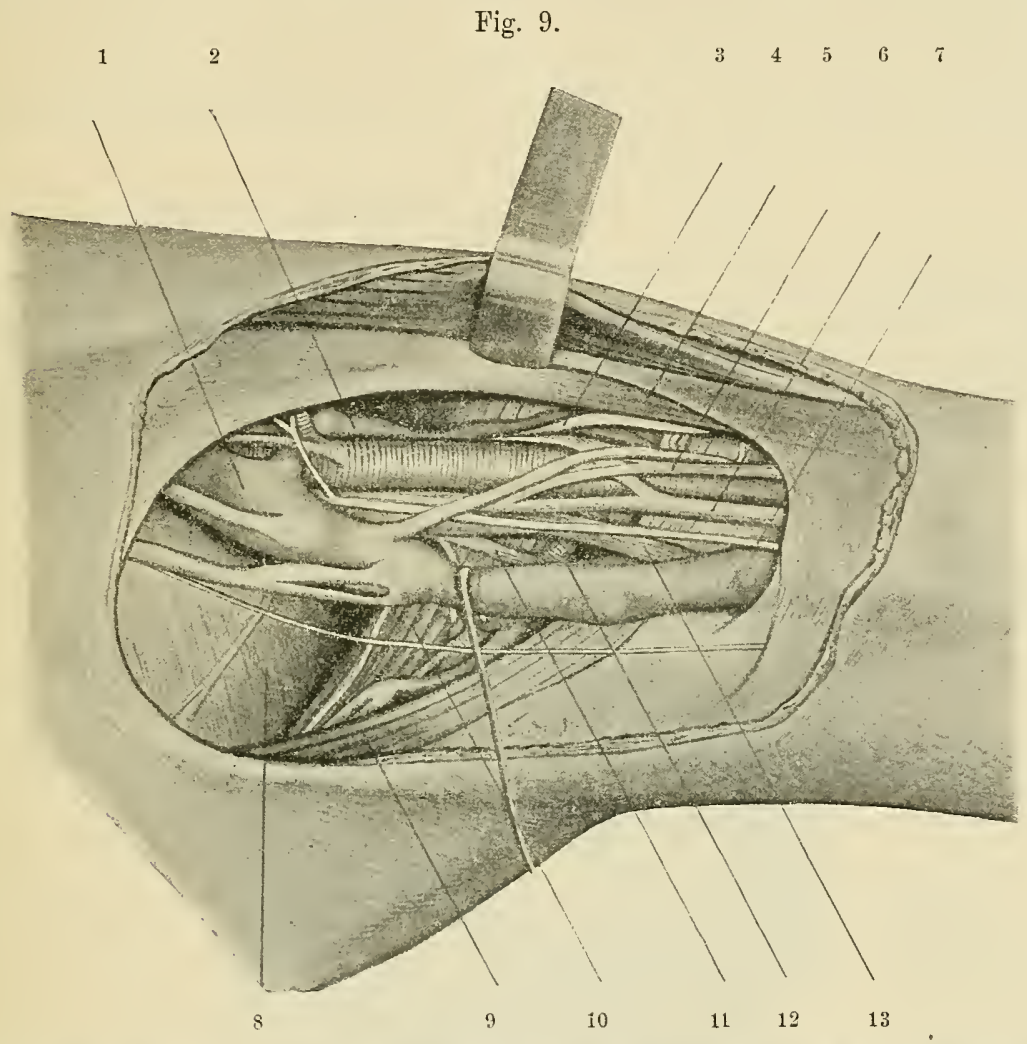

Der Arm befindet sich in Abductionsstellung. Ein stumpfer Haken zieht den Pectoralis major nach oben und legt das axillare Gefäss- und Nervenpacket frei. - 1. Vena axillaris. - 2. Vena brach. ext. - 3. Nervus musc. cut. (N. brachii ext.). - 4. Mf, coracobrach. - 5. Nervus medianus. - 6. Nervus cubitalis (N. ulnaris). - 7, Nerrus cut. brachii int. - 8. Musculus serratus magnus. - 9. Musculus latissimus dorsi. - 10. Musculus teres major. - 11. Nervus circumflexus. - 12. Art. seap. ext. (Art. subscap.). 13. Nervus radialis.

Die vordere und hintere Wand vereinigen sich unter einem spitzen Winkel längs der beiden Ränder der Bicipitalfurche. In diesem Winkel sind ron aussen nach innen gerichtet der lange Kopf des Biceps, sein liurzer Kopf und der M. coraco-brachialis.

Die Achselhöhle communicirt mit dem Supraclavicularrande durch eine dreieckige Lücke, Orificium costo-coraco-claviculare. Diese wird vorne rom Schlüsselbein und vom M. subclavins bedeckt, hinten und innen von der ersten Rippe durch den 
M. serratus magnus rerstirlit, aussen rom inneren Rande des Processus coracoides begrenzt. Nach unten wird die Aehselhöhle von der llaut abgesehlossen. Für einige Autoren dürfte sich noeh unter der llaut eine sehr dïnne schwer abzuläsende Fascie finden, die rom rorderen Rande des M. peet. major zum Rande des M. hatissimus dorsi und ron innen nach aussen ron der liascie des It. serratus maguus zu der des Oberarms ausgebreitet liegt.

Die tiefe Hantfläche der Achselhöhle ist längs des unteren Randes des M. pector. major und les M. latissimus dorsi durch ein fibröses zelliges Ligament rerbunden, das ligamentum suspensorium axillae.

\section{Inhalt der Achselhöhle.}

Die Arteria axillaris wendet sich nach aussen und unten gegen den Oberarn und ist zuerst auf der inneren Wand der Achselhöhle gelegen, ïbergeht dann auf die hintere Wand und rerläuft längs der Furche, welehe hinten rom M. subseapularis unıl II. latissimus dorsi, aussen und rorne rom M. coraco-brachialis begrenzt wird (Fig. 10).

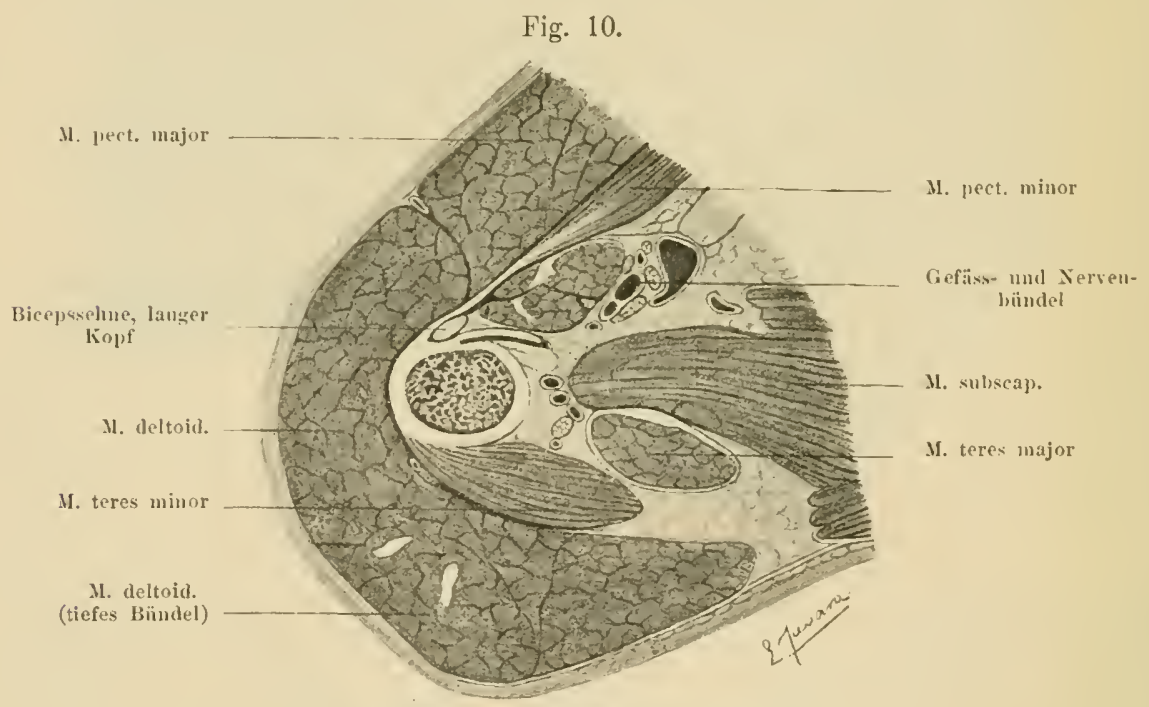

Ein Quersehnitt der linken Achselhöhle.

Jie Nerrenstrainge des Plexus brachialis liegen zuerst an der Aussenseite der Arteria subclavia, verlaufen dann röhrenförmig um die Arteria axillaris. Die Arteria axillaris dringt zwischen den Strängen durch eine Artlinopfloch, welehes von den beiden Wurzeln des Medianus gebildet wird.

Der Tervus medianus liegt ror und etwas aussen von der Arterie, an ihrer Aussenseite findet man den Nervus musculo-cutaneus, an der Innenseite den Nervus cubitalis. An der rorderen und inneren Seite des letzteren liegt der Nervus 
brachii cutaneus intern. Der Nervus circumflexus und Nervus radialis befinden sich hinter der Arterie. Zwischen diesen Nerven liegt die Arteria circumflexa.

Die Vena axillaris liegt mehr innen und hinter der Arterie, sie wird gebildet durch Vereinigung der Vena basilica mit den Oberarmvenen, letztere vereinigen sich gewöhnlich zu einem gemeinsamen Stamme, welcher in dem von beiden Wurzeln des Medianus gebildeten Winkel verläuft. Der nach Charles Bell benannte Nerv (Nervus thoracicus longus) steigt rertical an der Innenwand der Achselhöhle nach abwärts, etwas hinter der Axillarlinie, und rertheilt sich, von einer Arterie begleitet, in dem M. serratus magnus.

Die Arteria scapularis externa, ein Ast der Arteria axillaris, steigt an der hinteren Wand der Achselhöble nach abwärts dem Zwischenraume folgend, welcher den äusseren Rand des M. subscapularis rom Teres major und M. latissimus dorsi trennt.

Fig. 11.
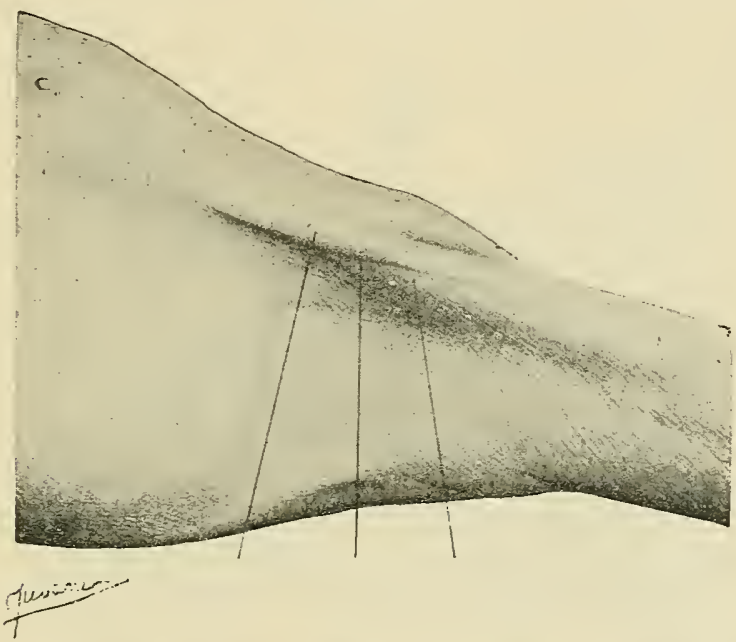
Das Relief des Randes $\begin{gathered}\text { Sulcus } \\ \text { subpectoral. }\end{gathered}$ Das Relief des Gefäss- und Nerven-
pactes major mes M. coraco-brachialis

Die Figur zeigt die Achselhöhle des in Abductionsstellung befindlichen Armes.

Technik zur Auffindung der Arteria axillaris. Legt man den Oberarm in Abductionsstellung, dann nimmt die Achselhöhle die Form einer Furche an und unter der Haut bildet der Humeruskopf eine Erhebung. Am inneren Rande des M. pectoralis major sieht man eine Erhebung (Fig. 11), welche längs des Oberarms absteigt; wenn man diese abtastet, dann fühlt man eine Reihe von Organen, welche auf der resistenten Fläche des Humeruskopfes unter der Fingerbeere hin und hergleiten, die Organe der Nervensträrige des Plexus brachialis. Nan führt unmittelbar unter dem Rande des M. pectoralis major einen langen Schnitt ron der höchsten Spitze der Achselhöhle bis zum Oberarme, zieht dann den II. pectoralis major ab und legt mittelst einer Hohlsonde den 1I. coraco-brachialis frei. Man reisst dann mit der Sonde das hintere Blättchen der aponemrotischen Scheide dieses Muskels durch und gelangt an das Gefïss- nnd Nerven- 
parket. Der Nervus medianus tritt wie eine gespannte Sehne hervor; man logt ihn mit der Spitze der Sonde frei, und linter ihm findet man die Arteria axillaris. Nan erblickt rings um dieselbe rersehiedene Nervenstränge und sieht die beiden Wurzeln des Medianus in dem oberen Theile durch eine ron Krenzfasern in Form eines $X$ gebildete Inastomose miteinander anastomosiren. Etwas nach imnen findet man die Tena axillaris ron der Dicke eines Fingers.

\section{Mnsculus coraco-brachialis. Nervus musculo-cutaneus (X. cutaneus} brachii ext.). Der M. coraco-brachialis reicht ron der Spitze des Processus coracoides bis zum mittleren Theile der Innenfläehe des Humerus. Oben ist er mit den kurzen Kopf des Biceps rereinigt, welcher mehr nach aussen und vorne gelagert ist. Er wird rom Nerrus musculo-cutaneus perforirt und rom axillaren Gefäss- und Nervenbündel begleitet, er stellt den „Satelliten“ dieser Organe dar.

Fig. 12.

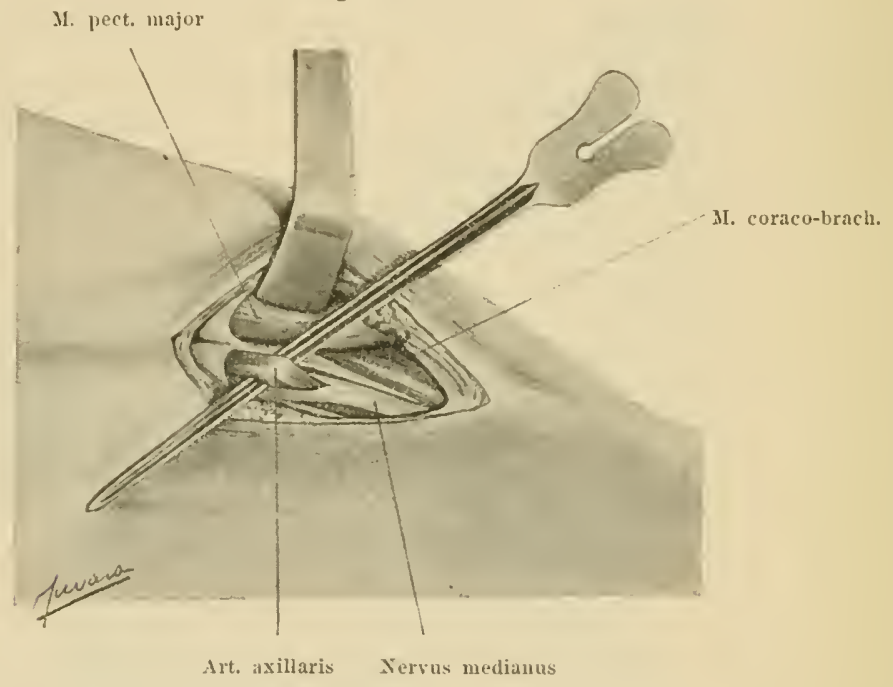

Diese Figur zeigt das Verfahren, um die Arteria axillaris aufzufinden. Der Pectoralis major wird mit einem stumpfen Haken abgezogen; die Arterie wird zwischen den beiden Wurzeln des Medianus auf eine Hohlsonde gehoben.

Technik zur Anffindung d. G. Man führt, wie für dic Arteria axillaris, einen Schnitt längs der Furche, welche sich unter dem Rande des II. pectoralis major befindet, und verlängert denselben bis zur llitte des Oberarms. Der MI. pectoralis major wird zur Scite geschoben und mit einer Holılsonde der Körper des II. coraco-brachialis freigelegt. An seiner inneren Fläche findet man den Nerrus musculo-eutaneus, welcher in das IIuskelfleisch eindringt.

Das Ligamentum suspensorium axillae wirt ron einer zellig-fibrösen dreieckigen Schichte gebildet und füllt den Winkel aus, welcher den M. coraco-brachialis rom II. pectoralis minor scheidet. Es bildet einen Theil der Clavico-coraco-axillar-Aponeurose. 
Das Ligamentum suspensorium inserirt sich oben an der Spitze des Processus coracoidens, unten ar der tiefen Fläche der Haut, aussen geht es über in die aponeurotische Scheide des M. coraco-brachialis und des kurzen Bicepskopfes, innen in die Fascie des II. pectoralis minor.

Andere zelligen Lagen verbinden die Haut der Achselhöhle am unteren Rande des M. latissimns dorsi mit dem Halse des Homerus. Somit hat das Ligamentum suspensorium die Form einer sagittalen Wand, welche im obereu Theile vom Gefäss und Nervenpacket dochbohrt wird.

Technik zur Auffundumg d. G. Man zieht die Haut der Achselhöhle und findet, dass sie nicht abgelöst werden kann. Der Oberarm wird nun in Abductionsstellung gebracht und die Achselhöhle bildet eine tiefe Furche. IIan führt längs des unteren Randes des M. pectoralis major einen Schnitt, nimmt den unteren Schnittrand zwischen die Finger, legt den Rand des Pectoralis frei und löst mit dem Finger seine ticfe Schichte bis zur Spitze des Processus coracoideus ab. Man erblickt dentlich eine zellig-fibröse dreieckige Fläche, das Ligamentum suspensorium, welche mit der Sonde genau begrenzt wird, indem man sie innen vom II. pector. minor, aussen vom II. coraco-brachialis loslöst. Durchschneidet man das Ligament transversal, so sieht man, dass die Haut nicht mehr fixirt ist, sondern herunterfällt.

Die Axillardriisen werden in drei Gruppen getheilt:

1. Eine rordere innere Pectoral-oder 11 a mmargruppe, unter dem Rande des Pectoralis rings um die Arteria mammaria externa gelegen. Diese Lymphdrüsengruppe erhält die Lymphgefässe ron der Hamma nnd wird zuerst bei einem Carcinoma mammae ergriffen.

2. Eine hintere orler Scapulargruppe ron einer Lymphdrüsenkette gebildet, welche rings un die Arteria scapularis externa längs der Scapulodorsalfurche liegt. Die Drüsengruppe wird bei einer Lymphangoitis des Rücliens entzündet.

3. Eine perivasculäre oder Brachialgruppe von mehreren Lymphdrüsen gebildet, welche in weichen Fette längs der Vena axillaris besonders an der Imnenseite gelegen sind. Diese Drüsengruppe erhält die Lymphgefässe aus der Gegend der oberen Extremität und wird bei einer Lymphangoitis der Hand ergriffen. Nach Poirier enthält jede dieser Gruppen: a) subcutane Drïsen, b) subfasciale Drüsen,

Technik zur Auffindung d. G. Um die vordere Gruppe freizulegen, führt man einen Einschnitt längs des Randes des M. pector. major, für die hintere Gruppe längs des Randes des M. latissimus dorsi und für die mittlere Gruppe in der Mitte der Axillarfurche.

Der Nervus costobrachialis bildet die Anastomose zwischen dem zweiten Costalnerv und dem Accessorius des Nerrus brachii cutaneus internus.

Technik zur Affindung' d. G. Bei dem in Abductionsstellung befindlichen Arme macht man eine Incision in der Vitte der Axillarfurche. Der vordere Rand des Schnittes wird ron einem Gehilfen abgezogen und mit der Hohlsonde und Pincette wird ein Nervenfaden blosgelegt, welcher rom zweiten Intercostalraume gegen dic innere Fläche des Armes gerichtet ist, wo er mit dem Acessorius des Brachialis anastomosirt.

Arteria circumflexa und Nervus circumflexus. Die drterie ist ein Ast der Arteria axillaris, der Nerv ein Zweig des Plexns brachialis. Diese beiden Gebilde sind 
nebencinander gelagert, der Nerr an der Innenseite der Arterie, und durchdringen den Raum, welcher begrenzt wird: oben rom II. subscapularis und Teres minor, unten rom I'eres major und M. latissimus dorsi, innen rom langen líopfe des Biceps und aussen rom Ilalse des Oberarms durch die Gelenkiapsel verstärlit. In der Tiefe des M. deltoides folgen sie ihm in Form eines Bogens, ihm zahlreiche Aeste zusendend. Vorn anastomosirt die Arteria circumflexa posterior mit der Arteria circumflexa anterior, indem sie rings um den Hals des Oberarms eine Arterienschleife oder einen wahren líranz bilden. Die von grossen Venen begleitete Arterie und der Nerv sind von Fett umgeben und an dem Musculus deltoides mit einem dünnen zellig-fibrösen Blättchen festgeheftet.

Techuik z. A. d. G. Bei abducirtem Arme macht man längs des Reliefs des unteren Randes des II. latissimus dorsi eine Incision. Der obere Rand des Schnittes wird abgezogen und mit der Hohlsonde die vordere Fläche der Sehne des II. latissimus dorsi rom Fette befreit. - Oberhalb dieser Sehne erbliekt man den vorher erwähnten Raum und am Humerushalse legt man mit der Pincette und Sonde die Arterie und den Tervus circumflexus frei. Die Gebilde kann man auch frei legen, indem man längs des unteren Randes des M. deltoides einen Einschnitt macht und unter sciner ticfen Schichte nach ihnen sucht.

\section{Oberarm.}

Hintere Fläclıe. Die hintere Fläche des Humerus ist von den vier liöpfen des II. quadriceps humeri bedeckt, eines sehr diclien durch die Hant hervortretenden Musliels. Der Quadriceps humeri besteht aus vier Bündeln:

Die lange Partie (caput longum) oder das Sub-gleuo-olecranon-Bündel erstreckt sich ron der Schulter bis zum Olecranon. Der Vastus externus (caput externum) oder äusseres Humero-olecranon-Bündel, zieht rom äusseren Rande des Humerus zur obern Fläche und dem äussern Rande des Olecranon.

Der Vastus internus (caput internum) oder inneres Humero-olecranon$B$ ündel zieht vom inmeren Rande des Humerus zur oberen Fläche und dem innern Rande des Olecranon.

Das hintere Humeralbündel zieht ron der hintern Fläche des Humerus zur obern Fläche des Olecranon. Diese beiden letzteren Bündel sind in einem einzigen Muskel zusammengefasst, der Vastus internus der Autoren. Man kann mitunter durch ein anfmerksames Präpariren die Grenze dieser Bündel ausfindig machen. Die lange Partie und die beiden Vasti rereinigt begrenzen eine Lüclie, welche schief nach unten nnd aussen gerichtet ist. Durch diese Lücke zieht der Nerrus radialis und die Ar teria humeralis profunda.

Technik z. A. d. G. Der lange Kopf des Triceps. Auf der hintern Seite des in starke Beugung gebrachten Oberarms, tritt das Relief les langen Kopfes hervor. Man macht vom Oleeranon zum äussem Rande des Sehulterblattes einen Einsehnitt und durchtrennt die Maut und die Faseie; am Grunde des Schnittes erseheint der Fleisehkörper des Muskels. Inter dem äussern Sehnittrande findet man mit dem langen Kople den Körper und die Sehne des Vastus extemus rereint. Wenn man mit den Fingern 
den langen Kopf rom Vastus externus scheidet und in den Raum dringt, der normal oben diese beiden Muskeln trennt, so schafft man auf diese Weise einen Muskelgang, in dessen Tiefe man auf dem Vastus internus den Nervus radialis sehen und freilegen kann; an seiner Innenseite liegt die Arteria humeralis profunda. Man folgt dem Strange des Nervus radialis unter dem Vastus externus, den man auch durchschneiden kann bis zu einer fibrösen Schlinge, unter welcher der Nerv hindurchgeht, um die äussere Region des Oberarms zu erreichen.

Aenssere Fläche. Diese wird in der obern Hälfte rom M. deltoides gebildet, welcher unter der Haut hervortritt.

Fig. 13.

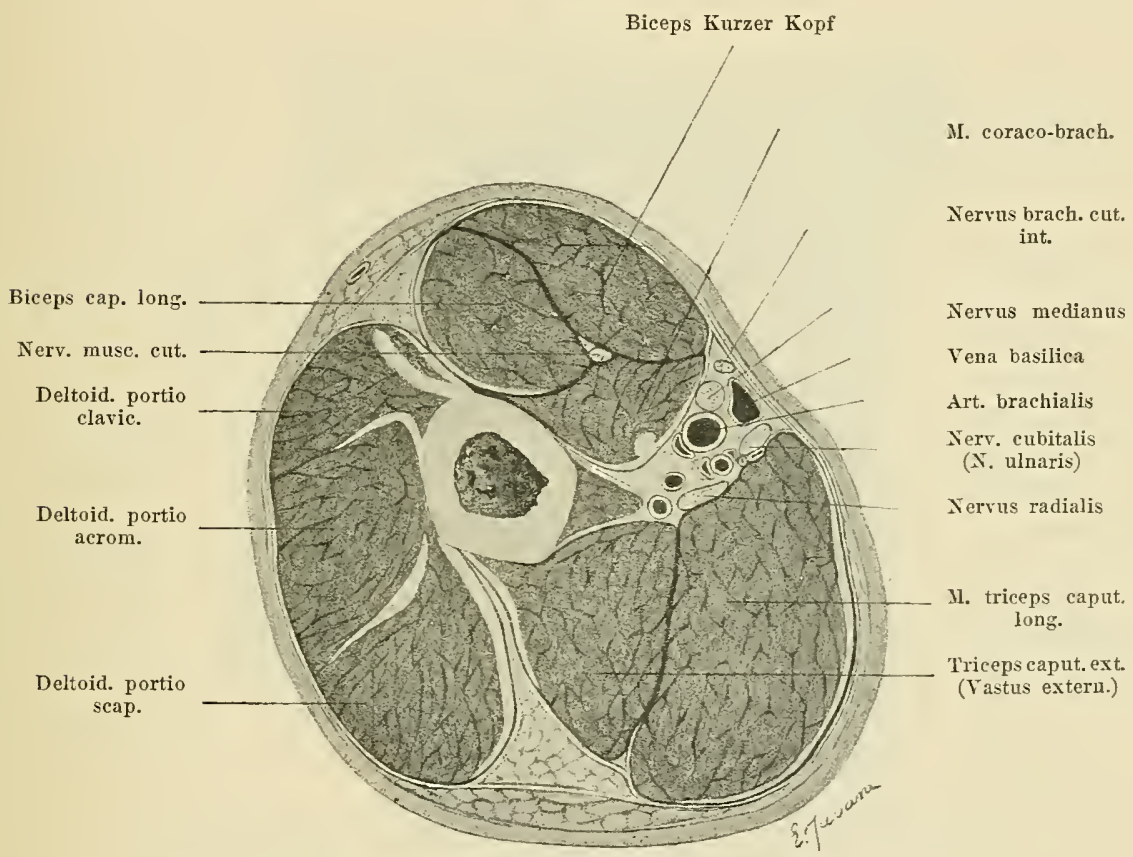

Ein Querschnitt durch das obere Drittel des Oberarmes.

Der Nervus radialis entsteht aus dem Circumflexoradialstamme des Plexus brach. und steigt schief nach abwärts hinter der Art. axillaris auf der vordern Fläche des M.subscapularis und der Sehne des M. latissimus dorsi ab. - Unter dem untern Rande des Teres major gelangt er an den Oberarm in den Gang, welcher ron den drei Körpern des Triceps gebildet wird. Er ist rom Humerus, dem er eine leichte Furche eingräbt, durch ein dünnes mnsculöses Blättchen des Tastus internus getrennt, zieht dann unter dem fibrösen Bogen des Vastus externus, umschlingt den äussern Rand des Humerus und gelangt an die äussere Vorderarmgegend, zieht von hier durch die tiefe Furche, welche rom M. supinator longus und M. radialis primus aussen und rom M. brachialis anterior innen begrenzt wird, weiter und ror der Gelenklinie des Radiocondylgelenkes und im Niveau der Tuberasitas bicipitalis theilt er sich in einen Ramus posterior, welcher 
den Supinator brevis perlorirt, und in cinen Ramus anterior, wolcher eine Strecke weit dic Arteria radialis begleitet.

Techunk z. Freilegung des Yerrus radialis an der Stelle, wo er den ïnsseren Rand des Humerns unschlingt.

Durch eine genaue Palpation an einer mageren Leiche kann man den Radialnerv unter der Haut gleitend auf der Flïche des Humerus fülılen. Man sucht den Nerv auf bevor man eingeschnitten hat und hält ihn unter der Fingerbeere fest. Man macht dann eine tiefe Incision bis zum Knochen, auf diesem findet man, mit der Hohlsonde suchend, den Nervus radialis.

Innere Fläclue. Diese Fläche hat die Form einer verticalen, rom untern Rande des Pectoralis maior bis zum Ellbogen reichenden Furche, wo sie sich in den innern

Fig. 14.

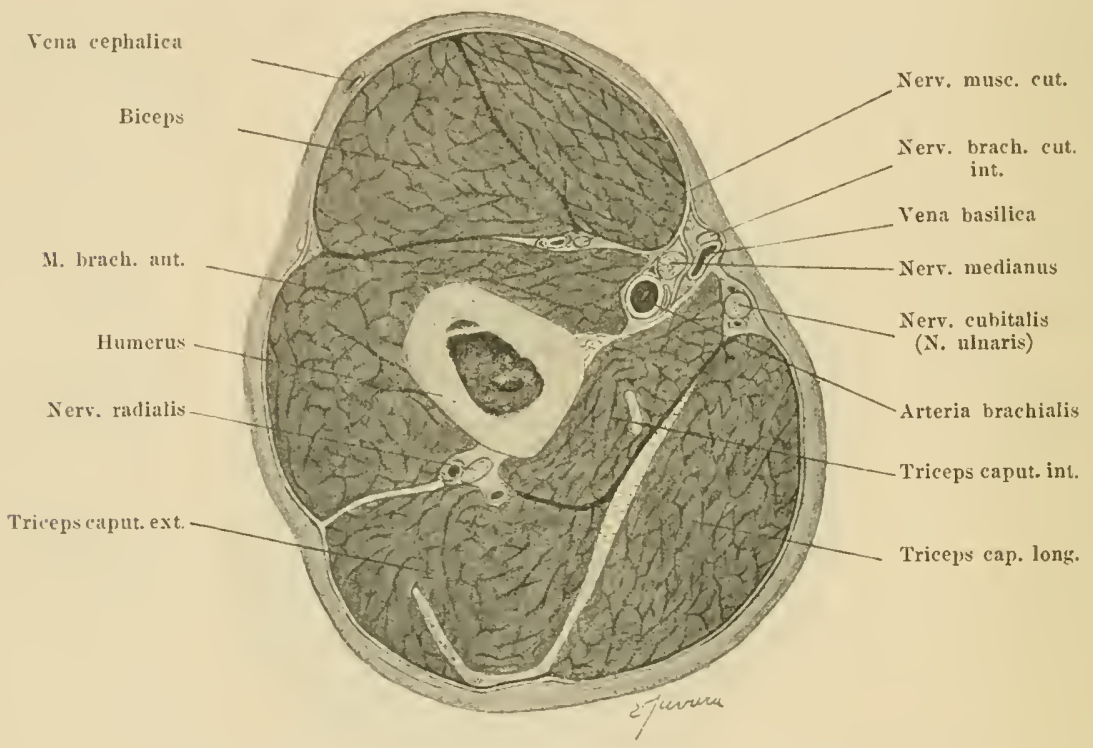

Ein Querschnitt durch den mittleren Theil des Oberarmes.

Schenliel des $V^{r}$. bicipitalis fortsetzt. Diese Furclie is aussen rom Körper des Biceps, hinten rom Brachialis anterior begrenzt. Darin liegen die Arteria humeralis mit ihren Venen, der Nerrus medianus und die Vena basilica mit dem Nervus brachii cutaneus internus.

Bei mageren Individuen ist die Furche der Art. humeralis immer sichtbar.

Arteria brachialis (Art. hmmeralis). Die Art. brachialis entspringt unter dem untern Rande des Pectoralis und endet in Niveau der Beugeseite des Ellbogengelenkes. Sie ist nebst den beiden Venen und dem Nerrus medianus in einer prismatischen, dreiecligen aponeurotischen Ilïlle enthalten, die fibröse Scheide der Oberarmgefässc. Auf dem innern liande des Biceps theilt siclı die Aponemrose in zwei Blättehen, ein tiefes, welches den Bicepsrand bedeckt und sich auf den Brachialis anterior fortsetzt und ein obertlächliches, welches direct rom Rande des Biceps zur Aponeurosis brachialis zieht. 
Der Nervus mediamus liegt zuerst ror und anssen von der Arteria humeralis, kreuzt dann diese an ihrer vordern Seite rorbeiziehend und lagert sich an der Innenseite.

Technik zur Anffindung d. G. Bei einem mageren Cadaver sieht man am abducirten Arme die Furche der Arteria humeralis; bei stärkerer Abduction tritt der Nervus medianus als ein Strang unter der Haut hervor; wenn man den Strang des Medianus nicht sieht, so fühlt man ihn in der Furche mit dem Finger. Man schneidet längs des innern Randes des Biceps die Haut und die Fascie durch, ergreift den inneren Rand des Schnittes und mit der Hohlsonde löst man leicht den innern Rand dieses Muskels ab und zieht ihn mit einem stumpfen Haken seitwärts. Durch

Fig. 15.

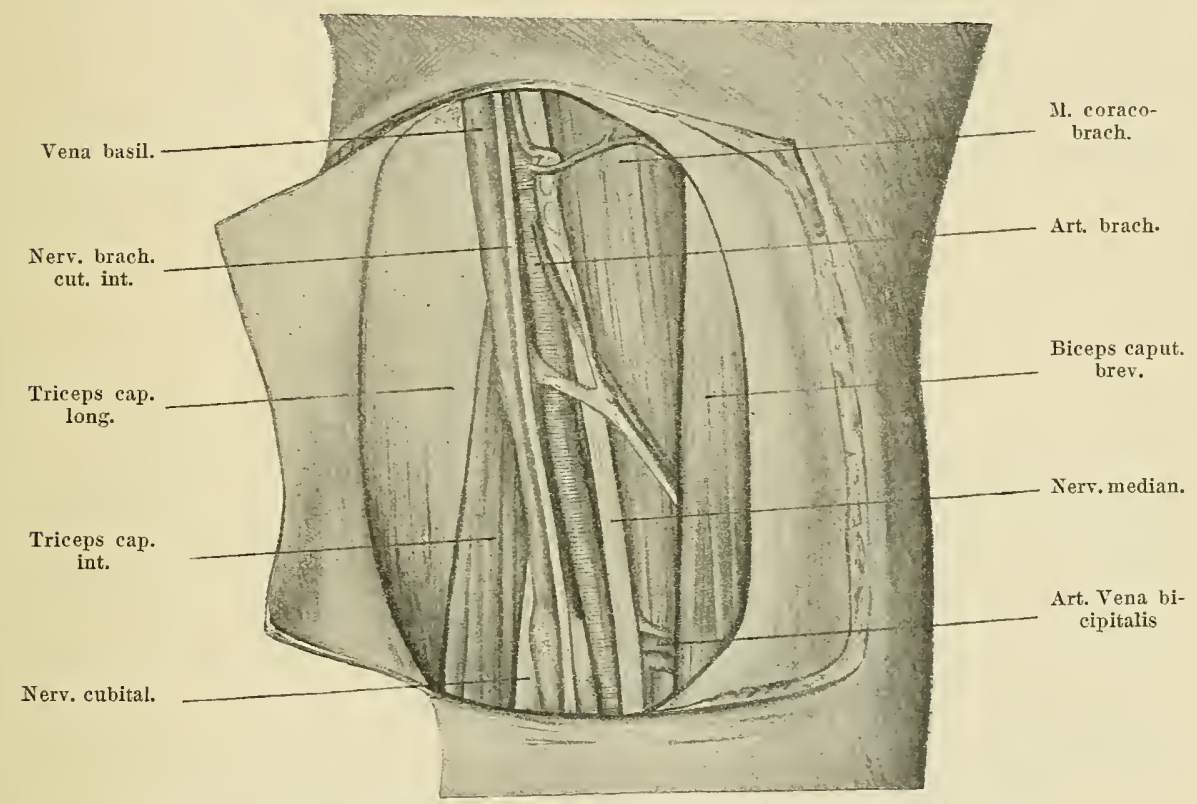

Die Region der Arteria brachialis im mittleren Drittel des Oberarmes.

das Fascienblatt sieht man den gespannten und weiss schimmernden Nerven. Mit der Hohlsonde wird längs des Nerven die Fascie losgelöst, der Nerv freigelegt und auf die Sonde gebracht und mit dem stumpfen Haken abgezogen. Unmittalbar hinter diesem findet man die Arteria humeralis und die beiden Tenen (Fig. 16).

Nervis musculo cutanens und seine Anastomose mit dem Nervus medianus. Der Nervus musculo-cutaneus steigt schief nach unten und aussen in den Raum, welcher zwischen Brachialis anterior und Biceps liegt. In der Höhe des äussern Randes der Bicipitalsehne wird er subcutan und theilt sich in Zweige für die rordere und äussere Hälfte der Vorderarmhaut.

Technik zur Auffindung d. G. Es wird dieselbe Incision wie für den 
Merliamus gemacht. Mit der Hohlsonde wird der iunere Rand des Biecps freimemacht und dieser Iluskel mit einem stumpfer Haken bei Seite gezogen; am rothen Körper des Brachialis anterior erkennt man den weissen Faden des Nerrus musculo-cutaneus und löst ihn mit der Hohlsonde los. Gegen die Mlitte des Oberarmes sucht man die Anastomose, welche den Nerr mit dem Medianus rerlindet. Man findet diese bald schief vom Iledianus zum Musculo-cutaneus, bald wieder schief rom Letzteren zum Mledianus. Ungefähr in dem Verhältnisse 1:10 kann die Anastomose fehlen.

Vena basilica mud Nerrus brachii cutaneus intermus. Die Vena basilica entsteht in der Ellbogengegend durch Znsammenfluss der Vena medio-basilica und der Vena cubitalis und liegt in der Furche der Gefässhülle des Oberarmes etwas oberIlächlich und innen ron der Arterie. Erst subeutan wird sie drei bis rier Finger ober-

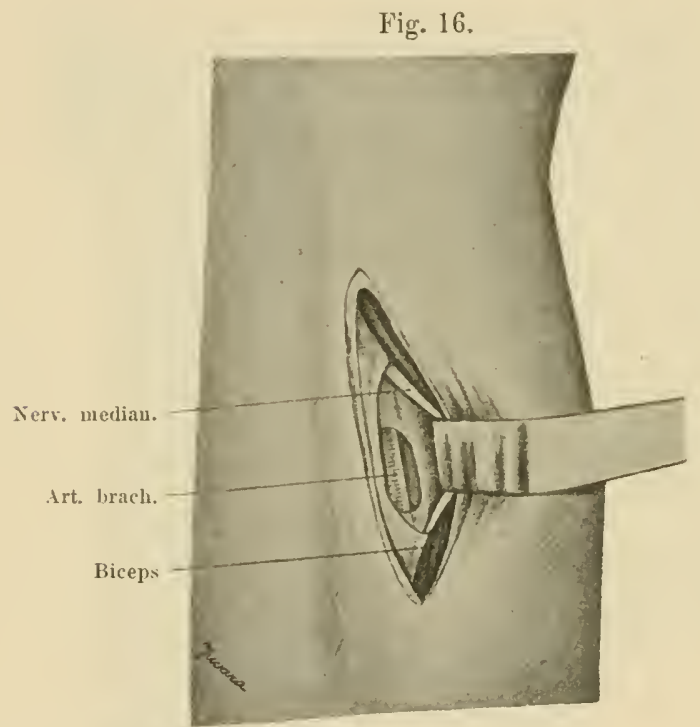

Das Unterbinden der Arteria brachialis im mitteren Theile des Oberarmes. Ein stumpfer Haken zieht den Rand des Biceps und den Medianus nach aussen.

halb der Ellbogengegend snbfascial und dringt unter einem sichelförmigen Bogen in eine Scheide, welche durch Theilung der vorderen und inneren Wand der Gefässhülle gebildet wird. In der Achselhöhle liegt sie, wie wir gesehen haben, unmittelbar an der Innenseite des Nerrus cubitalis, welcher sie ron der Arterie scheidet. Gegen die Mitte der Achselhöhle vereinigt sie sich mit dem Stamme der Oberarmrenen um die Vena axillaris zu bilden.

Der Yervus bracliii cutaneus intermus begleitet die Vena basilica, er theilt sich in drei oder vier Endzweige bestimmt für die rordere innere und hintere Hautfläehe des V'orderarmes. Einer dieser Zweige der Subepitrochlealfaden liegt unmittelbar unter der Epitrochlea.

Tecoluik zur Autfindung d. (d. Man durchschneidet die Haut auf der imnern Fläche des Oberarms längs der Rinne der Arteria humeralis und 
präparirt die Ränder des Schnittes leicht ab, durch die Fascie sieht man die Vena basilica oder den Nerrus brachii cutaneus internus wie eine Saite gespannt. Es wird darauf die Aponeurose mit der Sonde zerrissen und die Gebilde werden sichtbar. Zahlreiche Anastomosen ziehen von der Tena basilica zu den Oberarmvenen.

Nervus cubitalis (Nerrus uhnaris). Er entsteht aus der innern Wurzel des Medianus und steigt auf der innern Fläche des Oberarms unter der Fascie nach abwärts. Im untern Oberarmdrittel liegt er auf einer Muskelschichte des Vastus internus.

Techuik zur Auffindung d. 6. Bei abducirtem Oberarm sucht man den untern Rand des Pectoralis major und die Spitze der Epitrochlea auf. Die Richtung des Nerven wird durch die Linie, welche diese beiden Punkte verbindet, angezeigt. Im mittleren Drittel des Oberarmes wird die Haut durchschnitten und die Ränder des Schnittes abhebend, erkennt man leicht unter der Fascie den Strang des Nervus cubitalis, welchen man lospräparirt und auf die Sonde auflegt. Neben diesem findet man die Arteria collateralis superior interna der Arteria humeralis; welche gegen den Ellbogen abwärts zieht, wo sie hinter der Epitrochlea mit der Arteria recurrens cubitalis posterior anastomosirt; unter dem Cubitalis findet man einen vom Radialis abzweigenden Nervenfaden für den Tastus internus.

\section{Ellbogengegend.}

Vordere Fläche. Auf der vordern Fläche des gestreckten Ellbogengelenkes findet man drei Erhebungen: eine mittlere und obere rom Biceps gebildet, eine laterale innere und untere ron der an der Epitrochlea liegenden Mluskelmasse, welche schief nach unten und aussen gerichtet ist und eine äussere von den Muskeln des Epicondylus gebildet. Diese Muskelerhebungen sind von einander durch zwei Furchen geschieden, welche sich in Form eines $\mathrm{V}$ vereinigen unter der Bicipitalwölbung, das $\mathrm{V}$ bicipitalis. - Der innere Schenkel des $\mathrm{V}$ bicipitalis setzt sich nach oben in die Furche der Arteria humeralis, die Spitze des $\mathrm{V}$ bicipitalis übergeht nach unten in die Furche der Arteria radialis, die wir am Vorderarme kennen lernen werden. Diese Erhebungen sind bei sehr musculösen oder bei zarten Indiriduen besonders sichtbar.

Innerer Schenkel des $\mathbf{V}$ bicipitalis. Längs dieser Furche findet man, oberflächlich die Vena medio-basilica und den Nervus cutaneus brachii internus, in der Tiefe die Arteria brachialis und den Nerrus medianus (Fig. 17).

Vella medio-basilica. Diese stellt den innern Zweig der Bifurcation der Vena mediana dar, etwas oberhalb der Epitrochlea vereinigt sie sich mit der Vena cubitalis und bildet die Vena basilica. Sie befindet sich in der Verdopplung des oberflächlichen zellig-fibrösen Blättchens und liegt auf der faserigen Aponeurose des Biceps, welcher sie ron der Arteria humeralis scheidet. Der Nervus cutaneus brachii internus verläuft gewöhnlich hinter der Vene (Fig. 17-18).

Technik zur Auffindnng d. G. Bei in Extensionsstellung befindlichem Ellbogen erkennt man durch Palpation den inneren Schenkel des $T$ bicipitalis. Mitunter zeichnet sich bei mageren Leichen die Tene unter der Haut in Form eines braunen Streifens ab. Führt man einen langen und 
rorsichtigen Sehnitt lïngs dieser Furehe und präparirt bald den einen bald den anderen Rand der sichnittwunde, so findet man die Vena medio-basiliea und vor dieser den Nerus cutaneus brachii internus. Dic Tene ruht auf einer soliden fibrösen liläche, dor Aponeurose des Biceps.

Arteria humeralis (Arteria brachialis). Diese liegt am Ellbogen in einer limne, die aussen rom innern Rand der Bicepssehne, innen rom äussern Rand des II. pronator teres begrenzt wird. Der Boden dieser Rinne wirl rom Brachialis anterior gebildet. Die Aponeurose des Biceps zieht ror der Arterie, sie ist schief nach unten und innen ron der Bicepssehne bis zur Masse der Epitrochlealmuskeln gerichtet (Fig. 18 bis 20 ).

Nerrits medianus. (Fig. 18-20.) Dieser liegt ungefähr $1 \mathrm{~cm}$ weit an der Innenseite der Arterie, steigt dann in den Zwischenraum, weleher den Kiörper des $\mathbf{M}$. pronator teres rom M. brachialis anterior scheidet. Die Arteria ulnaris anterior recurrens

Fig. 17.

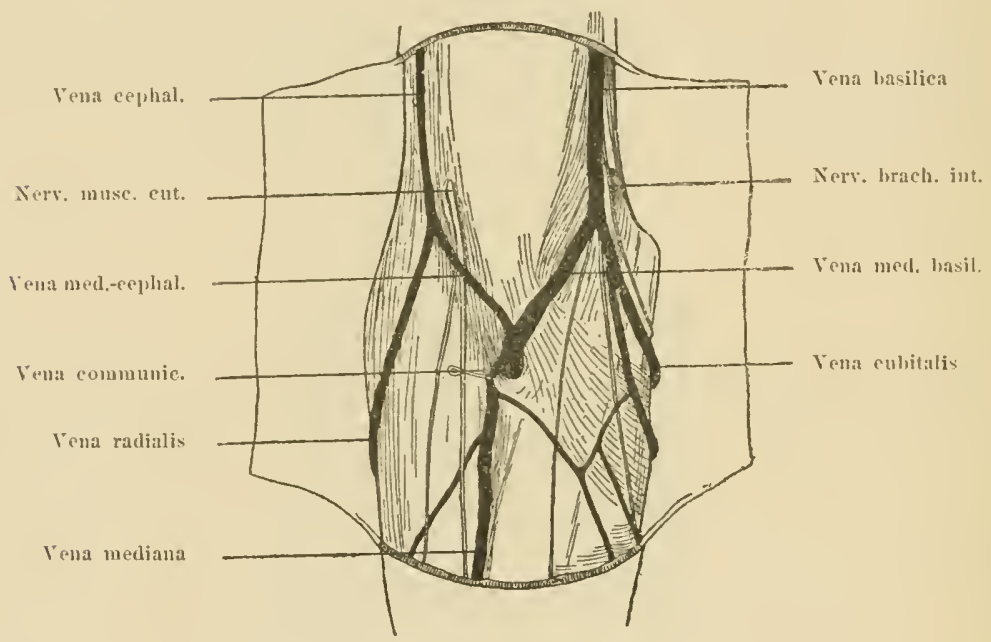

Vordere Ellbogenfläche, oberflächliche Schichte.

erhebt sich etwas nach innen rom Medianus und anastomosirt mit dem absteigenden Zweige der Collateralis inferior her Arteria humeralis (Fig. 26).

Technik zur Anffindung der Arteria humeralis. Es wird dieselbe Ineision wie für die Tena medio-basilica gemacht. Das Operationsfeld wird erwcitert, indem die Ränder des Schnittes leicht abpräparirt werden, die V'ena medio-basilica wird freigelegt und mit dem stumpfen Haken nach der Seite gezogen. Auf der Hohlsonde wird die Aponeurose des Biceps durchschnitten, und man findet unmittelbar unter derselben und an der Innenseite der Bicepssehne die Arteria brachialis mit den beiden sie begleitenden Venen (Fig. 22). Vehr nach innen findet man den Nervus medianus und an seiner Innenseite den vorleren Zweig der Arteria ulnaris recurrens.

Aeusserer Sclienkel des $\mathbf{V}$ bicipitalis. In dieser Furche findet man unter Aer Haut die Vena medio-cephalica und den Terrus musculo-cutaneus, in der 
Tiefe den Nervus radialis und die Arteria recurrens radialis anterior (Fig. 17).

Vena media cephalica. Diese stellt den äusseren Zweig der Vena mediana dar, der Nervus musculo-cutanens verläuft hinter derselben.

Technik zur Auffindnng d. G. Man sucht durch Palpation die äussere Bicipitalfurche und führt längs derselben einen schief nach oben und aussen gehenden Schnitt, und man findet in der Mitte derselben die Vene. Wenn

Fig. 1S.

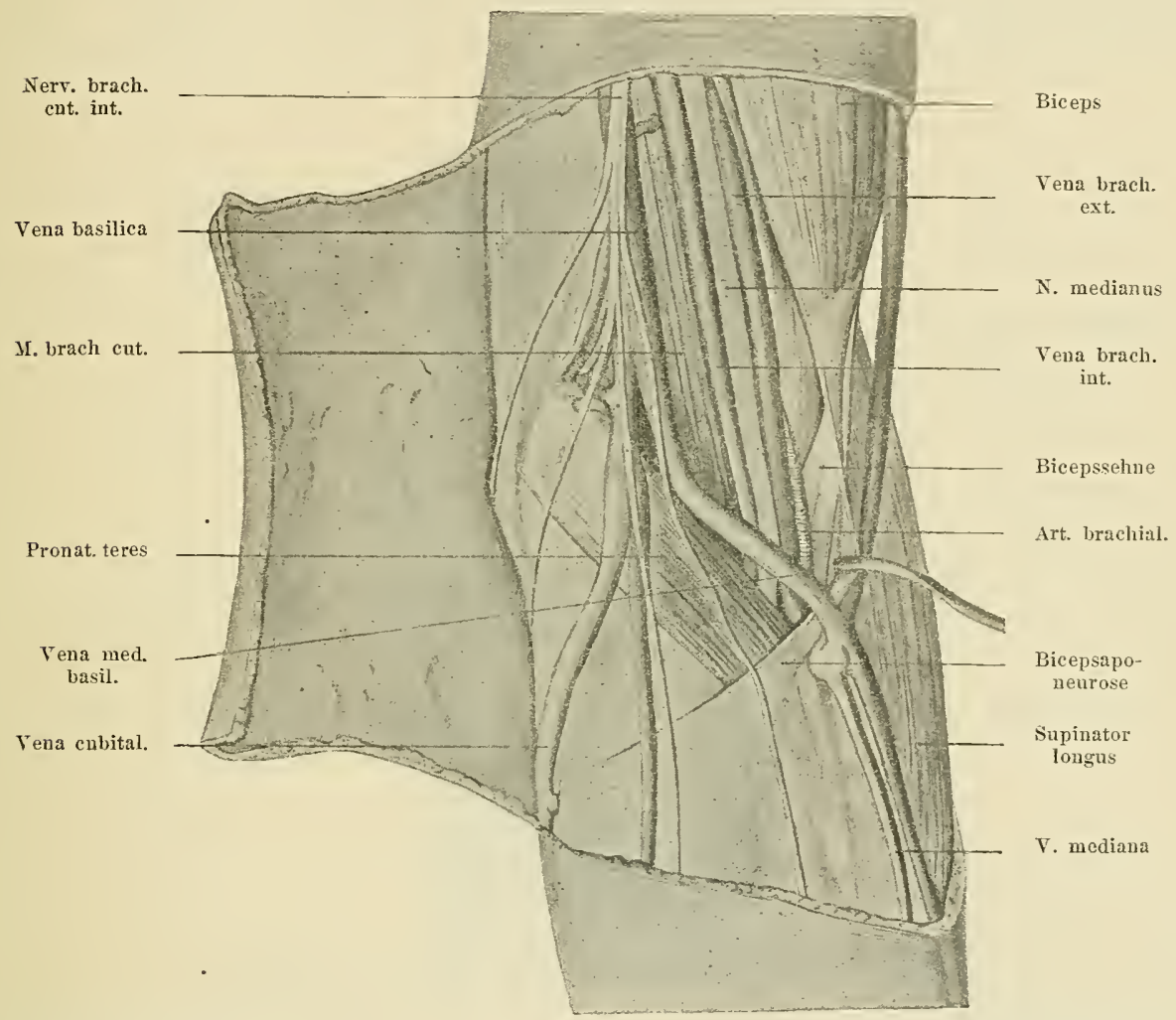

Die linke Ellbogengegend, von ihrer vorderen inneren Fläche gesehen. Ein Haken zieht die Aponeurose des Biceps nach aussen und man findet unter derselben den Nervus medianus und die Arteria humeralis (Art. brachialis).

die Incision nicht der Vene entspricht, dann sucht man sie mit der Sonde und Pincette unter jedem der Schnittränder. Die Tene wird freigelegt und mit dem stumpfen Haken seitwärts gezogen, man findet damn unter derselben den Nervus musculo-cutaneus, welcher am äusseren Rande der Bicepssehne an die Oberfläche tritt.

Nervus radialis. Dieser findet sich in der Tiefe ror dem Gelente in der Ellbogengegend in einer Rinne, welche innen rom Brachialis anterior, aussen rom Supinator longus und Brachialis primus begrenzt wird (Fig. 21). 
Teclunik zur Anflindmo d. fr. Man macht dieselbe Incision wie für die Vena medio-cephalica; die lene wird freigelegt und mit einem stumpfen Haken seitwärts gezogen; mit einem Bistouri wird die Aponeurose lïngs des imneren Randes des Supinator Jongus durchsehnitten. Der Assistent muss den Ellbogen leicht beugen, worauf mit der l'incette und Spitze der Sonde nach oben und unten der Supinator rom Brachialis losgetrennt wird. In der Tiefe auf dem Gelenke findet man den Strang des Nervus radialis ron einer kleinen Arterie begleitet, Arteria reeurrens radialis anterior. Man legt den Nerr frei, hebt iln auf die Hohlsonde und sieht, dass er sich in dem Nireau des Gelenkes theilt in einen Ramus posterior, der unter einer fibrösen Schlinge in den Muskelkörper des Supinator brevis cindringt, und

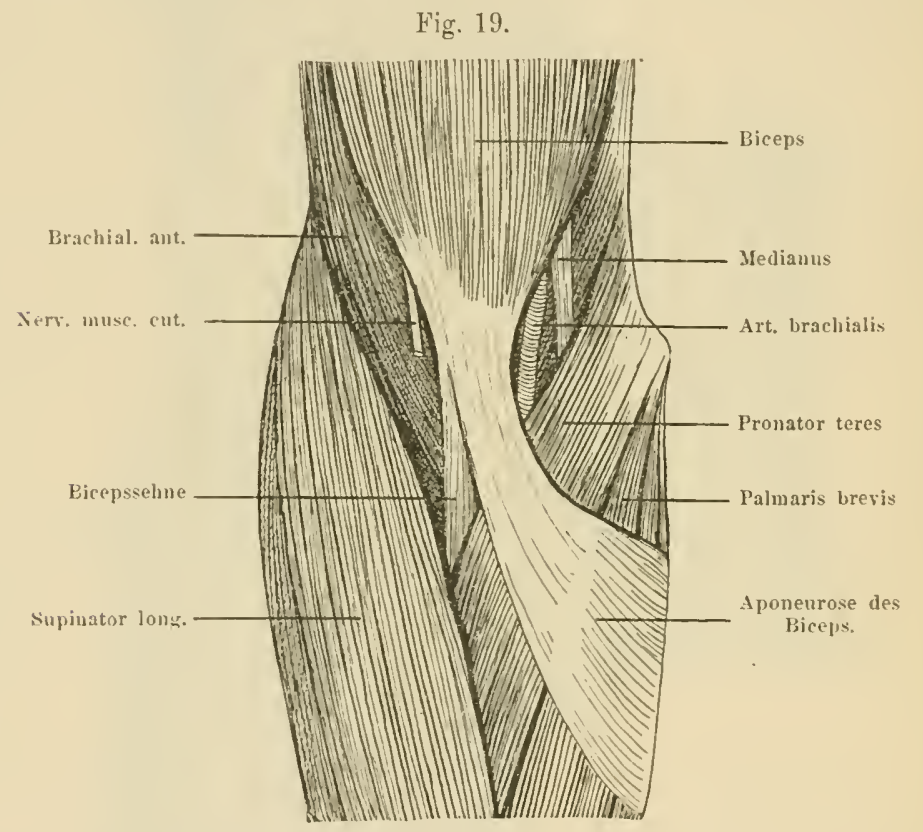

Die vordere Flïche des rechten Ellbogens. Die Fascie und die oberfläehlichen Gebilde sind abgetragen: man sieht die ciebilde der tiefen Schichte.

in einen Ramus anterior, der nach unten verläuft. Bei dieser Präjarirung muss man beachten, sich nicht in den Mluskelkörper des Brachialis anterior zu verlieren; man muss immer gegen das Gelenk zu suchen.

Die Sehme des Biceps liegt in der Medianlinie, gelangt in die Tiefe zum Nireau des Bicepswinkels unter dem Supinator longus, ist sehr fest und leicht gehrümmt, so dass der innere Rand zum rorderen wird (Fig. 18 u. 19). Unten inserirt sie sich an der T'uberositas bicipitalis. Ein Schleimbentel trennt sie ron der glatten und etwas erhobenen Oberfläche, welcher sich vor der Insertion der Selne und dem inneren Rande des Supinator brevis befindet. Dieser Schleimbeutel schickt oberhalb des oberen Randes der Sehne eine Ausbuchtung, welche zwischen der inneren Fläche der Bicepssehne und dem äusseren Rande der Sehne des Brarhialis anterior zu liegen kommt. 
Der Stamm der Arteria cubito-interossea folgt der inneren Fläche der Bicepssehne; die Arteria radialis kreuzt diese.

Technik zur Auffindung d. G. Am eigenen Ellbogen fühlt man die Bicepssehne sehr gut; sie bildet eine Erhebung unter der Haut, welche mit einem unter sie geschobenen Finger wie mit einem Haken gefasst werden kann. Macht man längs des Sehnenstranges einen Einschnitt, erscheint dieselbe unmittelbar. Es werden zwei stumpfe Haken eingelegt, die Sehne bis

Fig. 20 .

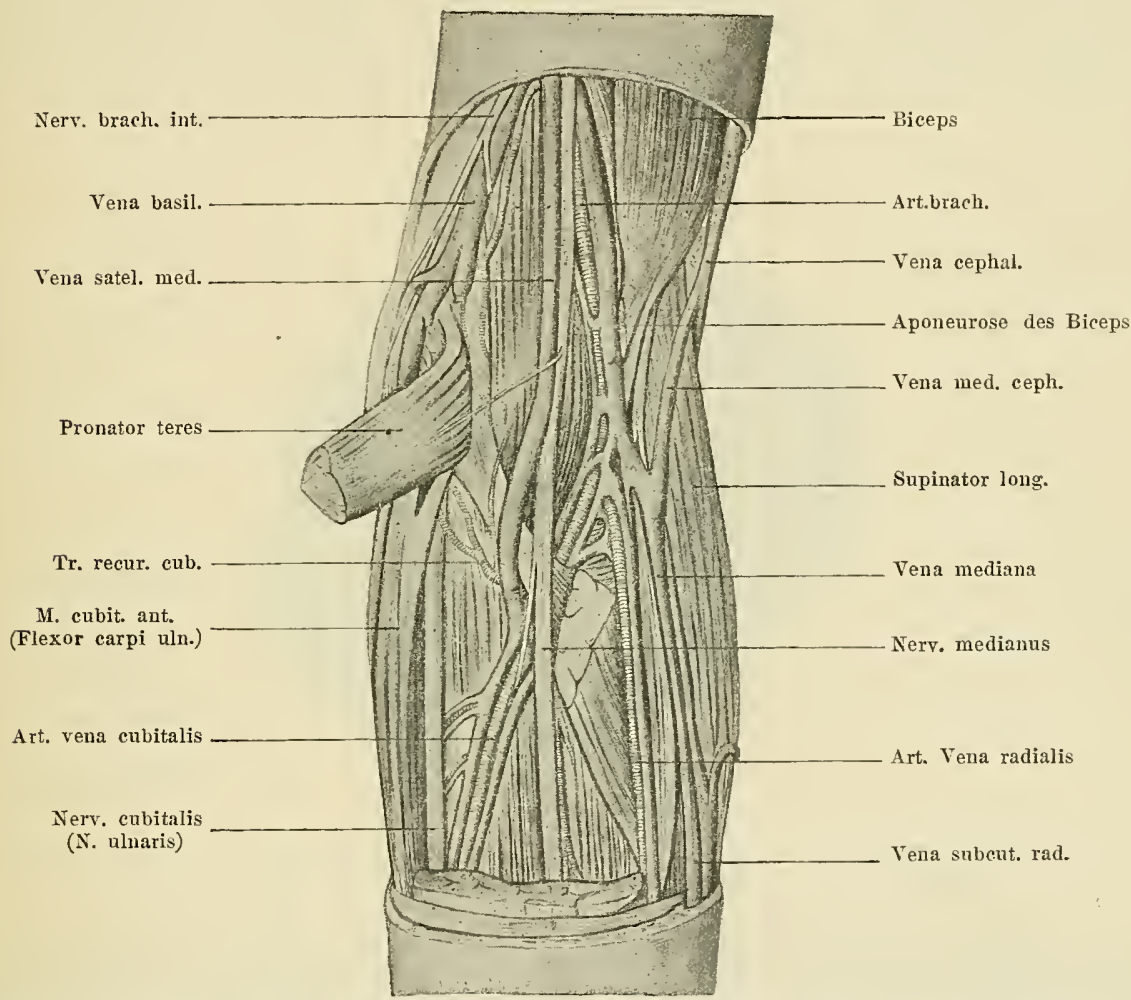

Die vordere Fläche des linken Ellbogens; die tiefliegende Schichte. Das Epitrochlealbündel des Pronator teres wurde durchschnitten und nach innen gezogen; man sieht den Nervus medianus, an seiner Innenseite ron einem venösen Kanale begleitet, $z$ wischen den beiden Bündeln des Pronator teres ziehen. Auch wurde, um die Arteria cubitalis freizulegen, die Gruppe folgender Muskeln: Palmaris major und minor und Flexor superficialis durchschnitten.

zur Insertion an der Tuberositas bicipitalis verfolgt. Es wird hierauf der Schleimbeutel, welcher sie vom Radius trennt, eröffnet und man erblickt an der Innenseite der Sehne die Arteria cubito-interossea. Giebt man den Finger in das Spatium interosseum und ertheilt dann dem Arme Pronationsund Supinationsbewegungen, so fühlt man die Tuberositas bicipitalis unter demselben sich bewegen.

Sobald der Vorderarm sich in starker Supination befindet, kann man 
im Spatimm interosseum im Niveau der Tuberositas bicipitalis den Weitbrecht'schen Strang, von der Ulna bis zum Radius gespannt, finden, an welchem er sich unmittelbar unter der Rauhigkeit anheftet. - Diesem Strange kommt bei der Pronations- und Supinationsbewegung keine Bedeutung zur.

Die Aponeurose des Biceps ist ein fibröses dreieckiges Blatt, das ron der äusseren Fläche, dem vorderen kande und der inneren Fläche der Bicepssehne bis zum Wulste der Epitrochlealmuskeln ausgebreitet ist. In diesem Niveau geht der grösste Theil seiner Fasern in die Fascie dieser Muskeln über oder dringt in den sie scheidenden Zwischenraum. Andere Fasern umlagern die Masse der Epitrochlealmuskeln und inseriren sich am hintern Rande der Una. Diese fibröse Aponeurose scheidet die Tena basilica und den Nerrus brachii cutaneus internus von der Arteria humeralis (Fig. 19, 22).

Fig. 21.

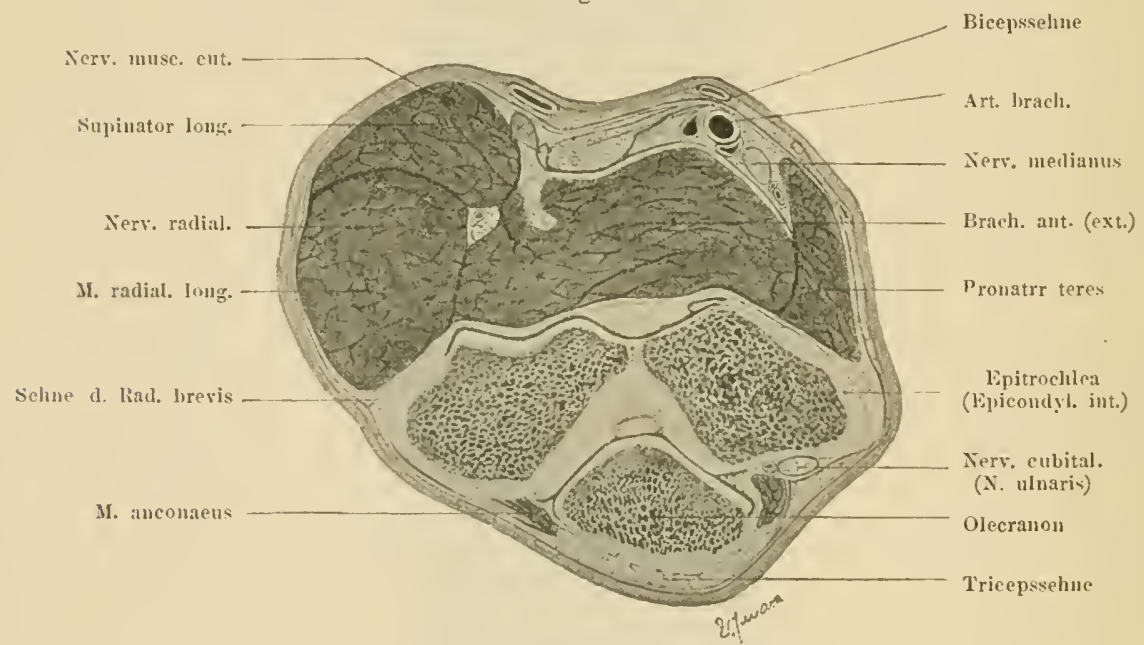

Ein Querschnitt durch die Ellbogenfalte.

Technik zur Auffindung d. (4. An einer mageren Leiche kann man bei gebeugtem EHbogen mit der Fingerspitze die Aponeurose des Biceps fassen. Nacht man von der Bicepssehne einen schiefen Einschnitt bis zum Relief der Epitrochlealmuskeln, so erblickt man in der Tiete die glänzenden Fasern der Bicepsaponeurose. Die Vena medio-basilica wurde hierbei durchschnitten.

Vella mediana. Diese hat einen spiralförmigen Lauf. Entsteht am äusseren Rande der Handwurzel, wo sie sich in die Tena cephalica des Daumens fortsetzt und endet an der Spitze des $\mathrm{V}$ bicipitalis, indem sie sich in einen inneren Ast theilt, die Vena medio-basilica, in einen äusseren Ast die Vena medio-cephalica und in einen tiefen die Vena communicans, welche eine Anastomose der Yena mediana mit den Brachialrenen bildet. Die Tena communicans dringt in die Tiefe unter der Aponeurose durch eine Lücke, welche nach unten durch einen sichelförmigen Rand begrenzt ist (Fig. 17).

Techuik zur Auffindung d. G. Nan macht unter dem V. bicipitalis 
einen verticalen und medianen Einschnitt. In diesem Schnitte findet man die Vena mediana. Wird diese freigelegt und auf die Sonde gehoben, so sieht man auch die Tena communicans. Die Aponeurose wird durchschnitten und man verfolgt diese bis zu den tiefen Tenen.

Supra-epitrochleale Lymphdrüse. Diese liegt zwei Finger breit oberhalb der Epitrochlea etwas nach innen von der Veua basilica am Tractus der oberflächlichen lymphatischen Canäle; sie ist die erste Barriere für eine aufsteigende Infection. Gelegentlich beobachtet man eine Entzündung, Adeno-Phlegmone der supraepitrochlealen Lymphdrüse in Folge einer Lymphangoitis, die zum Ausgangspunkte eine Verletzung am Finger hat. Im Allgemeinen sehr klein ist die Lymphdrüse rergrössert bei Syphilis und Tuberculose.

Fig. 22.

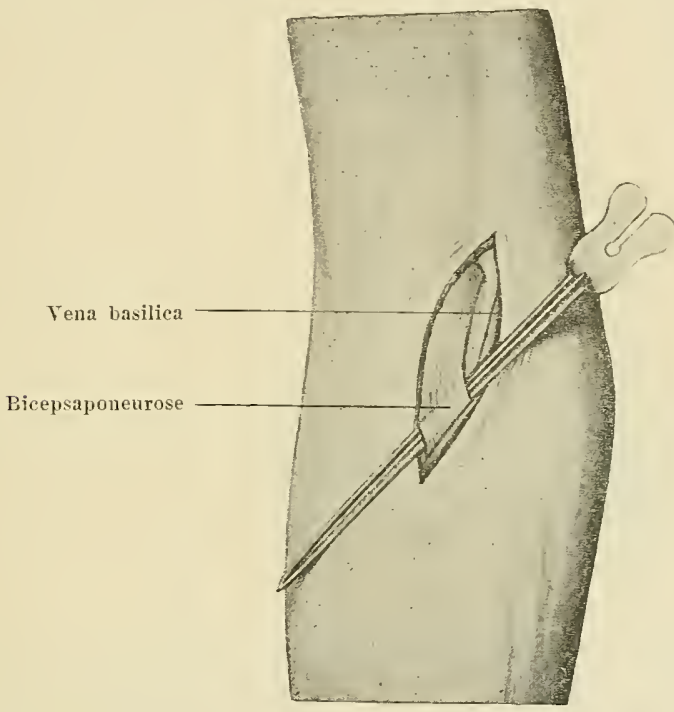

Die Bicepsaponeurose ist isolirt und auf eine Sonde gehoben.

Technik zur Auffindung d. G. Wenn man die Region oberhalb der Epitrochlea abtastet. so fühlt man oft, besonders an einem mageren Individuum, unter den Fingern die supra-epitrochleale Lymphdrüse gleiten.

Fühlt man die Lymphdrüse nicht, dann macht man oberhalb der Epitrochlea einen verticalen Einschnitt und aufmerksam präparirend findet man einen kleinen röthlichen Körper, die Lymphdrüse. Zuweilen kann sie auch fehlen.

Hintere Fläche des Ellbogens. An der hinteren Fläche findet man drei knöcherne Frhebungen, eine mittlere stark herrortretende, das Olecranon, eine innere, die Epitrochlea und eine äussere, den Epicondylus. Wenn der Ellbogen rollständig gestreckt ist, dann befinden sich diese Erhebungen in einer horizontalen Linie. Bei Beugung findet man das Olecranon an der Spitze eines Dreiecks, dessen Basis die Linie darstellt, die die Epitrochlea und den Epicondylus verbindet.

An jeder Seite des Olecranon findet man eine Furche, die änssere Furche, Sulcus 
olecrano-epicondylus, ist breit, aber wenig lief und wird aussen vom Epieondylus, immen ron der äisseren Fläche des Olecranon begrenzt.

Die innere Furehe, Sulcus olecrano-epitrochlearis, ist tiefer, aber weniger breit als die äussere und wird rom ron der Epitrochlea, aussen dnreh die innere Fläche des Olecranon begrenzt. In dieser Furche verläuft hinter der Epitrochlea der Nerrus ulnaris.

Epitrochlea (Fig. 23). Sie bildet eine stark herrorspringende lnöcherne Erhebung und liegt auf der innern Seite des untern Humerusrandes. Bei mageren Indiriduen sichtbar ist sie bei fetten der Palpation leicht zugänglich. An einem infiltrirten und entzündeten Ellenbogen kann das Auffinden der Epitrochlea Schwierigkeiten begegnen. In diesem Falle wird der innere Rand des IIumerus mit den Fingern langsam abgetastet und in einem gegebenen Momente fühlt der Finger durch die Weichtheile die Epitrochlea.

Oberhalb der Epitrochlea fühlt man einen fibrösen Strang rom Rande des Ifumerus bis zur Spitze der Epitrochlea gespannt, es ist dies der Rand der Laseia intermuseularis interna.

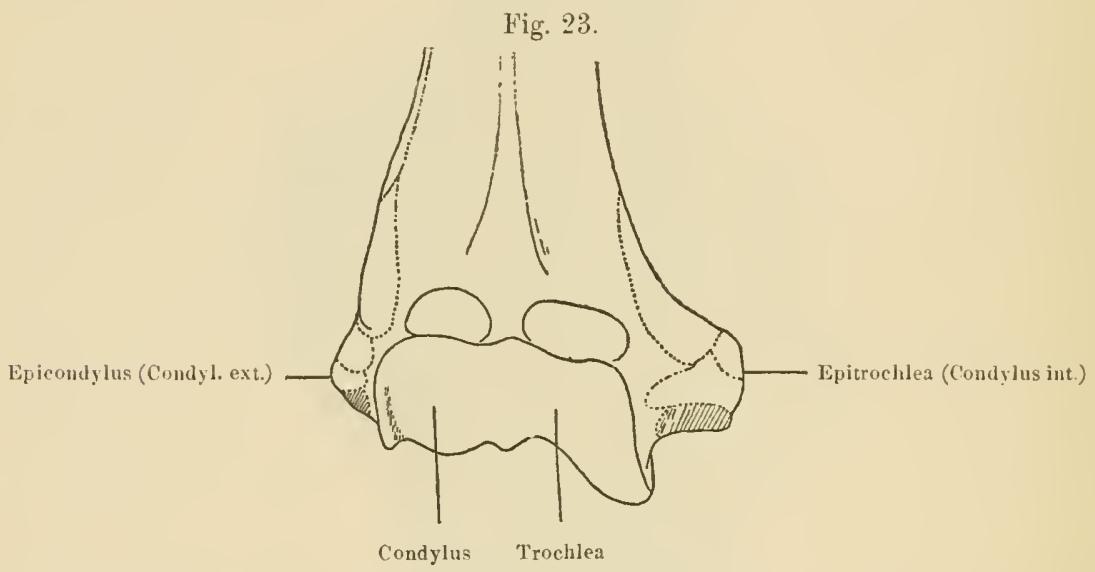

Die rordere Fläche des unteren Endes des Humerus. Die punktirten Linien begrenzen das Insertionsfeld folgender Muskeln: aussen von oben nach unten Supinator longus, Radialis primus, Radialis secundus und Supinator brevis; innen Pronator teres, die vereinigten Sehnen der Palmaris und des Flexor superficialis; die schwarz liniirte Oberfläche entspricht den Insertionen der Bündel des mittlern Ligamentes.

Der Epicondylus (Fig. 23) bildet eine wenig hervortretende knöcherne Erhabenheit und liegt an der äusseren Seite des untern Gelenlirandes des Humerus. Bei mageren Individuen ist diese leicht durchzufühlen, bei entwickeltem Panniculus adiposus oder Muskulatur ist das Auffinden schwieriger, umsomehr, wenn der Ellbogen in Extensionsstellung ist, da derEpicondylus sich unter der Masse der Muskeln verbirgt. Bei gebeugten Ellbogen tritt der Epicondylus hervor und kann leieht gefunden werden (Fig. 12).

Unterhalb des Epicondylus gelangt der untersuchende Finger in eine Vertiefung, unter welcher er eine neve knöcherne Erhebung prominirender als der Epicondylus fühlt, das Radiusköpfchen. Ertheilt man dem Vorderarme Pronations- und Supinationsbewegungen, dann sieht man, dass der Radiuskopf sich bewegt.

Die Grube zwischen Epicondylus und Radius entspricht der Interarticularlinie. In der Extensionsstellung ist das Capitulum radii vou Condylus ungefähr $1 \mathrm{~mm}$ entfernt. Die Klinge eines Messers in diese Vertiefung eingeführt dringt in das Gelenk ein. 
Geleuklinie. Diese ist oben von dem, imnen in die Trochlea, aussen in den Condylus getheilten, untern Rande des Humerus, unten und innen von der Ulna, unten und aussen von dem Radius begrenzt.

Vorn ist die Gelenklinie schwer zu bestimmen. Sie ist von dicken Muskeln, in der Medianlinie von Brachialis anterior und Biceps, innen von den Muskeln der Epitrochlea, aussen von den Muskeln des Epicondylus bedeckt. Sie kann nur auf der äusseren Seite bestimmt werden, wenn wir die Muskeln entspannen, indem wir den Ellbogen beugen.

Hinten kann das Gelenk von jedem Theile leicht gefühlt werden.

An den Seitentheilen des Olecranon macht die Synovia, wenn sie von Flüssigkeit oder Fungusmassen ausgedehnt ist, Erhebungen, die die Furchen des Olecranon ausfüllen.

Gelenkkapsel. Diese stellt eine vollständige Hülle dar; die Kapsel ist an jeder Seite des Gelenkes durch Bänder verstärlit, besonders aber an der innern und äussern Seite. -

Das innere Ligamentum laterale wird aus drei Bündeln gebildet, einem

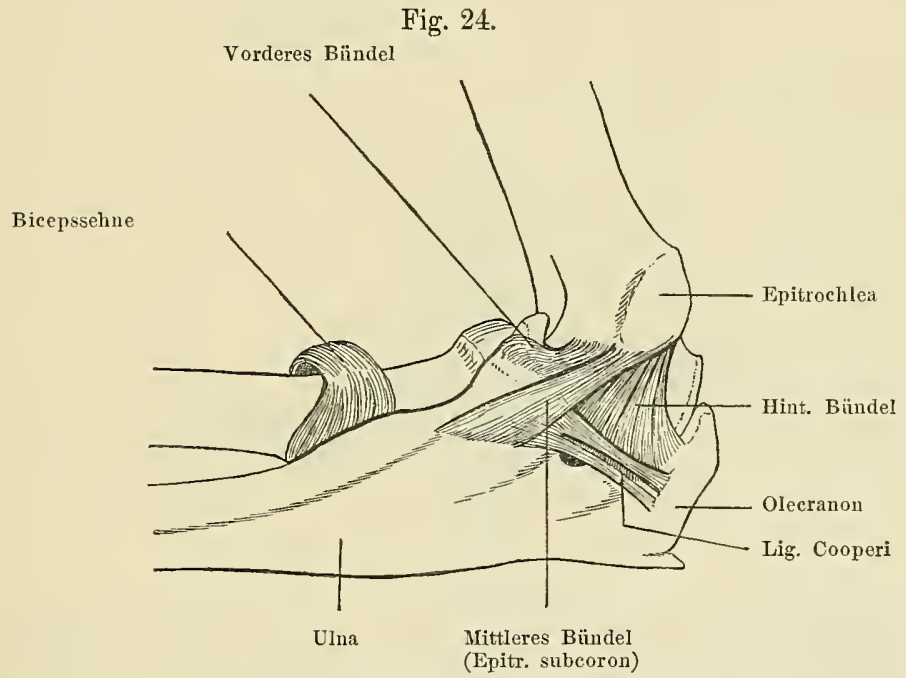

Das Ellbogengelenk; innere Fläche.

vorderen Epitrochleo-coronoidalbündel, einem mittleren Epitrochleo-subcoronoidalbündel und einem hinteren Epitrochleo-olecranonbündel.

Sie bilden einen Fächer, welcher ron der Epitrochlea zum innern Rande des Processus coronoides und Olecranon ausstrahlt (Fig. 24).

Das mittlere Bündel ist das stärliste und inserirt sich oben an der Spitze der Epitrochlea, unten am Tuberculum subcoronoideum und am innern Rande der Ulna.

Sehr fest spannt es sich bei der Abduction an und beschränkt sie. Dieses reisst das Tuberculum coronoideum bei imnern Verrenkungen des Ellbogengelenks ab.

Technik z. A. d. G. Man macht einen tiefen Einschnitt zwischen der Epitrochlea und dem inneren Rande der Ulna, erweitert darauf die Schnittränder, und man sieht in der Tiefe am Knochen die glänzenden Fasern des inneren Ligamentes, welche besser gefunden werden, wenn man die Epitrochlealmuskeln durchschneidet. 
Das änssepe Ligamentum laterale wird ebenso wie das innere ans drei Bündeln gebildet, cinem vorderen Epicondylo-praesigmoidalbündel, cinem mittleren Epicondylo-sub-sigmoidalbündel und einem hinteren Epicondyloolecranonbündel.

Das vordere Bündel ist gegen die vordere Wand der Fossa sigmoidea ulnae gerichtet; das mittlere ist vertieal. Diese beiden Bündel dureh schwache Fasern des ligamentum annulare rereinigt, begrenzen eine Oellnung, durch welche das Capitulum radii in den inneren Raum des Gelenkes eintritt (Fig. 25).

Technik z. A. d. G. Ton der Spitze des Epicondylus wird eine verticale Incision gemacht, die Hant und die oberflächliche Mluskelschicht bis zum Supinator brevis durchschnitten. Tom Epicondylus werden die Ansätze der Epicondylialmuskeln abgelöst, um einen grösseren Raum zu

\section{Fig. 25.}

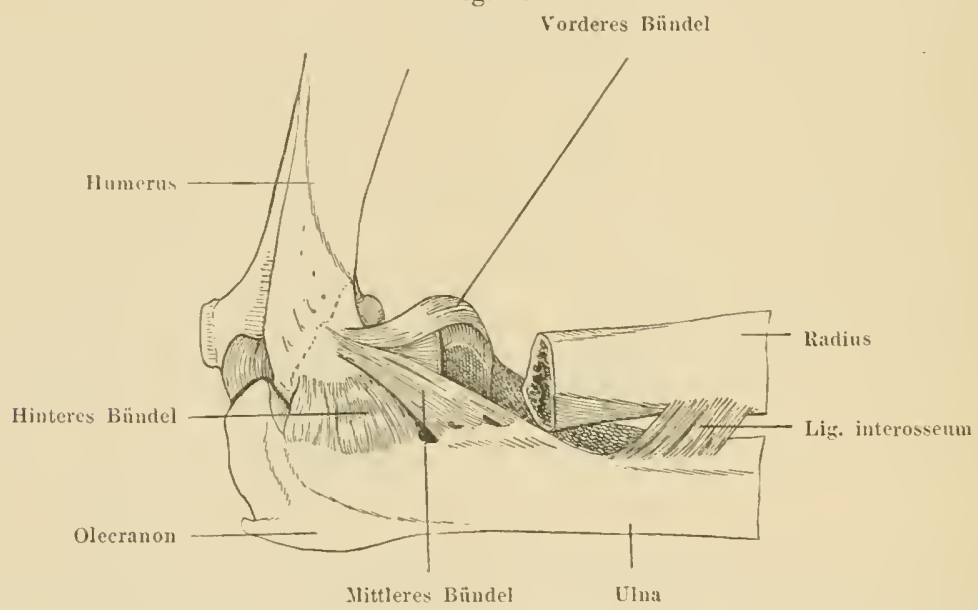

Die äussere Fläche des rechten Ellbogengelenkes. Das obere Ende des Radius ist entfernt, man sieht das Orificium, durch welches der Kopf des Radius in den Innenraum des (ielenkes dringt.

gewinnen. Wird darauf Schicht für Schicht die obere Insertion des Supinator brevis präparirt, so findet man damn hinten das mittlere $B$ ïndel und vorne das vordere Bündel, welches das Radiusköpfchen umschlingt.

Nervus cubitalis (Nerrus uluaris). Hinter der Epitrochlea. Der Nerr verläuft hinter der Epitrochlea und ist immer in der Furche an der hinteren Fläche sichtbar (Fig. 26).

Techunik z. A. d. (1). Wemn man die hintere Fläche der Epitrochlea abtastet, so fühlt man den Nerrus cubitalis als einen Strang. Mlit der Fingerbeere wird der Ners gegen das Olecranon gedrückt, darauf die Weichtheile bis zum Knochen durchschnitten, ohne dass man sich um den Nerv, 
der unter dem Finger sich befindet, zu kümmern hat; es erscheint sofort im Schnitte der Nerv von einem weichen Bindegewebe umgeben. Wird der Nerv auf die Hohlsonde gehoben, so sieht man an der Innenseite die Arteria recurrens ulnaris posterior. Wird der Nerv aus seiner Nische gezogen und bis über die Spitze der Epitrochlea gehoben, und beugt man das Ellbogengelenk, so spannt sich im Grunde des Schnittes das hintere Epitrochleo-olecranonbündel an.

Musculus anconaens (quart.) und sein Nerv. Der Anconaeus liegt in der äusseren Olecranonfurche und hat die Form eines Dreiecks, welches vom Epicondylus

Fig. 26.

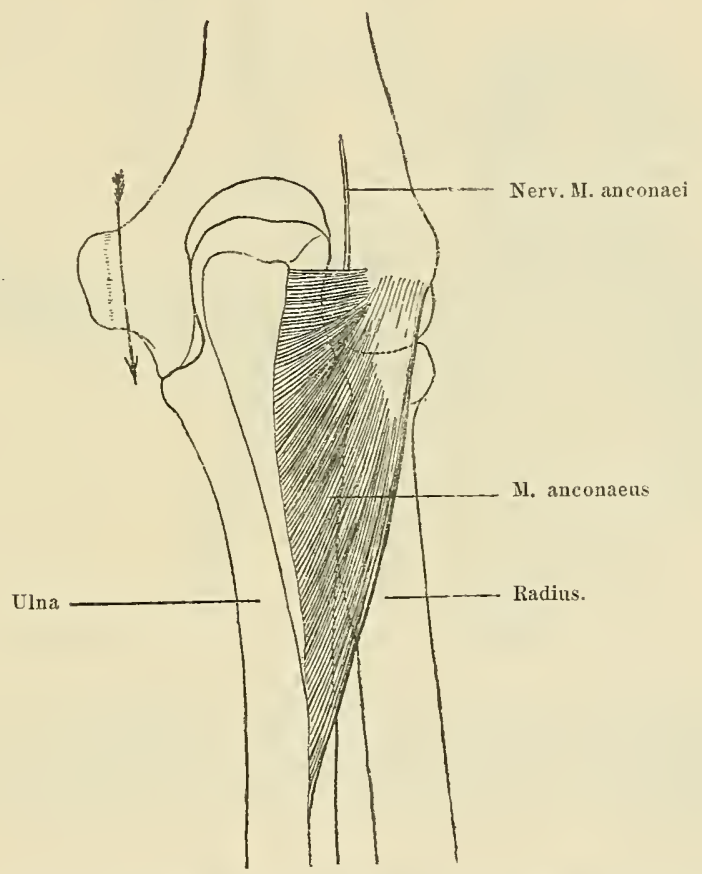

Die hintere Fläche des rechten Ellbogens. Der Musculus anconaeus und sein Nerv. Der Pfeil zeigt die Richtung des Nervus cubitalis in der Furche, welche an der hintern Fläche der Epitrochlea sich befindet.

zur dreieckigen Fläche, welche an der äusseren Seite des Olecranon und der Ulna besteht, sich erstreckt. Er entsteht auf der hinteren Fläche des Epicondylus mit einer schönen Sehne und inserirt sich mit Fleischfasern an der Ulna. Sein oberer sehr dünner Rand setzt sich in den unteren Rand des Vastus internus fort (Fig. 26).

Technị z. A. d. G. Führt man vom Epicondylus gegen den hinteren Rand der Ulna eine Incision und schneidet die unter der Haut befindliche feste fibröse Fläche durch, welche von den sehnigen Ausbreitungen des 
Vastus externus gebildet wird, dann erscheint der Fleischkörper des Aneonacus.

Wird scin äusserer Rand freigelegt, so findet man in der Tiefe die Arteria recurrens radialis posterior. Durchschneidet man vertieal den Fig. 27.

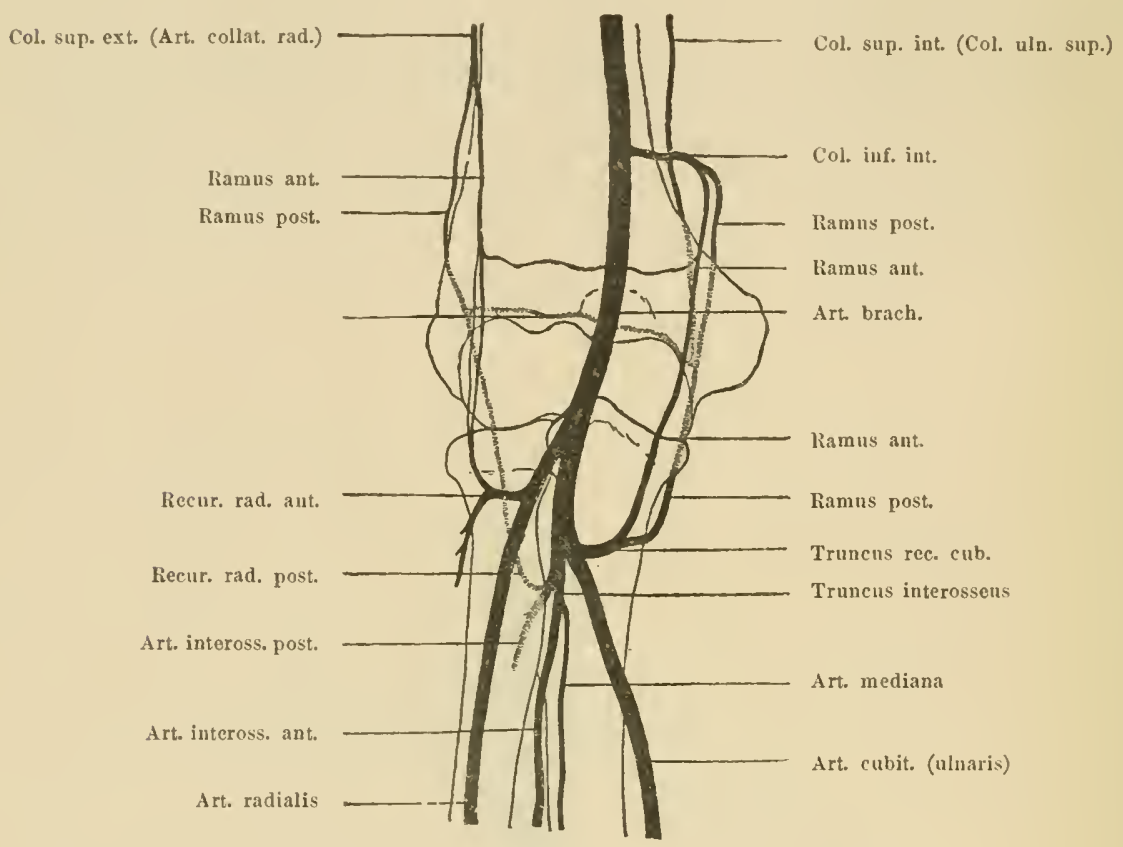

Der Plexus arteriosns rings um das Ellbogengelenk.

Muskelkörper des Anconacus in der Mitte zwischen Olecranon und Epicondylus, so findet man seinen Nervenfaden; verfolgt man diesen nach oben, so sicht man ihn von dem für den Vastus internus bestimmten Zweige des Radialis abgehen.

\section{Die Region des Vorderarmes.}

Vordere Fläche. Die rordere Fläche des Vorderarmes hat die Form einer Furche, Sulcus arteriae radialis, welche am Ellbogen beginnt und sich in das $\mathrm{r}$. bicipitalis fortsetzt und im Nireau der Handwurzel endigt. Diese Furche ist innen von dem Relief der Epitrochlealmusleln, oben rom Pronator teres, unten rom Palmaris longus und aussen durch die Erhebung des .I. supinator longus begrenzt.

Der Boden dieser Furche wird ron oben nach unten durch den Pronator teres, M. flexor sublimis und Pronator quadratus gebildet. Bei fetten Individnen ist die Furche wenig sichtbar. Man kann diese aber leicht bestimmen durch aufmerksame Untersuchung. 
Arteria radialis und der rordere oder Hautast des Nervus radialis. Die Arteria brachialis theilt sich in der Höhe der Ellbogenbeuge, oberhalb des obern Randes des Pronator teres in zwei Aeste: einen rordern, mehr oberflächlichen und äussern Ast, die Arteria radialis, er zieht oberhalb der Bicepssehne und des Pronator teres nach unten gegen die Handwurzel; einen hintern, tiefen und innern Ast, der Stamm der Arteria cubito-interossea; er verläuft längs der Bicepssehne und dringt unter dem Pronator teres durch und theilt sich in die Arteria cubitalis und in den Stamm der Arteria interossea.

Arteria radialis. Sie steigt längs der Huskelrinne, die früher erwähnt wurde, herab und theilt sich im Niveau des untern Radiusendes in die Arteria radio-palmaris und in die Arteria radio-dorsalis, welche auch die Fortsetzung der Arterie ist.

Fig. 28.

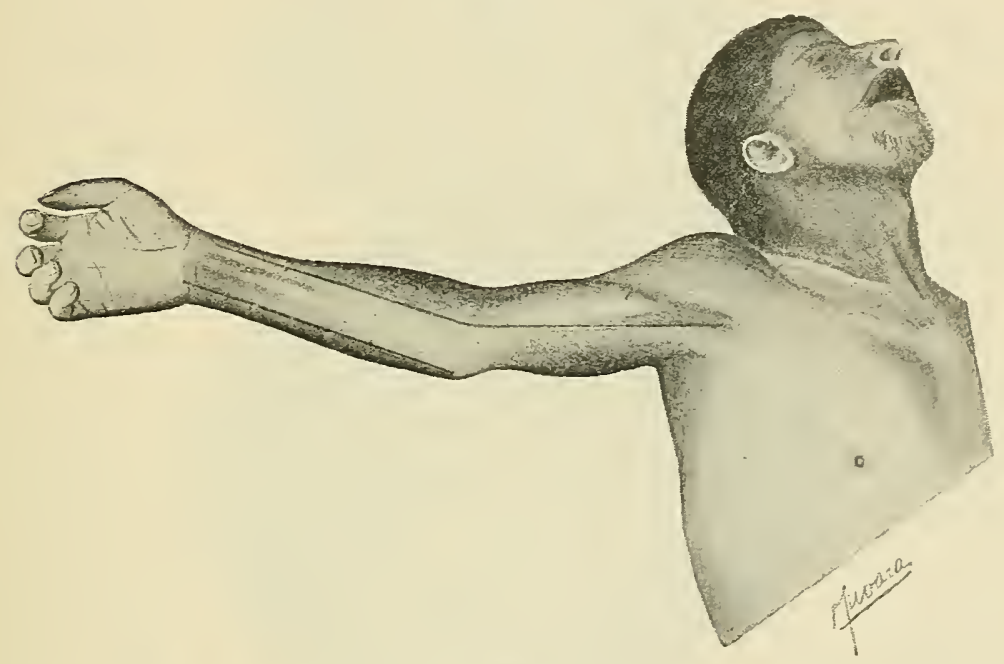

Die vordere Fläche der rechten oberen Extremität. Die äussere schwarze Linie, die unter dem Rande des Pectoralis beginnt und an der Handwurzel endigt, zeigt die Richtung der Arteria brachialis und ihrer Radialäste; die innere Linie, die an der Epitrochlea beginnt und am Erbsenbeine endigt, zeigt in den beiden unteren Dritteln des Vorderarmes den Verlauf der Arteria cubitalis (ulnaris) an.

Die Arteria radialis befindet sich in einer Scheide, die aus einem zellig fibrösen Blättchen gebildet wird, welche die vordern innern von den hintern äussern Muskeln scheidet. Unmittelbar unterhalb des Ursprunges giebt sie den Zweig ab, die Arteria recurrens radialis anterior, welche zahlreiche Muskel- und Hautäste entsendet.

Der vordere Ast des Nerrus radialis befindet sich nicht in derselben Scheide mit der Arteria radialis (Fig. 29), sondern ausserhalb der Arterie in der Scheide der Epicondylusmuskeln unter der tiefen Fläche des Supinator und am innern Rande des Radialis primus.

Der Nervus radialis entfernt sich ron der Arterie im Nireau der Vereinigung des untern Drittels mit den obern zwei Dritteln des Vorderarmes. Er durchbohrt die Fascie und verläuft unter dem untern Sehnenrande des Supinator longus. Bei einem stark musculösen Cadaver ist die Arteria radialis im oberen Theile rom innern Rande des Supinator longus bedeckt. 
Technik z. A. d. (4. Findet man die Arterialrinne, so wird in ihrem obern Theile cin Einschnitt von $4-5 \mathrm{~cm}$ gemacht. Dic Vena medianil, die im Schnitte gefunden wird, cntfernt man, und man sieht durch die Fascie lindurch den innern Rand des Supinator longus. Wird die Fascie längs dieses Randes durchschnitten, der Supinator freigemacht und mit einem Haken abgezogen, dann sicht man die Radialgefüsse durchschimmern, welche dem Pronator teres aufliegen. Mit der Sondenspitze wird das sie berleckende Blättchen durchrissen, die Arterie und die sie begleitenden Venen freigelegt und gehoben.

Fig. 29.

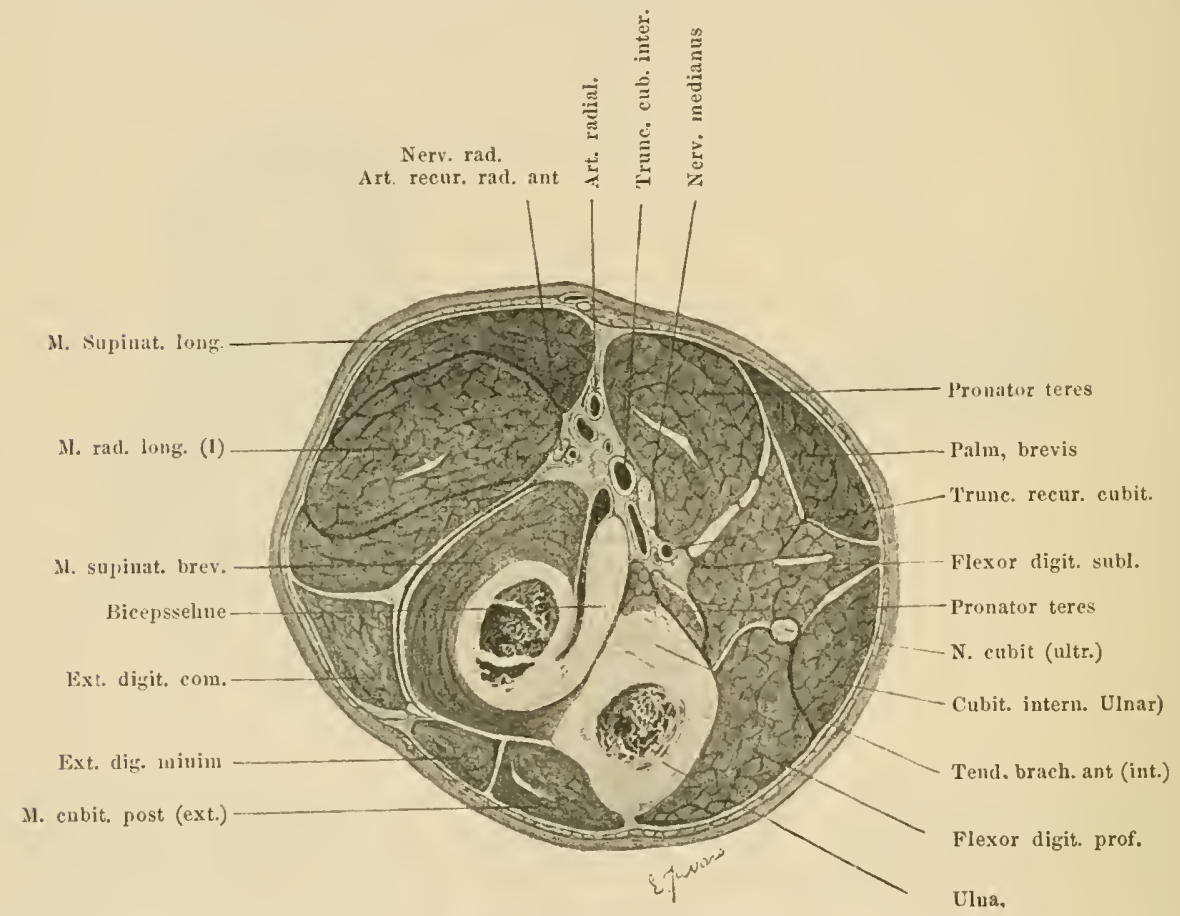

Ein Querschnitt durch das obere Drittel des Vorderarms. Die schwarze Linie an der Aussenseite der Bicepssehne zeigt den Schleimbeutel an, der in diesem Niveau existirt.

An der Aussenseite der Arterie und unter der tiefen Schichte des Supinator longus findet man den Nervus radialis. Im untern Drittel des Torderraums wird clie Arteria radialis subcutan. Macht man einen leichten Einschnitt in den Boden der Radialrimne einen halben Centimeter nach aussen von der Sehne des Palmaris longus, so sieht man durch dic Fascie das Gefässpaket. - Wird diese Fascie auf der Hohlsonde durchschnitten, so findet man unmittelbar unter derselben die Arterie und die sie begleitenden V'enen.

Die Epitrochlealmuskeln sind 5 an Zahl, die von aussen nach innen in folgender Ordnung liegen: Pronator teres, Palmaris brevis, Palmaris longus, Flexor superficialis und Cubitalis anterior. Dise Muskeln sind im obern Drittcl des Vorderarms zu 
einem gemeinsamen sehnig-musculösen Körper vereint und theilen sich unten fächerförmig; sie bilden zusammen die vordere und innere Hälfte der oberflächlichen Muskelschichte. Die hintere und äussere Hälfte wird von den Epicondylusmuskeln gebildet. Die Gruppe der Epitrochlealmuskeln wird von der Epicondylusgruppe hinten durch den hintern Rand

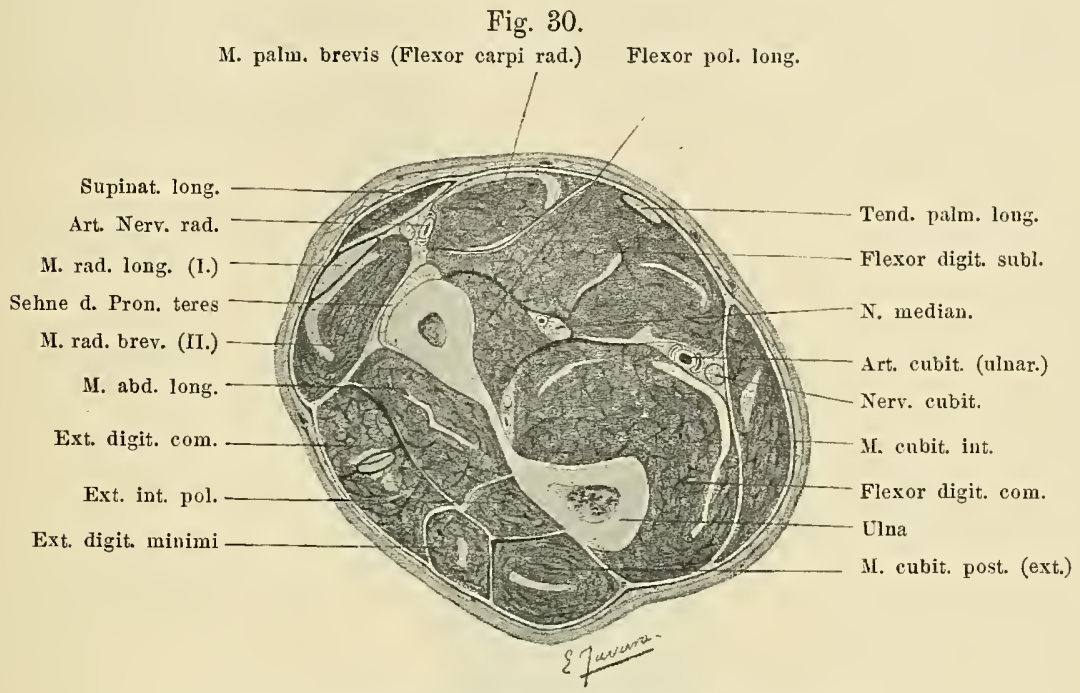

Ein Querschnitt durch die Mitte des Vorderarms.

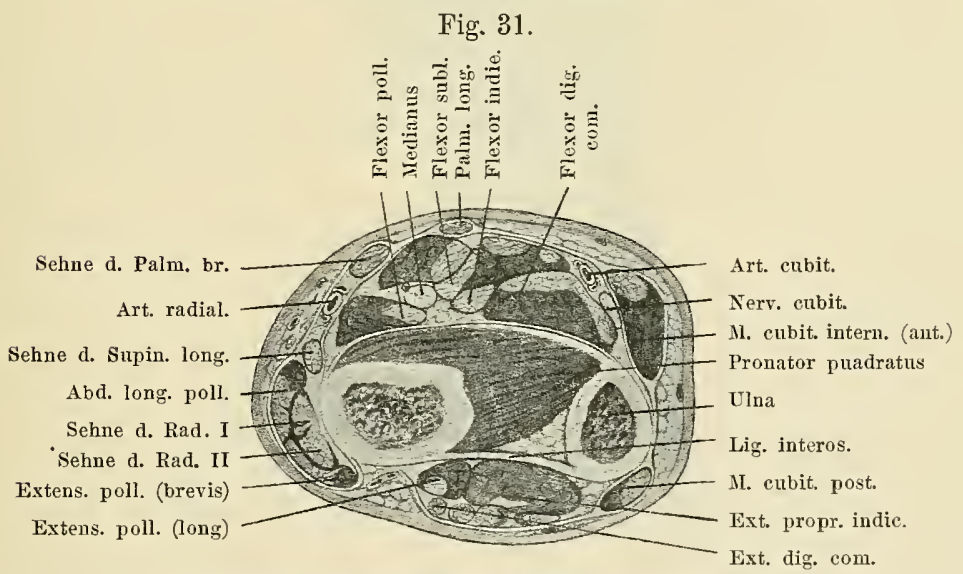

Ein Querschnitt im untern Drittel des Vorderarms.

der Ulna, vorne durch ein fibröses Blättchen geschieden, welches aus der oberflächlichen Fascie entsteht. Die Epitrochlealmuskelu sind vom Nervus medianus innervirt und zum grössten Theile von der Arteria cubitalis versorgt.

Der Pronator teres liegt schief gelagert zwischen der Epitrochlea und der rauhen Fläche, die an der mittleren und äussern Radiusfläche sich befindet. Er stellt zwei Bündel dar, ein oberfächliches oder Epitrochlealbündel und ein tiefes oder Coronoidalbündel. Diese beiden Bündel in ihrer äussern HäIfte vereinigt, sind innen ge- 
schienten, wo sie cine liielie bihden, dureh welche der Nerus medianns ron einer diclien Vene und der Arteria recurens culitalis anterior begleitet, hindurchgeht. Die radiale Ansatzstelle wirl ron einer schönen und festen Sehne gchildet, welche den obern Rand des Fleischlörpers cinnimmt. Diese Sehne ist rings um den Radius gewunden (Fig. 32).

Fig. 32 .

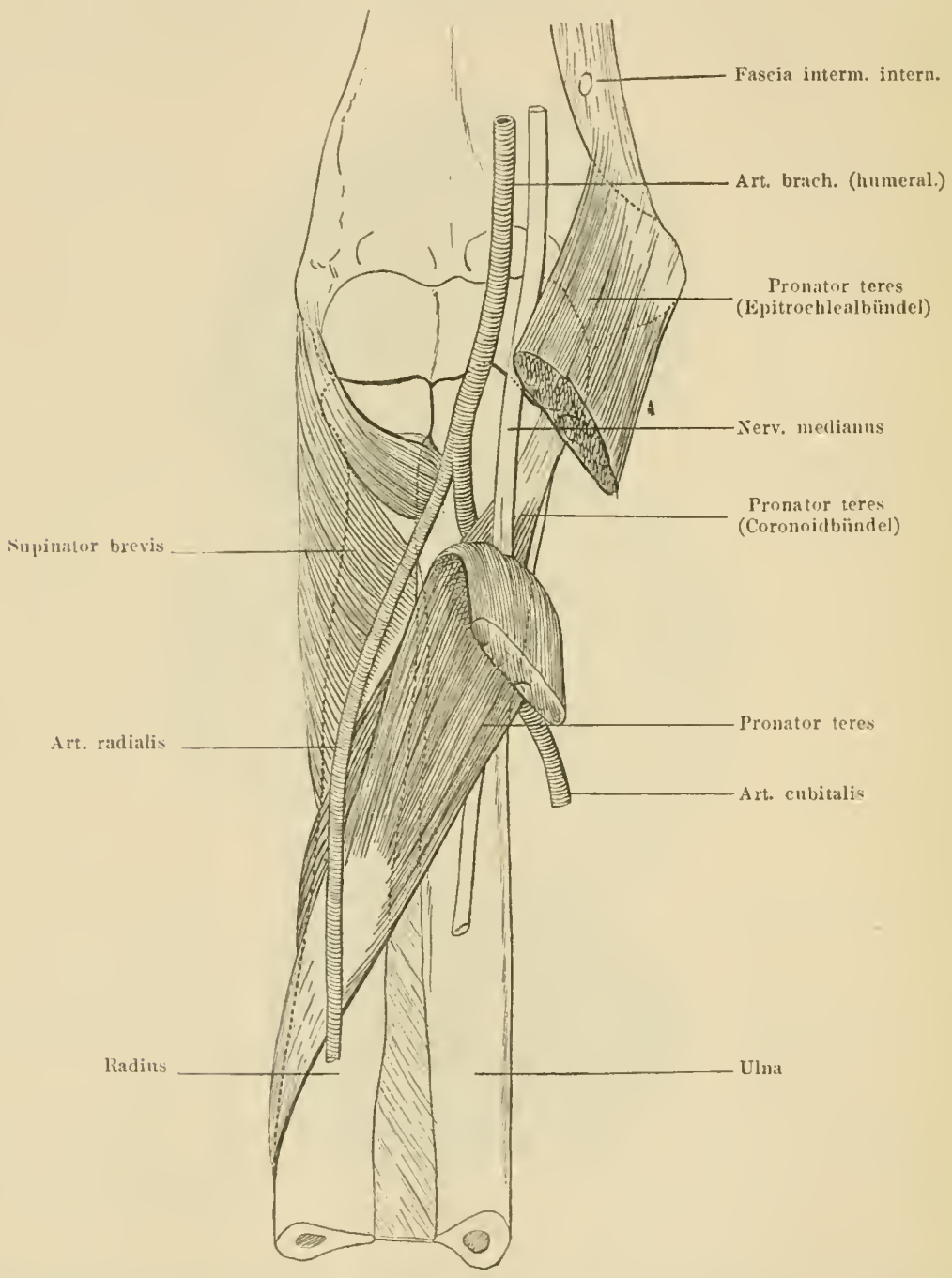

Der Museulus pronator teres der rechten Seite. Das oberfiächliche Bündel ist durchschnitten und das untere Fragment nach abwärts gezogen. Man sieht das tiefliegende Büıdel, auf dem der Nervus medianus liegt.

Terhnik z. A. A. (;. Am ïussern Rande der Erhebung der Epitrochleamuskeh macht man ron oberhalb der Epitrochlea bis zur Mitte des Radius cincu Sehnitt und schmeidet aussen die äussem Epicondylusmuskeln durch. 
Man erblickt dadurch den Fleischkörper und die Sehne des Pronator teres. Dieser Muskel wird nun sorgfältig von der Sehne des Palmaris brevis, an der er sich zum grössten Theile ansetzt, losgelöst. - Man erblickt nun den Medianus, schiebt eine Sonde längs des Nerven ein und schneidet Alles, was vor der Sonde sich befindet, durch. Auf diese Weise wird das tiefe Bündel des Pronator sichtbar; an dessen Oberfläche verläuft der Medianus, nach imen von diesem die Arteria recurrens cubitalis anterior. Den Stamm der Arteria cubito-interossea findet man hinter dem Coronoidalbündel, das die Arterie vom Medianus scheidet.

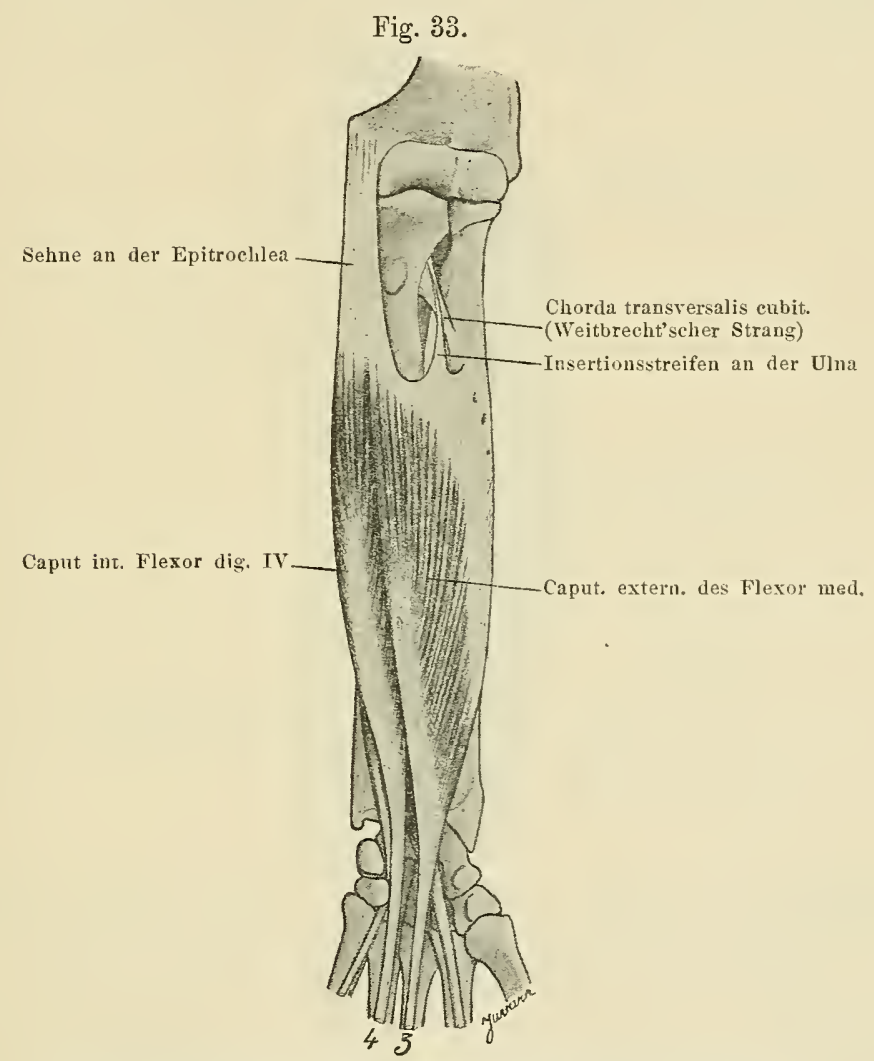

Der Musculus Flexor superficialis, oberflächliche Schichte.

Der Palmaris brevis (Flexor carpi radialis) zieht ron der Epitrochleaspitze zu dem Höcker der vorderen Fläche des oberen Randes des II. Metacarpus und durch eine fibröse Schichte zum Ende des III. Metacarpus. Er kreuzt diagonal die vordere Fläche des Vorderarms. An der Handwurzel liegt die Sehne tief an der äussern Seite des CarpalcanaIs in einer fibrös-lnöcherigen Lücke. - Eine Synorialscheide umgiebt sie in dieser Höhe.

Technik z. A. d. G. Nan bringt die Hand in starke Extensionsstellung und sieht und fühlt den Strang des Palmaris brevis. Längs des- 
solhen ron der Spitze des Epitrochlea lis oberlalb der Handwurzel wird cin Selnitt geführt, es erseheint unmittelbar unter der Fascie der Muskel, in seiner obern Hälfte fleischig, in der untern sehnig. Scin Fleischkörper wird innen rom Flexor superficialis und Palmaris longus aussen rom Pronator teres abpräparirt. Man findet dam den Nerr des Palmaris brevis; cr ist ein Ast des Mledianus und dringt in die Tiefe des Mluskelkörpers durch eine fibröse Rimne, welche rom Pronator teres und Flexor superfieialis begrenzt wird. An der Handwurzel führt man längs der Sehne die

Fig. 34.

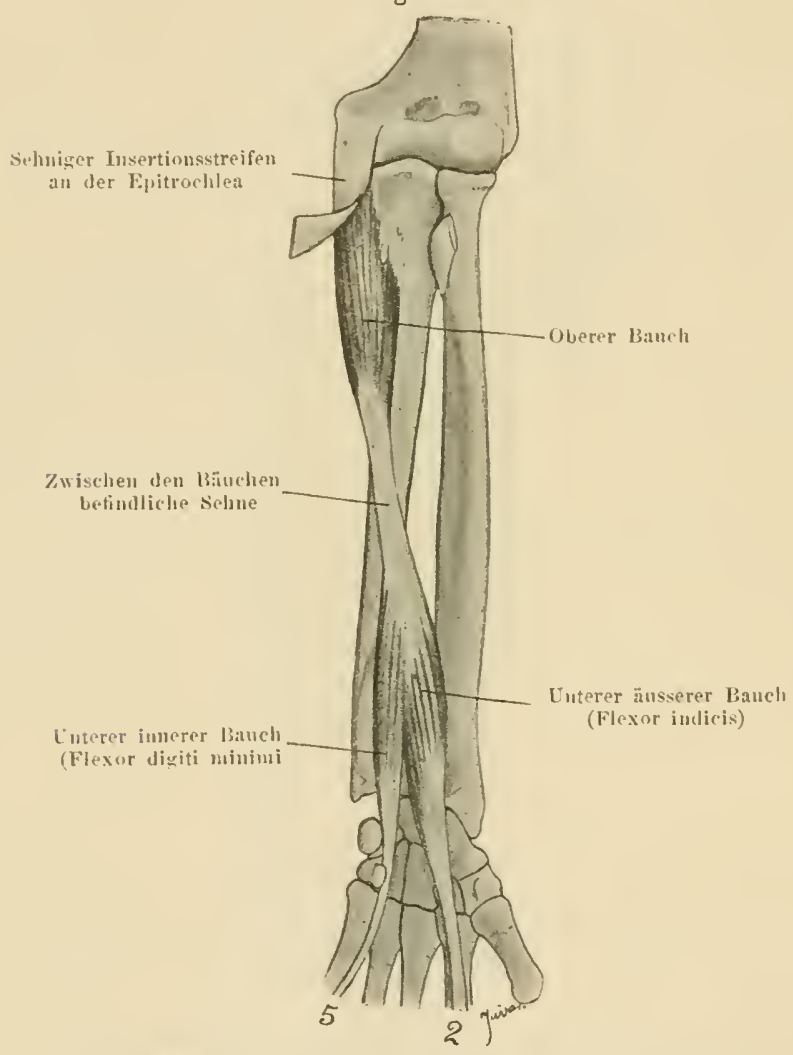

Der Musculus flexor superticialis, tiefe Schichte.

Hohlsonde ein und schneidet das Ligamentum carpi anterius und die Nuskelerhebung des Thenar durch, damit wird der fibrösknöcherne Canal cröffnet, welcher dic Schne des Palmaris enthïlt und dessen äussere Wände rom Höcker des Kahnbeins und vom Haken des Trapezbeins gebildet werden. Ian durchschneidet die Sehne, zicht sie nach abwärts und präparirt deren Insertion am II. und III. ILetacarpus.

Palmaris longus. Dieser oft fehlende Muskel liegt ron der Spitze der Epitrochlea lis zur Basis der Ilandworzel auscebreitet und iibergeht in die Fascia palmaris. 
- Sein Fleischkörper liegt in einer Furche, welche aussen rom Palmaris brevis, innen rom Flexor superficialis begrenzt wird.

Technik z. A. d. G. Man bringt die Hand in stärkste Flexionsstellung, sucht und fühlt einen halben Centimeter innerhalb des Palmaris brevis die gespannte Sehne des Palmaris longus. Nan macht längs dieser Sehne von der Handwurzel bis zur Epitrochleaspitze einen Schnitt und es erscheint unmittelbar unter der Fascie der Körper und die Sehne des Palmaris longus. Er wird rom Palmaris brevis getrennt und man findet seinen Nervenfaden. - Im Niveau der Handwurzel kann man beobachten, wie die Sehne in die Fascia palmaris übergeht und mit einigen Fortsätzen am Ligamentum annulare, am Erbsenbeine und Kahnbeine sich inserirt.

Fig. 35 .

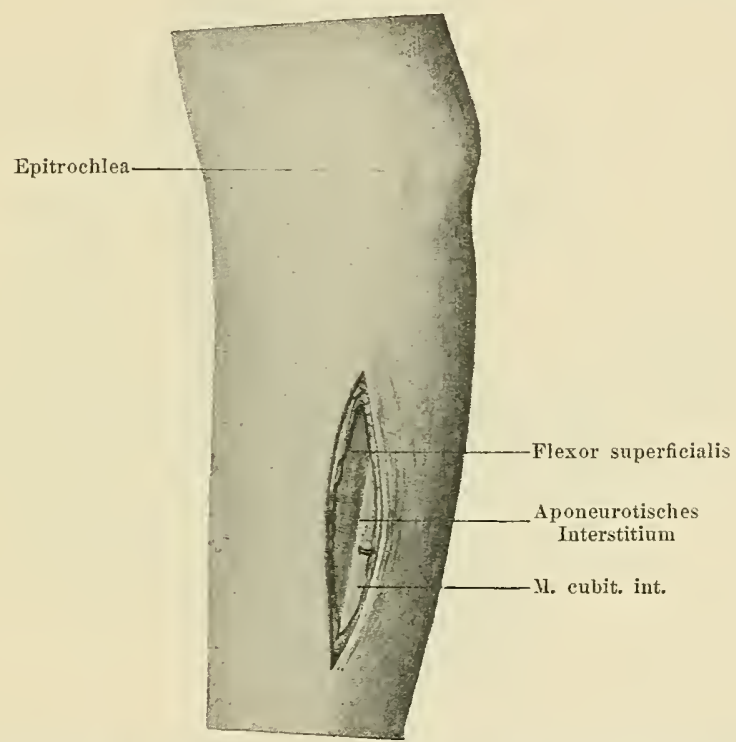

Das Auffinden der Arteria und des Nervus cubitalis. Die Haut ist durchschnitten und man sieht das aponeurotische Interstitium, welches den Fleischkörper des Flexor superficialis vom Körper des Musculus cubitalis internus scheidet.

Flexor superficialis (Fig. 33-34). Dieser breite Muskel liegt zuerst unter dem Pronator teres, Palmaris brevis und longus, wird dann superficial in dem Zwischenraume, welcher den Palmaris longus vom Cuhitalis anterior scheidet.

Der Flexor superficialis besteht aus zirei Schichten:

a) Die oberflächliche Schichte hat die Form eines mit der Spitze nach unten gerichteten Dreiecks, inserirt sich oben und innen an der Epitrochlea mittelst einer schönen Sehne, aussen am Olecranon, an der schiefen Leiste und am äussern Rande des Radius und mit einer fibrösen Schichte an der Ulna im Nireau des Höclers des Brachialis anterior. Auf diese Weise gebildet besitzt der Fleischlörper zwei Sehnen, eine äussere für den Mittelfinger, eine innere für den Ringfiger (Fig. 33).

b) Die tiefe Schichte liegt wie in einer Rinne unter dem inneren Theile der oberflächlichen Schichte in der Form eines dreibauchigen Muskels und heftet sich mit 
Aleischigen Bïndehn an der Epitrochlea, am Ligamentum laterale internum des Ellbogengelenkes und an der tiefen Fiäche der Sehne der oberflächlichen Schichte an. Dieser ubere prismatische Fleischliörper setzt sich in eine Sehne fort, an welcher andere zwei Muskellïruer sich ansetzen, ein stärlierer äusserer, welcher eine Sehne für den Zeigefinger, ein dïnner innerer, relcher eine Sehne fïr den kleinen Finger abgiebt (Fig. 34).

Techuik \%. A. I. F. Man prïparirt und durehschneidet den Pronator teres, Palmaris brevis und longus; unter denselben findet man die obere Sehicht des Flexor. Sein innerer Rand wird rom Cubitalis anterior losgeclist, und man bemerkt, dass von dieser Schicht die Sehnen für den Ilittel- und Ringfinger abgehen. Löst man die obere Schicht ab, gelangt

Fig. 36.

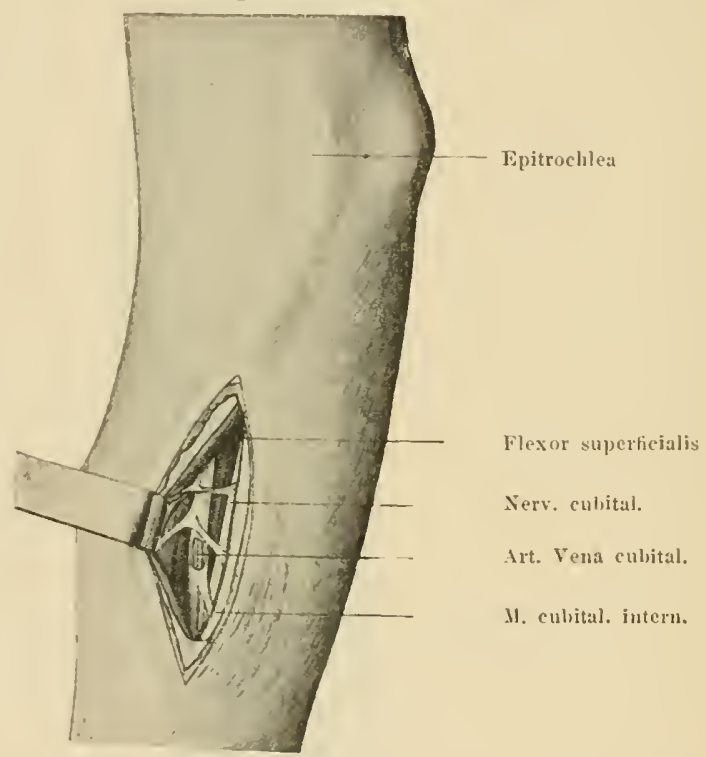

Fin stumpfer Haken zieht den Flexor superficialis nach vorne. Am Boden des so gebildeten Ganges sieht man die Arteria cubitalis und mehr innen von dieser den Nervus cubitalis.

man zur tiefen; prïft man deren Schne oder ihre Nitte, indem man an derselben zieht, so beugt man den Zeigefinger und kleinen Finger.

Cubitalis auterior (interu.). Dieser innere Muskel besetzt den inneren Rand des Vorderarms. Er reicht ron der Epitrochleaspitze einerseits, von dem inneren Bord des Olecranon nnd ron den oberen zwei Drittheilen des hinteren Ulnarrandes andererseits, bis zur unteren Hälfte der Vorderfläche des Erbsenbeines. In der Ulna inserirt er sich mit einem sehnigen, mit der oberflächlichen Fascíe fest adhärenten Blatte. Die Insertion am lirbsenbeine geschieht durch eine feste Sehne, welche vom rorderen Rand des Fleischlï̈pers abgeht. Znweilen liegt zwischen Erbsenbein nnd Sehne ein Schleimbentel. Der Cubitalis anterior liegt in der Duplicatur der oberflächlichen Fascie des Vorderarms und wird rom Nervas cubitalis innervirt.

Terhuik z. A. d. (r. Han führt von der Epitrochlea his zum Erbsen- 
beine einen langen Schnitt und findet unmittelbar unter der Haut den Fleischkörper und die Sehne des II. cubitalis internus.

Arteria ulnaris (cubitalis) und Nervus cubitalis. Etwas unterhalb der Tuberositas bicipitalis theilt sich der Stamm der Cubito-interossea in zwei Aeste, in die Art. cubitalis und in den Stamm der Interosseae.

DieArteria cubitalis zieht nach unten gegen das Erbsenbein und liegt tief unter den Epitrochlealmuskeln im Zwischenraume, der vom Flexor superficialis und Flexor communis profunilus gehildet wird. Schief nach unten und innen in seinem oberen Drittel verläuft er fast vertical an den unteren zwei Dritteln.

Hig. 37.

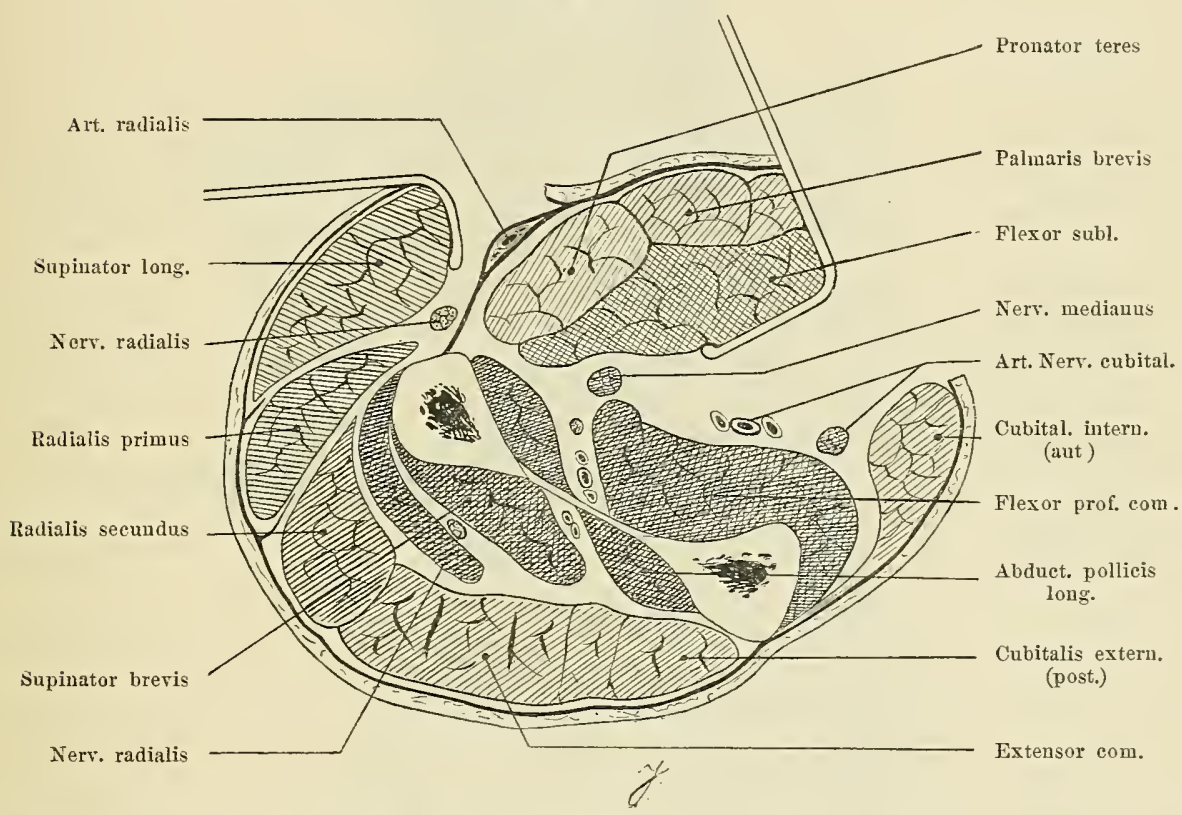

Ein schematischer Querschnitt des Vorderarmes, um den Weg zu zeigen, folgende Gebilde zu finden: innen die Arteria und deu Nervus cubitalis und den Nervus medianus, aussen die Arteria radialis. Die Muskeln der oberflächlichen Schichte sind gestreift; die der tiefliegenden sind kreuzweise gestreift. Die Arteria radialis liegt in einem aponeurotischen Blättchen, das die Gruppe der vorderen inneren oberflächlichen Muskeln von den hinteren äusseren Muskeln scheidet. Der Nervus radialis liegt in der Scheide des Supinator longus.

Der Nervus cubitalis (ulnaris) liegt an der Innenseite der Arter!e. In seinem oberen Theile ist er von derselben durch einen dreieckigen, mit derSpitze nach abwärts gerichteten Rauu geschieden; in den beiden unteren Vorderarmdritteln legt er sich an die Arterie an. Unmittelbar unter dem Erbsenbeine theilt sich die Arteria cubitalis in die Arteria cubito-palmaris superficialis und in die Arteria cubito-palmaris profunda.

Technik z. A. d. G. Am äusseren Rande der Iluskelerhebung des Pronator teres macht man eine lange Incision, durchschneidet die Haut und die Fascie, legt den äusseren Rand des Pronator teres frei, bringt den 
Vorderarm in leichte Pronationsstellung, wodureh der Muskel entspannt wird und zieht ihn dann mit einem stumpfen Haken zur Seite. Mlan findet sofort geen die Bieepssehne den Stamm der Arteria cubito-interossea und etwas nach innen den Nervus medianus. Man findet den Ursprung der Arteriae recurrentes cubitales, welche rom Stamme der Cubito-interossea unter der tiefen Fläche des Pronator teres entstehen.

Un die Arteria cubitalis im obern Drittheile des Vorderarms zu finden, sucht man die Spitze der Epitrochlea und das Erbsenbein auf. Die Linie

Fig. 38.

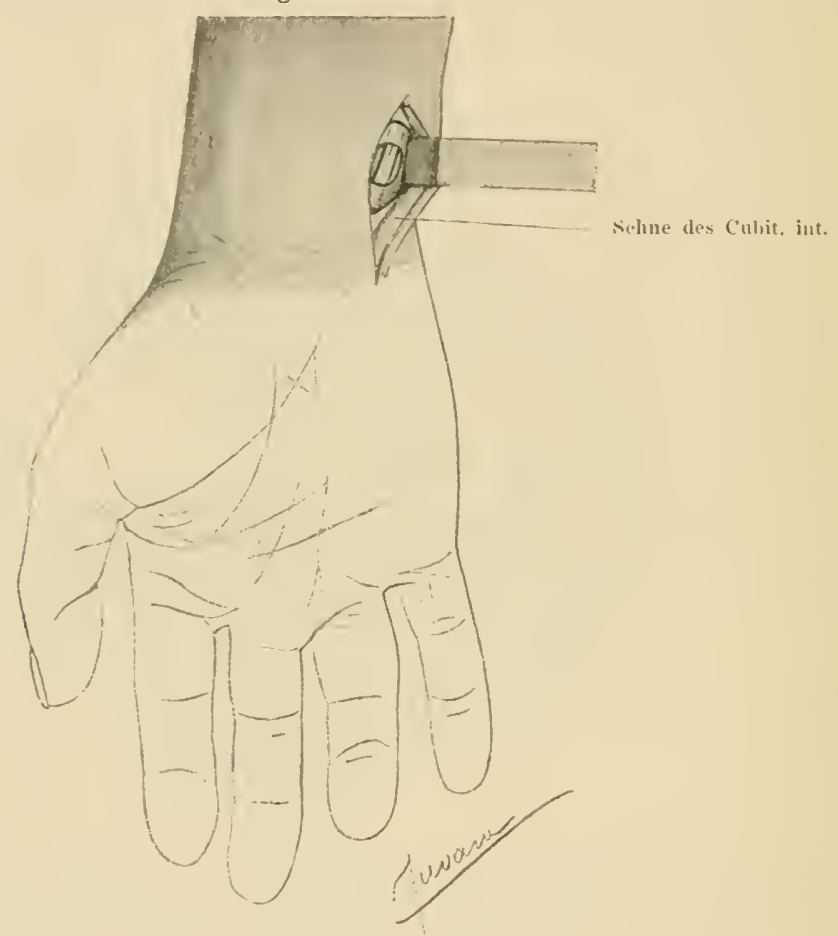

Das Aufsuchen der Arteria cubitalis oberhalb des Erbsenbeins. Ein stumpfer Haken zieht die Sehne des Cubitalis internus nach innen.

zwischen der Epitrochlea und dem Erbsenbeine giebt die Richtung der Arterie an (Fig. 28). Auf dieser Linie etwas oberhalb des mittleren Drittels des Vorderarms macht man eine $5 \mathrm{~cm}$ lange Incision, gelangt auf die Fascie und erkennt den Zwischenraum (Fig. 35), welcher den vordern Rand des Cubitalis rom innern Rande des Flexor superficialis scheidet. Längs des äussern Randes dieses Raumes wird die Fascic durchsehnitten und man gelangt auf den Körper des Flexor superficialis. Mit der Hohlsonde wird der innere Rand dieses Muskels, welchen ein Assistent bei Flexionsstellung der Hand entspannt, freigelegt. Man legt dann je einen stumpfen Haken an beide Winkel des Schnittes und anf diese Weise bildet man einen Muskel- 
gang, welcher vorne rom Körper des Flexor superficialis, hinten und innen vom Cubitalis internus und der Boden dieses Ganges rom Flexor communis profundus gebildet wird (Fig. 36). Auf diesem rothen Boden verläuft die Arteria cubitalis mit den sie begleitenden Venen und immen der Nervus cubitalis. Es ist sehr leicht jedes Einzelne dieser Gebilde freizulegen und zu zeigen. Ein stumpfer Haken wird an dem innern Rande des Flexor angelegt und ein Assistent zieht ihn nach aussen und rorme. Fingerbeit mehr aussen von der Arteria cubitalis und an der tiefen Schichte des Flexor superficialis an-

Fig. 39 .

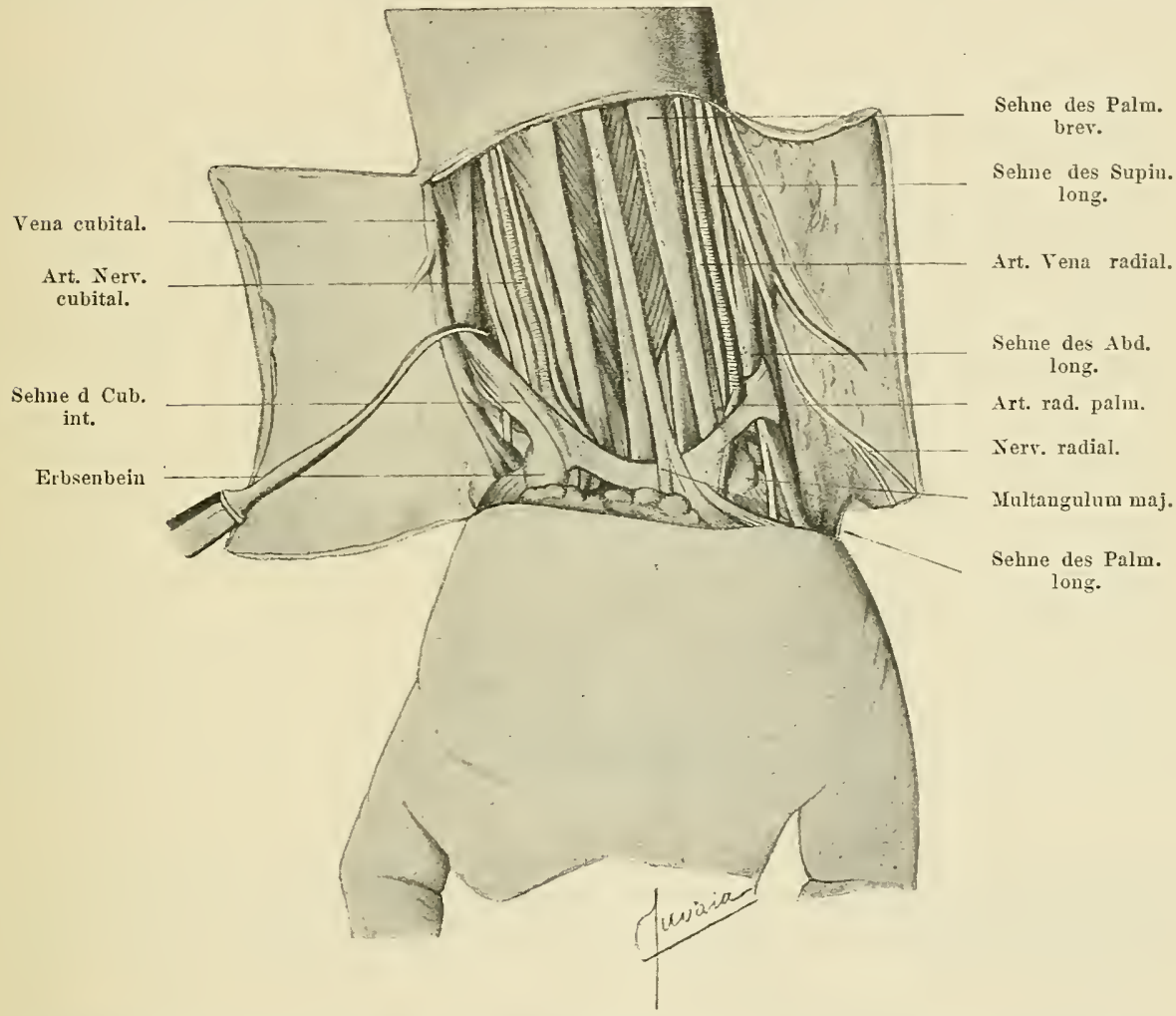

Die Region des unteren Drittels der vorderen Fläche des Vorderarmes. Ein Haken zieht die Sehne des Cubitalis internus nach innen und legt auf diese Weise die Arteria cubitalis und etwas innen von derselben den gleichnamigen Nerv frei.

geheftet, findet man den Nervus medianus. Um das cubitale Gefäss- und Nervenbündel in seinem untern Drittel zu finden, muss ein Assistent den Cubitalis internus anspannen, indem die Hand in äusserster Extensionsstellung sich befindet. Man macht längs der Erhebung der Cubitalsehne oberhalb des Erbsenbeins beginnend eine Incision Die Haut und die Fascia superficialis werden auf eimmal durchschnitten und man gelangt zur Cubitalsehne. Wird die Hand gebeugt, mit der Hohlsonde diese Sehne freigelegt und mit einem stumpfen Haken seitwärts gezogen, so sieht man unter dem tiefen Blatte seiner 
Fascienscheide das Gefïsspacket durehscheinen. Es muss nur die Fascie durchsehnitten worden, um aussen die Arterie und innen den Nerv su finden.

Der Nervits medianus folgt in der Medianlinie dem Raume, weleher den Flexor superficialis rom Flexor profundus scheidet; oberhalb der Ilandwurzel entsprieht er dem ron den Sehnen des Palmaris longns und brevis begrenzten Ranme.

Technik \%. A. d. (i. Wir haben nach einer Methode gesucht, den Medianus oberhalb des Pronator teres zu finden.

Man macht im mittleren Drittel des Vorderarms einen Sehnitt, sicht und legt den imnern Rand und die tiefe Lage des Palmaris brevis frei und giebt ihn in einen stumpfen Haken. Mit der Spitze der Sonde wird die

Fig. 40 .

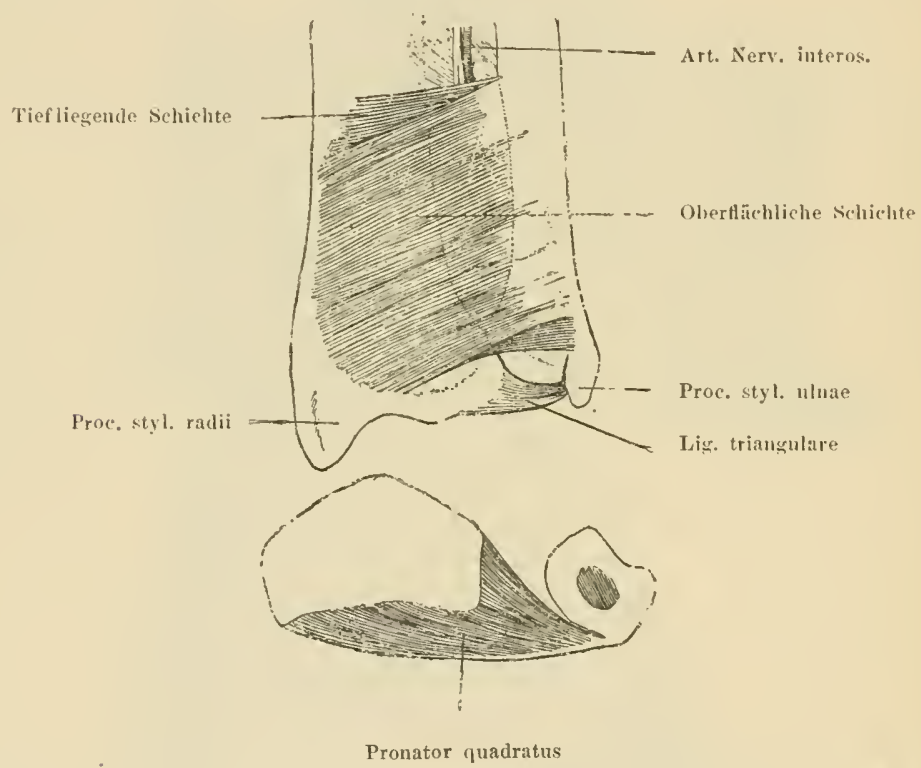

Der Pronator quadratus der rechten Seite. Unten ist ein Querschnitt des Muskels dargestellt. Seine Insertion ist am Radius sehr ausgebreitet, an der Ulna inserirt er sich mit einem sehnigen Blatte.

oberflächliche Schichte des Flexor superficialis losgelöst und man findet unter derselben den Stamm des Medianus. An der äussern Seite des Medianus findet man die ihn begleitende Arterie, einen Ast der Interossea anterior.

Oberhalb der Handwurzel an der innern Seite der Sehne des Palmaris brevis macht man eine Incision und man findet in deren unterm Theile (len palmaren Hantnerv, der die Fascie im Niveau dor Furche des gebeugten Handgelenkes durchbohrt.

Wenn man die Fascie auf der Sonde durchschneidet, gelangt man sofort an den Medianus, der ringsum von Fett umgeben ist. Er liegt anf derselben Fläche mit den Sehmen des Flexor superficialis und darf mit diesem nicht verwechselt werden. 
Flexor profundus. Diese gefiederte Muskelmasse inserirt sich an der vordern Fläche des Radius, am Ligamentum interosseum und an der vordern und innern Fläche der Ulna. Er besteht ans drei Bündeln, ein äusseres radiales nur für den Daumen, ein mittleres adhärirt am Ligamentum interosseum für den Zeigefinger und ein drittes inneres oder gemeinsames setzt sich an der Ulna an. Das Letztere hat drei Sehnen für den MittelRing und kleinen Finger.

Das radiale und mittlere Bündel und die äussere Seite des Cubitalbündels werden rom Medianus innervirt, der innere Theil des Cubitalbündels rom Cubitalis. Im Zwischenraume, welcher den Beuger des Daumens vom Beuger des Zeigefingers scheidet, verläuft die Arteria interossea anterior und der Nervus ińterosseus.

Technik z. A. d. G. An der vorderen Fläche des Vorderarms wird ein Einschnitt gemacht. Längs des Radialrandes unter dem Flexor superficialis findet man das Radialbündel des Flexor profundus. An der vordern Fläche des Vorderarms läng's des äussern Randes des Palmaris brevis durchschneidet man die Haut, die Fascie und die oberflächliche Schichte des Flexor, die beiden Schnittränder werden mit stumpfen Haken abgezogen und es erscheint in der Tiefe die Sebne des radialen und mittleren Beugers.

Mit der Hohlsonde findet man im Raume, der diese beiden Bündel scheidet, den Nervus interosseus anterior und tiefer am Ligamentum interosseum die Arteria interossea anterior und die sie begleitenden Tenen.

Der Pronator quadratus liegt im unteren Vorderarmviertel und hat die Form eines rechten Winkels. Die Fasern liegen zwischen den beiden Knochen des Vorderarms. Innen inserirt er sich mit sehnigen und Muskelfasern am Kamme, welcher am vorderen und unteren Theile der Ulna sich befindet, anssen an der vorderen Fläche, am inneren Rande und an der Suprasigmoidalfläche des Radius. Er besteht ans quer gelagerten Muskelbündeln, zuweilen in zwei Schichten angeordnet. Seine vordere Fläche ist von dem Sehnenpacket der Beuger, der Palmarmuskeln und des Cubitalis internus bedeckt; seine hintere Fläche ist mit dem Ligamentum interosseum, welches ihn von den hinteren Muskeln scheidet, in Contact; nach aussen liegt die Arteria radialis auf dem Pronator quadratus. Sein oberer Rand wird von Gefässen und dem Nervus interosseus, der unter ihn dringt, gekreuzt (Fig. 40).

Technik z. A. d. G. Im unteren Vorderarmdrittel wird eine verticale Incision gemacht. Die Sehnen der Benger werden entfernt, und man gelangt an eine rechtwinklige Muskelmasse, an den Pronator quadratus. Im Niveau seines oberen Randes findet man den Nervu's und die Arteria interossea, welche man weiter in den Muskel verfolgen kann.

\section{Aeussere Region.}

Der äussere Rand des Vorderarms ist in seiner oberen Hälfte dick und fleischig. Der Radins ist zuerst unter der Muskelmasse tief versteckt, in dem unteren Theile wird er oberfächlich und ist leicht zu fïhlen.

Längs des äusseren Randes des Vorderarıns findet man vier Muskeln: den Supinator Jongus, die beiden Musculi radiales und in der Tiefe des Supinator brevis.

Der Supinator longus, mit Unrecht zu den Epicondylusmuskeln gerechnet, ent- 
steht in einer länge ron $10-12 \mathrm{~cm}$ an äusseren liande des Humerus unterhalb des Sulcus subdeltoides. Sein likeischkörper hat die form eines gedrehten Bandes. Gegen den mittleren Theil des Vorderarms bilden die Muskelfasern eine Sehne, welche zuerst in

Fig. 41 .

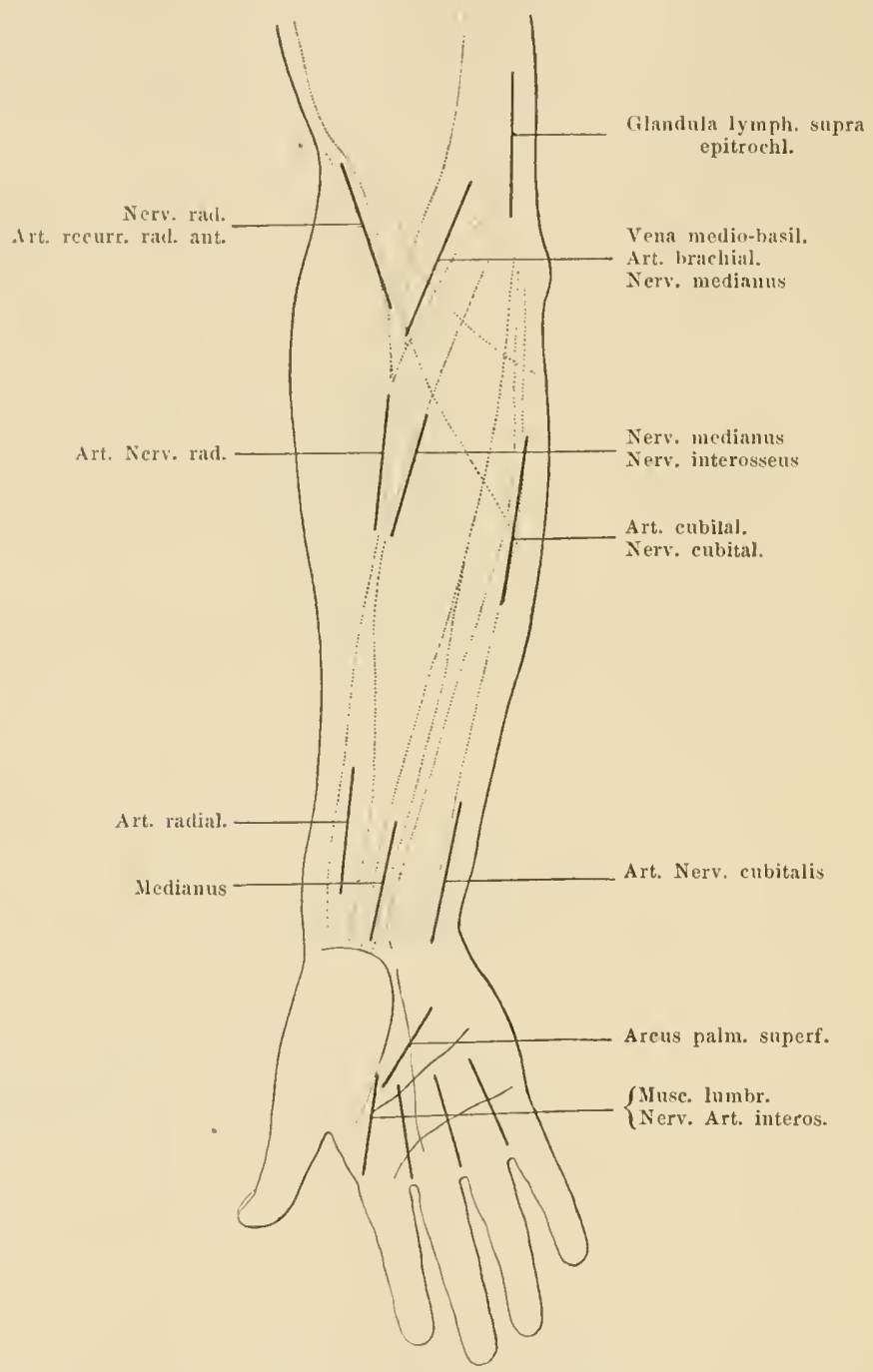

Diese ligur zeigt die Stelle und die Richtung der Incisionen, um die wichtigeren Gebilde an der vorderen Fläche des Ellbogens, des Vorderarmes und der Hand aufzufinden.

der Tiefe des Mluskels entsteht und sich unten an der änsseren Fläche der Basis des Processus styloides radii inserirt.

Der Supinator longus bildet in seinen Oberamtheile den äusseren Rand der tiefen Furehe, welche den Nervus radialis und die Arteria humeralis profunda enthält. 
Techuik z. A. d. f. Von der Mitte des Vorderarmes wird bis zur Basis des Processus styloides radï eine Incision gemacht, und unmittelbar unter der Fascie erscheint der Körper und die Sehne des Nuskels. Legt man den Muskel besser durch Präparirung frei, so kann man unter seiner tiefen Lage den Nervus radialis finden; der Supinator longus liegt oberhalb des Radialis primus.

Der Radialis primus ist von der rauhen Fläche, die unmittelbar oberhalb des Condylus sich befindet, in Form einer Virgula zum Höcker an der äusseren Seite der Hinterfläche des oberen zweiten Metacarpusendes gespannt. Sein prismatischer Fleischkörper ist sehr kurz.

Der Radialis secundus beginnt am Epicondylus, er entfernt sich unten vom vorhergehenden, und ihre Sehnen divergireu in einem äusserst spitzen Winkel. Sein Fleischkörper ist länger; die Fleischfasern begleiten die Sehne bis zum Anfang des unteren Vorderarmdrittels. Unten inserirt er sich an der Basis des Processus styloides des dritten Matacarpus.

Technik z. A. d. G. Führt man längs des äusseren Vorderarmrandes vom Epicondylus bis zur Höhe des Processus styloides radii einen Schnitt, so erscheint unmittelbar unter der Fascie der Körper und die Sehne des ersten Radialis.

Dieser Muskel wird rom zweiten Radialis, dem er aufliegt, abgehoben, und man merkt, dass sein Körper um vieles kürzer ist als der des zweiten. Die Radialissehnen werden von den Fleischkörpern und Muskelsehnen des Abductor longus und des Extensor pollicis brevis in Form eines X gekreuzt. Mit der Spitze eines Bistouri wird der obere Sehnenrand des Abductor longus von den Radialissehnen losgelöst und ein Schleimbeutel, aus den Reibungen der Sehnen untereinander entstanden, wird eröffnet, es ist dies der Schleimbentel der Radialismuskeln. Ich mache Sie besonders auf diesen Schleimbeutel aufmerksam, der gewöhnlich nicht mit der Synovialscheide der Radialissehnen communicirt, wie man sich überzeugen kann.

Eine trockene Entzündung dieses Schleimbeutels erzeugt jene feine Crepitation, die bei der Sehnenentzïndung so charakteristisch ist.

\section{Region der Handwurzel.}

Digitaluntersuchung. Die Handwurzel ist eine enge Region von der Form eines gedrehten Cylinders und liegt zwischen dem unteren Ende der Vorderarmknochen und der Wölbung der Hand. Sie entspricht dem Radio-carpalgelenke.

An der äussern Fläche der Handwurzel fühlt der untersuchende Finger, welcher von unten nach oben dem äussern Rande der Hand folgt, die Spitze des Processus styloides radii hervorspringen. - Innen fühlt man zuerst eine leichte Erhebung, welche dem Pyramidenbein entspricht und $1 \mathrm{~cm}$ höher tritt die Spitze des Processus styloides ulnae hervor.

Man sieht, dass die beiden Processus styloides sich nicht in derselben horizontalen Linie befinden, da der Processus styloides radii um $1 \mathrm{~cm}$ tiefer steht als der Processus ulnae (Fig. 42). An der hintern Fläche der Handwurzel erkennt der aufmerksam unter- 
suchende Finger den hintern liand des untern Radiusendes und etwas nach innen den Kopf der Ulua.

Die Gelenkzwischenlinic beschreibt einen mit der Concavität nach unten gerichteten Bogen.

An den untern Enden der beiden Vorderarmknochen findet man sieben Furchen, sechs an Radius und eine an der Ulna. An der äussern Seite des Processus styloides radii sind zwei wenig tiefe Furchen, eine vordere für den $\Lambda$ bductor longus, eine hintere

Fig. 42 .

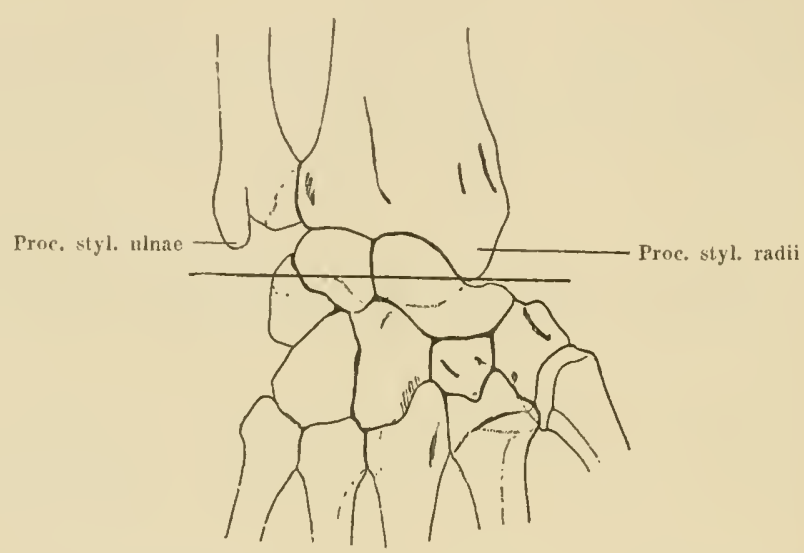

Diese Figur zeigt das Verhältniss an den unteren Enden der Vorderarmknochen und die massiven Handwurzelknochen. Die horizontale Linie, welche durch die Spitze des Processus styloides radii zieht, liegt etwas unterhalb vom Processus styloides ulnae.

Fig. 43.

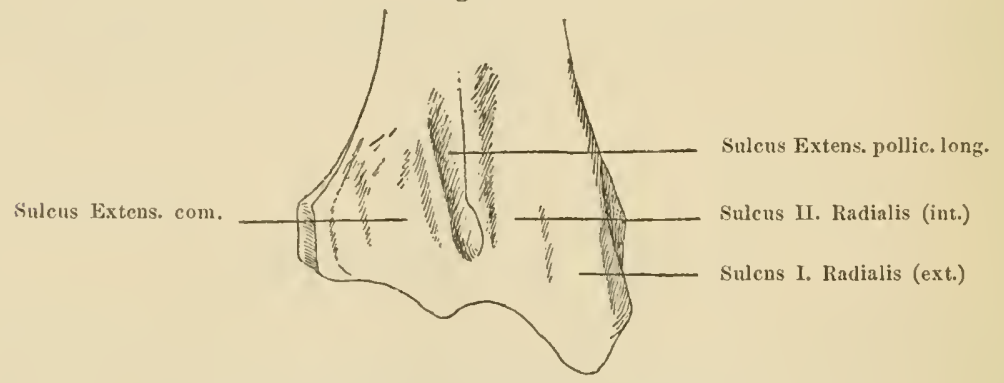

Die hintere Fläche des unteren Radiusendes.

für den Extensor brevis (Fig. 43). Die hintere Fläche des untern Radiusendes ist durch eine erhabene Leiste, welche sehief nach unten und aussen gerichtet ist, in zwei Ilälften oder Felder getheilt.

a) Das äusere Feld enthält die Radialmuskeln und hat die Form einer seichten Mulde, welche durch eine wenig sichtbare Leiste wierler in zwei Rinnen getheilt ist; durch die äussere Rinne zieht die Sehne des ersten $R$ adialis, durch die innere die des zweiten Radialis. 
b) Das innere Feld enthält die Extensoren. In der tiefen und engen Leitfurche, welche man unmittelbar an der Innenseite der Radialisleiste findet, verläuft die Sehne des Extensor longus; in der breiten weniger tiefen, auch mehr nach innen liegenden verlaufen die Sehnen des Extensor communis und unter denselben die Sehne des Extensor digiti indicis proprius (Fig. 43).

An der hintern Fläche des Ulnarkopfes zwischen dem Rande der Gelenksoberfläche und dem Processus styloides findet man die Leitfurche, welclıe für die Sehne des Cubitalis posterior bestimmt ist (Fig. 42). Diese Sehnen sind in den ihnen bestimmten Furchen durch eine feste fibröse Hülle, das hintere annulare Carpalband, festgehalten.

Das Ligamentum annulare posterius (Fig. 49) ist schief nach unten und innen gegen das Erbsenbein gerichtet und entsteht am Radius und an der UIna an den

Fig. $43 \mathrm{a}$.

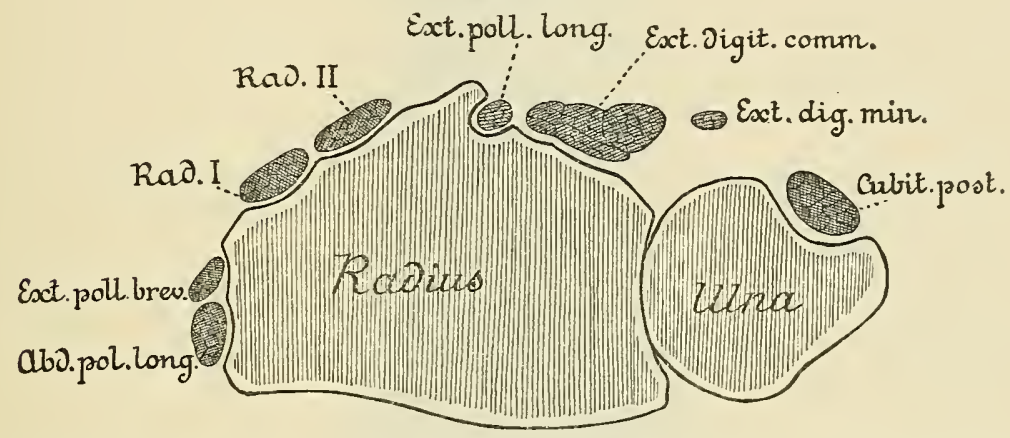

Die schematische Figur zeigt die Beziehungen der unteren Enden der Vorderarmknochen mit den Sehnen, welche an der äusseren und hinteren Fläche des Radius und an der hinteren Fläche der Ulna vorbeiziehen. Man sieht auch deutlich die beiden Felder der hinteren Fläche des Radius, welche durch die Crista radialis getrennt sind.

Leisten, welche die Leitfurchen der Sehnen begrenzen. Innen setzt es sich an der innern Fläche des Erbsenbeins an.

Die Sehne des Extensor digiti minimi proprius zieht durch das Ligament.

Techuik z. A. d. G. Das Ligamentum annulare dorsale findet man, wenn man oberhalb des Proc. styl. radii bis zur Erhabenheit des Erbsenbeins, die man an der vordern und innern Palmarfläche erkennt, die Haut durchschneidet. Das Ligament wird sofort sichtbar. Man präparirt die beiden Schnittränder nach oben und unten und controlirt seine Insertion an der Innenseite des Erbsenbeins.

\section{Aeussere Fläche der Handwurzel.}

Die anatomisclıe Tabaksgrube hat die Form einer dreiseitigen mit der Basis nach oben gerichteten Grube, welehe leicht sichtbar wird, sobald der Daumen abducirt oder abgezogen wird.

Diese Region wird aussen von der hervortretenden Sehne des Abductor long us 
und Extensor brevis, inmen ron der Sehne des Extensor longus begrenzt. Diese beiden Erhebungen vereinigen sich nach unten im Nireau des Metacarpo-phalangealgelenkes des ersten Fingers unter einem spitzen Winkel (Fig. 44).

An der Basis dieser Region fühlt man den Processus styloides radii; der Boden dieser Region ist knöchern und wird ron oben nach unten rom Kahn- und 'Trapezbeine gebildet.

Der Nervus radialis und die Tena cephalica des Daumens finden sich längs des äusseren Randes (Fig. 45).

Die Arteria radialis durchdringt den Grund der Tabaksgrube schief nach unten und innen, liegt am linochen mul ist ron Jer Haut durch ein doppeltes und dickes Fascienblatt, das zwischen den Sehnen dieser Region gespannt ist, getrennt (Fig. 46 ).

Fig. 44.

Boclell d. Tabakivruhe

Das lielief der Sielnte des listens. brevis

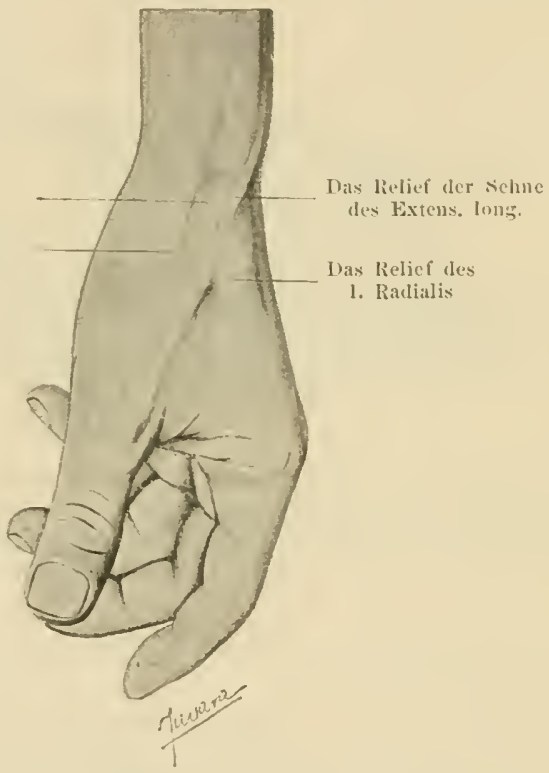

Die anatomische Tabaksgrube und die sehnigen Reliefs, welehe sie begrenzen.

Ahductor longens und Extensor pollicis brevis. Die Fleischliörper dieser Huskeln liegen in der hinteren Furche des Vorderarmes und entstehen mit selmigen unil musliulösen Fasern an der Ulna, am Radius und am Ligamentum interossenm.

Sie liegen zuerst tief unter den Extensor communis und dem Cubitalis posterior, gelangen dann mehr an die Oberfläche im Niveau des dreiseitigen Raumes, weleher innen rom äusseren Rande des Extensor communis, aussen von den Radialissehnen begrenzt ist. Ihre Sehnen ziehen oberhalb der Radialismuskeln und gleiten in den Leitfurchen, die in der äusseren Fläclıe des Processus styłoides radii liegen, indeñ sie mit ihrer unteren Seite den äusseren Rand der Tabalisgrube bilden. Die Sehue des Abductor longus inserirt sich am Trapezbeine und an der Basis des ersten Metacarpus und schickt einen vorderen Fortsatz, aus welchem der äussere Theil des Abductor pollicis brevis entsteht. Die Sehne des Extensor brevis ist dïnn und scheidet sich ron der soliden sehne des Abiluctor al, steigt an der Dorsalfläche des ersten Metacarpus herab und 
inserirt sich am hinteren Rande des oberen Endes der ersten Phalange. In diesem Niveau adhärirt sie innig mit dem Ligamentum annulare periarticulare.

Techuik z. A. d. G. Wenn man längs des äusseren Randes der Tabaksgrube die Haut und die Fascie durchschneidet, so sieht man die dicke Sehne des Abductor und etwas nach hinten die dümne. Sehne des Extensor. Man bemerkt, dass beide Sehnen mit einer gemeinsamen Synovialscheide bekleidet im osteo-fibrösen Leitkanale gleiten.

Extensor pollicis long'ıs. Sein Fleischkörper liegt tief unter der Huskelmasse

Fig. 45 .

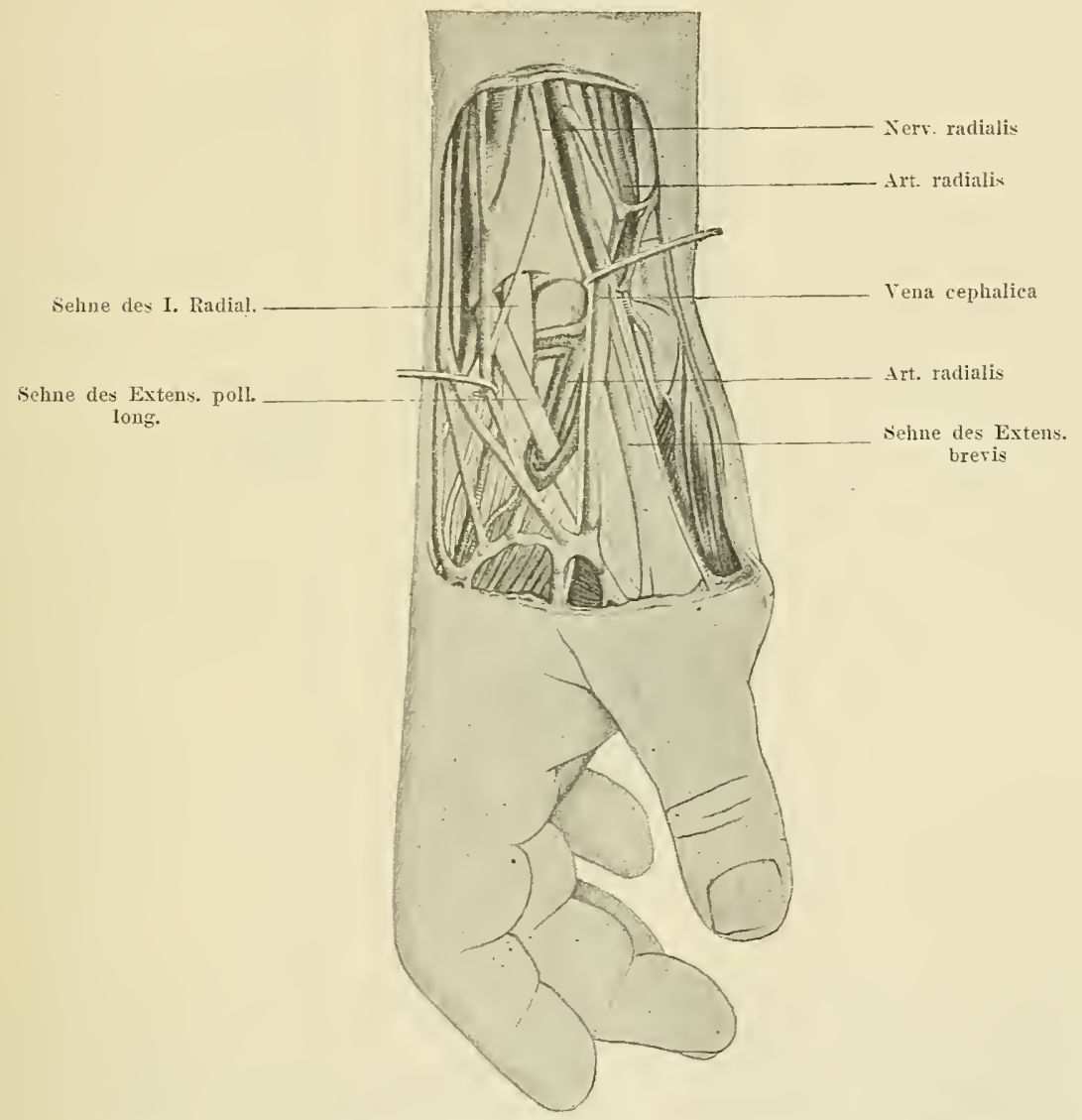

Die äussere Region der rechten Handwurzel; anatomische Tabaksgrube.

des Extensor communis und entsteht an der hinteren Fläche der Ulna und am Ligamentrum interosseum. Die Sehne gleitet in der tiefen Leitfurche, welche an der inneren Seite der Crista radialis sich befindet, kreuzt die Sehnen der Radialismuskeln, über welche sie hinweggeht, vereinigt sich an der hinteren Fläche des ersten Metacarpus mit der Sehne des Extensor brevis unter einem spitzen Winkel und inserirt sich am hinteren Rande des oberen Endes der zweiten Phalange des Daumens. Diese Sehne ist mit einer Synorial- 
scheide bekleidet, welche lingerbreit oberhalb der Gelenklinie des Radio-carpalgelenkes beginnt und $1 \mathrm{~cm}$ unterhalb des Trapezo-metacarpalgelenkes endigt. Diese Synovialscheide communieirt, wie wir sehen werden, mit der Scheide der Radialissehnen.

Techuik z. A. d. (t. Ein Assistent zieht den Daumen ab; dic Sehne des Extensor longus spannt sich an und erhebt die Haut. Durchschneidet man nun in dieser Länge die Haut und dic Faseic, so liegt die Schne in ihrer Synovialscheide frei. Man sucht darauf die runde Lücke, dureh welehe die Synorialis des Extensor longus mit der der Radialissehnen communicirt.

Fig. 46.

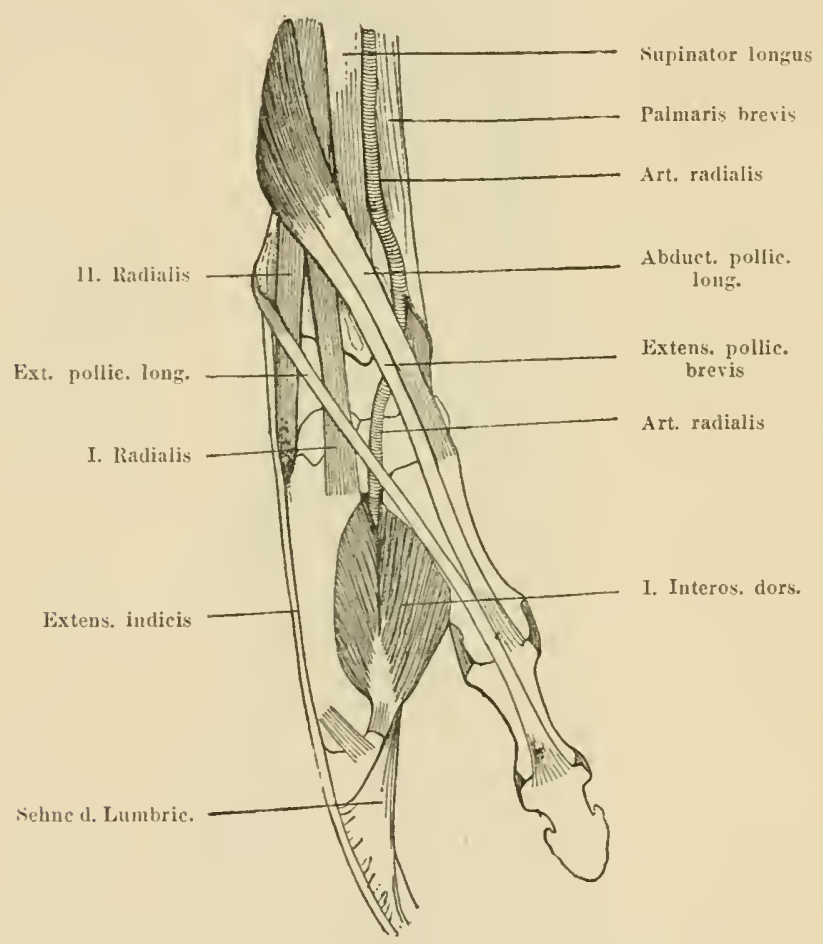

Die anatomische Tabaksgrube der rechten Seite.

Vena rephalica pollicis, Nerrus radialis mol Arteria radialis. Die Vena cephalic'a entsteht durch die Vereinigung der Venen des Daumens mit der Vena dorsalis der Hand, sie setzt sich in die Tena radialis fort (Fig. 45).

Die Aeste des Radialnerren für den Daumen rerlaufen an der Seite der Vena cephalica am äusseren Rande der Tabaksgrube. Diese beiden Gebilde liegen unter der Flaut in der Theilung des oberfliehlichen Blättchens.

Die Arteria radialis richtet sich unterhalb des Processus styloides nach hinten und unten gegen das crste Spatium interosseum, indem sie unter der Sehne des Abductor longus und des Extensor brevis hindurchzieht. Sie liegt in derTiefe am linochen und an dessen Gielenke, dringt dann in den ersten Zwischenknochenraum, und in der Palma 
manus angelangt, nennt man sie Arteria radio-palmaris profunda, welche mit der Arteria cubitalis anastomosirt und den Arcus palmaris profundus bildet.

Technik z. A. d. G. Itan macht in den Grund der Tabaksgrube einen Schnitt, welcher von der Spitze des ersten Zwischenknochenraumes gegen den Processus styloides radii schief gerichtet ist, und findet unter der Haut oder sehr häufig unter dem äussern Rande des Schnittes die Vena cephalica und den Nervus radialis. - Diese Gebilde werden isolirt und entfernt.

Man durchschneidet die beiden Fascien und legt stumpfe Haken an den beiden Schnitträndern an, wodurch das Gesichtsfeld deutlicher wird und

Fig. 47.

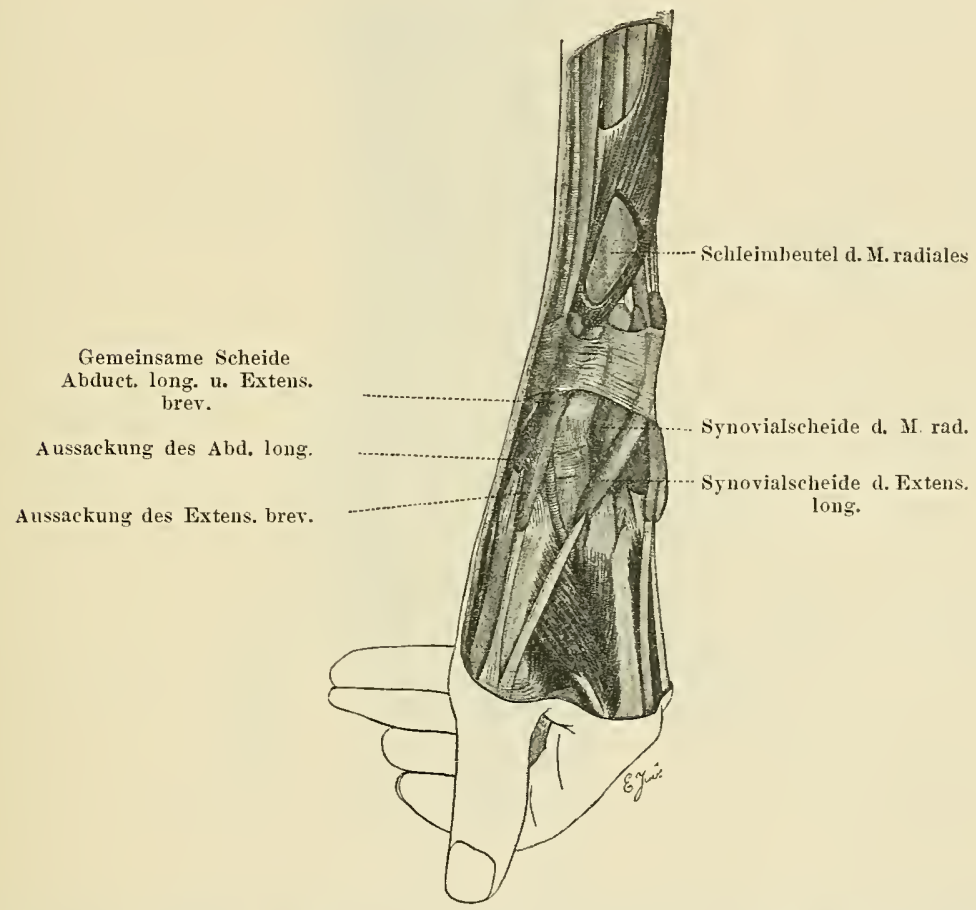

Die synovialen Scheiden der äusseren Fläche der Handwurzel. Eine Lücke durch die Muskelkörper des Abductor longus und des Extensor brevis hat den Schleimbeutel freigelegt, welcher diese Muskeln von den Sehnen der Musculi radiales trennt.

findet in der Tiefe am Knochen die Arteria radialis und die sie begleitenden Venen.

Die Sehnen der Radialismuskelı. Im Niveau des untern Radiusendes sind die beiden Sehnen der Radialismuskeln in derselben Synovialscheide enthalten. Unterhalb der Gelenklinie theilt sich die Synovia in zwei Arme: ein äusserer für die Sehne des Radialis primus, ein innerer für die des Radialis secundus. - Die Synovialscheide hat die Form eines mit der Spitze nach oben gerichteten V. Eine dreieckige Synorialfalte verbindet beide Sehnen. Die Synovialscheiden begleiten die Schnen der Radialismuskelu 
nirht his zu ihrer Ansatzololle an Metacarpus, sondern endigen fingerbreit oberhall, derselben (Fig. 4!-50).

Ein kleiner Schleimbentel befindet sich zwischen der Ansatzstelle der ersten liaJialisselne und dem äussern Processus des zweiten Metacaupus. Dieser Sehleimbentel communicirt oft mit dem Grunde der sehnigen Scheide. - Ein anderer Schleinbentel befindet sich zwischen der Sehue des zweiten Radialis und dem Processus styloides des dritten Metacarpus. - Die Synorialscheide der Radialismuskeln communicirt mit der Scheide des Extensor longus dureh ein rundes Loch, welches nach unten ron einem sichelfürmigen Rande begrenzt ist.

lig. 4s.

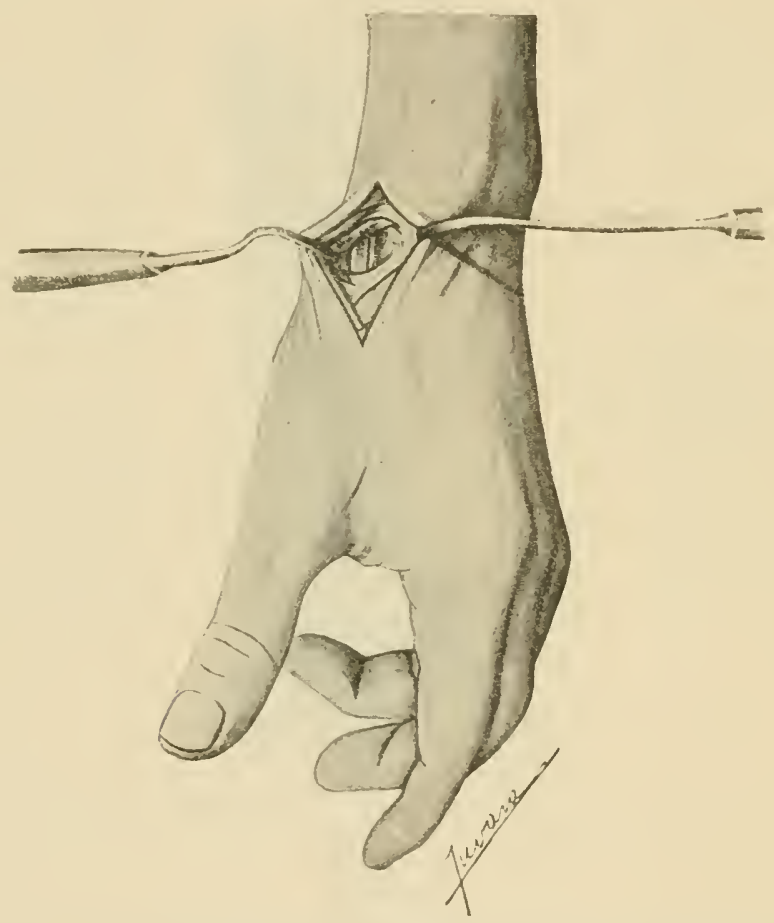

Das Aufsuchen der Arteria radio-dorsalis in der anatomischen Tabaksgrube. Zwei stumpfe Haken ziehen die Schnittränder ab.

Techuik z. A. d. G. Ein Assistent zieht am Zeigefinger; schneidet man längs des gespannten Stranges des ersten Radialis die Haut und das Ligamentum ammlare durch, so liegt die Sehne frei.

Man sieht ihre Ansatzstelle am 11. Metacarpus und sucht den Schlcimbentel, welcher oberhalb dieser Insertion liegt. Diese Operation wird auch für die Sehne des zweiten Radialis wiederholt.

Die Sehnen des Extensor communis. Der Fleischlörper des Extensor communis entsteht mit einem Sehnenblatte an der Epicondylusspitze und mit muskulösen Fasern an der Fascie des Torderarms und an fibrösen Blättern, welche ihn aussen rom 7.weiten Rarlialis und innen ron Extensor digiti minimi scheiden. - Dieser Fleischkïrper 
theilt sich im mittleren Vorderarmdrittel in drei Bündel, die in drei Sehnen übergehen: das äussere für den Zeigefinger, das mittlere für den Mittel- und das innere für den 4. und 5. Finger. Diese Sehnen sind zu einem Packete rereint und ziehen unter dem Ligamentum annulare in die Leitfurche, welche rom Radius and dem Ulnarkopfe begrenzt wird. Auf der Dorsalfläche der Hand theilen sich die Sehnen und jede zieht zu dem entsprechenden Finger. Nẹnig oberhalb der Metacarpalköpfchen sind die Extensorensehnen mit einander durch fibröse Ausbreitungen verbunden. Ein Schleimbertel von Sanduhr-

Fig. 49 .

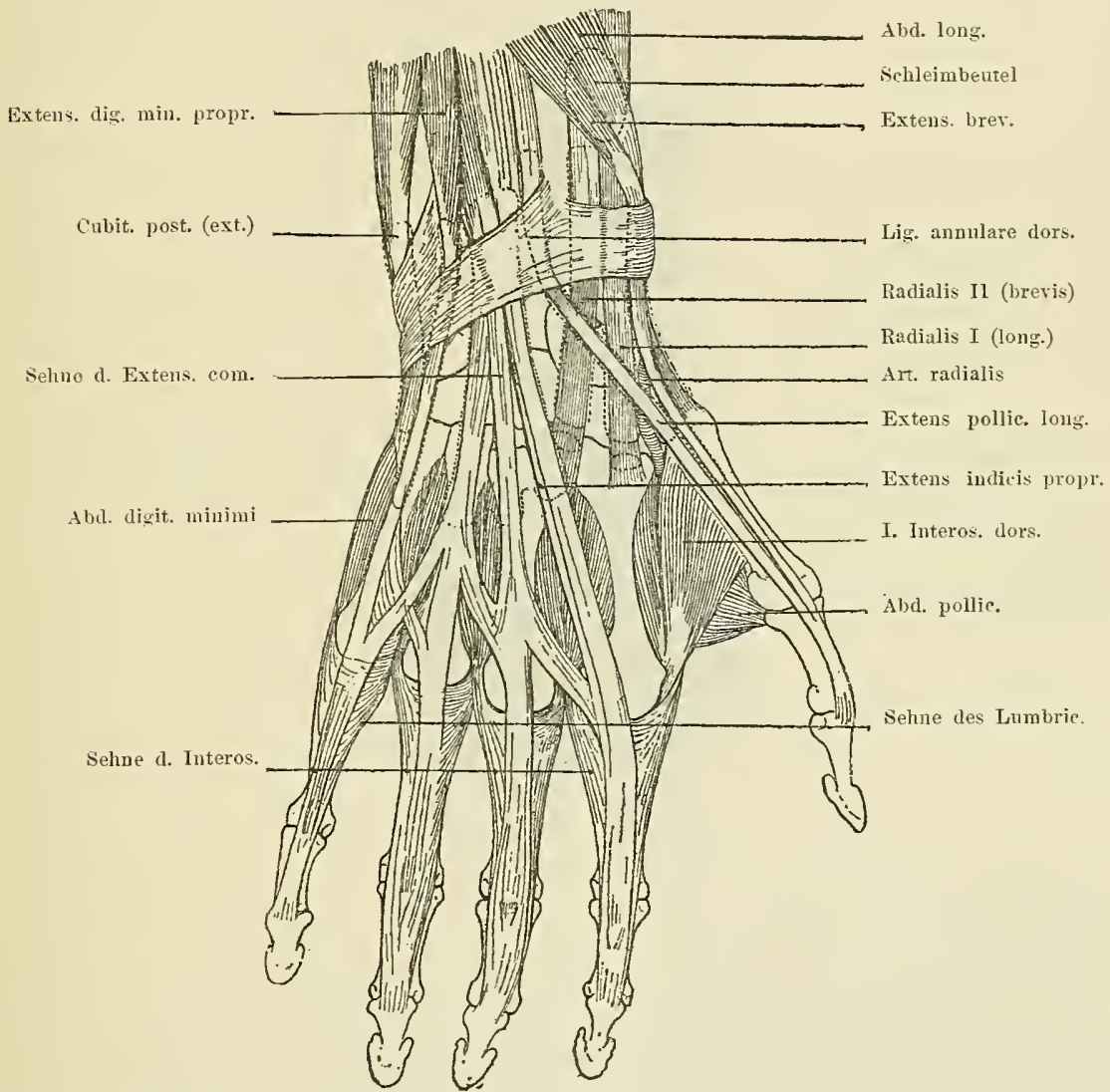

Die Dorsalfläche der Handwurzel und der Hand. Die punktirten Linien rings um die Sehnen zeigen deren Synovialscheiden an.

form im Nireau des Ligamentum annulare eingezogen, begleitet die Sehnen des Extensor. Der Boden des untern Sackes dieser Synorialscheide ist gezähnt und entspricht der Mitte der Hand. Im Innenraume der Synorialhöhle sind die Sehnen nicht frei, sondern ron einer dreiseitigen Mezosehne eingehüllt, welche an der hintern ITand der Synorialscheide sich ansetzt. - Der Boden des obern Sackes befindet sich fingerbreit oberhalb der Gelenklinie (Fig. 50, 51). 
In diesem Nirean ist die Synorialmembran gefaltet, indem sie rings un die Sehnen eine präputialartige Scheide bililet, welche den Sehnen ausgiebige Bewegungen gestattet.

Terhnik \%. A. d. (i. Nan mant einen verticalen, oberhalb der Gelenklinie begimnenden Schnitt über die Hitte der Dorsallläehe der Hand, durehschneidet das liganentum amnulare unter der Haut und es licgen die Sehnen der Extensoren, in einer Ilezosehne gehüllt, frei. Neben der Sehme, die der Extensor communis zum Zeigefinger sendet, findet man an ihrer innern und tiefen Seite die Sehne des Extensor indicis proprius. Die Sehne wird ron Iluskelfasern bis unterhalb des Radiocarpalgclenkes begleitet.

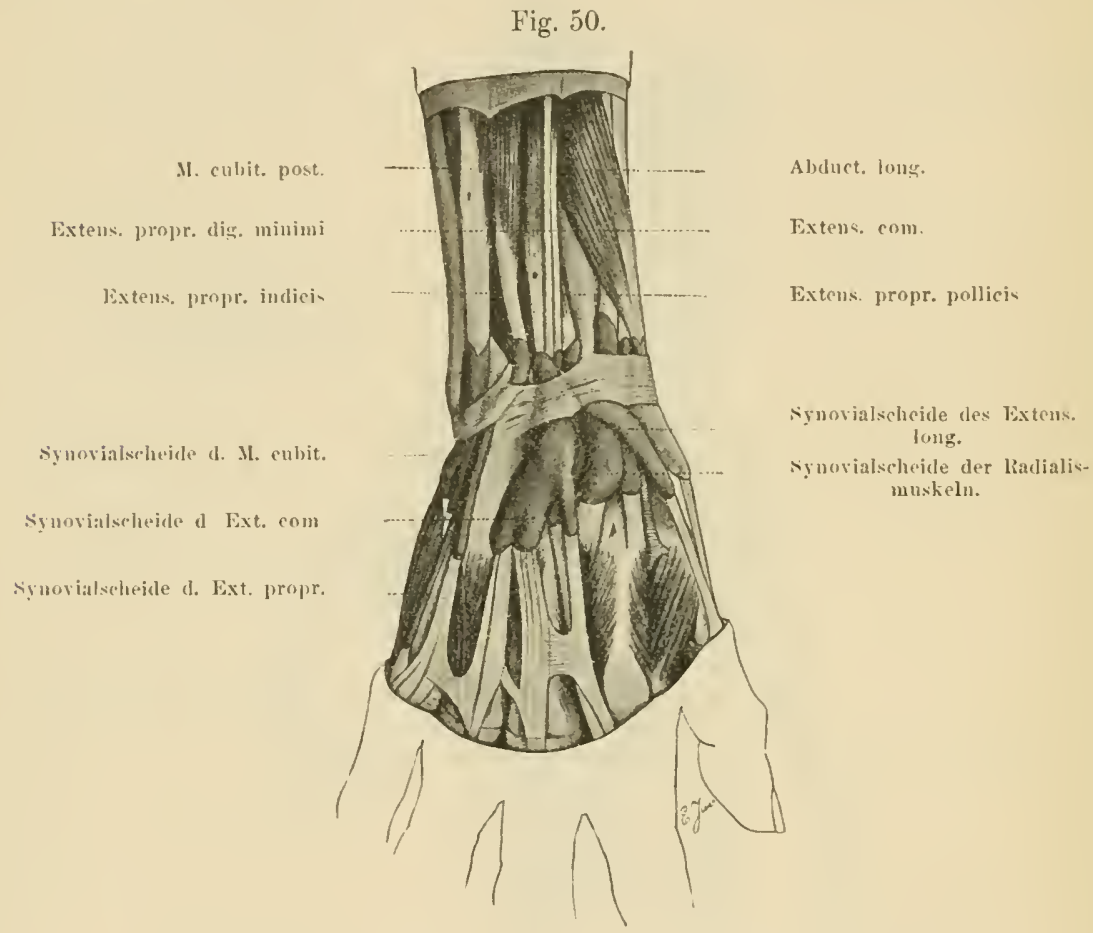

Die syuovialen Scheiden der dorsalen Fläehe der Handwurzel.

I) Sehne des Extensor digiti minimi proprins. Die Sehne verläuft nicht unterhalb, sondern durch das Ligamentum annulare.

Sehr oft in zwei Bündel getheilt, vereinigt sie sich im Nireau des 5. Metacarpalköpfchens mit einem Fortsalze, der ron der Sehne, die der Extensor communis zum Ringfinger schickt, abgeht. - Die Sehne des Extensor digiti minimi proprius wird ron einer Synorialscheide begleitet und diese beginnt oberhalb des Ulnarkopfes und endigt unterhalb des mittleren Theiles der Hand (Fig. 50).

Technik z. A. d. (6. Man macht, von der äussern Seite des Ulnarkopfes beginnend, bis zum Köpfchen des 5. Metacarpus, einen langen Einschnitt. Im untern Theile des Schnittes erscheint dic Schne, welche man nach oben in der Duplicatur des Ligamentum amnulare verfolgt. 
An der Innenseite der Sehne des Extensor digiti minimi findet man die starke Sehne des Cubitalis posterior, welche in der Leitfurche des Cubitalkopfs gleitet. - Man controlirt die Insertion dieser Sehne am Höcker des 5. Metacarpus und bemerkt, dass die sie begleitende Synovialscheide ein wenig oberhalb ihrer Ansatzstelle aufhört.

Der dorsale Hantast des Nervus cubitalis verläuft unter dem M. cubitalis anterior, umschlingt den innern Rand der Handwurzel im gleichen Abstande rom Erbsenbeine und vom Cubitalkopfe; auf die Dorsalseite der Hand gelangt, theilt er sich in Aeste, welche bestimmt sind: für die Haut der innern Hälfte der Hand, der dorsalen

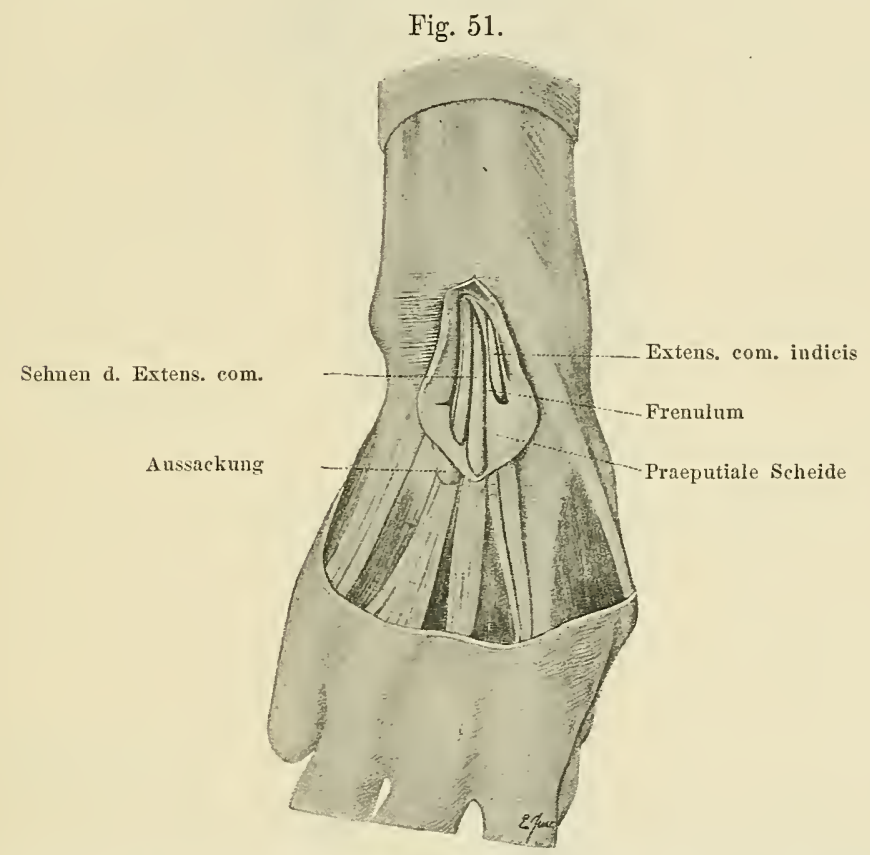

Die synoviale Scheide der Extensoren ist eröffnet und zeigt die innere Anordnung.

Fläche des kleinen Fingers, der Dorsalnäche, die der ersten Phalange des Ringfingers entspricht, und der innern Hälfte der ersten Phalange des Mittelfingers.

Technik z. A. d. G. Man sucht den Ulnarkopf und die Erhabenheit des Erbsenbeines auf, macht dann in der gleichen Entfernung ron beiden Erhabenheiten einen schief nach unten und innen gerichteten Hautschnitt, und man wird unter jedem der Schnittränder suchend, den Nervus cubitalis von einer kleinen Arterie begleitet finden.

Die Radiocarpalgelenklinie und das Ligamentum triangulare. - Die Gelenklinie hat die Form eines mit der Concavität nach abwärts befindlichen Bogens, welcher an der Spitze des Stylus radii beginnt und bis zum Processus styloides der Ulna reicht (Fig. 42).

An der hinteren Fläche des Gelenkes findet man zwei solide Ligamente (Fig 53).

Das Ligamentum radio-scapho-pisiforme. Das mittlere Bündel ist ron 
der innern Hälfte des hintern Randes des Radiusendes zur hintern Flärhe des Nlond besonders des Erbsenbeines ausgebreitet.

Es hat die Form eines schiefen Bandes, das nach nnten und innen gerichtet ist. Dieses Ligament und auch das Lig. annulare carpi, unter welchem es liegt, ïhermitteln

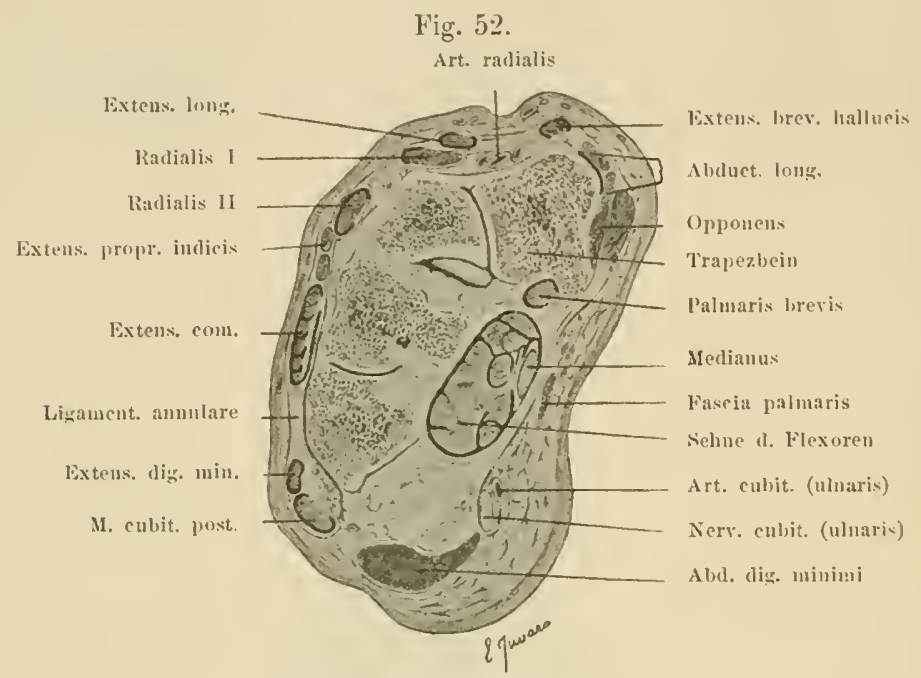

Ein Querschnitt der Handwurzel.

Fig. 53 .

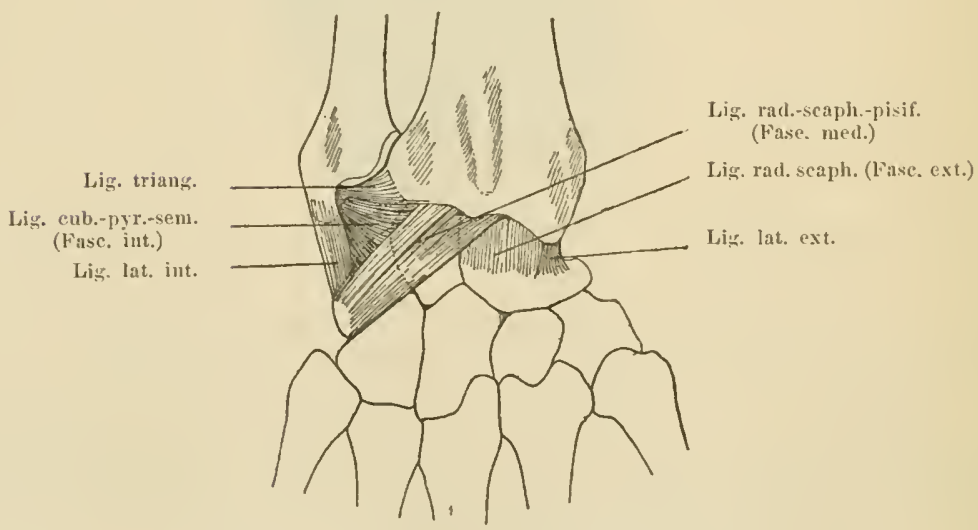

Die hintere Fläche des Handwurzelgelenkes.

die Pronationsbewegungen der Hand, weshalb es Poirier als Ligamentum pronator bezeichnet hat (Fig. 53).

Das Ligamentum cubito-pyramido-semilunare. Das innere Bündel hat die Form eines Fächers, welcher von der untern Fläche des Ulnarkopfes zur Dosalfläche des Pyramidenbeins und les Mondbeins ausgebreitet ist. - Es liegt unter der tiefen 
Schichte des Ligamentum annulare carpi und unter der Sehne des Cubitalis posterior. Vor der Gelenkkapsel wird es durch drei Bündel oder Ligamente verstärkt.

Das Ligamentum antero-externum oder Radio-carpi externum ist schief nach unten und innen gerichtet und hat die Form eines rechtwinkligen Bandes, welches wieder aus zwei Bündeln besteht. Es inserirt sich oben in der Grube des Kahnbeins des untern Endes des Radius, unten an der vordern Fläche des Kahn- des Mond- und grossen vieleckigen Beines.

Das Ligamentum antero-externum ist sehr dick und fest und übermittelt der Hand die Supinationsbewegungen, es ist das Ligamentum supinator.

Das mittlere Ligament besteht aus verticalen Fasern und inserirt sich oben an der innern Hälfte des vordern Randes des Radius, unten an der Vorderfläche des Kahnund Hondbeins. Das sehr dünne und wenig feste Ligament wird rom äussern Bündel durch eine kreisförmige Oeffnung getrennt, durch welche ein synorialer Blindsack herrortritt, welcher oft der Ursprung einer palmaren Synovialcyste ist.

Fig. 54.

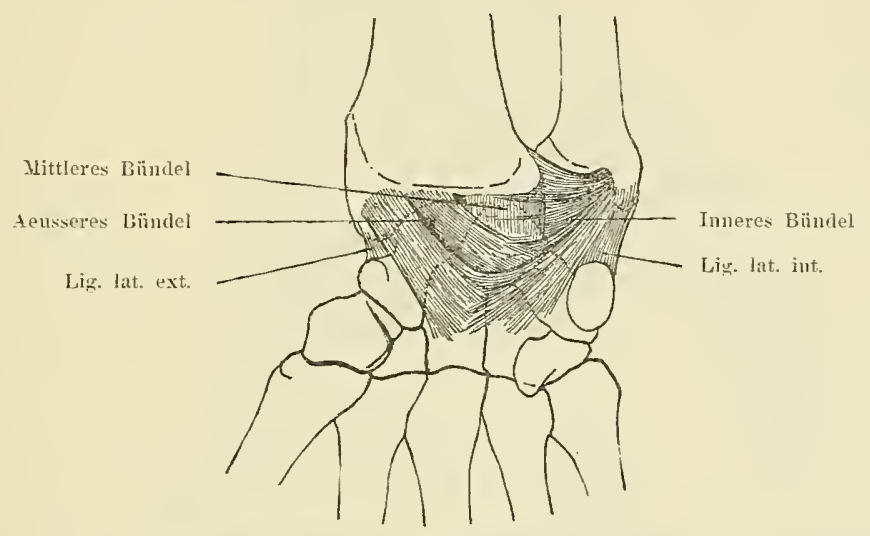

Die Fordere Fläche des Handwurzelgelenkes.

Das Ligamentum antero-internum oder Cubito-carpalligament ist dick und fest und nach unten und aussen gerichtet. Es inserirt sich oben an der untern Fläche des Capitulum ulnae in der Grube des Processes styloides, unten breitet es sich fächerförmig aus und setzt sich an der vordern Fläche des Pyramiden-, des Mond- und des grossen rieleckigen Beines an, wo es sich mit den Fasern des antero-externen Ligamentes rerwebt. An jeder Seite des Gelenkes existirt ein Lig. laterale (Fig. 54).

Das Ligamentum laterale-externum hat die Form eines Dreieckes mit der Basis nach unten und inserirt sich oben an der Spitze des Processus styl. radii, unten am Kahnbeine.

Das Ligamentum laterale internum setzt sich oben an der Spitze und am Halse des Processus styl. ulnae, unten am Pyramiden- und Erbsenbeine an.

In seinem obern Theile ist das Lig. lat. inter. hohl und seine Höhle communicirt durch eine Oeffnung mit der Gelenkhöhle.

Das dreiwinklige Ligament ist zwischen Ulna und Radius gespannt und ergänzt das innere Drittel der oberen Gelenkfläche und scheidet das Radio-carpalgelenk rom Cubito-radialgelenke. Es hat eine dreiwinklige Form und heftet sich mit seiner Spitze in 
der Rinne oberhalb des Processus styloides ulnae mit der Basis an dem untern Rande und an den beiden Höliern der Caritas sigmoidalis des unteren Radiusendes an. Längs seiner rordern und hintern Ränder ist es sehr resistent, im mittleren Theile wird es dünner; of finden wir es auch perforirt, als wem es in der Nähe seiner Insertion am Radius mit der Spitze eines Bistouri durchstochen wäre (Fig. 55).

Wenn nun diese Perforation vorhanden ist, communicirt durch dieselbe die radiocarpale Gelenkhöhle mit dem untern cubito-radialen Gelenke.

Es besteht aus einem fibrösen Gewebe und in seinem äussem Theile ist es linorpelig infiltrirt.

Technik z. A. d. G. Man sucht die beiden Proe. styloides auf und markirt sie mit dem Daumen und dem Zeigefinger der linken Hand. Durehschneidet dann gleichzeitig alle hintern Sehnen, folgt mit der Spitze des Hessers dem Rande des Radinsendes und präparirt die Kapsel, es erüfhnet sich das Gelenk, indem die Hand, wie in einem Gewinde, das von den rordern Ligamenten gebildet ist, sich bewegt. Es erseheint das Ligi-

Fig. 55 .

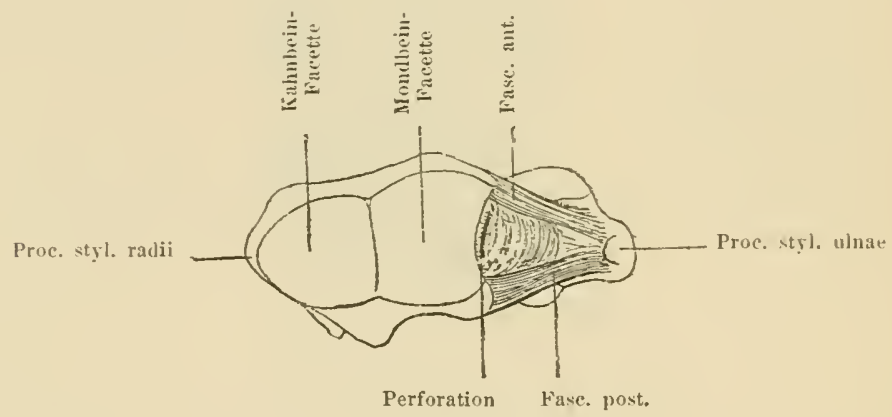

Das rechte Handwurzelgelenk. Die untere Fläche des Ligamentum triangulare.

mentum triangulare und man muss seine beiden Ränder suchen, den vordern und hintern, welche in die Gelenkkapsel sich fortsetzen. - Nan sieht, dass die untere Fläche des dreiwinkligen Ligamentes dem innern Drittel des Mondbeins entspricht, aber niemals dem des Pyramidenbeins, wie fast alle Autoren es angeben.

Man sucht die Perforation, welehe man bei diesem Ligamente oft längs seiner Insertion am Radius vorfindet. Mlan sieht, dass der Carpalcondylus von aussen nach innen aus dem Kahn- und Vondbein und in seinem innern Theile durch cine leichte Erhabenheit des Pyramidenbeins gebildet wird.

Ein anderes sehr elegantes Verfahren das Lig. triangulare zu präpariren besteht darin, die vordere und hintere Fläche der Ulna von den Muskeln freizumachen, indem man sic drei fingerbreit oberhalb des Gelenkes quer durchsehneidet und das untere Ulnarfragment innen luxirt, welches rings um das dreiwinklige Ligament schwingt. - Die Radio-cubitalkapsel wird geöffnet und es erscheint unter dem Ulnarkopfe das Ligamentum triangulare. 


\section{Die Region der Hand.}

Die Palma manus wird oben von einer transversalen Erhebung, dem Boden der Hand, welche durch Vereinigung des Thenar und Antithenar gebildet wird, unten durch die Beugungsfurchen der einzelnen.Finger und durch den Rand der Zwischenfingerfalten begrenzt. An der Innenseite ist die Hohlhand von einem dicken und fleischigen Rand, an der Aussenseite von einem winkligen Rand, aus dessen Spitze der Daumen abgeht,

Fig. 56.

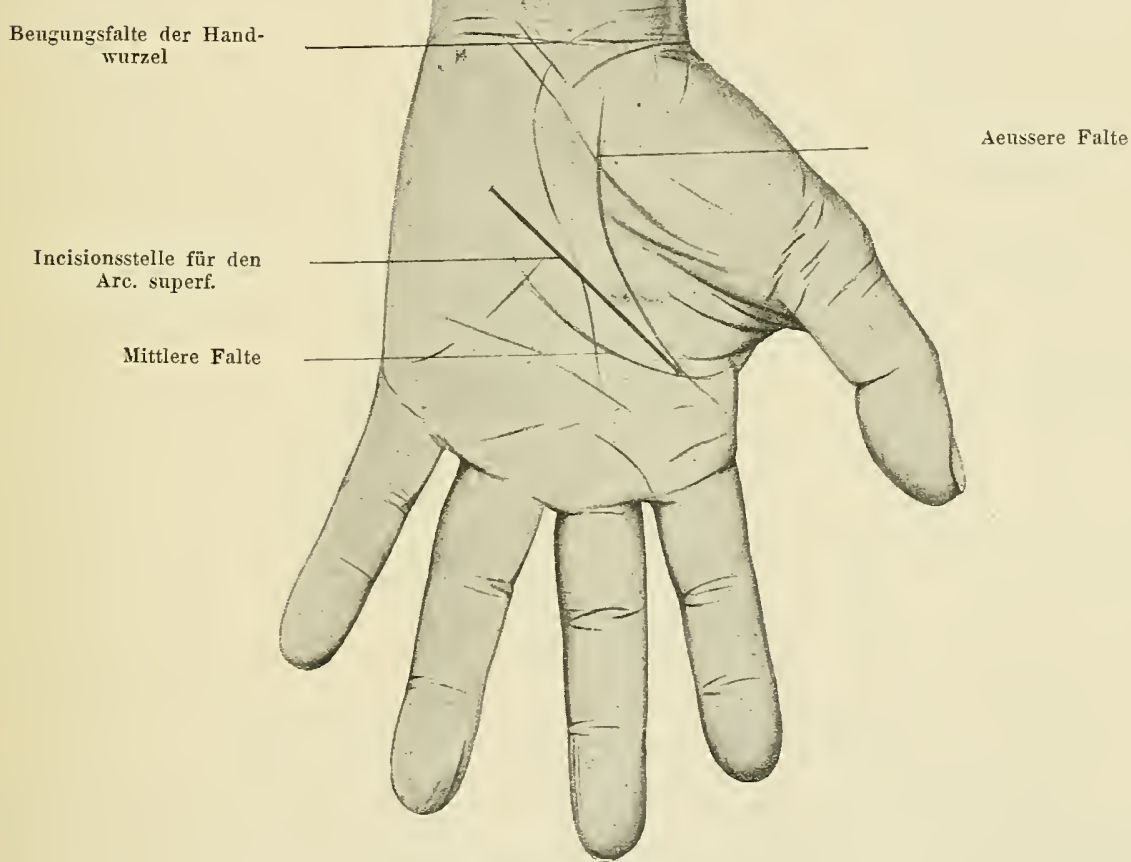

Die Hauptfalten der Hohlhand.

begrenzt. Die Hohlhand besitzt drei Regionen: eine centrale hohle Region, die Grube der Hohlhand und zwei Grenzwülste, ein äusserer, der Thenar, und ein innerer, der Antithenar genannt.

Die Grube der Hohlhand. Hier beobachtet man hauptsächlich vier Falten:

a) Die äussere Falte oder Oppositionsfalte des Daumens beschreibt einen mit der Concavität nach aussen gerichteten Bogen. - Sie beginnt am äussern Rande der Hand im Niveau des II. Metacarpalköpfchens, umgiebt den Ballen und endigt an der Basis des I. Metacarpus (Fig. 56, 57). 
b) Die mittlere Falte oder die Beugnngsfalte der vier innern Finger beginnt in demselben Nireau wie die äussere und endigt gegen die Mitte des Gegenballen. Diese Falte bildet mit der vorhergehenden einen spitzen Winkel, deren Senlirechte dem Verlaufe des palmaren Gefässbogens entspricht.

c) Die untere Falte oder die Beugungsfalte der drei innern Finger beginnt am zweiten Zwischenfingerraum und endigt im Niveau des 5. Metacarpalköpfehens (Fig.56,57).

d) Die mediane orler die Oppositionsfalte des lieinen Fingers folgt fast der Medianlinie der Ifand. Sie beginnt an der Wurzel des Zeigefingers und endigt am lioden der Hand. Diese rier Falten rereinigen sich, indem sie die Form eines M. bilden. Die Lebenslinien.

Die Fascia palmaris superficialis liegt unmittelbar unter der Haut und hat eine dreiwinlige mit der Basis nach unten gerichtete Form.

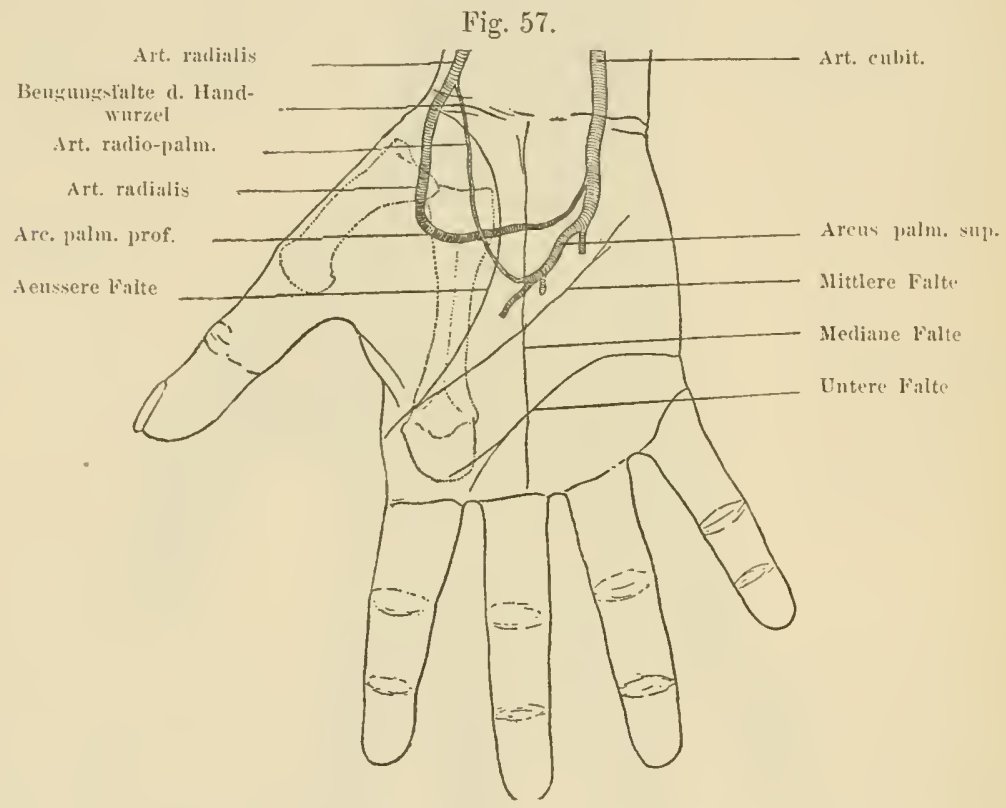

Die schematische Figur zeigt die Falten der Hohlhand und die arteriellen Gufässbugeu, die man durchscheinend übereinander gelagert sicht.

lhre Spitze hängt mit der Sehne des Palmaris longus zusammen oder wenn diese felılt übergeht sie in die Fascie des Vorderarms. Mit tiefen Fortsätzen inserirt sie sich an Lig. annulare und an der Spitze des Proc. des Hakenbeins.

Nach unten theilt sie sich in rier Zipfel; jeder dieser rier Zipfel theilt sich in drei Schichten, eine prätendinöse und zwei laterotendinöse Schichten.

Die prätendinöse Schichte setzt sich an der tiefen Lage der Hant an im Niveau der Metacarpalköpfe und an der Haut der Finger, wo die Bündel lis zum I. Interphalangealgelenke rordringen.

Die latero-tendinöşen Schichten sind um vieles fester; sie verlaufen an den lateralen Seiten der Beugersehnen, durchbohren das Intermetacarpal-Ligament, verweben sich mit den Sehnen der Zwischenknochenmuskeln und vereinimen sich an der dorsalen Fläche der Metacarpoplralangealgelenke, indem sie grösstentheils sur Bildung des Lig. 
annulare dieser Gelenke beitragen. - Die vier Zipfel der Fascia palmaris sind unter einander durch das Lig. palmare transversale verbunden. - Dieses Ligament ist aus fibrösen Bogen gebildet, welche den metacarpalen Antheil der Scheiden der Flexoren mit einander verbinden.

Technik z. A. d. G. Man macht eine verticale und mediane Incision oberhalb des Handbodens und verlängert den Schnitt zur oberen Fläche des Mittelfingers, ein anderer transversaler Schnitt längs des untern Randes der Hand kreuzt den ersteren in Form eines T. Nit der Pincette und dem Bistouri wird die Haut an der Innen- und Aussenseite präparirt, indem

Fig. 58.

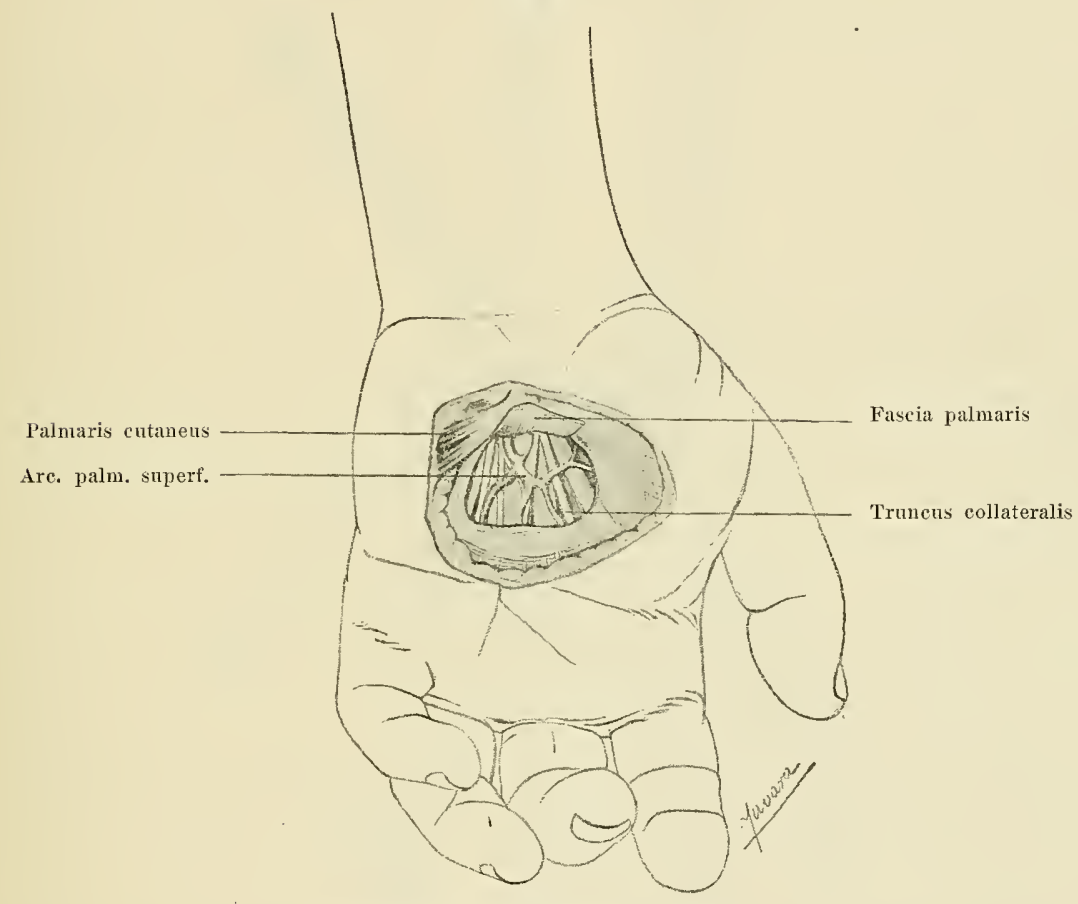

Die mittlere Region der Hohlhand.

man sich nahe an die weissen und glänzenden Fasem der Fascie hält und controlirt die Art ihrer Insertion.

Der Arcus palmaris superficialis wird durch Vereinigung der Art. cubitalis mit der Art. radio-palmaris, einem Aste der Radialis gebildet. Er liegt unmittelbar unterhalb der Fascia palmaris und vor den Sehnen der Beuger, hat die Form eines mit der Concavität nach unten gerichteten Bogens. Er ist sehr dehnbar und giebt vier Stämme, die Stämme der Collateralarterien, ab (Fig. 57-58).

Diese Stämme verlaufen vertical zwischen den Selnnen der Beuger, und etwas unterhalb der Metacarpophalangealgelenke theilen sie sich in je zwei Aeste, eine collaterale Arterie für den Rand eines jeden Fingers, welcher den Zwischenfingerraum begrenzt, an 
dessen Spitze sich die Arterie auch getheilt hat. Oft ist der oberflächliche Bogen doppelt und man findet den oberen um vieles dünner.

Den Nerrus cubilalis und Nervus medianns findet man auf derselben Ebene mit dem Gefässbogen, indem der Nervus cubitalis an der Innenseite der Arterie festhaftet.

Technik z. A. d. G. Man sueht das Erbsenbein, das stets leicht zu finden ist, auf. Fingerbreit unterhalb desselben wird in der Hohlhand eine $4 \mathrm{~cm}$ schief nach unten und aussen verlaufende Incision gemacht, wclche gegen den Kopf des zweiten Mittelhandknochens gerichtet ist. Man durchschneidet die Hant und gelangt an die Fascia palmaris. Vorsichtig durch-

Fig. 59.

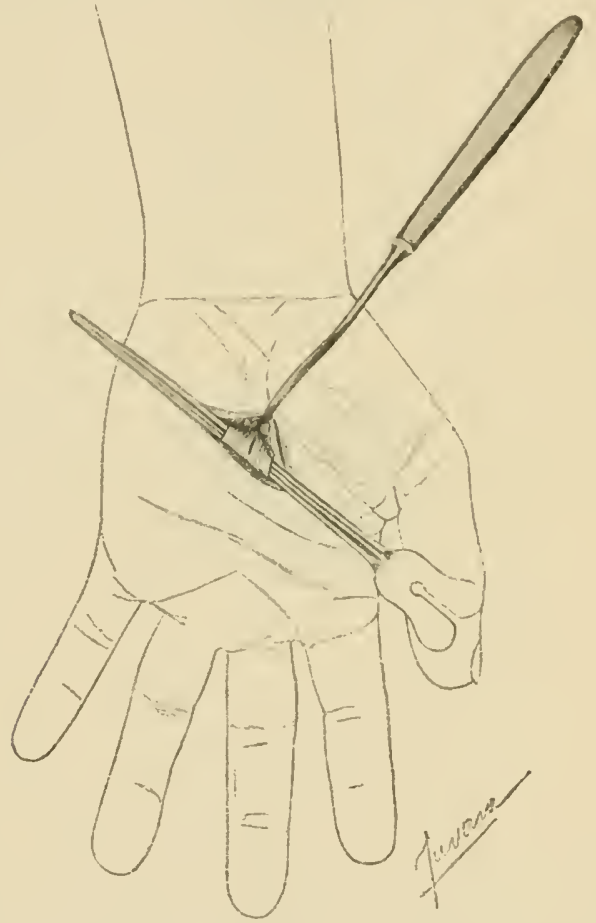

Das Aufsuchen des Arcus palmaris superficialis. Die Fascie ist auf eine Sonde gehoben.

schneidet man nun die Fascie auf der Hohlsonde, weil ummittelbar unter derselben der Gefässbogen sich befindet; dieser liegt nun im Schnitte frei, oder kamn mit Pincette und Sonde unter den Schnitträndern oder in einer Fettschichte ron zwei Tenen begleitet aufgefunden werden (Fig. 59).

Ein anderer Torgang besteht darin, dass man nach dem Verlaufe des Winkels, welcher von der Oppositionsfalte des Daumens und der Beugungsfalte der vier innern Finger cobildet wird, cine Ineision macht oder auch einen horizontalen Schnitt in der Hohlhand in der Mitte zwischen dem Erbsenbein und dem Kopfe des 5. Mittehandknochens führt.

Die Anastomose des Medianus mit dem Nervus cubitalis. Der Medianus 
und Ulnaris anastomosiren in der Hohlhand mittelst eines sehr dünnen Fadens, welcher vom Ulnaris gegen den Medianus schief gerichtet ist. Diese Anastomose liegt unmittelbar unter der hinteren Fläche des Gefässbogens; oft hat sie die Form eines X durch zwei Fäden, welche rom Cubitalis zum Medianus und umgekehrt verlaufen. Selten fehlt in der Hoblhand diese Anastomose.

Techuik z. A. d. G. Es wird dieselbe Incision wie für den Gefässbogen, doch um vieles länger geführt. Man sucht nun den Gefässbogen

Fig. 60 .

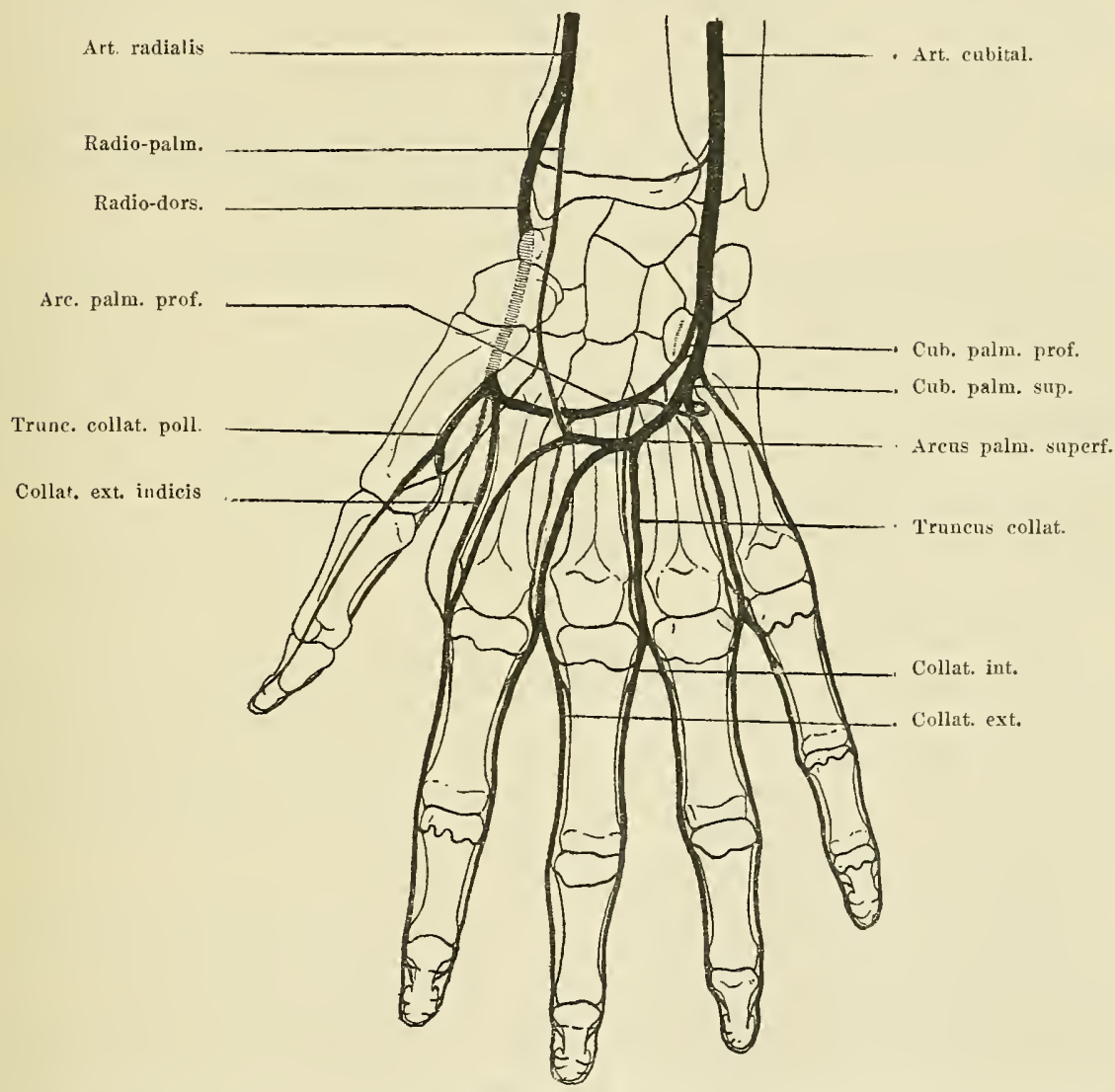

Der Blutkreislauf der Hand. Die gestreifte Linie zeigt den Verlauf der Radio-dorsalis an der hinteren Flä.che der Handwurzelknochen.

und an seiner inneren Seite den Nerrus cubitalis. Der Bogen wird freigelegt und auf die Sonde gehoben, dann sucht man sorgfältig unter demselben den anastomotischen Faden. Er wird leichter gefunden, wenn man mit einer Pincette den Nervus cubitalis abhebt.

Die Sehnen der Benger. Ein jeder der rier inneren Finger hat zwei Bengersehnen, welche hintereinander gelagert sind. In der Hohlhand theilen sich die un- 
mittelbar unter Jem Lig. annulare earpi anterius befindlichen Schnenpaare wie die Arme eines Fächers, indem jedes l'aar gegen den entsprechendei Finger sich richtet. Die Sehneu des oberllächlichen Beugers inseriren sich mit zwei Lefzen an den Rauhiglieiten, welche in der Mitte der Vordertläche der zweiten Phalange nahe ihren lateralen Rändern sich befinden. Diese Lefzen werden ron zwei in Form eines $\mathrm{X}$ gekreuzten Ausbreitungen rereinigt, so dass jeder der Arme, in welche sich der oberflächliche Beuger theilt, einen starken directen und einen indirecten Ansatz hat. Die Sehmen des tiefliegenden Beugers durchdringen die Oeffnung, welche ron den Schenkeln der Sehnen des Flexor superficialis gebildet wird, ziehen ror den Ansatzstellen dieser Sehnen, welche sie bedeclien, rorbei und inseriren sich zu einem Fächer ausgebreitet an den Rauhigkeiten, welche an der Vordertläche der Endphalangen, wenig oberhalb der oberen Grenze der Gelenkflächen sich befinden.

Der Daumen hat eine einzige Sehne, welche sich an der Endphalange inserirt.

In der unteren Hälfte der Hohlhand befinden sich die Sehnen derBeuger in fibrösen Hïllen, welche ron der Fascia palmaris profunda, ron den latero-tendiuösen und prätencinösen Ausbreitungen der Fascia palmaris superficialis gebildet werden.

In den ron den Selnnen der Beuger begrenzten Winkeln findet man die Fleischkïrper der Lumbricalmuslieln und vor denselben das Arterien- und Tervenbündel der Collaterales. Im Nireau des Ilandbodens sind die Sehnen der Beuger in einen osteofibrösen Canal eingeschlossen, im Carpalcanale; die hinteren und lateralen Wände dieses Canals sind linöchern, die rorderen Wände sind fibrös und werden als Ligam. carpi anterius bezeichnet. Dieses Ligament wird ron Fasern gebildet, welche transiersal rom Höcker des Kiahnbeins und Processus des Trapezbeins an der Aussenseite, zum Erbsenbein und Processus des Hakenbeins nach innen ausgebreitet liegen.

Die Synorialscheiden der Hohlhand. Die Bewegungen der Sehnen der Beuger im Carpalcanale und in der Ilohlhand haben zwei Synovialscheiden herrorgebracht.

1. Die äussere Synovial-oder äussere Digit o pal mars che i de ist für die Beugersehne des Daumens bestimnt. Sie beginnt fingerbreit oberhalb des Handbodens und endigt im Nireau des Interphalangealgelenlies des Daumens. In ihrem oberen Theile hat sie eine Sanduhrform, in ihrem unteren oder Metacarpo-digitaltheile hat sie eine Röhrenform. Die Beugersehne ist mit der inneren Wand der Synorialis durch eine dreiwinlilige membranöse, mit der Spitze nach unten gerichteten Falte verbunden, es ist eine llezosehne, durch welche die Gefässe den inneren Raum der Sehne erreichen.

Im Niveau des Grundes des oberen Sackes ist die Synorialmembran an der Sehne wenig adhärent, sie bildet rings um sie eine dreiwinklige Falte, welche Präputialscheide genannt wird und rom Gileiten der Sehne in der Synorialscheide entstanden ist.

2. Die innere Synovialscheide oder innere Digito-palmarschei de gemeinsam für alle anderen Beugerselnen beginnt fingerbreit oberhalb der Hand und endigt im Niveau des letzten Phalangealgelenkes des kleinen Fingers. Sie hat die Form einer Sanduhr, welche eine Ausbuchtung an den Kleinfinger sendet. Im Innenraum der Synorialhöhle findet man zwei Falten oder Mezosehnen. Jede dieser Falten haftet an der äusseren Wand der Scheide.

Die rorlere IIezosehne enthält die Sehnen des oberflächlichen Beugers für die drei inneren Finger. Die Sehne des kleinen Fingers findet man am freien Rande dieses Bandes,

Die hintere Mezosehne umfasst die Sehnen, welche der tiefliegende Beuger für den Mittel-, Ring- und kleinen Finger entsendet. Diese beiden Synovialfalten theilen die - Synovialhöhle in drei liäume, einen vordern oder prätendinösen, einen mittlern oder 
intertendinösen und einen hintern oder retrotendinösen Raum. Am obern Theile bildet die Synovialscheide rings um die Sehnen eine dreiwinklige Falte, die obere Präputialscheide. Unten gegen das Metacarpo-phalangealgelenk des fünften Fingers findet man wieder eine Falte, die untere Präputialscheide, welche an der hintern Wand der Synovialis mittelst eines Frenulums, das Frenulum der Präputialscheide, befestigt ist.

Technik z. A. d. G. Mlan macht an der innern Seite des Thenar einen tiefen Einschnitt und findet die Sehne des Daumenbeugers; mit der Pincette fasst man das rings $\mathrm{um}$ die Sehne befindliche Zellgewebe, schneidet es mit der Scheere weg und findet die äussere Synovialscheide.

Macht man längs des Antithenar einen Einschnitt, so findet man die Sehne des kleinen Fingers. - Rings um diese Sehne legt man die Synovialscheide frei und geht in dieselbe durch eine mit der Hohlsonde geschaffene Oeffuung ein, indem man alle Weichtheile auf derselben durchschneidet. Auf diese Weise wird die innere Synovialscheide weit eröffnet und man kann die beiden Mezosehnen finden.

Der Nerrus medianus durchdringt den Carpalkanal, um in die Hohlhand zu gelangen und liegt unmittelbar an der Innenseite der Sehne des Daumenbeugers. An seiner äussern Seite ist der Medianus mit einem parietalen Blatt der äussern Synorialscheide belileidet, an der innern Seite mit einem parietalen Blatt der innern Synovialscheide. Hinter dem Nerv legen sich die Wände dieser beiden Synorialschichten an einander und zuweilen communiciren die Synovialhöhlen mit einander, wenn die gemeinsame Wand. durch Usur verschwindet.

Im Niveau des untern Randes des vordern Ligamentum carpi annulare erweitert sich der Medianus dreiwinklig, aus dessen Basis drei Aeste abgehen, die Stämme der Collateraläste.

a) Der Stamm des Collateralis externus entsendet die beiden Collaterales des Daumens und den Collateralis externus des Zeigefingers.

b) Der Stamm des Collateralis medius entsendet den Collateralis internus des Zeigefingers und den Collateralis externus des Mittelfingers.

c) Der Stamm des Collateralis internus entsendet den Collateralis internus des Mittelfingers und den Collateralis externus des Ringfingers.

Auf diese Weise giebt der Medianus sieben Collateraläste ab. Von seinem Ende gehen noch andere Zweige ab, die für die Muskeln des Ballen bestimmt sind.

Technik z. A. d. G. Man macht auf dem Handboden einen rerticalen, 3 bis $5 \mathrm{~cm}$ langen Einschnitt, welcher durch die Oppositionsfalte des Daumens geht. Man durchschneidet die Haut und das Ligamentum annulare, legt an die Schnittränder stumpfe Haken an und findet im Grunde den Nervus medianus.

Die Musculi lumbricales sind vier an der Zahl; für jeden der vier innern Finger. Diese Muskeln entstehen an den Sehnen des tiefliegenden Beugers und am dichten Bindegewebe, welches rings um die Sehne sich befindet. - Ihr Fleischkörper ist dünn und spindelförmig. - Die dünne Endsehne eines jeden Lumbricalis gleitet an der äussern Fläche des obern Endes der ersten Phalange und breitet sich an ihrer lateralen Dorsalfläche in einen schönen Fächer aus, welcher am äussern Rande und an der dorsalen Fläche der Sehne des Extensor sich arheftet. - Nit den äussersten und längsten Fasern heftet sich die Sehne eines jeden Lumbricalis an dem äussern Rand der entsprechenden Extensorsehne, welcher sie folgt und neben welcher sie anch an der Basis 
der Endphalange sich ansetzt. - Nach ilnen Ansat»stellen sincl die Lumhricales Beuger und Strecker, denn sie entstehen an den Beugerselnnen und inseriren sich an den Sehnen der Strecker. Dic beiden äussern Lumbricales werden rom Medianus, die beiden innern rom Cubitalis innervirt.

Mit ihren rorderen Fliichen treten sie zum Stamme der Collateralarterien und Collateralvenen in Beziehung. Die Sehnen der Lumbricales bilden mit denen der Interossei eine fibröse Sclilinge, welche hinter dem Körper ler ersten Phalange zielst.

1. Ier erste Lumbricalis entsteht an der äussern Fläche der Sehne des tiefliegenden Beugers und ist für den Zeigefinger bestimmt.

Techuik z. A. d. G. Man macht in der Hohlhand längs der Oppositionsfalte des Dammens cinen etwas schiefen Schnitt. Man durchschneidet die Haut und die Fascie und der blasse Körper des ersten Lumbricalis liegt frei auf der äussern Seite der Sehne des Bengers, die für den Zeigefinger bestimmt ist. Han sucht den Stamm der Collateralarterien und der Nerven auf und sorgfältig präparirend findet man den Faden, den diese Collateralis dem ersten Lumbricalis sendet.

2. Iner zweite Lumbricalis entsteht an der äussern Fläche der Sehne des tiefliegenden Beugers, die für den Mittelfinger bestimmt ist.

Technik z. A. d. G. Man legt denselben frei, wenn man wie frïher •rerführt, indem man den Schnitt längs des zweiten Zwischenknochenrammes macht. Dieser I mmbricalis liegt in der Furche, welche aussen von den Beugersehnen des Zeigefingers und inmen ron der des Nittelfingers gebildet wird. Man sucht seinen Nerrenfaden auf, welcher vom zweiten Truncus collateralis abgeht.

3. Der dritte Lumbricalis entsteht in einem Winkel, welcher ron der Sehne des Zeigefingers und der des Ringfingers gebildet wird.

Technik z. A. d. G. Man führt den Schnitt im dritten Zwischenlinochenraume und man gelangt an den Körper des Lumbricalis. - Man sucht seinen Nerv auf, der rom Cubitalbogen abgeht und den Muskel unter seiner tiefen Schichte durchdringt.

4. Der vierte Lumbricalis entsteht in dem Winkel, der ron den Sehnen des Ring- und lileinen Fingers gebildet wird.

Technik z. A. d. G. Ein Sehnitt im rierten Zwischenknochenramme legt den Nuskel frei. Sein Nerv geht rom Cubitalbogen ab.

Der tiefliegende oder radiale Bogen wird durch Anatomose der Art. rad. mit der Art. cubito-palmaris gebildet (Fig. 60). Nachdem die Art. rad. den ersten Zwischenraum dorchdringt, richtet sie sich nach rorne, zieht unter dem obern Bündel des Adductor pollicis, wird im winkelförmigen Zwischenraum, welcher das obere Bündel des Adductor rom mittleren scheirlet, sichtbar und anastomosirt ror den fünften Vetacarpus mit der Arteria cubito-palmaris profunda.

Diese Arterie geht ron der Cubitalis ab unmittelbar unterhalb des Erbsenbeines und, vom tiefliegenden Aste des Nerrus cubitalis begleitet, dringt sie in den Opponens des lileinen Fingers ein. Eine lileine ron der innern Seite des oberflächlichen Bogens stammende Arterie umschlingt den innern Rand der Beugersehnen und tritt in den tiefliegenden Bogen ein. 
Der tiefliegende Bogen liegt unmittelbar vor den Einkerbungen des 1I., III. und IV. Metacarpus und ror den Musculi interossei; ron diesem Bogen gehen fünf $\Delta$ rt. interosseae anteriores ab, welche vertical unter der tieflieg'enden Fascie ziehen.

Die Arteria interossea anterior ist für den ersten Zwischenknochenraum bestimmt, geht von der Art. radialis im Niveau des obern Endes des I. Metacarpus ab und steigt an seiner innern Seite herab, welche sie oft in Form einer Rinne leicht eindrückt.

Oberhalb des Metacarpo-phalangealgelenkes theilt sich diese Arterie. Der äussere Ast zieht an der äussern Seite der Sehne des Flexor proprius, steigt längs des äussern Randes des Daumens herab, anastomosirt mit dem äussern Aste des ersten Collateralstammes und bildet die Collateralis externa des Daumens. Der innere $\Lambda$ st zieht an der innern Seite der Sehne des Beugers und anastomosirt mit dem innern Ast des I. Callateralstammes, mit welchem er die Collateralis interna des Daumens bildet. Der tiefiegende Bogen wird von der Sehnenmasse der Beuger bedeckt; den tiefen Ast des Nerrus cubitalis findet man unmittelbar unter diesem. - Dieser Nerr giebt auch Aeste für die Interossei ab, für die beiden inneren Lumbricales, und endigt im Musculus abductor pollicis. - Der oberflächliche oder Cubitalbogen wird hauptsächlich von der Art. cubitalis; der tiefliegende besonders von der Art. radialis gebildet.

Techuik z. A. d. G. Nan macht in der Hohlhand einen Schnitt, welcher schief vom obern Theile des Thenar bis zum Niveau des II. Metacarpalköpfens reicht.

Dieser Schnitt muss wenig ausserhalb der Convexität des Oppositionsfalte des Daumens geführt werden. Man durchschneidet die Haut und die Fascie und gelangt an den Körper des I. Lumbricalis. Man legt die hintere Fläche der Sehnen der Flexoren ron der vordern Fläche des Abductor mit der Hohlsonde frei und zieht mit einem stumpfen Haken diese Gebilde nach vorne und innen. Nan findet auf dem vom Adductor gebildeten rothen Grunde und zwar im obern Zwischenraume am Knochen den radialen Gefässbogen.

An der Palma entspricht die Richtung des tiefliegenden Bogens einer transversalen Linie, welche durch das Metacarpo-phalangealgelenk des abducirten Daumens zieht.

Der Thenar liegt an der äussern Seite der Palma manus und wird von vier Muskeln gebildet, welche in drei Schichten oder Ebenen gelagert sind.

a) Die erste Schichte wird vom Abductor brevis gebildet, welcher die Form eines mit der Spitze nach unteu gerichteten Dreiecks hat. - Seine Insertionen befiuden sich an den Handwurzelknochen und Phalangen. Er entsteht ron innen nach anssen an der fibrösen Ausbreitung, weIche die Sehne des Abductor longus ausschicht, an der Scheide des Palmaris brevis, am Kahnbein, und an einer Ausbreitung, welche von der Sehne des Palmaris longus kommt, und am Ligamentum anulare.

Der dreieckig Fleischkörper dieses Muskels liegt unten auf einem Sehnenblatte, welches an der obern und äussern Seite der I. Phalange des Daumens sich inserirt; mit einer dreieckigen Ausbreitung umschlingt el das Gelenk und inserirt sich am äussern Rande der Sehne des Extensor. Die Arteria radio-palmaris zieht durch diesen Muskel (Fig. 61).

b) Die zweite Schichte wird ron zwei Muskeln gebildet aussen rom Opponens und innen rom vorderen Bündel des Flexor brevis.

Der Opponens entsteht mit einem fibrösen Blatte und mit Fleischbündeln an der vordern Fläche des Lig. annulare und am freien Rande des Processus am Trapezbeine. 
(Das an Lig. anmulare entstehende Bündel kamn bis zum Erbsenbein und zum Processus des Irakenbeins verfolgt werden.)

Der Fleischlörper ist an seiner innern Seite sehr dick und inserirt sich unten an der vordern llälfte der Innenflïehe des ersten Metacarpus.

c) Die dritte Schichte wird rom Addnctor und rom tiefen Biindel des liJeror breris gebildet.

Fig. 61 .

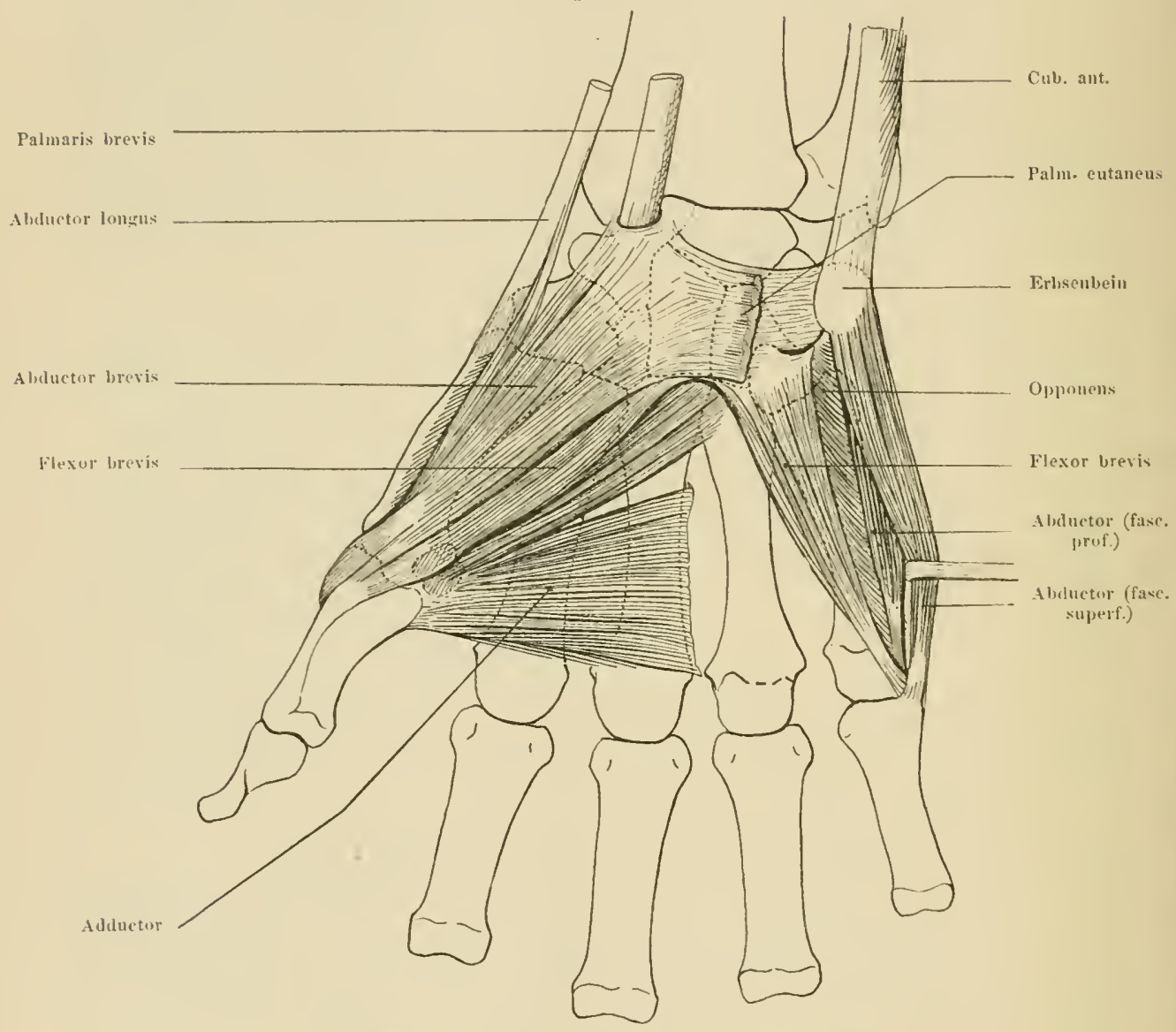

Die Muskeln des Thenar und des Antithenar.

Der Flexor breris besteht aus zrei Bündeln und hat die Form eines V.

Das rordere Bündel entsteht mit einem Sehnenblatte am untern Kande des Processus des Trajuezbeines und des Lig. annulare. - Sein prismatischer Fleischkïrper vereinigt sich in der Nitte des I. Hetacarpus mit dem tiefen Bündel.

Das tiefe $B$ ündel hat die Form einer Rinne und entsteht mit einem festen Sehnenblatte am Trapezoidbeine, an der Scheide des Palmaris brevis und an der vordern Fläche des grossen vieleckigen Beines. Sein Fleischlörper ist zunächst mit dem $\Lambda d-$ ductor vereint, theilt sich dann von ihu ab, lehnt an die vordere Fläche des rordern 
Bündels und inseriren sich gemeinsam am obern äussern Rande des Gelenkendes der I. Phalange am äusseren Sesambeine und an der Gelenkkapsel. Im obern Theile sind die beiden Bündel des Flexor durch ein fibröses durchscheinendes mit der Basis nach unten gerichteten Dreieck getheilt.

In der tiefen Furche, welche ron den Bündeln des Flexor brevis gebildet wird, verlänft die Sehne des Flexor longus.

Der Adductor pollicis hat die Form eines breiten Dreiecks, mit der Basis nach innen mit der Spitze nach aussen gegen das Metacarpophalangealgelenk gerichtet, in seinem äussern Theile ist er dick und wird am innern Theile lamellenförmig. - Gewöhnlich ist der Adductor in mehrere Bündel zerlegt, welche man in drei Theile gruppiren kann.

a) Das obere Bündel entsteht mit sehnigen und Muslielfasern an der rorderen Fläche des Multangulum majus, des Hakenbeins und am obern Ende des 3. und 4. Metacarpus, auch an den oberen Intermetacarpal-Ligamenten.

b) Das untere oder transversale Bündel entsteht am Rande des II. Metacarpus an der tiefliegenden Fascie und hauptsächlich an den fibrösen Blättchen, welche es vom I. und II. Interosseus scheiden, und am unteren Intermetacarpalligament.

Ein dreieckiger Zwischenraum mit der Basis nach innen scheidet das obere Bündel vom unteren; durch diesen Raum zieht die Arteria palmaris profunda (Fig. 31).

c) Das äussere Bündel ist gewöhnlich sehr dünn und entsteht an der rordern Fläche des Trapezbeins und an einer fibrösen Schlinge, welche ron der vordern Fläche des Trapezbeins zur hiutern Fläche desselben und des Trapezoidbeines zieht.

Dieses Bündel liegt längs der innern Fläche des I. Metacarpus und am äussern Rande des obern Bündels und stellt nach Henle den wirklichen Musculns palmaris interosseus des ersten Zwischenraumes dar.

Nach unten und aussen vereinigen sich diese drei Bündel und inseriren sich am hintern Sesambeine und am innern Höcker des oberen Endes der I.Phalange des Daumens.

Das äussere Bündel inserirt sich nur wenig am Sesambeine und mit einer fächerförmig ausgebreiteten Sehne gleitet es an der I. Phalange und inserirt sich am innern Rande der Sehne des Extensor.

Der Abductor brevis, Opponens und Flexor brevis werden vom Medianus, der Adductor rom Arcus profundus des Cubitalnerven innervirt.

Techuik z. A. d. G. Man macht über die Mitte des Thenar eine schiefe Incision und findet unmittelbar unter der Haut den Muskelkörper des Abductor brevis. Ein anderer Schnitt über den inneren Rand des Thenar führt zum vorderen Bündel des Flexor brevis. Man bildet am Thenar einen Hautlappen in Form eines mit der Convexität nach aussen gerichteten $U$ und findet unter der Fascie den Abductor und das oberflächliche Bündel des Beugers. Man durchschneidet transversal den Abductor und findet den Opponens, hierauf den Nerrenstamm, der rom Medianus abgeht und für diese Muskeln des Thenar bestimmt ist. Macht man eine analoge Incision wie bei der Aufsuchung des Arcus palmaris profundus, so gelangt man auch zum Körper des Adductor. Den Adductor kann man auch auf der Dorsalfläche des I. Zwischenknochenraumes finden. Längss dieses Raumes durchschneidet man die Haut und den ersten Interosseus dorsalis, erweitert die Schnittränder und erblickt im Grunde den Adductor. Unter dem äusseren Schnittrande längs des ersten Metacarpus findet man die erste Art. interossea profunda, die von der Art. radialis abzweigt.

Man macht über den inneren Theil des Thenar einen Schnitt, welcher 
sich mit der Oppositionsfalte des Daumens in Form eines $X$ kreuzt. Durehschneidet man dic llaut und die Faseie, so gelangt man an den Medianus, welcher in diesem Niveau einen Ramus recurrens abgiebt, der für die Nuskeln des Thenar bestimmt ist, mit Ausnahme des Adductor, der rom Cubitalis innerrirt wird.

Jel Antithenar liegt an inneren Rande der fland und hat die Form einer dreieckigen, mit "ler S.jitze nach abwärts gerichteten Lrhebung, welche von rer Muskeln in Irei Schichten geordnet, gebildet wird.

a) Die oberflïrhliche Schicht wird rom M. palmaris eutaneus gebillet. Lieser. Iuskiel hat die Form eines rechten Winkels, entsteht innen mit Sehnenfasern an der rorderen Fliehe des Liganentun annulare. Sein blasser Fleischliörper besteht aus einer Reile ron Bündeln, welche durch mehr oller weniger breite Zwischenräume anseinanler gehalten werden. Jedes dieser Nuskelbündel inserirt sich imen mit einem Büschnl von

Fig. 62 .

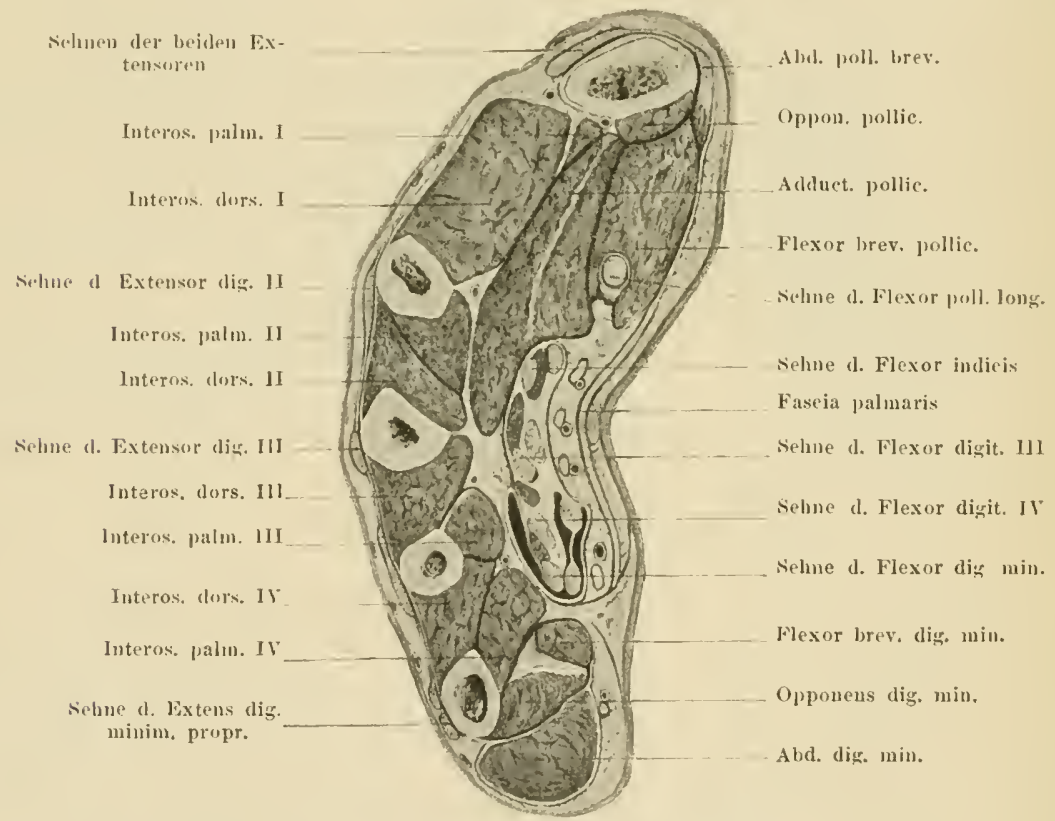

Ein Querschnitt durch die Nitte der Palma manus.

Sehnenbündeln, an der tiefen Fläche der IIant eine mit der Coneavität nach hinten gerichtete Curve bildend.

b) Die zweite S(lhicht wird rom Abduetor und Flexor digiti minimi proprius gebildet. Der Abductor, welcher rom Erbsenbeine bis zur ersten Phalange des kleinen Fingers reicht, ist spindelförmig und ron der Dicke eines Federstiels. Er entsteht mit Selinen und IJuslielfasern an der unteren Fläche des Erbsenbeins, an der inneren Fläche des Ligamentum annulare und an den Ligamenten, welche das Erbsenbein mit den Processus des Halienbeins und dem fïnten Hetacarpus verbinten. 

Bündel.

Gegen die Mitte des Metacarpus theilt sich der Fleischliörper des Abductor in zwei

Das oberflächliche Bündel geht in eine Sehne über, welche sich am oberen und inneren Höcker der ersten Phalange, an der Gelenkkapsel und mit einer dreieckigen Ausbreitung am inneren Rande der Sehne des Extensor digiti minimi ansetzt.

Das tiefliegende Bündel, gewöhnlich dicker als das oberflächliche, inserirt sich mit einer dünnen Sehne am oberen und inneren Höcker der ersten Phalange und an der Gelenkkapsel. Oft ist das tiefliegende Bündel in zwei Bäuche getheilt (Fig. 61).

Der Flexor brevis liegt am äusseren Rande des Abductor. Er hat die Form eines von vorne nach hinten ausgebreiteten Bandes, welches mit Sehnenfasern am vorderen Rande des Processus des Hakenbeins, an der vorderen Fläche des Ligamentum annulare und an einem vom Processus des Os hamatum zum Os pisiforme ausgebreiteten fibrösen Bogen sich anheftet. Sein Fleischkörper entsendet im Niveau des Netacarpophalangealgelenkes ein Sehnenblatt, welches zwischen die Sehnen der beiden BündeI des Abductor dringt und sich am oberen und inneren Höcker der ersten Phalange inserirt.

Eine fibröse Ausbreitung verbindet die Sehne des Flexor mit der Gelenkkapsel and mit dem Sesambein, welches sich in dieser liapsel befindet.

c) Die dritte Schichte wird rom Opponens gebildet. Dieser ist ein dicker dreiechiger Muskel und zieht vom Processus des Hakenbenbeins zu dem 5. Metacarpus. Er entsteht mit Sehnenfasern am Ligamentum annulare am vordern Rande und an der äussern Fläche des Proc. des Os hamatum nnd am Lig. pisi-metacarpeum, unten und innen inserirt er sich an der innern Hälfte der vordern Fläche des 5. Metacarpus und wenig am Lig. inter-metacarpeum inferius.

Der Opponens ist in seinem oberen Theile in zwei Schichten getheilt, zwischen welche die Arteria cubito-paImaris profunda und der Nervus cubitalis ziehen. Die Muskeln des Antithenar werden vom Nervns cubitalis innervirt.

Technik z. A. d. G. Man macht einen langen Schnitt am iunern Rande der Hand vom Erbsenbeine bis unter das Köpfehen des 5. Metacarpus und gelangt an den Körper des Abductor.

Nan macht eine lange Incision, indem man etwas unterhalb und innen vom Erbsenbeine beginnt und in der Beugungsfalte des kleinen Fingers endigt, man findet den Körper des Flexor proprius. - Nit der Hohlsonde wird der äussere Rand dieses Nuskels abgelöst und nach innen gezogen; man findet den Körper des Opponens.

Die Musculi interossei liegen in den Zwischenknochen- oder Zwischenmetacarpalräumen. 7 an der Zahl, 2 für jeden Zwischenknochenraum mit Ausnahme des ersten Raumes, der nur einen besitzt, sind sie in dorsale und palmare eingetheilt. Um die Anordnung der Musculi interossei zu verstehen, stellt man sich eine mediane Ebene durch die Mitte der Hand durch den Mittelfinger vor und nennen alles, was in diese Ebene fällt axial, das ausserhalb befindliche nicht axial.

Die Interossei dorsales sind fiederförmig und prismatisch und jeder Muskel hat zwei Bündel. Das eine Bündel entsteht an der ganzen lateralen nicht axialen Fläche des Metacarpus, das zweite ist dreieckig, um vieles dïnner und entsteht an der hintern Hälfte der lateralen axialen Fläche des andern Hetacarpus. Fleischfasern eines jeden Bündels sind zu einem fibrösen Blättchen verbunden, welche sich zusammen zu einer festen Sehne vereinigen.- Diese inserirt sich am obern nicht axialen Höcker der ersten Phalange und mit einer fächerförmigen Ausdehnung am correspondirenden Rande der Sehne des Extensor. 
Die Ausbreitung verwebt sich mit der Schne des Lumbriealis.

Die dorsalen Interossei des II. und III. '/wischenknochenraumes sind lür den Mittelfinger bestimnt, je einer von jeder Seite. Der Interosseus des ersten /wischenraumes gehört dem Zeigelinger, der des vierten Zwischenrames dem lingfinger an. -

Die Interossei palmares sind drei an der Zahl. Wir haben gesehen, dass der Interosseus palmaris des ersten Zwischenraumes vom äussern Bündel des Adductor gebildet wird. - Die Interossei palmares sind wie die Dorsalen fiederförmig. - Sie entstehen an der rorderen IIälfte der axialen Fläche des Metaearpus desjenigen Fingers, für welchen der Nuskel bestimmt ist und mit einem musculös-fibrösen Bündel an der obersten Seite des vordern Randes des andern Metacarpus.

Die Endsehne inserirt sich am axialen Höcker der ersten Phalange und mit einer fibrösen Ausbreitung am Rande der Sehne des Extensor.

Im Niveau der Metacarpo-phalangealgelenlie verweben sich die Sehnen der Interossei mit den Fasern des lig. annulare. Ein seröses Gewebe oder gar einen Schleimbeutel findet man zwischen den Sehnen der Interossei und den lateralen ligamenten der Gelentie. Einen zweiten Schlembeutel findet man zwischen den Sehmen der beiden Interossei desselben Raumes.

Die Musculi interossei werden rom Cubitalis mittelst Fäden, welche von den tiefliegenden palmaren Nerrenschlingen abgehen, innervirt.

Die dorsalen Interossei sind $A$ bductoren, die palmaren sind $A d$ duetoren. Jene beiden Interossei, welche zu einem Finger ziehen, dienen als Flexoren der ersten und als Extensoren der beiden andern Phalangen, dank einer fibrösen Schlinge, welche die Sehnen der beiden Iuskeln hinter der ersten Phalange bilden und der Ausbreitungen, welehe die Sehnen der Extensoren abschiclien.

Technik z. A. d. (†. Man führt an der Dorsalfläiche der Jand, Jängs eines Zwischenknochenrammes eineri verticalen Schnitt und man sieht dureh die dorsale Fascie den Fleischkörper des Interosseus dorsalis.

Nan macht in der Hohlhand Jängs eines Zwischenknochenraumes eine Incision und findet unter der palmaren Fascie den Lmmbricalis, welcher zugleich mit den Sehnen der Beuger abpräparirt wird. Man findet nun längs der axialen Fläche des Vittelhandknochens einen Fleischkörper, den Interosseus palmaris; der Fleischkörper der nicht-axialen Fläche des andern Mittelhandknochens stellt den Interosseus dorsalis dar. - Man rerfolgt die Sehne des Interossens bis zu ihrer Insertion an der Phalange mod bemerkt die Ausbreitung, die diese der Sehne des Extensor zusendet. Man sucht noch den Schleimbeutel auf, welcher zwischen den Sehnen der Interossej sich befindet.

\section{Die Finger.}

Das Köpfuhen eines jeden Hittelhandlinochens artieulirt mit der Cavitas glenoidalis der ersten Phalange. Eine rollständige Gelenkliapsel vereinigt die beiden Gelenkenden.

Diese Kapsel wird ans zwei fibrösen Fïhern gebililet, welche sich an den äussern Flächen des Metaearpallï̈pfehens und am circulären Rande der Cavitas glenoidalis der Phalange inseriren. 
Die Gelenkkapsel wird vorne rom Lig. glenoidale, an den Seiten durch die Lig. laterali a verstärkt.

Das Ligamentum laterale ist weiss glänzend, sehr fest und rom Höker des Metacarpalköpfchen bis zum obern Höcker dos Phalangialendes ausgebreitet.

Die Sehnen der Interossei gleiten auf den lateralen Lig., ron welchen sie durch ein weiches Bindgewebe oder einen Schleimbentel getrennt sind.

Das Metacapo-phalangealgelenk ist ron einem fibrösen Cylinder, dem Lig a men tum annulare, umschlungen, dessen Fasern von sehr complicirter Structur sich mit den Sehnen der Extensoren verweben.

Ein weiches Bindegewebe gestattet die Bewegungen zwischen Gelenkkapsel und Lig. annulare.

Technik z. A. d. G. Bei in Extensionsstellung befindlichem Finger ist das Köpfchen des Metacarpus schwer abzutasten, weil es von der Cavitas glenoidalis der Phalange bedeckt ist. Wenn der Finger in Flexionsstellung gebracht wird, so wird das Metacarpalköpfehen frei und prominirt nach hinten.

Lässt man die Fingerbeere des Daumens, auf der dorsalen Fläche der ersten in Flexionsstellung befindlichen Phalange von unten nach oben gleiten, so fühlt man ummittelbar unter der Erhebung des Metacarpalköpfchens eine Rinne, welche der Gelenklinie entspricht. In diesem Niveau sticht man die Spitze eines Bistouri ein und sie dringt in die Zwischengelenkslinie. - Man durchschneidet transversal und tief unmittelbar oberhalb der Phalange am Mletacarpalköpfchen die Hant, die Sehne des Extensor mol die Gelenkkapsel. Die Gelenkhöhle ist eröffnet und die Gelenkoberfläche des Metacarpalknochens erscheint dann. Macht man an der lateralen Fläche des Metacarpo-phalangealgelenkes des zweiten Fingers einen tiefen schief nach untes und innen gerichteten Schnitt, so sieht man im Grunde desselben das feste Lig. laterale externum.

Die vier innern Finger werden aus drei mit einander articulirenden Phalangen gebildet, nur der Daumen besitzt zwei Phalangen.

Die Sehnen der Flexoren. An der vordern Fläche der Finger findet man die Sehnen der Beuger, für jeden Finger existiren zwei Beugersehnen mit Ausnahme des ersten, welcher nur eine einzige besitzt. Die Beugersehnen sind in einer fibrösen knöcherigen Scheide enthalten, deren hintern Wände zum grössten Theil knöchern sind; sie wird von oben nach unten von dem Lig. glenoidale des Metacarpo-phalangealgelenties, von der vordern leicht zu einer Rinne ausgehöhlten Fläche der ersten und zweiten Phalange und rom Lig. glenoidale der beiden Phalangealgelenke gebildet. - Die vordere Wand der Sehnenscheiden der Beuger ist fibrös. - Vor dem Metacarpo-phalangealgelenke, dem Körper der ersten und zweiten Phalange ist sie sehr fest, und wird danu vor den Interphalangealgelenkon dünner.

Vor dem Metacarpo-phalangealgelenke wird diese Wand ron einem fibrösen Blatte gebildet, welches an seinen lateralen Rändern mit der vordern Fläche des Lig. glenoidale verwebt ist. - Vor dem Körper der ersten Phalange hat die Scheide der Beuger die Form einer fibrösen, sehr resistenten $2 \mathrm{~cm}$ breiten Schlinge, sie inserirt sich mit ihren lateralen Rändern an den rerticalen Leisten, welche der Förper der Phalange zeigt.

Die Dicke dieser Schlinge wächst ron oben nach unten, wo sie mehr als zwei Millimeter haben dürfte. - Vor dem ersten Phalangealgelenke ist die fibröse Scheide genug dünn, um die Sehnen durchscheinen zu lassen, sie wird von schief gelireuzten Bändern 
in der Form eines $X$ und ron transversalen Faseru, gewöhnlich als ein dünmes Blättchen ror der Gelenklinie, gebildet. Im Nirean des Körpers der zweiteu P'halange erhält die Scheide wieder die Form einer Schlinge, die sich mit ihren lateralen Räntern an mittleren Theile der beiden Phalangealränder inserirt.

Vor dem zweiten Phalangealgelenke wird die fibröse Scheide in derselhen Weise wie im Niveau des ersten Gelenkes gebildet. - Im Innenranme dieses tibrösen knöcherigen Kanals befinden sich die Sehnen der Beuger eng an einander. Eine Synovia hat sich aus den Bewegungen der Sehnen entwickelt. Diese Serosa beginnt mit einem oberen und lireisförmigen Blindsack fingerbreit oberhalb des Metacarpophalangealgelenlies und endigt mit einem unteren und conrexen Blindsack zwei Mlillimeter unterhalb des zweiten Interphalangealgelenkes; man findet also das Ende der Bengersehme ausserhalb der Synorialhöhle.

Das parjetale Blättehen dieser Synorialhülle bedeckt die tiefliegende f'läche des knöcherig-fibrösen lianals, das viscerale sehr dünne Blättchen jede Sehne nur zum Theile. Eine Synovialfalte ron dreieckiger Form findet nan, wenn man die Sehne des oberflïehlichen Beugers abhebt und zwar in dem Winkel, den diese Sehne mit dem Kopfe der II. Phalange bildet.

Fig. 63.

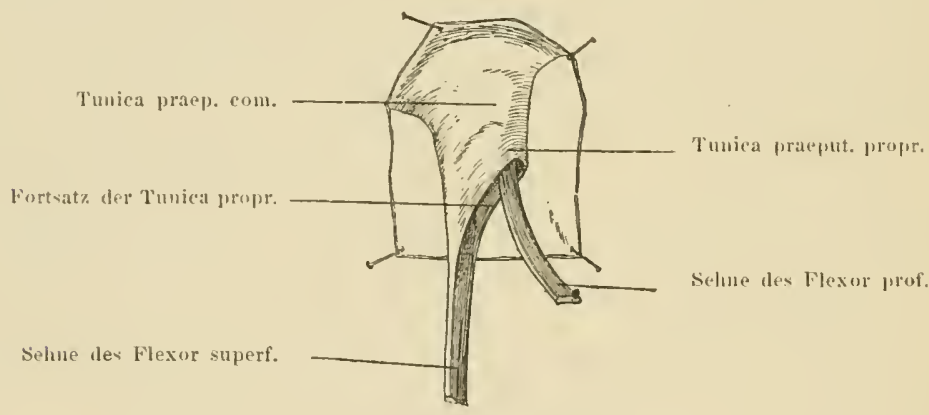

Die obere Aussackung der Synovialseheide der Sehnen der Flexoren.

Eine andere rechtwinklige Falte befindet sich zwischen den gekreuzten Ausbreitungen der Sehne des oberflächlichen Beugers und dem Kiörper der zweiten Phalange und zwei Fädchen, die Frenula der Sehne des oberflächlichen Beugers, verbinden jeden $\mathrm{Arm}$ dieser Sehne mit dem mittleren Theile des Körpers der ersten Phalange.

Im Nireau des obern Blindsackes der Synovialselseide in der Länge einer Fingerbreite verdickt sich das viscerale Blättchen und bildet rings um die Sehnen eine Hülle, die Tunica praeputialis communis. Ein weiches Bindegewebe befindet sich zwisehen den Sehnen und der Iülle.

In der Richtung wo die beiden Beugesehnen, welche zunächst in derselben gemeinschaftlichen Hülle sich befinden, sich theilen, bildet das viscerale Synovialblättchen hinten und an den Seitentheilen der Schnen des Flexor profundus eine Falte, die Tunica praeputialis propria, welche sich mit zwei Ausläufern bis zu den Rändern der oberflächlichen Sehne verlängert und auch dort sich inserirt (Fig. 63).

Ein lireisförmiger Blindsack existirt also rings um die Sehne des Flexor profundus, welcher rorne von der Sehne des Flexor superficialis, hinten und an den Seitentheilen ron einer Synovialfalte begrenzt wird. Diese Anordnung entsteht erst rom 
Gleiten der Sehnen, da die gemeinsame Präputialhülle sich einwärts oder auswärts je nach der Bewegung der Sehne stülpt. - Weil der zurückzulegende Weg für die Sehne des Flexor profundus länger ist, deshalb hat sich für diese Sehne eine eigene Synovial falte, die eigene Präputialhülle, gebildet.

Technik z. A. d. G. Man macht eine lange von der Mitte der Palma bis zur Spitze des Fingers reichende Incision. Man arbeitet sorgfältig, um nicht die Scheide der Beugersehnen zu eröffnen. Nit der Pincette und dem Bistouri werden die Schnittränder präparirt und die vordere fibröse Wand der Scheide freigelegt. Man merkt, dass an der einen und an der andern Seite des Fingers an der tiefliegenden Fläche der Haut sich die fibrösen sehr resistenten Ausbreitungen, welche an den Enden der Phalangen und ihrer Gelenke entstehen, inseriren. Man durchschneidet mit der Spitze des Bistouri die vordere Wand der Sehnenscheide und es liegen die Sehnen der Beuger in ihrer Scheide Irei. - Man sieht, wie die Sehne des tiefliegenden Beugers, welche zuerst hinter der Sehne des oberflächlichen liegt, diese durchbohrt; hebt man die Sehnen in die Höhe, so sieht man sie durch Synovialfalten mit den Phalangen verbunden; gleichzeitig untersucht man die Tunica praeputialis communis und die Tunica propria der Sehne des Flexor profundus.

Die Sehne des Extensor ist verbreitert und oft in mehrere Bändchen an der Dorsalfläche der Hand aufgelöst, im Niveau des Metacarpalköpfchens und des Metacarpophalangealgelenkes rundet sie sich ab.

An der Dorsalfläche der ersten Phalange breitet sich die Sehne des Extensor in einen Fächer aus und theilt sich in drei Bänder:

Das mittlere Band inserirt sich am hintern Rande der Cavitas-glenoidalis der zweiten Phalange. Der hintere Blindsack der Gelenkhöhle des ersten Interphalangealgelenkes adhärirt sehr fest mit der tiefen Fläche der Sehne.

Die seitlichen Bänder entfernen sich zunächst von einander, indem sie an den latero-dorsalen Theilen des Fingers verlaufen und unterhalb des ersten Interphalangealgelenkes nähern sie sich und vereinigen sich an der Dorsalfläche der zweiten Phalange zu einem gemeinsamen dreieckigen Blatte, welches am hintern Rande der Gelenkfläche der III. Phalange sich inserirt. Ein Synovialblättchen adhärirt wie früher an der tiefen Schichte der Sehnen. - Die lateralen Bänder der Sehne des Extensor sind aussen von der Sehne des Lumbricalis, innen von der Streckaponeurose der Sehne des Interossens palmaris des zweiten Fingers und von der Ausbreitung des Interosseus dorsalis des dritten und vierten Fingers verstärkt. Die Streckersehnen des ersten Fingers nehmen die Ausbreitung des Abductor brevis und des Adductor auf; die Sehnen des fünften Fingers sind an ihrem innern Rande von einer Ausbreitung des Abductor verstärkt. Die Sehne des Lumbricalis löst sich an der lateralen Fläche der ersten Phalange in einen Fächer auf.

Mit seinen hintersten Fasern inserirt sich dieser Fächer am Rande und an der oberflächlichen Lage der Streckersehne.

Die mittleren Fasern kreuzen das laterale Band der Streckersehne, gehen über in das mittlere Band oder verlanfen mit diesem, um sich an der zweiten Phalange zn inseriren. - Die längsten und äusseren Fasern der Sehne des Lumbricalis heften sich am lateralen Bande des Extensor an, gehen in dasselbe über oder inseriren sich mit diesem an der dritten Phalange. Die Selme des Interosseus verläuft am innern Rande der Streckersehne in derselben Weise wie die Sehne des Lumbricalis. 
Im Nireau des Metacarpo-plablangealgelenkes ist die Streckersehne mit dem ligamentum annulare rerwebt; ein weiches Bindegewebe findet man unter der ticfen Schichte des Extensor, welches durch die Reibung der Sehne an der Phalange entstanden ist.

Ian findet zwischen der llaut und der Streckersehne im Niveau des Metacarprophalangeal- und des Interphalangealgelenkes Schleimbeutcl.

Technik z. A. d. (*. Man macht cine longitudinale, oberhalb des Reliefs des Iletacapalköpfehens beginnende Incision bis zum Nireau des Tagels und man findet ummittelbar unter der Ilaut dic Streckerschne. Man präparirt dann die beiden Schnittränder und sucht an den Rändern der Streckersehne die Ausbreitungen, welche sie an den Lumbricalis und an die Interossei abschickt.

Tervi collaterales. Jeder Finger hat vier Collateralnerveu, zwei palmare und zwei dorsale.

Nervi collaterales palmares. Es giebt deren zehn. Die für den Dammen, Zeige- und Mittelfinger und äussere Hälfte des Ringfingers bestimmten Terven, sieben also grchen rom Nerrus medianus ab; die drei innern, also der Collateralis internus des Ringfingers und die Collaterales des kleinen Fingers trehen rom Nerrus cubitalis ab.

Jeder collaterale Palmarast gicbt etwas unterhalb des Metacarpo-phalangealgelenlies cinen dorsalen $\mathrm{Ast} \mathrm{ab}$, welcher die erste Phalange umschlingt, auf die hintere Fläche les Fingers gelangt und sich.in der Ilaut, welche die zweite und dritte Phalange bedeckt, rerzweigt.

Nervicollaterales dorsales. Fünf äussere gehen rom Radialis, fünf innere rom hintern Aste des Cubitalis ab; die Collaterales dorsales, die für den zweiten, dritten und vierten Finger bestimmt sind, rertheilen sich nur in der Haut, welche die erste Phalange bedeclit.

Teclmik z. A. I. G. Man macht auf einer der lateralen Flächen irgend eines Fingers eine lange Incision rom Metacarpalköpfchen bis zur Spitze des Fingers, präparirt dic beiden Schnittränder ab und folgt im Grunde des Schnittes dem Rande der Phalange; anf diese Weise findet man den Nervus und die Arteria collateralis. - Man sucht dann den dorsalen Ast des Nervus collateralis auf. 


\section{Untere Extremität.}

\section{Die Region der Inguinalbeuge.}

Die Inguinalfalte ist eine ron der Spina iliaca anterior superior schief nach abwärts und innen gegen die Spina pubica gerichtete Furche; sie ist wenig tief und entspricht dem Poupart'schen Bande. Die Beuge- oder Gelenkfalte des Oberschenkels liegt etwas unterhalb der Inguinalfalte. Sie keginnt unterhalb der Spina iliaca anterior superior, am äussern Pande der Torderfläche des Oberschenkels und innen setzt sie sich in die Scrotocrnralfurche fort.

Zellig-fibröse Adhärenzen haften an der tiefen Fläche der Haut des Fallope'schen Kanals. Diese Adhärenzen wurden ron Petrequin als Lig. suspensorium der Leiste beschrieben.

Die Spina iliaca anterior superior hat die Form eines Dorns nnd liegt im Vereinigungspunlite des oberen Randes des Os ilium, nnd dessen rorderm Rande.

Diese knöcherne Erhebung ist an magern Individnen sehr leicht zu erkennen, an fetten dagegen ist sie nur schwer zn bestimmen.

Man tastet mit der Fingerbeere von hinten nach vorne den obern Rand des Darmbeins ab. Der untersuchende Finger fühlt in einem gewissen Iomente eine kuöcherne Erhebung, unterhalb welcher er in eine Einbuchtung fällt, es ist dies die Spina iliaca anterior superior; auch die Inguinalbeuge eindrückend, indem man die Fingerbeere ron innen nach aussen gleiten lässt, kommt man auf die Erhebung dieser Spina.

Man wiederhole so oft als möglich diese wichtige Untersuchung, weil die Spina iliaca ein wichtiger Ausgangspunkt ist, weun man die untere Extremität messen will, - oder auch um die Lage des Trochanter major zu bestimmen. Nach zahlreichen Versuchen überzeugt man sich, dass das, was sehr leicht scheint, sehr schwer fällt.

Man sticht an der Fingerbeere, welche sie markirt, gegen den Knochen die Spitze eines Bistouris ein, oder bezeichnet an der Haut mit einem Hautstifte ihren Ort, man muss aber achten, dass die Haut während der Untersuchung sich nicht versehiebt.

Die Spina pubica liegt an der innern Grenze der Inguinalfalte. Die knöcherne Erhebung hat die Form einer Pyramide und entsteht am Körper des Schambeins mit 
einer breiten liasis. - lhre ober Fläche ist zu eimer leichten Rinue ausgehöhlt, welche dom simenstrange entspricht. In mageren Individuen ist sie wie die Spina iliaca anterior superior sehr leicht zu fühlen, an fetten nur sehr schwer zu bestimmen und hesonders an weiblichen Indiriduen, bei welchen sie wenig ausgebildet ist.

Yan gleitet mit der Fingerbeere von aussen nach innen längs der Inguinalbeuge; man fühlt und kann auch mit den Fingern die Spma pubica 2 cm imerhalb der Medianlinje fassen, und oberhalb derselben das $V$ as deferens auffinden.

Man nimmt die Inguinalfalten zwischen den Fingerbeeren des Daumens und Zeigefingers derselben Hand und nähert nun die Finger, ron jeder Seite der Medianlinie gelangen sje an die Spina pubica.

Bei in Ibductionsstellung befindlichem Obersehenkel spannen sich die Adductoren an und ler innere Rand des mittleren Adduetors springt unter der Haut vor. Jlan folgt nun mit dem Finger dem gespannten Rande

Fig. 64 .

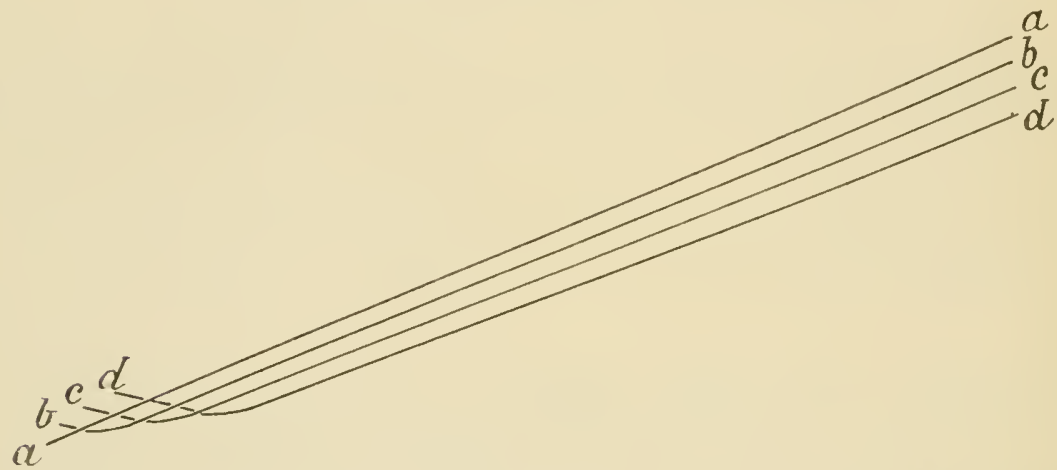

Diese Figur zeigt die schematische Structur des Poupart'schen Bandes. Man sieht seine Fasern abbiegen und der Reihe nach jede einzelne unterhalb der anderen aufwärts dringen. Diese gewundene und aufsteigende Partie bildet den Theil, den wir Ligamentum Gimbernati bezeichnen.

dieses Muskels und gelangt zum Körper des Schambeins und unmittelbar oberhalb des Selnnenansatzes fühlt man die Spina pubica. IIan wiederhole recht oft diese Untersuchung; man befleissige sich mit der grössten Leichtigkeit die Spina pulica aufznfinden, um leicht eine Hernia cruralis von einer Hernia inguinalis unterscheiden zu können.

\section{Der Arcus r'ruralis oder das Fallope'sche oder das Poupart'sche Band.}

- Die Cruralschlinge ist ein fibröser fester mit der Convexität nach unten gekrümmter Bogen, der zwisehen der Spina iliaea anterior superior und der Spina pubiea gespannt ist, nnd ron einer Fortsetzung der breiten sehne des Obliquus major gebildet wird, welche unmittelbar oberhalb der Spina iliaca zieht und sich nach abwärts und innen gecen die Spina pubiea richtet. Etwas unterhalb der Spina iliaca dreht sich die Cruralsehlinge, ilhre vordere Flärhe wird zur hinteren unteren, nimmt die Gestalt einer Furche an, welche die untere Wand des Inguinalkanales bildet, wird leirht anfsteigend und inserirt sich am äussern liande der Suina pubica unı an der Crista peetinea, wo ihre Fasern mit dem sehr verdickten Perioste, welches diese Crista umgiebt, sich rer- 
wehen, das Ligamentum Cooperi. - Diese aufsteigende und dreieckige Partie der Cruralschlinge führt den Namen Ligamentum Gimbernati (Fig. 65).

In der äusseren Hälfte ist die obere Fläche der Cruralschlinge sehr eng vermengt mit sehnigen Fasern, welche den Muskeln Obliquus minor und Transversus angehören. Die obere Grenze der Crurạlschlinge setzt sich ohne Grenze in das Sehnenbündel des Obliquus major fort, welches vorderer und unterer Schenkel des Ingninalkanals genannt wird.

Die Fascia femoralis inserirt sich längs des untern Randes der Cruralschlinge.

Der Arcus femoralis profundus oder Lig. iliopectinemm ist eine Verstärkung. der Fascia iliaca, in welche er ohne Grenze übergeht, er liegt hinter und unter dem oberflächlichen Bogen und entsteht: aussen an der Spina iliaca anterior superior und am innern Rande der Crista iliaca, und inserirt sich innen an der Crista ilio-pectinea. In seinem äussern Theile ist der Arcus ilio-pectineus innig verbunden mit dem

Fig. 65 .

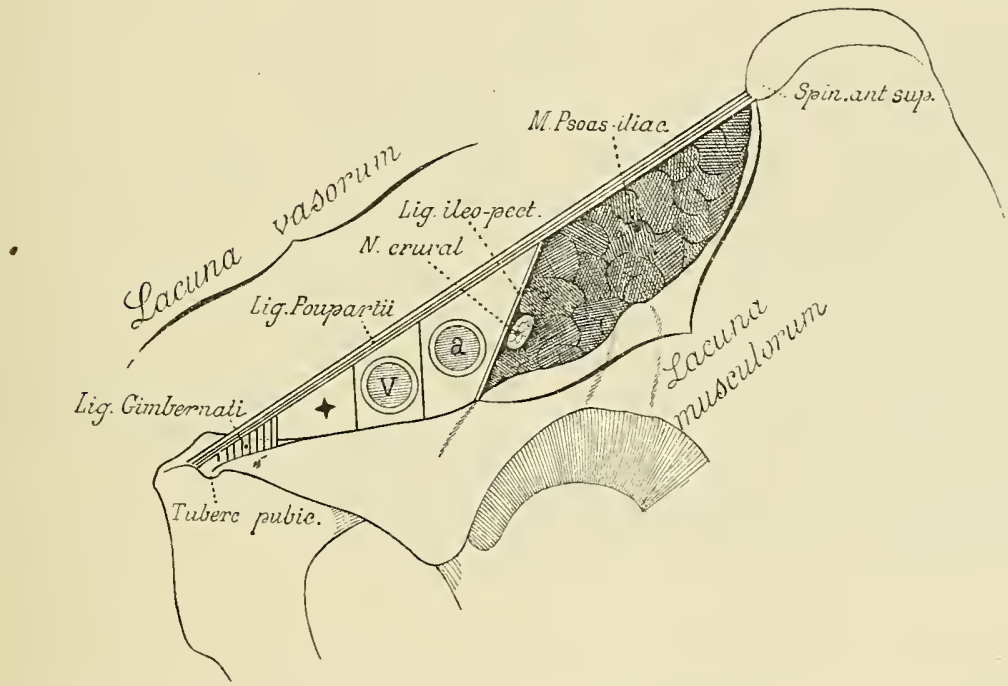

Eine schematische Figur des Ligamentum Pouparti + . Durch diesen innern Theil der Lacuna vasorum ziehen Lymphcanäle. Dieser Paum, in welchem sich auch das untere Ende der Glandula Cloqueti befindet, stellt das Orificium superius des Schenkelkanals dar.

Arcus cruralis und besonders mit Sehnenfasern, die dem Transversus und Oliquus minor angehören.

Der vordere Rand des Os ilium hat die Form einer rechtwinkligen Grube, welche vorne und innen geöffnet ist, die äussere verticale Seite dieses Winkels zeigt ron oben nach abwärts die Spina iliaca anterior superior, die Ausbuchtung des Os ilium nnd die Spina iliaca anterior inferior mit der Verdickung des Os ilium durch die Cotyloidrorsprünge.

Die schiefe Seite bietet uns von aussen nach innen dar: Die Pectinealerhebung mit der Furche, in welcher die Sehne des Musculus psoas gleitet, die Pectinealoberfläche mit ihrer Leiste, die Spina pubica und den Winkel des Schambeins.

Diese breite Eröffnuug des vordern Randes des Os ilium wird durch das Ligamentum Pouparti in eine Lücke umgewandelt und in zwei Räume durch den Arcus femoralis profundus getheilt (Fig. 65). 
Durch den änsseru liam oder Lacuna musculorum zieht der lleo-psoas und Nerrus cruralis, durch den innern liaum oder Lacuna vasorum zieht dio Arteria femoralis, die Tene und Lymphgefïsse.

Die Lacuna rasorum hat die Form eines dreieckigen nach abwärts geöffneten Rahmens, die rordere Seite wird ron der Cruralsehlinge, die äussere und hintere Seite ron Lig. ileo-pectineum und die hintere Seite rom Lig. Cooperi gebildet. In ilhrem innern Winkel findet man die unter dem Namen Lig. Gimbernati belannte Partie der Cruralschlinge; im äussern Winkel zieht die Arteria femoralis unmittelbar an deren Innenseite und etwas ror derselben die Vena femoralis. Das innere Drittel der Lacuna vasorum benützen die Lymphgefässe zum Durehtritt. Nur dieser innere Theil der Lacuna vasorum, dureh welche fast alle Cruralhernien entstehen, darf als Cruralring bezeichnet werden.

An jenen drei Seitentheilen der Lacuna rasorum inseriren sich jene drei Wände der femoralen Gefässscheide, ein prismatischer und dreieckiger Fasciencaul, in dessen Innenraum man die Art. und Vena femoralis und die tiefen Lymphgefässe findet.

Technik z. A. d. G. An einem magern Individuum ist dic Cruralschlinge sehr leicht zu erkennen. - Die Inguinalbenge drückend, können die untersuchenden Finger diese wie einen Strang fühlen, welchen man in sciner innern Hälfte abtasten kann. - Zuwcilen ist der Bogen sichtbar, an sehr fetten Individnen mit weichen und herabhängenden Abdomen, wie man dies oft bei weiblichen Individuen findet, ist die Cruralschlinge sehr schwer zu fühlen und zu erkennen. Man untersucht mit den Fingern durch verticalen Eindruck die Inguinalbenge drïckend und man fühlt die innete Hälfte wie eine Saite, unter welche man dic Spitzen der zu einem Haken gekrümmten Finger schicben kann. - Man sucht aussen die Spina iliaca anterior superior, innen die Spina pubica rereinigt die beiden Punkte durch einc Linie, und diese entspricht dem Verlanfe der Schlinge.

Jan gewöhne sich diese Linie zu zichen, welche dic Grenze zwischen ciner Cruralhernic und Inguinalhernie darstellt.

\section{Region der Hüfte.}

Die Ilïfte entspricht der gelenkigen Verbindung der untern Extremität mit dem Becken. Das Skelet der Hüfte wird aus dem Os ilium und dem obern Ende des Femur gebildet.

Das obere Ende dis Femur. Der Gelenkliopf stellt die drei Viertel eines Kíeises dar und wird nach aussen ron drei krummen Linien mit der Conearität nach aussen begrenzt (Fig. 66).

Den fingerförmigen Eindruck des Kopfes findet man in seinem hintern Rahmen. Der obere Theil dieser Grube ist rauh und dient dem Ligamentum rotundun zur Insertion. Sein unterer Theil ist glatt undeonear und dient dem Ligament als Gleitfläche.

Der Hals des Femur ron vorme nach hinten rerbreitert, verschmälert sich von aussen nach innen. In seiner rordern Fläche und in der Nähe der Gelenlifläche findet man eine kreisförmige rauhe Oberfläche, welche sich innen auf den Gelenkliopf fortsetzt, es ist der Abiruck des Os ilium, welche durch den Contact des obern Randes des Pfannenwulstes und des IIalses des Femur beim Sitzen gebildet wird.

Nach aussen wird die rordere Fläche des Halses von einer rauhen Line begrenzt, 
die Linea intertrochanterica anterior, welche am obern Rande des Halses am Tuberculum cervicale superius beginnt und an seinem untern Rande durch eine dreieckige rauhe Oberfläche, die dreiseitige oder unter dem Trochanter befindliche Oberfläche, endigt. An der hintern Oberfläche des Halses bemerlit man eine wenig tiefe Furche, welche ron unten nach oben sich verschmälert und im Grunde des fingerförmigen Eindruckes des grossen Trochanter endigt, es ist die Leitfurche für die Sehne des Musculus obturator externus.

Der grosse Trochanter ist eine knöcherne Erhebung von der Form eines rechten Winkels (Fig. 66). Seine äussere Fläche setzt sich nach oben in die äusscre Fläche des Femur fort, von welcher sie durch eine rauhe nach unten etwas concaven Linie geschieden ist; an dieser inserirt sich der grösste Theil der Anfangssehne des Vastus externus. Diese Fläche wird diagonal von einer kleinen Fläche in Form einer Virgula, an welcher sich die Sehne des Glutaeus medius inserirt, dnrchzogen. Der Kopf der Virgula entspricht dem obern hintern Winkel des grossen Trochanter.

Fig. 66.

Fläche für Obturat. int.

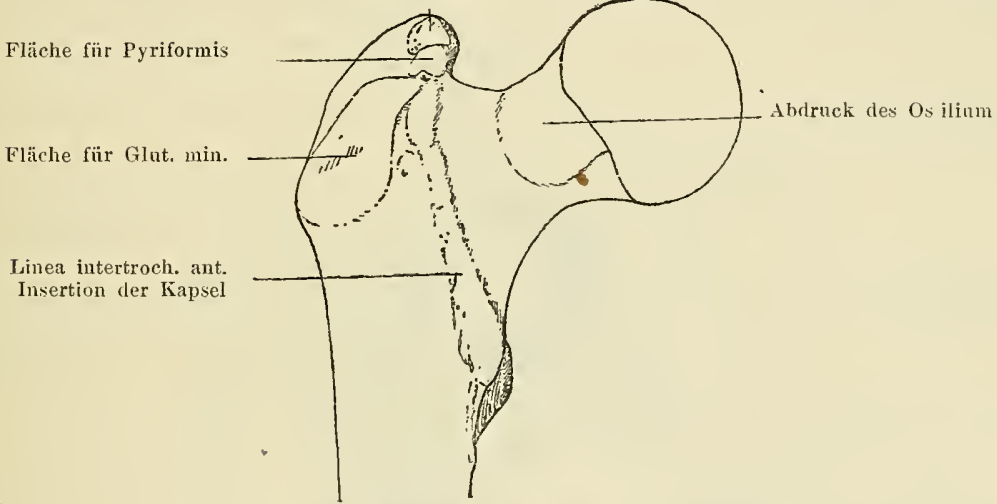

Die vordere Fläche des oberen Femurendes.

Die innere Fläche des grossen Trochanter ist nur in ihrem oberen hinteren Theile frei, denn die restliche Erhebung wird von der Basis des Femurhalses bedeclit. Diese Fläche stellt im unteren Theile die fingerförmige Grube dar, in deren Grunde an einer rauhen und kreisförmigen Oberfläche die Sehne des Obturator externus sich inserirt. Vor und oberhalb der fingerförmigen Grube findet man die Oberfläche der Insertion der "vereinigten Sehne" des Obturator internus und der beiden Musculi Gemelli. Diese matte und rechtwinkelige Oberfläche erhebt sich nach vorne bis zum oberen Rande des grossen Trochanter.

Der vordere Rand des grossen Trochanter stellt eine unregelmässige Facette in Form einer Virgula dar, welche mit dem Köpfchen nach abwärts gerichtet ist; an dieser inserirt sich die Sehne des Glutaeus minimus.

Der hintere Rand des grossen Trochanter wird von der oberen Hälfte der Linea intertrochanterica posterior gebildet.

Der obere Rand des grossen Trochanter stellt hinten eine stark erhobene Ecke dar, welche unter der Haut zu berühren ist, es ist der Angulus posterosuperior oder die Trochanterecke. Gegen den mittleren Theil stellt er eine kleine 
matte Fläche von eiförmiger Form dar, auf welcher sich die Sehne des Musculus pyriformis inserirt.

Del Kleine Trochanter ist eine linöcherne Erhebung in Form einer Manma und liegt unterhalb und ein wenig hinter dem Femurhalse. Vom kleinen 'Trochanter erlreben sich wie ron einem Centrum drei knöcherne Wälle: ein oberer äusserer, die Linea intertrochanterica posterior, ein anderer innerer gegen den Hals des Femur gerichtet und ein dritter unterer gegen den Förper des Femur.

An der Spitze des lileinen Trochanter, an einer lireisförmigen matten Oberfläche, inserirt sich die feste Sehne des Psoas. Vor dem kleinen Trochanter findet man eine glatte und dreieclige Fläche. Facetta practrochanterica, an welcher sich die Fleischbündel des I'soas inseriren.

Digitaluntersuchumg. Man fühlt an der äusseren Fläche der IJüfte handbreit unterhalb der Crista iliaca eine knöcherne unter der Haut befindliche Nasse, es ist der grosse Trochanter. Nimmt man denselben einerseits zwischen Danmen, andererseits zwischen die anderen Fingerbeeren und drïckt die ITeichtheile nicder, so wird or vorne und hinten äusserst leicht begrenzt. Nach oben werden die Finger von einer fibrösen resistenten

Fig. 67.

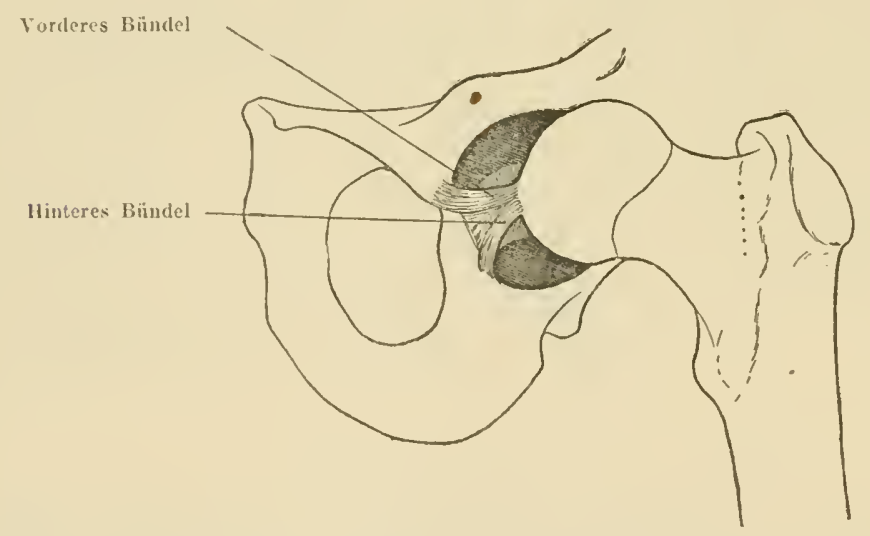

Articulatio coxo-femoralis sinistra. Das Ligamentum rotundum. Der Kopf des Femur ist aus seiner Gelenkhöhle luxirt.

Fläche aufgehalten, welche das Liqamentum Messias bildet und rom Os ilium oberhalb des grossen Trochanter bis zum Tuberculum Gerdy ausgebreitet ist.

Bei in Abductionsstellung befindlichem Oberschenkel entpanut sich das Ligamentum Messias und die Finger dringen tief oberhalh des oberen Randes des Trochanter.

Yan bemerkt, dass der hintere Rand des Trochanter normaler Weise, wenn das Indiriduum im Bette liegt, das Bett nicht berührt, aber bei einer Fractur des Femurhalses rollt sich die untere Extremität nach aussen, und der grosse Trochanter legt sich auf die Fläche des Bettes. Tereinigt man mit cinel geraden Linie, einer Schnur z. B., die Spina iliaca anterior superior mit der Tuberositas ischiadica; so bildet man die Roser-NélatonLinie; normaler Weise findet man, wenn der Oberschenkel gegen das Ab- 
domen leicht gebeugt ist, die Trochanterecke auf dieser Linie. So oft der grosse Trochanter oberhalb der Linea ilio-ischiadica sich befindet, hat man es mit einem pathologischen Zustand zu thun, mit einer Fractur des Femurhalses, begleitet von einem Hervortreten des unteren Fragmentes oder sehr oft mit einer Luxatio coxo-femoralis.

Technik z. A. d. G. Man macht einen langen verticalen Schnitt über die Mitte des grossen Trochanter, indem man zweifingerbreit oberhalb desselben beginnt; unter der Haut und dem subcutanen Fettgewebe gelangt man an die fibröse und sehr resistente Fläche, welche das Ligamentum Messias darstellt. Wenn ein Assistent den Oberschenkel zuerst in Adductions-, dann in Abductionsstellung bringt, so sieht man dieses Band sich spannen oder entspannen. Man durchschneidet es vertical, führt eine Abduction aus und findet zwischen demselben und der änsseren Fläche des Trochanter einen breiten Schleimbeutel, welcher durch die Bewegungen des Trochanter

Fig. 68.

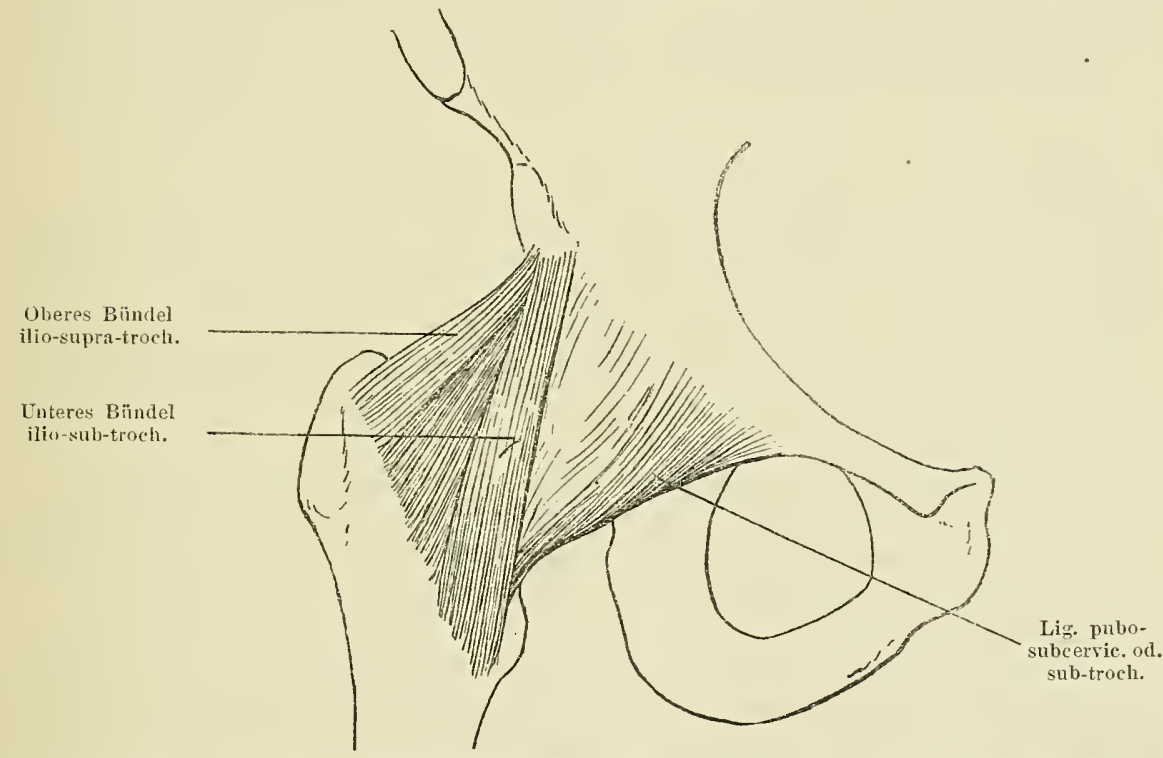

Die vordere Fläche der coxo-femoralen Gelenkkapsel; das Ligamentum anterius in $\mathrm{V}$ oder besser Ligamentum triangulare.

unter dieser fibrösen Fläche entstanden ist. Man befleissige sich, diesen Schleimbeutel zu erkennen, weil dessen Entzündung, Peritrochanteritis, besonders tuberkulöser Natur, sehr häufig ist, und gar oft kommt man in die Lage, diese Diagnose zu stellen oder bei dieser Affection zu interveniren.

Das Coxo-femoralgelenk. Der Kopf des Femur einerseits und die Pfanne des Hüftbeins andererseits sind die knöchernen Oberflächen, welche in Contact kommen. Eine Schicht von hyalinem Knorpel bedeckt die Gelenkflächen. Dieser Linorpel wird auf der Wölbung der Pfanne und rings um die Femurinsertion des Ligamentum rotundum faserig-knorpelig. Ein fibröser Bogen, Labrum oder Limbus inserirt sich rings um den Rand der Pfanne auf diese Weise die Cavitas cotyloidalis rergrössernd. 
Das Ligamentum rotundum (teres) liegt im Innenraume des Gelenkes und hat die Form eines ausgehöhlten liegels. Es inserirt sich mit der Basis an den beiden Vorsprüngen der l'fanne an dem Ranile der Grube, welche an Grunde dieser Höhle sich befindet, und am liganentum transrersum; mit der Spitze inserirt es sich am Caput femoris, am oberen Rande des fingerförmigen Eindruckes. Man unterscheidet am Ligamentum zwei feste Bündel, welche sich am Caput femoris zu einem V vereinigen (Fig. 67).

Das rordere Bïndel entsteht an vordern Vorsprunge der Pfanne; das hintere $B$ üudel auf der nichtgelenkigen Fläche des hintern Vorsprunges der Pfanne und, um in das Gelenk zu gelangen, zieht es unter dem Ligamentum transversum. Die Grube des Ligamentum rotundum ist mit Fett ausgefüllt, welches sich bei den Bewegungen des Gelenkies nnitbewegt.

Die Capsula articularis coxo-femoralis hat die Form eines gestutzten liegels mit der Basis nach aussen, inserirt sich innen am Rande der Pfanne und am Ligamentum transrersum. Am cotyloidalen Wulste inserirt sich die Kapsel nicht und die Synovialmembran bildet zwischen Kapsel und diesem Wulste einen kreisförmigen Blindsick. Nach aussen inserirt sich die Gelenkliapsel rings um die Basis des Femurhalses, vorne an der rauhen Linea intertrochanterica, hinten an der hintern Fläche des Halses.

Der rordere Theil der Coxo-femoralkapsel, unter dem Namen Ligamentum triangulare anterius oder in Form eines $\mathrm{V}$ beschrieben, ist der festeste.

Im Ligamentum anterius, das dic Form eines mit der Spitze nach oben gerichteten Dreieckes hat, unterscheidet man zwei wichtigere Bündel (Fig. 6S).

a) Ein oberes Bündel, das schief nach unten und aussen ron dem Pfannenwulste des Os ilium zum Tuberculum supra-cervicale der Linea intertrochanterica anterior gespannt ist. Es hat die Breite des kleinen Fingers und ist $5-6 \mathrm{~mm}$ dick.

b) Ein unteres Bündel, das sehr schief ist und fast rertical von dem Wulste des Os ilium zur rauhen dreiecliggen Oberfläche, mit welcher die Linea intertrochanterica anterior endigt, gespannt ist. Dieses Bündel ist ebenso fest wie das vorhergehende und kireuzt das Caput femoris in Form einer Schärpe.

Sehnige intermediäre sehr feste Bündel ergänzen das Dreieck, rom obern und untern Bündel begrenzt und inseriren sich am mittlern Theil der Linea inter-trochanterica.

Bertin hat dieses dreieckige Ligament so beschrieben, wie es hier beschrieben ist, um rieles früher als Byglow, welcher es wieder unter dem Namen Ligamentum in $\mathrm{I}$ beschrieben hat.

Unter dem Ligamentum in $\mathrm{V}$ am Rande der liapsel findet man ein anderes Ligament, das Ligamentum pubo-subcervicale, welches ron der Tuberositas pubica zum Femurhalse grespannt ist, an welchem es sich unmittelbar hinter der Insertion des untern Bündels des Ligamentum anterius inserirt (Fig. 6S).

Lieses Ligament bildet mit den beiden Bündeln des Ligamentnm triangulare ein liegendes $\mathrm{N}$.

Zwischen Ligamentum triangulare und Ligamentum pubo-femorale ist die Gelenklapsel sehr dünn und oft ron einem circulären Orificinm durchbrochen, durch welches jene mit einem Schleimbentel des Psoas communicirt.

Am hintern Theile der liapsel ist der Verlauf der Fasern grösstentheils dem Verlanfe der rordern entgegengesetzt.

Das hintere Ligament, Ligamentum ischio-supracervicale, hat die Form eines mit der Spitze nach oben und aussen gerichteten Fächers und ist in Form von Hosenträgern rom obern Rande des Femurhalses zu dem Pfannenwulste des Os ischii gespannt.

Hinten gegen den äussem Rand der Kapsel bilden Circulärfasern ein Band, das Ligamentum arcuatum, welches rom obern Rande des Femurhalses, wo es mit dem Ij- 
gamentum posterius sich rermengt, zu seinem untern Rande gespannt ist, wo es mit dem Ligamentum pubo-femorale sich verwebt.

Die vordere Fläche des Coxo-femoralgelenkes ist in Beziehung vorne und von innen nach aussen mit dem Musculus pectineus und mit dem Ilio-psoas, unter welchen die Sehne des Rectus anterior dringt. In der ron diesen beiden Muskeln begrenzten Rinne verlaufen von aussen nach innen: der Nervus cruralis, die Arteria und Vena femoralis.

Die hintere Fläche steht von der Oberfläche zur Tiefe in Beziehung mit dem Glutaeus maximus, Pyriformis, Obturator internus und den beiden Gemelli; der Quadratus femoris and die hintere Partie des Glutaeus minimus liegen direct auf dem Gelenke.

Die äussere Fläche ist von aussen nach innen rom Glutaeus medius und minimus bedeckt.

Die innere und untere Fläche entspricht dem Musculus obturator externus, welcher zuerst unter dem Gelenke dann rings um den Femurhals zieht, um in den fingerförmig'en Eindruck zu gelangen.

Digitaluntersuchung des Gelenkes. In seinem vordern Theile längs der Rimne der Arteria femoralis, unmittelbar unter dem Poupart'schen Bande fühlen die tief eingedrückten Finger die vordere Fläche des Femurkopfes. Hier sollen bei der Coxitis die Schmerzpunkte gesucht werden.

Nach aussen ist das Gelenk unmöglich abzutasten, weil die Muskelschichten sehr dick sind.

Innen erreichen die kräftig eindrückenden Finger hinter der Fläche des mittleren Adductor die innere Fläche des Femurkopfes, dessen Bewegungen man fühlt, wenn man dem Oberschenkel Rotationsbewegungen ertheilt. Hinten ist das Gelenk für die tastenden Finger durch den sehr dicken Fleischkörper des Glutaeus maximus rersteckt. Bringt man aber den Oberschenkel in Flexionsstellung und innere Rotation, so kann man die hintere Fläche des Femurkopfes, die zum grössten Theile aus der Gelenkpfanne ausgetreten ist, abtasten.

Techuik z. A. d. G. Man macht von der Spina iliaca anterior einen langen verticalen Schnitt und gelangt unter der Fascie an das Dreieck, welches den Sartorius von dem Tensor synoviae scheidet.

Im Grunde dieses Raumes findet man den Körper des Rectus anterior. Man legt diesen Muskel frei und zieht ihn und den ganzen äussern Schnittrand mit einem stumpfen Haken seitwärts ab; auf diese Weise gelangt man an die vordere Fläche des Gelenkes, welche mit Pincette und Bistouri gereinigt wird. Man durchschneidet quer die Kapsel und sieht wie dick diese ist; es erscheint auch der Kopf des Femur.

Um das Ligamentum rotundum aufzufinden, durchschneidet man unter dem Poupart'schen Bande von der Spina iliaca bis zur Spina pubica alle vor dem Gelenke liegenden Weichtheile; auf diese Weise wird die vordere Fläche des Gelenkes freigelegt.

Nan durchschneidet den vordern Theil der Kapsel und drückt man den Oberschenkel, so tritt der Femurkopf mit einem pfeifenden Geräusch aus der Gelenkhöhle heraus. Nan sieht und fasst mit einer zu einem Haken gebogenen Hohlsonde das Ligamentum rotundum. Durchschneidet man dasselbe, so schwingt der Femur und entfernt sich von der Pfanne.

Die Region der Glutaeen hat eine rechtwinklige Form und ist bei einem männlichen Individuum mehr oder weniger verbreitert, beim weiblichen rund oder halblingel- 
förmig. Sie wird nach oben ron dem obern conrexen Rand des Os ileum begrenzt, weleher sie rom dem hreuze scheidet, innen ron der Crista sacralis und rom Sulcus interglutaealis und anssen ron einer, ron der Crista iliaea bis zum grossen Trochanter gezogenen Linie. Nach unten sind die Nates ron einer horizontalen tiefen Furche, Suleus glutaealis, begrenzt. Diese tiefe Furche beginnt im Nireau des Os ischii und endigt an der hintern Fläche des Femur handbreit unter der Trochanterecke. Längs der Glutaealfurche längt die IIaut innen am 0 s ischii und aussen an der Aponeurose durch zellig-fibröse Fortsätze, welche als Ligamentum suspensorium plicae glutaealis beschrieben sind.

An den Grenzen der Glutaealregion findet man vier Ausgangspunkte, vier knöcherne Erhebungen, mit deren Ilülfe man sich in der Tiefe dieser Region orientiren kann.

rig. 69.

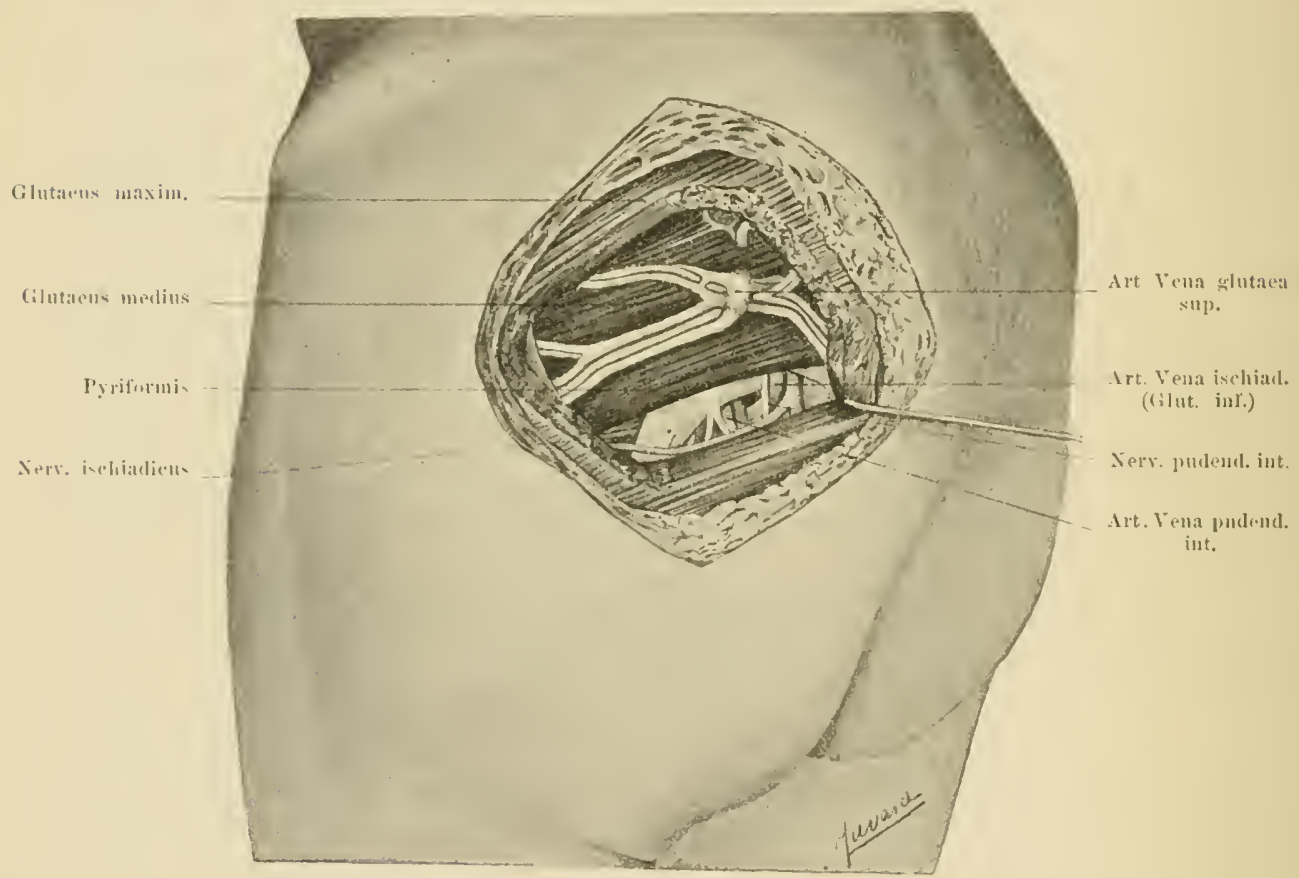

Die linke Region der Glutaten. In dem Mnsculus glutaeus maximus wurde ein rundes stück weggeschnitten, um die mittlere Schichte zu sehen.

Oben und innen findet man die Spina iliaea posterior superior. Nit dem Daumen folgt man Schritt für Schritt dem obern convexen Rande des Os ilium nnd fühlt in einem gewissen Momente drei fingerbreit ausserhalb der Jedianlinie eine linöcherne Ecke, die Spina iliaca posterior superior.

Nach innen dringen die Fingerbeeren in die llio-sacralfurche, welche der Articulatio sacro-iliaca entspricht. Ein schmerzhafter Punkt in diesem Nireau zeigt die Sacrocoxalgia; die Kilinge eines Messers dringt hier tief in die Interlinea sacro-iliaca.

Die Aufeinamderfolge der Schichtell. In der Glutaealgegend sind die Schichten in folgender Weise über einander gelagert. 
a) Die dicke $\mathrm{Haut}$, beweglich und gefaltet an mageren Individuen, ist sie bei fettem und besonders bei Franen gespannt. Sie ist in der Tiefe in der Medianlinie durch eine mediane Raphe mit der Crista sacralis verbunden. Längs der Glutaealfalte hängt die Haut, wie wir gesehen haben, am Os ischii und an der Aponeurose mittelst eines elastischen Ligamentes, Ligamentum suspensorium.

Die subcutane Fettschichte ist sehr entwickelt, besonders gegen den untern und innern Theil der Glutaeen, wo sie ein wahres Fettpolster bildet. Sie wird von einem röthlichen Fette gebildet, das in fibrösen elastischen Alreolen enthalten ist.

Die oberflächliche Fascie ist dünn und bedeckt den Glutaeus maximus, nach unten geht sie über in die Fascia cruralis, nach aussen und oben verliert sie sich in dem nichtmuskulösen Antheil des Deltoides glutaeus, innen begrenzt sie sich an der Crista sacralis und am Hüftknochen.

Längs des untern Randes des Glutaeus maximus umschlingt sie diesen Rand und geht über in die Fascia profunda.

Die Muskelmasse wird von drei Schichten gebildet:

I. Die erste Schichte hat die Form eines breiten, mit der Spitze nach unten gerichteten, durch das Messiasband bis zur Tibia verlängerten Dreiecks, wo sie sich am Tuberculum Gerdy inserirt; es ist der Deltoides glutaeus. Sie wird innen und nach unten zum grossen Theilo ron dem Glutaeus maximus in der Mitte von einer nichtmuskulösen fibrösen Partie, rorne rom 'Tensor fasciae gebildet.

Der Glutaeus maximus ist ein sehr breiter Muskel, hat eine Rhombenform und ist etwas mehr als $3 \mathrm{~cm}$ dick, er ist rom Os ilium und Sacralbeine zur obern und äussern Bifurcation der Linea aspera des Femur gespannt.

Er entsteht mit Fleischfasern und Bündeln oder fibrösen Strängen an der hintern Seite des Darmbeinkammes am Rande und an der Spina des Sacralbeines am Rande und an der Spitze des Hüftbeines endlich am Ligamentum tuberoso-sacrum. Die Fleischbündel in Form ron prismatischen Säulen sind von einander durch zellig-fibröse Blättchen getrennt, weIche an den Fascien des Muskels entstehen. Nach aussen geht die obere Hälfte des Glutaeus maximus in eine Sehne über, welche sich mit dem ftbrösen Ligamentum iliosubtrochantericum am obern Ende der Linea glutaea ansetzt, die oft zu einem grossen Höcker entwickelt ist, einem dritten Trochanter; die untere Hälfte inserirt sich mit Sehnenfasern an der Linea glutaea und dringt unter die Sehne des Vastus externus, von dessen Rande sie durch einen Schleimbeutel getrennt ist.

Die fibröse nichtmuskulöse Partie ist mehr als $2 \mathrm{~mm}$ dick und liegt zwischen dem Glutaeus maximus und dem Tensor fasciae. Sie entsteht am äussern Rande der Crista iliaca und theilt sich in zwei Partien. Die hintere Partie, das Ligamentum iliosubtrochantericum, verwebt sich mit der Sehne des Glutaeus und inserirt sich am obern Ende der Linea des Glutaeus maximus; die rordere Partie, das Messiasband, schlägt sich über den grossen Trochanter hinüber und verläuft an der äussern Fläche des Oberschenkels und inserirt sich an der Tibia, am Tuberculum Gerdy.

Der Tensor fasciae bildet den dritten Theil des Deltoides glutaens. Er befindet sich in der Verdoppelung der Fascie und entsteht mit einem sehnigen Blatte am äussern Rande der Crista iliaca unmittelbar hinter der Spina iliaca anterior superior. Sein Fleischkörper, von der Länge der Hand und drei Finger breit, verläuft schief nach unten und hinten und geht über in ein fibröses Band, welches ror dem Messiasbande zieht, neben welchem es sich am Tuberculum Gerdy inserirt. Der Tensor fasciae wird von einem Nervenfaden, dem Aste des Nervus glutaeus superior innervirt.

Unter diesem Muskelfelde findet man eine Fettschichte und ein feines zellig-fibröses Blättchen, die mittlere Fascie. 
Il. Diezweite muskulöse Schichte wird ron rorne nach hintem: rom mittleren Gilutius und rom Pyriformis gebildet.

Der Glutaeus medius ist dick und kräftiø, ist fächerförmig rom Os ilcum zum grossen 'Trochanter gespannt. Er entsteht mit Fleischfisern und einigen fibrösen Bündeln an der äussern Fiäche des Os ilium, an dessen Oberfläche in der Form eines Hornes, welche nach oben ron dem äussern Rande des Darmbeinkammes, nach unten ron den obern Rand der Furche derArteria glutaea begrenzt wird und ron vorne nach hinten ron der Spina iliaca anterior superior bis zur Linie, an welcher sich der Glutacus maximus inserirt, gespannt ist.

Andere Fasern entstchen an der tiefen Fläche der fibrösen Partic der obern Schichte und an der Schne des Tensor. Nach unten rereinigen sich die Muskelbündel an fibrösen Bändern. Diese lefinden sich zuerst in Fleischliörper, verbinden sich dann

Fig. 70 .

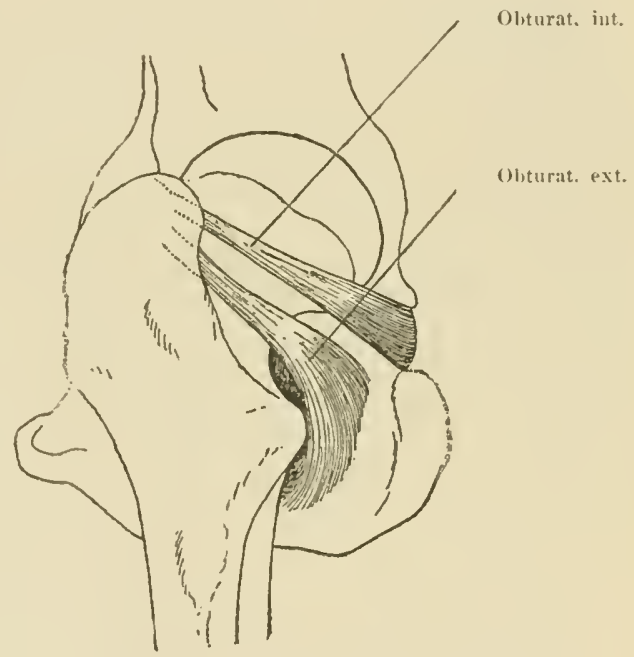

Die Museuli obturatores und ihre Insertionen am grossen Trochanter. Die Sehne des Obturator externus liegt auf der hinteren Fläehe des Femurhalses, der Obturator internus umschlingt den Hals des Os ischii.

zu einer festen breiten Sehne, welche sich an der Obernäche in der Form einer Virgula inserirt, die an der äussern Fläche des Trochanter major ron der Trochanterecke bcginnend besteht.

Der Musculus pyriformis ist ron der Beckenfläche des Kreuzbeines zum Trochanter major gespannt; er entsteht mit Fleischfasern und fibrösen Bündeln an der vordern Fläche dos Kreuzbeins rings um das zweite und dritte líreuzbeinloch und im Grunde der Furchen, welchen er folgt, am obern Raude der Iliosacralfurche und an der tiefen Fläche des grossen Ligamentum sacro-iliacum. Der Fleischlörper des Muskels geht schief nach unten und aussen durch die grosse Ilio-sacralgrube und wird ein langer 3-4 fingerdicker sehniger Strang. Diese Sehne dringt unter der tiefen Fläche der Sehne des Glutaeus medius und inserirt sich am obern Rande des Trochanter major (Fig. i1).

Die Arteria glutaea entsteht aus der Art. hypogastrica, rcrläuft nach abwärts und hinten, zieht durch den Winkel, der rom Nerrus sacro-lumbilis und rom ersten 
Sacralnerven gebildet wird, durchdringt den rom obern Rande des Pyriformis und der Wölbung der grossen Iliacalgrube begrenzten Zwischenraum und theilt sich in drei Aeste: einen Ramus posterior für den Ghntaeus maximus, einen Ramus medius, in den der Stamm der Arterie sich fortsetzt, er umschlingt den Rand des Os ilei, folgt der sichtbaren Furche in der Fossa ilaca externa und giebt eine grosse Zahl ron Aesten für den Glutaeus medius und minimus ab, einen Ramus inferior besonders für den Glutaeus minimus und mit einem Ramus perforans, Arteria supracotyioidea, für den Knochen und die Gelenkkapsel (Fig. 72).

Zwei grosse Venen begleiten die Arteria glutaea.

Den Nerrus glutaeus superior findet man etwas nach unten und aussen von

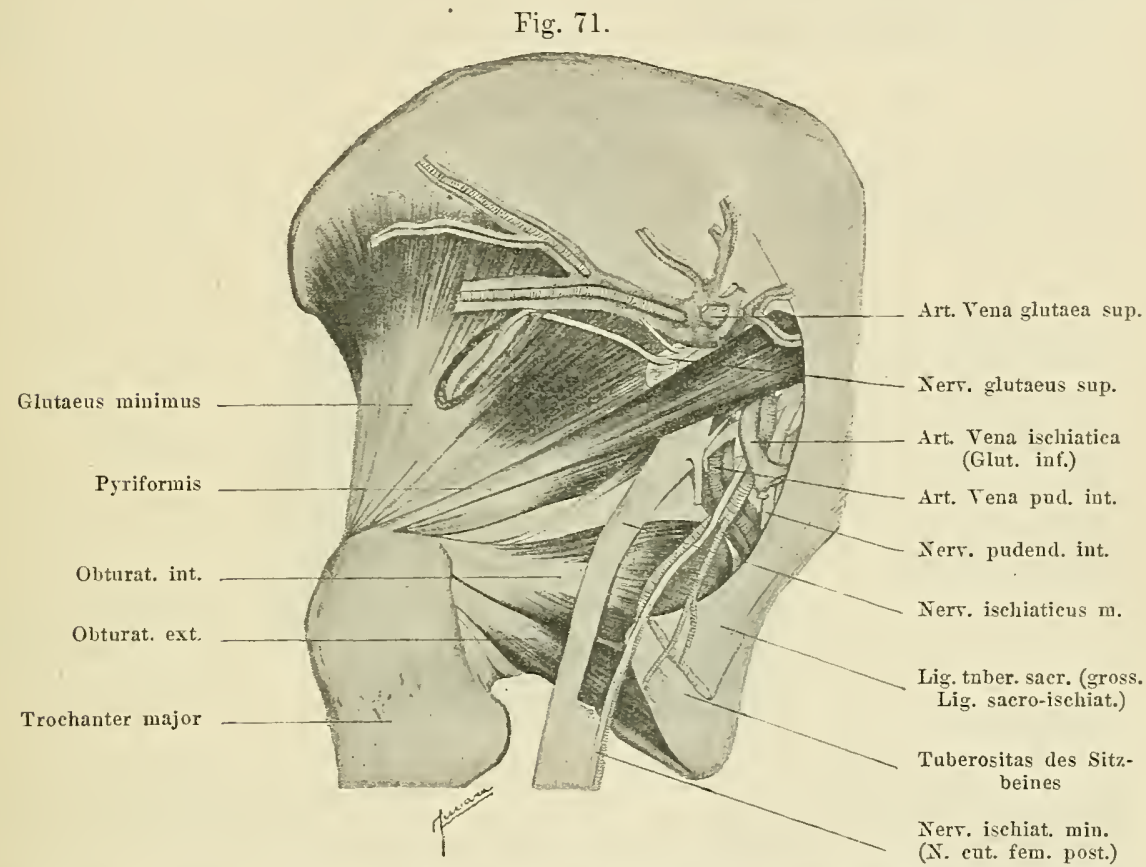

Die Gebilde, welche durch das grosse und kleine Orificium sacro-ischiadicum austreten.

der Arteria, er theilt sich in Reste für den Glutaeus maximus, Tensor fasciae, Glutaeus minimus und medius.

III. Die dritte Muskelschichte wird von rorne nach hinten ron dem Glutaeus minimus, Obturator und den beiden G'emelli gebildet.

Der Glutaens minimus hat die Form eines breiten Fächers und ist rom Os ilium zum Tochanter major gespannt. Er entsteht mit Fleischfasern und fibrösen Bündeln in der Fossa iliaca externa an der ganzen Oberfläche, die ron dem untern Rande der Furche der Arteria glutaea bis zwei fingerbreit oberhalb des Pfannenwulstes ausgebreitet ist, dann von der Spina iliaca anterior superior bis zur Fossa iliaca rom obern und vordern Raude der Fossa iliaca und ron der obern Hälfte der Oberfläche der hinter der P.fanne gelegenen viereckigen Fläche. Die Fleischfasern übergehen nach unten in ein schönes sehniges Blatt, welches sich an der Oberfläche in der Form einer Virgula inserirt, welche den rordern Rand des Trochanter major einnimmt (Fig. 71). 
Diese Sehne ist oberhalb des Femurhalses leicht gewunden; ein Schleimbeutel besteht zwischen dieser und dem rordem obern Winliel des 'Trochanter; feste $\Lambda$ dhärenzen rerbinden ihn mit der Gelenkikapsel.

Der Obturator interulus entsteht an der Beckenlläche des linöchernen Rahmens rings um das Foramen obturatorium und an der innern Fläche der Membrana oburans, gelangt aus der Beckenhöhle durch das Foramen ischiadicum minus, umschlingt in spitzem Winliel den Hals des Os ischii, auf welchem er mit einem grossen Schleimbentel gleitet und inserirt sich mit einer festen Sehne an der innern Fäche des grossen Trochanter unmittelbar unterhalb und etwas ror der fnsertion des Pyriformis (Fig. 71).

Der Gemellus superior entsteht an der äussern Fläche der Spina ischiadica und folgt dem obern liande der Selne des Obturator internus.

Der fermellus inferior ist um vieles dicker, entsteht am llalse des Os ischii

Fig. 72.

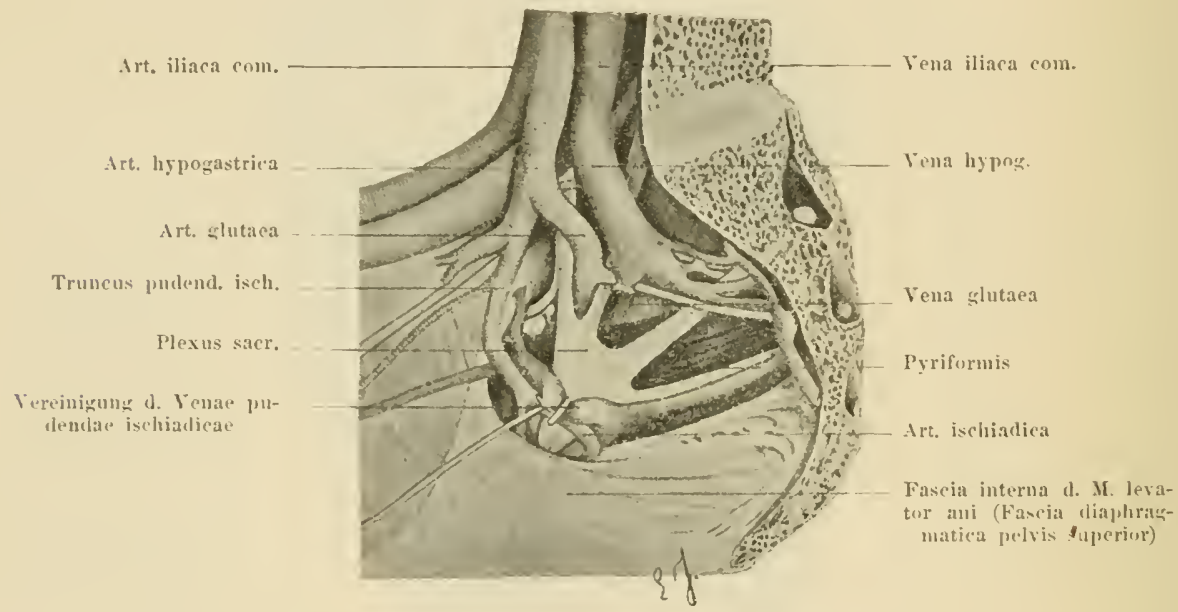

Die Artcria hypogastrica und ihre Aeste, an der inneren Fläche des Beckens gesehen; die Arteria glutaea zieht durch den Winkel, der vom Truncus sacro-lumbalis und dem ersten Nervus sacralis gebildet wird.

und folgt dem untern Rande des Obturator internus. Zuweilen ist dieser Muskel stark entfaltet und enthält wie in einer Furche die Selme des Obturator.

Nach aussen inseriren sich die beiden Gemelli, welche als zwei Bündel des Obturator internus betrachtet werden können, mit dessen Schne am grossen Trochanter.

Der grosse Nerrus ischiadicus wird ron den Anastomosen der Wurzeln des Plexus sacralis gebildet, gelangt aus der Beckenhöhle durch das Foramen sacrale majus unter dem untern Rand des Pyriformis.

Er liegt ron rorne nach hinten breiter werdend, ron der Dicke eines Fingers etwas schief nach abwärts und aussen gerichtet auf dem Glutaeus minimus, Obturator internus auf den beiden Gemelli und am Musculus quadratus femoris (Fig. 71.)

Der kleine Nervus ischiadicus findet sich am innern Rande des grossen Nerrus ischiadicus. Er giebt Zweige für den Glutaens maximus, einen perinealen Ast ab und verläuft zuerst unter der fascie dann unter der Haut.bis in die Kniekehle.

Die Arteria ischiadica, ein Ast der Epigastrica, kommt aus der Beclienhöhle unter- 
halb des Pyriformis und vou grossen Venen begleitet liegt sie an der Seite des kleinen Nervus ischiadicus (Fig. 71).

Das Packet der Arteria, Vena und Nervis pudendus internus kommt aus der Beckenhöhle durch das grosse Foramen ischiadicum, umschlingt die Spina ischiadica und dringt von neuem in das Becken durch das kleine Foramen ischiadicum.

Die beiden Fossae sacro-ischiadicae werden durch die beiden Ligamenta sacroischiadica in Foramina umgewandelt.

Das Ligamentum tuberoso-sacium oder das grosse Ligamentum sacro-ischiadicum hat die Form eines breiten festen fibrösen Fächers, der von dem hintern Theile des Os ilium, von der Tuberositas iliaca posterior und vom äussern Rande des Sacralbeines und des Os coccygeum zum innern Rande der Tuberositas ischiadica und des Ramus ischiopubicus gespannt ist. Es wird von mehreren fibrösen Schichten, von denen die tiefsten auch die festesten sind, gebildet (Fig. 71).

Das kleine Ligamentum sacro-ischiadicum liegt unmittelbar unter dem grossen Bande und hat die Form eines mit der Basis nach innen gekehrten Dreieckes. Es ist rom Rande des Kreuzbeines und des Os coccygeum zur Spitze und Beckenfläche der Spina ischiadica ausgespannt; innen ist es mit dem grossen Ligament verwebt, aussen werden sie von einer Fettschichte geschieden.

Das Foramen ischiadicum majus wird begrenzt: nach oben und vorne von dem untern Rande des Os ilium, hinten vom vordern Rande des grossen Ligamentes, nach unten rom obern Rande des kleinen Ligamentes und von der Spina ischiadica (Fig. 69).

Dieses Foramen wird zum grössten Theile rom Fleischkörper des Pyriformis ausgefüllt, welcher es nach unten und anssen durchzieht. Die Arteria glutaea mit ihren Venen und der Nervus glutaeus superior ziehen vom Becken zwischen dem obern Rand des Pyriformis und Os ilium. Unter dem untern Rande des Pyriformis zieht aus dem Becken auf derselben Fläche von aussen nach innen liegend: der grosse Nervus ischiadicus, der kleine Tervus ischiadicus, die Arteria ischiadica mit ihren beiden zuweilen sehr dicken Venen, auf einer tiefern und innern Schichte unmittelbar am Knochen die Arteria und die Venae pudendae internae und der Nervus pudendus internus.

Das Foramen ischiadicum minus hat eine dreieckige Form und wird hinten vom oberen Rande des grossen Ligamentes, oben vom unteren Rande des kleinen Ligamentes, vorne vom Halse des Os ischii begrenzt.

Durch dieses Foramen zieht aus dem Becken, den Hals des Os ischii umschlingend, der Musculus obturator internus, und es tritt in das Becken wieder ein, die Spina ischiadica umschlingend, die Arteria und Vena pudenda interna und der Nervus pudendus internus.

Technik zur Auffindung des Mruscultus Tensor fasciae. Nan macht von der Spina iliaca anterior superior einen langen Schnitt nach unten und hinten gegen den unteren Theil des grossen Trochanter. Unter der Fascie kommt man auf den Fleischkörper des Mnskels.

Nan präparirt ihn in der Fascienscheide, welche ihn umhült, und sieht nnter seiner tiefen Fläche sein Gefässbündel und einen sehr dünnen Nervenast, welchen er durch das Interstitium der Glutaeen rom Nervus glutaeus superior erhält. Der Schnitt wird nach abwärts verlängert, und man sieht, dass die Fleischbündel sich in ein fibröses Band fortsetzen, welches in die Tiefe dringt und an der Tibia sich inserirt.

Inserfionen am grossen Trochanter. Legt man den Cadarer anf die Seite, so erkennt man den grossen Trochanter und legt ihn frei, wenn man 
in die Haut und in den Nuskel des Glutaeus maximus hinein einen breiten lappen in Form eines U schneidet, welelien ein Assistent nach oben hebt. Aul diese Weise legt man den grossen Troehanter ziemlich breit frei und crïffnet den rings um den Trochanter befindlichen Schleimbeutel. Oberhalb des Trochanter sielıt und isolirt man den Glutaeus medius, und mit dem Finger dringt man in das Interstitium, welehes ilın vom Glutaens minimus scheidet, ein. Man durehschneidet ihn quer und studirt seine Insertion an ler äusseren Fläche des Trochanter.

Unter dem Glutacus medius findet man die Sehne des Pyriformis und des Clutacus minimus. Man studirt die Insertion des Pyriformis am oberen Rande des Trochanter und bemerkt, dass die hinteren fibrösen Bündel der Sehne des Glutacus minimus sich verknoten und über den Femurhals ziehen, um sich am rorderen Rande des Trochanter zu inseriren.

Man durchschneidet quer die Schne des Glutaeus minimus und präpa-

Fig. 73.

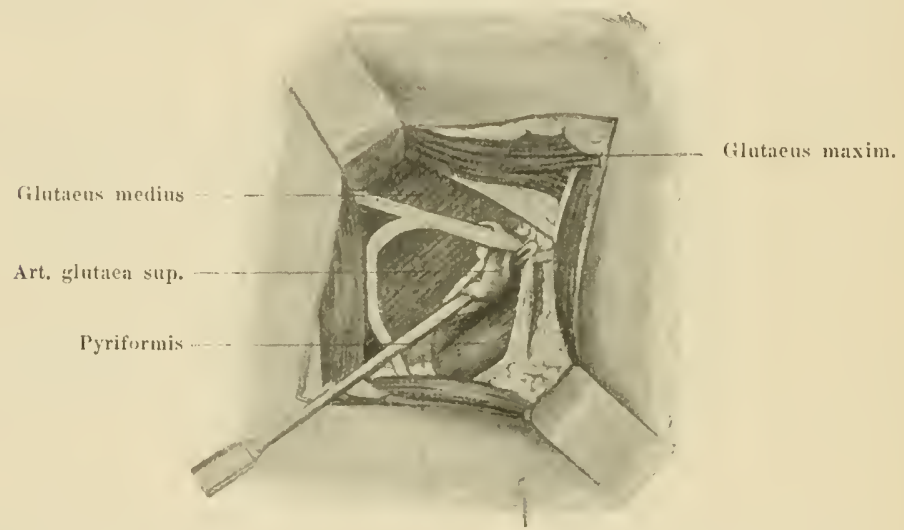

Das Aufsuchen fer Arteria glutaea superior. Die Schnittränder des Glutaeus maximus sind durch stumpfe Haken weit auscinander gezogen.

rirt die tiefe Fläche des unteren Fragmentes, welches sehr innig mit der Gelenkkapsel adhärirt.

Ein Assistent dreht den Femur nach innen; man rrkennt und isolirt die Sehne des Obturator internus von den beiden Gemelli begleitet und unter diesen den Quadratus femoris. Nan verfolgt die Sehne des Obturator internus bis zu ilurer Insertion am Femurhalse und sicht, dass sie sich hier mit der Sehne des Pyriformis, an welcher sie sehr innig adhärirt, kreuzt.

Man isolirt den oberen Rand des Quadratus femoris und sucht unter ihm hinter dem Femurhalse den Fleischkörper und die Sehne des Obturator externus, deren Insertion in der Digitalgrube man studiren muss.

Arteria glutaea. Legt man das Individum auf den Banch, so crkennt man nach oben und imnen die Spina iliaca posterior superior, nach unten und aussen die Trochanterecke.

Die Linie, die diese beiden Punkte verbindet, entspricht dem Zwischenraume, welcher vom Glutaens medius und Pyriformis begrenzt wirl, der Zwischenraum, durch welchen die Arteria glutaea hindurchtritt. 
Man macht zwischen diesen beiden Punkten eine lange Incision, durchschneidet den Glutaeus maximus einer seiner Insertionen mit dem Bistouri folgend, oder besser noch, man löst ihn mit der Spitze der zu einem Haken gekrümmten Finger los. Unter ihm legt man an die Schnittränder stumpfe Haken und untersucht das Operationsfeld; sieht man nicht den Zwischenraum zwischen Glutaeus medius und Pyriformis, so wird mit dem Zeigefinger der Grund des Schnittes abgetastet, man fühlt dann immer den oberen Rand der Fossa iliaca (Fig. 73). Arbeitet man dann mit der Hohlsonde und Pincette behutsam und aufmerksam am knöchernen Rande, so findet man am Knoshen anliegend und unter einer dünnen Muskellage dem Glutaeus medius angehörend, die Arteria glutaea, welche man mit den sie begleitenden oft sehr grossen Venen in die Höhe hebt. Unter der Arteria findet man den weissen Strang des Nervus glutaeus superior.

Techmik zur Anffindung der Gebilde, welche ans dem Becken unter dem Musculus pyriformis anstreten. Man erkennt in der Medianlinie das untere getheilte Ende der Linea sacralis und macht fingerbreit nach aussen von diesem Punkte eine lange, schief nach unten und aussen gegen den unteren Theil des grossen Trochanter gerichtete Incision. Man schneidet den Glutaeus maximus durch, indem man einem seiner Zwischenräume folgt, legt stumpfe Haken ein, und sieht unter einem feinen zelligen Blättchen im äusseren Winkel des Schnittes am Körper des Obturator internus gelegen den grossen Nervus ischiadicus, den man isolirt. Am inneren Rand dieses Nerven findet man den kleinen Nervus ischiadicus, begleitet von der Arteria ischiadica. Mit der Fingerbeere erkennt man gegen den inneren Theil des Schnittes die Spina ischiadica, und an diese anliegend findet man aussen das Gefässpacket der Arteria und Vena pudenda interna und innen den Nervus pudendus internus.

Das grosse und kleine ligamentum sacro-ischiadicum. An dem lateralen Theile des Anus drückt man die Finger in die Ischio-rectalgrube, die Spitzen der zu einem Haken gekrümmten Finger greifen das Ligamentum tuberoso-sacrum. Man macht von der Spina iliaca posterior inferior zur Tuberositas ischiadica eine lange Incision, durchschneidet den Glutaeus maximus Schicht für Schicht und gelangt an die fibröse Fläche, welche das grosse Ligament darstellt, welches man besser studirt, indem man beide Schnittränder präparirt. Mit der Fingerspitze sucht man die Spina ischiadica auf und vor derselben durchschneidet man das grosse Ligament, man gelangt an das fibröse Dreieck, welches das kleine Ligament darstellt.

Nervus ischiadicus nud Quadratus femoris in der Regio ischio-trochanterica. Nan sucht aussen den Trochanter, innen die Tuberositas ischiadica auf; zwischen beide dringen die Fingerspitzen in eine Furche, Sulcus nervi ischiadici. In diesem Niveau macht man einen verticalen Schnitt, durchschneidet quer den Glutaeus maximus und gelangt an den Strang des Nervus ischiadicus, der auf einer rothen Unterlage dem Körper des Quadratus femoris aufliegt. 


\section{Die Region des Oberschenkels.}

Die vordere Fläche. Die rordere Fläche des Obersehenkels heginnt unter dem Poupart'schen Bande und endigt etwas oberhalb der Kniescheibe, wo sie sich in das linie fortsetzt.

Priift man bei einem muskulösen Indiridunm die rordere Fläche des in $\Lambda$ bductionsstellumg befindlichen Obersehenkels, so sieht man, dass diese die Form einer Furche hat, welche nach aussen ron einer cylindrischen verticalen Erhabenheit begrenzt wird, die ron dem mit dem Psoas und Quadriceps bedeckten Femur gebildet wird; nach innen wird sie ron der gespannten Cruppe der Adductoren begrenzt.

Fig. 74.

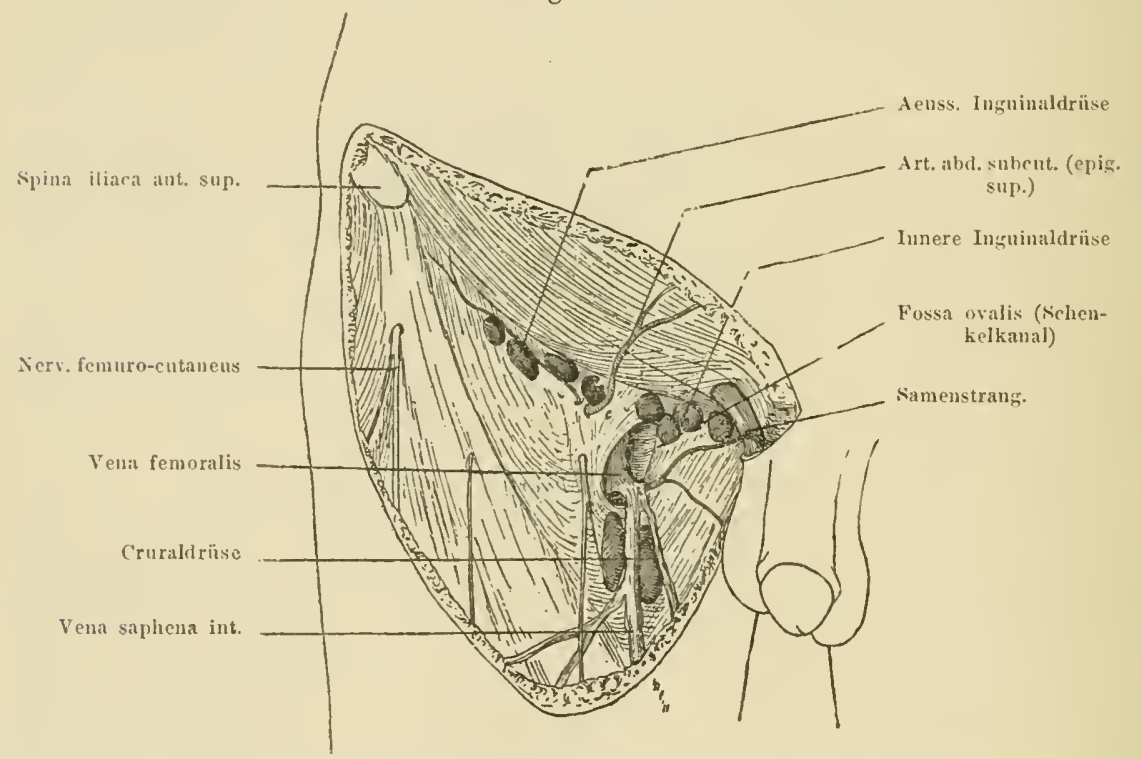

Die oberflächliche Schichte des Scarpa'schen Dreiecks.

In dieser Furche, der Rinne der Arteria femoralis, rerlänft die Arteria und Vena femoralis. Folgt man von oben nach unten mit der Spitze der linger der Rinne der Arterie, so sieht man diese handbreit oberhalb des Condylus internus, dort wo die Arterie femoralis zur Arteria poplitea wird, endigen. Bei Frauen mit stark entwickeltem Panniculus adiposus rundet sich der Oberschenkel und die Gefässrinne, die mit Fett rollgefüllt ist, kann um so schwerer begrenzt werden.

Das Scarpa'sche Dreieck ist eine mit der Spitze nach unten gerichtete Furche, eine Mulde, welche nach aussen rom inneren Rande des Sartorius, innen rom äusscren Raude des $\Lambda$ dductor medius, nach oben rom Poupart'schen Bande begrenzt wird. Seine Spitze entspricht dem Punkte, wo der Sartorins mit dem Adductor medius sich lireuzt (Fig. i4).

An einem mageren Individuum fühlt man oben das Poupart'sche Band und die 
beiden Spinae, zwischen welchen es gespannt ist, aussen die Erhabenheit des Rectus anterior, vor welchem man den Sartorins findet, innen den Adductor medius. Unter der Haut fühlt man die Lymphdrüsen, und drückt man die Finger in den Grund der Furche, so fühlt man das Pulsiren der Arteria femoralis, welche auf der Erhabenheit des Femurkopfes liegt.

Die Anfeinanderfolge der Schichten:

a) Die feine nnd bewegliche Haut ist an der oberen und inneren Seite mit Haar bedeckt. Längs der Beugefurche ist sie mit dem Poupartschen Bande durch zellig-fibröse Fortsätze verbunden, es ist das Ligamentum suspensorium inguinale Petrequini.

Fig. 75 .

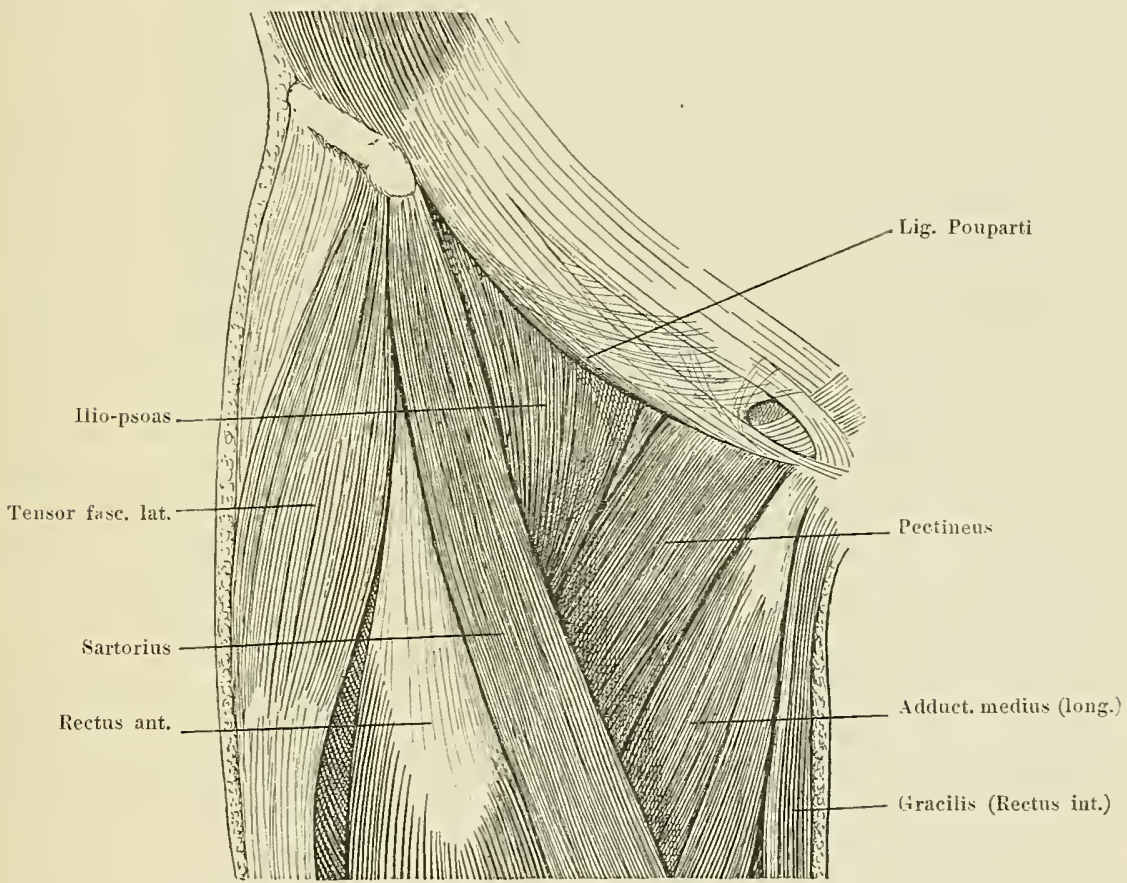

Das Scarpa'sche Dreieck seines Inhaltes entledigt.

b) Die subcutane Fettschicht, mehr oder weniger stark entwickelt, wird von einem gelblichen Fett gebildet.

c) Das oberflächliche Blättchen ist fest gefügt und adhärirt oben am Poupart'schen Bande und geht oberhalb desselben in die Abdominalwand über. Es ist doppelt und enthält zwischen den beiden Blättchen die Vena saphena interna und lymphatische Drüsen (Fig. 74).

Die Vena saphena interna verläuft rertical in der Länge der inneren Wand des Schenkeldreieckes; zweifingerdick unterhalb des Poupart'schen Bandes erweitert sie sich zu dem "Golf der Saphena" und ergiesst sich mit einem Bogen, welcher die Fascie durchbohrt, in die Vena femoralis. 
In den Golf der Saphena münden ein: die subcutanen Abdominalienen, die Venae circumflexae und die Venac pudendae superficiales.

Dic Arteria abdominalis subcutanea (epig. sup.) entsteht aus der Arteria femoralis und richtet sich gegen den Nabel, den mittleren Theil des Poupart'schen Bandes kreuzend.

Die Arteria iliaca circumflexa superficialis entsteht aus der rorigen oder aus der Arteria femoralis und richtet sich nach aussen gegen die Spina iliaca anterior superior.

Die Arteria pudenda superficialis superior entsteht gewölnnlich aus der Arteria abdominalis subcutanea, richtet sich nach innen, kireuzt den Leistenkanal oder den Samenstrang und vertheilt sich am Schambeine.

Die Arteria pudenda superficialis inferior entsteht aus der Arteria femoralis, zieht unter dem Bogen der Saphena, wird oberflächlich und rertheilt sich in den Lymphdrïsen, in dem Hodensack oder bei Frauen in den grossen Lefzen.

Die lymphatischen Inguinaldrüseu werden nach ihrer Lage in Inguinalund Schenkeldrïsen eingetheilt (Fig. 74).

A. Die Inguinaldrüisen liegen unmittelbar unter dem Poupart'schen Bande und sind in zwei Gruppen rereinigt.

1. Die äussere Inguinalgruppe liegt unter der äusseren Hälfte des Poupartschen Bandes rings $\mathrm{nm}$ die Arteria circumflexa iliaca superficialis. Sie wird aus mehreren Drüsen gebildet, welche längs des Poupart'schen Bandes angeordnet sind; in diese münden die Lymphgefässe, die ron der Abdominalwand, rom Gesäss, rom Analrande und Anus herunterziehen.

2. Die innere oder genitale lnguinalgruppe wird ron mehreren runden Inrïsen gebiIdet, welche unter dem inneren Drittel des Poupart'schen Bandes und unter der Spina pubica liegen.

Nicht selten findet man eine dieser Drüsen mehr nach oben gelagert, oberhalb des Poupart'schen Bandes ror dem Leistencanale oder dem Schambeine, die Glandula lymphatica prac-pubica.

In diese Drïsengruppe münden die Lymphgefässe von der Haut des Penis, rom Praeputium, ron der Glans, rom Scrotum, ron der Schamgegend und ron Anus ein. So oft die innere Inguinalgruppe entzündet ist, muss man die Eintrittsstelle des specifischen Giftes an diesen Stellen nachsuchen: auch darf man nicht rergessen, dass ein auf der rechten Seite des Penis gelegener Schanker, regen der líreuzung der Lymphgefässe eine linksseitige Lymphadenitis inguinalis erzeugen kann.

B. Die crualen Lymphdrisen bilden eine Gruppe, welche an der Spitze des Scarpa`schen Dreieckes drei bis rier fingerbreit unter dem Poupart'schen Bande sich befinden (Fig. 74).

Diese wird aus mehreren in verticaler Richtung angeordneten Drüsen gebildet. Oft findet man an jeder Seite der Tena saphena je eine Drüse.

Die Cruralgruppe erhält die obertlächlichen Lymphgefässe der untern Extremität; sie wird also bei ciner Lymphangoitis des Unterschenkels, rerursacht z. B. durch eine Excoriation einer Zehe angeschwollen.

Diese Drüsengruppen sind untereinander durch ein sebr complicirtes lymphatisches Netz verbunden.

Die Nerrenfiden gehören folgenden Nerren an: genito-cruralis, femuro-cutaneus und musculo-cutaneus externus, letzterer vertheilt sich in der Haut des Scarpa schen Dreieckes. Die feste und an elastischen Fasern sehr reiche Aponeurose ist ron gelblicher Farbe. An dem innern Rande des Sartorius theilt sie sich in zwei Blättchen: 
1. Das tiefliegende Blättchen kleidet den Grund der Arterienriune aus, es bedeckt die vordere Fläche des Psoas als Fascie des Psoas, mit welcher sie in den Boden der Mulde herabsteigt und sich auf die vordere Fläche des Pectineus verlängert, als Fascie des Pectineus, mit welcher sie aufsteigt.

Fig. 76.

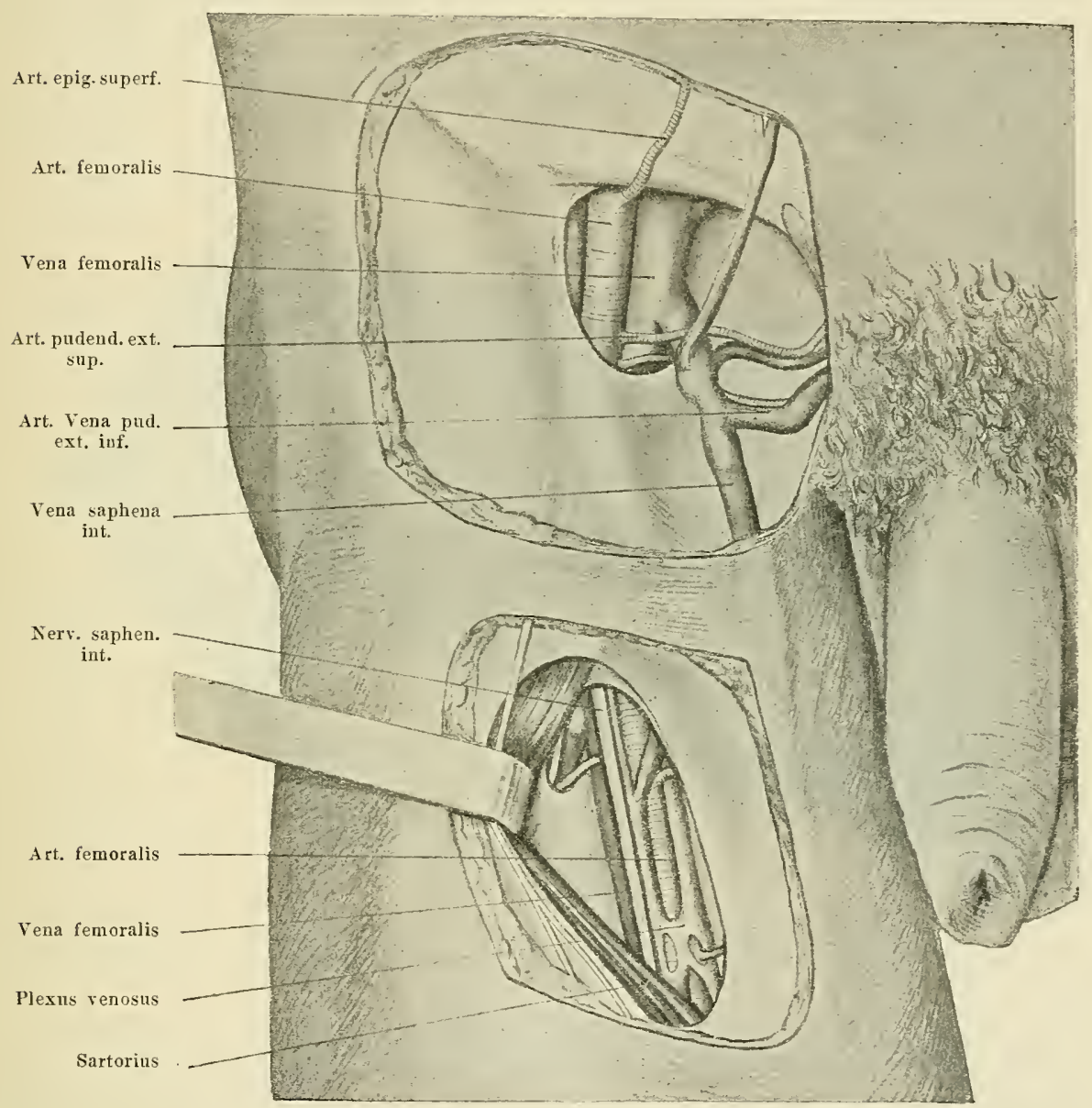

Die Beziehungen der Arteria femoralis unter dem Poupart'schen Bande und an der Spitze des Scarpa'schen Dreiecks. In diesem Niveau sieht man die Arterie ron einem Plexus venosus begleitet.

Nach oben inserirt sich die aponemrotische Decke, auf welcher die Oberschenkelgefässe liegen, am ilio-femoralen Bande und am Ligamentum Cooperi; im Grunde der Furche adhärirt sie an der Erhabenheit des Pectineus und an der Gelenkiapsel, auf diese Weise den Psoas rom Pectineus scheidend.

2. Das oberflächliche Blättchen zieht direct ror den Oberschenlielgefässen und 
rereingt sich imnen mit der Fascie des Pectinens; anf diese Vreise wirl cin prismatiseher und dreiwinkliger zellig-fibröser lianal gebildet, die Seheide der Obersehenlelgefïsse. Der obere Theil der Gefässseheide ist leicht dilatirt in der form cines dreieckigen T'richters. Nach oben inserirt sich dieser T'riehter an einem fibrösen Rahmen, weleher vorne vom l'onpart'schen Bande, hinten und aussen rom Ligamentum ilio-pectinenm, hinten nnd innen rom Ligamentum Cooperi grebildet wird.

Das Liganentum Gimbernati ist frei in inneren Winkel des Cruralrahmens.

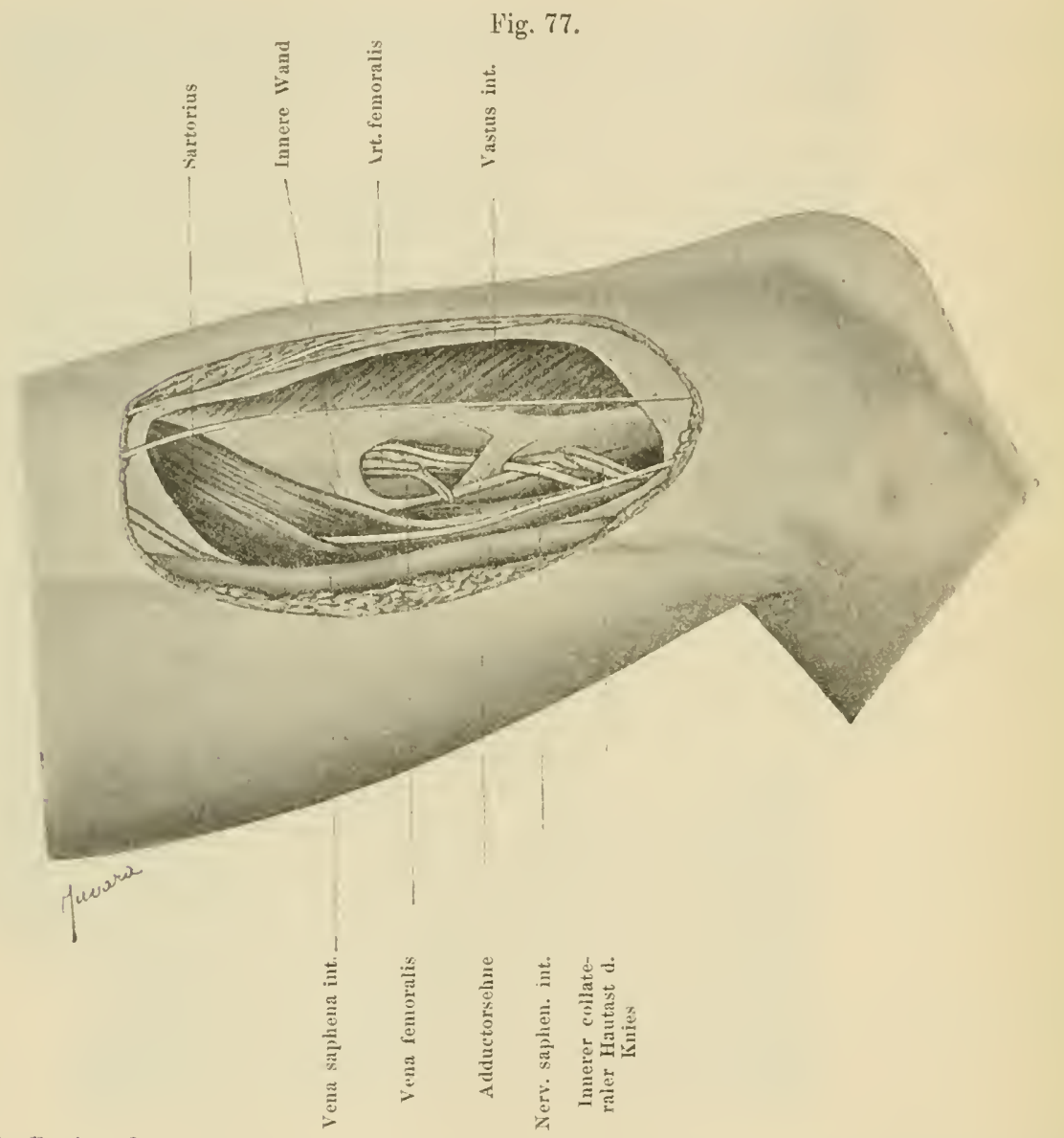

Die Region des Ilunter'scben Kanales. Der ausgehöhlte Hautmuskel legt die innere Waur des Kanales frei. In dieser Wand wurde eine kleine Lücke ausgeschnitten, durch welche. man dic Arteria und Vena femoralis und den Nervus saphenus internus sieht.

Die rordere Wand des Gefässtrichters wird in einer Schichte, wie wir geschen haben, rom rordern Blättchen der Fascie gebildet, in einer zweiten Schichte ron der Aponemrose des Transversus, welehe unter dem Poupart'sehen Bande entlang zieht und an welchem sie adhärirt und weiter unten geht sie in die oberflächliche Fascie über.

Diese vordere Iland wird ron einer grossen Anzahl ron Gefässlöchern durchsetzt, besonders an der innern Seite, wo sie sehr schwer zu präpariren ist; ron Löcliern durchbohrt bildet sic die Fiseia eribrosa, durch welche die Lymphgefässe von der Oberlläche 
in die Tiefe dringen. Gegen den untern Theil der rordern Wand findet man ein grösseres Loch für den Durchgang des Bogens der Saphena interna.

Dieses Loch wird nach unten von einem festen sichelförmigen Rand begrenzt, das Ligamentum falciforme oder Ligamentum Alan Burns.

Die Gefässscheide enthält im Innenraume: aussen die Arteria femoralis, die arterielle Partie, in der Mitte die Vene, die venöse Partie, innen die Lymphgefässe, die lymphatische Partie oder den Schenkelkanal.

Ein vorderes hinteres zellig-fibröses Blättchen theilt diese drei Räume.

Nach oben ist die Gefässscheide durch ein sehr dünnes zellig-fibröses Blättchen abgeschlossen, das Cruralblättchen, welches wie ein Vorhang im Schenleelrahmen ausgebreitet ist.

Der Schenkelkanal (Cruralcanal) oder die innere Partie der Gefässscheide hat

Fig. 78 .

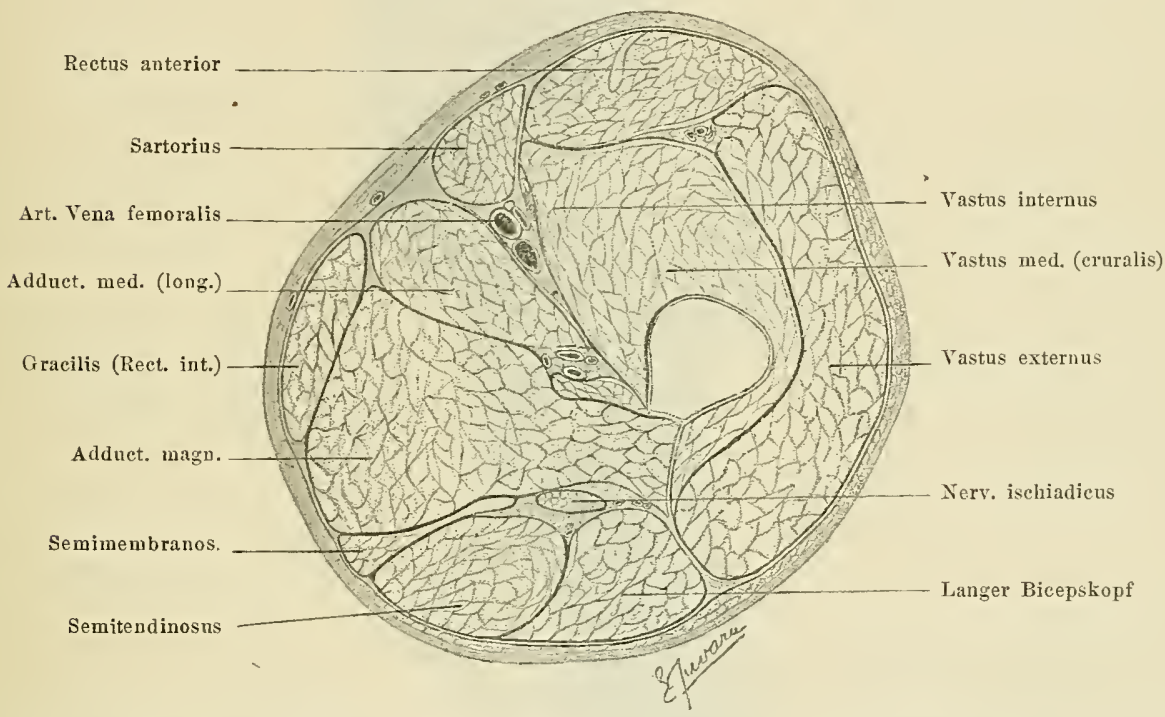

Ein Querschnitt im mittleren Drittel des Oberschenkels. Die Gefässscheide wird rom Sartorius bedeckt.

die Form einer prismatischen mit der Spitze nach unten gerichteten Höhle. Seine hintere Wand wird ron dem mit der Fascie bekleideten Pectineus gebildet, seine äussere Wand von einem zellig fibrösen Blättchen, welches ihn von der Vena femoralis scheidet und die vordere Wand von der durchlochten Fascie. Diese vordere Wand ist, wie wir erwähnt haben, sehr schwer zu präpariren und war den alten dnatomen unbekannt, welche den Schenkelkanal unter dem Tamen Foramen orale beschrieben haben (Fig. 74).

Der Nervus cruralis zieht unter dem Poupart'schen Bande durch dieselbe Oeffnung wie der M. psoas. Er liegt zuerst in der Scheide des Psoas nach aussen ron der Arteria femoralis, von welcher er durch die Fascie dieses Muskels geschieden ist.

Das Muskelpolster oder der Boden des Scarpa'schen Dreieckes wird aussen rom Psoas, innen rom Pectineus gebildet (Fig. 75).

Der Ilio-psoas inserirt sich mit einer festen Sehne, welche am innern und tiefen Rande des Fleischkörpers liegt, am kleinen Trochanter. Die Fleischbündel, welche am 
roldern Rande des Os ilimm entstehen, inseriren sich direct am Femur, an der ror dem 'I'rochantel' befindlichen (Oberlläche. Ein sehr breiter Schleimbeutel trennt die Sehne des l'soas ron der vordern lïiche der Gelenkiajsel. Dieser Schleimbeutel beginnt an der Erhebung des l'ectineus und endigt im Nivean des kleinon Trochanter; oft, besonllers bei Cireisen, communicirt der Schleimbeutel des Psoas dureh ein kreisförmiges Orificium mit der Gelenkhöhle und dureh dieses Thor kanı der Fiter eines kalten Abscesses ron der Scheide des Psoas das Gelenk inficiren.

Der Pectineus ist schief nach unten hinten und anssen gerichtet und rom Os ilium zum Femur ausgebreitet. Er hat die Form eines rechten Winkels und entsteht

Fig. 79.

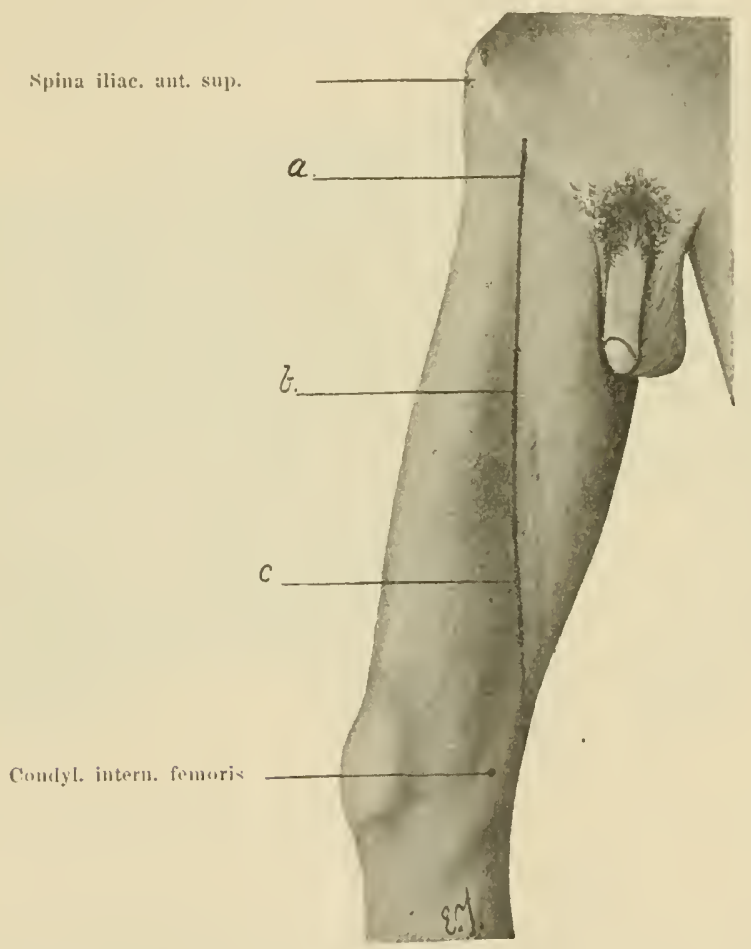

Dic ïussere Fläehe des rechten Oberschenkels. Die sehwarze Linie zeigt den Weg der Art. femoralis an, a die Incisionsstelle unter dem Poupart'sehen Bande, b die Ineisionsstelle an der Spitze des Scarpa'sehen Dreiecks, c die Ineisionsstelle im Niveau des Hunter'sehen Kanales.

mit Fleischfasem an der äussern Fläche der Spina pubica, am Ligamentum Cooperi und an der Crista pectinea. Die Muskelbündel, welche längs des äussern Randes dieker werden, gehen in ein fibröses Blatt über, welches an dem mittleren Aste, an der Crista pectinea, der Linea aspera des Femur sich inserirt. Er wird nach oben vom Psoas durch ein mit der Spitze mach unten geriehtetes Dreieck geschieden, welches von der Gelenkliapsel gebildet wird.

Nachdem wir diesen leichten Ueberblick ïber das Scarpa'sche Dreieck gewonnen 
haben, müssen wir im Detail einige wichtigere von den in diesem enthaltenen Gebilden beschreiben.

Arteria femoralis. Die Fortsetzung der Arteria iliaca externa, die Arteria femoralis, beginnt unter dem Poupart'schen Bande etwas innen von dessen Nitte und endigt an der innern Fläche des Femur handbreit oberhalb des Tuberculum condyloideum internum im Nivean des vierten Ringes des grossen Adductor.

Sie durchläuft vertical, von oben nach unten in einer Mnskelrinne gelagert, die Rinne der Arteria femoralis. Die äussere Wand dieser Furche wird von oben nach unten vom Ilio-psoas und Vastus internus, die innere und hintere Wand rom Pectineus, rom Adductor medius und Adductor magnus gebildet.

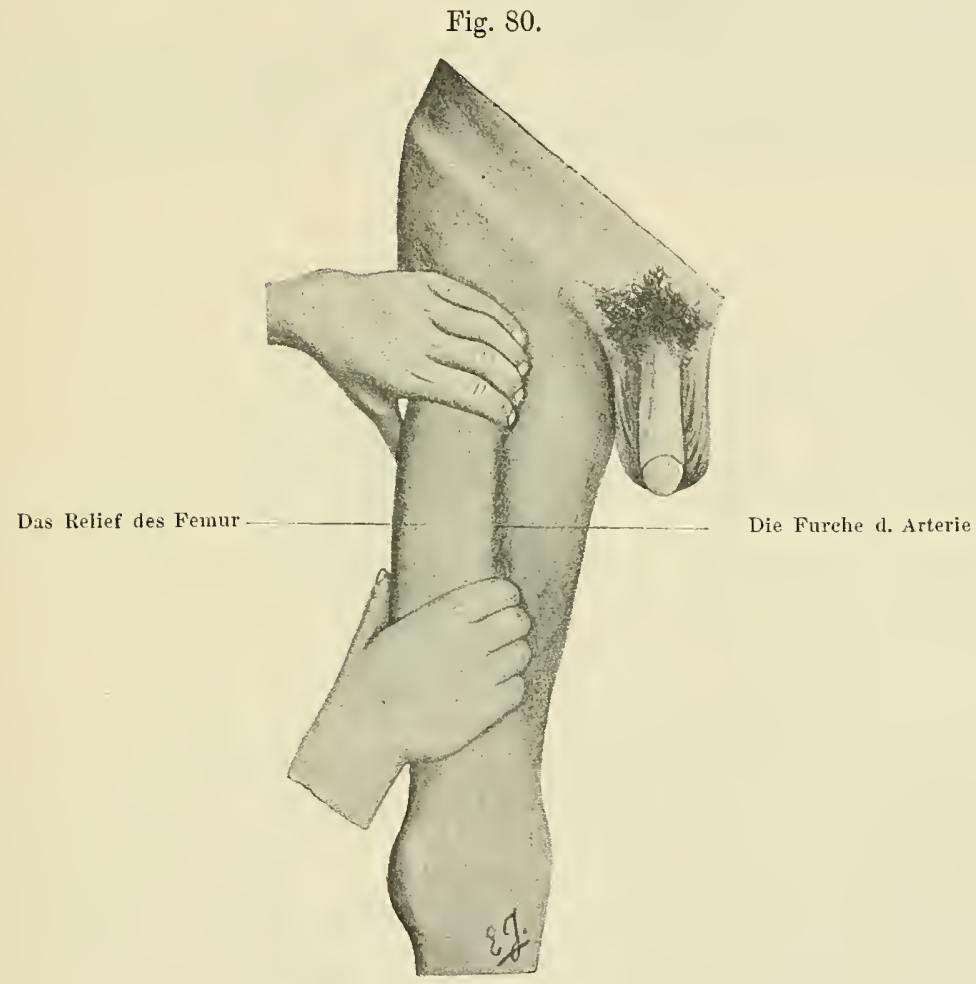

Die Art, die Furche der Arteria femoralis aufzusuchen.

Gegen den mittlern Theil des Oberschenkels unter dem Scarpa'schen Dreieck liegt der Sartorius in der Arterienrinne und bildet diese zu einem wirlilichen Kanale um (Fig. 76).

Von oben nach unten ist die Arteria femoralis mit der gleichnamigen Vene und mit dem Nervus saphenus internus in einer zellig-fibrösen, prismatischen und dreieckigen Scheide enthalten, die von den Fascien der Muskeln abstammt, die Scheide der Oberschenkelgefässe. - Den obern Theil der Gefässhülle haben wir im Scarpaschen Dreieck gesehen unter dem Namen: der Trichter der Oberschenkelgefässe. Der untere Theil, in einer speciellen Weise gebildet, ist unter dem Namen des Hunter- 
sclien Kanales beschricben (Fig. Ti). Die äussere und rordere Wand dieses lianales wird rom Sehnenblatte gehildet, welches die Initialselne des Vastus internus darste llt.

Die hintere II and wird ron der Selne des grossen Adduetor und ron dem Fortsatze, welchen der mittlere Alduetor dieser Sehne zuschickt, gebildet.

Die vordere innere Wand wirk ron einem selunigen dreieckigen Blatte gebildet, wolches linten am rordern liande der Endsehne des grossen Adductor entsteht und sich rome an der Initialschne des Vastus externus inserirt. Diese fibröse Wand stellt zwei Zwischenrïume dar: einen oberen kleineren, durch welchen aus dem Huntersehen Kanale eine kleine Arterie und der Nervus accessorius des Saphenus internus heraustreten, einen unteren grösseren, der unmiltelbar ror der Sehne des Adductor liegt, zum Durehtritte des Nerrus saphenus internus.

Die Arteria femoralis giebt zweifingerbreit unterhalb des Poupart'schen Bandes die Arteria femoralis profunda ab. Diese liegt zuerst hinten und etwas nach aussen ron der Arteria femoralis superficialis, richtet sich dann nach unten und aussen, dringt

Fig. 81 .

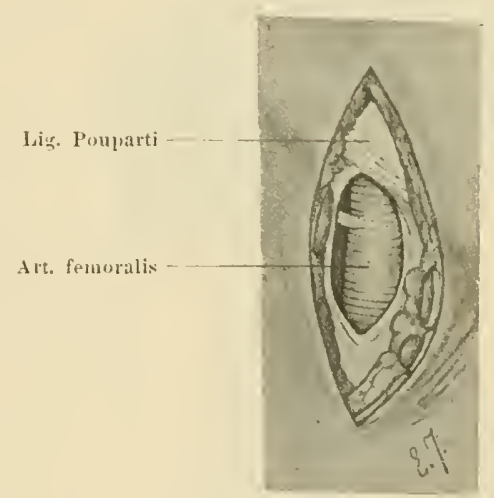

Das Auffinden der Arteria femoralis unter dem Poupart'sehen Bande an der Basis des Searpa'schen Dreiecks.

in len Zwischenraum, der zwischen Pectineus und dem zweiten Adductor sich befindet, durchläuft diesen Raum, durchzieht den grossen Adductor und verliert sich in dem kurzen Kopfe des Biceps.

Von dieser Arterie entstehen zahlreiche deste, welche für den Quadriceps femoris bestimmt sind, die beiden vordern und hintern Arteriac circumflexae und die Arteriae perforantes. Diese, drei bis vier an Zahl, durchziehen den grossen Adductor, anastomosiren in einem Bogen längs der Linea aspera und verbreiten sich in den lintern Muskielı.

In Nireau des letzten Ringes des grossen $\Lambda$ dductor giebt die Arteria femoralis die Arteria anastomotica ab. Diese dringt in die Ticfe vor der Sehne des Adductor; mit einem tiefen Aste anastomosirt sie mit der Arteria articularis superior interna, mit einem oberflächliclien Aste übergeht sie in die Haut und folgt dem Nervus saphenus internus.

Die Vena femoralis liegt zuerst imnen und etwas vor der Arteria, kommt danmweiter unten nach innon und etwas hinten zu liegen und im IIunter'sehen Kanale liegt 
sie hinten und etwas nach aussen. Die Vena femoralis beschreibt also rings um die Arterie eine halbe Schraubenwindung.

Der Nervus saphenus interuus dringt in die Gefässhülle an der Spitze des Scarpa'schen Dreieckes. Er liegt zuerst aussen dann innen von der Arterie und lagert sich im Hunter'schen Kanale an der vordern und innern Seite der Arterie.

Der Nervus accessorius des Saphenus internus ist sehr dünn und in der Gefässhülle enthalten; er liegt vor der Arteria femoralis.

Technik z. A. des Gefässpackets. In der Basis des Scarpa'schen Dreieckes. Man bringt den Oberschenkel in leichte Abductionsstellung und sucht die Arterienrinne und das Poupart'sche Band auf, dessen mittleren Theil man fixirt. Man macht einen verticalen Schnitt, welcher am Bande etwas nach innen von der Mitte beginnt und drei bis vier fingerbreit darunter reicht (Fig. 79-81).

Mit der Pincette und Hohlsonde wird nach oben der Rand des Poupart'schen Bandes freigelegt, nach unten die Lymphdrüsen, die im Wege liegen,

Fig. 82.

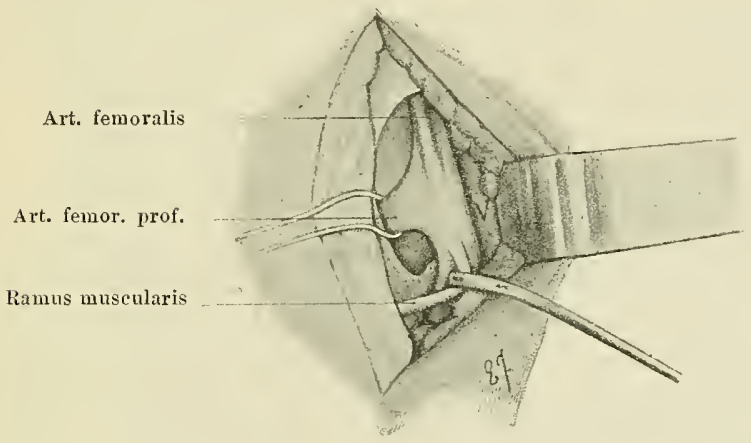

Das Aufsuchen der Arteria femoralis profunda.

entfernt, darauf die Fascie auf die Sonde gehoben und durchschnitten und unmittelbar unter dieser findet man die Arterie. Wenn man diese freilegt und anf die Sonde hebt, so sieht man von ihr die Arteria femoralis profunda abgehen. Man sucht an der Innenseite der Arterie, von dieser durch ein dünnes zellig-fibröses Blättchen getrennt, die Vena femoralis auf (Fig. 82).

Man bemerkt, dass diese beiden Gefässe auf einer zellig-fibrösen Decke liegen, welche aussen auf dem Körper des Psoas, innen auf dem Körper des Pectineus gelagert ist.

Die Arteria femoralis. An der Spitze des Scarpa'schen Dreieckes. Man - macht längs der Arterialrinne, handbreit unter dem Poupart'schen Bande beginnend, einen verticalen, vier fingerbreit langen Schnitt. Unter der Fascie gelangt man an den Sartorius; man legt diesen mit Pincette und Hohlsonde frei und zieht ihn mit einem stumpfen Haken nach aussen oder innen ab, damn sieht man unter einem feinen zellig-fibrösen Blatte das Gefässpacket durchseheinen. Mit der Hohlsonde wird dieses Fascienblatt zerrissen, die Arterie freigelegt und gezeigt; sie wird zuerst sichtbar; hinter 
dieser findet man die Vene und an der äussem Seite den Nerrus saphenus internus (Fig. 85).

Vor der Arterie sucht man deu dünnen Nervenfaden, weleher den Accessorius des Saphenus daristellt.

Man studirt die Muskelrinne, in welcher die Arterie liegt und findet, dass diese aussen rom Tastus internus, imnen rom Adductor medius gebildet wirl.

Im Hunterschen Kanale. Nan legt den Oberschenkel in Adductionsstellung und beugt den Untersehenkel gegen denselben. IIan tastet mit den zu einem Haken gekrïmmten Fingern das untere Drittel der innern Fläche des Obersehenkels ab und fühlt als gespannten Strang die Sehne

Fig. 83.

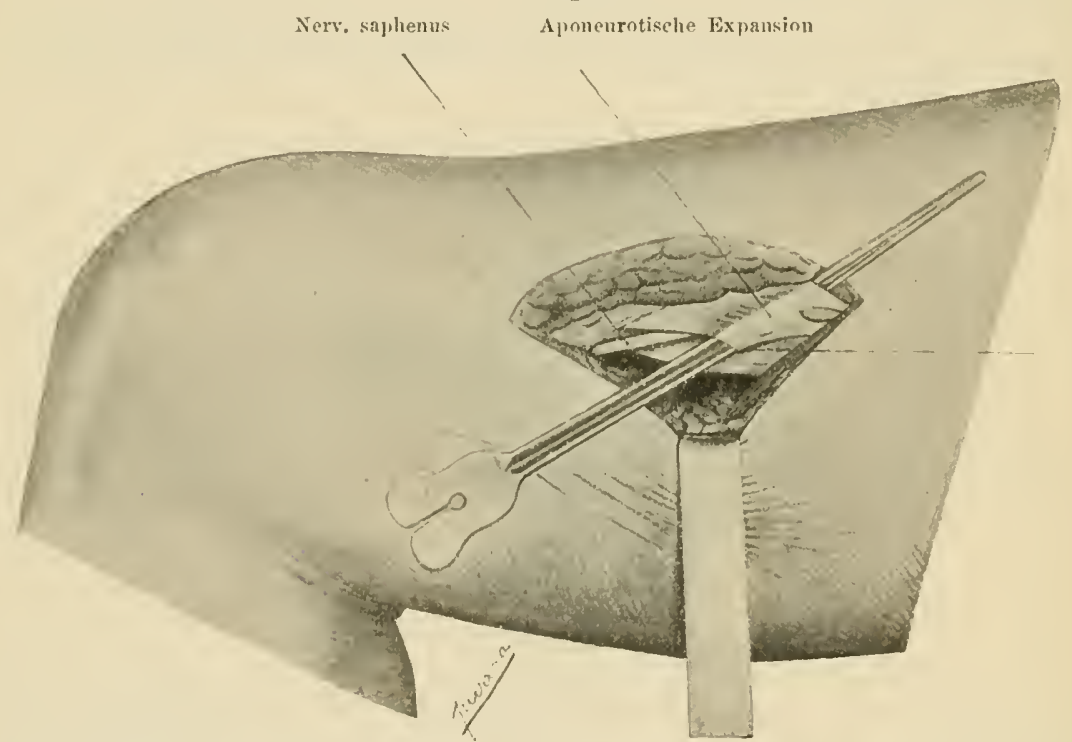

Sehne des A dlutuct. ma!n!.

Das Aufsuchen der Arteria femoralis im Hunter'sehen Kanale. Die aponeurotisehe Expansion des Adduetor magnus - die innere Wand des Kanales - ist auf eine Sonde gehoben, um durchschnitten zu werden. Ein stumpfer Haken zieht den Sartorius nach hinten.

des grossen Adductor - den Adductorstrang. Nan folgt diesem Strange bis zu seiner Insertion am Tuberculum des Condylus internus femoris.

Man macht längs der Arterialrime, in welche man die Finger eindrückt, eine lange Incision, welche handbreit bis oberhalb des Höckers des Condylus internus reicht. Unter der Aponeurose gelangt man an den vordern Rand des Sartorius, dessen Fasern parallel mit den Schnitträndern laufen.

Oft passirt es, dass man die Fascie auf dem Vastus internus durchschneidet, dessen Mluskelfasern schief vor den Schnitträndern gerichtet sind; dann wird die Fascie fingerbreit mehr nach innen geschnitten und man gelangt sicher an den Sartorius. 
Mit der Hohlsonde und Pincette wird die innere Fläche des Sartorius freigelegt und mit einem stumpfen Haken nach innen gezogen. Man untersucht den Grund des Schnittes und sieht die innere Wand des Hunter'schen Kanales, den Sehnenstrang der Adductoren und vor diesem eine Oeffnung, durch welche der Nervus saphenus internus heraustritt. Durch diese Oeffnung wird eine Hohlsonde eingeführt, dessen Spitze man zweifingerbreit höher herauszieht. Nachdem man sich überzengt hat, dass man mit der Sonde nichts anderes als die innere Wand des Hunter'schen Kanales gehoben hat, durchschneidet man diese; auf diese Weise eröffnet man den fibrösen Kanal. Die Arterie wird freigelegt und aufgehoben, an deren innern

Fig. 84.

Adductorsehne Nerv. saph. Art. fem. Sartorius

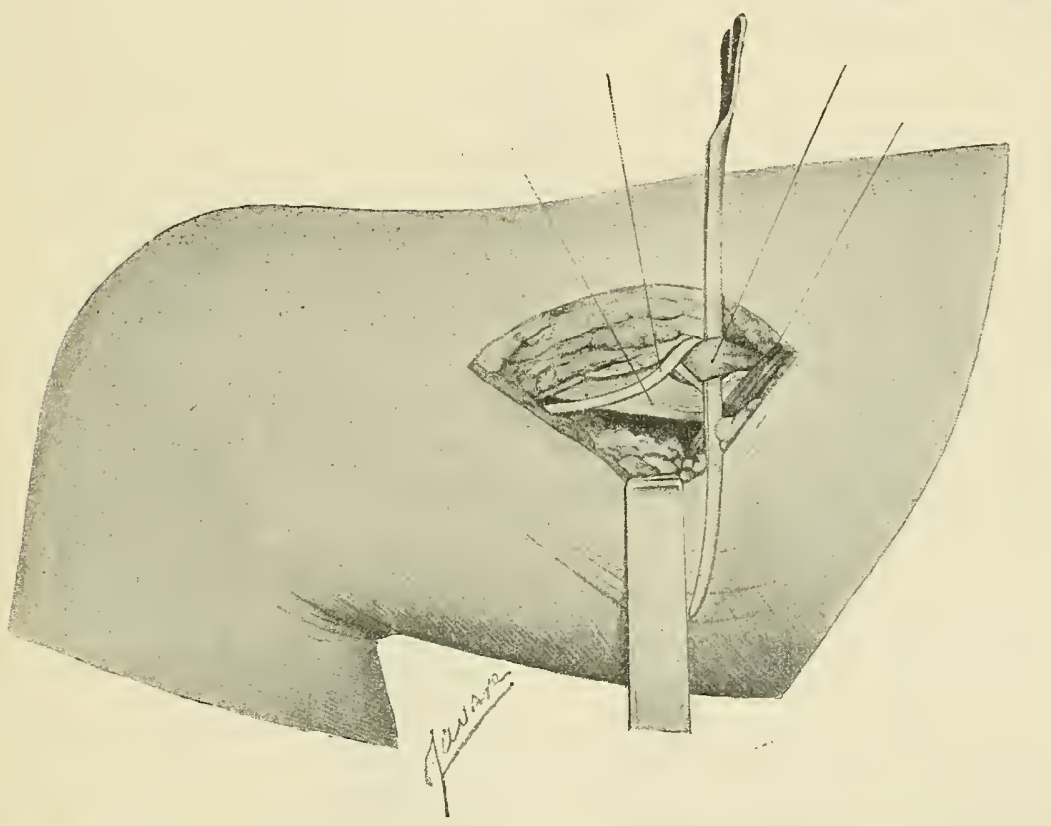

Das Aufsuchen der Arteria femoralis im Hunter'schen Kanale. Die isolirte Arterie ist auf eine Sonde gehoben.

Seite findet man immer eine kleine Vene; tiefer gegen den Grund der Furche, an der Aussenseite der Arterie und etwas nach hinten findet man die Vene (Fig. 83-84).

Den Nervus saphenus internus findet man im vordern Winkel des Hunter'schen Kanales.

Arteria anastomotica magna. Man bringt die Extremität in dieselbe Lage wie für die Ligatur der Femoralis. Man macht längs des Stranges des Adductor einen Schnitt bis zum Nivean des Tuberculum condyloideum, durchschneidet die Fascie und folgt mit der Sonde der Sehne des Adductor. Man löst diesen und den fibrösen Fächer, Fasern des Vastns internus, 
weleher ihn mit dem Femur verbindet. los und findet in der Tiefe nahe am Kunochen auf einer fibrïsen Fläehe gelagert den tiefen Ast der Arteria anastomatica.

Der Nervus crumalis entsteht durch Vereinigung der zweiten, dritten und vierten Fig. 85.

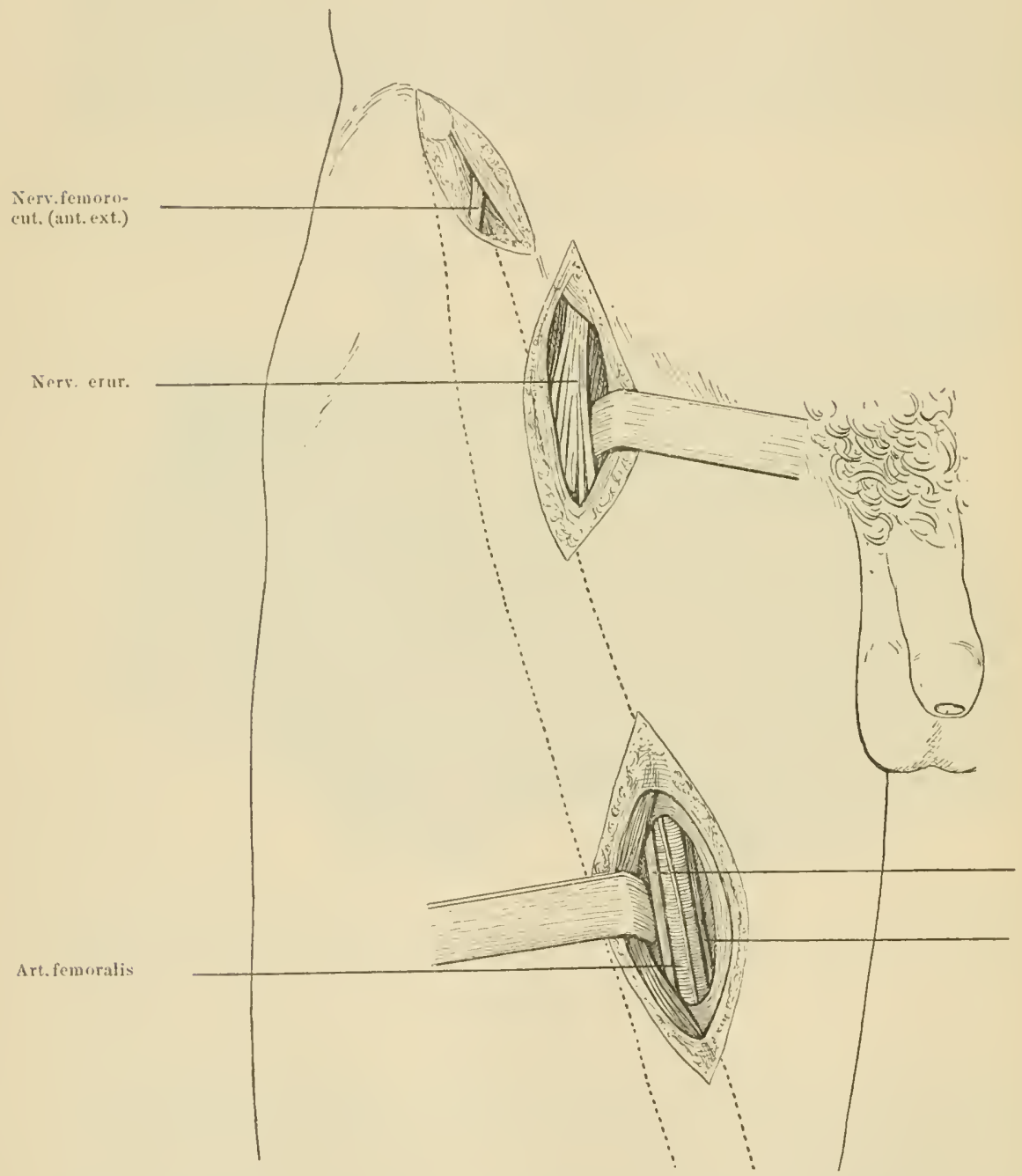

Nerv. saph.

Die vordere Fläche des rechten Oberschenkels. Das Auffinden des Nervus femoro-cutaneus, des Nervus cruralis und an der Spitze des Searpa'schen Dreiecks des femoralen Gefäss- und Nervenpacketes. - Ein stumpfer Haken zieht den Sartorius nach aussen, dessen Verlauf durch die punctirte Linie dargestellt ist.

Wurzel des Plexus lumbalis, steigt in die Fossa iliaca interna herab, zuerst im Interstitium, welches den Psoas rom lliacus scheidet, verborgen zieht or dann unter dem Pou- 
part'schen Bande durch dieselbe Oeffnnng wie der Ilio-psoas. Am Oberschenkel liegt der Stamm des Cruralis am Körper des Psoas, von der Arterie, welche mehr nach innen und anf einer oberflächlichen Lage sich befindet, durch die Fascie dieses Muskels getrennt.

Etwas unter dem Poupart'schen Bande theilt sich der Nervus cruralis in ein wahres Büschel ron Endzweigen:

1. Der Nerrus musculo-cutaneus externus entsteht im Niveau des Poupart'schen Bandes, verläuft zuerst unter der tiefen Fläche des Sartorius, giebt für diesen Muskel zahlreiche Fäden ab und zwei oder drei Rami perforantes, welche den Sartorius und die Fascie durchdringen und sich in der Haut des Oberschenkels vorne und innen bis oberhalb des Knies vertheilen.

Der Nervus musculo-cutaneus liegt etwas tiefer und entsteht zuweilen oberhalb des Poupart'schen Bandes; ein Muskelast dringt in den äussern Rand des Pectinens, hinter der Arterie verlaufend; ein Hautast, der Accessorius des Saphenus internus, dringt in die Gefässscheide, verläuft an der vordern Fläche der Arterie, anastomosirt mit dem Saphenus internus, tritt aus dem Hunter'schen Kanale und verzweigt sich in der Haut an der innern Fläche des Knies.

II. Der Nervfür den Quadriceps theilt sich in vier Aeste:

a) Der Nerr für den Rectus anterior dringt in den Körper dieses Muskels durch seine hintere Fläche und seinen innern Rand.

b) Der Nerv für den Vastus externus giebt Zweige für den obern Theil dieses Muskels, kreuzt die vordere Fläche des Musculus cruralis und dringt in den mittlern Theil des vordern Randes des Vastus externus.

c) Der Nerv für den Vastus internus giebt Zweige für den obern Theil dieses Huskels, verläuft an seiner innern Fläche an der Aussenseite der Gefässscheide und dringt in den Fleischkörper durch dessen untern Theil.

Von diesem Nerv entsteht oft der Nervus saphenus internus, welcher zweifingerbreit unter dem Poupart'schen Bande in die Gefässscheide eindringt, in der er zuerst aussen, dann vor der Arterie bis zum untern Theile des Hunter'schen Kanales gelagert ist.

d) Der Nerv für den II culus cruralis giebt zahlreiche Aeste für die obere Partie dieses Muskels und einen Faden, welcher durch den Muskel dringt; er läuft längs des Femur nach abwärts und endigt im Tensor der Synovia.

Techuik z. A. des Nervus crumalis. Man sucht das Poupart'sche Band auf und macht etwas nach aussen von dessen Mitte beginnend, über die äussere Wand der Arterialrinne eine verticale, 3-4 fingerbreit lange Incision, durchschneidet die Fascie am innern Rande des Sartorius und gelangt an den Körper des Psoas; man legt stumpfe Haken ein und sieht dann am Grunde des Psoas den Stamm des Nervus cruralis in zahlreiche Aeste getheilt. Man sucht unter der Arteria femoralis den Nervus musculo-cutaneus internus auf und in die Gefässscheide dringend, den Nervus saphenus internus und seinen Accessorius; man findet die Muskeläste für den Quadriceps und sieht, dass sie ron zahlreichen kleinen Arterien und Tenen, welche für diesen Muskel bestimmt sind, begleitet werden (Fig. 85).

Man folgt dem Nerv für den Vastus externus und dem für den Vastus internus und bemerkt, dass der Letztere rom Saphenus internus durch eine dünne Wand der Gefässscheide geschieden ist.

Vena saphena interna. Sehr oft sieht man den Verlauf der Vene in Form bläulicher Spuren, welche durch die Färbung der Gerrebe, durch 
cxtratasirtes Blut bedingt, entstehen. Man macht fingerbeit, unterhalb des Poupart'sehen Bandes beginmend und auf der inneren Wand der Gefässfurche einen langen verticalen Sehnitt und man findet in Grunde desselben die Tena saphena interna. Man folgt derselben bis zu deren Einmündung in die I cna femoralis obcrhalb des Ligamentum falciforme, welehes mit

lig. 86.

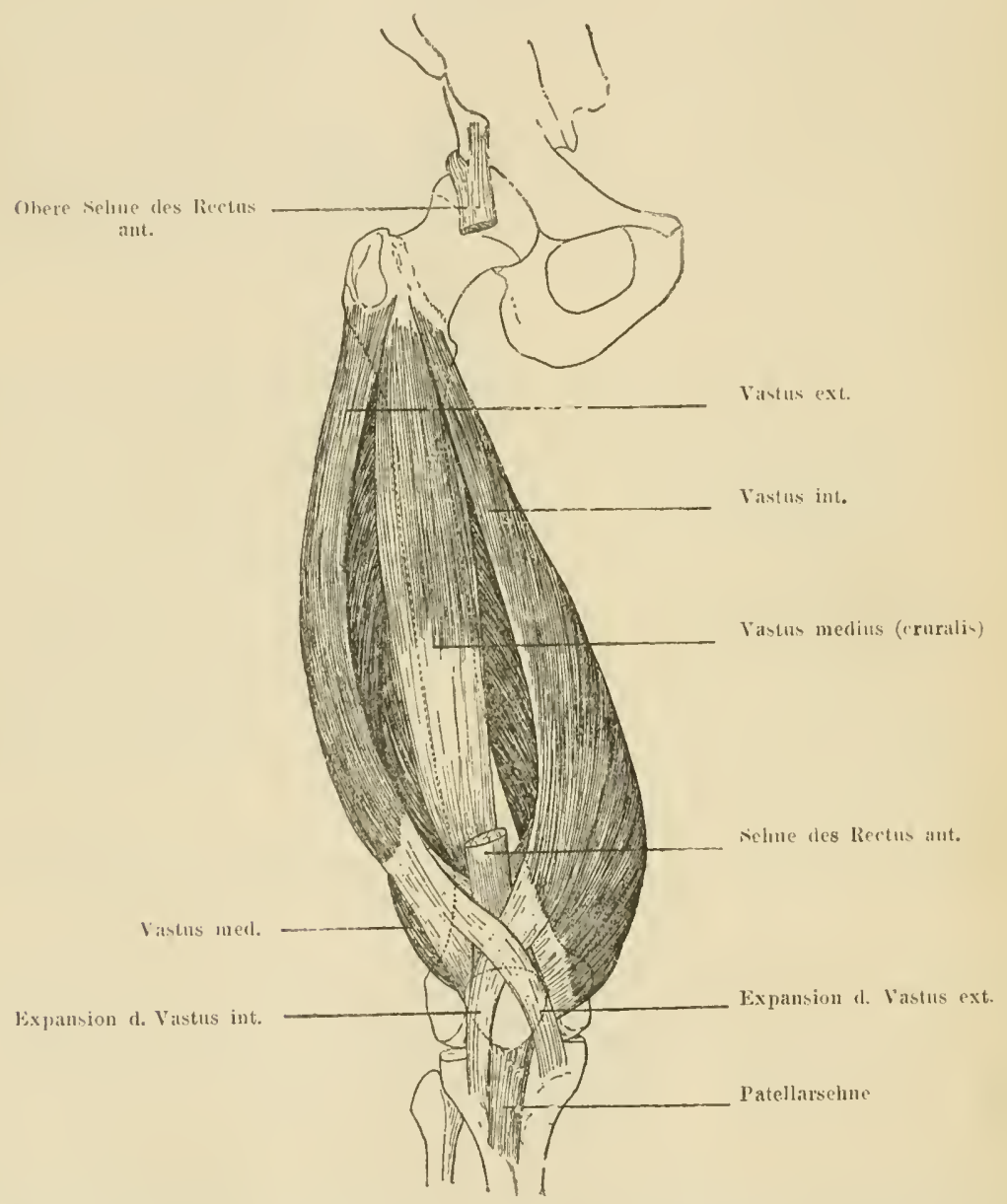

Der Musculus quadriceps. Der Rectus anterior ist durchschnitten und abgetragen, um den Vastus medius (cruralis) zu sehen, welcher unter ihm liegt.

der Hohlsonde freigelegt wird. In diesem Niveau sieht man die Vene gewöhnlich von zwei $2-3 \mathrm{~cm}$ langen Jymphdrüsen begleitet.

Ilan sucht unter dem Bogen der Vena saphena die Arteria pudenda externa inferior.

Wenn die Vene nicht im Grunde des Schnittes erscheint, sucht man dieselbe, indem man jeden der Schnittränder präparirt. 
Del Nervus femoro-glutaeus (femoro-cutaneus), ein Collateralast des Plexus lumbalis, entsteht aus der ersten und zweiten Wurzel, durchdringt die Lumbalgrube, zieht hinter der Niere, steigt unter der Fascia iliaca in die Fossa iliaca interna herab und verlässt das Becken etwas nach innen von der Spina iliaca anterior superior durch ein Orificium im Poupart'schen Bande; drei- oder vierfingerbreit darunter durchbohrt er die Cruralfascie und theilt sich in Glutaealäste, welche sich in der Haut des Gesässes vertheilen und in Femoraläste, welche für die Haut der äussern Fläche des Oberschenkels und des Knies bestimmt sind.

Technik z. A. d. G. Man sucht die Spina iliaca anterior superior auf und macht längs des äussern Drittels des Poupartschen Bandes einen Schnitt, welcher an der Crista iliaca endigt.

Man schneidet längs des Poupartschen Bandes die Fascie Schichte für Schichte durch und gelangt an den Nervenstamm, welchen man auf die Hohlsonde hebt (Fig. 85).

Der Quadriceps femoris. Der Schaft des Femur ist in einen muskulösen Cylinder eingeschlossen, welcher aus vier Partien besteht: Rectus anterior, Vastus internus, Vastus externus und Cruralis. Diese vier Muskeln sind rings um den Femur in zwei Schichten getheilt.

Die tiefliegende Schichte wird rom Cruralis gebildet, die oberflächliche Schichte von aussen nach innen: vom Vastus externus, Rectus anterior und Vastus internus. Diese vier Muskeln inseriren sich nach unten an der Kniescheibe und mit dem Ligamentum patellare an der Tuberositas tibiae (Fig. 86).

Der Rectus anterior zieht vom Os ilinm zur Basis der Patella und entsteht am Os ilinm mit einer Sehne, welche "die Directe" genannt wird, an der Spina iliaca anterior" superior unmittelbar oberhalb des Ligamentum anterius des Coxo-femoralgelenkes und mit einer zweiten Sehne, welche "die Reflexa" genannt wird, die in Form eines Bandes an der hintern obern Seite des Pfannenrandes verbreitert ist, wo sie sich auch mit den Fasern der Kapsel verwebt. Diese beiden Sehnen vereinigen sich in einem rechten Winkel fingerbreit unter der Spina iliaca anterior inferior. Die gemeinsame Initialsehne, entstanden durch die Verschmelzung dieser beiden Primärsehnen, breitet sich fächerförmig aus. An ihrer hintern Fläche, zum Theile auch an der vordern, entstehen Muskelbündel, welche auf die vordere Fläche des sehnigen Endblattes übergehen, welches sie drei- bis vierfingerbreit oberhalb der Kniescheibe bedecken.

Diese Endsehne verengt sich von oben nach unten und etwas oberhalb der Patella verbreitet sie sich wieder und inserirt sich am vordern Rand der Basis der Patella und am obern Drittel ihrer vordern Fläche.

Technik z. A. d. G. Man macht eine verticale Incision von der Spina iliaca anterior superior im obern Drittel des Oberschenkels und gelangt in den Winkel, welcher innen rom Sartorius, aussen rom Tensor fasciae begrenzt wird.

Man legt nun stumpfe Haken ein und findet im Grunde dieses Dreieckes in der Terdopplung einer festen Fascie den Rectus anterior. Man sucht unter dem Psoas die "directe Selone", welche sich an der Spina iliaca anterior inferior inserirt, auf; die "reflexa" genannte Sehne legt man frei, wenn man die Glutaeenmasse, unter welche die Sehne eindringt, transversal durchschneidet. Man studire aufmerksam die eigenthümliche Art der Insertion dieser beiden Sehnen und bemerke, dass die "directe" Sehne bei Beugung des Oberschenkels zur "reflexa" wird. 
Inel Vastus exteruus, äuserer Femoro-patellanuskel, hat die form eines handbreit langen Muskels und ist ron der Dicke eines Dammens (Fig. 86).

È entsteht mit einem sehnigen, schönen und festen Blatte, der lnitialsehne: a) am rordern Rande des grossen Trochanter, unmittelbar an der Innenseite des Glutaeus minimus, b) an dem untern Rande der äussern Fläche des grossen Trochanter und c) am Schafte des Schenkelbeines, an dew obern Theile des äussern Pandes des Kammes des Glutaeus maximus.

Die Ursurungsehne rerbreitet sich nach Art eines Palmenblattes; an ihrer tiefen Fläche entstehen dicke Fleischbündel, welche schief nach unten und rorne ziehen und auf die äussere Fläche der Endsehne übergehen, welche sie auch ungefähr zweifingerbreit oberhalb der Patella bedecken.

Die Endsehne theilt sich am äussern Rande der Sehne des Rectus anterior in zwei Sclichiten:

a) Die sehr feste tiefliegende Sehichte inserirt sich an der Basis der liniescheibe unnittelbar hinter der Sehne des Rectus anterior, mit weleher sie sich auch am änssern Rande der Patella rerwebt.

b) Die oberflächliche Schichte, die Ausbreitung des Tastus externas, zieht ror der Selme des Rectus anterior, gleitet an der rordern Fläche und innerm Rande der Patella und inserirt sich an der innern Fläche der Tibia oberhalb der Insertion der Muskeln des Pes anserinus.

Techuik z. A. d. G. Man führt über die äussere Fläche des Oberschenkels einen langen Schnitt ron dem grossen Trochanter bis zur Patella, durehsehneidet die sehr feste Fascic und findet den Vastus externus, welcher ron der Fascic durch ein weiches Bindegewebe gretrennt ist. Man sucht zwischen dem hintern Rande der Initialschne des Tastus und der Sehne des Glutaeus maximus einen ausqerlehnten Schleimbeutel auf, welcher sie scheidet.

Jer Vastus interums oder innerer Femoro-patellarmuskel ist fleischig, breit und dick wie der Vastus externus, entsteht mit einem fibrösen Blatte, der Ursprungsehne, an der Spirallinie und an dem innern Rande der Linea aspera bis gegen die Mitte des Schenkelbeines (Fig. S6).

Die Fleischbünde] entstehen direct oder an der tiefen Fläche der Initialsehne, richten sich dann schief nach unten und rorne, inden sie Bogen mit der Conearität nach aussen beschreiben. Die Endsehne liegt zuerst im Fleischkörper, ist ron Muskelfasern bis nahe an die Kniescheibe bedeckt und oberhalb derselben theilt sie sich in zwei Schichten.

a) Die tiefliegende Schicht inserirt sich am oberen und inneren Rande der Patella unmittelbar hinter der Sehne des Vastus externus, mit welcher sie sich am oberen Rande der Kniescheibe rermengt.

b) Die oberflächliche Schicht, die Ausbreitung des Vastus internus, zieht vor der Sehne des Riectus anterior, lireuzt und rermengt sich mit der Ausbreitung des Tastus externus, gleitet an der vorderen Fläche und dem äusserem Rande der Patella und inserirt sich an der Tibia am inmeren liande des Tubereulum Gerdy.

Die Initialschme des Vastus internus ist mit den lamellenförmigen Sehnen der Adductoren rerlilebt. Wir haben geseben, dass in der rom Vastus internus und den Adductoren begrenzten Furche die Arteria und die Tena femoralis verläuft und wie der Hunter"sche Canal gebildet wird.

Der Musculus repulis, der tiefe Femoro-patellarmusliel entsteht mit 
Fleischfasern an den zwei oberen Dritteln der vorderen und äusseren Fläche des Schenkelbeines und an der äusseren intermusculären Fascie bis nahe an den Condylus externus (Fig. 84).

Die Fleischfasern gehen auf die tiefliegende Fläche derEndsehne über, welche sich von oben nach unten verschmälert, und sich am oberen Rande der Patella hinter der Sehne des Vastus internus inserirt. Der innere Rand des Cruralis ist meistentheils mit dem vorderen Rande des Vastus internus vermengt.

Seine äussere Fläche ist mit der tiefliegenden Fläche des Vastus externus vermengt, denn die tiefe Schicht der Muskelfasern dieses Vastus übergeht in die Sehne des Cruralis. Mitunter werden diese von einem Bindeblättchen geschieden.

c) Oberhalb der Patella wird die "vereinigte Sehne" der Vasti von vorne nach hinten von fünf übereinander gelagerten Schichten gebildet:

a) die erste Schicht von den Ausbreitungen der Vasti;

b) die zweite von der Sehne des Rectus anterior;

c) die dritte von der Sehne des Vastus externus;

d) die vierte von der Sehne des Vastus internus;

e) die fünfte von der Sehne des Muscnlus cruralis.

Technik z. A. d. G. Mlan führt über die vordere Fläche des Oberschenkels längs des Reliefs des Femur einen langen verticalen Schnitt bis zur Patella und gelangt an den Körper des Rectus anterior. Isolirt und schneidet man diesen Muskel entzwei, so gelangt man an die Sehne des Musculus cruralis. Man scheidet den Cruralis vom Vastus internus und bemerkt, dass die innere Fläche des Femur von jeder Muskelinsertion frei ist. Löst man nun längs des Femur den Cruralis los und entfernt beide Theile, so sieht man unter demselben den Musculus tensor synoviae sehr oft in zwei Bündel getheilt sich am oberen Grunde der Synovia inseriren.

Die Adductorengruppe bildet eine dreieckige Muskelmasse und liegt in dem Winkel, welcher oben vom Os ilium, unten und aussen vom Schafte des Femur begrenzt wird. Sie sind vier an Zahl und liegen in drei Schichten angeordnet.

Die erste Schicht wird von oben nach unten vom Musculus pectineus und Adductor medius gebildet. Wir kennen bereits diese Schicht, auf welcher die Art. femoralis liegt. Diese beiden Muskeln werden durch ein dreieckiges, mit der Basis nach aussen gerichtetes Interstitium getrennt, durch welches die Arteria femoralis profunda in die Tiefe dringt.

Der Adductor medius (loug'us) entsteht an der rauhen Oberfläche, welche sich unter der Spina pubica befindet, mit einer festen Sehne, welche sich in ein dreieckiges Blatt verbreitet, an deren Flächen der dreieckige Fleischkörper des Muskels entsteht. Er inserirt sich mit einer lamellenförmigen Sehne am mittleren Theile des inneren Randes der Linea aspera und mit einer fibrösen Ausbreitung an der vorderen Fläche der Sehne des Adductor magnus (Fig. 87).

Die zweite Schicht wird rom Adductor minimus (brevis) gebildet. Dieser dreieckige Muskel entsteht mit einem fibrösen Blatte und mit Fleischfasern an der vorderen Fläche des Schambeins, an der rauhen Leiste, welche einige Millimeter nach aussen von dessen innerem Rande sich befindet.

Diese Sehne schickt einen dreieckigen, dicken und prismatischen Fleischlörper ab, welcher mit einem fibrösen, von zwei oder drei Oeffnungen durchbohrten Blatte unten am Femur am inneren Rande der Crista pectinea der Linea aspera sich inserirt. Diese Insertion beginnt im Niveau des kleinen Trochanter und endet handlireit darunter. 
Die rordere fläehe des . Ilduetor brevis ist in zwei Theile getheilt: eine obere, welche mit dem Pectineus und eine untere, die mit dem mittleren $A$ dductor in Beziehung stelit: die Leiste, welehe sie seheidet, bildet den Grund des Zwisehenraumes, weleher rom l'eetineus und ersten Adductor begrenzt wird.

Die dritte Sehieht wird vom Adductor magnus gebildet. Dieser Muskel ist zwischen dem Ramus isehio-pubicus und Os ischii einerseits und der ganzen Höhe

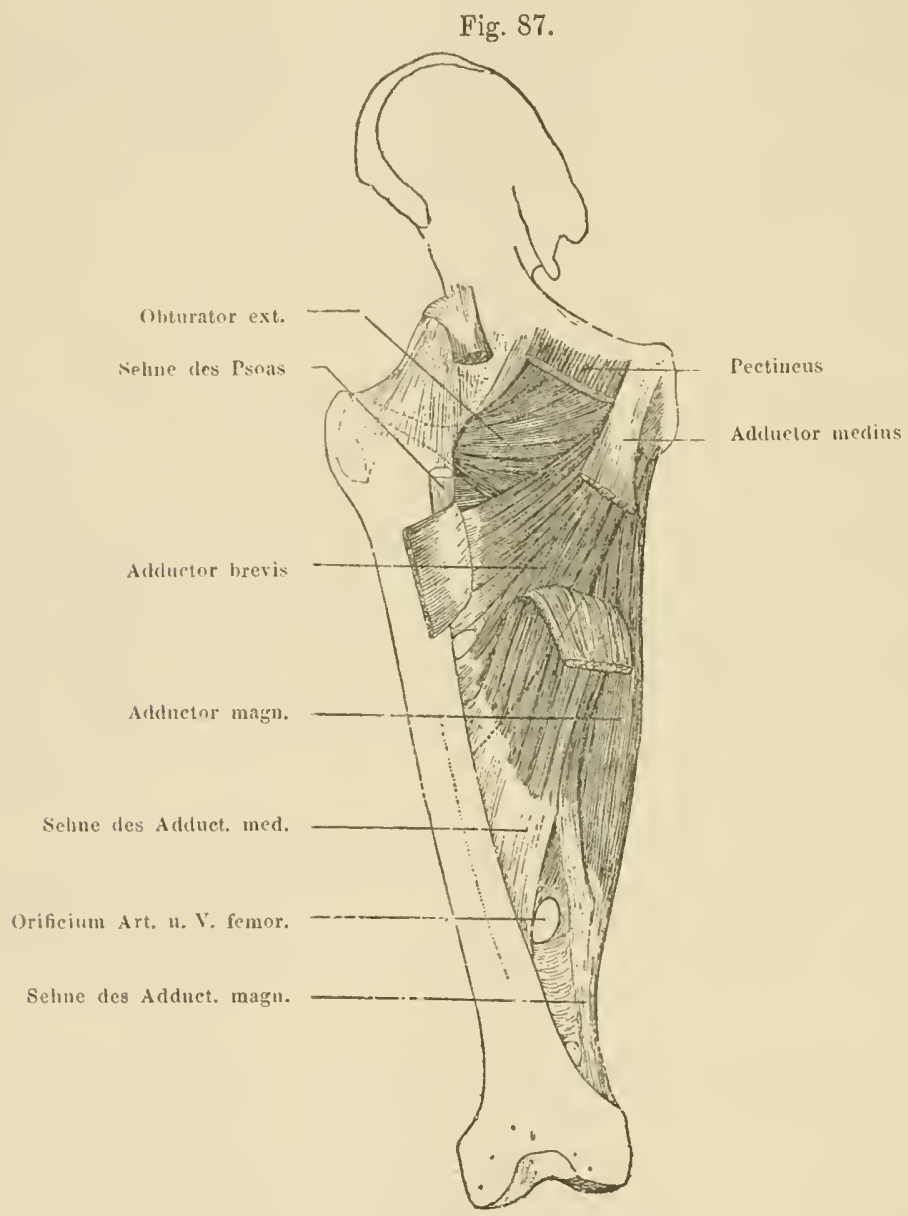

Museuli adductores. Die erste Schichte der Adduetoren wurde wegpräparirt und die Muskelenden abgetragen, um den kleinen Adductor freizulegen, den sie bedecken.

der Linea aspera des Femur andererseits gespannt; er hat die Form eines Dreieckes, welches den ganzen ilio-femoralen Winkelraum füilt (Fig. 87). Dieses breite musculöse Dreieck liann in zwei Partien zerlegt werden.

a) Die obere Partie entsteht mit Fleischfasern und fibrösen Bündeln von vorne naeh hinten an der äusseren Fläche des Ramus ischio-pubicus an der rauhen Leiste, welehe er längs seines unteren Randes darbietet. Die Fleischbündel lagern sich hintereinander und inlem sie Bogen mit nach oben und aussen gerichteter Concavität beschreiben, 
inseriren sie sich mit einer Reihe von sehnigen Blättchen am Schafte des Schenkelbeines am inneren Rande der Linea glutaea und am Interstitium der Linea aspera bis handbreit oberhalb des Condyls.

b) Die verticale Partie oder Portio ischiadica entsteht mit einer Sehne an der unteren Fläche der Tuberositas ischiadica und mit einem Muskelblatte an der hinteren Hälfte des Ramus ischio-pubicus. Diese lange und feste Sehne schickt von ihrer vorderen Fläche einen spindelförmigen Fleischkörper ab, welcher vertical nach abwärts steigt und in eine runde Sehne in Form eines Stranges übergeht - der Strang oder die Sehne des Adductor - dieser inserirt sich am Höcker, welcher oberhalb des Condylus internus sich befindet und mit einer fibrösen fächerförmigen Ausbreitung an der rauhen Leiste, welche oberhalb dieses Tuberculums liegt.

Wir kennen schon die Ausbreitung, welche die Sehne des Adductor magnus rom ersten Adductor bekommt, und jene, welche sie dem Vastus internus zuschickit und die innere Wand des Hunter'schen Canales bildet. Die Femurinsertion des Adductor magnus ist nicht continuirlich, sondern hat vier oder mehrere Löcher, durch die oberen ziehen die Rami perforantes der Art. femoralis profunda und durch das untere Loch, Orificium arteriae femoralis, zieht in das Planum popliteum die Arteria und Vena femoralis, wo sie Arteria und Vena poplitea genannt werden.

Dieses Orificium wird begrenzt: aussen vom Schafte des Schenkelbəines, der von der oberen Endpartie des Adductor bedeckt ist, innen vom Strange des Adductor, oben von einem fibrösen Bogen, an welchem sich Fasern inseriren, die dem Adductor magnus angehören und unten rom oberen Rande der Ausbreitung, welche die Sehne des Adductor dem Femur zuschickt.

Im Zwischenraume, welcher zuerst von der ersten und zweiten Schicht, dann von der ersten und dritten Schicht der Adductoren begrenzt wird, findet man die Arteria femoralis profunda und die sie begleitenden Venen; Zweige des Nervus obturatorius ziehen theils vor, theils hinter dem Adductor brevis.

Technik z. A. d. G. Man legt den Oberschenkel in Abductionsstellung; an einem magern Individuum sieht und fühlt man dann die gespannte und starke Masse der Adductoren. Am Rande der Adductoren macht man einen langen Schnitt, durchschneidet die Aponeurose, löst diese mit den Fingern von oben nach unten ab und legt stumpfe Haken ein; man findet von oben nach unten den Nusculus pectineus und den ersten Adductor. Man sucht den Zwischenraum auf, welcher diese beiden Muskeln scheidet, sein Grund wird vom Adductor brevis gebildet und durch seinen innern Theil dringt die Arteria femoralis profunda. Man löst mit der Hand die hintere Fläche der ersten Schichte $a b$ und gelangt an den Adductor brevis und trennt diesen rom dritten Adductor, auf welchem er liegt.

Der Rectus interuus (Musculus gracilis) liegt auf der innern Fläche des Oberschenkels längs der Adductorenmasse zwischen dem Schambeine und Os ilium und hat die Form eines mit der Spitze nach unten gerichteten Dreieckes. Er entsteht mit einem fibrösen dreifingerbreit breiten Blatte an der Symphyse des Schambeines und an dem vordern Theile des Ramus ischio-pubicus unmittelbar an der Innenseite der Insertion des kleinen lind grossen Adductor. Sei Fleischkörper übergeht im untern Drittel des Oberschenkels in eine runde Sehne in Form eines Stranges, welche wir später mit dem „Pes anserinus" studiren werden.

Technik z. A. d. G. Man führt an der innern Fläche des Ober- 
schenkels einen langen Schnitt und gelangt unter der Aponeurose an den Muskelkörper, welchen man in der aponeurotischen Scheide, die ihn enthält, isolirt.

Canalis subpubicus. Musculus obturator externus. Arteria und Yerrus obturatorius. Der Canalis subpubicus liegt unter dem Ramus ilio-pubicus und hat die l'orm eines verbreiterten mit der Basis nach unten gerichteten IIorns, dessen grosse Achse rertical liegt. Seine vordere äussere linöcherne Wand wird rom Sulcus subpubicus gebildet, die hintere innere Wand ron einem fibrösen Blatte, das zwischen beiden Rändern des Sulcus subpubicus gespannt ist; es rerlängert sich nach oben in die Membrana obturans. Dieses Blatt wird nach unten ron einer fibrösen Schlinge - Ligamentum subpubicum inferius - rerstärkt.

Das Orificium erurale oder inferius des Canalis subpubicus ist oval und wird vorne und aussen rom untern Rande der Pectinealoberfläche und ron der innern Fläche jener Partie des Schambeines begrenzt, welche an der Bildung der Gelenkpfanne betheiligt ist. Dieses Orificium, breit genug, um den Daumen einzuführen, entspricht dem Interstitium der Adductoren.

Das Orificium subperitoneale oder oberes Beckenorificium hat eine ovale Form und ist um rieles kleiner als das untere; mit Schwierigkeit nur kann man den kleinen Finger einführen.

Es wird aussen rom linochen, innen ron einer fibrösen sichelförmigen Schlinge begrenzt, welche durch die Vereinigung der fibrösen Wand des Canalis subpubicus mit der inıern Fascie des Obturator internus gebildet wird.

Wenn die Blase leer ist, dann bedeclit ein zelliges subperitoneales Blatt dieses Orificium, vor welchem das Peritoneum sich in eine leichte Grube wölbt, Fossula subpubica, wenn dic Blase ron Flüssigkeit gespannt wird, dann ist das Peritoneum abgelöst und nach hinten gedrängt, die laterale Wand der Blase aber bedeckt das Orificium des Canalis subpubicus. Im \ireau dieses urificium findet man zuweilen eine Lymphdrüse, Glandula subpubica, welche der Ansgangspunlt einer Phlegmone sein kann, die sich im Spatium latero-resicale und bei Fraven im Ligamentum latum entwickelt.

In normalem Zustande zieht durch den Canalsis ubpubicus dieArterie, Vene und der Terrus obturatorius und Lymphgefässe; in pathologischeu Fällen kann der Canalis subpubicus ron einem Herniensaclie ausgefullt sein, Hernia subpubica oder obturatoria.

Ter(hnik z. A. d. f. Yan bringt den Oberschenkel in Abductionsstellung und macht ron der Symphyse längs des rordern Randes des mittlern Adductor einen langen Schnitt. Man sucht darauf das Interstitium, welches die rordere Schichte der Adductoren ron der mittleren scheidet, auf und trennt mit den Fingerspitzen ron oben nach unten diese beiden Muskelschichten. Man legt stumpfe Haken ein und sieht am vordern Schnittrande gegen den rothen Grund des kleinen Adductor ziehend die weissen Stränge des Nerrus obturatorius; man folgt diesem Nerr nach oben und gelangt an das Orificium des Canalis subpubicus, in welchen die Fingerspitze eingeführt wird.

Ilan bemerkt, dass der Nerrus obturatorius am obern Rande des kleinen Adductor Acste in zwei Schichten abschickt: die vordere Schichte zieht ror dem kleinen Adduetor und übergeht in die rordere Fläche dieses Muskels, in den mittlern Adductor und in den Rectus internus; die hintere Schichte zieht hinter den kleinen Adductor und ist für den Adductor magnus bestimmt. 
Die hintere Fläche des Oberschenkels beginnt im Tireau der Glutaealfalte. Sie hat die Form einer Furche, Sulcus nervi ischiadici, welche oben in den Sulcus ischio-trochantericus übergeht und unten im Planum popliteum endigt.

Diese Furche wird aussen von der Erhabenheit des Femur, innen ron der Masse der Muskeln des Sitzbeines begrenzt, und ist in den beiden oberen Dritteln leicht zu fühlen; in dem untern Drittel wird sie rom langen Kopfe des Biceps ausgefüllt, welcher den Oberschenkel in Form einer Schärpe kreuzt und sich nach unten und aussen richtet.

In dieser Furche findet man der grossen Nervus ischiadicus, welcher an der hintern Fläche des grossen Adductor liegt.

Die Mnskelmasse des Sitzbeines. An der Tuberositas ischiadica entstehen drei Muskeln, welche zuerst in einem einzigen Bündel rereinigt sich dann theilen:

Fig. SS.

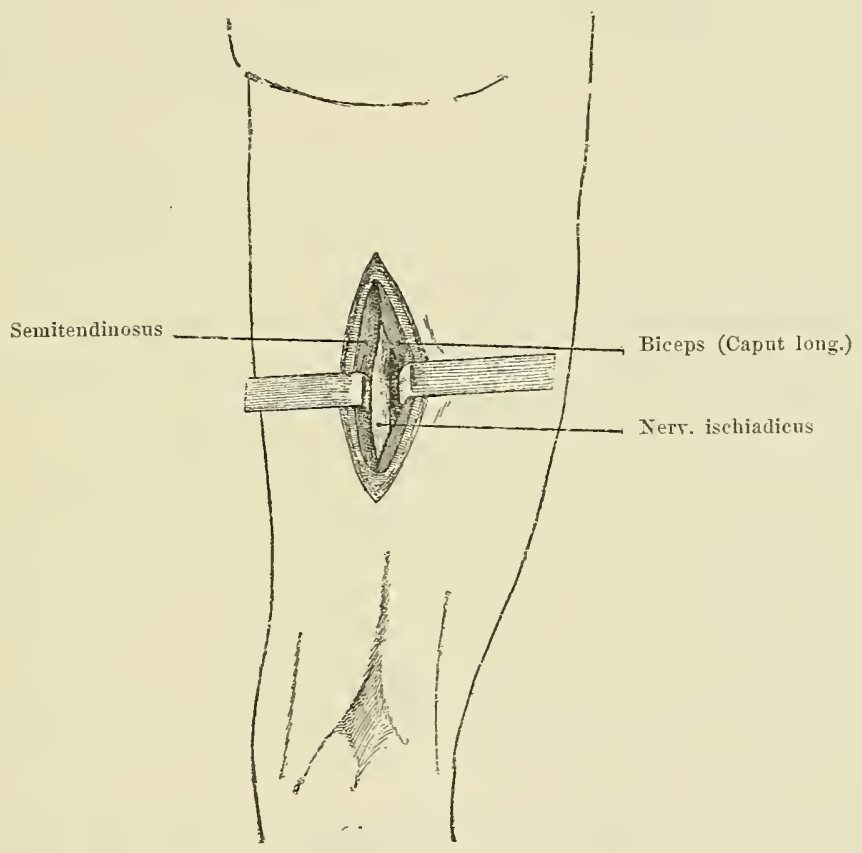

Die hintere Fläche des rechten Oberschenkels. Das Aufsuchen des Nervus ischiadicus: je ein stumpfer Haken zieht beide Schnittränder ab.

einer richtet sich nach aussen gegen den Körper der Fibula, der Biceps, zwei ziehen gegen den Condylus internus tibiae, der Semimembranosus und der Semitendinosus.

Der Biceps femoris stellt zwei Köpfe dar: a) der lange Kopf, Portio ischiofibularis, entsteht mit einer kräftigen Sehne an der mittleren dreieckigen mit der Spitze nach unten gerichteten Stelle der hintern Fläche des Os ischii. Diese Initialsehne ist zuerst rund, entwickelt sich dann fächerförmig an der hintern Fläche ausgebreitet, ron welcher Muskelbündel entstehen.

Sein kurzer Fleischkörper ist dick und spindelförmig und legt sich an die rordere Fläche der Endsehne, welche er vier- bis fünffingerbreit oberhalb des Fibulaköpfchens bedeckt. 
b) Der kurze Kopf, Portio femoro-fibularis, liegt unter und etwas anssen von dem langen Kopfe. Er entsteht mit Fleischfasern und fibrösen Bündeln an den beiden mittlern Vierteln der Linea aspera femoris und an der innersten Seite der hintern Fläche der äussern intermusculären Fascie. Dieser prismatische Fleischkürper legt sich an dic rordere Fläche der Endsehne, welche er mit Muskelfasern bis oberhalb der Fibula bedeckt.

Die Enđsehne theilt sich im Niveau des Fibulaköpfehens in zwei Schichten: 1. die tiefliegende Fläche inserirt sich an der hintern Seite des Fibulaköpfehens und an der 'T'uberositas externa tibiae; 2. die oberflïchliche Schichte inserirt sich an der vordern Seite der obern Fläche des Fibulalöpfehens, an der Tibia unmittelbar vor dem obern Tibio-fibulargelenke und mit einer festen fibrösen Ausbreitung in Form eines Fächers an der Fascie des Unterschenkels. Zwischen diesen beiden schnigen Schichten findet man, ron cinem Schleimbeutel umgeben, das Ende des Ligamentum laterale externum des Knies.

Der Semitendinosus, Musculus ischio-tibialis, entsteht mit sehnigen und Fleischfasern an der hintern Fläche des grossen Ligamentum sacro-ischiadicum und mit Fleischfasern an der Bicepssehne.

Sein spindelförmiger Fleischkörper, gegen seinen mittlern Theil durch einen aponeurotischen Streifen unterbrochen, legt sich im untern Drittel des Unterschenkels auf eine lange und breite Sehne, welche den Condylus internus umschlingt, beschreibt eine Curve mit der Concavität nach oben und vorne und inserirt sich an der innern Fläche der Tibia unter der Insertion des Rectus internus (Gracilis).

Der Semimembranosus entsteht mit einem festen sehnigen Blatte, die Ursprungssehne, an der virgulaförmigen Fläche, welche am äussern Drittel der hintern Fläche des Os ischii sich tefindet. Diese Sehne liegt zuerst an der Aussenseite der Bicepssehne, zieht dann vor derselben und entfaltet sich zu einem Fächer.

Er ist sehr lang, denn er zieht nach unten ron der Vitte des Oberschenkels, dick und gerundet an seinem äussern Rande und theilt sich an seinem innern Rande in zwei Lamellen. Im Winkel, der ron diesen beiden Blättchen begrenzt ist, entstehen Muskelbïndel, welche sich vereinigen, um einen langen, $2-3 \mathrm{~cm}$ breiten, in seinem untern Theile sehr dicken Fleischkörper zu bilden, welcher sich auf die hintere Fläche der Endschne legt, die gegen die Mitte des Oberschenkels beginnt.

Diese Sehne wird ron Muskelfasern bis oberhalb des Condylus internus femoris begieitet, verbreitet sich fïcherförmig und inserirt sich an der hintern Fläche des Condylus internus tibiae:

a) an der rauhen Oberfläche, welche an der äussern Hälfte der hintern Fläche, Portio directa, sich befindet, b) an dem hügelförmigen untern Rande der Furche des Semimembranosus, an der vordern Grenze dieser Furche und mit einigen Fasern an der innern Flïche des Condylus tibialis, Portio reflexa, c) an der rauhen dreieckigen Oberfläche, welche unter der erwähnten Furche sich befindet.

Hit einer dreieckigen Ausbreitung inserirt sich noch der Semimembranosus am Rande und etwas an der innern Fläche der Tibia, hinter der Insertion des Ligamentum laterale internum und an der Aponenrose des Popliteus, mit welcher er an der schiefen Leiste der Tibia endet. Ein fibröses Band entsteht an der hintern Fläche der Endsehne, Tendo recurrens, richtet sich nach oben und anssen, verbreitert sich zu einem Fächer und rorliert sich an der Ḱapsel des Condylus externus und an dem in dieser befindlichen'Sesambeine. Eine sichelförmige Ausbreitung vereinigt die hintere Fläche der Kapsel des Condylus internus mit der Sehne des Semimembranosus.

Die Portio reflexa ist in dieser Lage durch einen fibrösen Haken festgehaiten, welcher oben an dem obern Rande des Sulcus semimembranosus entsteht und unten an der innerm 
Fläche der Tibia sich inserirt, wo auch diese Insertion mit der des Ligamentum laterale internum sich vereinigt (Fig. 90).

Technik z. A. des Biceps. Man macht von der Tuberositas ischiadica, welche man aufgesucht hat, bis zum Fibulaköpfchen eine lange Incision und gelangt unter der Aponeurose an den Körper des langen Bicepskopfes. Man studirt seine Insertion am Os ischii und bemerkt, dass die Sehnen jener drei Muskeln unter einander durch einen fibrösen Gang vereint sind. Ein Schleimbeutel existirt zwischen der Sehne des Semimembranosus und der Bicepssehne. Man isolirt und hebt den langen Kopf und unter diesem findet man den kurzen Kopf.

Technik z. A. des Semitendinosus und Semimembranosms. Man macht von der Tuberositas ischiadica einen langen Schnitt gegen den Condylus internus femoris und gelangt unter der Aponeurose an den Körper des Semitendinosus; man isolirt diesen Muskel, findet unter demselben den Körper des Semimembranosus, dessen Insertion am Os ischii und am Condylus tibialis internus man studirt. Diese drei Muskeln bekommen Nervenäste vom grossen Nervus ischiadicus.

Der kleine Nervus ischiadicus (femor. cut. post.) verläuft am Oberschenkel vertical bis an das Planum popliteum, wo er mit der innern Warzel des Nervus saphenus internus anastomosirt.

Er liegt zuerst unter der Aponeurose im langen Interstitium, welches den Biceps rom Semitendinosus scheidet, wird dann subcutan gegen das untere Drittel des Oberschenkels.

Technik z. A. d. fr. Man sucht die Furche des grossen Nervus ischiadicus auf und macht in seinem Verlaufe im mittleren Drittel des Oberschenkels einen langen Schnitt, durchschneidet die Aponeurose und sucht mit Pincette und Hohlsonde unter diesem; man findet an die tiefliegende Fläche der Aponeurose den kleinen Nervus ischiadicus angelöthet.

Der grosse Nervus ischiadicus liegt längs des Femur an der hintern Fläche des grossen Adductor und entspricht von oben nach unten zuerst dem äussern Rande des langen Bicepskopfes, dann seiner hintern Fläche und dem Interstitium, welches diesen Muskel vom Semitendinosus und Semimembranosus scheidet.

An der Spitze des Planum popliteum theilt sich der Nervus ischiadicus in die beiden Endäste: den Nervus popliteus internus und Nervus popliteus ex ternus.

Technik z. A. d. G. Man sucht im obern Drittel des Oberschenkels die Tuberositas ischiadica und den Sulcus des Nervus ischiadicus auf, macht längs desselben, etwas oberhalb der Glutaealfalte beginnend, einen langen verticalen Schnitt. Nachdem man eine kleinere oder grössere Fettschichte und die Fascie durchschnitten hat, erkennt man den äussern Rand des Biceps und legt ihn frei; damn findet man auf dem rothen Felde des grossen Adductor, von einer Fettschichte umgeben, den grossen Nervus ischiadicus von der Dicke des kleinen Fingers. In der Mlitte des Oberschenkels macht man längs der Furche, welche diesem Nerv entspricht, einen verticalen Schnitt; unter der Fascie gelangt man an den langen Bicepskopf und im Grunde des Interstitiums, welches diesen Muskel vom Semitendinosus scheidet - man legt stumpfe Haken ein — findet man den grossen Nervus ischiadicus (Fig. 88). 


\section{Die Region des Knies.}

Digitahnutersuchung. Das Kuie entspricht dem Gelenke des untern Femurendes mit dem obern Ende der Tibia. In der llitte der vordern Fläche des linies sieht man die convexe Erhabenheit der Patella oben und an den Seiten ron einer hufeisenförmigen Grube, Depressio peripatell aris, umgeben.

Ilam nimmt die Patella zwischen den Fingern und folgt Schritt für Scluritt dem kreisförmigen Rande; man bemerkt, dass die Patella im normalen Zustande beweglich ist und dass man diese mit der grössten Leichtigkeit nach innen, aussen, oben und unten bewregen kann. Unterhalb der Patella, zu beiden Seiten des Ligamentum patellare, existirt eine leichte Lirhabenheit, rom Ligamentum adiposum gebildet, welche bei Extensionsstellung rom Gelenke heraustritt und unter der Haut vorspringt. Nan drückt die Kniescheibe nach innen und tastet mit den Fingerspitzen längs ihres ïussern Randes den Rand und die Hälfte der äusseren Fläche der Trochlea, die auf diese Weise aufgefunden wird; man wiederhole dieses Manöver innen und fühlt etwas weniger deutlich den innern Rand der Trochlea.

Dreifingerbreit unter der Spitze der Kniescheibe findet man die Tuberositas tibiac anterior.

Mit der Fingerbeere des Daumens tastet man von vorne nach hinten die knöcherne fast subcutan liegende Fläche ab, welche den Grund der Depressio patellaris externa bildet, dreifingerbreit hinter der Kniescheibe fühlt man das Tuberculum condyli externi.

Unter dem IÖ̈cker des äussern Condyls an der Grenze der äussern Fläche des linies fühlt man das Fibulaköpfehen.

Man explorirt die innere Fläche des Knies, indem man von vorn nach hinten der knöchernen subcutanen Fläche, welche die Depressio patellaris interna bildet, folgt und fïhlt 3-4 cm hinter der Patella das Tuberculum condyli interni.

Unter der Kniescheibe führt man an jeder Seite des Ligamentum patellare die Fingerspitzen tief in den Winkel ein, welcher der Gelenklinie entspricht; drückt man die Finger ron vorne nach hinten, so gleiten sie längs des Sulcus articularis. An den Seiten ist die Gelenklinie schwer zu fïhlen, weil die fibrösen Flächen, welche sie ron der Haut trennen, sehr resistent sind. Man nähere die Finger; diese folgen von hinten wach vorne demselben Weg, don sie auch zuerst gegen die Medianlinie durchlaufen haben; sie bleiben getrennt ron einander durch die Dicke des Ligamentum patellare. IIan bringt das linie in Flexionsstellung, die Patella dringt in den Winkel, weleher ron den Femurcondylen gebildet wird; unter diesem sicht man das Relief des Ligamentum patellare und an jeder Seite desselben eine Vertiefung.

Oberhalb der Kniescheibe tastet man die so aufgefundene Trochlea femoris ab; an der Innenseite der Patella folgt die Fingerbeere der untern convexen Fläche des Condylus internus und mit wenig Nühe fühlt man rorne die Ecke, welche das Condylusfeld von der innern Fläche der Troch- 
lea scheidet; an der Aussenseite der Kniescheibe folgt der Finger der Convexität des Condylus externus und fühlt vorne die Furehe des äussern Meniscus, welche das Feld des Condylus externus von der äussern Fläche der Trochlea scheidet.

In Flexionsstellung gestattet die stark geöffnete Gelenklinie den innen und aussen rom Ligameutum patellare eingedrückten Fingerspitzen auf beiden Seiten die untere Fläche der Condylen und den vordern Theil des Tibialplateaus abzutasten; am mittlern Theil aber schliesst die Kniescheibe und das Ligamentum patellare die Gelenklinie.

Man fasst mit der einen Hand das untere Ende des Femur und mit der andern das obere Ende des Unterschenkels und bemerkt, dass man in Flexionsstellung leichte Seiten- und Rotationsbewegungen ausführen kann. Man muss nämlich wissen, dass in der Flexionsstellung die Ligamenta lateralia und die Ligamenta cruciata im normalen Zustande diese Bewegungen gestatten.

Diese Untersuchungen mögen recht oft wiederholt werden.

Fig. 89 .

Vorderes Ende des inneren Meniscus Lig. eruc. ant. ext.

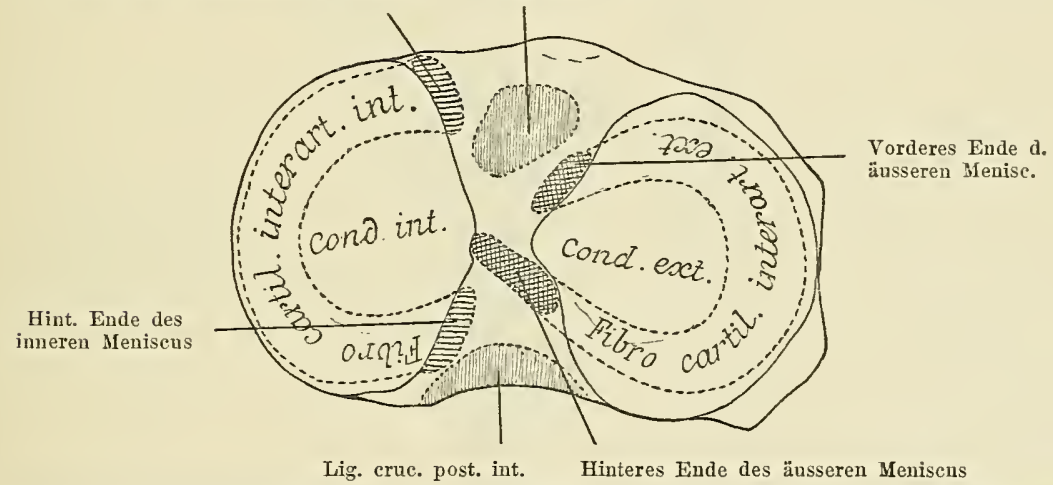

Die obere Fläche des Tibiaplateaus. Die liniirten Oberflächen zeigen die Insertionsfelder der Ligamenta cruciata und der Enden der Menisci.

Bursae serosae praepatellares. Es sind drei an Zahl:

1. Der erste Schleimbeutel ist subcutan und befindet sich unter der Haut, gewöhnlich ist er ebenso breit als die vordere Fläche der Kniescheibe; seine innere unregelmässige Fläche stellt Zotten dar und kann durch Falten in mehrere secundäre Höhlen getheilt sein.

2. Der zweite Schleimbeutel liegt unter der Fascie, zwischen derselben und der vordern Fläche der Kniescheibe. Er ist um vieles kleiner als der erste und seine Höhle ist glatt: Er kann auch oft fehlen und wird durch ein weiches Bindegewebe ersetzt.

Zuweilen kann der subcutane Schleimbeutel mit dem subaponeurotischen communiciren.

3. Der dritte Schleimbeutel ist sehr klein und nicht beständig, er liegt in Nireau des obern innern Winkels der Kniescheibe, zwischen derselben und der Ausbreitung des Vastus externus.

Technik z. A. d. G. Man macht über die vordere Fläche der Kniescheibe einen verticalen Schnitt und eröffnet den subcutanen Schleimbeutel; 
durchtrennt man seine hintere Wand und die Fascie, so findet man den mittlern Schleimbeutel.

Die Sehne oder das Ligamentum patellare ist ron der Spitze der Patella und ron der untern Hälfte ihrer vordern Fläche bis zum Tuberculum tibiae gespannt. Das Ligament ist $4-5 \mathrm{~cm}$ lang und $3-4 \mathrm{~mm}$ diek, rerschmälert sich leicht ron oben nach unten, wo es die Breite eines Daumens hat. Sein Verlauf ist nicht rertical, sondern etwas schief nach abwärts und aussen. Die rordere Fläche des Ligannentum patellare entspricht der Haut und der Aponenrose; ein Schleimbentel findet sich oft unter der Haut nahe seiner untern Insertion; seine hintere Fläche entspricht ron oben nach unten der vordern

Fig. 90.

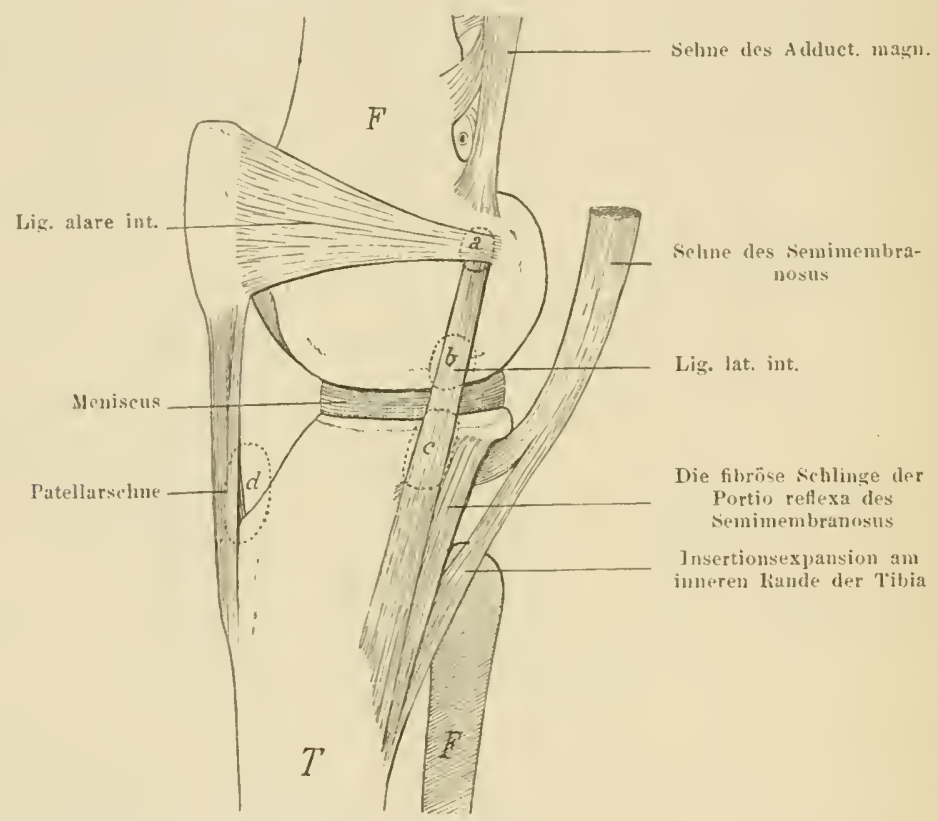

Die innere laterale Fläche des rechten Knies. a) Ein kleiner Schleimbeutel, der zuweilen zwischen der Spitze des Lig. alare und dem Anfange des Lig. lat. int. sich befindet; b), c) Schleimbeutel unter dem Lig. lat. int.; d) ein Schleimbeutel unter der Patellarsehne.

Fläche des Ligamentum adiposum und der dreiecligen Oberfläche der Tibia, ron weIcher es durch einen breiten Schleimbeutel getrennt ist.

Technik z. A. d. (') llan führt ron der Spitze der Patella zum Tuberculum tibiae einen langen rerticalen Schnitt nnd gelangt unter der Fascie an das Ligamentum patellare. Man isolirt mit Pincette und Bistouri die beiden Ränder dieser Sehne, durchschneidet sie transversal und sieht, wie dick sie ist.

Man präparirt aufmerksam die tiefe Fläche des unteren Fragmentes und eröffnet in einem gewissen Momente die seröse IIöhle, welche vom Gleiten der Sehne am Knochen entsteht.

Unter der tiefen Fläche des oberen Fragmentes findet man die Basis des Ligamentum adiposum. 
Das Kniegelenk verbindet miteinander das untere Ende des Femur mit dem oberen Ende der Tibia und mit der Patella. Es kann in zwei sekundäre Gelenke zerlegt werden, eine Articulatio femoro-patellaris und eine Articulatio femorotibialis.

Prüft man das untere Ende des Femur, so bemerkt man, dass das Feld der Patella oder die Trochlea femoris an jeder Seite der Condylusflächen ảurch eine Furche getrennt ist, welche am Femur von den oberen Rändern der Gelenkmenisci, Meniseusspuren, eingedrückt werden. Die Gelenkflächen, welche die Tibia jedem Condyl des Femur bietet, werden voneinander durch einen Raum, Spatium interglenoidale, geschieden, welcher die Form zweier mit ihren abgehackten Spitzen vereinigter Dreiecke hat (Fig. 89).

Jede der Gelenkflächen wird durch einen fibrösen prismatischen Knorpel, Meniscus articularis, ergänzt.

Der Meniscus externus hat die Form eines Reifens, der nur an der inneren Seite durch die Spina tibialis externa unterbrochen ist (Fig. 89).

Der Meniscus internus ist stark geöffnet und hat die Form eines Bogens oder Hornes.

Die Gelenkkapsel entsteht an jeder Seite an den Hautflächen der Femurcondylen, ron dort strahlt sie nach vorne gegen die Patella, nach unten gegen den oberen Rand der Menisci aus und von diesen zur Tibia.

Der hintere Theil der Kapsel, jener, welcher die Condylen bedeckt, führt den Namen „Condylenmütze".

Die Verdickungen, welche die Gelenkkapsel an den Seiten und im Niveau des Spatium intercondyloideum aufweist, nennt man Ligamente.

Das Ligamentum adiposum stellt eine breite mit Fett gefüllte Falte der Synovialmembran dar. Es liegt unmittelbar unter der Patella und hat die Form einer unregelmässigen pyramidenförmigen Masse, deren Spitze durch ein fibröses Band, Frenulum, mit dem vorderen Rande des Spatium intercondyloideum verbunden ist. Es hat wie jede Synovialfalte die Aufgabe eines Pfropfens, welcher die durch Flexion geschaffene Gelenkgrube ausfüllt; in der Extensionsstellung dagegen ist er aus der Gelenkhöhle ausgetreten, er verbreitet sich unter dem unteren Rande der Patella und springt an jeder Seite des Ligamentum patellare hervor.

Poirier hat gezeigt, dass dieses Pseudoligament zuerst eine verticale Wand darstellt, welche die beiden Condylgelenke voneinander scheidet. Bei Neugeboren hat es in den meisten Fällen diese Form; zuweilen findet man es in dieser Form auch beim Erwachsenen.

Technik z. A. d. G. Man führt um die Patella, nachdem man sie aufgefunden hat, einen in Form eines Hufeisens nach aussen oben und innen verlaufenden Schnitt, durchschneidet auf einmal bis zum Knochen alle Weichtheile, führt eine Flexion aus und zieht den Lappen nach unten, welcher die Patella enthält. Unter diesem sieht man die Synovialfalte, welche das Ligamentum adiposum darstellt, und kann sie auch mit den Fingern fassen. Nan bemerkt ferner, dass die obere Fläche des Ligamentum adiposum unmittelbar unter der Patella eine sichelförmige Falte macht, deren Fortsätze an jeder Seite derselben sich verlieren.

Die Kenntniss dieser Falte ist wichtig, weil sie in der Extensionsstellung zwischen Patella und Trochlea eindringt. Unter dem Ligamentum adiposum führt man die Spitze des kleinen Fingers in einen Blindsack der 
Gelenksynoria ein; rorne ist diese Grube ron einer fibrösen Schlinge begrenzt, welche ron Frenulum intermeniscale gebildet wird.

Aripae patellares (Ligamenta alaria). Es giebt zwei Ligamenta alaria, an jeder Seite eines: sie haben eine dreieckige mit der Basis nach rorne gerichtete Form und stellen rerstärkte Partien der Kapsel dar.

Das Liganentum alare externum inserirt sich mit seiner Spitze am Tuberculum condyli externi und mit der Basis am äusseren Rande der Patella unter der Insertion des Vastus externus.

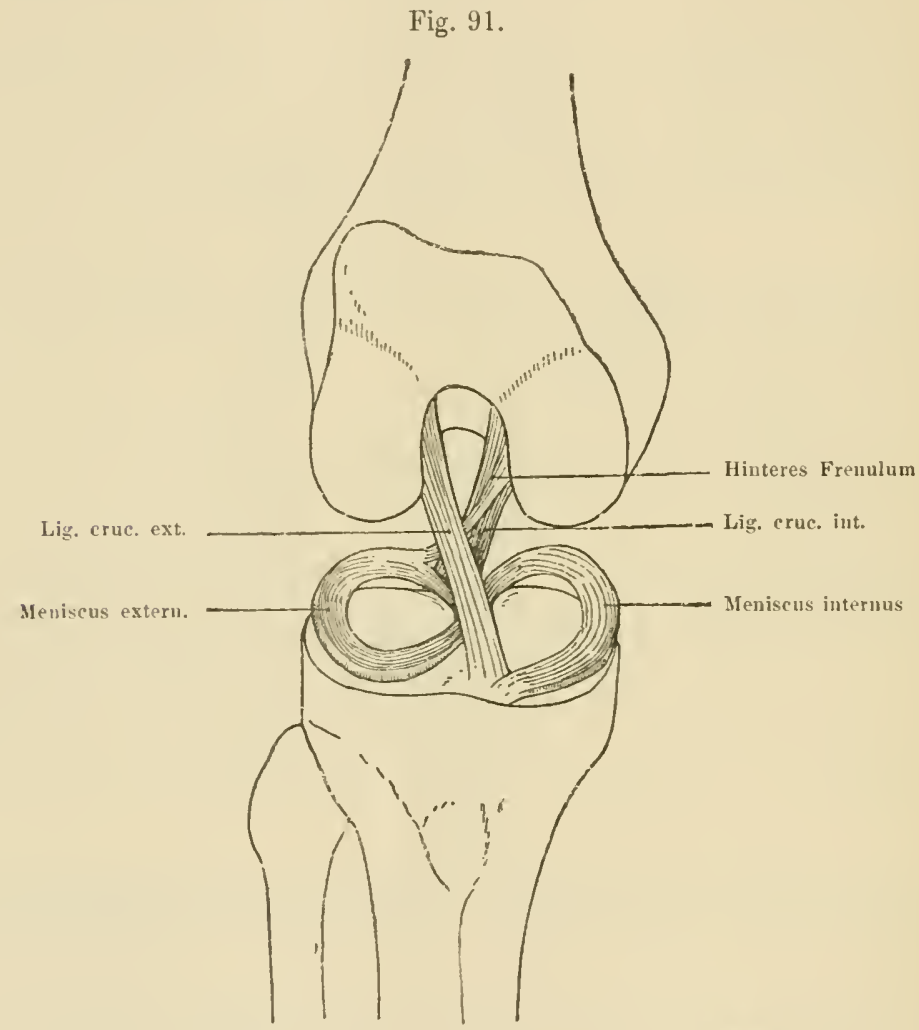

Das Kniegelenk; die Ligamenta crueiata und die Menisei.

Das Ligamentum alare internum inserirt sich mit seiner Spitze am Tuberculum condyli interni etwas hinter dem Ligamentum lalerale internum und mit seiner Basis am inneren Rande der Patella unter der Insertion des Vastus internus.

Ein kleiner Schleimbeutel existirt zwischen der Spitze des Ligamentum alare internum und dem oberen Ende des Ligamentum laterale internum (Fig. 90). An ihrer Oberfläche sind die Ligamente mit den Sehnen und Ausbreitungen der Vasti und mit der Fascie, welche das Knie umkleidet, innig rerwebt; ihre tiefe Fläche entspricht den lateralen Blindsäcken der Synorialhöhlen.

Das Ligamentum alare internum ist um rieles fester als das äussere, spielt die 
Rolle eines Zügels, welcher die Patella festhält und mit der äusseren Fläche der Trochlea sie verhindert, sich nach aussen zu luxiren.

Technik z. A. d. G. Für das Ligamentum alare internum umrahmt man die Patella mit einem Schnitt in Form eines nach oben aussen und unten gerichteten $U$, schneidet bis zum Knochen alle Weichtheile durch und schlägt nach innen den rechtwinkeligen so gemachten Lappen. Mit Pincette und Bistouri präparirt man die Synovialmembran und unter derselben unter einer Bindegewebsschicht erscheinen die fibrösen Bändchen, die dem Liga-

Fig. 92.

Lig. cruc. ant. ext.

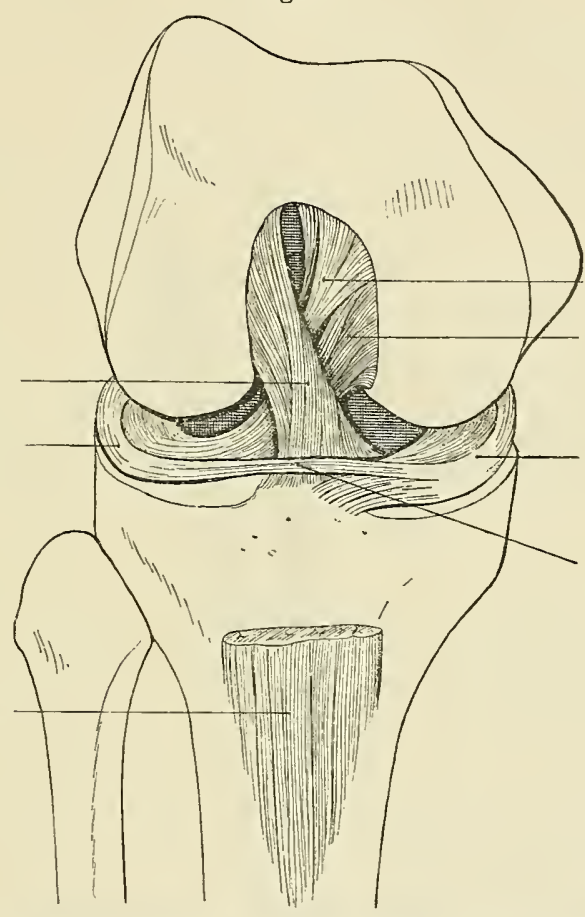

Hint. Strang (Frenulum) des Menise ext.

Lig. cruc. post. int.

Meniscus ext

Patellarsehne

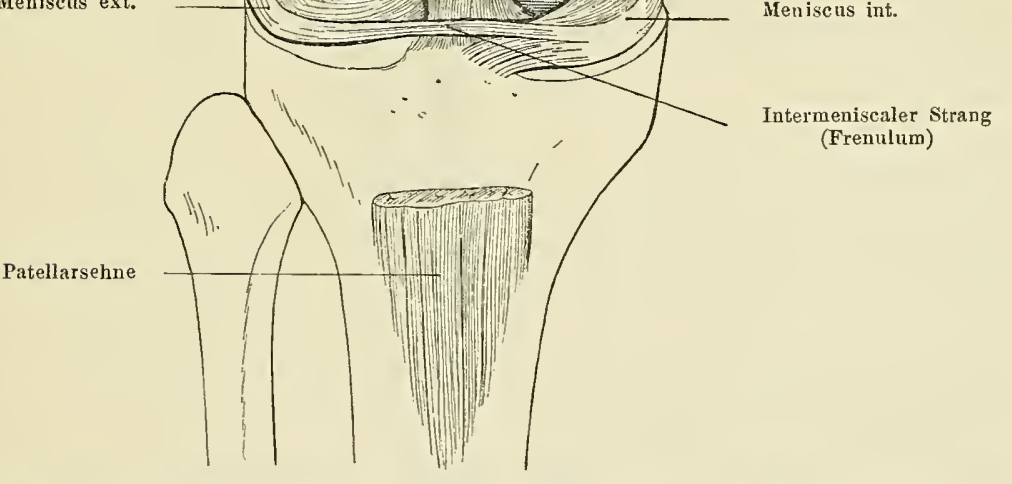

Die vordere Fläche des Kniegelenkes. Die Gelenkhöhle ist durch Flexion des Femur eröffnet; man sieht die Ligamenta cruciata.

mentum alare internum angehören. Man macht einen entgegengesetzten Schnitt für das Ligamentum alare externum.

Die Ligamenta cruciata sind zwei an Zahl und liegen im Spatium intercondyleoideum.

Das Ligamentum cruciatum antero-externum inserirt sich unten am Tibiaplateau an der Fläche, welche die hintere Hälfte des Spatium praespinosum einnimmt, unmittelbar an der Innenseite der Insertion des vorderen Fortsatzes des äusseren fibrösen Knorpels und vor der Insertion des vorderen Fortsatzes des innern fibrösen Knorpels. Von hier richtet es sich schief nach oben, hinten und aussen und inserirt sich mit seinem oberen Ende an der dreieckigen mit der Spitze nach unten gekehrten 
Fläche, welche sich an der imneren Fäche des Condylus externus findet. Dicses ligament ist schr dick und fest und besteht aus fibrösen Bündeln, welche von innen nach aussen ring's $4 m$ ihre longitudinale Achse gedreht sind (Fig. 91 u. 95).

Das Ligamentum eruciatum postero-internum ist dreieckig, prismatisch und leicht ron rome nach hinten verbreitert. Es inserirt sich mit dem unteren Ende

Fig. 93 .

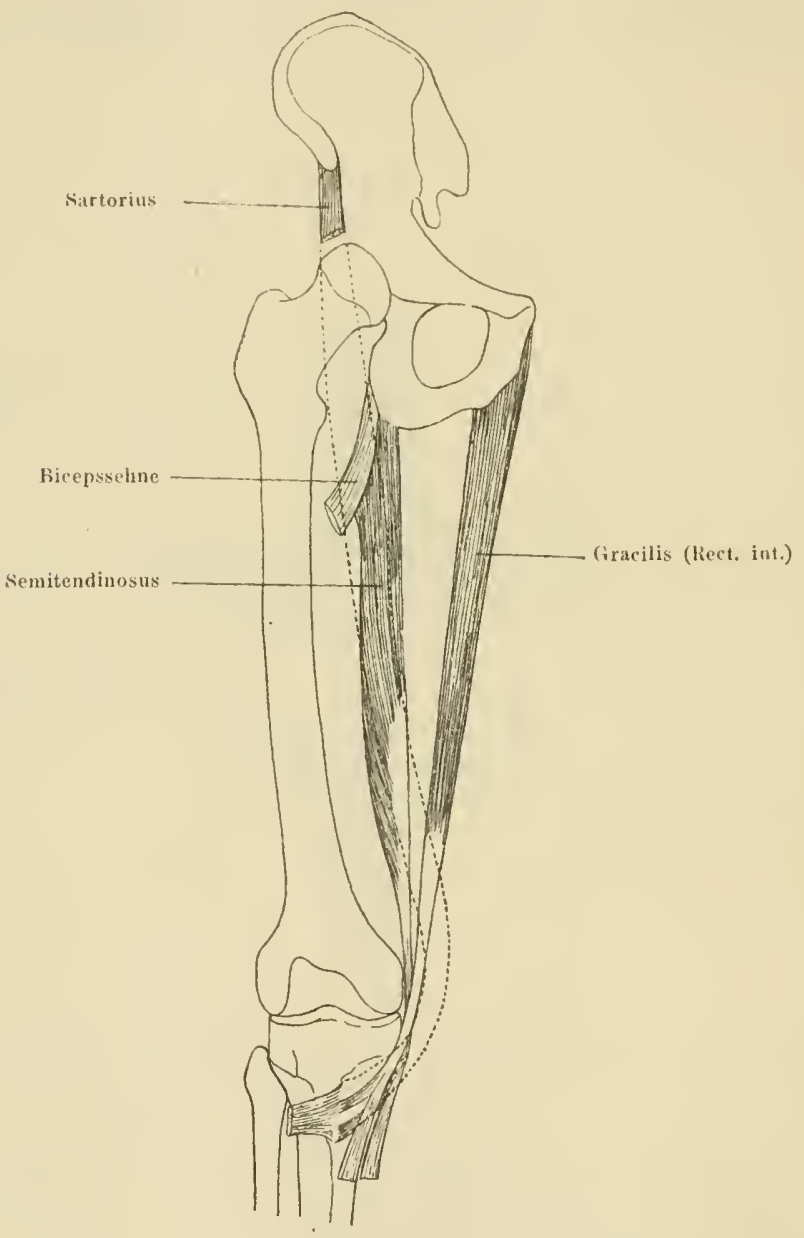

Die Muskeln des Pes anserinus. Der Sartorius wurde durchsehnitten uud seine Richtung ist mit punktirten Linien bezeichnet.

an der Tibia an der rechtwinkligen Fläche, welche mehr als die hintere untere Hälfte des Spatium retro-spinosum einnimmt, unter der Insertion des hinteren Fortsatzes des Meniscus internus. Von hier richtet es sich nach oben, vorne und etwas innen, indem es in dem hinteren offenen Winkel liegt, welchen die hinteren Fortsätze der beiden Menisci bilden. 
Nit seinem vordern Ende inserirt sich das Ligamentum cruciatum internum an der halbmondförmigen Fläche, welche den vordern untern Theil des akgerundeten Winkels

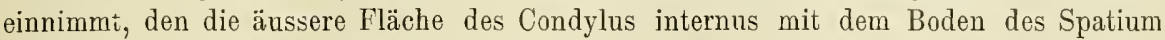
intercondyloideum bildet (Fig. 91-92).

Am äussern Rande des Ligamentum cruciatum internum theilt sich das Frenulum des hintern Endes des Meniscus externus in zwei Partien: a) die vordere Partie zieht über die vordere Fläche des Ligamentum cruciatum internum, verbreitet sich fächerförmig und inserirt sich am Femur vor der Insertion dieses Ligamentes; a) die hintere Partie zieht hinter dem Ligamentum cruciatum internum und inserirt sich an der äusseren Fläche des Condylus internus.

Die Ligamenta cruciata haben neben der Aufgabe die Enden der Knochen festzuhalten auch Widerstand den Propulsions- and Retropulsionsbewegungen entgegenzusetzen.

Technik z. A. d. G. Man bringt das Knie in Flexionsstellung und macht einen Schnitt in Form eines U, welcher am Tuberculum condyloideum internum beginnt, bis zum Niveau des Tuberculum tibiale zieht und am Tuberculum condyloideum externum endigt.

Man durchschneidet alle Weichtheile bis zum Knochen, hebt.den so gemachten Lappen auf und giebt ihn einem Assistenten, auf diese Weise eröffnet man breit die Gelenkhöhle.

- Man sucht im Spatium intercondyloideum die Ligamenta cruciata auf, welche man durchscheinen sieht, weil sie von Synovialblättchen umkleidet sind; diese löst man ab und legt weisse und glänzende Fasern frei, welche diese Ligamente bilden.

Man bemerkt, dass vorne die gekreuzten Ligamente durch ein Fettpolster getrennt sind.

Nachdem man das Ligamentum cruciatum externum isolirt hat, schneidet man es Schichte für Schichte und sieht seine Dicke.

Zuweilen findet man zwischen diesem und dem Ligamentum cruciatum internum einen Schleimbentel, welcher von den Reibungen, die zwischen diesen Bändern stattfinden, entsteht.

Man luxirt jetzt das Tibiaplateau nach vorne und studirt das Ligamentum cruciatum postero-internum; man bemerkt, dass eine synoviale Aussackung zwischen seinem hintern Ende und den hintern Fortsätzen der Menisci besteht. Man durchschneidet dieses Ligament transversal und sieht, dass es ebenso dick ist als das erste.

Man bemerkt, dass das Tibiaplateau, welches anfangs an den Condylen des Femur angenietet schien, sich jetzt, nachdem man die beiden Lig. cruciata durchschnitten hat: mit der grössten Leichtigkeit nach hinten oder vorne bewegt.

Vene saphena interna und Nervus saphenns intermus. Die Vena saphena interna umschlingt an der innern Fläche des Knies die Erhabenheit des Condylus internus; sie ist in einer Verdopplung des oberflächlichen Fascienblattes enthalten.

Der Nervus saphenus internus unter der tiefen Fläche und hinterm Rande des Sartorius gelagert, lehnt sich handbreit unter der Gelenklinie des Knnies an die Vena saphena an.

Technik z. a. d. G. Der Verlauf der Vene ist sehr oft durch einen farbigen Weg angezeigt, hervorgerufen durch die Diffusion des Blutes. Man 
sucht mit der Fingerbeere des Daumens die Weichtheile niederdrïckend die Erhabenheit des Condylus internus, die Depressio articularis und den innern Rand des Tibiaplateaus auf. Einen Finger dahinter macht man einen langen verticalen Schnitt und präparirend sucht man unter jedem der Schnittränder die Vena saphena interna.

Man sucht den bintern Rand des Sartorius ant, den man isolirt, und findet unter seiner tiefen Schichte den Nervus saphenus internus, welcher von einem Hautaste der Arteria anastomotica magna begleitet ist.

Pes anserinns. Die Sehnen, welche denselben bilden. Der Pes anserinus wird von drei Sehnen gebildet, welche in zwei Schichten liegen:

Fig. 94.

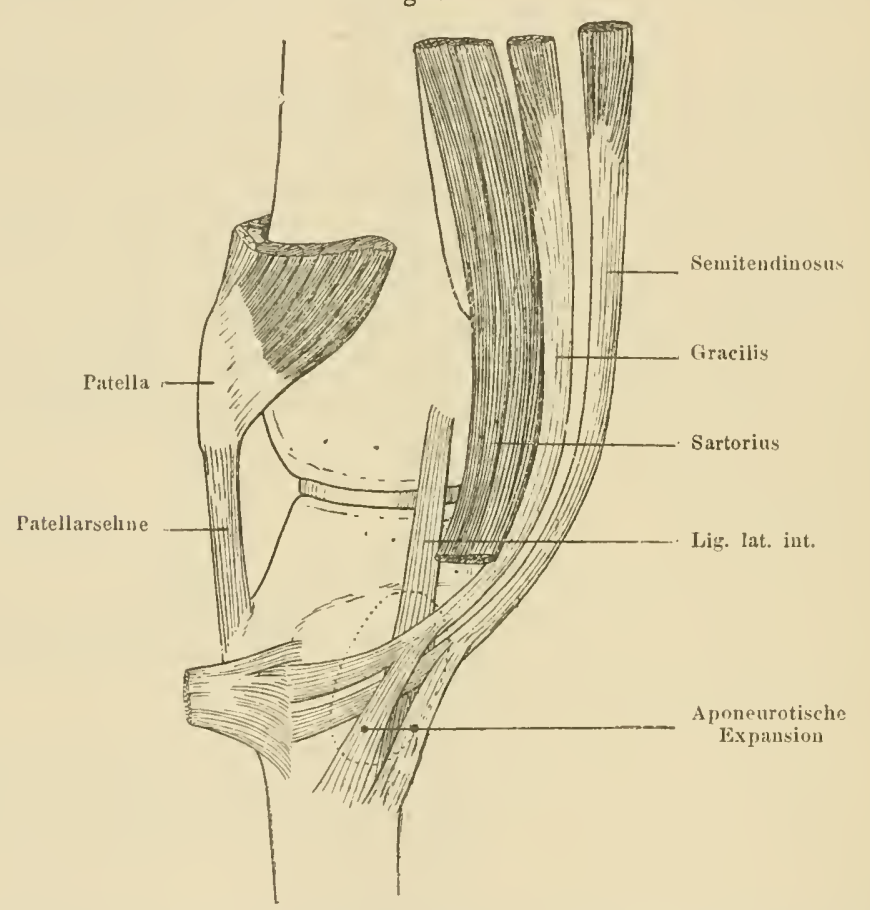

Die innere Fläche des rechten Knies. Die Sehnen des Pes anserinus; der Sartorius wurde durchschnitten, um die unter demselben befindlichen Sehnen freizulegen. Die punktirte Linie entspricht den Sehleimbenteln.

1. Die erste Schichte wird von der breiten Sehne des Sartorius gebildet. Der Fleischlö̈rper dieses Muskels umsehlingt den Condylus internus und etwas unterhalb desselben übergeht er in ein selniges Blatt, welches sich nach unten und vorne gegen die Tuberositas tibialis richtet: er inserirt sich an deren inneren Fläche nahe dem vordern Rande auf einer 2-3 fingerbreit langen Linie (Fig. 93-94).

2. Die zweite Schichte wird von oben nach unten von der Schne des Rectus interior und der des Semitendinosus gebildet.

Die Selune des Rectus intermus (Musculus gracilis) ist lang und dünn, umschlingt den Condylus internus, richtet sich nach unten und vorne, dringt unter der 
tiefen Fläche des Sartorius, berührt die Erhabenheit des Ligamentum laterale internum, verbreitert und inserirt sich an der innern Fläche der Tibia im Niveau der untern Partie der Tuberositas tibialis. Eine fibröse Ausbreitung in Form eines Fächers entsteht am untern Rande dieser Sehne an dem Punkte, wo sie mit dem Ligamentum laterale internum sich kreuzt und übergeht in die Fascie des Unterschenkels (Fig. 93-94).

Die Selme des Semitendinossus ist lang und dünn wie die des Vorhergehenden und liegt zuerst an der Aussenseite des Rectus internus, nähert sich daun demselben und berührt die Erhabenheit des Ligamentum laterale internum, verbreitert sich dann fächerförmig und inserirt sich an der innern Fläche der Tibia unter der Insertion des Rectus internus (Fig. 93-94).

Die obern Fasern der Sehne des Semitendinosus kreuzen sich mit den untern Fasern der Sehne des Rectus internus.

Eine fibröse Expansion in Form eines Fächers entsteht am untern Rande der Sehne des Semitendinosus und übergeht in die Fascie des Unterschenkels. Ein in verticaler Richtung verlängerter Schleimbeutel befindet sich zwischen der Sehne des Rectus internus und der des Semitendinosus einerseits und dem Ligamentum laterale internum andererseits. Dieser Schleimbeutel, welcher zuweilen durch eine sichelförmige Falte in zwei über einander gelagerte Räume getheilt sein kann, schickt oft durch das Interstitium, welches die Sehnen der tiefen Schichte scheidet, eine Aussackung aus, welche sich zwischen den Sehnen dieser Schichte und der Sehne des Sartorius entwickelt.

Technik z. a. d. G. Man führt von dem hintern Theile des Condylus internus gegen die Tuberositas tibialis anterior einen langen Schnitt.

Man sucht auf und isolirt die Sehne des Sartorius, welche man transversal durchschneidet, löst das untere Fragment los und zieht es nach vorne und findet unter demselben die zweite Sehnenschichte.

Man trennt die Sehnen, welche diese Schichte bilden, oben den Rectus internus, unten den Semitendinosos und studirt ihre Insertion an der Tibia und die Ausbreitungen, welche sie der Fascie des Unterschenkels zuschicken. Man durchschneidet dann transversal diese beiden Sehnen und findet unter ihmen und von denselben durch einen breiten Schleimbeutel getrennt ein glänzendes fibröses Band, welches das Ligamentnm laterale internum darstellt.

Der subpatellare Nervenfaden. Der Nervus saphenus internus entsendet unter dem Condylus internus einen Nervenfaden, welcher sich nach unten und vorne richtet; er beschreibt einen Bogen mit der Concavität nach innen und theilt sich in zahlreiche Aeste in der Haut zwischen der vordern und innern Fläche des Knies.

Technik z. a. d. G. Man macht von der Spitze der Patella eine gegen den innern Rand der Tibia schief nach unten und innen gerichtete Incision. Man sucht mit Sorgfalt, indem man Schichte für Schichte aufmerksam präparirt, den Nervenfaden, welcher die ausgeführte Incision in $\times$ kreuzt.

Das Ligamentum laterale interunun ist ein fibröses Band, das zwischen dem Condylus internus femoris und der innern Fläche der Tibia gespannt ist. Es ist 10-12 cm lang und seine Breite nimmt von oben nach unten zu, wo sie mehr als fingerbreit wird; der Verlauf des Bandes ist nicht vertical, sondern etwas schief nach unten und vorne.

Das Ligamentum laterale internum inserirt sich mit seinem obern Ende am Tuber- 
culum condyloideum internum, mit seinem untern Ende an der innern Fläehe und etwas am innern Rande der Tibia drei linger ungefähr unter der Gelenklinie.

Seine tiefe Fläche entspricht ron oben nach unten der tiefen Schichte der Gelenkkapsel, dem Meniscus und der innern Fläehe des obern Endes der Tibia, von welcher sie dureh einen Raum gesehieden ist; in diesem findet man die Arteria articularis inferior interna.

Zwei Schleimbeutel findet man unter der tiefen Fläche des Liganentum loterale internum; einen obern zwischen diesem und der tiefen Schichte der Gelenkkapsel im Niveau des untern Randes des Condylus femoris; einen untern im Nireau der innern Fläche des Tibialplateaus. Oft communiciren beide Schleimbeutel mit einander. Die Oberfläche

Fig. 95 .

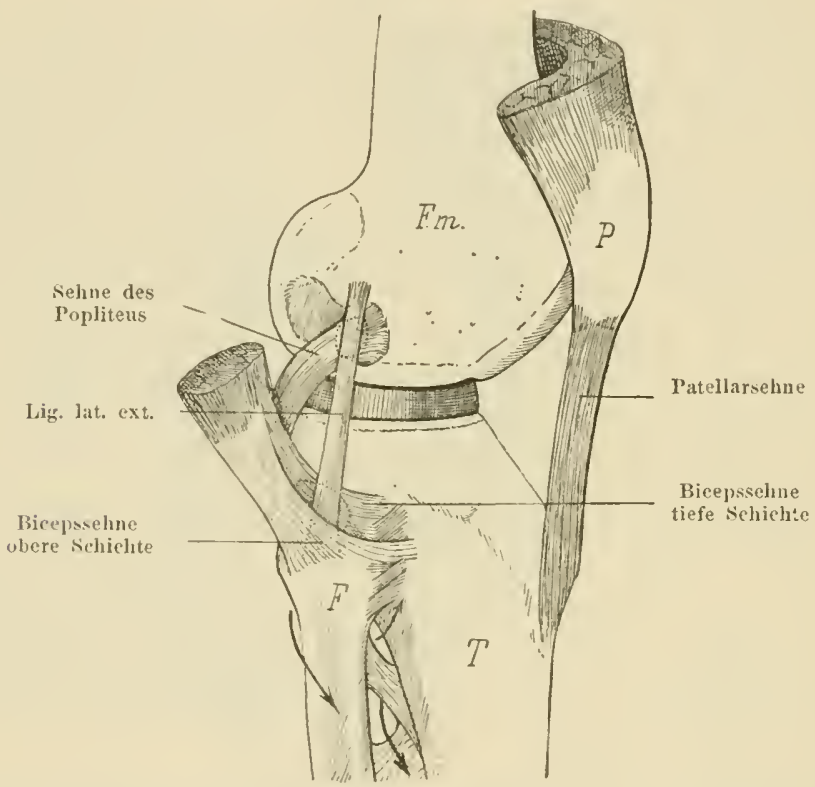

Die äussere laterale Fläche des rechten linies. Der obere punktirte Reifen stellt den Schleimbeutel $z$ wischen Popliteus und Ligamentum externum dar. Der untere punktirte Reifen stellt den unteren Schleimbeutel dar, welcher zwischen den beiden Schichten der Bicepssehne liegt.

des ligamentum laterale internum steht in Beziehung zu den beiden Sehnensehichten des Pes anserinus, von welehem sie, wie wir gesehen haben, durch cinen breiten Schleimbeutel geschieden ist.

Teronik z. A. d. G. Man sucht oben gegen den hintern Theil der Hautflïche des Condylus femoris internus die Erhabenheit, welche das Tuberculum darstellt, und nach unten das obere Drittel des innernRandes der Tibia auf. Zwischen diesen beiden Punkten macht man eine lange Incision, durchschneidet die Sehuen des Pes anserinus - legt stumpfe Haken ein - und sicht im Grunde des Schnittes weiss und glänzend das Ligamentum laterale internum. 
Man begrent seinen vordern und hintern Rand, durchschneidet ihn transversal in seinem untern Drittel und löst von oben nach unten die tiefe Fläche des obern Fragmentes ab; auf diese Weise eröffnet man der Reihe nach die beiden Schleimbeutel, welche unter ihm sich befinden. Man löst auch die tiefe Fläche des untern Fragmentes ab, man findet unter diesem, am Knochen aufliegend, die Arteria articularis inferior interna.

Die Sehne des Biceps steigt vertical an der hintern Grenze der äussern Fläche des Knies herab und theilt sich im Niveau des Fibulaköpfehens in 2 Schichten:

a) Die tiefe Schichte inserirt sich fächerförmig ausgebreitet an dem vordern Rande des Processus styloides, an dem hintern Theile der obern Fläche des Fibulaköpfchens und an der äussern Fläche des Condylus tibialis.

b) Die oberflächliche Schichte, um vieles fester als die tiefe, inserirt sich an den vordern Theile des Fibulaköpfchens, an der äussern Fläche des Condylus tibiae unmittelbar vor der tibio-fibularen Gelenklinie und an der vordern Fascie des Unterschenkels mit einer breiten Ausbreitung in Form eines Fächers, dessen Fasern am vordern Rande der Tibia endigen (Fig. 95).

Zwischen diesen beiden Schichten der Bicepssehne dringt das untere Ende des Ligamentum laterale externum. Ein Schleibeutel in Form eines Hufeisens befindet sich zwischen den beiden Schichten des Bicepssehne und dem Ende des Ligamentes.

Technik z. A. d. G. Man prüft die äussere Fläche eines in Extensionsstellung befindlichen Knies, man sieht am hintern Rande die verticale Erhebung der Bicepssehne, die zuweilen stark hervortritt.

Man folgt mit den Fingern von oben nach unten der Erhabenheit der Bicepssehne und gelangt an das Fibulaköpfchen.

Ian führt einen langen Schnitt, der oberhalb des Condylus femoris internus beginnt, dem sehnigen Strange folgt, über das Fibulaköpfchen hinübergeht und am vordern Rande der Fibula endigt; unmittelbar unter der Fascie gelangt man an die Sehne des Biceps. Mit Pincette und Bistouri isolirt man die beiden Ränder der Sehne und studirt ihre Insertion am Fibulaköpfchen, ihre Beziehungen zum Ligamentum laterale externum und die feste Ausbreitung, die sie der Unterschenkelfascie zuschickt.

Das Ligamentum Maessias, die verstärkte Partie der Fascia lata, verläuft an der äussern Fläche des Kinies und inserirt sich an dem hintern Theile des Tuberculum Gerdy.

Technik z. A. d. G. Wan findet in der gleichen Distanz vom Fibulaköpfchen und der Tuberositas anterior der Tibia das Tuberculum Gerdy. Man macht dann an der äusseın Fläche des Knies gegen das Tuberculum einen langen verticalen Schnitt und gelangt unmittelbar unter der Haut an eine fibröse Fläche weiss glänzend und sehr resistent - das Ende des Ligamentum Mlaessias. Nit Pincette und Hohlsonde isolirt man vorne und hinten dieses fibröse Band und hebt es auf die Hohlsonde; man sieht, dass es so resistent ist, dass eher die Sonde sich einbiegt, als dies reisst. Es wird transversal durchschnitten und man überzeugt sich von seiner Festigkeit; es ist nämlich mehr als $2 \mathrm{~mm}$ dick.

Das Ligamentum laterale externum ist ein Strang ron der Dicke einer mittlern Hohlsonde; 4-5 fingerbreit lang ist es zwischen Condylus femoris externus und Fibulaköpfehen ausgespannt; sein Verlauf ist nicht vertical, sondern schief nach unten und hinten. 
Es inserirt sich mit seinem obern Ende an der Spitze des Tuberculum condyloideum externum unmittelbar vor der Insertion der äussern Gemellussehne und oberhalb der Insertion des Popliteus; mit seinem untern Ende leicht in Form eines Kegels entwiclielt, inserirt es sich an der oblongen Fläche, welche das mittlere Drittel der obern Fläche des Fibulaköpfelıens etwas nach innen ron der Basis des Processus styloides fibulae einnimmt (Fig. 95).

Das Ligamentum laterale externum, von einer sehr festen aponeurotischen Schichte bedeckt, welche rom Ligamentum Maessias gebildet wird, entspricht mit der tiefen liäche und ron olien nach unten der Sehne des Popliteus und dem Meniscus articularis externus, von welchem es durch einen zelligen Raum getrennt ist, in welchem man die Arteria articularis inferior externa findet.

Wir haben gesehen, wie das untere Ende des Ligamentum laterale externum in dem Gange sich befindet, welcher die beiden Schichten der Bicepssehne scheidet und wio es ron diesen durch einen 5-10 mm hohen Schleimbentel geschieden ist, welcher die Form eines nach hinten offenen Hufeisens hat.

Hinten sind die beiden Räume der Serosa durch eine fibröse Wand geschieden, welche den Bifurcationswinkel der Bicipitalsehne mit dem Ligamentum laterale externum verbindet. Oft fehlt diese Wand ind der Schleimbeutel hat die Form eines Cylinders, welcher von allen Seiten das Ende des Ligamentes umschlingt.

Technik z. A. d. G. Durch eine aufmerksame Palpation sucht man oben das Tubereulum condyloideum externum, unten und hinten das Fibulaköpfehen auf. Han macht zwischen diesen Punkten eine lange verticale Incision, durchschneidet das ligamentum Maessias und untel diesem isolirt man den fibrösen Strang, welcher das ligamentum laterale externum darstellt. Gegen das Fibulaköpfehen durchschneidet man die oberflächliche Schichte der Bicepssehne, man sieht das untere Ende des Ligamentes von seinem Schleimbeutel umgeben.

Nan studirt anfmerksam seine Insertion oben am Condyl und unten an der Fibula; durchschneidet ihn transversal und löst die tiefe Fläche des obern Fragmentes ab, unter diesem sucht man die Sehne des Popliteus auf, von welcher er oft durch cinen Sehleimbeutel getrennt ist.

Im Niveau der Gelenklinie präparirt man die Arteria articularis inferior externa, welche am Meniscus gelagert ist. sehne.

Unter dem untern Fragmente sucht man die tiefe Schichte der Biceps-

\section{Die Kniekehle.}

Digitaluntersuchumg. Man prüft die hintere Fläche des wenig in Flexionsstellung befindlichen Knies, diese hat die Form einer vertiealen Furche, welche aussen von der Erhabenheit des Biceps und des Condylus externus, der von dem entspreehenden Gemellus bedeckt ist, begrenzt wird, innen von der Erhabenheit des Semimembranosus und des Condylus internus, der vom Gemellus internus bedeckt ist.

Man drückt die Finger tief in die Furehe, indem man derselben von oben nach unten folgt, und fühlt eine knöeherne Fläehe - den Grund der Kniekehle - welche oben vom Femur unten von der Fossa intereon- 
dyloidea begrenzt ist; man fasst mit den Fingern aussen den Körper des Biceps, innen die sehr dicke Muskelmasse, welche vom Semimenbranosus gebildet wird, hinter diesem befindet sich der Semitendinosus und innen der Rectus internus und der Sartorius.

Fig. 96.

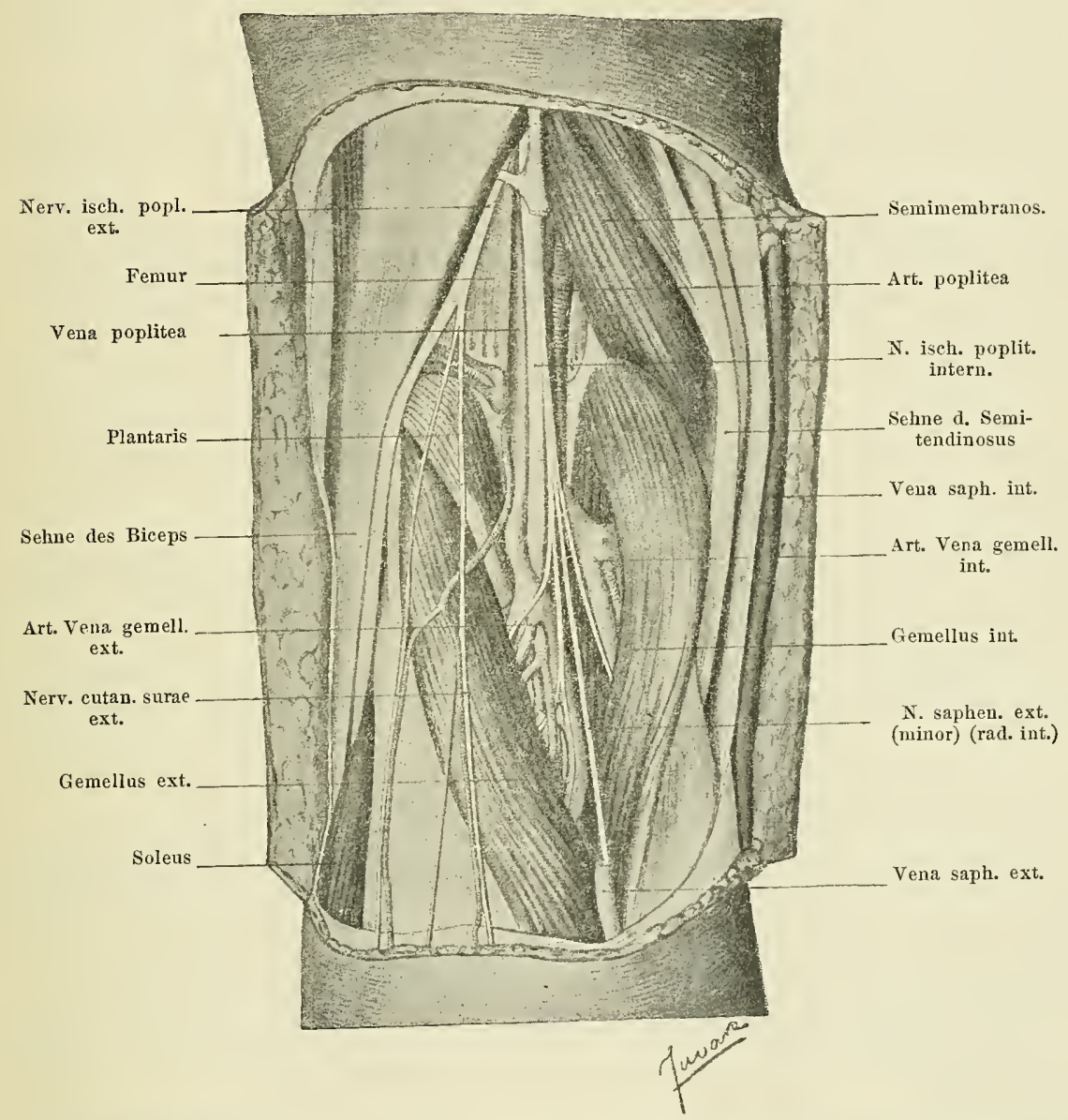

Die Kniekehle und ihr Inhalt. Die oberflächliche Fascie wurde abgetragen. Die inneren Ränder der Gemelli wurden nach aussen gekehrt, um besser die Grefässe und Nerven sehen zu können.

Im Niveau der Fossa intercondyloidea tastet man der Reihe nach mit den Fingern jeden Condylus ab.

Unter dem Condylus externus sieht und fühlt man die Erhabenheit des Fibulaköpfchens, welches mehr der hintern Fläche als der äussern Fläche des Knies angehört.

IIan beugt das Knie in einem rechten Winkel; es entspannen sich die 
Muskeln und die Weichtheile sind jetzt leichter niederzudrücken; die Finger tasten leichter $a b$ und fühlen auf der Popliteafläche des Femur gleitend den Strang des Nervus ischiadieus popliteus internus.

In dieser Stellung muss man eine Knniekehle untersuchen, weun man mit Leichtigkeit und Genauigkeit die Lage der W'eichtheile untersuchen will.

Man prüft die Kniekelıle, wenn sich das Knie in Extensionsstellung befindet und sieht, dass die vorher erwähnte Furche durch eine verticale Erhebung ersetzt ist, verursacht durch die Anspannung der Aponeurose am Strange, welchen der Nervus ischiadicus popliteus internus bildet.

In dieser Lage wird man grosse Schwierigkeit haben, die Knickehle abzutasten, weil die Spitze der Finger der resistenten Fläche, welche die gespannte Aponeurose bildet, begegnen.

Die Beugung des Unterschenkels begrenzt an der hintern Fläche des Knies eine Hautfalte - die Beugungsfalte - in Form eines Bogens, dessen Enden gegen die Tubercula der Condylen sich verlieren (Fig. 96).

Die Kniekehle stelit eine Höhle von rhomboider Form dar, welche durch eine horizontal gelegte Ebene in zwei Dreiecke oder Partien getheilt werden liann.

Das grössere Dreieck wird innen rom transversal verbreiteten Körper des Biceps, aussen rom dicken und kräftigen Körper des Semimembranosus begrenzt. An der hintern Fläche dieses Muskels findet man den Semitendinosus, an der innern Fläche den Rectus internus und Sartorius.

Das untere Dreieck wird aussen rom innern Rande des Gemellus externus, längs dessen man den dünnen PIantaris findet, innen vom äussern Rande des Gemellus interns begrenzt.

Die Gemelli inseriren sich oberhalb der Condylen mit einer festen etwas fächerförmig verbreiterten Sehne, welche wie eine Mütze die Condylerhabenheit bedeckt, und mit ihrer tiefen Fläche an der Gelenkliapsel adhärirt.

Die Insertionsoberflächen der Gemelli haben die Form eines mit der Spitze nach oben gerichteten Winkels, welcher den obern Rand der Condylen umfasst.

Die Sehne des Gemellus externus entsteht mit ihrer äussern weissen und glänzenden Partie an der dreieckigen Fläche, welche man an der Ilautfläche des Condylus externus unmittelbar oberhalb des Tuberculum condyloideum findet, mit ihrer innern Partie an Tuberculum supra-condyloineum externum und an der Reihe von Rauhigkeiten, welche sich nach innen gegen die Fossa intercondyloidea fortsetzen.

Zwischen den Bündeln, welche den innern Theil dieser Sehne bilden, befinden sich kleine Fettläppchen und kleine synoviale Aussackungen - Processus supracondyloidei externi.

Diese Initialsehne entwickelt sich unter dem Condylus zu einem breiten fibrösen Fächer, an dessen vorderer Fläche und innerm Rande Muskelbündel entstehen, welche nach abwärts ziehen und an der hintern Fläche der Endsehne sich inseriren.

Die Sehne des Gemellus internus entsteht an der rechtwinkligen Fläche, welohe oberhalb der Lücke des obern Randes des Condylus internus gelegen ist, am Tuberculum supracondyloideum internum und an der Leiste, welche nach innen gegen die Fossa intercondyloidea sich fortsetzt.

Wie für den Gemellus externus befinden sich zwischen den fibrösen Bündeln, welche die Partie der Sehne bilden, die am Tuberculum supracondyloideum entsteht, synoviale Aussackungen - Processus supracondyloidei interni. 
Der dünne Musculus plantaris entsteht mit Fleischfasern an der untersten Partie des äussern Randes des Femur, an der Sehne des Gemellus externus und an der Capsula condyloidea externa. Sein prismatischer und dreiwinkliger Fleischkörper liegt am innern Rande und etwas unter der tiefen Fläche des Gemellus externus; er ist von der Länge einer Handbreite und geht in ein fibröses Band über, welches in den Zwischenraum zieht, der vom Soleus und den Gemelli begrenzt ist, erscheint am innern Rande der Achillessehne und inserirt sich neben dieser am innern Pande der hintern Fläche des Calcaneus.

Die vordere Wand oder der Boden der Kniekehle wird von oben nach unten: a) von der Popliteafläche des Femur, die von den beiden divergirenden Lefzen der Linea aspera begrenzt ist, b) von der fibrösen sehr resistenten Fläche zwischen den Capsulae condyloideae gespannt und c) von der hintern Fläche des Musculus popliteus begrenzt.

Der Musculus popliteus entsteht mit einer schönen Sehne an der vordern Hälfte der Furche in Form eines Bogens, welcher an der Hautfläche des Condylus externus sich befindet, mit aponeurotischen Bändchen an dem hintern Rande des Ligamentum arcuatum und an der Gelenkkapsel. Unten inserirt sich der dreieckige Fleischkörper des Muskels an der innern Hälfte der Popliteafläche der Tibia und mit einigen Fasern geht er in die Initialehne des Sulcus über.

Die hintere Wand der Kiniekehle wird von oben in die Tiefe von der Haut, der subcutanen Fettschichte und von der Aponeurose gebildet.

Die Aponeurosis poplitea ist sehr fest und wird zum grössten Theile von transversalen fibrösen Bogen gebildet, gegen den mittlern Theil ist sie in zwei Blättchen getheilt, zwischen welchen man die Vena saphena externa findet.

Oben geht sie in die Fascia femoris, unten in die Fascie des Unterschenkels über, aussen verdoppelt sie sich, um den Biceps aufzunehmen. - Das zellig-fibröse tiefe Blatt bekleidet die innere Fläche des Biceps und inserirt sich am äussern Bifurcationsaste der Linea aspera, das oberflächliche Blatt bedeckt den Biceps und geht in die innere Fascie des Unterschenkels über.

Innen theilt sich die Aponeurosis poplitea, um den Semimembranosus aufzunehmen; das tiefe Blatt hört an der innern Bifurcationsleiste der Linea aspera auf; das oberflächliche Blatt bedeckt den Semimembranosus und bildet auf dem Wege gegen die innere Fläche des Knies eigene Scheiden für den Semitendinosus, Rectus internus und Sartorius.

Technik z. A. d. G. Man macht eine verticale Incision an der äusseren Erhabenheit der Kniekehle und sucht unter der Aponeurose von oben nach unten den Biceps und den Gemellus externus auf. Man durchschneidet quer den Biceps, zieht ihn nach unten und studirt die Insertion des Gemellus externus. Man durchschneidet quer den Gemellus, erhebt das obere Fragment und präparirt seine tiefe Fläche; man findet das Sesambein, welches in der Sehne dieses Nuskels sich befindet. Unter dem Gemellus findet man den äusseren Theil des Popliteus.

Man macht eine verticale Incision an der inneren Erhabenheit der Kniekehle, sucht oben den Semimembranosus auf, an dessen hinterer Fläche man den Semitendinosus findet; unten findet man den Gemellus internus. Man bemerkt, dass der innere concave Rand des Gemellus sich an der äusseren Fläche des Semimembranosus zurückschläot; in diesem Niveau eröffnet man mit dem Bistouri einen Schleimbeutel - der gemeinsame Schleimbeutel des Semimembranosus und Gemellus, welcher stets zwischen 
diesen beiden Selmen sich befindet. Mit einem stumpfen Haken hebt man die Sehne des Gemellus internus, zwischen dieser und der Capsula am Condylus internus existirt ein anderer Schleimbeutel - der Schleimbentel des Gemellus internus, welcher oft durch ein kreisförmiges Loch mit der Gelenkhöhle communicirt. Oft kann der Schleimbeutel des Gemellus internus von dem gemeinsamen Schleimbeutel des Gemellus und Semimembranosus getrennt sein.

Nan durchschneidet quer die Sehne des Semimembranosus, präparirt seine tiefe Fläche, sucht die rücklanfende Ausbreitung und auch jene, welche er der Capsula condyloidea interna zuschickt, auf und durchschneidet sie.

Nahe der Tuberositas tibialis eröffnet man cinen Schleimbeutel - der Schleimbeutel des Semimembranosus -, welcher zwischen diesem und dem oberen Rande der Furche, welche wir an der hinteren Fläche der Tuberositas tibialis interna kennen, sich befindet. Dieser Schleimbeutel schickt eine Aussackung rings um die Portio reflexa der Sehne ab.

\section{Inhalt der Kniekehle, das Gefäss- und Nervenpacket.}

Die Knickehle wird ron oben nach unten ron einem Gefäss- und Nerrenpacket durchzogen, welches in einer zellig-fihrösen Scheide enthalten und ron etner Fettschicht umgeben ist; es wird rom Ramus internus des Nervus ischiadicus, von der Arteria und Vena poplitea gebildet.

Der grosse Nervus ischiadicus theilt sich an der Spitze der Kniekehle in dic beiden Endäste: Nervus ischiadicus popliteus internus und Nerrus ischiadicus popliteus externus.

Der Nervus popliteus internus liegt unmittelbar unter der Aponemrose, steigt rertical in ler Achse der Kniekehle herab und endigt im Niveau des Ringes des Soleus, wo er als Nervus tibialis posticus bezeichnet wird.

Techuik z. A. d. G. Bei in Beugung befindlichem Knie palpirt man mit Sorgfalt die Knickehle; drückt man die Weichtheile tief ein, so fühlt man an der knöchernen Fläche, welche von der Popliteafläche des Femur gebildet wird, den Nervus isehiadicus popliteus internus gleiten.

Man bringt das Knie in Extensionsstellung, sucht die Popliteafurche auf und führt längs derselben cine lange verticale Incision. Nlan durchschneidet die Haut und die Aponeurose und findet unmittelbar darunter den Nervus ischiadicus popliteus internus, den man isolirt und auf die Hohlsonde hebt. Man bemerkt, dass gegen seinen unteren Theil, im unteren Winkel der Kniekehle, der Nervus ischiadicus popliteus internus ein ganzes Büschel von Aesten abgiebt, welche nach innen für den Gemellus internus, nach aussen für den Gemellus extermus, Plantaris longus, Soleus und Popliteus bestimmt sind. Der Faden dieses letzteren Muskels ist schwer aufzufinden, deshalb erhebt man mit dem hakenförmig gekrümmten Finger den Nerrenstamm; man sieht nun ron ilm einen kleinen Faden abgehen, welcher nach unten zieht, die Arteria poplitea umschlingt, an ihre ïussere Fläche gelangt und unter dieser in den oberen Rand des Popliteus eindringt, nachdem er einige Aeste für das Gelenk abgeschickt hat. 
Der Nervis ischiadicns poplitens externus. Er begleitet den inneren Rand der Bicepssehne und richtet sich schief nach unten und aussen gegen den Hals der Fibula; in diesem Niveau dringt er in das Interstitium, welches den Soleus rom langen Peroneus lateralis scheidet, umschlingt den Hals der Fibula, auf welchem er liegt, und theit sich in die beiden Endäste: Nerrus tibialis anticus und Nerrus musculo-

Fig. 97.

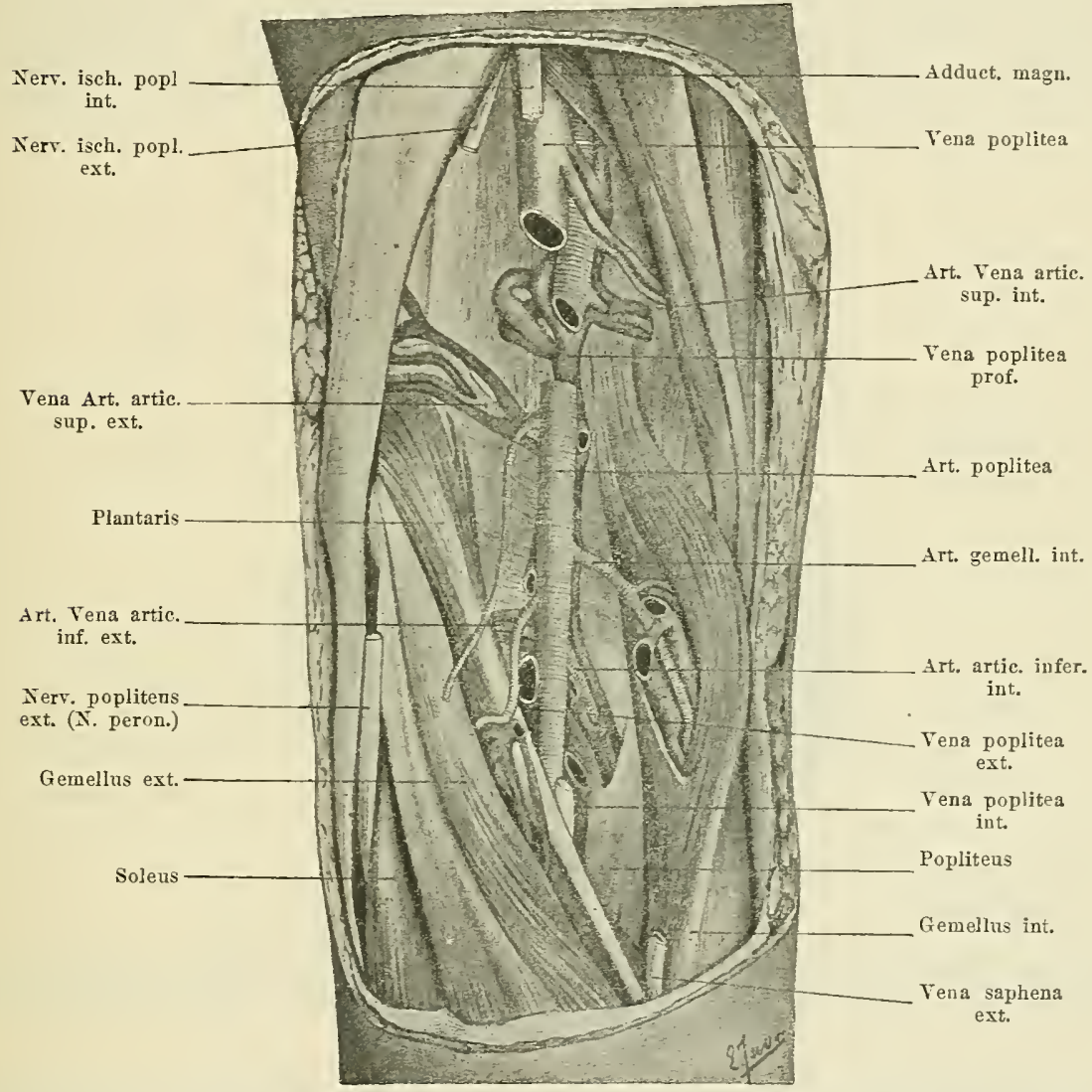

Die Kniekehle der linken Seite. Die Arteriae, Venae und Nervi poplitei wurden resecirt. Vor der Arterie sieht man einen renösen Kanal, dem fast alle Venae articulares und musculares der Kniekehle angehören. Diese Vene kann Vena poplitea profunda genannt werden. Sie anastomosirt in mehreren Reihen mit der Vena poplitea, der sie als "Sicherheitskanal" dient.

cutaneus. Der Nervus ischiadicus externus ist in einer aponeurotischen Scheide enthalten, welche durch die Duplicatur der Aponeurosis poplitea' gebildet wird; handbreit oberhalb des Fibulaköpfchens schickt er einen Ast ab, welcher sich in die äussere II urzel des Nervus saphenus externus und in den Nervus cutaneus peroneus theilt.

Technik z. A. d. G. Oberhalb des Fibulaköpfchens. Man sucht die Bicepssehne auf und folgt derselben mit dem Finger bis zum Fibula- 
köpfehen. Man macht längs dieser Sehne cinen Schnitt und findet unmittelbar unter der Aponeurose den Nervus ischiadicus popliteus externus. Ian isolirt und hebt ihn auf eine Hohlsonde und sieht von ihm die iussere Wurzel des Nerrus saphenus internus abgehen.

Luterhalb des Fibulakïpf(clens. Man sucht unmittelbar unter der Erhabenheit des Fibulaköpfchens die Vertiefung auf, welche dem Halse dieses Knnochens entspricht. Mit (ler Fingerbeere tastet man die hintere Fläche des Fibulaköpfchens ab, man kann so den Nervenstrang fühlen, welcher an der knöchernen Fläche gleitet. Man macht am Fibulaköpfchen beginnend eine lange verticale, dreifingerbreite Incision. Ilan durchschneidet rorsichtig die Aponeurose und den langen Peroneus lateralis,

Fig. 9S.

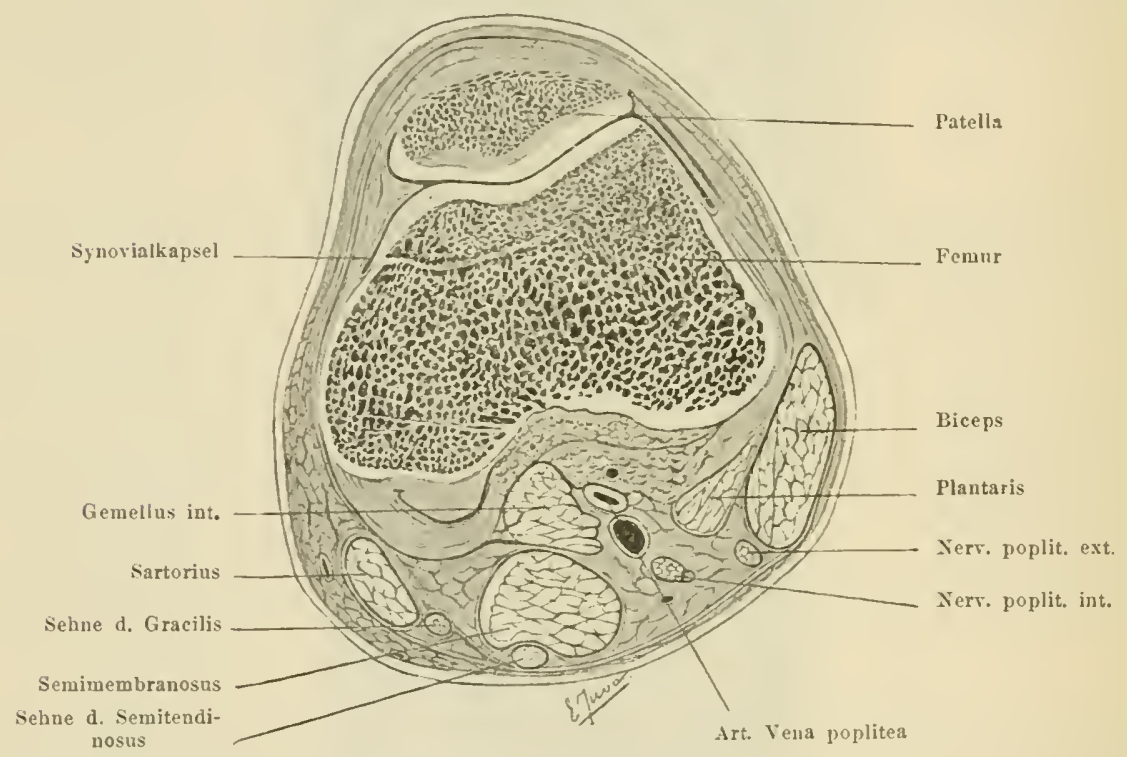

Ein Querschnitt durch das untere Ende des Femur. Die rechte Seite. An dieser Figur sieht man die drei Stufen der Leiter, nach welchen die Gebilde des Gefäss- und Nervenpacketes gelagert sind.

legt stumpfe Haken ein und sucht im Grunde des Schnittes, den Hals der Fibula umschlingend, den Nerrenstamm, den man isolirt und auf die Hohlsonde hebt. Sehr oft ist er in seine Endäste getheilt.

Die Arteria poplitea (Fig. 97). Die Verlängerung der Femoralis beginnt 4 fingerbreit oberhalb des Condylus internus femoris im Xiveau des rierten Ringes des dritten Adductor uud endigt am Ringe des Soleus, wo sie sich in die Arteria tibialis antica und in den Truncus tibio-peroneus theilt.

Schief nach unten und aussen gerichtet stellt die Arteria poplitea drei Partien dar:

a) Eine obere supra-condyloide Partie an der hinteren Fläche des Femur gelegen.

b) Eine mittlere inter-condyloide oder articuläre Partie an der hinteren Fläche des Gelenkes zwischen beiden Condylen gelegen. 
c) Eine untere subcondyloide Partie am Musculus popliteus gelegen.

Von der Arteria poplitea gehen 7 Hauptäste ab, fünf sind für das Gelenk und zwei für die Gemelli bestimmt.

Die Arteriae articulares superiores gehen oberhalb der Condylen ab.

Die Arteria articularis supero-externa zieht ïber den Condylus externus, perforirt die Aponeurosis intermuscularis externa, umschlingt den Femur bogenförmig und theilt sich in Aeste für das Gelenk, für die Muskeln und für das Periost.

Die Arteria articularis supero-interna (Fig. 99) zieht über den Condylus internus, perforirt die Sehne des grossen Adductor und anastomosirt mit der Arteria anastomotica magna.

Fig. 99 .

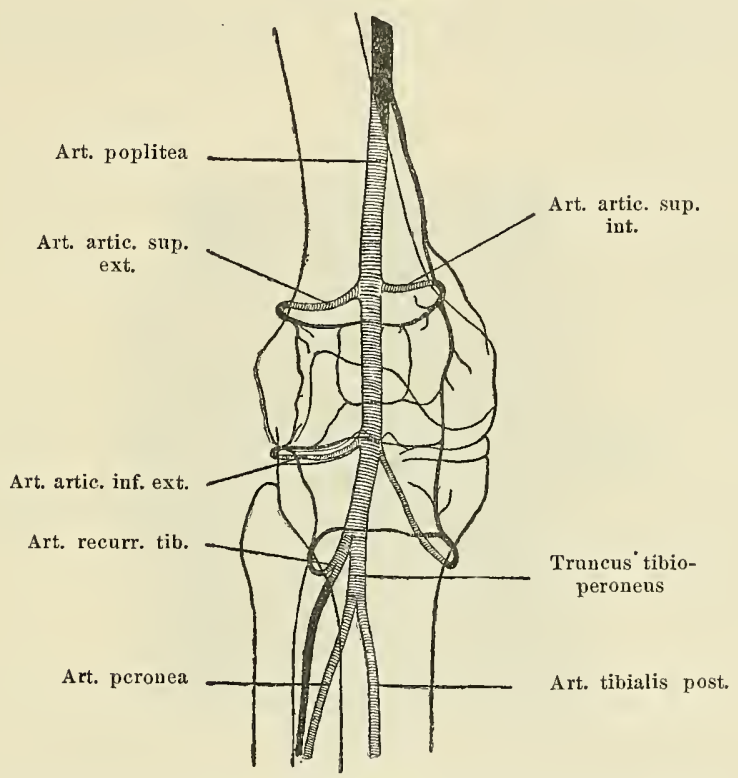

Der arterielle periarticuläre Plexus des Kniegelenkes. Die gestreiften Arterien findet man hinter dem Skelette.

Die Arteria articularis media geht von Aer Portio intercondyloidea der Arteria poplitea ab und dringt in den Innenraum des Gelenkes, wo sie sich verzweigt.

Die Arteria articularis inferior externa richtet sich quer nach aussen, zieht unter dem Ligamentum arcuatum und unter dem Ligamentum laterale externum und folgt der äusseren Fläche des Meniscus externus, welcher sie aufliegt.

Die Arteria articularis inferior interna entsteht etwas unter der Articularis externa, richtet sich sehr schief nach unten und innen, dringt unter die Aponeurosis poplitea, umschlingt die Tibia, und nachdem sie unter dem Ligamentum laterale internum und auf der inneren Fläche der Tibia durchzieht, erhebt sie sich gegen das Gelenk.

Diese vier Arteriae articulares superiores und inferiores theilen sich in Aeste für die Muskeln, für das Periost, für das Gelenk, und indem sie mit der Recurrens tibialis anterior anastomosiren, bilden sie rings $\mathrm{um}$ das Gelenk einen sehr complicirten Plexus 
arteriosus, Plexus poriarticularis (Fig. 99). In diesem Plexus unterscheidet man z wei grosso arterielle Bogen, einen oberen supracondyloiden, welcher von der bogenförmigen Inastomose der beiden Articulares superiores gebildet wirl, einen unteren, welcher von der Anastomose der Articulares inferiores mit der Recurrens tibialis entstanden ist. Diese beiden Bogen communiciren untereinander durch zahlreiche verticale Anastomosen.

Die Arterien dor Gemelli entstehen oft mittelst eines gemeinsamen Stammes an der hinteren Flächo der Portio intercondyloidea der Arteria poplitea. Sie ziehen nach abwärts, eine nach aussen gegen den Gemellus externus, die andere nach innen gegen den Gemellus interus.

Die Vena poplitea wird durch die Vereinigung des venösen Truncus tibio-peronous mit der Tena tibialis anterior gebildet; sie beginnt sehr oft etwas oberhalb des Ringes des Soleus.

Sie liegt zuerst hinten und innen ron der Arteria poplitea, dann oben hinten und etwas anssen ron der $\Lambda$ rterie, um welche sio also ein Viertel einer Spirale beschreibt.

Fig. 100.

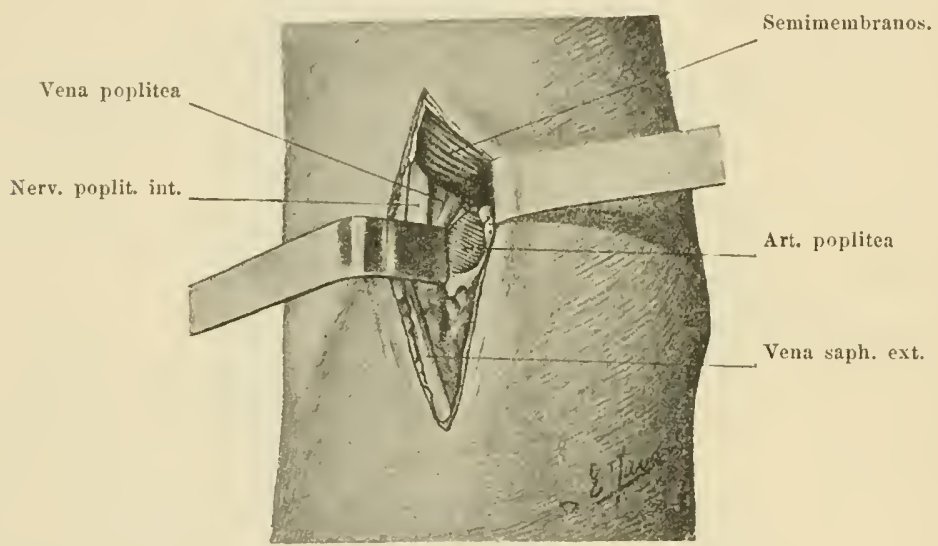

Das Aufsuchen der Arteria poplitea; linke Seite.

Die Arterie und Vene sind in oiner gemeinsamen zellig-fibrösen Scheide enthalton und mit einander durch ein dichtes Bindegewebe innig rereinigt, weshalb die Trennnng der Arterie von der Vene sehr schwer gelingt.

Die Vena saphena externa mündet gegen die Mitte der Kiniekehle in die Vena poplitea ein, indem sie an der innern Seite des Nervus ischiadicus popliteus internus vorbeizieht.

Die Venen der Gemelli und die Venae articulares gehören zur Vena poplitea. Bei an Varices Leidenden sind diese Venen und besonders die Venen der Gemelli und die Vona saphena stark entwickelt, indem sie ein enormes Packet bilden, welches den ganzen untern Winkel der Kniekehle füllt.

Das Packet derGefässe und des Nervus popliteus wird in der oberflächlichen Schichte vom Nervus ischiadicus popliteus internus, in der tiefen Schichte von der Vena und Arteria poplitea gebildet und stellt oberhalb der Condylen eine Leiter mit drei nach innen gerichteten Sprossen dar. Die erste oberflächliche und äussere Sprosse wird rom Nerv gebildet, die zweite von der Vone, die letzte, tiefste und innere, von der Arterie. 
Im Spatium intercondyloideum sind die drei Gebilde des Gefäss- und Nervenpacketes fast in der gleichen antero-posterioren Fläche gelegen.

Unter dem Gelenke befindet sich der Nerv an der Innenseite der Vene und der Arterie; die obere Leiter ist statt nach innen im Gegentheil nach aussen gerichtet, so dass der Nervus ischiadicus popliteus internus den Verlauf der Arterie und Vene in einem sehr verlängerten $\mathrm{X}$ kreuzt.

Technik z. A. d. G. Man sucht den Sulcus popliteus auf und macht in seiner Länge etwas innen von der Medianlinie einen Schnitt, welcher an der Spitze der Kniekehle beginnt und unter der Erhabenheit der Condylen

Fig. 101.

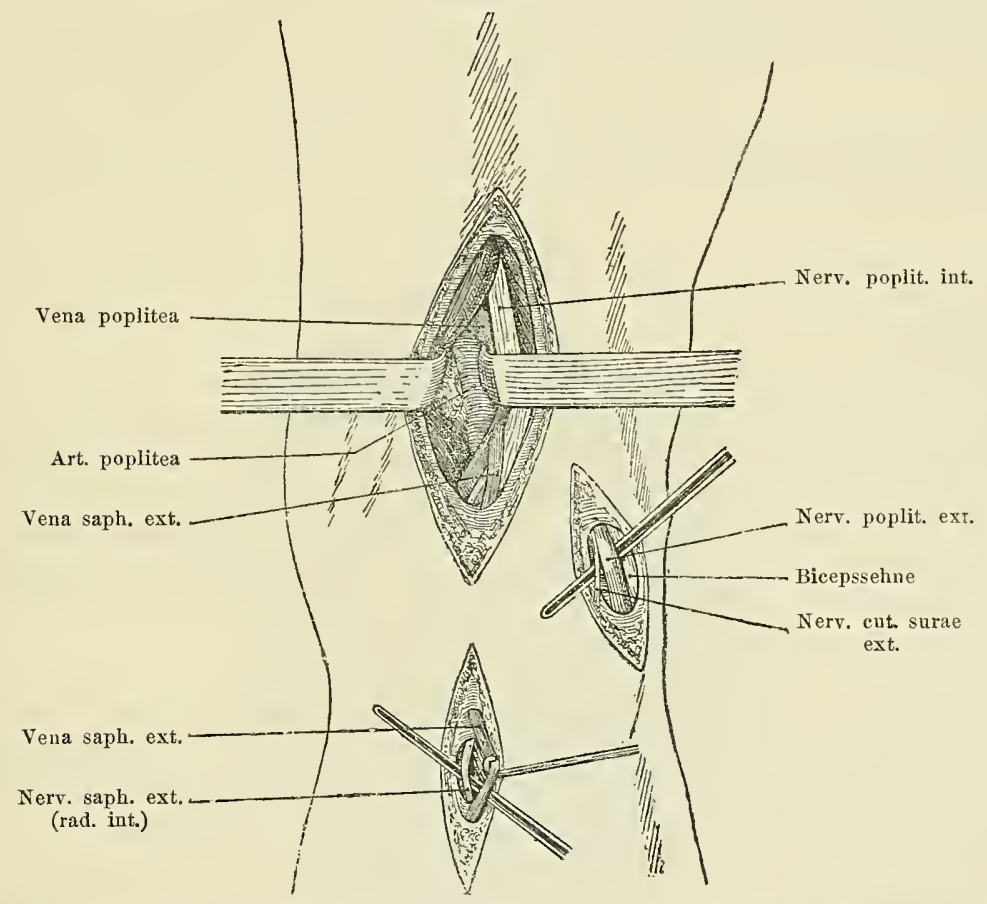

Das Aufsuchen des Gefäss- und Nervenpacketes, des Nervus poplitens externus, der Venen und des Nervus saphenus externus.

endigt. Man durchschneidet die Haut und die Aponeurose und unter dieser erscheint der Nervus ischiadicus popliteus internus. Man legt Haken ein, einen aussen am Biceps, den andern innen am Semimembranosus und isolirt den Nerv. An seiner Innenseite auf einer tiefern Fläche findet man das Gefässpacket von Fett umgeben.

Zuerst findet man die Vena poplitea, mit Pincette und Hohlsonde wird diese von der Arterie getrennt, welche unter der Vene und an ihrer Innenseite sich befindet (Fig. 100).

Man muss mit viel Aufmerksamkeit vorgehen, weil die Vene sehr fest 
an der Arteric allhaerirt und leicht mit der Holslsonde zerrissen werden kann.

Unter der Arterie in einer Fettschichte, welche sie umgiebt, fundet man oft likine hörper ron brauner Farbe - die tiefen Lymphdrïsen der Kiniekchle.

Die Vena saphena exterıa entsteht am äussern Rande des Fusses, durch Vereinigung der Venen des äussern Randes mit dem Dorsalbogen des Fusses, zieht fingerbreit unter und hinter dem Malleolus externus und erhebt sich längs des äussern Randes der Achillessehne, welche sie lireuzt, um median zu werden.

Zuerst in der Fascia superficialis enthalten, dringt sie dann gegen das obere Drittel des Unterschenkels in einer Verdoppelung der Aponeurose.

Gegen die Mitte der Kiniekehle theilt sich die Vena saphena externa in einen Ast, welcher die Aponeurose perforirt und in die Vena poplitea einmündet und in einen andern Ast, welcher den Lauf der Saphena beibehält und gegen die Spitze der Kniekehle in eine Muskelrene, welche sehr oft dem Semimembranosus angehört, mündet.

Der Nervus saphenus externus wird durch Vereinigung von zwei Wurzeln gebildet.

a) Die innere Wurzel oder der Nervus saphenus tibialis entsteht im untern Winkel der Kniekehle vom Nervus ischiadicus popliteus internus, verläuft im Interstitium der beiden Gemelli und gelangt oberhalb der Aponeurose an den mittlern Theil des Unterschenkels.

b) Die äussere Wurzel oder Nervus saphenus peroneus entsteht vom Nervus ischiadicus popliteus externus, steigt schief nach unten und innen auf der hinteren Fläche des Gemellus externus, perforirt die Aponeurose nnd vereinigt sich mit der innern Wurzel an der Mitte des Unterschenkels. Der Nerrus saphenus externus steigt, auf diese Weise gebildet, an der äussern Seite der Vena saphena externa herab, zieht mit ihr hinter dem Nalleolus und folgt dem äussern Rande des Fusses. Die äussere Wurzel des Saphenus giebt einen Faden ab, den Nervus peroneus cutaneus, welcher sich in der Ilaut der obern hintern und äussern IIälfte des Unterschenkels verzweigt.

Technik z. A. Ier Vena saphena in der Kuiekehle und des Nervus saphenus tibialis. Ilan macht an der untern Hälfte des Sulcus popliteus eine Incision, durehschneidet die Haut und sieht durch das aponeurotische Blättchen den bläulichen Streifon, welcher der Vene entspricht. Nan durchschneidet auf der Hohlsonde die Aponeurose, isolirt die Vena saphena und folgt derselben bis zu ihrer Einmündung in die Vena poplitea; man bemerkt, dass sie deshalb an die imnere Seite des Nervus saphenus popliteus internus zieht. Nan hebt die Vene und giebt sie in einen stumpfen Haken, mit der Hohlsonde reisst man das Blättchen, welches die tiefe Wand der aponeurotischen Scheide der Tene bildet, durch; darunter findet man nun den Nervus ischiadicus poplitcus internus, von welchem der Nervus saphenus tibialis abgeht, der zuerst tief in das Interstitium der Gemelli eindringt.

Der Nerrus saphenus peroneus. Man macht zweifingerbreit unter der Bicepsschne an der hintern Fläche des Gemellus externus einen schief nach unten und aussen gerichteten Schnitt. Man durchschneidet rorsiehtig die Aponeurose und sucht im subaponeurotischen Bindegewebe den Nervus saphenus peroneus auf. Man hebt diesen auf die Hohlsonde und zieht an 
ihm; man sieht dann, wenn der Cadaver mager ist, wie er die Haut bis gegen die Mitte des Unterschenkels abhebt, wo er sich mit dem Saphenus tibialis vereinigt. Man sucht, aus dem Saphenus peroneus kommend, den Nervus peroneus cutaneus auf.

\section{Region des Unterschenkels.}

Betrachtet man einen Querschnitt des Unterschenkel, so sieht man, dass der Knochen desselben innen von der Tibia, deren Schnittfläche ein Dreieck darstellt, aussen und etwas hinten von der Fibula, deren Schnitt eine Rhombenform hat, gebildet wird.

Der innere Rand der Fibula ist mit dem äussern Rande der Tibia durch das Ligamentum interosscum verbunden.

Die Fascie des Unterschenkels entsteht am vordern Rande des Schienbeines, beschreibt einen Bogen, indem sie an die Aussenseite des Wadenbeines ziebt und inserirt sich wieder

Fig. 102.

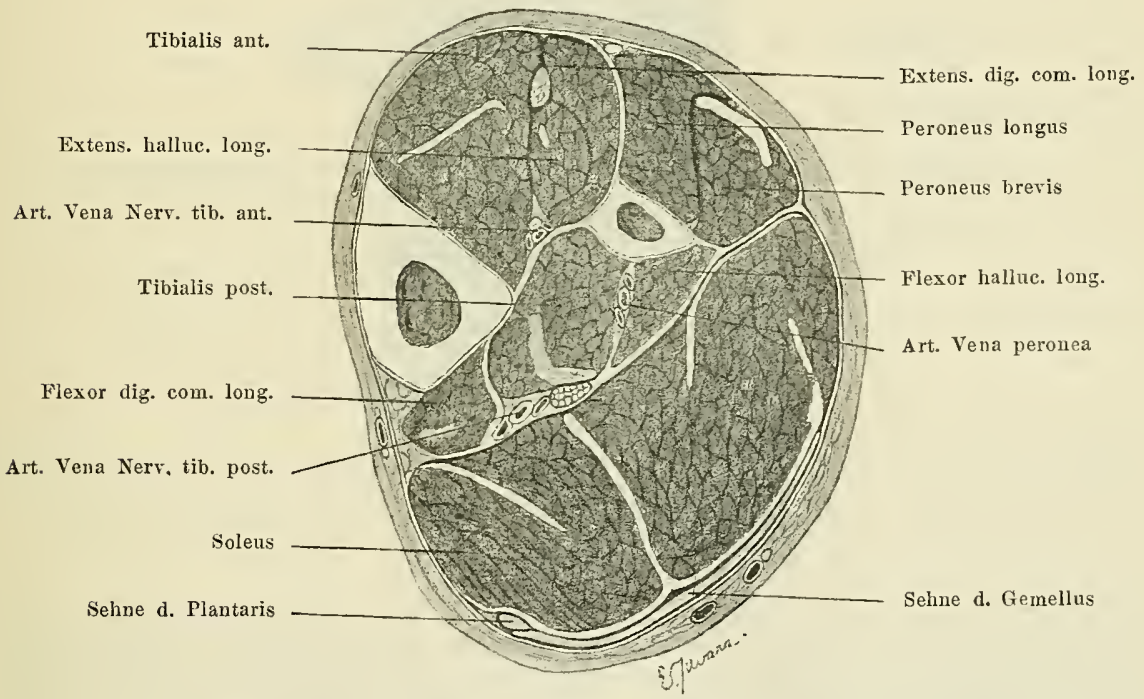

Ein Querschnitt im mittleren Drittheile des rechten Unterschenkels.

am hintern Rande desselben Knochens. Ton dem vordern und änssern Rande der Fibula gehen zwei aponeurotische Blättchen ab, eines richtet sich nach rorne, das andere nach aussen und inserirt sich an der tiefen Fläche der Unterschenkelfascie.

Auf diese Treise wird der Unterschenkel von oben nach unten in drei Räume, einen vordern, einen äussern und einen hintern getheilt.

Der vordere Raum hat die Form eines rechtseitigen, pyramidenförmigen líanales, dessen Dimensionen von oben nach unten abnehmen. Die Wände dieses Kianales werden gebildet: innen von der innern Fläche der Tibia, aussen und hinten ron der 
Fascia intermuscularis - das aponeurotische Blättchen, das den rordern rom äussern Raume scheidet - hinten ron der Fibula und rom Ligamentum interosseum, rorne und aussen ron der sehr festen Fascie des Unterschenkels, die in ilırem obern Theile durch eine fibröse Expansion der Bicepssehne und in ihrem untern Theile durch das Jigamentum annulare des Unterschenliels befestigt wird.

Diesen knöcherigen aponemrotischen hanal nimmt in seinem obern Drittel ron innen nach aussen der Tibialis anticus und der Extensor conmunis ein, etwas nach unten zwischen diesen beiden Muskeln legt sich der Extensor proprius der Grosszehe ein und in dem untern Drittel findet man aussen den Extensor communis und Musculus peroneus anterior.

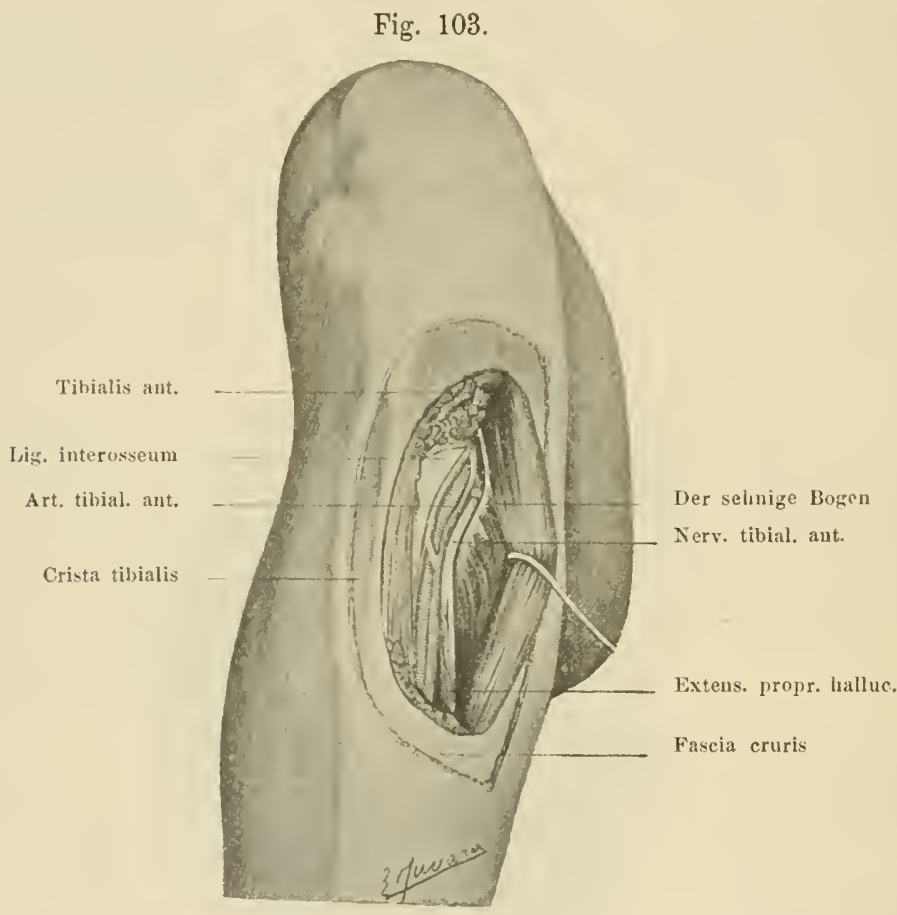

Die Beziehungen der Arteria tibialis antica im oberen Drittheile des Unterschenkels. Der Musculus tibialis anticus wurde resecirt; der Extensor communis longus der Zehen ist nach aussen gezogen, um deu sehnigen Bogen, an welchem sich einige der Ursprungsfasern dieses Muskels inseriren, zu sehen. Unter diesem Bogen zieht der Nervus tibialis anterior.

Zwischen den Muskeln längs des Musculus tibialis anticus verläuft das Packet der Gefässe und des Nerrus tibialis anticus.

Digitaluntersuchung: An der rorderen Fläche des Unterschenkels sieht und fühlt man in Form eines $\mathrm{S}$ die Crista tibiae, die unterhalb der Tuberositas tibialis beginnt. Scharf in ihrem oberen Theile, rundet sie sich gegen das untere Drittel des Unterschenkels ab und rerliert sich gegen den inneren Knöchel. 
An der inneren Fläche des Unterschenkels folgen die Finger von oben nach unten der inneren subcutanen Fläche der Tibia. Mlan nimmt die Tibia zwischen die Finger, indem man ihren vorderen Rand mit der Fingerbeere des Daumens und ihren hinteren Rand mit der des Zeigefingers prüft die von oben nach unten gleitenden Finger fühlen, dass der Knochen in dieser Richtung dünner wird.

In der oberen Hälfte des Unterschenkels verhindert die sehr dicke Fleischmasse eine oberflächliche Digitaluntersuchung der Fibula; nach unten aber wird sie oberflächlich, subcutan und ist sehr leicht abzutasten.

Der IIusculus tibialis anticus, dreieckig und prismatisch, entsteht mit Fleischfasern etwas mehr als an der obern Hälfte der äussern Fläche der Tibia, am obern

Fig. 104.

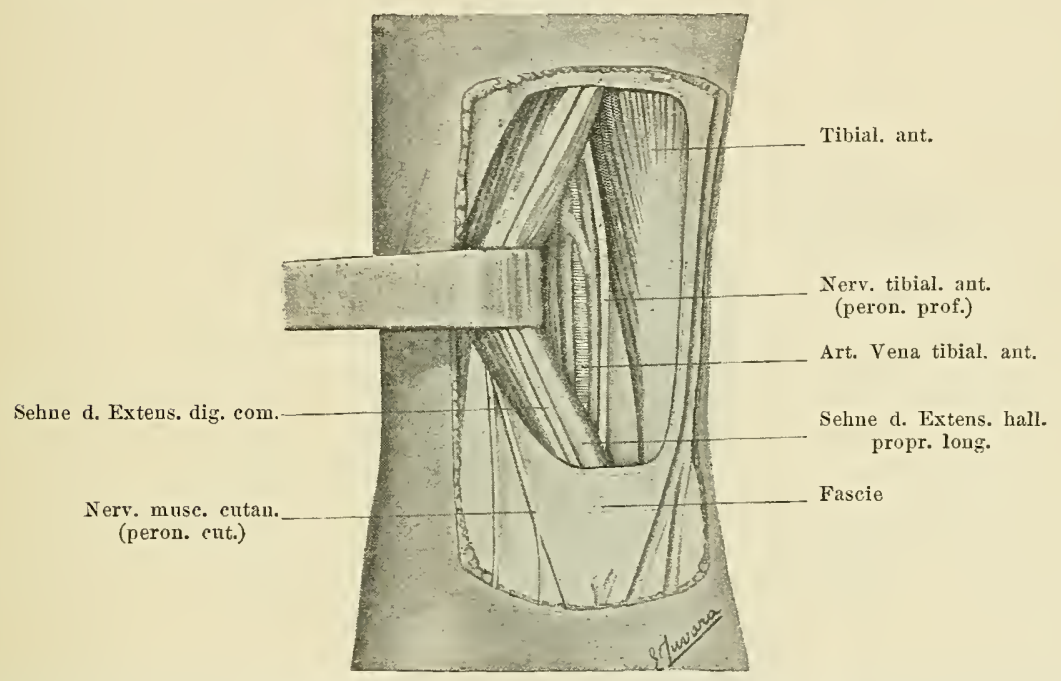

Die Beziehungen des Gefässpacketes und des Nerrus tibialis anticus im unteren Dritttheile des Unterschenkels. Ein stumpfer Haken zieht die Sehnen der Extensoren nach aussen und legt auf diese Weise das Gefässpacket, das auf der Tibia liegt, frei.

Drittel der hintern Fläche der Fascia cruris, am Ligamentum interosseum und an dem fibrösen Blatte, das ihn oben rom Extensor communis scheidet.

Die Fleischfasern gehen in die Endsehne über, welche zunächst in dem Fleischkörper verborgen liegt, gegen die Mitte des Unterschenkels sichtbar und an ihrer hintern Fläche von Muskelfasern bis nahe dem untern Ende der Tibia begleitet wird.

Diese sehr feste Sehne, fast so dick als der Ḱleinfinger, kreuzt in Form einer Schärpe die vordere Fläche der Articulatio talotibialis und inserirt sich an der Rauhigkeit, welche an der innern Fläche des ersten Os cuneiforme und am hintern Ende des ersten Metatarsus sich befindet.

Techuik z. A. d. G. Man macht fingerbreit nach aussen vom vorderen Rande der Tibia einen Schnitt, durchschneidet die Fascie und es erscheint unter derselben oben der Fleischkörper, unten die Sehne des Musculus tibialis anticus. 
Dep Extensor (communis entsteht mit Fleischfasern a) an der äussern Fläche der Tibia unterhalb des Tuberculum Cerdy, b) am Fibulaköpfchen, c) an einer fibrösen Schlinge, unter welcher der Nervus tibialis anticus zieht, d) an der vordern Hälfte der innern Fläche der Fibula, e) am Ligamentum interosseum, f) an der Fascia cruris und am fibrösen Blatte, welches ihn oben rom 'Tibialis anticus scheidet, endlich g) an der innern Fläche der fibrösen Wand, welche ilın ron den beiden Musculi peronei laterales scheidet.

Dieser sehr lange und dümne Fleischliörper, quer ausgebreitet, geht in eine Sehne ïber, die zunächst im Fleischliörper enthalten ist, wird dann an seinem vorderen Rande sichtbar und theilt sich in rier Bündel, je eines für jede der vier äussern Zehen. Diese Sehnen ziehen ror dem Talo-tibialgelenke theilen sich unter demselben und inseriren sich jede einzelne an der Basis der dritten Phalange der entsprechenden Zehe.

Technik z. A. d. G. Man macht, am Tuberculum Gerdy beginnend,

Fig. 105.

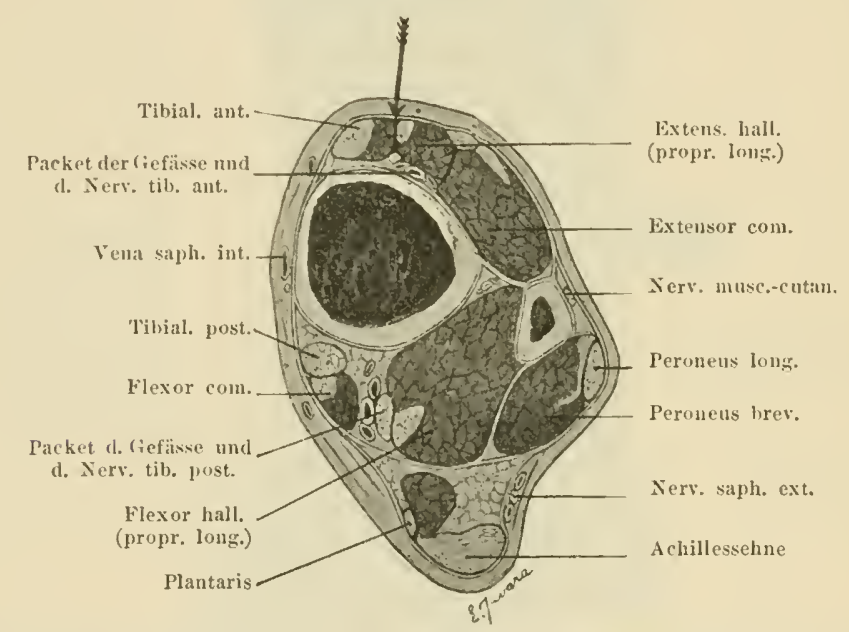

Ein Schnitt im unteren Drittheile des rechten Unterschenkels. Der Pfeil zeigt den Muskelzwischenraum, der direct zum Gefässpackete führt.

eine lange Incision und gelangt moter der Fascie an den Fleischkörper und an die Sehne des Extensor communis.

Del Extensor proprius hallucis entsteht mit Fleischfasern a) am mittlern Theile der vordern Fläche der Fibula an der Innenseite des Extensor communis, b) am Ligamentum interosseum; ron hier gehen die Muskelbündel in die Endsebne über, die am vordern Rande des Fleischliörpers gelegen am hintern Rande der zweiten Phalange der Grosszehe sich inserirt.

Technik z. A. d. G. Nan macht in den beiden unteren Dritteln des Unterschenkels, etwas näher der Tibia als der Fibula, eine lange Incision, durchschneidet die Fascie und erblickt das von cinem gelblichen Fette ausgefüllte Interstitium, das den Tibialis antiens vom Extensor communis scheidet. Mit der Hohlsonde eröffnet man diesen Zwischenraum und sieht den vorderen sehnigen Rand des Extensor proprius; mit der Sonde isolirt 
man den dünnen, quer ausgebreiteten Fleischkörper dieses Muskels. Man bemerkt, dass, je mehr man nach unten dringt, die Tiefe des obgenannten Zwischenraumes sich vermindert und dass der Extensor communis in derselben Ebene mit den anderen Sehnen sich zu legen sucht.

Der Musculus peroneus anterior liegt an der Aussenseite des Extensor communis und entsteht mit Fleischfaser'n am untern Drittel des vordern Randes der Fibula und an der Fascie.

Sein spindelförmiger Fleischkörper geht in eine Sehne über, die seinen vordern Rand einnimmt und leicht fächerförmig entwickelt, am hintersten Theil des obern Randes des vierten Metatarsus sich inserirt; mit einer Expansion verstärkt er die Sehne des Extensor communis, welche für die Kleinzehe bestimmt ist.

Fig. 106.

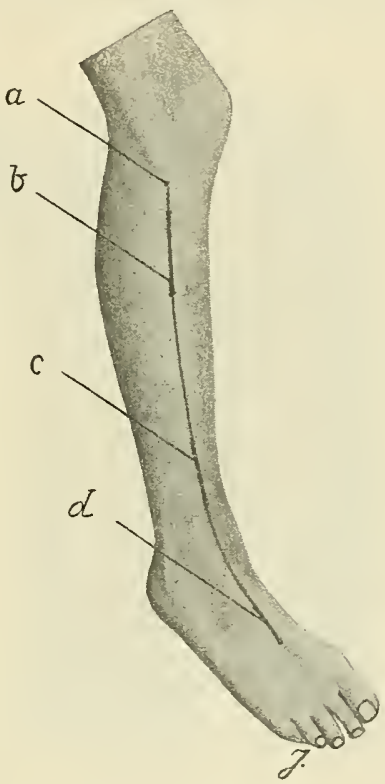

Die Richtung des Gefässpacketes und des Nervus tibialis anticus. a) Tuberculum Gerdy; b) Incision im oberen Drittheile; c) untere Incision; d) Incision im ersten Spatium interosseum.

Technik z. A. d. G. Man macht fingerbreit vor dem vorderen Rande der Fibula im unteren Drittel des Unterschenkels einen Schnitt, durchschneidet die sehr feste Fascie und erblickt den Körper des Extensor communis und an seiner äusseren Fläche den Peroneus anterior; letzterer kann zuweilen fehlen.

Das Packet der Gefässe und des Nervus tibialis anticus liegt tief im Interstitium musculare, welches innen ron der äussern Fläche des Fleischkörpers und der Sehne des Tibialis anticus aussen im obern Viertel von der innern Fläche des Extensor communis in den drei untern Vierteln von der innern Fläche des Fleischlörpers and der Sehne des Extensor proprius begrenzt wird. 
Der Grund oder die lintere Wand dieses Interstitiums wird oben ron den beiden obern Dritteln des Liganentum interosseum, unten ron der vordern äussern Fläche der Tibia gebildet.

Der Yerlauf des Gefäss- und Nerrenpacketes ist leicht schief nach unten, innen und rorne gerichtet, wird durch eine Linie bezeichnet, die den vordern Theil des Fibulaköpfehens mit der Mitte der Linea inter-malleolaris rerbindet (Fig. 106).

Die Arteria tibialis antica, der vordere $\Lambda$ st der Bifurcation der Arteria poplitea, durchdringt den obern Theil des Ligamentum interosseum durch die kreisförmige Lïiclie, die unter der Articulatio tibio-fibularis superior sich befindet, und endigt im Niveau der Fusswurzel, wo sie Arteria dorsalis pedis genannt wird.

In ihrer ersten $2-3 \mathrm{~cm}$ langen Partie liegt sie hinter dem Ligamentum interosseum in dem Interstitium, das aussen ron den Insertionen des Soleus am Fibulaköpfchen, innen rom Tibialis posticus und oben rom untern Rande des Popliteus begrenzt wird.

Fig. $10 \bar{\gamma}$.

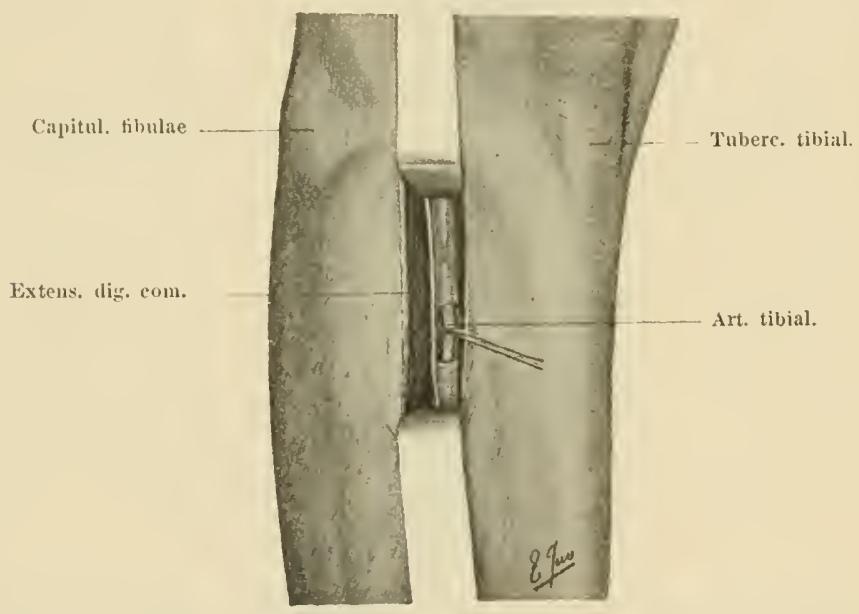

Das Aufsuchen der Arteria tibialis antica im oberen Drittheile.

Die Arteria recurrens tibialis entsteht aus diesem Theile der Arteria tibialis antica, richtet sich ron rorne nach hinten und durchdringt das Ligamentum interosseum oberhalb der Lüclie der Arteria tibialis antica.

Längs dem ganzen Unterschenliel wird die Arteria tibialis ron zwei Venen begleitet; aus jener entstehen im recliten Winkel zahlreiche Aeste für diejenigen Muskel bestimmt, welche das Interstitium, das die Arterie enthält, begrenzen.

Der Nervus tibialis anticus, der innere Endast des Nervus ischiadicus popliteus externus, durchbohrt die Fascia intermuscularis, welche die vordern Muskeln von den äussern scheidet und zieht unter einer fibrösen Schlinge, an der sich der Extensor communis und Peroneus longus inseriren.

Er liegt zuerst aussen von der Arterie, zieht dann vor derselben und gelangt dann an ilsrer Innenseite.

Der Nerv giebt Aeste für den Extensor communis, Extensor proprius und Muculus tibialis anticus ab. 
Technik z. A. d. G. Nan bringt den Unterschenkel in leichte Flexionsund innere Rotationsstellung und ersucht einen Assistenten, denselben in dieser Lage festzuhalten.

Man sucht das Fibulaköpfchen, die Depressio praefibularis und das Tuberculum Gerdy auf, welches fingerdick oberhalb der Mitte des Abstandes zwischen Fibulaköpfchen und Tuberositas tibialis sich befindet.

Die Richtung des vasculären Interstitiums ist durch die Linie, die das Tuberculum Gerdy mit der Mitte des Intermalleolarabstandes verbindet, angezeigt; längs dieser Linie, 2 bis 3 Finger breit unter dem Fibulaköpfchen beginnend, macht man eine 5-6 cm lange Incision. Nan schneidet die Haut und die Fascie durch, fasst mit der Pincette der Reihe nach einzeln

Fig. 108 .

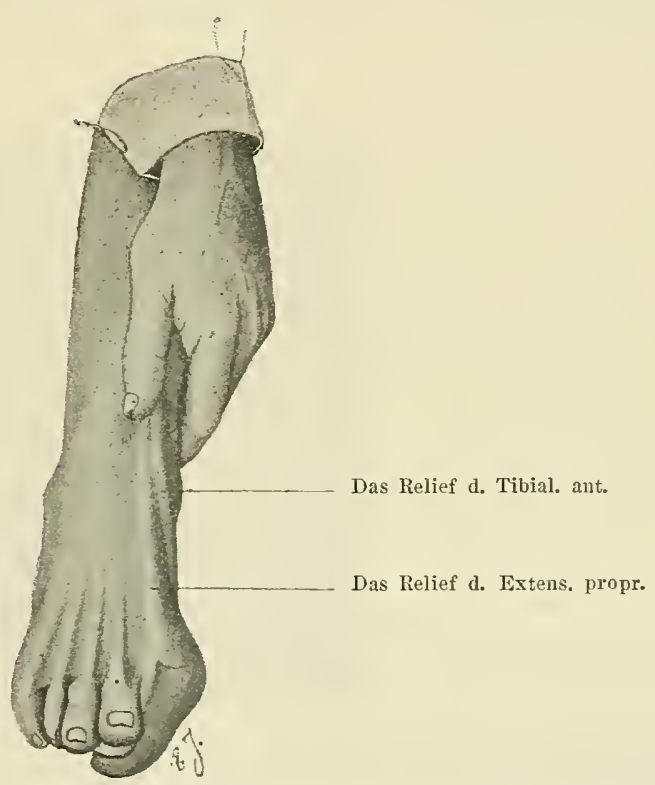

Die Art, das untere Drittheil des Unterschenkels abzutasten und die Furche des Gefässpacketes aufzufinden.

die Ränder des aponeurotischen Schnittes und legt die Huskeln, welche sich an ihrer tiefen Fläche inseriren, von unten nach oben mit der Hohlsonde frei.

Geht man auf diese Weise vor, so erkennt man mit Leichtigkeit das Interstitium der Gefässe in Form einer gelblichen Spur, in welcher kleine arterielle Aeste sich schlängeln.

Man eröffnet dieses, indem man mit der Sonde der änsseren Fläche des Musculus tibialis anticus folgt und legt in jedem Winkel des Schnittes je einen stumpfen Haken ein; auf diese Weise schafft man einen tiefen Gang, in dessen Grunde man das Gefäss- und Nervenpacket sieht, welches auf eine Cooper'sche Nadel gehoben wird. Aussen findet man den Nerv, innen die Arterie von zwei Venen begleitet (Fig. 107). 
InI unteren Drittel des Unterschenkels. Man findet unmittelbar an der Aussenseite der Crista tibiae die feste Sehne des Tibialis anticus (Fig. 108). An der Aussenseite derselben gleitet die Fingerbeere in einer rerticalen Furche, welche diese Sehne ron den Schnen der Extensoren scheidet, die Furche, die dem Gefässpackete entspricht.

Man macht längs des äusseren Randes der Sehne des Tibialis cine ungefähr 3 fingerbreit lange Incision, sclineidet die feste Fascic dureh und gelangt an das Interstitium der Gefïsse (Fig. 109); dieses eröffnet man, indem man die Hohlsonde leieht nach oben und unten führt. Wan legt einen stumpfen Haken in die Sehnen der Extensoren ein, die man dadurch entspannt, dass man den Fuss in Extensionsstellung bringt. Man sieht dann hinter der Sehne des Tibialis, an der äusseren Fläche der Tibia gelagert, das Gefüsspacket, das aussen von der Arteric, imnen rom Nerv gebildet wird (Fig. 110).

Fig. 109.

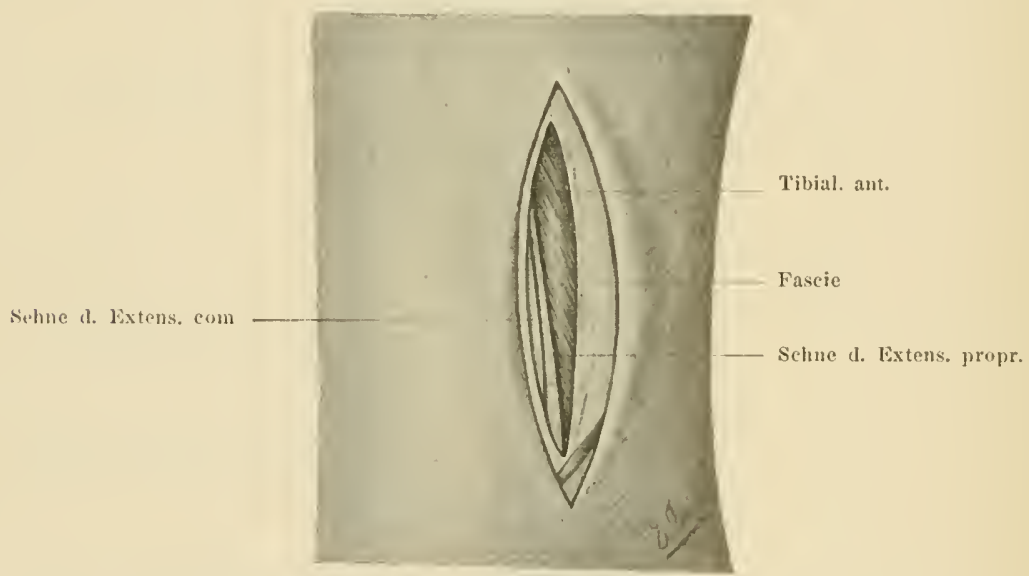

Das Aufsuchen des Tibial. ant. im unteren Drittheile des Unterschenkels. Das Auffinden des richtigen Interstitiums, das vom Tibialis anticus und Extensor proprius begrenzt ist.

Der äussere Raum oder der Raum der lateralen Peronei hat die Form eines prismatischen osteo-fibrösen Kanales, welcher vorne ron einem fibrösen Blatte, das ihn von dem vordern Raume, hinten ron einem fibrösen Blatte, das ihn von der hintern Region trennt, innen von der äussern und hintern Fläche der Fibula und aussen von der Fascie des Unterschenkels begrenzt wird.

Der Peroneus longus lateralis entsteht mit Fleisehfasern a) am Kopfe und an der obern Hälfte der äussern Fläche der Fibula, b) an fibrösen Blättern, welche den Raum der Peronei von dem vordern und hintern Raum des Unterschenkels scheidet und c) an der tiefen Fläche des obern Theiles der Fascia cruris. Die Nluskelbündel vereinigen sich und bilden einen prismatischen Fleischliörper, welcher in eine schöne Endsehne übergeht, die zunächst im Fleische verborgen liegt, dann an der äussern Fläche des Fleischliörpers sichtbar wird.

Diese Sehne, ron Fleischfasern bis zum untern Drittel des Unterschenkels begleitet, zieht hinter dem äussern Knöchel, gelangt an die äussere Fläche des Calcaneus, biegt 
in einem rechten Winkel vor dem Tuberculum cuboideum ab, dringt und durchzieht die Fusssohle im osteo-fibrösen Kanale und inserirt sich an dem Tuberculum posterius des ersten Metatarsus.

Der Peronens brevis liegt unter dem Peroneus longus und nimmt nur die untere Hälfte des Raumes der Peronei ein. Er entsteht mit Fleischfasern an den beiden untern Dritteln der äussern Fläche der Fibula und an aponeurotischen intermuscnlären Blättchen, einem vordern und einem hintern.

Sein prismatischer Fleischkörper geht über auf die tiefe Fläche der Endsehne, welche Muskelfasern bis nahe der Spitze des änssern Knöchels begleiten.

Diese Sehne gleitet hinter dem äussern Knöchel, zwischen dem Knochen und der Sehne des Peroneus longus gelagert, bildet einen Bogen, verläuft an der äussern Fläche

Fig. 110.

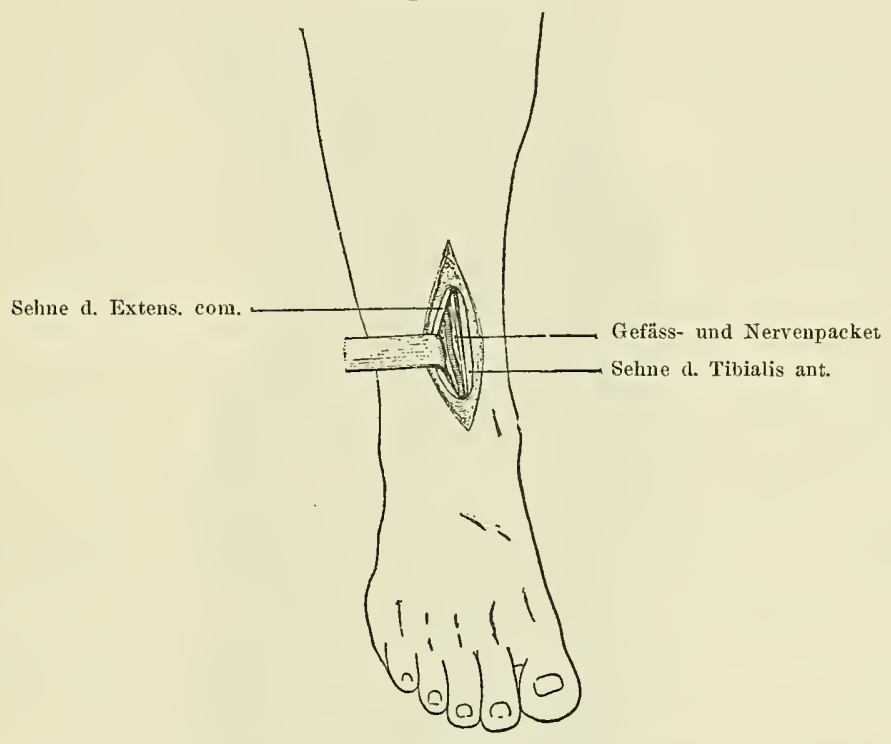

Rechter Unterschenkel; das Auffinden der Gefässe und des Nervus tibialis anticus im untern Drittheile.

des Calcaneus, entfernt sich in einem spitzen Winkel von der Sehne des Peroneus longus und inserirt sich an der dorsalen Fläche des Höckers des fünften Metatarsus.

Technik z. A. d. G. Man macht längs der Fibula einen langen Schnitt und findet unter der Fascie den Körper und die Sehne des Peroneus longus; man präparirt diesen Muskel und findet unter demselben den Peroneus brevis.

Der Nervus musculo-cutaneus (Nerrus peroneus cutaneus), der Ast der änssern Bifurcation des Nervus ischiadicus popliteus externus, ist schief vom Fibulaköpfchen zur Mitte des Spatium intermalleolare gerichtet.

Er liegt im Raume der Peronei, zuerst unter den Insertionen des Peroneus longus, dann nähert er sich und folgt der Fascia intermuscularis anterior, durchbohrt die Fascia cruris handbreit oberhalb des äussern Knöchels, wird subcutan, zieht gegen die Mitte der vorden Fläche der Fusswurzel und giebt Aeste für die Haut der Dorsalfläche des 
Fusses und Collateraläste für die Zehen ab. In seinem Verlaufe zwischen den Musculi peronei giebt der Nerrus musculo-cutaneus Aeste für diese Muskeln ab.

Technik z. A. d. fr. Im Raume der Peronei. Man macht in der oberen Uälfte des Raumes der Peronei eine lange Incision und findet unter dem Peroneus longus den Nervus musculo-cutaneus, den man isolirt.

Unter der Haut. An einem mageren Individuum sicht und füllt man in Form eines Stranges den Nervus musculo-cutaneus, der auf der Fiäche der Fibula gleitet.

Ifan macht im unteren Drittel des Unterschenkels cine lange, schief nach unten und imnen gerichtete Incision, welche am vorderen Rande der

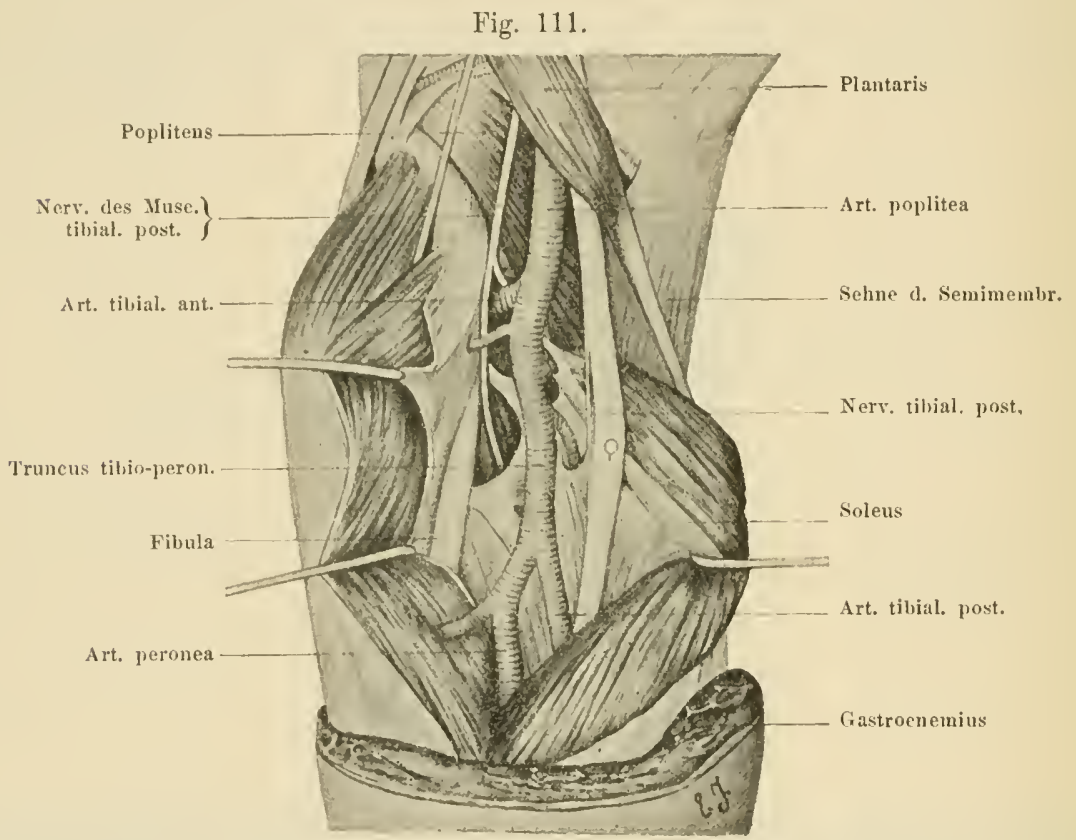

Der Ring des Soleus; linke Seite. Der Soleus ist von oben nach unten abgelöst, durch Haken in zwei Theile getheilt. Der Nervus tibialis ist nach innen gezogen.

Fibula handbreit obcrhalb des Knöchels beginnt und gegen die Nitte der Fusswurzel endigt; in dem Schnitte oder unter cinem der Schnittränder findet man den Nerv, den man isolirt. Mlan folgt demselben nach oben und studirt das aponeurotische Orificium, durch welehes er aus der Tiefe kommt.

Die lintere Fläche des Unterschenkels, oben breit und abgerundet, verschmälert sich nach unten und bildet in ihrem untern Drittel eine verticale mediane, stark sichtbare Erhabenhcit, die in Form eines Stranges am Calcaneus endigt, die Achillessehne. An fetten und wenig muskulösen Individuen, besonders an Frauen, wird die hintere Fläche des Unterschenkels durch abgerundete Umrisse begrenzt, an muskulösen Individuen sind die Grenzen eckig. 
Die stark entwickelte Muskelmasse des Musculus triceps surae überragt fast zweifingerbreit nach aussen die Fibula und nach innen die Tibia.

Digitaluntersuchung. Wegen der Dicke der Muskelschichte ist die tiefe Digitaluntersuchung der oberen Hälfte des Unterschenkels, besonders in der Medianlinie, sehr schwierig.

Aussen fülilt man mit Leichtigkeit oben das Fibulaköpfchen; weil der Schaft von dicken Muskelmassen umkleidet ist, muss man mit Kraft die Weichtheile niederdrücken.

Man folgt innen von oben nach unten dem inneren Rande der Tibia. Man ersucht einen Assistenten, den Fuss in Extensionsstellung zu bringen; die Nuskelmasse erhebt sich. Drängt man sie mit den Fingerspitzen nach aussen, so tastet man die hintere Fläche der Tibia, die von der Insertion des Soleus bedeckt ist, den Sulcus interosseus und auch die innere Fläche der Fibula ab; auf diese Weise kann man eine Exostose, einen entzündlichen Herd am Perioste oder einen tief im Spatium interosseum gelagerten Tumor fühlen.

Technik z. A. der Vena saphena externa und des Nervus saphenns externus. In der Mitte des Unterschenkels. Man sucht mit den Fingerspitzen in der Medianlinie die Furche auf, welche dem Interstitium der beiden Gemelli entspricht. Längs derselben macht man eine drei Finger breit lange Incision, schneidet die Haut und das subcutane Gewebe durch und man sieht durch das aponeurotische Blättchen die Vena saphena durchscheinen, welche in einer fibrösen Scheide, durch Duplicatur der Fascie gebildet, enthalten ist. Mit der Hohlsonde zerreisst man die aponeurotische Hülle, legt die Vena saphena externa frei und hebt sie auf; man präparirt das tiefe Blatt der aponeurotischen Scheide, die sie enthält und findet unter derselben auf einer rothen Fläche, vom Gemellus externus gebildet, den Nervus saphenus externus von einer kleinen Arterie begleitet.

Im unteren Drittel. Man sucht die Achillessehne auf und macht längs ihres äusseren Randes einen Schnitt, welcher 3 bis 4 Finger breit oberhalb des äusseren Knöchels endigt. Unmittelbar unter der Haut findet man in der Duplicatur des oberflächlichen Blättchens die Vena saphena, die am inneren Rande vom gleichnamigen Nerv begleitet ist.

Die Vena saphena und der Nervus saphenus intermus in der Mitte des Unterșchenkels. An zarten Individuen ist die sehr grosse Vena saphena interna sehr oft durchscheinend, am Cadaver kann sich dieselbe in Form bläulicher Streifen abzeichnen, durch die Transfusion des Blutes hervorgerufen. Mit den Fingerbeeren sucht man den inneren Rand der Tibia auf und macht längs desselben, fingerbreit dahinter, eine ungefähr $4 \mathrm{~cm}$ lange Incision. Unmittelbar unter der Haut, in der Duplicatur des oberflächlichen Blättchens, sieht man die Vene, die isolirt wird; findet man diese nicht im Schnitte, so sucht man sie mit Pincette und Sonde der Reihe nach unter jedem der Schnittränder.

Der Nervus saphenus internus, meistentheils klein, befindet sich am äusseren Rande der Vene.

Die hintern Muskeln des Unterschenkels bilden zwei durch ein zelligfibröses Blättchen, Fascia media, getrennte Schichten. Die oberflächliche Schichte, 
aus den Musculus triceps surae bestehend, wird wieder von zwei Schichten gebildet:

a) Die oberflächliche Schichte wird rom rerbreiteten Körper der beiden Gemelli gebildet. Diese beiden Muslieln, oben durch einen Raum in Form eines V getrennt, rereinigen sich unten mit ihren entsprechenden Rändern. Sie entstehen, wie

Fig. 112.

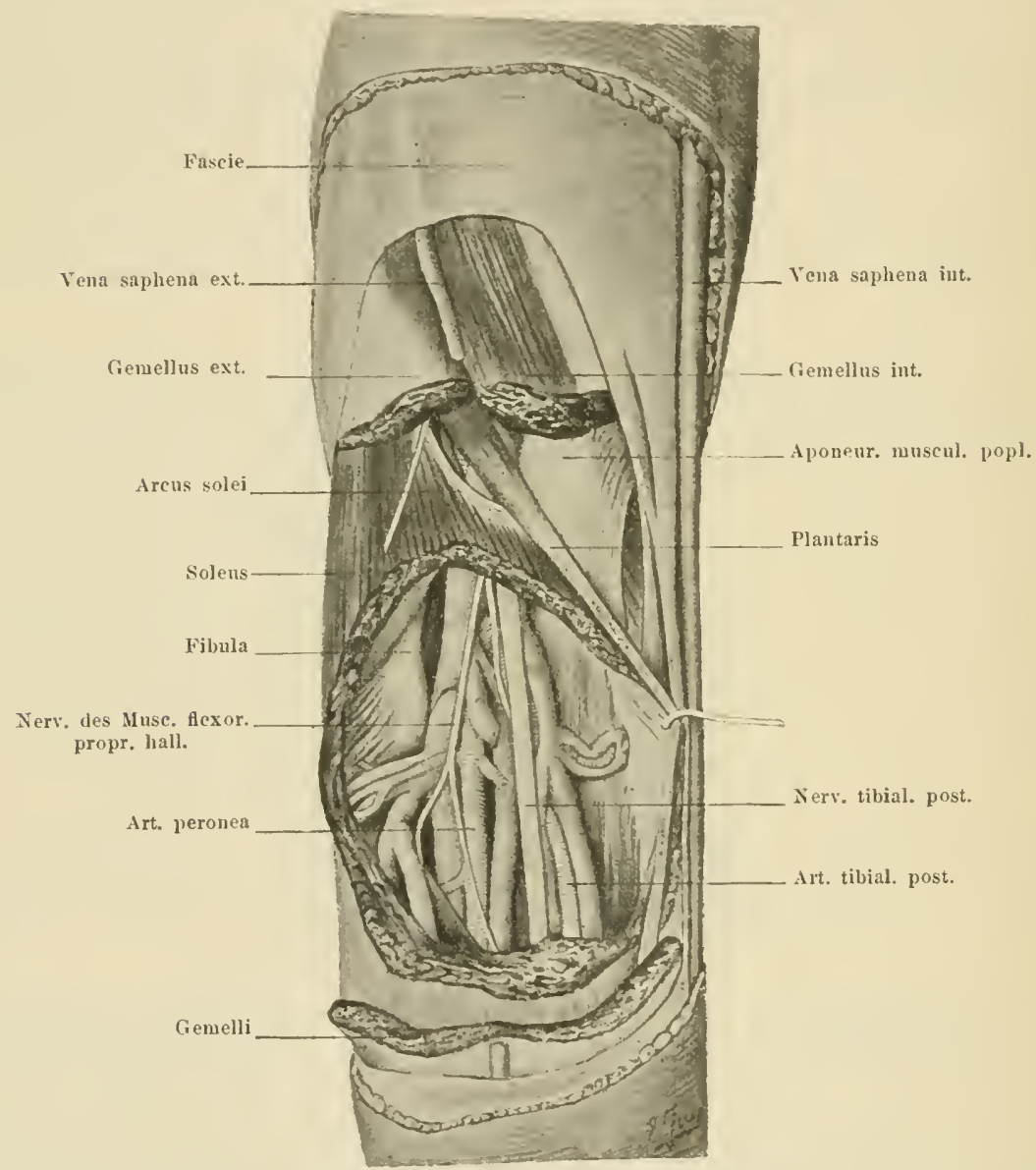

Die tiefliegende Region des oberen Drittheils des Unterschenkels. Die Gemelli wurden resecirt und im Soleus wurde eine weite Lücke ausgeschnitten.

wir gesehen haben, mit liräftigen Sehnen an den Condylen des Fomur und an den oberhalb der Condylen befindlichen Höckern.

Ihre Initialsehnen ergänzen und verstärken die retro-condylen Partien der Gelenkkapsel und bedecken die Condylen des Femur, hinter welchen sie wahre Hauben bilden.

Die Fleischkörper der Gemelli entstehen an der tiefen Fläche der Initialsehne nnd sind an der hintern Fläche der lamellenförmigen Endsehne gesammelt, auf welcher sie 
etwas unterhalb der Unterschenkelmitte durch zwej krumne, mit der Convexität nach unten gerichtete Linien endigen.

Für gen Gemellus internus steigt diese Linie einen Finger unter dem Gemellus externus herunter.

b) Die tiefliegende Schichte wird vom Soleus gebildet. Der sehr dicke und kräftige Soleus wird von den Gemelli durch eine mehr weniger fettreiche Bindegewebsschichte getrennt.

Der Soleus entsteht an der Fibula und an der Tibia mit einem schönen und festen sehnigen Blatte, die Initial- oder Ursprungsehne, und mit Fleischfasern.

Die Insertion an der Fibula geschieht von oben nach unten an den Rauhigkeiten, welche man an der hintern Fläche des Köpfchens und des obern Viertels der hintern Fläche des Fibulaschaftes sieht und an der obern Hälfte des äussern Randes desselben Knochens.

Die Insertionen an der Tibia geschehen an der Linea obliqua der Tibia und am mittlern Drittel des innern Randes dieses Knochens.

Die sehnigen Bündel, die an der Fibula entstehen, sind die stärksten. Die Fleischfasern entstehen an den beiden Flächen der Ursprungsehne, besonders aber an der hintern Fläche und eine grosse Zahl entsteht direct an der Tibia und an der Fibula. Die Endsehne ist in ihrem obern Theile in zwei Blätter getheilt, welche sich in einem sehr spitzen Winkel theilen.

Das hintere Blatt ist das am meisten entwickelte; auf seine tiefe Fläche gehen Fasern über, die an der hintern Fläche der Ursprungsehne entstehen. Das vordere Blatt oder accessorisches erhält die Muskelschichte, welche an der vordern Fläche der Ursprungsehne entsteht; diese Schichte ist zuweilen stark entwickelt, zuweilen auf einen kleinen fiederförmigen Huskel beschränkt.

Fleischfasern bedecken die vordere Fläche der Insertionsendsehne bis zwei- oder dreifingerdick über dem Calcaneus.

Die Endsehnen der Gemelli einerseits und des Soleus andererseits sind zuerst getheilt, vereinigen und verweben sich dann zusammen um eine gemeinsame Sehne, die Achillessehne, zu bilden.

Die Achillessehne verschmälert und verdickt sich von oben nach unten; über dem Calcaneus ist sie fast rund, dann verbreitert sie sich leicht und inserirt sich an der Facette, die den mittlern Theil der hintern Fläche des Calcaneus einnimmt und am sehr verdickten Perioste, welches diesen Knochen bedeckt; sie ist vom obern glänzenden Theile der hintern Calcaneusfläche durch einen Schleimbeutel geschieden, die Bursa serosa retro-calcanea, welche oft von Tuberculose und Blennorrhoe ergriffen wird.

Die Achillessehne ist in einer fibrösen Scheide enthalten, welche hinten und an den Seiten ron der Fascia superficialis cruris, vorne ron der Fascia media cruris begrenzt wird.

Sie ist von der hintern Wand dieser Scheide durch ein weiches Bindegewebe, das zuweilen in einen wahren Schleimbeutel umgewandelt wird, geschieden; ron der rordern Wand durch eine Fettschichte, die sich von oben nach unten verdickt und sehr innig mit dem untern Theile der Sehne und mit der obern Aussackung der Bursa retro-calcanea adhärirt.

In der Scheide der Achillessehne verbreiten sich zuerst die Fungusmassen, die ron einer tuberculösen Synovitis der Bursa retro-calcanea ausgehen; in dieser muss man ihnen folgen und sie vollständig extirpiren.

Technik z. A. d. G. Man sucht die Erhabenheit der Achillessehne auf und macht längs derselben einen Schnitt, der am Calcaneus endigt. 
Man schneidet die Haut und die Fascie dureh, es erseheinen die weissen und glänzenden Fasern der Sehme. Man isolirt und schneidet diese handbreit über dem Calcaneus quer durch, und sieht daraus, wie dick und kräftig diese ist. Mlan zieht das untere Fragment nach abwärts und präparirt seine tiefe Fläche, indem man es rom Fette, das es bedeckt, reinigt; in einem gewissen. Homente eröffnet man die Bursa retro-calcanea, welche sich zwischen diesem und dem oberen Drittel der hinteren Calcaneusfläche befindet.

Die Bursa supra-calcanea. Ein weiches Bindegewebe, das hinter der Achillessehne zwischen dieser und der Fascie sich befindet, formt sich zuweilen in einen wahren Schleimbeutel, Bursa supra-calcanea, um.

Teclmik z. A. d. G. Man macht an dem unteren Drittel der Achillessehne einen verticalen Schnitt, durchschneidet gleichzeitig die Haut und die Faseie und hebt mit der Pincette die Schnittränder. Oft sieht man 2 bis 3 Finger dick über dem Caleaneus die eröffnete Höhle der Bursa supracalcanea.

Der Ring des Soleus, zwischen Tibia und Fibula, etwa 2 Finger unter dem Fibulaköpfchen gelegen, ist ein mehr als ein Centimeter hoher Kanal (Fig. 111-112).

Er hat die Form einer schief nach unten und innen gerichteten Lücke von vorne nach hinten rerbreitert und so breit wie ein Daumen.

Seine Grenzen werden binten rom obern concaven freien Rande und der Fascie des Soleus, arcus solei, der wie eine Brücke oberhalb des Sulcus interosseus zwischen Tibia und Fibula gespannt ist, vorne von der hintern Fläche des Popliteus, vom obern Ende des Tibialis posticus und von der Fascie des Flexor communis, an den Seitentheilen von den Insertionen des Soleus, aussen von der Fibula, innen von der Tibia gebildet.

Die Gebilde, welche durch diesen Ring ziehen, sind folgende:

a) Auf der ersten Ebene findet man den Nervus tibialis posticus und an seiner äussern Seite seine drei Aeste: den Nervus inferior für den Popliteus, den Nerv für den Tibialis posticus und den Nerr für den Soleus, welcher unmittelbar über dem Bogen dieses Muskels entsteht.

b) Anf der zweiten Ebene unter dem Nerv findet man den Truncus arteriosus tibio-peroneus, denn die Arteria poplitea theilt sich im Niveau des Arcus in die Arteria tibialis antica und in den Truncus tibio-peroneus (Fig. 111). Der Trnncus arteriosus tibio-peroneus wird ron zwei Sehnen begleitet, eine innere und etwas nach vorne gelegene, aus der Vereinigung der Venae tibiales posteriores gebildet, eine äussere, etwas nach hinten gelegene, welche aus der Vereinigung der Venae peroneae mit der Vena tibialis antica gebildet wird. Diese renösen Kanäte communiciren breit mit einander durch eine Anastomose, die in dem ron der Arteria tibialis antica mit dem Truncus tibio-peroneus gebildeten Winkel liegt.

c) Die dritte Ebene wird ron der Arteria tibialis antica gebildet, welche schief nach vorne, unten und aussen gerichtet ist; die gleichnamige Vene findet man an der äussern und oberen Seite der Arterie.

Ein zellig-fibröses Blatt, welches sich rings um das Packet der Gefässe und des Nerrus popliteus befindet, geht im Nireau des Soleusringes in das zellig-fibröse Blättchen über, das diesen Muskel bedeckt.

Techunik z. A. d. G. Man macht in der Nedianlinie eine Incision, 
welche etwas oberhalb des Niveaus des Fibulaköpfchens beginnt und handbreit darunter endigt.

Man schneidet die Haut und die Fascie durch und schont die Vena saphena externa; man eröffnet mit der Sonde das Interstitium der Gemelli in der ganzen Länge des Schnittes. Nan legt stumpfe Haken ein und reinigt die hintere Fläche des Soleus von der zellig-fibrösen Schichte, die sie bedeckt; man sucht den Areus solei auf und tastet unter demselben mit der Fingerspitze den Ring dieses Muskels ab, den man auf der Hohlsonde eröffnet, und studirt die Gebilde, die ihn durchziehen.

Fig. 113 .

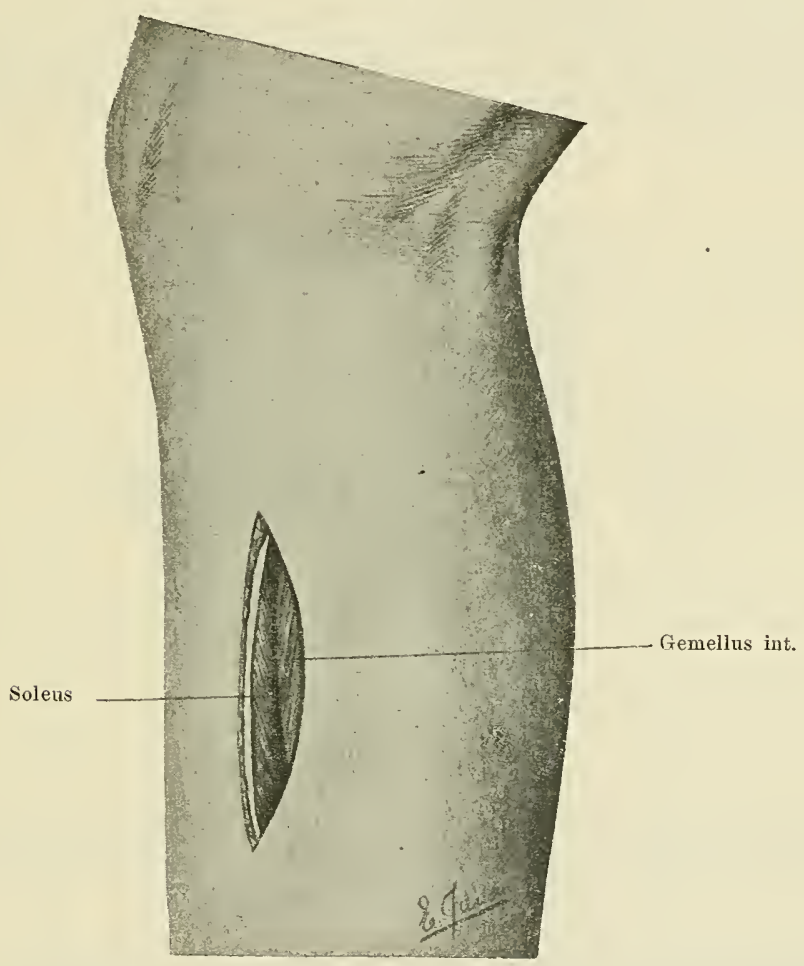

Das Aufsuchen der Arteria und des Nervus tibialis posticus. Das Auffinden des inneren Randes des Gemellus internus.

Die Sehne des dïnnen Plantaris durchzieht schief nach unten und innen das Interstitium, welches die Gemelli rom Soleus scheidet, tritt ans diesem Zwischenraume durch seinen untern und innern Theil heraus, lagert sich am innern Rande der Achillessehne, welcher sie bis zum Calcaneus folgt und inserirt sich an der innern Seite.

Technik z. A. d. G. Man macht an dem inneren Rande der Achillessehne einen langen Schnitt und findet an diese Sehne gelagert: die Sehne des dünnen Plantaris. Man folgt derselben nach unten bis zum Calcaneus, nach oben in das Interstitium des Triceps surae. 
I)ie mittlere Fascie des Unterschenkels ist zellig-fibrös und schr dünn in den zwei obern Dritteln des Cnterschenkels, wird dann in untern Theile fibrös und resistent. In dieser Parthie wird sie zum grössten Theile ron fibrösen Schlingen gebildet, welehe sich aussen und innen mit der oberfläehlichen Fascie rerweben, unten endigt sie an dem obern Rande des Calcaneus.

Die tiefe Schichte. Die Mnskeln dieser Schichte sind in einer osteo-fibrösen Furche gelagert, die sich ron oben nach unten verengt und aussen von der Fibula, innen ron der Tibia und rorne rom Ligamentum interosseum, das zwischen dem äussern Rande der Tibia und der mittlern Leiste der innern Fläche der Fibula gespannt ist, begrenzt wird. Diese Mluskeln sind drei an der Zahl und in zwei Schichten gelagert:

A. Die erste Sehichte wird ron den beiden Flexoren gebildet.

1. Der Flexor proprius hallucis, dick und prismatisch, liegt an dem innern Thleile der Fibula und ist ron diesem linochen bis zur zweiten Phalange der Grosszehe gespannt. Fleischig in seiner Unterschenkelpartie wird er dann in der Fusssolle sehnig.

Fig. 114 .

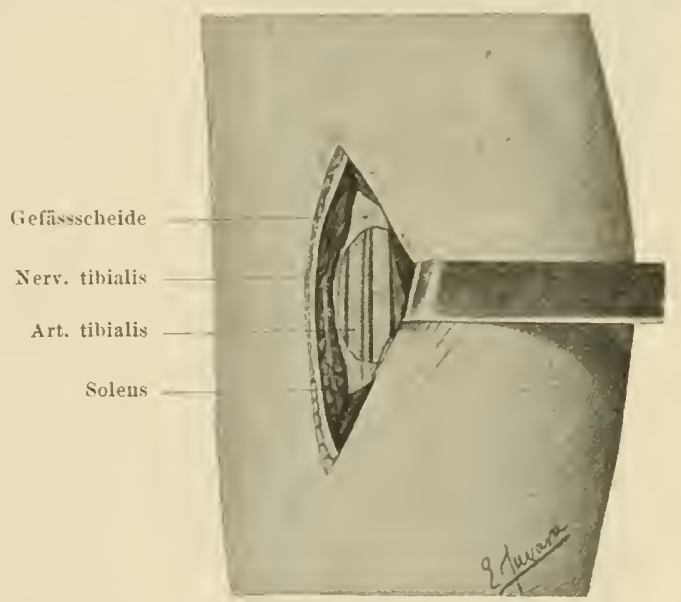

Das Aufsuchen rer Arteria und des Nervus tibialis posticus. Der Soleus ist abgelöst und der hintere Schnittrand mit einem stumpfen Haken kräftig abgezogen, das Gefässund Nerrenpacket ist freigelegt.

Er entsteht mit Fleischfasern und fibrösen Bündeln: an den beiden untern Dritteln der hintern innern Fläche der Fibula, an den beiden Rändern dieser Fläche, an der Ursprungsehne des Solens, am Ligamentum interosseum und am fibrösen Bogen des Flexor communis. Die lamellenförmige Endsehne ist zuerst in dem Muskelkörper selbst rerborgen, welche ihn fingerbreit bis unterhalb des Tarsotibialgelenkes begleitet. Diese Sehne biegt an dem hintern Rande des Talus ab, wird horizontal, gleitet in der Furche des Calcaneus, lirenzt sich mit der Sehne des Flexor communis, mit der sie Fasern austauscht, lagert sich dann zwischen den beiden Bündeln des Flexor brevis hallucis und inserirt sich, etwas breiter werdend, in Form eines Horns an der Rauhigkeit, die sich an dem hintern Theile der untern Fläche der zweiten Phalange der Grosszehe befindet.

Der Musculus flexor ' 0 mmunis ist ron der 'Tibia bis zur dritten P'halange der rier äussern Zehen gespannt. Er liegt an der hintern Fläche der Tibia und entsteht: 
a) an der Linea obliqua tibiae mit Fleischfasern und fibrösen Bündeln, b) am mittlern Drittel der hintern Flä.che der Tibia an einer dreieckigen, mit der Spitze nach unten gerichteten Oberfläche mit Fleischfasern, c) mit einem schönen und sehnigen Blatte, das an der tiefen Fläche des Musliels liegt, an der innern Fläche der Tibia nahe ihrem innern Rande - diese Insertion beginnt im Niveau der Linea obliqua und endigt gegen den untern Theil des mittlern Drittels jenes Knochens - d) an einem fibrösen Bogen, wie eine Brücke gespannt oberhalb des Tibialis posticus, ron dem mittlern Theile der hintern Fläche der Tibia zu dem untern Tbeile derselben Fläche nahe dem Tibio. fibulargelenke, e) mit einem aponeurotischen, zuweilen stark entwickelten Blatte an dem obern Drittel des hintern Randes der Fibula.

Die Endsehne ist zuerst in dem Fleischkörper verborgen, wird dann an der äussern Seite bis oberhalb des innern Knöchels ron Muskelfasern bcgleitet. Sie liegt hinter der Sehne des Tibialis posticus, umschlingt mit dieser den innern Knöchel, gleitet an der Spitze des Processus minor calcanei, zieht unter der Sehne des Flexor proprius und in der Mitte der Fusssoble angelangt, verbreitet sie sich zu einem Fächer und theilt sich in vier Zweige oder Secundärsehnen, je eine für jede einzelne der vier äussern Zehen.

Jede dieser Sehnen dringt im Niveau der Metacarpophalangealgelenke in die osteofibrösen Kanäle der Beuger, zieht durch eine Art Knopfloch der Sehne des Flexor communis brevis und inserirt sich an der untern Fläche der dritten Phalange der entsprechenden Zehe.

B. Die zweite Schichte wird rom Tibialis posticus gebildet:

Der Tibialis posticus liegt im Grunde des Sulcus interosseus und ist von der Tibia und Fibula einerseits zu der rordern Hälfte des Tarsus andererseits gespannt. Dick und fleischig in seinem obern Theile wird er lamellenförmig und besonders sehnig in seinem untern Theile.

Er entsteht mit Fleischfasern und aponeurotischen Fasern a) an der hintern äussern Fläche der Tibia an derjenigen dreieckigen mit der Spitze nach unten gerichteten Oberfläche, die vorne vom äussern Rande der Tibia, oben ron der Linea obliqua und hinten von jener Leiste begrenzt wird, welche aus der Linea obliqua abgeht und am äussern Rande dieses Knochens sich verliert, b) an den beiden obern Dritteln der innern Fläche der Fibula, c) an der hintern Fläche des Ligamentum interosseum. In der obern Hälfte des Unterschenkels geschieht die Insertion an der ganzen Breite der Hembrana interossea, unten nur an der Fibulaseite des Ligamentum interosseum und oft an einer fibrösen Schlinge, die von der Fibula bis zur Membrana interossea gespannt ist.

Die Endsehne des Tibialis posticus, sehr fest und zuerst in dem Fleischkörper verborgen, wird gegen die Mitte des Lnterschenkels sichtbar und bekommt noch Muskelfasern an der äussern Seite bis nahe dem innern Knöchel.

Sie umschlingt den Malleolus internus, wird horizontal, gleitet an der innern Fläche des Talo-tibialgelenkes, verbreitet und theilt sich in mehrere Arme und inserirt sich von innen nach aussen: am Kahnbeinhöcker zum grössten Theile, am Tuberculum inferius des ersten Os cuneiforme, am Tuberculum des dritten Os cuneiforme, am innern Rande des Os cuboideum und am hintern Ende des II., III. and IV. Metatarsus; eine fibröse Schlinge verbindet zuweilen die Sehne des Tibialis posticus mit der Sehne des Peroneus longus. Zwischen Os naviculare und dem Processus minor calcanei ist die Sehne des Tibialis posticus mit dem zwischen beiden Knochen gespannten Ligamente rerwebt, welches einige Autoren als "rücklanfende Sehne" bezeichnen.

Technik z. A. d. G. Man macht längs der Fibula eine lange In- 
cision, sucht den Soleus auf, löst ihn ron der Fibula ab und giebt ihn in einem stumpfen Haken: auf der Fibula liegend, unter einem dünnen, zelligfibrösen Blättchen, findet man den Körper des Flexor proprius.

Man macht dieselbe Ineision an der inneren Seite des Unterschenkels längs der Tibia und findet, auf derselben liegend, den breiten Körper des Flexor communis und unter demselben den Tibialis postieus.

Arteria und Nervus tibialis posticus. Arteria peronea. Der Tibio-peroneusstamm theilt sich 3-4 fingerbreit unter der horizontalen Linie, die unter dem Fibulalïpfehen ziehen würde, in dic beiden Endäste: Art. tibialis postica und Art. peronea.

Fig. 115.

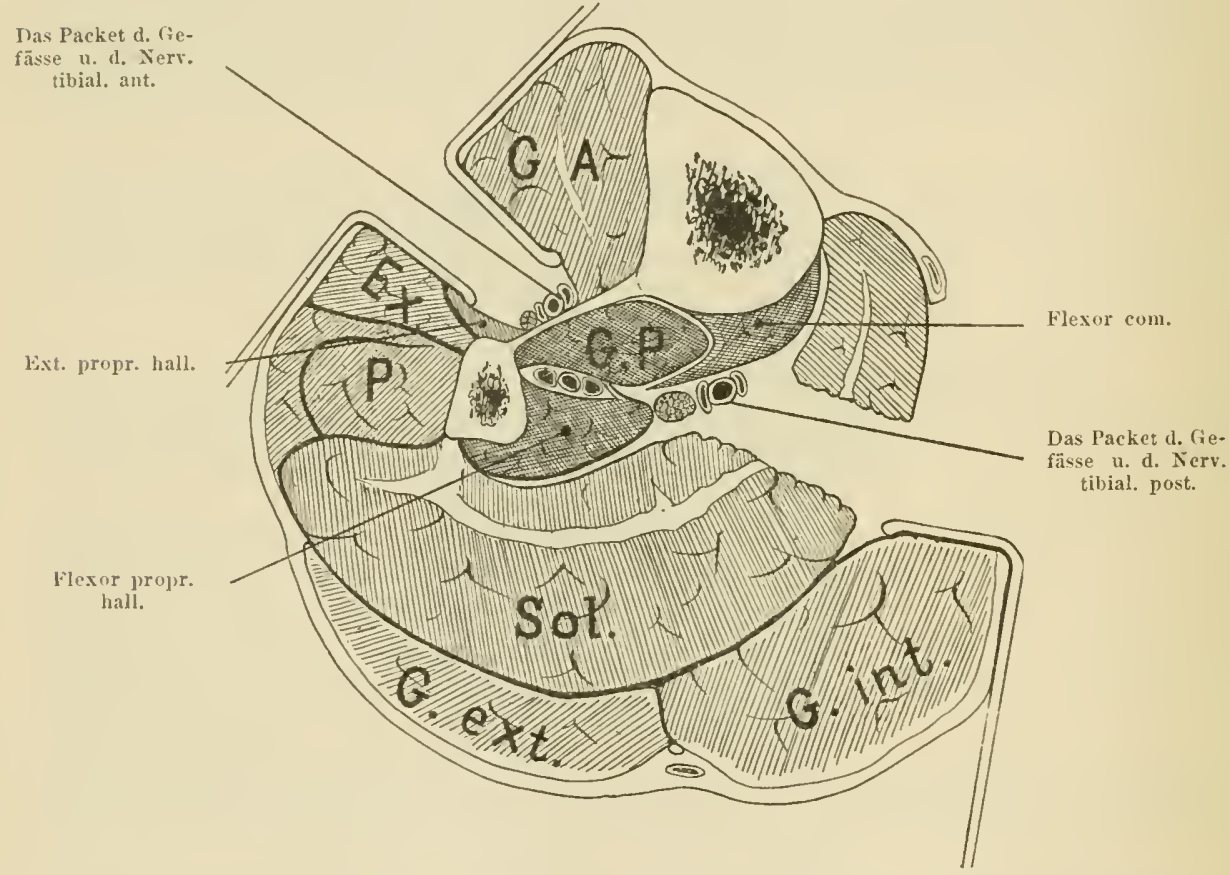

Ein Querschuitt im mittleren Drittheile des rechten Unterschenkels. Diese Figur zeigt den Weg, den mau einschlagen muss zur Unterbindung aussen der Tibialis antica, innen der Tibialis postica.

Die Arteria tibialis postica rerläuft längs der Tibia sehr wenig schief nach unten und innen gerichtet, liegt auf dem sehr dïnnen oberflächlichen Theile des Flexor communis, der sie vom Tibialis posticus scheidet; sie wird rom Soleus und ron einem zellig-fibrösen Blättchen, welches die mittlere Fascie darstellt, bedeckt (Fig. 111-112).

Die Arteria tibialis zieht hinter dem untern Ende der Tibia und hinter dem Talotibialgelenke: gegen das untere Ende der Tibia ist sie mit den sie begleitenden Venen und mit dem Yerrus tibialis posticus gemeinsam in einer Scheide enthalten, die in der Furche liegt, welche rom Tibialis posticus und Flexor communis innen und rom Flexor proprius aussen begrenzt wird. In dem obern Theile des Sulcus calcanei, nahe 
dem Niveau des obern Calcaneusrandes theilt sich die Arteria tibialis in die beiden Endäste: Arteria plantaris externa und Arteria plantaris interna. Die Arteria tibialis postica schickt von oben nach unten eine grosse Anzahl von Muskelästen und oft Arteriae nutritiae für die Tibia ab.

Die Richtung der Arteria tibialis postica ist durch eine Linie angezeigt, welche die Mitte der Kniekehle mit der knöchernen Erhabenheit verbinden würde, die unter und etwas hinter dem äussern Knöchel sich befindet, die Erhabenheit, die vom innern und hintern Höcker des Sprungbeines gebildet wird.

Die Arteria peronea verläuft vertical an der innern Seite der Fibula, liegt zuerst am Tibialis posticus oder besser an der Fascie, mit.welcher der Flexor communis sich an dem Wadenbeine inserirt, und dringt, vom Soleus bedeckt, gegen das mittlere Drittel des Unterschenkels unter dem Flexor proprius; hier ist sie in einem wahren Kanal enthalten, der vorne vom Tibialis posticus, hinten vom Flexor proprius, aussen von der Fibula, welcher sie oft eine Rinne eingräbt und innen von fibrösen Muskelbündeln, die dem Flexor proprius angehören, begrenzt wird.; diese Bündel entstehen an der Insertionsfascie des Tibialis posticus. Eine dünne zellig-fibröse Fascie bedeckt sie, löthet sie an die Muskeln an und versteckt sie unsichtbar dem beobachtenden Auge. Gegen das untere Drittel des Unterschenkels ist die Arteria peronea von der Fibula durch die Insertion des Flexor proprius geschieden.

Die Arteria peronea theilt sich im untern Theile des Spatium interosseum in zwei Aeste: ein Ramus anterior perforans, der das Ligamentum interosseum unmittelbar oberhalb des Tibio-fibulargelenkes durchdringt und ein Ramus posterior, der hinter der Interlinea articularis tibio-fibularis verläuft, unter dem Körper des Flexor communis zieht und sich im Talo-tibialgelenke und in der äussern Region der Ferse verbreitet.

Der Nervus tibialis posticus, der Begleiter der Arteria tibialis postica, liegt an der äussern Seite dieser Arterie, zuerst zwischen derselben und der Arteria peronea, dann zwischen derselben und dem imnern Rande des Flexor communis. Im Sulcus calcanei theilt sich der Nervus tibialis posticus in den Nervus plantaris externus und Nervus plantaris internus.

Technik z. A. d. G. Nan macht im mittlern Drittel der hintern Fläche des Unterschenkels einen Finger hinter dem innern Rande der Tibia eine $5-6 \mathrm{~cm}$ lange Incision; man beseitigt die Vena saphena interna, die man grösstentheils im Schnitte findet, schneidet die Fascie durch und sucht den innern Rand des Gemellus internus auf, den man isolirt und in einen stumpfen Haken legt (Fig. 113). Der Grund des Schnittes wird vom Soleus gebildet. NIan präparirt diesen Muskel schichtenweise, indem man sich gegen das Schienbein richtet, und gelangt an die fibröse Fläche, welche die Ursprungsfascie des Soleus darstellt. Man legt das Messer weg, nimmt die Sonde und mit deren Spitze zerreist man die Fascie und die Mluskelschichte, die sich unter derselben befindet.

Man legt zwei stumpfe Haken der Länge nach in die beiden Winkel der Oeffnung ein, die man im Soleus geschaffen hat; im Grunde des Schnittes, unter einem dünnen zellig-fibrösen Blättchen, sieht man den Nervus tibialis posticus durchscheinen; mit der Sonde zerreisst man dieses Blättchen und legt an der innern Seite des Nerven die Arteria tibialis postica mit den sie begleitenden Venen frei (Fig. 114).

Man sucht an der äussern Seite des Nerven den Rand des Flexor communis auf, mit der Sonde eröffnet man das Interstitium, welches diesen 
Nuskel rom Tibialis posticus scheidet und findet in diesem Zwischenraume gegen die Fibula die Arterie und die sie begleitenden Venae peroneac, die man in die Höhe hebt.

Das Auffinden der Art. tibialis postica scheint beim ersten Eindrucke schwierig, es wird aber dies stets gelingen, wenn man mit kaltem Blute vorgeht und die Nethode beherzigt, das Operationsfeld dureh gut eingelegte stumpfe Haken deutlich genug zu machen.

\section{Die Fusswurzel (der Hals des Fusses).}

Die Fusswurzel ist eine intermediäre Region zwischen Unterschenkel einerseits und zwischen dem Fusse andererseits; sie entspricht dem Talo-tibialgelenke.

Fig. 116.

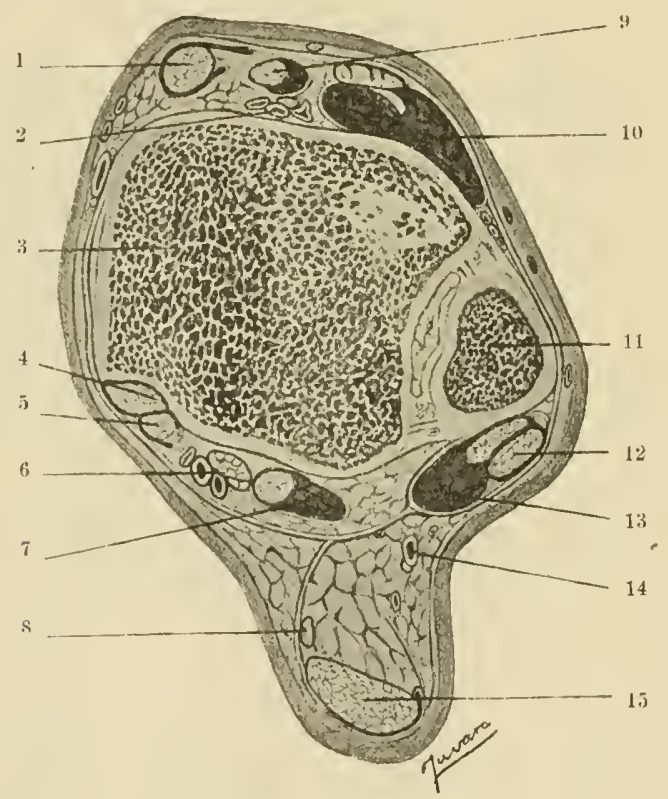

Ein Querschnitt etwas schief nach unten und hinten, ungefähr $1 \mathrm{~cm}$ oberhalb der Linea artieularis talo-tibialis: rechte Seite. 1. Die Sehne des Tibialis anticus: 2. das Packet der Gefässe und des Nervus tibialis anticus; 3. die Tibia; 4. die Sehne des Tibialis posticus; 5. die Sehne des Elexor communis longus; 6. das Packet der Gefässe und des Nervus tibialis posticus; 7. der Flexor hallucis longus; 8. die Sehne des Plantaris; 9. der Extensor hallucis longus; 10. Extensor communis longus; 11. Fibula; 12. die Sehne des Peroneus longus; 13. Peroneus brevis; 14. Vena saphena externa; 15. die Achillessehne.

Digitaluntersuchung. Man besichtigt und tastet die äussere Fläche der Fusswurzel ab; man sieht und fühlt eine verticale, oblonge, mit der Spitze nach unten gerichtete Erhabenheit, dic unmittelbar unter der Haut 
liegt, es ist der Malleolus externus; mit der Fingerbeere kann man sehr leicht den beiden Rändern folgen, dem vordern und hintern Rande des Knöchels.

Einen Finger vor dem vordern Rande des Knöchels fühlt man bei in Extensionsstellung befindlichem Fusse eine Erhabenheit in Form einer Ecke, es ist der obere und äussere Winkel des Sprungbeins.

Lnter dieser Erhebung dringt die Fingerspitze in eine Vertiefung, welche dem Orificium externum des Talo-calcaneus-Kanales entspricht, die Fossa talo-calcanea.

Gegen den untern und vordern Theil der Vertiefung der Talo-calcaneuslinie findet man eine andere Erhebung, den Processus major calcanei.

Wenn man den Fuss in Extensionsstellung bringt, verschwindet die Erhabenheit des Taluswinkels, indem sie in der Tibio-fibularhöhle zu liegen kommt.

Unter dem äussern Knöchel fühlen die untersuchenden Finger an der knöchernen resistenten Ebene, welche von der äussern Fläche des Calcaneus gebildet wird, eine kleine Erhabenheit, die von dem Tuberculum externum calcanei gebildet wird.

An der innern Fläche der Fusswurzel findet man die sehr sichtbare Erhabenheit des Malleolus internus, man nimmt denselben zwischen den Fingern und folgt mit den Fingerbeeren seinen Umrissen.

Man tastet $a b$, indem man rings um den innern Knöchel kräftig eindrückt und fühlt vor der knöchernen resistenten Ebene, die von der innern Fläche des Halses und des Kopfes des Talus gebildet wird, unten die Erhabenheit des Processus minor calcanei; unten und mehr hinten fühlt man bei in dorsaler Flexion befindlichem Fusse die Erhabenheit des Tuberculum externum posterius tali; bei plantarer Flexion versteckt sich dieser Höcker in der Tibio-fibularhöhle. Man bringt den Fuss in dorsale Halbflexion; die Sehnen der Extensoren entspamnen sich und man kann im Flexionswinkel zwischen beiden Malleolen den vordern Theil der Gelenkzwischenlinie der Fusswurzel und den vordern Rand des Tibialendes leicht abtasten.

\section{Vordere Region.}

Der Nervus musculo-cutaneus krenzt die vordere Fläche der Fusswurzel gegen die Mitte des Intermalleolarabstandes.

Technik z. A. d. G. Man macht in der Mitte des Intermalleolarabstandes einen schief nach unten und innen gerichteten Schnitt, im Grunde desselben oder unter einem der Ränder findet man den Nervenstrang.

Die Sehnen der Extensoren und des Tibialis anticus. Die vordere Fläche des Talo-tibialgelenkes wird von den Sehnen der Muskeln gekreuzt, welche vom Unterschenkel zum Fusse ziehen. Diese Sehnen sind von aussen nach innen:

Die Sehne des Peroneus anterior, die Sehne des Extensor commnnis, die Sehne des Extensor proprius und die Sehne des Tibialis anticus, sie sind an dem Gelenke durch 
eine fibröse Schlinge, Ligamentum annulare anterius der Fusswurzel oder Ligamentum in $Y$ festgehalten, welches wie ein Bogen rom Processus major calcanei zur Tibia einerseits, zum hahnbeine und zum ersten Os cuneiforme andererseits gespannt ist (Fig. 117). Zuerst einfach theilt sich dann das Ligamentum annulare anterius gegen die Mitte der Fusswurzel in zwei Bänder, indem sie die Form eines $\mathrm{I}$ annehmen (Fig. 118).

Fig. 117.

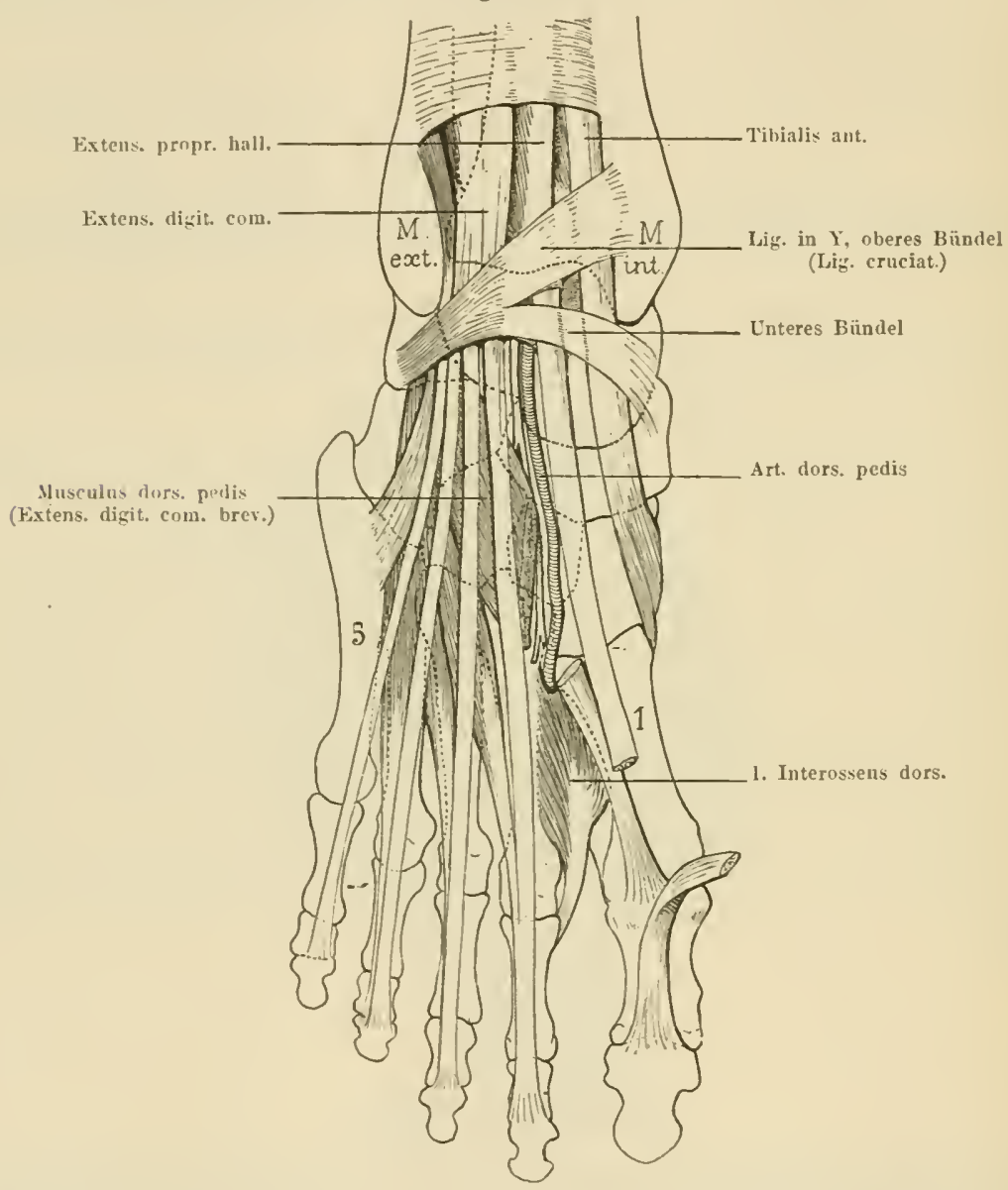

Die vordere Fläche der Fusswurzel und die dorsale des Fusses. Die Sehne des Extensor proprius ist durchschnitten und man sieht die Insertion der Sehne des Musculus dorsalis pedis: der hörper des ILusculus dorsalis pedis ist resecirt, um die Arteria dorsalis pedis und den Nerrus tibialis, die unter demselben liegen, zu sehen.

Dieses Band entsteht in der Form eines fibrösen Stranges am Höcker des Processus major calcanei, richtet sich nach oben und innen, erweitert sich fächerförmig, zieht ror den Sehnen des Peroneus anterior und des Extensor communis und theilt sich an deren innerem Rande in zwei Schichten:

a) Die tiefe Schichte umschlingt die Sehnen des Extensor communis, zieht unter 
denselben, richtet sich gegen das Fersenbein und verengt sich von oben nach unten; sie inserirt sich an demselben etwas innen von der Insertion des Ligamentum in $\mathrm{Y}$; auf diese Weise wird eine kräftige fibröse Schlinge gebildet, Ligamentum fundiforme, in welcher die Sehnen des Extensor communis und des Peroneus anterior in einen rechten Winkel sich biegend, gleiten.

b) Die obcrflächliche Schichte theilt sich am innern Rande der Sehne des Extensor proprius wieder in zwei Schichten:

1. Die tiefe Schichte umschlingt die Sehne des Extensor communis, bildet eine Schlinge, indem sie sich nach unten richtet und heftet sich an die innere Wand der Schlinge des Extensor communis, mit welcher sie sich am Calcaneus inserirt.

2. Die oberflächlichə Schichte theilt sich in zwei Bänder, das obere Band theilt sich, um die Sehne des Tibialis aufzunehmen und inserirt sich an der vordern innern Fläche der Tibia etwas oberhalb des Malleolus; das untere Band, dünner und breiter als das vorhergehende, zieht vor der Sehne des Tibialis und verliert sich an der innern Fläche des Kahnbeins, des ersten Keilbeins und an der Fascia plantaris.

Fig. 118.

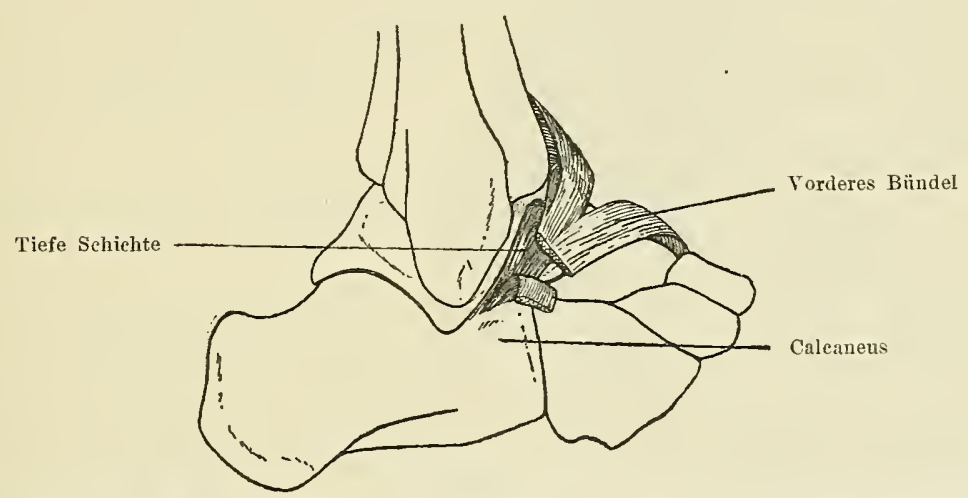

Die äussere Fläche des rechten Fusses; Ligamentum annulare anterius oder Ligamentum cruciatum.

Das Ligamentum annulare anterius bildet also drei Scheiden, eine äussere, sehr feste für den Extensor communis und Peroneus anterior, eine mittlere für den Extensor proprius und eine innere für den Tibialis anticus.

Diese Letztere ist sehr schlecht zusammengesetzt und die Sehne des Tibialis, weniger als die andern eingezogen, bildet eine mehr hervortretende Erhabenheit unter der Haut. Drei Synovialscheiden, aus den Reibungen der Sehnen entstanden, befinden sich rings um die Sehnen.

Die Scheide des Extensor commnnis hat die Form eines eingezogenen Sackes, indem die rerschmälerte Partie dem Ligamentum in Y entspricht. Sie beginnt zmeifingerbreit oberhalb des Gelenkes der Fusswurzel nnd endigt mit einer etwas breiten und gezähnten Aussackung gegen die Mitte des Fusses.

Die Sehnen sind im Innenraume der renösen Höhle nicht frei, sondern in einer Mesosehne enthalten, welche an der hintern Wand der Synovia entsteht und die Synorialhöhle in zwei Räume theilt, einen prätendinösen und einen retro-tendinösen, welche miteinander am freien innern Rande der Mesosehne communiciren. 
Am obern Theile der Synovialscheide findet man rings um die Sehnen eine schöne Plica praeputialis.

Die Scheide iles Extensor proprins hat die Form einer Tubenhöhle; sie beginnt eswas oberhalb der Scheide des Extensor communis und endigt etwas hinter dem Gelenke des ersten Mittelfussknochens mit seinem Keilbeine.

Die Sehne ist mit der hintern und äussern Wand der Seheide durch eine Mesosehne verbunden.

Die Scheide des Tibialis anticus beginnt $3-4 \mathrm{~cm}$ oberhalb des innern Knöchels und endigt im Niveau des Kíahnbeinhöckers; eine Synorialfalte verbindet die Sehne mit der hintern und äussern Wand der Scheide.

Teclunik z. A. I. G. Nan macht eine lange Incision, die am Processus major calcanei in der Rinne unter dem Sprungbeine beginnt und an der Tibia fingerbreit oberhalb des innern Knöchels endigt; man präparirt so breit als möglich die beiden Schnittränder, untersucht die Fascie und sicht sie durch das Ligamentum annulare verdickt, welches mit der Spitze des Bistouri begrenzt wird.

Man durchschneidet das Ligamentum annulare längs der Erhabenheit der Sehnen des Extensor communis und sieht wie dick es ist; die Sehnen werden frej und treten sofort aus ihrer fibrösen Synovialseheide hervor.

Man wiederholt diesen Versuch für den Extensor communis und Tibialis anticus.

Man schnejdet das Ligamentum annulare quer durch und löst die tiefe Fläche des äussern Fragmentes ab; man bemerkt, dass es den Hals des 'Talus umschlingt, ron dem es durch einen Schleimbeutel, der zuweilen sehr breit ist, geschieden wird.

Tibialis anticus. Man bringt den Fuss in Extensionsstellung; die Sehne des Tibialis macht eine bedeutende Erhabenheit; längs derselben macht man eine lange Incision, durchschneidet gleichzeitig die Haut und die Fascie. Die Sehne erscheint sofort weiss und glänzend in ihrer Synovialscheide.

Extensor proprius. Man macht in der Nitte der Fusswurzel eine Ineision, durchschneidet die Haut und die Fascie und gelangt an die Sehne des Extensor proprius.

Extensor communis und Peromens anterior. Man macht daumenbreit nach aussen von der Mitte der Fusswurzel eine Incision und gelangt an die Sehnen des Extensor communis und des Peroneus anterior, die in einer gemeinschaftlichen Synovialscheide enthalten sind.

\section{Die hintere Region.}

Die hintere Region der Fusswurzel nimmt in der Medianlinie die Erhabenheit der Achillessehne ein, die an jeder Seite jo eine Furche hat, die Retromalleolarfurchen. 


\section{Regio malleolaris externa.}

Die äussere Malleolarfurche wird aussen vom hintern Rande des Knöchels, innen vom innern Rande der Achillessehne begrenzt.

Die Vena saphena externa und der Nervus saphenus externus ziehen unter und hinter dem äussern Knöchel in der Verdoppelung des oberflächlichen Blättchens enthalten.

Technik z. A. d. G.. Man macht hinter dem Knöchel einen Hautschnitt, welcher unter der Spitze des Malleolus beginnt und sich nach oben

Fig. 119 .

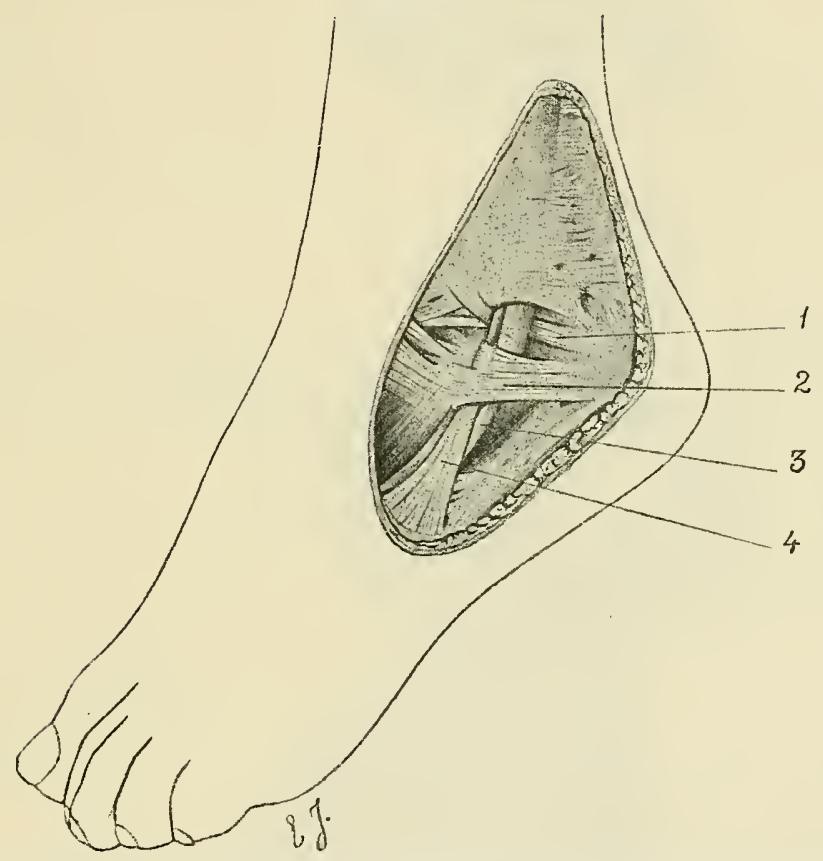

Regio malleolaris externa sinistra. 1. Ligamentum calcaneo-fibulare; 2. Retinaculum der Sehnen der Peronei; 3. die Sehne des Peroneus longus; 4. die Sehne des Peroneus brevis.

gegen die Achillessehne richtet. Im Grunde des Schnittes gelangt man unmittelbar unter der Haut an die Vene, neben derselben findet man den Nervus saphenus externus.

Die Sehnen der Peronei laterales. Die Sehnen der Peronei gleiten hinter dem äussern Knöchel in einem osteo-fibrösen Kanale, der vorne von der hintern Fläche des Knöchels in Form einer Rinne, hinten von einer fibrösen festen Schlinge, die vom äussern Rande der Malleolarfurche zur Fläche und seinem hintern Rande gespannt ist, begrenzt wird.

In diesem Kanale siud die Sehnen der Peronei, von vorne nach hinten ausgebreitet, hinter einander gelagert; die Sehne des Peroneus brevis haftet direct am Knöchel, sie ist die tiefste oder vordere. 
Unter der Spitze des Malleolus kreuzen sich die beiden Sehnen mit dem Ligamentum calcaneo-fibulare, biegen nach rorne $a b$ und steigen auf die äussere Fläche des Calcaneus schief herab.

Die Selne des Peronens brevis wird die obere, zieht oberhalb des äussern Höckers des Fersenbeines und auf die äussere Fläche des Calcaneo-cuboidalgelenkes und inserirt sich an der obern Fläche des Höekers des 5. Metatarsus.

Die Sehne des Peroneus longus zieht unter dem Höcker des Calcaneus, biegt in einem Winkel am Höcker der hintern Lefze der Würfelbeinfurche ab, durehdringt die Sohle des Fusses in einem osteo-fibrösen Kanale und inserirt sich am hintern äussern Höcker des I. Mittelfussknochen.

Fig. 120 .

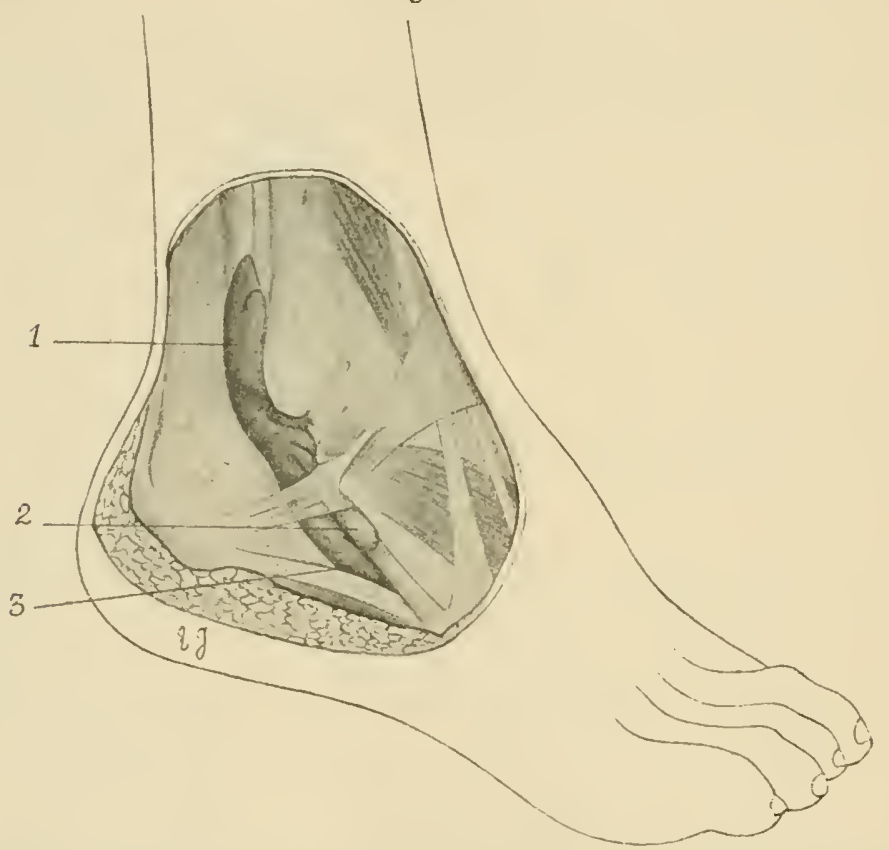

Regio malleolaris externa dextra. Die synoviale Scheide der Sehnen der Peronei ist mit Talg injicirt. 1. Die gemeinsame Scheide; 2. der obere Schenkel für den Peroneus brevis: 3 . der untere Schenkel für den Peroneus longus.

Im Niveau des Tuber caleanei sind die Sehnen der Peronei durch je einen fibrösen Ring festgehalten.

Die Synovialscheide der Sehnen der Peronei. Hinter dem linöchel und an der äussern Fläche des Fersenbeines werden die Sehnen der Peronei ron einer Synovialscheide begleitet. Die Scheide beginnt mit einer Aussackung 3 fingerbreit oberhalb der Malleolusspitze. Zuerst für die beiden Sehnen gemeinsam, theilt sie sich im Niveau des hintern Endes des Fersenhöckers in 2 Arme, indem sie die Form eines Y erhält (Fig. 120).

a) Der obere Arm begleitet die Sehne des Peroneus brevis und endigt einen Finger hinter der Insertion dieser Sehne in einer Aussackung.

b) Der untere Arm folgt der Sehne des Peroneus longus und endigt otwas oberhalb des Punktes, wo die Sehne in die Fusssohle dringt, als eine Aussackung. Eine zu- 
weilen sehr dünne Wand theilt diesen Blindsack rom äussern Blindsack der plantaren Synovia des Peroneus longus. Sehr oft schwindet diese Wand und die beiden Scheiden communiciren mit einander durch ein mehr oder weniger breites Orificium.

Eine Mesosehne befindet sich für jede Sehne; die Mesosehne des Peroneus brevis

Fig. 121.

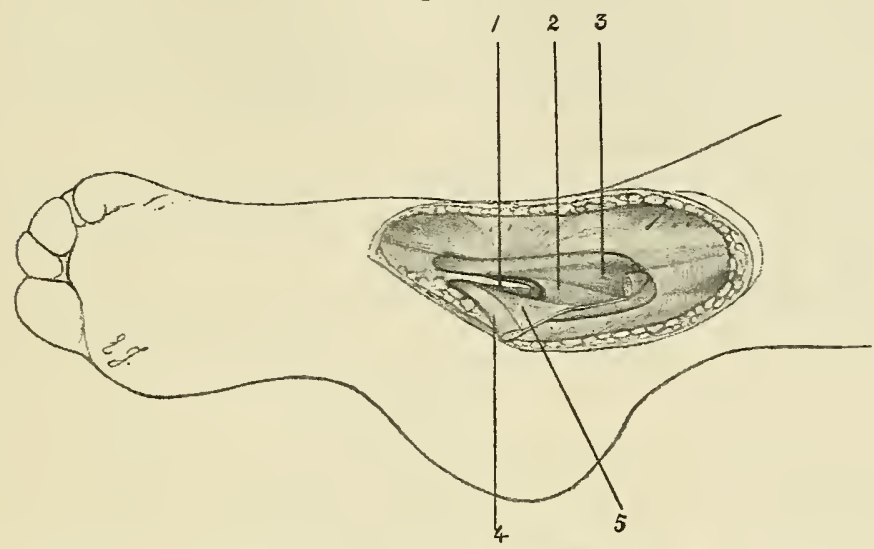

Die synoviale Scheide der Sehnen der Peronei ist eröffnet. Man sieht die Mesosehnen. 1. Die fibröse Wand, welche die Sehnen scheidet; 2. die Mesosehne des Peroneus brevis; 3. der Peroneus brevis; 4. die durchschnittene Sehne des Peroneus longus; 5 . die Mesosehne desselben.

Fig. 122.

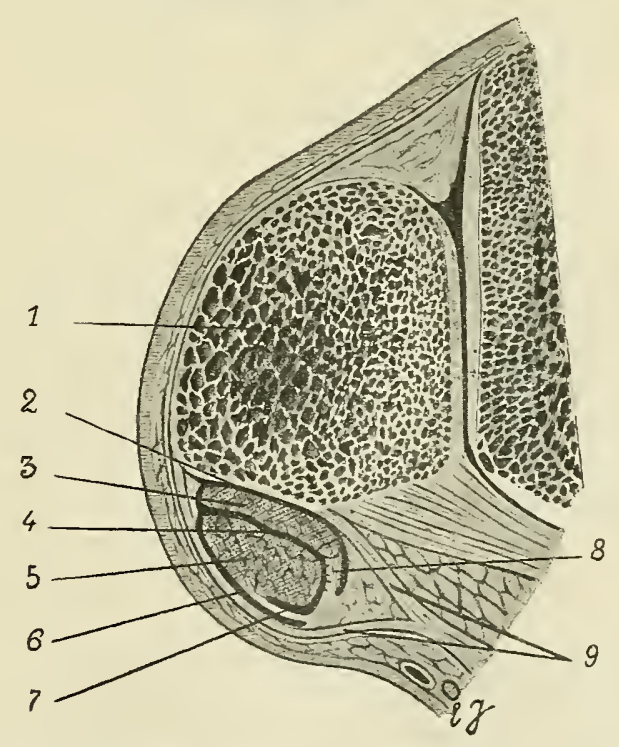

Ein Querschnitt durch die Knöchel, etwas oberhalb des Talo-tibialgelenkes. 1. Malleolus externus; 2. der prae-tendinöse Raum; 3. Peroneus brevis; 4. der inter-tendinöse Raum: 5. die Sehne des Peroneus longus; 6. der retro-tendinöse Raum; 7. die Mesosehne des Peroneus longus; S. die Mesosehne des Peroneus brevis; 9. die Wände der fibrösen Scheide, durch Theilung der Fascie entstanden. 
hat die Form einer dreieckigen Falte, sie entsteht an der hintern äussern Wand der gemeinsamen Partie del Scheide und dringt mit ihrem untern Fortsatze in die eigene Scheide dieser Sehne; die Mesosehne des Peroneus longus begleitet die Sehne in ihrer ganzen Länge, sie entsteht an der hintern Wand der gemeinsamen Scheide, nahe der Insertion der Mesosehne für den Peroneus breris und an der lintern Wand der eigenen Scheide des Peroneus longus (Fig. 121).

Oft bekommen die beiden Mesosehnen, indem sie mit einer gemeinsamen Wurzel entstehen, die Form eines Y ; sie theilen die Synovialhöhle in drei Räume: einen prätendinösen, einen intertendinösen und einen retrotendinösen Raum, die aussen am äussern liande der Sehnen communiciren (Fig. 122).

Technik z. A. d. G. Mit dem Nagel sucht man die äussere Lefze der äussern Malleolusfurche auf, die Crista malleoli, und macht unmittelbar an deren Innenseite eine verticale Incision.

Man schneidet die hintere Wand der Sehnenscheide durch und sieht

$$
\text { Fig. } 123 .
$$

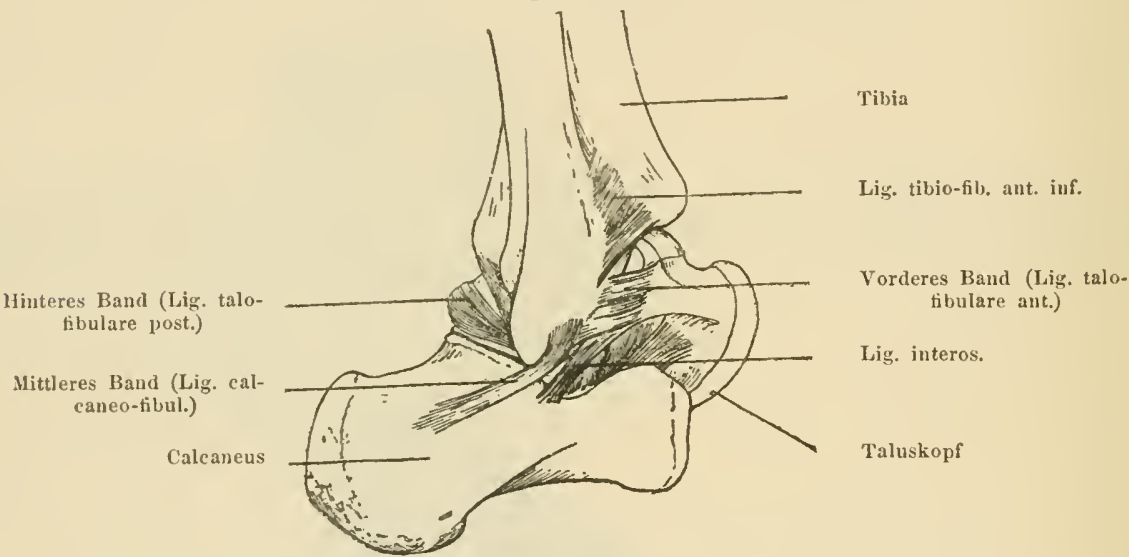

Die laterale äussere Fläche des Talo-tibialgelenkes der rechten Seite.

zuerst die breite und kräftige Sehne des Peroneus longus und vor demselben, am Malleolus gelagert, die Sehne des Peroneus brevis.

Man folgt den Sehnen und verlängert die Incision nach vorne; man löst die Insertion des Peroneus brevis ab und folgt dem Peroneus longus bis zum Fussrande. Man sieht, dass sie gegen die Mitte des Fersenbeines durch eine knöcherne Leiste, die an der untern Fläche von einem fibrösen Knorpel bedeckt ist, geschieden werden, durch den äussern Höcker des Calcaneus.

Man studirt die Synovialscheide und die sehr eigenthümliche Anordnung der Mesosehnen.

Der äussere Bandapparat besteht aus drei Bändern:

1. Das rordere Talo-fibularband hat die Form eines rechtwinkligen Blattes, das durch einen Zwischenraum, in dem ein kleiner synovialer Blindsack sich bewegt, in zwei Bänder getrennt ist. Es inserirt sich hinten am vordern Rande des äussern Knöchels rorne am Talus, an der Leiste, die längs des rordern Randes der Fibulafläche dieses Knochens sich befindet (Fig. 123). 
Technik z. A. d. G. Mit der Fingerbeere sucht man durch Abtasten den vorderen Rand des äusseren Knöchels auf, der schief nach abwärts und hinten gerichtet ist. Längs diesem führt man einen 3-4 cm langen Schnitt, welcher unter der Knöchelspitze endigt. Unter der Haut findet man den äusseren Ast des Nervus musculo-cutaneus. Man durchschneidet die Fascie und gelangt unter derselben und unter einer dünnen Fettschichte an die weissen und glänzenden Fasern des transversal gelagerten Ligamentum talofibulare anterius. Oft begegnet man zwischen den bejden Bündeln dieses Bandes einer Synovialcyste. Man präparirt vertical das Ligament, es eröffnet sich das Gelenk und man erblickt die Fibulafläche des Talus. In dem vor dem Bande befindlichen Fette sieht man eine kleine Arterie, den Ramus prae-malleolaris der Arteria peronea.

2. Das mittlere oder Calcaneo-fibularband ist ein fibröser, $3-5 \mathrm{~mm}$ dicker Strang und fast 2 fingerbreit lang. Es entsteht am vordern Rande des Knöchels an der drei-eckigen Fläche, die etwas oberhalb von seiner Spitze sich befindet, biegt ab und richtet sich nach unten und hinten, indem es etwas nach innen von der Knöchelspitze zieht, verbreitert sich ein wenig und inserirt sich an der Rauhigkeit oder am Höcker, welcher gegen die Mitte der obern Hälfte der äussern Calcaneusfläche sich befindet. Das Ligamentum calcaneo-fibulare wird von den Sehnen der lateralen Peronei gekreuzt, von welchen es durch die innere Wand der fibrösen Synovialscheide dieser Sehnen getrennt ist.

Technik z. A. d. G. Man macht hinter dem Knöchel eine verticale Incision, eröffnet die Scheide der Peronei, nimmt die Sehnen aus der Scheide heraus und legt sie in stumpfe Haken; an der innern Wand der Scheide unter einem synovialen Blättchen sieht man den fibrösen, fast horizontalen Strang, den man isolirt. Dieser stellt das Ligamentum ealcaneo-fibulare dar.

Man löst dasselbe hinten vom Calcaneus, vorne vom Rande des Knöchels ab, von dessen Spitze es oft durch eine seröse Höhle getrennt ist.

3. Das hintere Talo-fibularband, das stärkste unter allen, ist ein fibröser dicker Kegel, tief rersteckt im Spatium talo-fibulare. Es entsteht aussen im untern Drittel der innern Fläche des Knöchels an jener genügend breiten Oberfläche von mattem Aussehen, die sich hinter der Gelenkoberfläche und unter der fingerförmigen Vertiefung befindet. Von hier richtet es sich nach innen und sehr wenig nach hinten und inserirt sich an der äussern Fläche des Sprungbeins an der dreieckigen Oberfläche, die sich unter der Fibulafacette befindet. Eines der obern Bündel, das Ligamentum talo-fibulare posticum, richtet sich nach oben und innen und inserirt sich am hintern Rande des Schienbeinendes, nahe dem Malleolus internus (Fig. 123).

Technik z. A. d. G. Man macht hinter dem Knöchel dieselbe Incision wie für das Auffinden der Sehnen der Peronei, man nimmt die Sehnen aus der Scheide heraus, bringt den Fuss in kräftige Flexionsstellung und löst die hintere Wand ihrer fibrösen Scheide ab.

Auf diese Weise eröffnet man das Spatium talo-fibulare, in welchem man das Ligamentum talo-fibulare posticum findet; man schneidet dieses schichtenweise quer durch und sieht wie dick und fest dasselbe ist. 


\section{Regio malleolaris interna.}

Vella und Yervus saphenus interuls. Die Vena saphena interna entsteht durch Vereinigung der Vene des innern Randes mit dem innern Ende des Arcus dorsalis pedis, kreuzt schief von unten nach oben die vordere Hälfte des Malleolns internus. Nerrenäste, die dem Saphenus internus angehören, begleiten dic V'ene.

Technik z. A. d. G. Nan sieht und fühlt meistentheils durch eine aufmerksame Palpation die Vene in Form eines Bandes, welches auf der resistenten Fläche des Knöchels gleitet. Auf dem vordern Rande des Knöchels macht man einen Hautschnitt; man muss rorsichtig sein, weil die

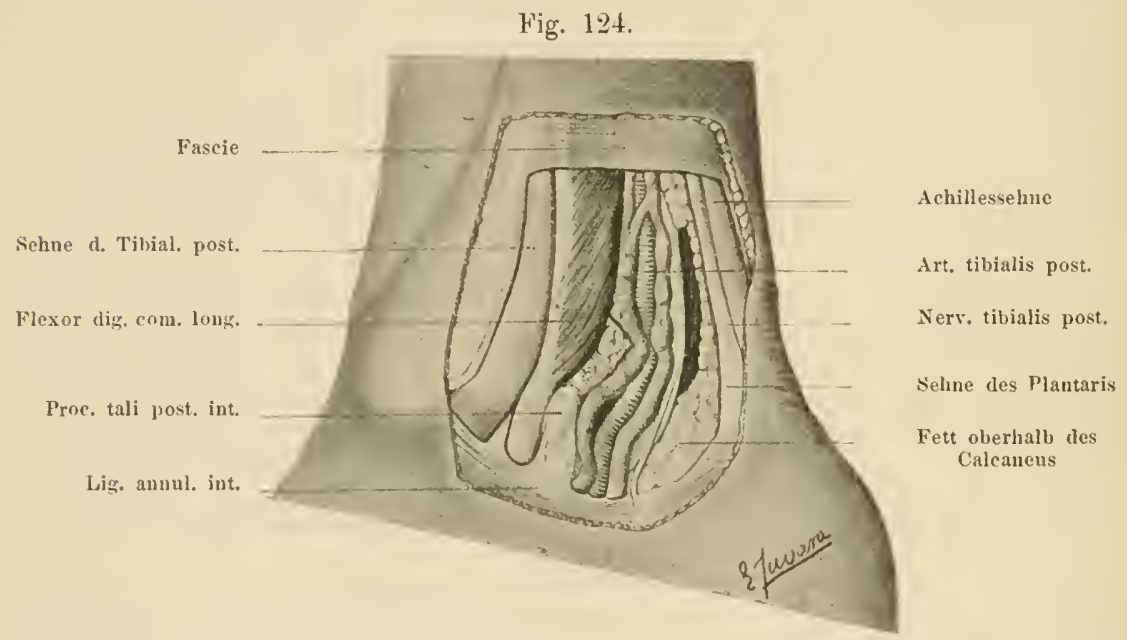

Regio malleolaris interna dextra.

Vene unmittelbar unter der Hant liegt; sic kreuzt in Form eines $\mathbf{X}$ diese gemachte Incision; neben derselben findet man den Nervus saphenus intermus.

Sulcus retro-malleolaris interuus. Diese innere Retromalleolarfurche wird vorne und innen von der Crista des Malleolus internus, hinten und aussen durch den innern Rand der Achillessehne begrenzt; unten geht dieselbe ohne Grenze in die Furche des Fersenbeines ïber.

Die Sehnen des Tibialis posticus und des Flexor communis der Zehen. Diese beiden Sehnen liegen hintereinander und gleiten hinter dem Malleolus internus in einem osteo-fibrösen Kanale, der vorne rom línöchel und hinten ron einem fibrösen Blatte, das zwischen beiden Rändern der Nalleolarfurche gespannt ist, gebildet wird. getheilt.

Gegen die Spitze des Knöchels werden die beiden Sehnen durch eine fibröse Wand

Die dicke und verbreitete Sehne des Tibialis postions gleitet in der an der hintern Fläche des Knöchels ansgehöhlten Furche, faltet sich gegen dessen Spitze am Ligamen- 
tum laterale internum, indem sie sich gegen den Kahnbeinhöcker richtet und inserirt sich mit einem Büschel von sehnigen Fasern am Kahnbeine, am ersten und dritten Keilbeine, am Würfelbeine und an den drei mittlern Mittelfusskochen (Fig. 125).

Die Sehme des Flexor communis long'ıs, zur Hälfte dick wie die Sehne des Tibialis posticus, liegt hinten und etwas aussen von dieser Sehne. Gegen die Spitze des Knöchels biegt sie ab, zieht unter der Sehne des Tibialis, von welcher sie durch ein fibröses Blatt getrennt ist, gleitet an der Spitze des kleinen Calcaneushöckers, auf welchem sie sich etwas nach aussen biegt, indem sie sich gegen die Mitte der Sohle richtet.

Fig. 125.

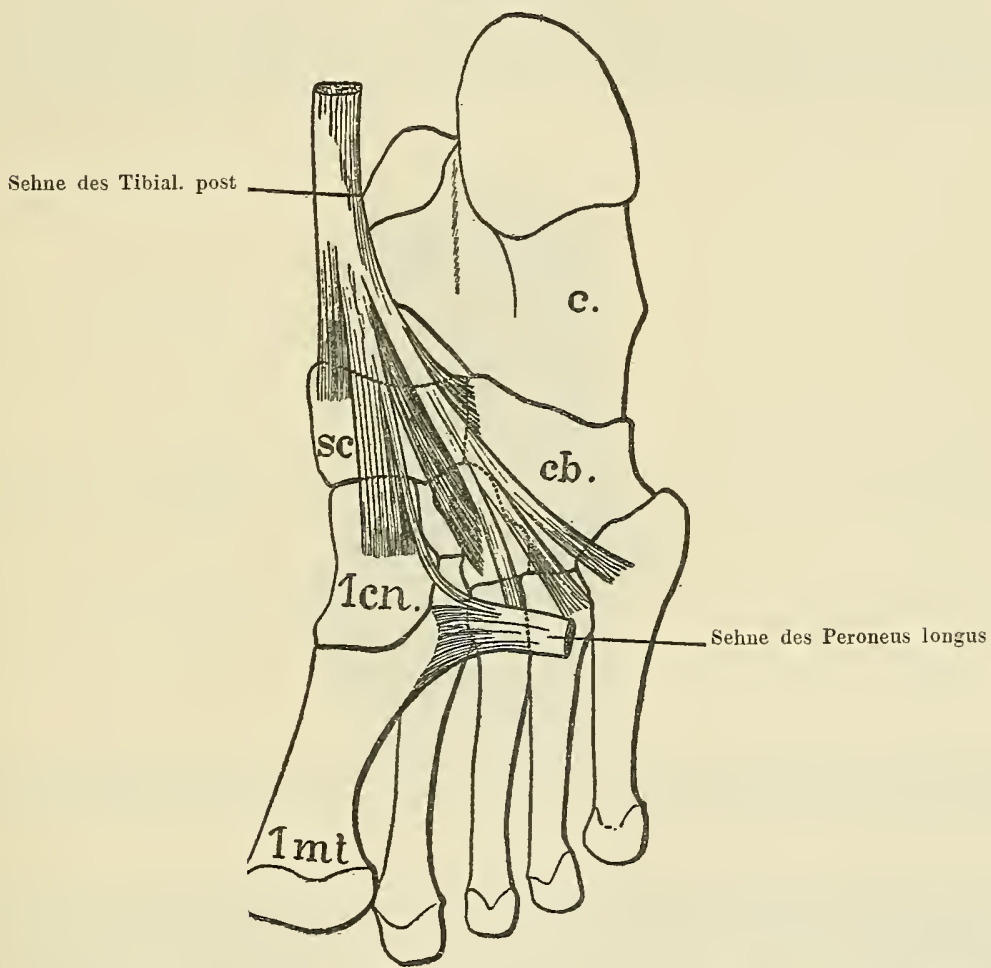

Die untere Fläche des rechten Fussskelettes; die Insertionen des Tibialis posticus und des Peroneas longus.

Diese beidən Sehnen sind von einer Synovialscheide begleitet, welche mit einem Blindsack 2 Finger oberhalb des Knöchels beginnt uud sich gegen dessen Spitze in zwei Schenkel theilt: a) der obere Schenkel folgt der: Sehne des Tibialis posticus und endigt hinter dem Kahnbeinhöcker in Blindsackform, b) der untere Schenkel begleitet die Sehne des Flexor communis bis gegen die Mitte der Sohle.

Techuik z. A. d. G. Man tastet mit den Fingern die hintere Fläche des Knöchels ab und fühlt die Retro-malleolarsehnen gleiten; mit den Nägeln fasst man die Crista malleoli und macht unmittelbar hinter derselben eine 
verticale Incision, indem man gleichzeitig die Hant und die sehr dicke Fascie durchschneidet. In dem Schnitte erseheint die weiss glänzende Sehne les Tibialis posticus; diese wird mit der Sondenspitze gehoben und man sicht wie dick und fest sic ist. Man sucht unter dem äussern Schnittrande und findet die Sehne des Flexor communis, die mit der Sonde gehoben wird.

Jan lässt die Sonde nach oben längs der Sehnen gleiten, sie wird rom obern Blindsack ihrer Synovialscheide aufgehalten. Nach unten tastet man der Reihe nach mit der Sonde oder besser noch mit einem Stilet die Scheide des Tibialis und die des Flexor ab.

Die Sehne des Flexor longus hallucis beschreibt hinter dem Sprungbeine einen grossen, mit der Concavität nach oben gericliteten Bogeri. Sie gleitet zuerst in der Furche, die am mittlern Theile des untern Schienbeinendes sich befindet, kreuzt dic Gelenklinie und folgt der am hintern Talusende und an der untern Fläche des Processus minor

Fig. 126.

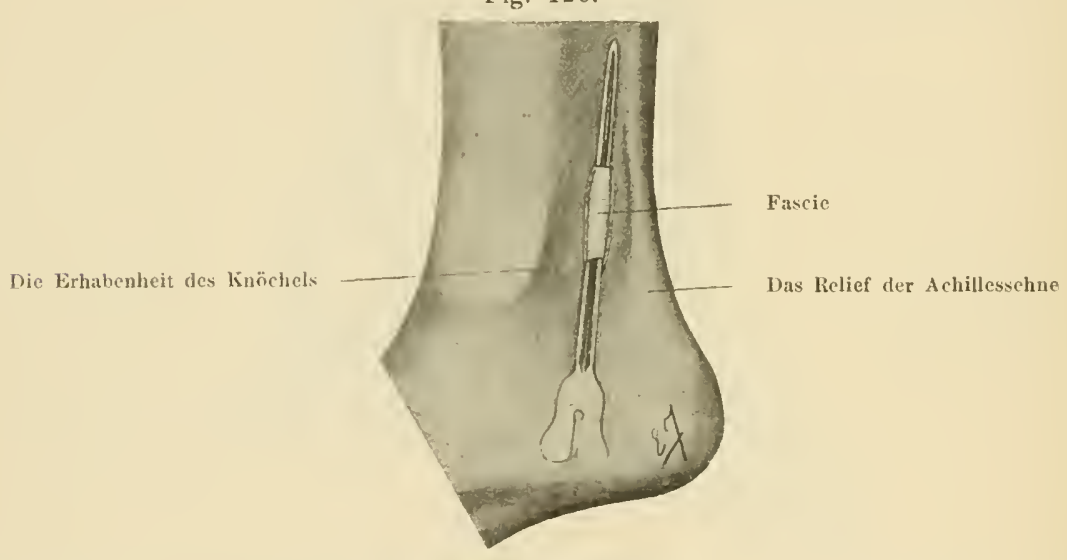

Das Aufsuchen der Arteria und des Nervus tibialis posticus. Eine Hohlsonde ist unter die Fascie geschoben.

calcanei ausgehöhlten Furche, dem Sulcus talo-calcaneus. Diese Furche wird zu einem oste0-fibrösen Kanale durch ein wie eine Brücke zwischen ihren beiden Rändern gespanntes Blatt umgewandelt.

In diesem Verlanfe ist die Sehne des Flexor proprius ron einer Synovialscheide begleitet, welche einen Finger oberhalb des Tibialendes beginnt und gegen das vordere Ende des Calcaneus auf hört.

Technik z. A. d. A. Man sucht das Tuberculum postero-externum tali auf und macht unmittelbar nach aussen von demselben cine tiefe Incision, indem man gleichzeitig die Haut und die Fascie durchschneidet, es erscheint die Sehne des Flexor proprius in ihrer Furche.

Mit einem Stilet sondirt man nach oben und unten ihre Synovialscheide.

Die Gefässe und der Nervus tibialis posticus. Das Packct der Gefässe und 
des Nervus tibialis posticus liegt an der hintern Fläche des Tibialendes iu der Furche, welche aussen von der Sehne des Flexor proprius, innen von der Sehne des Tibialis pasticus und des Flexor communis begrenzt wird. Es wird von einer festen Fascie bedeckt, welche durch Vereinigung der oberflächlichen Fascie mit der tiefen gebildet wird.

Technik z. A. d. G. Yan bringt den Fuss in äussere Rotationsstellung und tastet ron oben nach unten die Malleolarfurche ab. Gegen den untern Theil fühlen die Fingerbeeren die Erhabenheit des Tuberculum postero-internum tali; diese wird mit dem Nagel bezeichnet. Im gleichen Abstande von der Crista malleoli und dem Rande der Achillessehne macht man einen 3 fingerbreit langen verticalen Hautschnitt, der nach unten im Niveau des Tuberculum tali endigt.

Man reinigt die Fascie, indem man sie leicht mit der Spitze des Bistouri abschabt und kann oft durch dieselbe das Gefässpacket erkennen;

Fig. 127.

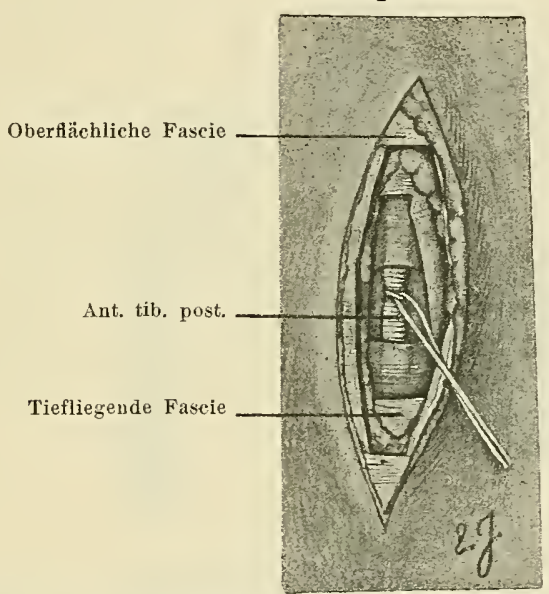

Das Aufsuchen der Arteria tibialis postica. Man sieht die beiden Fascien, welche die Artorie bedecken.

man schneidet die Fascie auf der Hohlsonde durch und gelangt unter derselben an das Gefässpacket. Man legt dasselbe frei und hebt die Arterie und ihre Venen in die Höhe; den Nerv findet man etwas mehr nach aussen (Fig. 127).

Der innere Bandapparat. Der innere ligamentöse Apparat hat die Form eines Fächers, der von dem vordern untern Rande des Malleolus internus zum Os naviculare, Calcaneus und Talus ausstrahlt.

Er besteht aus drei Bändern:

1. Das vordere oder Tibio-tal $0-n$ avicularband, von dreieckiger Form, entsteht an dem vordern Rande des Knöchels und theilt sich in zwei Faserschichten: a) die tiefe, dünne und zellig-fibröse Schichte inserirt sich an dem vordern Rande der innern Gelenkfacette des Talus, b) die dickere und fibröse obsrflächliche Schichte inserirt sich an der innern Fläche des Os naviculare an der Leiste, welche etwas vor dem Gelenlirande 
und an dem inneru Rande des Ligamentum calcaneo-naviculare oder glenoidale sich befindet (Fig. 12s).

Terhnik \%. A. d. G. Man präparirt ror dem Malleolus internus das zelligg-fibröse Gewebe und gelangt an eine fibröse Ebene, die sich spannt und entspannt, je nach den Bewegungen des Fusses, es ist das Ligamontum anterius. IIan studirt dessen Insertionen, indem man es transversal durchschneidet; man sieht wie es gerade wie das vordere Talo-fibularband wenig fest ist.

2. Das mittlere oder Calcaneo-tibialband hat die Form cines rechtwinkligen Bandes, das ron dem rordern Rande und der Spitzc des Malleolus internus bis zur innern Fläche des Processus minor calcanei gespannt ist.

Mit seinen vorderm Fasern verwebt sich das mittlere Band mit dem hintern Theile

Fig. 128.

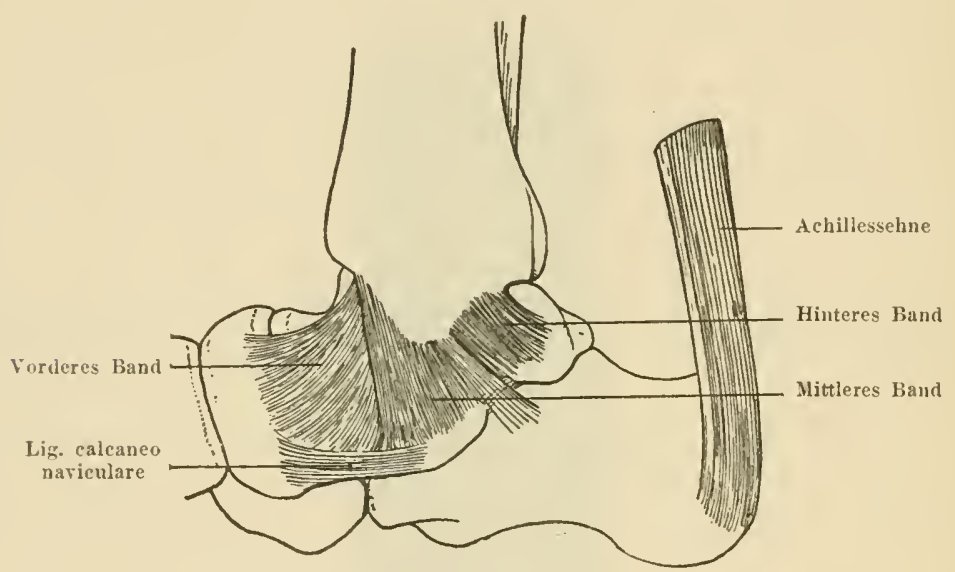

Die innere Fläche des rechten Talo-tibialgelenkes.

des Ligamentum glenoidale, mit einigen seiner hintern Fasern gleitet es an dem hintern Theile des Processus minor und inserirt sich an der innern Fläche des Calcaneus.

Das rordere und mittlere Band bilden zusammen ein fibröses Blatt in Form eines $\triangle$, daher der Name Ligamentum deltoides (Fig. 128).

Technik z. A. d. (G. Nlan macht eine verticale Incision, welche oberhalb der Malleolusspitze beginnt und zwei Finger unter derselben endigt. Man schneidet die Fascie und die Sehme des Tibialis posticus durch und findet unter Letzterem die verticalen Fasern des mittlern Ligamentes; man präparirt und schneidet es quer durch und sieht, dass es um vieles dicker ist als das vordere.

3. Das hintere oder Talo-tibialband, sehr dick und fest, hat die Form eines fibrösen Bündels, inserirt sich oben in der Grube, die sich hinter der Knöchelspitze befindet, unten an der kreisförmigen rauhen Oberfläche, die den hintern Theil der innern Schienbeinfläche unterhalb des Endes der innern Gelenkfacette dieses Knochens einnimmt.

Der rordere Theil des hintern Bandes ist rom mittlern Bande bedeckt, weshalb es 
mit der tiefen Schichte desselben beschrieben wurde; hinten ist es entfaltet und leicht zu sehen, ohne eine specielle Präparation nöthig zu haben (Fig. 128).

Die hintern äussern und innern Bänder sind sehr kurz und fast transversal gerichtet, sie sind die kräftigsten des Talo-tibialgelenkes; sie stellen die Achse dar, um welche fast alle Bewegungen dieses Gelenkes ausgeführt werden.

Technik z. A. d. G. Man macht hinter und unter dem Knöchel eine Incision, eröffnet die Scheide des Tibialis und zieht aus derselben die Sehne heraus; unter dieser sieht man kurze und glänzende Fasern des hintern Ligamentes, die sich spannen, wenn der Fuss in Flexionsstellung gebracht wird.

Mit der Spitze eines Bistouri schneidet man schichtenweise das Ligament durch und sieht wie dick und kräftig dasselbe, wenn man die Klinge zwischen Knöchel und Talus einführt.

Man kann das hintere Talo-tibialband durchschneiden, wenn man es von der Gelenkhöhle angeht; zu diesem Zwecke eröffnet man die Gelenkhöhle am vordern Rande des Malleolus internus, bringt den Fuss in leichte Extensionsstellung und lässt die Klinge eines Bistouri mit der Scheide nach unten im Gelenke zwischen Knöchel und Sprungbein gleiten. Man drückt den Stiel des Messers nach oben. Dieser stützt sich mit dem Rücken an der Tibia und seine Spitze beschreibt einen Bogen und durchschneidet von vorne nach hinten das hintere Ligament.

Man wiederhole oft diesen interessanten Versuch, denn man wird sich desselben in der Chirurgie bedienen, um die Resection des Talus vorzunehmen.

\section{Der Fuss.}

Dorsalfläche. DigitaInntersuchung. Man präparirt aufmerksam den hintern Theil der Dorsalfäche des Fusses und fühlt in der Medianlinie einen Finger vor dem Talo-tibialgelenke die Erhabenheit des Caput tali, die noch mehr hervortritt, wenn man der vordern Hälfte des Fusses eine innere Rotationsbewegung ertheilt.

Im vordern Theile des Fusses füblt man unter der sehr beweglichen Haut die Körper der Metatarsi und die Zwischenknochenräume, welche sie scheiden.

An mageren Cadavern kann man unter der Haut die Sehnen der Extensoren sehen und fühlen; zuweilen auch die Aeste des Nervus musculocutaneus.

Der Musculus pedis, Musmlus extensor digitorum communis breris, strahlt vom Processus major calcanei zu den vier innern Zehen aus (Fig. 117).

Er entsteht mit Fleischfasern und fibrösen Blättern: a) an der vordern äussern Hälfte der Dorsalfäche des Processus major calcanei, b) an den beiden Bündeln des Ligamentum annulare und c) am Ligamentum calcaneo-cuboideum dorsale.

Juvara, Practiseher Auszug aus der ehirurgischen Anatomie. 
Der Fleischkörper des Fussmuskels wird breiter und dïnner, bevor er sich in vier Bündelchen oder Köpfe theilt.

1. Das innere Bündel, der Extensor hallucis breris, das breiteste kreuzt diagonal den Rücken des Fusses, unter dessen Mitte sein Fleischkörper zu einer Sehne gesammelt ist, die sich in einem spitzen Winkel der Sehne des Extensor proprius longus nähert. Fäeherförmig ausgebreitet inserirt es sich am obern Rande des hintern Endes der ersten Phalange der Grosszehe.

Die Fleischkörper der drei äussern Bündel schicken je eine dïnne Sehne ab, welche sich der Zehenpartie der entsprechenden Strecksehnen nähern und vermengen, um sich mit ihnen am hintern Ende der dritten Phalange der II., IlI. und IV. Zehe zu inseriren (Fig. 117).

Technik z. A. d. G. Man, macht cine diagonal verlaufende Incision, die an der Depressio talo-calcanea beginnt und bis zur Grosszehe reicht;

Fig. 129.

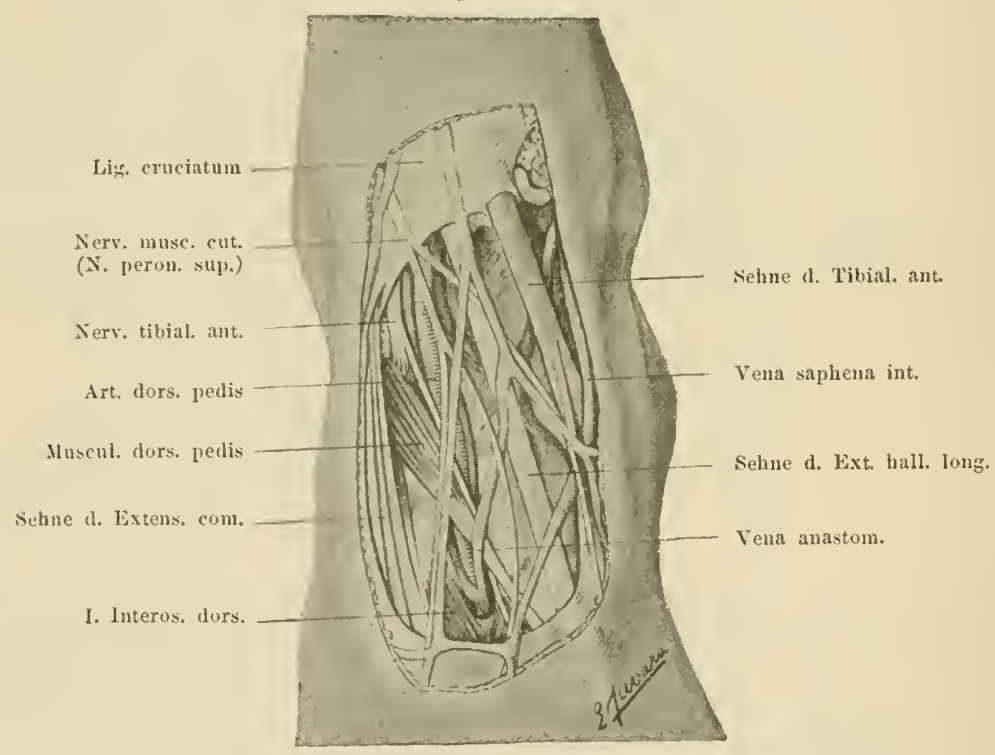

Die mittlere Region der dorsalen Fläche des rechten Fusses.

unter der Fascic in den Interstitien der Strecksehnen sieht man den rothen Fleischkörper des Fussmuskels.

Man schneidet die Strecksehnen durch, präparirt ziemlich weit den äussern Schnittrand, isolirt die vier Bündel des Fussmuskels und studirt die vollständige Insertion dieses Muskels am Calcaneus und an den Wurzeln des Ligamentum annulare.

IIan durchschneidet transversal den Fussmuskel und präparirt die tiefo Fläche des hintern Fragmentes; auf diese Weise kann man dessen Insertion am Ligamentum calcaneo-cuboideum dorsale studiren.

Arteria dorsalis pedis und Nerrus tibialis anticus. Die Arteria dorsalis pe- 
dis bildet die Fortsetzung der Arteria tibialis antica, sie beginnt in der Mitte der Fusswurzel am vordern Rande des Tibialendes, verläuft zuerst auf der Capsula talo-tibialis, dann am Tarsus und endigt im hintern Theile des ersten Spatium interosseum, welches sie ron unten nach oben durchdringt; sie anastomosirt in der Fusssohle mit dem Arcus plantaris profundus.

Im Niveau der Fusswurzel, unter der Sehne des Extensor proprius, wird die Arteria dorsalis pedis gegen das hintere Ende des ersten Spatium interosseum von der Sehne des Extensor hallucis brevis gekreuzt (Fig. 129).

Der Nervus tibialis anticus liegt zuerst an der äussern Seite der Arterie, kreuzt diese, zieht an deren Innenseite, perforirt die Fascie, anastomosirt mit dem Musculo-cutaneus und theilt sich in den Collateralis externus der Grosszehe und Collateralis internus der zweiten Zehe.

Die Richtung des Gefäss- und Nerrenpacketes ist durch eine Linie gegeben, welche die Mitte des Spatium intermalleolare mit dem hintern Ende des ersten Zwischenknochenraumes verbindet.

Fig. 130 .

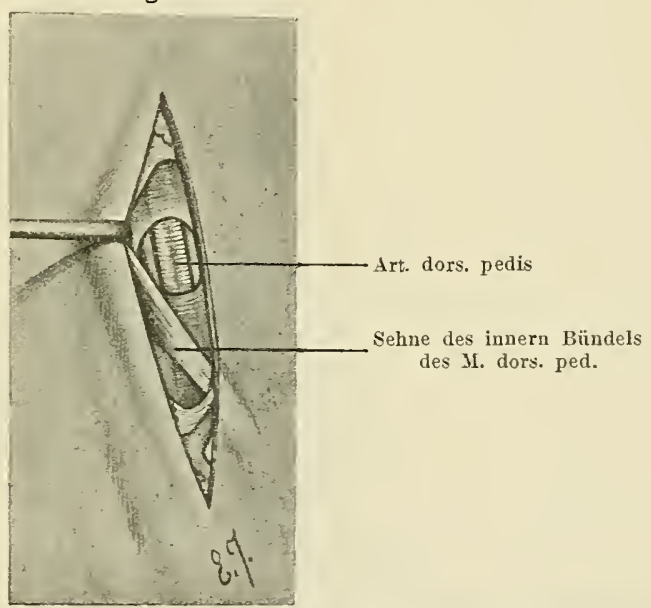

Die dorsale Fläche des rechten Fusses. Das Aufsuchen der Arteria dorsalis pedis und des Nervus tibialis anticus unmittelbar oberhalb des Spatium interosseum; ein stumpfer Haken zieht den Musculus dorsalis pedis nach aussen und legt die Arterie frei.

Techuik z. A. d. G. Man sucht die Mitte des Intermalleolarabstandes und das hintere Ende des ersten Spatium interosseum auf; auf der Linie, welche diese beiden Punkte verbindet, macht man eine Incision, die in der Vitte der Fusswurzel an der Erhabenheit der Sehne des Extensor communis beginnt und drei Finger früher endet.

Nan durchschneidet mit Pincette und Bistouri die durch das Ligamentum annulare verstärkte Fascie und sieht in der Tiefe am Skelette haftend die Arteria dorsalis pedis, an deren äussern Seite der Nerrus tibialis anticus liegt.

Im Niveau des Spatinm interosseum. Man sucht aussen die Sehne des Extensor proprius und den ersten Sulcus interosseus auf, oberhalb desselben an einer Erhabenheit gleiten die Fingerspitzen in einer engen und wenig tiefen Furche, es ist dies die Furche, welche der Gelenklinie des ersten Os 
cunciforme mit dem zweiten Metatarsus entspricht, in dieser findet man dic Arteria dorsalis pedis.

In diesem Niveau macht man einen Hantschnitt, der im obern Theile des Spatium interosseum endigt; mit der Sonde befreit man den innern Rand des innern Bündels des VI. dorsalis pedis und findet unter demselben unter einem zellig-fibrösen Blättchen, in der früher genannten Furche liegend, die Arteria dorsalis pedis und an ihrer Innenseite den Nervus tibialis (Fig. 130). Nitunter, in Fällen von 1:10, findet man die Arteria dorsalis pedis nieht

Fig. 131.

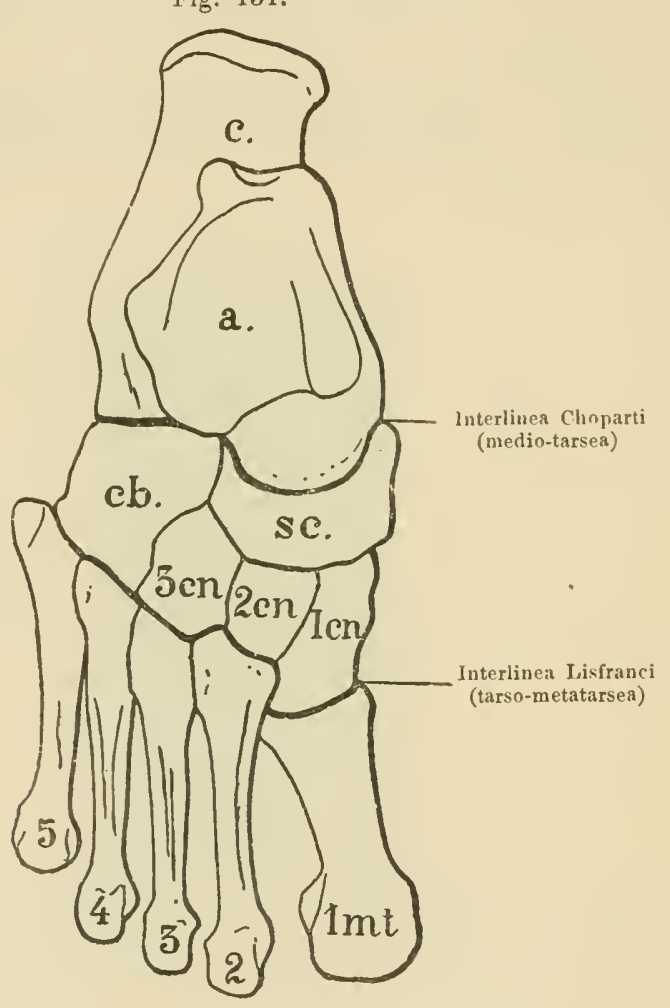

Die obere Fläche des rechten Fussskelettes.

als Fortsetzung der Arteria tibialis antica sondern als vordern Ast der Arteria peronea; in diesem Falle ist die Richtung der Arterie durch die Linie gegeben, welche den vordern Rand des äussern Knöchels mit dem ersten Zwischenknochenraume verbindet.

Findet man unter der Fusswurzel die Arterie nicht an ihrem Orte, so sucht man sie etwas nach aussen unter dem Körper des llusculus dorsalis pedis. Welehen Ursprung aber auch immer die Arterie haben mag, man findet dieselbe stets im Spatium interosseum.

Der Schleimbentel der Sehue des Extensor proprins lallucis. Die Sehne des Extensor proprius ist ron der Erhabenheit, die das erste Os cuneiforme mit dem 
ersten Metatarsus darstellt, durch eine seröse Höhle getrennt, die oft mit der eigenen Synovialscheide der Sehne communicirt.

Technik z. A. d. G. Man macht längs der Sehne des Extensor einen Schnitt, isolirt diese und präparirt ihre tiefe Fläche; man eröffnet ihren Schleimbeutel.

Ligamentum in Y, der Schlüissel des Chopart'schen Gelenkes. Die Interlinea Choparti oder die Interlinea articularis medio-tarsea entspricht dem Gelenke des hintern Tarsus mit dem vordern. Von der Form eines gestreckten S wird die Interlinea Choparti von innen nach aussen begrenzt: hinten vom Taluskopfe und der vordern Fläche des Processus major calcanei vorne sowohl von der Cavitas glenoidalis des Os naviculare als auch von der hintern Fläche des Os cuboideum (Fig. 132).

Eine fibröse Kapsel findet man rings um das Gelenk. Diese Kapsel ist sehr fest an der Fusssohle, wo sie das Ligamentum calcaneo-naviculare und Ligamentum calcaneocuboideum und im Spatium interosseum, das Liganentum in $Y$ bildet. Das Liga-

Fig. 132.

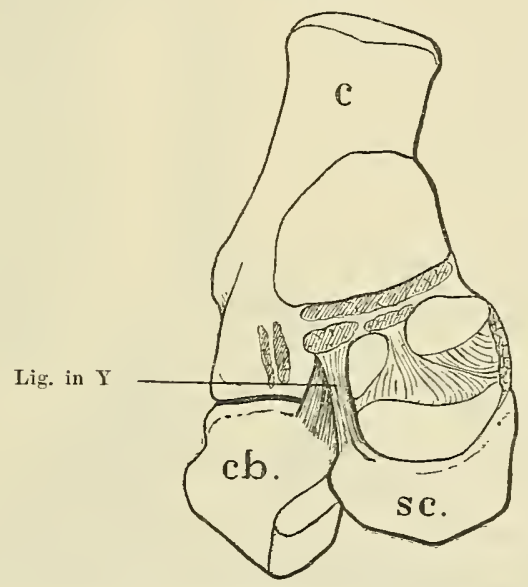

Das Ligament in Form eines Y; rechte Seite; der Schlüssel des Chopart'schen Gelenkes.

mentum in $Y$, Ligamentum talo-calcaneum interosseum, liegt im vordern Theile des Spatium interosseum talo-calcaneum, rom Processus major calcanei zu dem Os naviculare nnd Os cuboideum gespannt; es wird aus zwei Bündeln zusammengesetzt (Fig. 132).

a) Das innere Bündel, Ligamentum calcaneo-naviculare, inserirt sich hinten an der innern und vordern Hälfte der obern Fläche des Processus minor calcanei, unmittelbar nach aussen von der vordern Talusfacette, vorne an dem untern Theile der äussern Fläche des Kahnbeines. Nach unten und imnen setzt sich das Ligamentum calcaneo-naviculare in die fibröse sehr kurze Wand fort, welche den untern Rand der Kahnbeinfläche mit der äussern Hälfte des vordern Randes der vordern Talusfacette des Calcaneus verbindet.

b) Das äussere Bündel, Ligamentum calcaneo-cuboideum, liegt unter und etwas aussen vom obern Bündel. Etwas dünner als dasselbe inserirt es sich hinten am innern Theile des obern Randes des Processus major calcanei, vorne an der kileinen Rauhigkeit, welche man im innern Winkel der obern Fläche des Würfelbeines findet. 
Diese beiden Bündel, hinten vereinigt, sind vorne durch ein fettreiches Bindewebe getrennt, in welches eine kleine Arterie eindringt.

Technik z. A. d. G. Man sucht den Processus major calcanei und die Depressio talo-calcanea aul.

Man macht eine Incision, welche an Processus major calcanei beginnt und gegen die Mitte des Fusses endigt; man prïparirt und durchschneidet den Körper des Fussmuskels. Mit den Fingerspitzen tastet man die knöcherne Cavitas talo-calcanea ab und sucht die Leiste des Processus major calcanei und die äussere Fläche des Kahnbeins auf. Man präparirt

Fig. 133 .

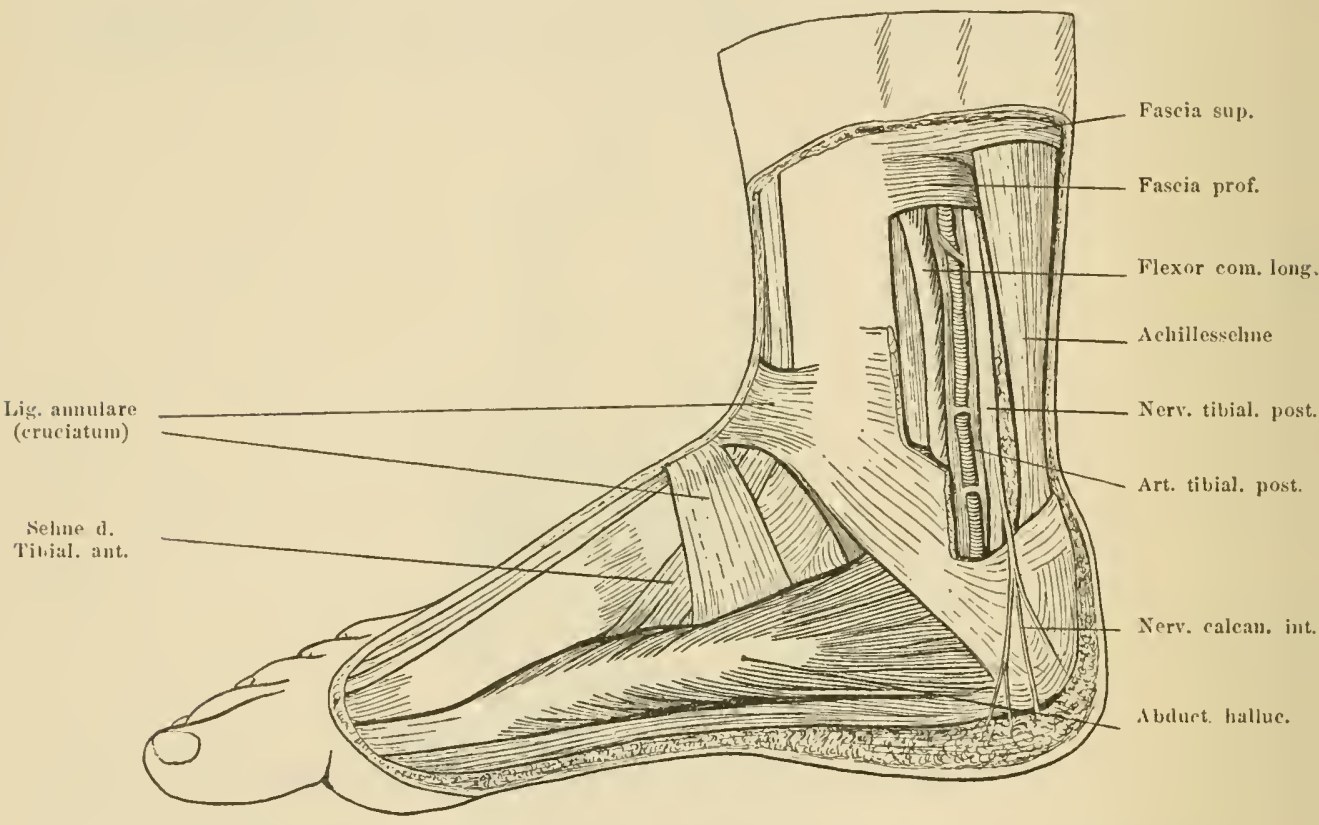

Die innere Fläche des Fusses und der unteren Partie des rechten Unterschenkels; Regio malleolaris interna.

in diesem Winkel das fette zellige Gewebe und findet die weissen und glänzenden Fasern der beiden Bündel des Ligamentum in Y.

Dieses Auffinden ist schwierig, man kann nämlich leicht irren, wenn man nicht genau die Osteologie des Fusses und die Lage des Ligamentes weiss.

Man schneidet alle Weichtheile, die man vor der Articulatio mediotarsea findet, durch und präparirt die Gelenkkapsel aussen und innen, das Ligamentum in I berüeksichtigend; man bemerkt, dass das Gelenk sich nicht eröffnet, auch wenn man die Spitze des Fusses niederdrückt. Man durchschneidet ganz das Ligamentum in $\mathrm{I}$, sofort eröffnet sich die Gelenklinie. 
Der Canalis interossens talo-calcaneus ist horizontal schief nach hinten und innen gerichtet, er theilt das hintere Talo-calcaneusgelenk von dem vordern. Sehr breit in seiner äussern Hälfte - die Cavitas talo-calcaneo - verschmälert sich derselbe innen und seine innere Oeffnung liegt oberhalb und hinten vom Processus minor calcanei.

Die obere Wand, das Dach des Canalis interosseus, wird von der an der untern Fläche des Talushalses ausgehöhlten Furche gebildet, die untere Wand oder der Boden wird rom Calcaneus durch eine dreieckige Oberfläche gebildet, welche die beiden Gelenkfacetten des Talus scheidet.

Im Canalis interosseus ist das feste Ligamentum interosseum enthalten, der Schlüssel des Talo-calcaneusgelenkes. Dieses Band wird in der Cavitas talocalcanea von fibrösen, dicken und sehr festen Bündeln gebildet, welche gerade wie Säulen das äussere Orificium des Kanales begrenzen. In seinem innern Theile wird das Ligamentum interosseum von kurzen fibrösen, schief nach innen gerichteten Bündeln gebildet.

Technik z. A. d. G. Im Grunde der Cavitas talo-calcanea macht man einen bogenförmigen Schnitt mit der Convexität nach unten gerichtet, welcher am Rande des äussern Knöchels beginnt und vor dem Taluskopfe endigt. Man präparirt den obern Hautlappen, isolirt das Ligamentum annulare mit den Insertionen des Musculus dorsalis pedis und durchschneidet dasselbe; mit der Pincette entfernt man den Fettknäuel, den man in der Excaration findet und legt das äussere Bündel frei, die Säulen des Ligamentum interosseum.

Man führt in den Canalis interosseus die dünne Klinge eines Bistouri ein, schneidet vorne and hinten am Talus das Ligamentum interosseum durch, unmittelbar eröffnen sich die Talo-calcaneusgelenke.

Drückt man eine Sonde leicht nach hinten und innen ein, so durchdringt sie den knöchernen Kanal und ihre Spitze erscheint unter der Haut unter dem innern Knöchel.

Der äussere Rand des Fusses. Digitaluntersuchung. Mit den Fingerbeeren folgt man von hinten nach vorne dem äussern Rande des Fusses und fühlt gegen die Nitte die Erhabenheit des V. Metatarsushöckers, der im mittleren Abstande zwischen der Fersenspitze und der Spitze der Kleinzehe liegt. Mit einer Schnur oder dem Rande einer Schürze misst man diese Distanz, halbirt dieselbe und geht am Fussrande in der der Fersenspitze entsprechenden Hälfte nach vorne und gelangt gerade an den Metatarsushöcker, welcher dem äussern Ende der Interlinea Lisfranci entspricht (Fig. 131).

Mit einem Bistouri schneidet man unmittelbar hinter dem Höcker die Weichtheile durch und dringt, wenn man die Klinge eines Messers nach vorne und innen richtet, in die Interlinea Lisfranci.

Der Nervus saphenns extermus folgt dem äussern Rande des Fusses und endigt in der Haut der äussern Fläche der Kleinzehe. Zwei Finger vor dem äussern Kinöchel anastomirt er mit dem Nervus musculo-cutaneus durch einen mit der Concarität nach hinten gerichteten Bogen.

Technik z. A. d. G. Man macht am Höcker und Schafte des V. Metatarsus einen Hautschnitt und findet am Skelete im Fettgewebe den Nerrenfaden auf.

Die Auffindung ist delicat, weil der Nerv klein ist und im Fette verborgen liegt. 
Der imnere Raud des Fusses. Digitaluntersuchung. Ebenso wic für den äussern Rand folgt man mit der Fingerbeere des Daumens schrittweise dem innern concaren Rande des Fusses.

Zwei Finger unterhalb und vor dem innern Knöchel fühlt man dic Erhabeuheit des Kahnbeinhöckers und mehr nach vorne gegen die Fusssohle den Höcker des ersten Os cunciforme; ror diesem fällt der untersuchende Finger in eine rerticale Furche, die rorne durch eine erhabene Leiste, den innern und hintern Höcker des ersten Metatarsus begrenzt wird. Dieser Höcker liegt wie der äussere in der Mitte des Dbstandes zwischen der Fersenspitze und der Spitze der Grosszehe und entspricht dem innern Ende der Interlinea Lisfranci (Fig. 131).

Technik z. A. d. (t). Man begrenzt die Lage des ersten Metatarsus zuerst durch Palpation, dann durch Nlessung. IIan bezeichnet mit der Nagelspitze den Höcker und schneidet hinter demselben bis zum Knochen alle Weichtheile durch; auf diese IIeise eröffnet man und dringt auch mit der Spitze eines Bistouri in das innere Ende der Interlinea Lisfranci.

Durchschneidet man gleichzeitig unmittelbar hinter dem Kahnbeinhöcker die grösstentheils fibrösen Weichtheile, so eröffnet man das Talo-naricularGelenk und der Taluskopf erscheint im Grunde des Schnittes.

Man sucht den Höcker des ersten Os cunciforme auf. Man macht, ron diesem Höcker beginnend, am imnern Rande des Fusses einen schief nach oben und hinten gerichteten Schnitt; schneidet glcichzeitig die Haut und die Fascie durch und gelaingt an die dicke und feste Sehne des Musculus tibialis anticus. Man isolirt diese Schne und controlirt ihre Insertion, die zum grössten Theile am ersten Os cuneiforme und durch eine kleine Expansion am ersten Metatarsus gesehieht; unter der tiefen Lage der Sehne sucht man einen kleinen Schleimbeutel auf, der sie ron der innern Fläche des Os cunciforme scheidet (Fig. 133).

\section{Die Fusssohle.}

Die Sohle rerbreitet sich ron hinten nach rorne, wo sie ron den Zehen durch eine tiefe lirumme Furche mit der Convexität nach rorne geschieden ist, durch die Digito-plantarfurche. Im Grunde dieser Furche findet man die oftmalige Ursache, die Pforte der Infection, einer Lymphangitis der untern Extremität oder einer Adenitis cruralis. Die Sohlenfläche des Fusses ist concar und in innern Theile ausgehöhlt, die Höhlung oder II ̈̈lbung des Fusses, sie ist nach hinten, aussen und vorne erhaben. Die Erhabenheit der Sohle entspricht hinten dem Calcanens, aussen dem äussern Rande des Fusses und rorne den Erhebungen der Metatarsuslöpfchen. Durch diese erhobene Region stützt sich die Fusssohle am Boden, im pathologischen Zustande aber, wie bei Plattfuss, schwindet die Fusswölbung und die Sohlentläche berührt den Boden in ihrer ganzen A usdehnung.

Die Haut der Sohle ist ron einer Fettschicht bedeckt, welche hinten, aussen und innen, wo sie sogar ein elastisches Polster bildet, sehr dick ist; sie wird gegen die Fusswölbung dünner. Dieses Fettlager, ron der Dicke eines Daumens, wird von Fettläppchen gebildet, die in elastischen fibrösen Alreolen enthalten sind. 
Wenn man die Sohle des Fusses abtastet, so fühlt man, den innern Theil stark niederdrückend, das Skelet; hinten, aussen und vorne verbergen die sehr dicken Weichtheile jedes Detail.

Fascia plantaris. Unter der Haut und durch zahlreiche fibröse Expansionen an diese geheftet, findet man die Fascia plantaris, welche eine feste fibröse Fläche bildet, die vom Calcaneus gegen den Kopf der Metatarsi ausstrahlt. Die Fascia plantaris stellt zwei getrennte Partien dar:

a) Die innere Partie hat die Form eines mit der Basis nach vorne gerichteten Dreieckes. Sie entsteht an der untern Fläche des imern untern Calcaneushörkers; im hintern Theile ist dieselbe sehr dick. Von hinten nach vorne verschmälert sie sich und wird dünner und theilt sich im rordern Drittel der Sohlenfläche in fünf Bündel.

Jedes einzelne dieser Bündel inserirt sich mit einem Theile der Fasern an der tiefen Lage der Haut der Soble und der Zehen; der Rest der Fasern zieht von jeder Seite der Beugersehnen, um welche sie eine Scheide bilden, verweben sich dann mit dem vordern Intermetatarsusligamente, indem sie rings um die Metetarso-phalangealgelenke eine cylindrische, fibröse Scheide bilden, das Ligamentum annulare. Von den innern Randpartien der Fascia plantaris gehen zellig-fibröse Expansionen ab, welche in die Tiefe dringen und sich am Skelete inseriren; diese theilen den mittlern Raum der Sohle von den lateralen Räumen.

b) Die äussere Partie entsteht am äussern untern Calcaneushöcker, verbreitet sich dreieckig und theilt sich im Niveau des hintern Endes des V. Metatarsus in zwei Theile; der äussere festere Theil inserirt sich an der untern Fläche des V. Metatarsushöckers, indem er ein wahres Ligamentum calcaneo-metatarseum bildet. Der innere dünnere Theil verwebt sich innen mit dem innern Theil der Fascia plantaris, nach unten schickt er Fasern ab, von denen sich einige an der untern Fläche des V. Hetatarsus inseriren und die Lücke begrenzen, durch welche der Abductor digiti minimi heraustritt; andere wieder dringen tief in die Fusssohle ein. Zu beiden Seiten der Erhabenheit, welche die innere Partie der Fascia plantaris bildet, befindet sich je eine Furche, Sulcus plantaris internus und externus, in deren Tiefe man die gleichnamigen Arterien findet.

Die Fusssohle wird in drei Räume oder Nischen durch die zellig-fibrösen Expansionen getheilt, welche rom Rande der Fascia plantaris abgehen; eine mittlere und zwei seitliche Räume.

A. Der mittlere Raum liegt unter der innern Partie der Fascia plantaris und wird von vier Schichten gebildet.

1. Die erste Schichte wird rom Flexor communis brevis der Zehen gebildet. Dieser Muskel entsteht: mit einem fibrösen Bande am vordern Rande des innern Calcaneushöckers, mit Fleischfasern und fibrösen Bündeln am hintern Drittel der tiefen Fläche der Fascia plantaris und an den fibrösen Wänden, welche den mittlern Raum ron den lateralen trennt, besonders an der innern.

Der verbreitete Fleischkörper des MLuskels theilt sich vorne in rier Bündel, von welchen vier runde und dünne Sehnen entstehen, je eine für jede der vier innern Zehen. Die Sehne der Kleinzehe ist die kleinste und zuweilen nur so dick wie ein Faden.

Jede einzelne Sehne des Flexor brevis theilt sich im Nivean des ersten Phalangealkörpers in zwei Zipfel, welche die Sehne des Flexor longus umschlingen; sie liegen zuerst an den Seiten dieser Sehne, ziehen dann unter derselben, kreuzen sich zum Theile in $\mathrm{X}$ und inseriren sich am hintern Theile der untern Fläche des II. Phalangealkörpers an jeder Seite der Medianlinie (Fig. 134). 
In jeder Seite sind die Sehnen der Benger, ron dem Kopfe der Metatarsi angefangen, in einer osteo-fibrösen Scheide enthalten und mit einer Synovialbülle versehen.

Technik z. A. d. (*. Man macht eine lange Incision, welche am innern Theile des Ferse beginnt und an der Spitze der Nittelzehe endigt.

Man schneidet die Haut und die subcutane Fettschichte durch und präparirt die Fascia plantaris; unter derselben findet man oben den Fleischkörper des Flexor brevis, unten die Sehne, welche er der Mittelzehe zuschickt.

Indem man stumpfe Haken einlegt, präparirt man breit die beiden aponeurotischen Schnittränder und sieht, dass der Muskel sich an denselben inserirt. Man folgt dann der Sehne in der osteo-fibrösen Scheide und studirt ihre Insertion an der II. Phalange. Unter der Sehne des Flexor longus bemerkt man die partielle Kreuzung, das Chiasma, der beiden Bündel der Sehne des Flexor brevis.

Die erste Schichte ist von der zweiten durch ein zellig-fibröses Blättchen getheilt, welches um so mehr dünner wird, je mehr es sich der Spitze des Fusses nähert. Es enthält im obern Theile seines äussern Randes das äıssere plantare Gefäss- und Nervenpacket.

2) Die zweite Schichte wird ron der Sehne des Flexor communis longus von der Caro quadrata und ron den M usculi lumbrieales gebildet. Diese Schichte, im mittlern Theile gekerbt, hat die Form eines $\mathrm{X}$.

a) Die gemeinschaftliche Sehne des Flexor rommunis longus ist schief nach aussen gerichtet, zieht unter der Sehne des Flexor longus proprius hallucis, mit welcher sie sich in Form eines $X$ lireuzt, verbreitet sich fächerförmig und theilt sich in vier Bündel, je eines für jede der vier äussern Zehen.

Jede einzelne Sehne des Flexor longus durchdringt die Sehnè des Flexor brevis, welche sie auch begleitet; znerst in der Tiefe gelegen, wird sie damn oberflächlich und inserirt sich an der III. Phalange an der Leiste, welehe am hintern 'Theile ihrer untern Fläche sich befindet (Fig. 134).

Die Sehne des Flexor cnmmunis longus bekommt gegen die Mitte des Fusses von der Sehne des Flexor proprius eine fibröse Expansion, welche besonders jenes Bündel verstärkt, das diese Sehne der zweiten Zehe zuschickt.

Die Caro quadrata (Flexor accessorius) wird ron zwei Bündeln gebildet, die hinten durch einen dreieckigen laum getreunt sind, in welchem man die weissen Fasern des Ligamentum calcaneo-cuboideum majus sieht.

Das innere stärkere Bündel entsteht mit Fleischfasern an der ganzen innern Fläche des Calcaneus, unter der Furche der Selne des Flexor longus proprius; einige Fasern entstehen auch oben an der Scheide des Flexor proprius, andere am Ligamentum calcaneo-naviculare und Ligamentum calcaneo-cuboideum. Der Fleischkörper ist auf einem sehnigen Blatte, welches an der innern Fläche des Muskels durchscheint, gesammelt.

Das äussere Bündel entsteht mit einem fibrösen Band am äussern Rande der untern Fläche des Calcaneus nnmittelbar ror der Tuberositas externa calcanei und an dem äussern Theile des grossen Ligamentum calcaneo-cuboideum.

Sein langer und dünnor Fleischkörper schneidet diagonal die untere Fläche des Calcaneus, nähert und verbindet sich mit dem innern Bündel.

Vorne inserirt sich die Caro quadrata mit Fleischfasern an der untern Fläche und an dem äussern Rande der Sehne des Flexor communis longus und mit einem fibrösen Blatte an der tiefen Fläche derselben Sehne, in seine vier Bündel übergehend (Fig. 134). 
Mit einigen tiefen Fleischfasern geht die Caro quadrata in den Körper der Lumbricales über.

An der Stelle, wo das Fleisch des kurzen Kopfes sich mit der Sehne des Flexor communis longus verbindet, findet man 3 Schichten: eine oberflächliche von der Sehne des Flexor communis longus, eine mittlere von der Caro quadrata und eine tiefe von der

Fig. 134.

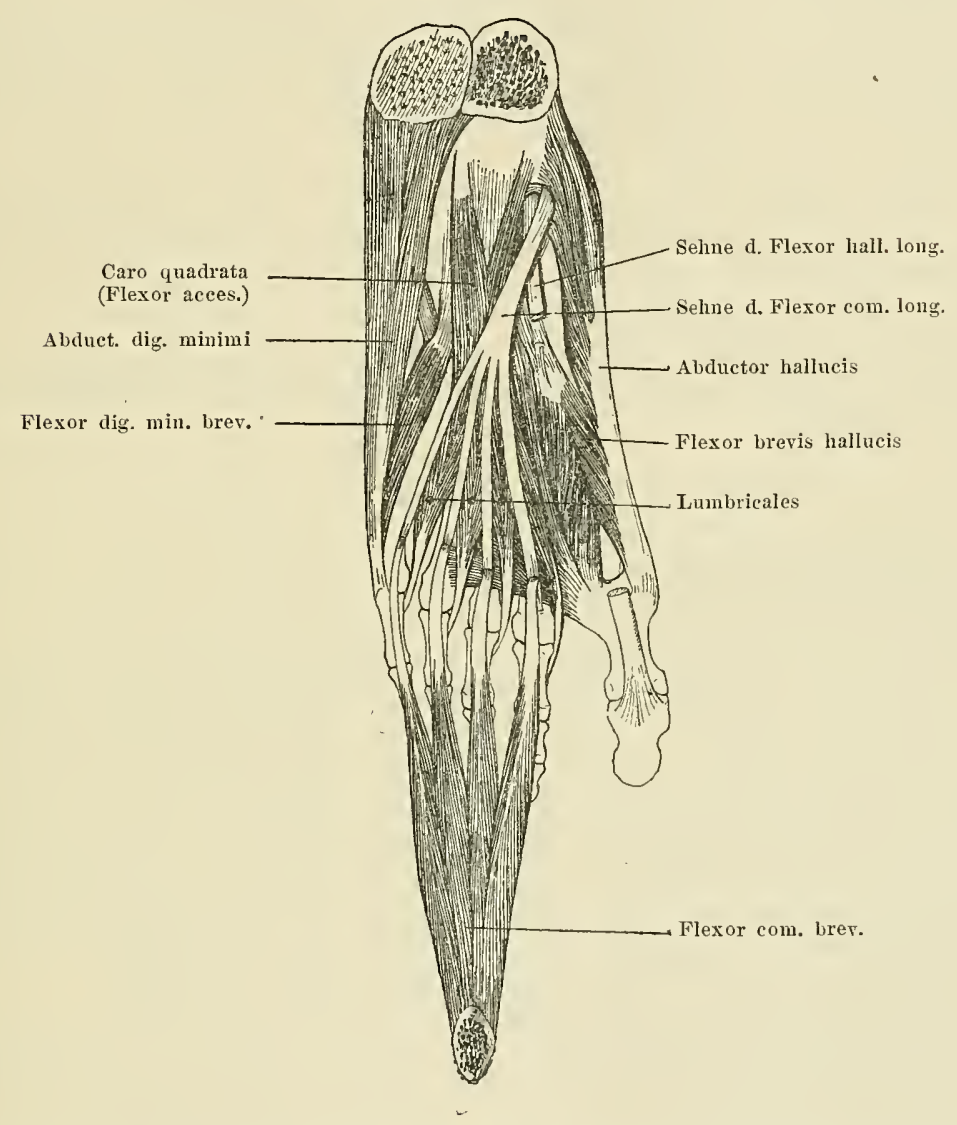

Die linke Sohle; der Flexor brevis ist nach unten gezogen, der Abductor digiti minimi nach aussen gekehrt. Mit einer Säge wurde am Calcaneus jener knöcherne Theil geschnitten, an dem diese beiden Muskeln sich inseriren. Es ist dies das Verfahren, um die Fusssohle zu präpariren.

Expansion, welche die Sehne des Flexor longus proprius mit der Sehne des Flexor communis verbindet, gebildet.

c) Die Musculi lumbricales sind vier an der Zahl. Die drei äussern liegen in den Winkelräumen der Sehnen des Flexor communis longus, der innere liegt an der innern Seite derjenigen Beugersehne, welche für die zweite Zehe bestimmt ist. Sie entstehen mit Fleischfasern an den Sehnen des Flexor communis longus und an dem sehnigen Blatie 
der Caro quadrata, mit welcher sie Bündel austauschen: der innere Lumbricalis entsteht auch an der Expansion, welche den Flexor proprius mit dem Flexor communis verbindet (Fig. 134).

Dem fiederförmigen, runden Fleischliörper folgt eine dünne Sehne, welche zuerst am vordern Ligamentun intermetatarseum, dann an der innern Fläche des Netatarsophalangealgelenlies gleitet; sie rerbreitet sich fächerförnig und inserirt sich am innern Rande der Strecksehne.

Technik z. A. d. G. Man macht dieselbe Incision wie fïr den Flexor communis brevis. Man schneidet die Haut, dic subcutane Schichte, die Fascial plantaris und den Flexor communis brevis dureh; unter diesen sieht man unter einem zellig-fibrösen Blättchen cin rothes Lager, die Caro quadrata.

Man präparirt weit innen und aussen die beiden Schnittränder, zerreisst mit der Sonde das zellig-fibröse Blättchen und löst es ab; im Grunde des Schnittes findet man dic Sehne des Flexor communis mit der Caro quadrata hinten, mit den Lumbricales rolne.

Unter der Sehne des Flexor communis longus sucht man die Sehne des Flexor proprius longus und die fibröse Expansion auf, welche die beiden Sehnen rerbindet.

3. Die dritte Schichte wird rom Adductor obliquus und von dem Adductor transversus hallueis gebildet.

Der Adductor obliquus, sehr dick und pyramidenförmig, liegt in der tiefen Grube, die innen rom ersten Metatarsus und rom Flexor brevis hallucis, aussen rom II., IIl. und IV. Metatarsus, die von den Musculi interossei bedeckt sind, begrenzt wird.

Er entsteht mit Fleischfasern: a) an der oberfächlichen Schichte des Ligamentum calcaneo-cuboideum majus, b) an dem festen Liganente, welches das Os cuboidenm mit dem ersten Os cuneiforme verbindet, c) an den Intermetatarsalligamenten, d) an der Fascia interossea und zuweilen an einer fibrösen Schlinge, unter welchen die Gefässe und der Nervus plantaris externus dringen; mit sehnigen Fasern, die mit den Fasern des Ligamentum calcaneo-cuboideum rerwebt sind, entsteht er an der Crista cuboidei und an dem hintern Ende des II., III. und IS. Metatarsus. Der Fleischliörper geht in eine schöne Endsehne über, welche sich vorne an dem äussern Sesambeine und am hintern äussern Höcker der ersten Phalange der Grosszehe inserirt (Fig. 134).

Der Adductor transversus liegt transversal linter den Metatarsusköpfchen.

Er entsteht mit einigen fibrösen Bündeln und Fleischfasern a) am hintern Rande des Ligamentum glenoidale des III., IV. und V. Metatarso-phalangealgelenkes und b) am tiefen Ligamentum intermetatarseum, welches die Gelenkliapseln rerbindet.

Die Ursprungsbündel vereinigen sich zu einem kleinen Fleischlörper, der sich in der Richtung des äussern Sesambeines an der Sehne des Adductor obliquus inserirt (Fig. 134).

Technik z. A. d. (4. Man macht eine schiefe Incision, die gegen die Mitte des äussern Fussrandes beginnt und an der Wurzel der Grosszehe endet. Man schneidet die Haut, die Fascia plantaris und die Sehnen der Beuger durch und gelangt im Grunde des Schuittes an den halb sehnigen, halb fleischigen Körper des Adductor obliquus. Nan präparirt in der Tiefe den äussern Schnittrand und findet, transversal hinter den Metatarsusköpfehen gelegen, den kleinen Musculus adductor tıansversus. 
Man kann den Adductor transversus leichter auffinden, wenn man in folgender Weise vorgeht: man macht unmittelbar hinter den Netatarsusköpfchen eine transversale Incision und schneidet die Sehnen der Beuger durch; unter diesen findet man, dem Schnitte parallel, den Körper des Transversus.

4. Die vierte Schichte wird von den Musculi interossei gebildet. Diese Muskeln, sieben an der Zahl, vier dorsale und drei plantare, füllen die Zwischenknochenräume und bedecken die plantare Fläche der Metatarsi mit einer vollständigen Muskelschichte, welche sich von innen nach aussen verdickt, weil die Zwischenknochenräume zum grössten Theil von den dorsalen Interossei besetzt sind; die plantaren Interossei entwickeln sich an der untern Fläche der Metatarsi. Die Interossei decken sich übereinander wie die Hohlziegel eines Daches, wie die Blätter einiger Bücher, die sich unten und von aussen nach innen öffnen würden

5. Die fünfte und letzte Schichte wird rom Skelete und von dem Ligamente gebildet.

Vorne ist der Metatarsus von den Interossei bedeckt; hinten an der untern Fläche des Tarsus findet man das kräftige Ligamentum calcaneo-cuboideum.

Das Ligamentum calcaneo-cuboideum inserirt sich hinten an der untern Fläche und an der vordern Rauhigkeit des Calcaneus vorne an der Crista cuboidei und am hintern Ende der drei äussern Metatarsi.

Sehr dick und kräftig besteht es aus mehreren Faserschichten:

a) Die oberflächliche Schichte, Ligamentum plantare longum, bildet ein rechtwinkliges Blatt, das am hintern Theile der untern Fläche des Calcaneus entsteht, zieht unter der Sehne des Peroneus longus, welche es bedeckt und inserirt sich an den hintern Enden der drei äussern Metatarsi, wo es sich mit den Fasern des Ligamentum cuboideo-metatarseum und intermetatarseum posticum kreuzt,

Wir haben gesehen, dass diese Schichte in ihrem vordern Theile von den Insertionen des Adductor obliquus bedeckt ist.

b) Die mittlere Schichte inserirt sich hinten am vordern Theile der untern Fläche und am vordern Höcker des Calcaneus, vorne an der Crista cuboidei; sie zieht wie eine Brücke über das Calcaneo-cuboidalgelenk.

c) Die tiefliegende Schichte wird von kurzen, sehr schief nach innen gerichteten Fasern gebildet; sie inserirt sich aussen am innern Theile des Tuber calcanei und innen an der innern Eske des Os cuboidenm.

Das Ligamentum calcaneo-cuboideum majus wird von dicken fibrösen Bündeln gebildet, die gegen die Tiefe immer kürzer werden und von einander durch Fettläppchen getrennt sind.

Technik z. A. d. G. Man macht eine antero-posteriore Incision, die am Fersenbeine beginnt und am vordern Drittel des Fusses endigt. Man schneidet gleichzeitig bis zum Knochen alle Weichtheile durch, erweitert die Schnittränder und sieht im Grunde die weissen und glänzenden Fasern des Ligamentum calçaneo-cuboideum majus. Man präparirt dasselbe und durchschneidet es transversal, um zu sehen, wie dick und fest es ist.

B. Der innere Muskelraum (dem Thenar entsprechend). Den innern Muske]raum nimmt der $A b d u c t o r$ und der Flexor hallucis breris ein.

1. Der Abductor hallucis; dick und fleischig in seinem hintern Theile, ist längs des innern Fusses rom Fersenbeine zur ersten Phalange der Grosszehe gespannt.

Er entsteht: an der innern Rauhigkeit des Fersenbeins mit eiuem schönen sehnigen 
Bande, welches die äussere Flïche des Muskels einnimmt; am Ligamentum annulare mit fibrösen Bündeln, welche sich mit den Scheiden des Musculns tibialis anticus und der Flexoren verweben; an voldern liande des Processus minor calcanei mit einem sehnigen Blatte, das unter die Sehne des Flexor proprius dringt und endlich an der Faseia intermuscularis interna.

Der Fleischlörper wird ron einer Endsehne rereinigt, die zuerst im Muskel verbargen liegt, dann an seiner innern Fläche sichtlar wird, am innern 'Theile des I. Metatarsusköpfeliens gleitet und sich an der innern Fläche des innern Sesambeines und am innern hintern Höcker der crsten Phalange inserirt und eine Expansion der Strecksehne zuschickt (Fig. 134).

Der Floxor brevis theilt sich vorne in zwei Bündel, je eines für jedes Sesambein.

Er entsteht: an dritten Os cuneiforme und am innern Rande des Os cuboideum mit einem liräftigen fibrösen Bündel, der wahren Ursprungsehne; andere Fasern entstehen an einer Expansion der Sehne des Musculus tibialis posticus und an einer Expansion der Fascia plantaris.

Von diesem sehnigen Büschel entsteht der Fleischlörper, der an der untern Fläche des ersten Metatarsus liegt und sich in zwei Bündel theilt: a) das äussere Bündel liegt an der äussern Seite des Adductor obliquus, inserirt sich mit Fleisch- und Muskelfasern an der hintern Fläche des äussern Sesambeines; das innere Bündel liegt neben der Sehne des Abductol und inserirt sich am vordern Theile der äussern Fläche dieser Sehne am äussern Sesambeine und an der Gelenkkapsel (Fig. 134).

Ein zuweilen stark entwickelter Schleimbeutel trennt die Ursprungsehne des Beugers von der Erhabenheit, welche das erste Os cuneiforme mit dem ersten Metatarsus bildet und an der die Sehne sich reibt.

Die Sehne des Flexor longus liegt in der Furche, welche die beiden Bündel des Flexor brevis theilt.

Technik z. A. d. G. Man macht am innern Rande des Fusses eine Incision vom Fersenbeine bis zur ersten Phalange; unter der Fascie gelangt man an die Sehne und an den Körper des Adduetor.

In der vordern Hälfte des Schnittes am Metatarsuskörper gelagert sieht man den Körper des Flexor brevis; man präparirt denselben und studirt seine hintere nud vordere Insertion und sucht den Schleimbeutel unter seiner Ursprungsehne auf.

Das imnere plantare Gefäss- nud Nervenpacket liegt ron hinten nach vorne in dem äussern Zwischenmuskelspalt.

Die Arteria plantaris interna ist klein. Sie giebt Zweige für die Grosszehe und anastomosirt unter der Fascia plantaris mit der Arteria plantaris externa, mit der sie einen nicht constanten diinnen Bogen bildet, den Arcus plantaris superficialis.

Der Nervus plantaris internus theilt sich in vier Endäste, welche plantare Collaterales für die drei innern Zehen und den Collateralis internus für die vierte Zehe abgeben (eine Analogie mit der Vertheilung des Medianus in der Hand).

In seinem Verlaufe giebt der Nervus plantaris internus Muskeläste für den Abductor und Flexor brevis hallucis, für den Flexor communis brevis und für die Caro quadrata ab.

Technik z. A. d. G. Man macht im mittlern Drittel des innern Fussrandes eine Incision und legt den Abduetor frei. Hit Pincette und der Hohlsonde löst man dic äussere Fläche des Muskels von der Fascia intermuseularis interna ab und sieht dureh diese den Nervus plantaris internus. 
Man isolirt ihn mit der Sonde und findet neben demselben die kleine Arteria plantaris interna.

C. Der äussere Muskelraum (dem Antithenar entsprechend). Der äussere Muskelraum wird innen von der äussern intermuskulären Wand begrenzt, er enthält zwei Muskeln, den Abductor und Flexor digiti minimi.

a) Der Abductor digiti minimi, fleischig und dreieckig in seinem hintern Theile, ist vom Fersenbeine zur ersten Phalange der Kleinzehe gespannt.

Er entsteht mit Fleischfasern: a) am Fersenbeine, an der innern Fläche der innern Rauhigkeit, an dem hintersten Theile der untern Fläche und an der äussern Rauhigkeit, b) an der tiefen Fläche der äussern Partie der Fascia plantaris und besonders am Ligamentum calcaneo-metatarseum und an der Wand, die ihn vom Flexor communis brevis trennt. Die Nuskelfasern sammeln sich zn einer Endsehne, welche zuerst bündelförmig im Fleische verborgen liegt; sie wird dann einzig und sichtbar. Der Fleischliöper tritt unter der Fascia

Fig. 135 .

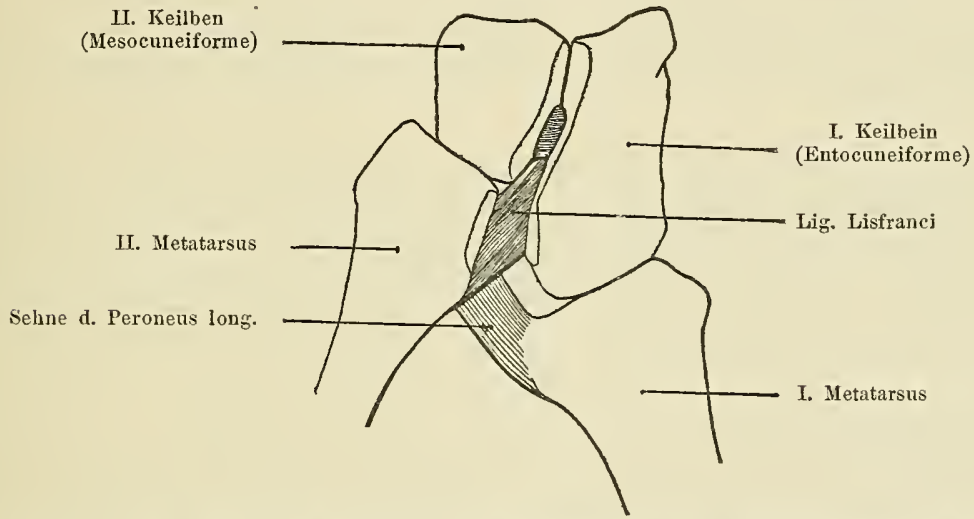

Die Insertion der Sehne des Peroneus longus lateralis und des Ligamentum cuneo-metatarseum; der Schlüssel der Interlinea Lisfranci.

plantaris durch das Orificium, welches diese im Niveau des hintern V. Metatarsusendes begrenzt, heraus, gleitet an Köpfchen dieses Metatarsus und inserirt sich am hintern äussern Höcker der ersten Phalange der Kleinzehe (Fig. 134).

b) Der Flexor proprins brevis digiti minimi. Der Fleischkörper des Flexor brevis der Kleinzehe liegt an der untern Fläche des V. Metatarsus.

Er entsteht mit einem sehnigen Büschel an dem hintern Ende des V. Metatarsus, an der Scheide und Sehne des Peroneus lateralis longus, an einer Expansion der Fascia plantaris und am Ligamentum calcaneo-cuboideum. Sein prismatischer Fleischlörper inserirt sich vorn mit fibrösen Bündeln an der Basis der ersten Phalange der Kleinzehe und an der Gelenkkapsel (Fig. 134).

Technik z. A. d. G. Nan macht am innern Fussrande eine Incision rom Fersenbeine bis zur Wurzel der Kleinzehe, gelangt unter der Fascie an den Körper und an die Sehne des Abductor, der am Metatarsus gelagert ist, neben der Abductorsehne findet man den Flexor brevis, den man innen von der Muskelmasse der Interossei scheidet. 
Das iussere plantare Gefäs- und Nervenpacket. Die Arteria plantaris externa, der hintere Ast ler Arteria tibialis postica, richtet sich schief nach aussen, inden sie, in der Duplicatur der Fascia intermuscularis externa enthalten, dem innern Rande les Abductor digiti minimi folgt. In der Riohtung des hintern Endes des V. Metatarsus dringt sie unter einer fibrösen Schlinge unter den Adductor obliquus; zwischen demselben und der Schichte ler Interossei wird sie immer tiefer und ramificirt sich mit der Arteria dorsalis pedis, mit der sie den $A$ reus plantaris profundus bildet. Aus diesen gehen vier tiefe $\Lambda$ rteriae interosseae ab, die sich in Collaterales für die Zehen theilen.

Der Nervos plantaris externus folgt der Arterie, schickt in der Richtung des V. Metatarsushöckers zwei Aeste ab. welche die Collaterales der Kileinzehe und den äussern Collateralis für die IV. Zehe abgeben, dringt unter den Abductor und bildet den nerrösen Arcus plantaris profundus, der sich im Adductor und in den Interossei vertheilt.

Techuik z. A. d. (4. Man macht an der hintern Fusshälfte eine schicfe lncision, welehe am imneru Theile des Fersenheins heginnt und einen Finger ungeführ innen von der Rauhigkeit des V. Metatarsus endigt. Man schneidet die Haut, die Faseia plantaris und den Flexor communis brevis durch, sucht den innern Rand des Abructor der Kileinzehe anf; etwas nach innen findet man den Nerrus plantaris externus und neben diesem die Arterie.

Die Sehne des Peroneus lateralis longus. Am äussern Fussrande biegt die Sehne des Peroneus lateralis longus, an dem äussern erhabenen Theil der Crista cuboidei ab, dringt in einen osteo-fibrösen Kanal und inserirt sich am hintern äussern Höcker des crsten Metatarsus (Fig. 125 и. 135). In diesem Verlanfe wird sie von einer Synovialscheide begleitet. Im Nivean des Winkels, welchen sie am Os cuboideum macht, ist die rerdickte Sehne ron knorpeligem Gewebe infiltrirt und stellt zuweilen ein kleines Sesambein ror.

Technik z. A. d. G. Man sucht an den Eussrändern aussen den V. Metatarsus, innen den Höcker des I. Metatarsus auf; ron dem cinen zum andern macht man in der Solnlenfläche des Fusses cine tiefe Incision bis zum Knochen - man erweitert die Schnittränder mit stumpfen Haken und findet im Grunde die dicke und feste Sehne des Peroneus longus und hebt diese mit der Sonde; man findet an dieser Sehne aussen den knorpeligfibrösen Knoten oder das Sesambein, wenn es existirt. 


\section{Der Kopf.}

\section{Das Gesicht. Regio supraorbitalis.}

Der Nervus ophthalmicus, der obere Ast des Ganglion Gasseri, theilt sich im Niveau der Fissura sphenoidalis in 3 Endäste: Nervus nasalis, Nervus frontalis und Nervus lacrymalis.

Der Nervus froutalis dringt in die Orbita durch den mittlern Theil der Fissura orbitalis sup., folgt dem Dache der Orbita und liegt oberhalb des Musculus levator palpeprae superioris in einer dünnen Fettschichte, die sich unter dem Perioste befindet. Er theilt sich gegen die Nitte der Orbita in zwei Aeste: in den Nerrus frontalis externus und Nervus frontalis internus.

a) Der Nervus frontalis externus folgt der Richtung des gemeinsamen Stammes, tritt aus der Orbita durch die Incisura supra-orbitalis, wird vertical und theilt sich in ein Büschel von Aesten, welche gegen das Schädeldach ausstrahlen. Diese Aeste liegen zuerst in dem Perioste, gelangen oberhalb des Periostes, durchziehen den Musculus frontalis und verbreiten sich in der Haut der Stirne.

b) Der Nervus frontalis internus, dünner als der äussere, richtet sich etwas nach innen, zieht oberhalb des Winkels, welchen die Sehne des Obliquus major macht in der Schlinge dieser Sehne - umschlingt dann den innern dicken Theil des obern Orbitalrandes ungefähr $7-8 \mathrm{~mm}$ innen von dem supra-orbitalen Ansschnitte, durchzieht den Muskel der Augenbraue und vertheilt sich in der Haut oberhalb der Augenbrauenwölbung.

Technik z. A. d. G. Hit der Fingerbeere des Zeigefingers untersucht man von aussen nach innen den obern Rand der Orbita; an der Vereinigungsstelle der beiden äussern Drittel mit dem innern Drittel findet man einen tiefen Ausschnitt, in welchen der Nagel eindringt, es ist die Incisura supraorbitalis; an der Innenseite desselben verdickt sich der Rand der Orbita und rundet sich ab.

Man macht unter der Augenbraue und derselben parallel eine Incision an der innern Hälfte des Orbitalrandes. Unter der Haut schneidet man vorsichtig die Fasern des Musculus frontalis und des Muskels der Braue durch; unter diesem, am Perioste haftend und aus dem supraorbitalen Ausschnitt austretend, findet man den Nervus frontalis externus. An $7-8 \mathrm{~mm}$ mehr nach innen findet man den kleinen Nervus frontalis internus. 
Man sehafli oberhalb der Lugenbraue cinen Lappen in der Form eines mit der Basis nach unten gerichteten $U$, in welchem man gleichzeitig alle Weichtheile bis zum Knochen durchschneidet; man löst den Hantmuskellappen rom Skelete los und sieht an seiner tiefen Fläche durch das Periost die dirergirenden Fasern des Nerrus frontalis externus. Mit der Spitze des Bistouri folgt man demselben bis zur Ineisura supraorbitalis. Etwas mehr nach innen präparirt man den Nervus frontalis interuss.

Der Muskel der Brate, Corrugator supercilii, entsteht an innern Theile der Erhabenheit, welche man unmittelbar oberhalb der Orbita findet. Die Fleischfasern richten sich nach aussen, verweben sich mit den Fasern des Musculus frontalis und inseriren sich an der tiefen Fläche der Haut der Braue.

Technik z. A. d. (t. Man macht einen Finger oberhalb der Braue eine ticfe Incision bis zum Knochen und präparirt mit der Spitze des Bistouri den untern Schnittrand; man sicht vom Mlusculus frontalis die Fleischfasern des Mluskels der Braue abgehen.

Der Sintus frontalis, im 0s frontale unmittelbar oberlialb der Orbita ausgehöhlt, hat die Form einer pyramidenförmigen dreieckigen Grube mit vier Wänden.

a) Die vordere diclie und rerticale Wand ist ron der Stirnhaut bedeckt.

b) Die hintere obere oder cerebrale Wand ist dünn, wird von der Dura mater bedeckt, entspricht dem rordern Horn des Lobulus frontalis des Gehirns.

c) Die innere oder mediane Wand trennt ihn rom entgegengesetzten Sinus frontalis. Zuweilen ist diese sehr dünne Wand ron einem Orificium durchlocht, durch welches die beiden Sinus frontales miteinander communiciren.

d) Die untere oder Orbitalwand, dünn und trichterförmig, stellt eine kreisförmige Lïcke dar, Orificium canalis frontalis superius, durch welche der Sinus in die entsprechende Nasenöfinung sich öffnet.

Der Canalis frontalis, fast ein $\mathrm{cm}$ lang, schief nach unten und hinten gerichtet, ist in transversaler Richtung ansgebreitet; nach unten öfinet er sich in die Nasenöffnungen in dem rordersten Theile des mittlern Nasenganges.

Der Sinus und Canalis frontalis sind von einer dünnen Mucosa bedeckt, welche in die Nasenschleimhant übergeht.

Technik z. A. d. G. Man palpirt den innern Theil des untern Orbitalrandes und fïhlt gegen die Nasenwurzel eine wenig hervortretende Erhabenheit, die dem Sinus entspricht.

Man soll diese Erhabenheit mit der hintern spitzen und stechenden, welehe mehr hinten sich befindet, nicht verwechseln, diese wird ron der Schlinge der Sehne des Obliquus major gebildet.

Man macht an der Erhabenheit des Sinus an der innerm Hälfte des obern Orbitalrandes eine tiefe Incision, löst das Periost ab und schneidet mit dem Ileissel im Niveau der Erhabenheit ein rundes Knochenstück aus: man eröffnet auf diese Weise den Sinus.

Mit ciner gebogenen Sonde untersucht man die Sinushöhle; man lässt die Sonde nach unten hinter die vordere Wrand gleiten; sie dringt in den Canalis frontalis und durch denselben in die Nasenöffnung. 


\section{Regio orbitalis.}

Das Ligamentum palpebrale internum hat die Form eines mit der Spitze nach aussen gerichteten $V$. Es inserirt sich innen mit seinem vordern Schenkel am kleinen Höcker, der sich am äussern Rande des verticalen Fortsatzes des Oberkiefers befindet und mit seinem hintern Schenkel an der Thränenleiste. Aussen inserirt sich das Ligamentum palpebrale internum an dem innern Ende des Lidknorpels der Lider. Zwischen beiden Schenkeln des Ligamentum palpebrale internum findet man den Thränensack.

Am vordern Schenkel des Ligamentes entstehen einige Fasern des Musculus orbicularis, weshalb es auch als Sehnedes Musculus orbicularis bezeichnet wird.

Fig. 136.

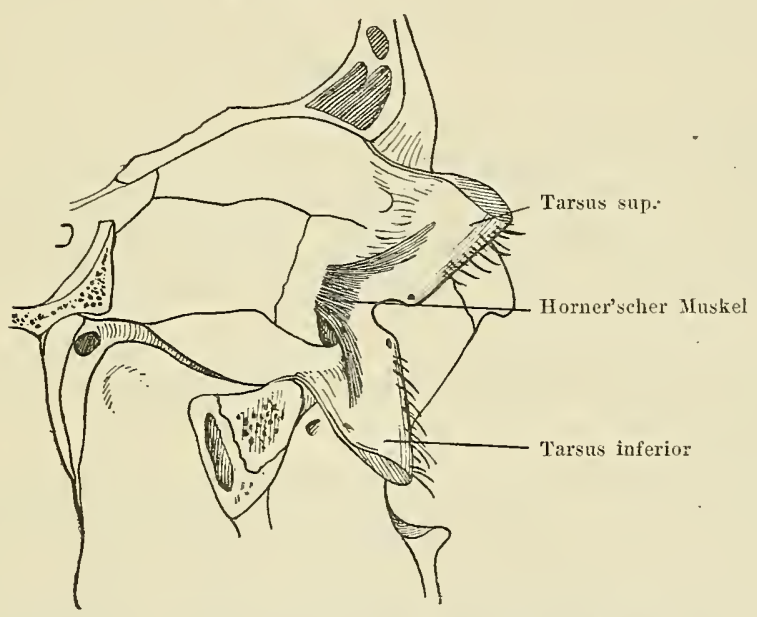

Die innore Wand der rechten Orbita; der Horner'sche Muskel.

Technik z. A. d. G. Mit einer Pincette fasst man die äussere Commissur der Lider und zieht diese nach aussen, man sieht und fühlt an der immern Commissur eine Erhabenheit, einen Strang, es ist das vordere Bündel des Ligamentum palpebrale. Nachdem man die Haut durchschnitten hat, legt man es frei, indem man auf demselben die Fasern des Musculus orbicularis präparirt. Nan gehe mit Aufmerksamkeit und Vorsicht vor.

Das Ligamentum palpebrale exterınum inserirt sich aussen am kleinen Höcker, welchen man an der äussern Wand der Orbita nahe der Mitte des äusseren Randes findet und innen am äussern Ende des Lid-knorpels.

Technik z. A. d. G. Man tastet mit der Fingerbeere des Zeigefingers die äussere Tand der Orbita ab und fühlt unmittelbar hinter seinem äussern Rande den Höcker des Ligamentum palpebrale externum. Man fasst die innere Lidcommissur mit einer Pincette und zieht diese nach innen; unter 
der Haut, wic ein Strang gespannt, fühlt man das ligamentum palpebrale externum.

Man schneidet die Haut und die Fasern des Musculus orbicularis durch und gelangt an das Ligament; zieht man stärker an dem Lide, so löst es sich ron seinem Höcker los.

Der Thräinensack liegt in der Thränengrube zwischen den beiden Bündeln des Ligamentum palpebrale internum; nach oben blindsackförmig geschlossen geht er unten in den Nasenkanal über, der sich in die Nasenöfrnungen im hintern und vordern Theile des untern Nasenganges öffnet. An seiner äussern Wand bekommt der Thränensack den Thränenkanal, durch Vereinigung der Thränenröhrchen gebildet, die sich durch Thränenpunkte an dem innern Ende der freien Lidränder öffnen.

Technik z. A. d. G. Man sticht die Spitze eines Bistouri im innern Winkel der Orbita unterhalb der innern Lideommissur ein und sehneidet von oben nach unten, die Klinge eines Nessers am innern Orbitalrande führend, die Weichtheile in einer Länge von $6-7 \mathrm{~mm}$ durch. Mlan führt in das so geschaffene Art Knopfloch eine kleine Drahtsonde ein und drückt leicht nach unten, sie dringt in den Nasenkanal ein und erscheint in den Nasenöffnungen.

Der Horner'sche Muskel, lilein, breit und dünn, hat die Form eines Vierecks, liegt hinter dem T'hränensacke am hintern Bündel des Ligamentum palpebrale internum. Er entsteht am Ligamentum palpebrale, an der Leiste und an der Orbitalfläche des Thränenbeins, richtet sich nach vorne und theilt sich an der innern Lidcomissur in zwei Bündclchen, je eines für jedes Lid. (Fig. 136).

Jedes Bündelchen iuserirt sich an der innern Fläche des Lidknorpels in der Nachbarschaft der Thränenröhrchen und der Thränenpunkte, um welche rings Muskelfasern bogenförmig ziehen.

Technik z. A. d. G. Man durchschneidet vertical an ihrer Mitte die Lider und fasst mit der Pincette den innern Lidlappen und zieht diesen nach innen. Man sticht die Conjunctiva im innern Winkel des Auges ein, drückt mit der Pincette den Augapfel, den Rectus internus und das Fett nach aussen; an der tiefen Fläche der Lider sieht man unter einem feinen aponeurotischen Blättchen den rothen Körper des Horner'schen Muskels.

IIan präparirt rorsichtig den kleinen blassen Fleischkörper, der 8 bis $10 \mathrm{~mm}$ hoch und $1 \mathrm{~cm}$ lang und nach aussen in zwei dreieckige Bündelchen getheilt ist.

IIan durchschneidet ihn vertical, er ist weniger als $1 \mathrm{~mm}$ dick und liegt am hintern Bündel des Ligamentum palpebrale, welches ihn von der innern Fläche des Thränensackes scheidet.

Die Sehne mnd der sehnige Ring des 0bliquns major. Der Obliquus major entsteht an der innern Fläche der Orbita, unmittelbar ror dem rordern Orificium des Canalis opticus. Sein dünner Fleischliörper folgt dem obern innern Winkel der Orbita, geht in eine Sehne über, die in einem spitzen Winkel durch einen fibrösen Ring, die Trochlea, abbiegt, richtet sich dann nach unten und aussen, rerbreitet sich fächerförmig, zieht unter den Rectus superior und inserirt sich am obern Rande der hintern Hälfte des Bulbus.

Die sehnige Schlinge der Sehne des Obliquns major ist in dem Grunde der Girnbe inserirt, lie am rordern und innern Theile des Daches der Orbita sich befindet. 
Ein kleiner cylinderförmiger Schleimbeutel existirt rings um den Winkel der Sehne, zwischen derselben und ihrem fibrösen Ringe.

Technik z. A. d. G. Man tastet den obern und innern Theil der Orbita mit der Spitze des Fingers, die Fingerbeere nach oben gerichtet, ab und fühlt unter der Haut die Erhabenheit der Trochlea des Obliquus major.

Mlan macht in diesem Niveau eine Incision, schneidet die Haut, die Fasern des M. orbicularis und die Fascia palpebralis durch; mit der Sondenspitze drückt man das Fett und den Bulbus nach unten und hinten und sieht den Winkel der Sehne vom Dache der Orbita durch einen fibrösen Ring festgehalten. Man schneidet den Ring durch und zieht aus demselben die Sehne heraus.

Die Thränendrüse liegt im obern, vordern und äussern Theil der Orbita im Nirean der Thränengrube.

Rechtwinklig nach hinten abgebogen, stell sie zwei Partien dar: eine orbitale und eine palpebrale Partie.

a) Die Pars orbitalis von der Form und Grösse eines Mandelkerns liegt in der Thränengrube oberhalb der Fascia orbitalis und des äussern Ursprungs der Tenon-' schen Kapsel nach aussen rom Musculus rectus superior und rom Musculus levator palpebrae superioris. Von einer fetten zelligen Gewebsschicht umgeben, bekommt sie an ihrem hintern Theile Aeste des Nerrus und der Arteria lacrymalis.

b) Die Pars palpebralis liegt vertical unter der Conjunctiva im äussern Theile des obern Lides. Ausführungskanälchen der Thränendrüse öffnen sich nebeneinander im äussern Theile des obern Conjunctivalsackes.

Technik z. A. d. G. Man durchschneidet gleichzeitig an der äussern Hälfte des obern Orbitalrandes die Haut und die Fasern des M. orbicularis und legt die Fascia palpebralis frei. Man schneidet die Fascie am knöchernen Rande durch, eröffnet auf diese Veise die Nische der Drüse, in der man die Pars orbitalis der Drüse ron der Form einer kleinen aschgrauen llasse und mit Fett umgeben findet.

Man folgt dem vordern Rande der Drüse im Lide und findet kleine an der Conjunctiva gelagerte Granulationen, die Pars palpebralis, auf.

Die Muskeln der Orbita sind 7 an Zahl, von denen sechs dem Bulbus angehören, vier Recti und zwei Obliqui und einer dem obern Lide, der Misculus levator palpebrae. Die vier Recti und der Obliquus major vereinigen sich im Grunde der Orbita rings um den Canalis opticus. Der Obliquus minor inserirt sich am untern Orbitalrande.

Der Obliquus major, Musculus levator palpehrae, die Recti und die Fascie, welche sie enthält, bilden einen musculösen aponeurotischen Kegel, der mit der Spitze hinten, mit der Basis vorne am Bulbus sich inserirt; die Achse dieses Kegels wird vom Nerrus opticus gebildet, den vordern Theil nehmen die Augen ein.

Der äussere Oculomotorius, der Sympathicus, die Arteria ophthalmica und die V'enen sind im Innenraume des muskulös fibrösen líegels enthalten; der Kerrus lacrymalis und $\mathrm{N}$. frontalis findet man aussen rom Huskelkegel, der Nerrus nasalis durchdringt denselben.

Der Musculus levator palpebrae entsteht am obern innern Theile des Foramen opticum an der Innenseite des Rectus superior. Sein dïnner und verbreiterter Fleischkörper folgt der Mitte des Orbitaldaches, verbreitet sich fächerförmig und inserirt sich im obern Lide mit einem sehnigen Blatte, am obern Rande des Lidknorpels. Er wird ron einem Nervenfaden, der vom gemeinsamen Oculomotorins abgeht, innervirt. 
Technik z. A. d. (t. Nan macht am obern Rande der Orbita eine Incision, schneidet die Haut, die Fasern des II. orbicularis und die Fascie durch. Mit einer Pincette fasst man den untern Schnittrand und zicht denselben nach unten; unter einem feinen aponeurotischen Blättchen findet man den Förper des M. lerator palpebrae; man präparirt seine Insertion an obern Lidknorpel.

Die Recti; der Rectus superior entsteht am obern Theile des Randes des Foramen opticum, im Canalis opticus und an der fibrösen Scheido des Nervus opticus. Der breite und dïnne Fleischlörper, unter den Lerator palpebrae gelagert, zieht oberhalb der Sehne des Obliquus major und inserirt sich am rordern und obern Theile des Bulbus.

Der Rectus interums, in seinen obern Theile breit, hat die Form einer Röhre, in welcher der Nerrus opticus liegt. Er entsteht am innern und untern Theile des rordern Orificiums des Canalis opticus und an der Scheide des Nerrus opticus. Torne geht der Fleischliörper in ein sehniges Blatt ïber, das sich am rordern und innern Theile des Bulbus inserirt.

Der Rectus exteruns entsteht mit zwei Bündeln: das untere Bündel inserirt sich an der äussern Wand des Canalis opticus und an den knöchernen Dornen, die an diesem Punlite existiren; das obere Bündel inserirt sich im obern und äussern Theile des Randes des Foramen opticum, wo es sich mit dem Rectus superior verbindet; rorne geht der Fleischliörper in ein sehniges Blatt über, das am vordern und äussern Theile des Bulbus sich inserirt.

In dem Winkel, der ron den beiden Insertionsbündeln des Rectus externus gebildet wird, zieht der äussere Nerrus oculomotorius für diesen Muskel bestimmt.

Der Rectus inferior entsteht an denselben Punkte mit dem untern Bündel des Rectus externus, in diesem Nireau sind die beiden Muskeln vereint. Vorne inserirt sich der Rectus inferior mit einem sehnigen Blatte an dem unteren und vorderen Theile des Bulbus.

Die vordere"Insertion der Recti geschieht an der Sclera einige Millimeter rings um den Rand der Cornea; diese Insertion geschieht nicht in einem Bogen, sondern in einer Spirallinie.

Jeder Muskel ist in einer aponeurotischen Scheide enthalten, von der Fascia orbitalis stammend; jede Muskelscheide rereinigt sich vorne mit der fibrösen Káapsel des Bulbus, Cansula bulbi tenoni, welche die Sehnen der Mluskeln perforiren, um sich an der Sclera zu inseriren.

Der Obliquus major wird rom Sympathicus, der Rectus externus rom äussern Oculomotorius, die andern Muskeln rom Oculomotorius communis innervirt.

Technik z. A. d. G. Mit einer Schieberpincette fasst man die Cornea und zieht den Bulbus nach vorne; schneidet mit der Scheere die Conjunctiva rings um die Cornea durch, löst dieselbe mit der Spitze ab und drängt sie nach hinten; man sieht darüber wic eine krumme Nadel den Fleischkörper und die Sehne des Rectus superior, die man isolirt und abhebt; innen den Rectus internus, unten den Rectus inferior und aussen den Rectus externus.

Der 0bliquus minor entsteht am untern Rande der Orbita, an jenem kleinen Höcker, den man $4 \mathrm{~mm}$ ausserhalb des untern Endes der Thränensackgrube findet. Sein Fleischlörper richtet sich schief nach aussen und hinten, zieht unter den Rectus inferior, beschreibt einen mit der Concarität nach innen und rorne gerichteten Bogen, rerbreitet 
sich, wird dünner und inserirt sich mit Fleischfasern am hintern, untern und äussern Rahmen des Bulbus.

Technik z. A. d. G. Man macht an der innern Hälfte des untern Orbitalrandes eine Incision, schneidet die Haut, die Fasern des II. orbicularis und die Fascia orbitalis durch und findet hinten im Fette den Obliquus minor, den man mit einer krummen Nadel abhebt.

Die Tenon'sche Kapsel. Der Bulbus ist in einer fibrösen Kapsel, in der Capsula Tenoni, beweglich enthalten, welche am Orbitalrande mit fibrösen Expansionen, Aripa interna und externa capsulae, besonders innen nnd aussen fixirt ist. Die Fascia orbitalis und die Muskelscheiden inseriren sich an der Capsula Tenoni und die Muskeln d̉ringen in ihren Innenraum durch die Lücken, welche sich an der Vereinigung der Kapsel mit ibren fibrösen Scheiden befinden. Hinten stellt die Capsula Tenoni ein breites Foramen für den Nervus opticus dar, rorne wird sie sehr dünn, rermengt sich mit der Conjunctiva des Bulbus und inserirt sich mit derselben rings um die Cornea. Ein weiches Bindegewebe, nach der Bildung eine wahre Serosa, existirt zwischen Bulbus und seiner fibrösen Kapsel.

Techuik z. A. d. G. Mit einer Pincette fasst man den vordern Pol des Auges und schneidet mit der Scheere rings um die Cornea die Conjunctiva durch. Nan durchschneidet der Reihe nach die Nuskeln, zuerst die Recti, dann die Obliqui; der Bulbus, aus der Orbita ausgetreten, hält nur noch am Nervus opticus, den man mit der Scheere durchschneidet unmittelbar hinter dem Auge. Man sieht dann die Hülle des Auges, die Capsula Tenoni, in Form einer fibrösen Halbkugel gehöhlt, in deren Grunde der Querschnitt des Nervus opticus von einem gelblichen Fette umgeben erscheint.

\section{Die Nasenregion.}

Der Nerrus naso-lobnlaris. Der Nerrus ethmoidalis, ein Ast des Nerrus nasalis, dringt in die Nasenöffnung durch den Canalis fronto-ethmoidalis anterior und theilt sich in 2 Aeste; der Nervus nasalis internus folgt der Scheidewand der Nasenöffnungen, der Nervus nasalis externus oder N. naso-lobularis folgt der äusseren Wand der Nasenöffnungen, tritt durch eine Grube, die man am unteren Rande des Nasenbeines findet, wird oberflächlich, verläuft gegen die Spitze der Nase und rertheilt sich in ibrer Haut.

Technik z. A. d. G. Man tastet mit dem Nagel den untern Rand der Nasenbeine ab, ihr Rand dringt 5-6 mm ron dem Rücken der Nase in die Tertiefung, durch welche der Nervus naso-lobularis heraustritt. An dieser Vertiefung beginnend macht man, gegen die Nasenspitze gerichtet, einen Hautschnitt, durchschneidet die Fasern des Transversus, präparirt leicht und entfernt die Schnittränder; man sucht sorgfältig unter einem fibrösen Blättchen, direct am Knorpel haftend, und findet den Nervenfaden, den Nervus naso-lobularis. 


\section{Regio infraorbitalis.}

Der Insculus levator communis labii superioris alaeque masi liegt in der Naso-labialfurche. Er entsteht mit blassen Fasern in Nivean des inneren Angenwinkels, an der äusseren Fläche des verticalen Fortsatzes des Oberkiefers. Sein dünner Fleischkörper verbreitet sich von oben nach unten und inserirt sich unten: innen am Nasenflügel, aussen an der Haut des inneren Theiles der Oberlippe (Fig. 137).

Fig. 137.

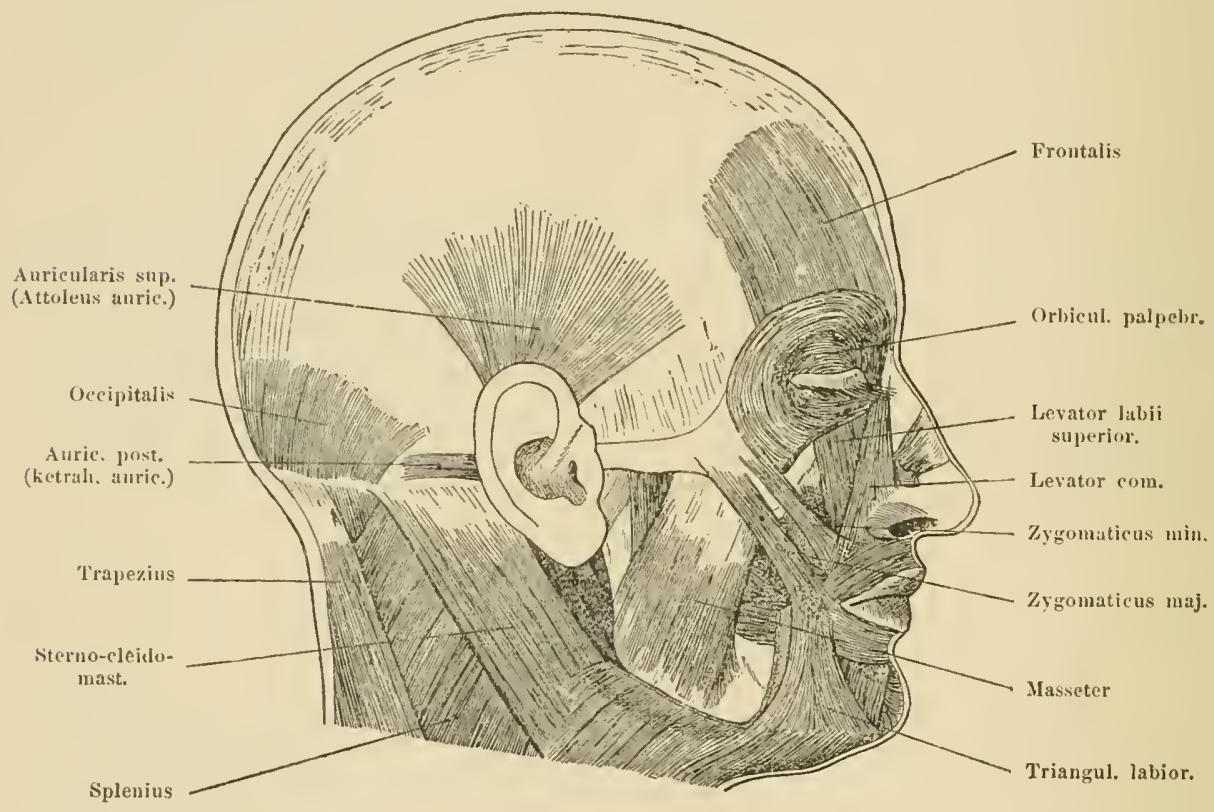

Die rechte Fläche des Kopfes, die Muskeln des Gesichts.

Technik z. A. d. G. Man lässt die untersuchende Fingerbeere im Sulcus naso-labialis gleiten und macht einen Hautschnitt, der im innern Augenwinkel beginnt und am hintern Theile des Nasenflügels endigt; unter der Haut findet man die blassen Fasern des M. levator communis.

Dej Musculus levator labii superioris hat die Form eines viereckigen Bündels von der Breite des Daumens. Er entsteht an der Leiste, welche man etwas unterhalb der beiden inneren Drittel des unteren Orbitalrandes findet. Die Fleischfasern richten sich nach unten und inseriren sich an der tiefen Fläche der Haut der Oberlippe, wo sie sich mit den Fasern des M. orbicularis oris verweben (Fig. 137).

Technik z. A. d. G. Man macht von dem innern Theile des untern Orbitalrandes bis zur Oberlippe eine Incision und findet unter der Haut die rerticalen Fasern des Iusculus levator proprius dieser Lippe. 
Der Musculus caninus (Musculus levator anguli oris) liegt auf einer tieferen Fläche unterhalb und etwas nach aussen vom Levator proprius.

Von rechtwinkliger Form, entsteht er im Grunde der Fossa canina an der horizontalen wenig hervortretenden Leiste, welche fingerbreit unter der Orbita sich befindet.

Der rothe, breite und dünne Fleischkörper richtet sich nach unten und etwas aussen gegen den Mundwinkel; in diesem Niveau werden seine Fasern blass und inseriren sich einige an der Haut der Commissur, andere gehen in die äusseren Fasern des M. triangularis labii über.

Fig. 138.

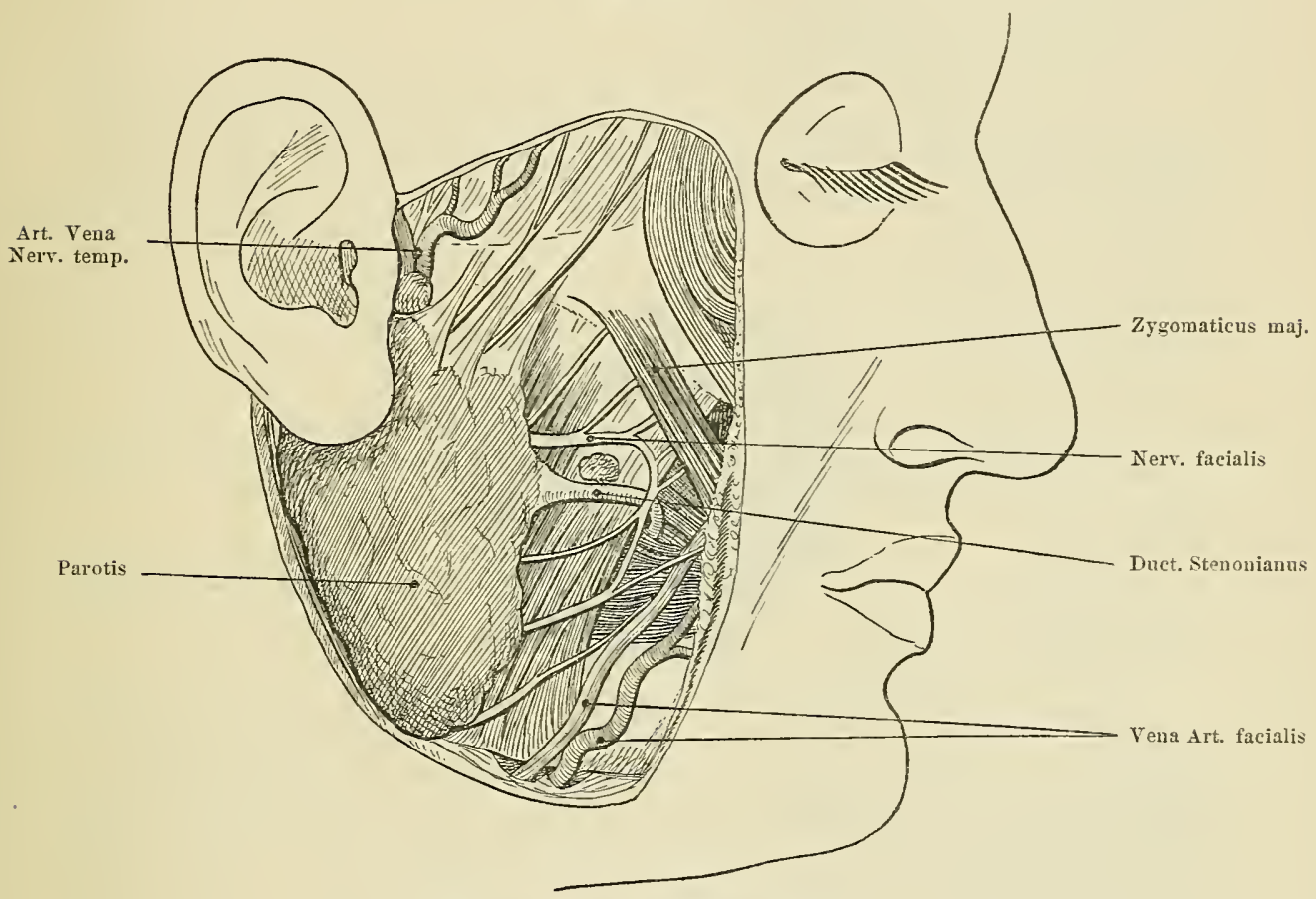

Regio parotideo-masseterica dextra.

Technik z. A. d. G. Man sucht unter der Orbita die Fossa canina oder maxillaris auf und macht eine Incision, die unter der Hitte des untern Orbitalrandes beginnt und am Mundwinkel endigt. Man schneidet die Haut, die subcutane Fettschichte und eine dünne Schichte ron Huskelfasern durch; im Grunde des Schnittes am Skelette gelangt man an die verticalen Fasern des M. caninus.

Der Mnsculus zygomaticus major entsteht mit kurzen sehnigen Fasern an der äusseren Fläche des Jochbeines. Sein Fleischkörper richtet sich nach unten und vorne gegen den Mundwinkel; hier inseriren sich eine grosse Anzahl ron Fasern an der tiefen Fläche der Haut der Commissur; einige gehen auch in einen Bogen über mit den Fasern des M. orbicularis der Unterlippe, andere mit denen des M. triangularis (Fig. 137). 
Technik z. A. d. G. Man macht von der Mitte der äussern Fläche des Jochbeins bis zum IIundwinkel cine Incision und gelangt an die schiefen Fasern des Zygomaticus.

Der Musculus zygomaticus minor liegt etwas innen vom grossen. Er entsteht an der äusseren Fläche des Jochbeines und am Orbicularis palpebrarum und inserirt sich unten und vorne an der Ilaut des äusseren T'heiles der Unterlippe.

Techuik z. A. d. G. Man prïparirt den vordern Rand der Incision, die man zur Auffindung des Zygomaticus major gemacht hat; ror demselben findet man den dümmen Körper des Zygomaticus minor, der zuweilen nur auf einige Fasern, reducirt ist.

Oft fehlt der Zygomaticus minor.

Der Nerrns infraorbitalis. Der Nervus maxillaris superior, der zweite Ast des Ganglion Gasseri, tritt ans der Schädelhöhle dureh das Foramen rotundum majus heraus, durehdringt den obern Theil des Cirundes der Fossa pterygo-maxillaris, umschlingt unter einem kleinen knöehernen lFaken deu hintern Rand des Orbitalbodens - wird hier Nerv. infraorbitalis genannt - durehdringt die Furche und den Canalis infraorbitalis, tritt durch das gleichnamige Foramen aus und theilt sich in ein Büsehel ron Endästen. Diese Zweige verlaufen im lnterstitium, welches hinten rom Caninus, rorne rom Levator proprius begrenzt wird und theilen sich witder in zahlreiche Aeste, die durch die Interstitien des Orbicularis labii superioris ziehen und in der Mundschleimhaut endigen.

In der Fossa pterygo-maxillaris liegt der Nerrns maxillaris inferior im Niveau der Spheno-maxillarfuge in einem linöchernen Gange, der rorne und innen durch die T'uberositas maxillaris, hinten und aussen durch den untern Rand des grossen Keilbeinflügels begrenzt wird.

Techuik z. A. d. G. Beim Anstritte ans dem kuöchernen Kanale. Das Foramen infraorbitale entspricht der Mitte des Abstandes vom Höcker des Jochbeines zum innern Augenwinkel.

An 5-6 $\mathrm{mm}$ unter der Orbita macht man cine rerticale Incision, schneidet die Haut und dic Muskelschichte des Levator proprius durch und gelangt an eine Fettschicht, in welcher man mit der Sondenspitze und mit Pincette die divergirenden Aeste des Infraorbitalis isolirt. Man sieht die Aeste der gleichnamigen Arterie; sie liegen am II. caninus.

In der Orbita. An don beiden änssern Drittehn des untern Orbitalrandes macht man cine Incision, durehschneidet die Haut, die Fasem des II. palpebrarum und die Fascia palpebralis; es erscheint das Fett der Orbita. Nit dem hintern 'T'heile der Pincette löst man den Bulbus los, reinigt den Boden der Orbita und legt stumpfe Haken ein, welche das Auge nach oben zieben und schützen; mit der Spitze der Pincette sucht man am Boden der Orbita den Sulcus infra-orbitalis auf, zieht aus demselben und hebt mit einer krummen Nadel den Nervus infraorbitalis und die Arterie, welehe ihn begleitet, heraus. 


\section{Regio parotideo-masseterica.}

Der Ductus Stenonianns, der Ausführungsgang der Glandula parotis, entsteht im Innern der Drüse am untern Winkel des Unterkiefers, richtet sich nach oben und vorne, tritt aus der Drüse aus, legt sich an die äussere Fläche des Masseter einen Finger unterhalb der Jochbrücke, umschlingt den rordern Rand dieses Nuskels, haftet sich an die Wange und öfthet sich, den Buccinator durchdringend, im Munde durch ein kieines Orificium, das gerade ror dem zweiten obern Backenzahne gelagert ist (Fig. 138). Die Fasern des M. buccinatorius sind rings um den Kanal in Form eines wahren Sphineter vertheilt; kleine Drüsenläppchen findet man rings um das Orificium. Die Fascia buccalis inserirt sich fest an der Wand des Kanales.

Der Nervus transversus faciei zieht unmittelbar unter dem Kanale der Parotis; die Vena facialis liegt etwas innen rom Winkel, den der Canal ror dem vorderen Rande des Masseter bildet.

Fig. 139.

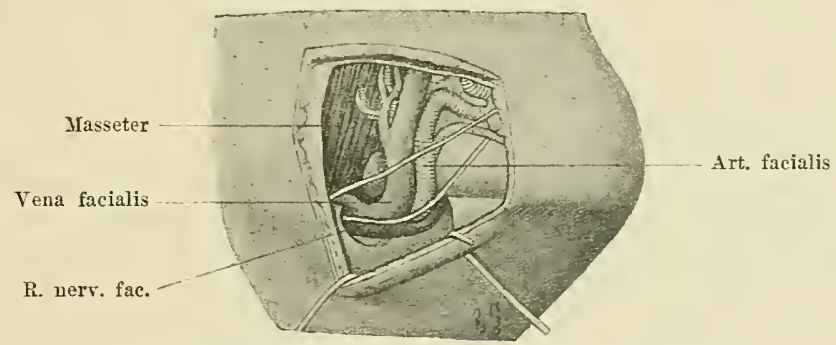

Die Region der Arterie und der Vena facialis.

Technik. z. A. d. G. Man tastet den untern Rand der Jochbrücke ab und sucht an seinem vordern Ende den Höcker des Jochbeines auf. Einen Finger unter diesem Höcker macht man eine horizontale Incision und schneidet das subcutane Fett durch. Im vordern Winkel des Schnittes erscheinen die Fasern des Zygomaticus major; in seinem Grunde sieht man unter einem aponeurotischen Blättchen ein weissliches Gebilde, den Ductus Stenonianus. Man durchschneidet die Fascie und isolirt denselben; hinten geht er in die Drüse über, vorne umschlingt er den Masseter, von dem er durch eine weiche Bindegewebsschichte, zuweilen durch einen Schleimbeutel getrennt ist (Fig. 140).

Oft findet man nahe dem Ductus ein kleines Drüsenläppchen, die Glandula parotis accessoria.

MIan hüte sich, den Ductus Stenonianus mit dem Nerrus transrersalis des Gesichtes zu verwechseln, der um vieles kleiner bald oberhalb bald unterhalb vom Canale liegt.

Die Arteria transversalis faciei, ein Ast der Arteria temporalis, liegt unter der Jochbrücke und oberhalb des Kanals der Parotis.

Der Nerrns und die Arteria buccalis. Der Nerrus bucealis, ein Ast des Ner- 
rus maxillaris inferior, zieht zwischen den beiden Bündeln des Pterygoideus externus, kreuzt die Arteria maxillaris interna, verläuft vertical unter der tiefen Fläche des T'emporalis und des Masseter, haftet sich am Buccinator, richtet sich nach vorne und theilt sich in mehrere Aeste, die diesen Muskel durchdringen, indem er in der Wangenschleimhaut endigt (Fig. 141).

Der Nerrus buccalis wird ron der Arteria buccalis, dem Aste der Arteria maxillaris interna begleitet.

Technik z. A. l. (4. Man macht an der mntern Hälfte des vordern Hasseterrandes eine verticale Incision, isolirt diesen Muskel und legt stumpfe Haken ein, welche ihn mach hinten ziehen. Unter dem Masseter einen Finger oberhalb des Alveolarrandes des Unterkiefers findet man an der Bucealwand von Fett umgeben den Nervus bncealis und die Arteria buccalis.

Die Arteria und Vena facialis. Die Arteria facialis, ein Ast der Carotis externa, durchdringt von innen nach aussen die Fossa inframaxillaris, umschlingt den untern Rand des Kiefers an der Vereinigung seines hintern Drittels mit den beiden rordern und gebogenen, richtet sich gegen den Mundwirkel, dann gegen den innern Augenwinkel, wo sie Arteria angularis genannt wirl.

Die Vena facialis, der Vena jugularis interna angehörend, liegt hinter der Arteric; unter dem Kiefer wird sie ron der Arterie durch die Glandula inframaxillaris getrennt; oberhalb des Zungenbeines rereinigt sie sich mit folgenden Venen:

Vena lingualis, Vena pharyngea inferior und Vena thyreoidea superior, mit denen sie den Truncus thyro-linguo-facialis bildet.

Technik z. A. d. (4. Gegen die Vereinigung des hintern Drittels mit den beiden vordern Dritteln des untern Randes des Unterkiefers fühlt man, mit der Fingerspitze abtastend, die Arteria facialis am Kinochen gleiten. In diesem Niveau macht man längs des Kieferrandes eine Ineision, schneidet die Haut und die Fasem des Platysma myoides durch. Man sucht mit der Pincette und Sonde und findet an einer dünnen, dem Masseter gehörenden Muskelschichte haftend, die Arterie und hinter derselben die Vena facialis (Fig. 140).

Man kann diese Gebilde auch durch eine verticale Incision auffinden; erscheinen sie nicht im Grunde des Schnittes, dann sucht man dieselben del Reihe nach unter den Schnitträndern.

\section{Regio prae-auricularis.}

Die Arteria temporalis superficialis, der äussere Endast der Carotis externa, entsteht im Niveau der innern Fläche des Oberkieferfortsatzes, richtet sich nach oben, zicht an der hintern Fläche des Fortsatzes, umschlingt die hintere Wurzel der Jochbrücke und theilt sich in zwei Aeste, wclche sich in der Kopfhaut rerzweigen: der vordere gebogene Ast liegt etwas oberhalb der Jochbrïcke und richtet sich nach vorne gegen dic Stirne; der hintere Ast richtet sich nach oben gegen die Spitze des Kopfes.

Diese Aeste liegen auf der Fascia epicranea und sind mit einem zellig-fibrösen Blättchen bedeckt; ihre stark gebogenen Endäste, zum grössten Theile von vorne nach hinten ge- 
richtet, liegen in der Kopfhaut, und um diese zu präpariren muss man in der Haut selbst arbeiten.

Die Vena temporalis liegt hinter der Arterie, der oberen venös en Confluenz der Carotis externa angehörend und anastomosirt mit der Vena jugularis externa.

Der Nervus auriculo-temporalis, ein Ast des Nervus maxillaris inferior, richtet sich nach aussen, umschlingt ringförmig die Arteria meningea media; zieht hinter. den Fortsatz zwischen den Fasern des Ligamentum tympano-maxillare, anastomosirt mit dem Facialis, umschlingt die Jochbrücke unter den Temporalgefässen gelagert und vertheilt sich in der Haut der Schläfe, nachdem er einige Aeste für das Ohr abgegeben hat.

Fig. 140.

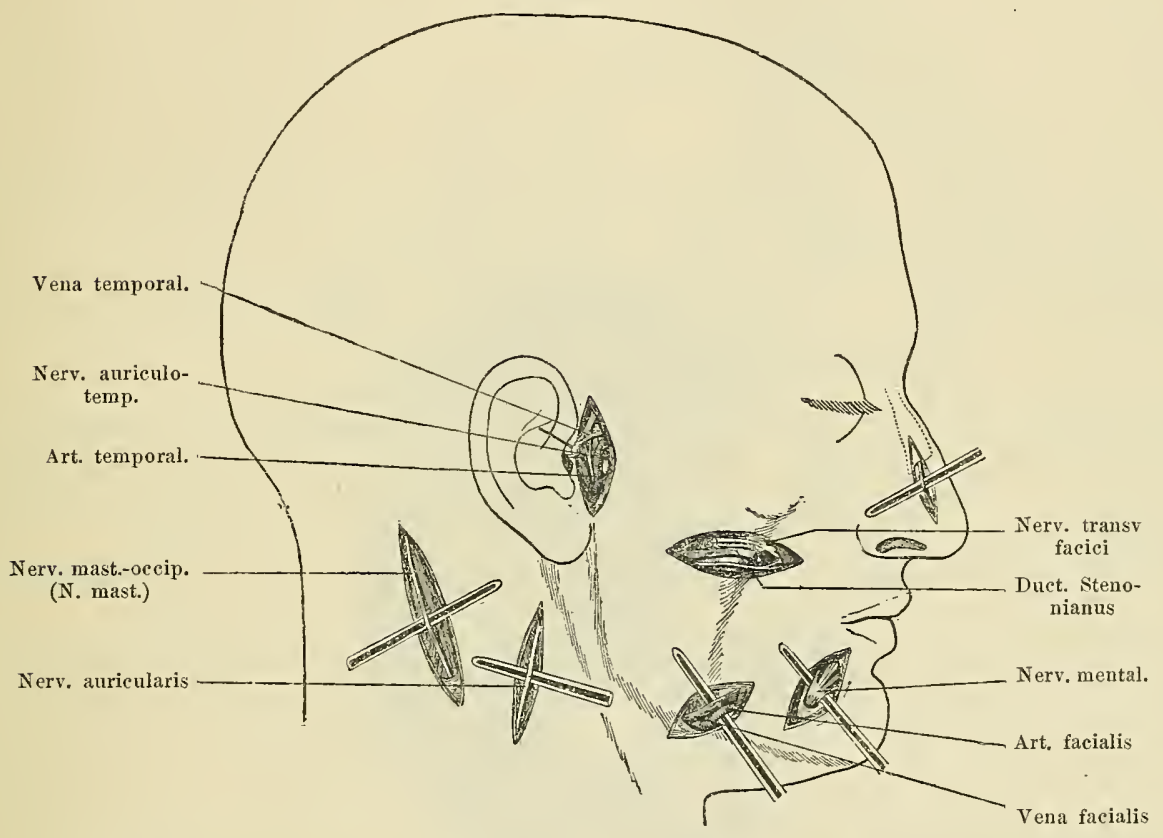

Die rechte Fläche des Kopfes; Incisionen, die zum Auffinden der verschiedenen Gebilde gemacht werden müssen.

Technik z. A. d. G. Man tastet die Depressio prae-auricularis ab, sie hat die Form einer verticalen Furche, die hinten von der vordern Fläche des Antitragus, vorne vom Tuberculum zygomaticum nnd der hintern Fläche des Fortsatzes begrenzt ist. Hält man die Fingerbeere an der prae-auricularen Erhabenheit und verleiht man dem Kiefer Bewegungen, so fühlt man den Höcker des Fortsatzes unter der Haut sich bewegen.

Im Sulcus prae-auricularis sucht man in Form einer Leiste die hintere Wurzel der Jochbrücke auf und macht im Grunde der Depressio prae-aurieularis an der Jochbrücke einen verticalen Hautschnitt. Man schneidet sorgfältig das subcutane zellig-fibröse Blatt durch und gelangt an die Arteria temporalis und findet hinter derselben die Vene. Der Nerv ist schwer zu finden, er liegt tiefer im fibrösen Gewebe, das den Bogen bedeckt (Fig. 140). 


\section{Regio pterygo-maxillaris.}

Man präparirt die äussere Fläche des Masseter und die Fascia temporalis; die Parotis schneidet man nicht durch, sondern löst dieselbe rom Mlasseter ab und sehlägt sie nach hinten in Form einer dreieckigen Fläche zurïick.

Fig. 141 .

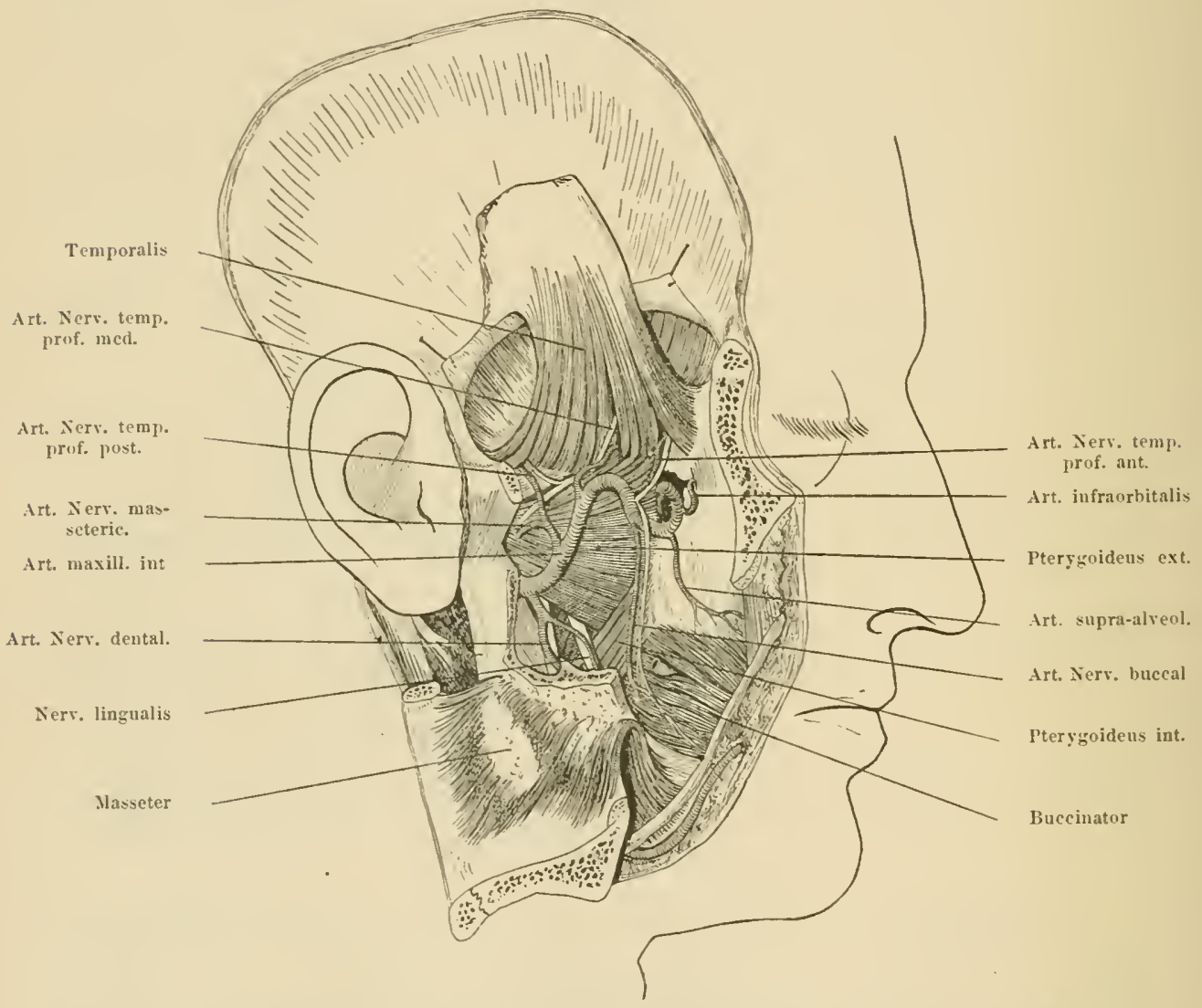

Regio pteryo-maxillaris; der Musculus temporalis ist nach oben gehoben, der Masseter mit dem Arcus zrgomaticus ist heruntergezogen.

Ian schneidet dic Fascia temporalis längs ihrer Insertion am hintern Rande des Jochbeins und der Jochbrïcke durch; man bemerkt, dass sie in dem untern Theile aus zwei Schichten besteht, die durch eine Fettschichte geschieden sind, in weleher ein grosser venöser Canal sich schlängelt, der sich hinter dem Fortsatze in die Tena temporalis ergiesst.

IIan hebt nach oben den aponeurotischen Lappen, indem man ihn 
vom M. temporalis ablöst und schneidet von der Tiefe gegen die Oberfläche mit der Farabeuf'schen Säge die vordere und hintere Wurzel der Jochbrücke durch.

Man kehrt die Jochbrücke mit den Insertionen des Masseter nach unten und legt den untern Theil des Temporalis frei; man sucht aus der Fossa sygmoidalis austretend den Nervus massetericus und die Gefässe, die in den Fleischkörper des Nasseter eindringen.

Man durchschneidet diese, nachdem man mit einem Faden ihre hintern Enden unterbunden hat.

Fig. 142.

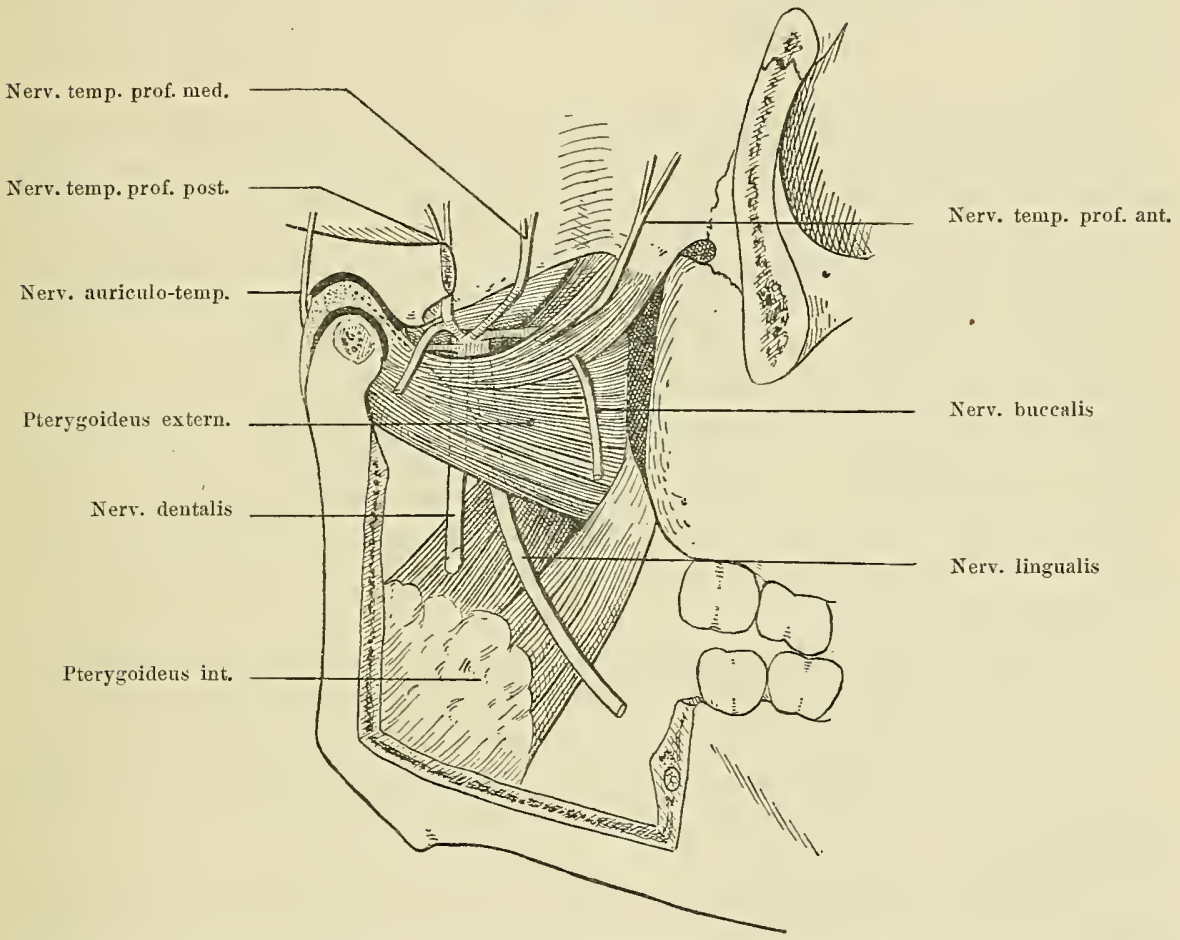

Regio pterygo-maxillaris dextra; die Musculi pterygoidei und die Aeste des Nervus maxillaris inferior.

Man löst mit dem Schaber den Masseter von der äussern Fläche des Kiefers los und bemerkt, dass das sehr dünne Periost sich mit der grössten Leichtigkeit ablöst.

Nit einer Pincette schneidet man den Processus coronoides durch und hebt das Fragmentum coronoideum mit den Insertionen des M. temporalis in die Höhe.

Man präparirt die Fettschichte, die man unter dem Temporalis findet und sieht dann oben den II. pterygoideus externus und unter diesem den II. pterygoideus internus, auf welchem der Nervus dentalis inferior 
und Nerrus lingualis liegen. Die Musculi pterygoidei, 2 an der Zahl, bilden cin V, dessen gestutzte. Spitze dem Processus pterygoideus entspricht.

Der Musculus pterygoileus externus oder superior hat die Vorm einer Pyramide. Er besteht aus zwei Bündeln, a) das obere oder sphenoidale Bündel entsteht an der untern Fläche des grossen Keilbeinflïgels mit Fleischfasern; an der Leiste und am Höcker des lieilbeins mit fibrösen, von den Ursprungsbündeln des M. temporalis gelirenzten Bündeln, b) das untere oder pterygoidale Bündel entsteht mit Fleischfasern und fibrösen Schlingen an der äussern Fläche, an dem vordern und hintern Rande des äussern Keilbeintlügels. Das obere Bündel richtet sich direct nach hinten, das nntere dagegen nach oben und linten; sie rereinigen sich mit einander und inseriren sich mit fibrösen und einigen Muskelfasern, an der rauhen dreieckigen Facette, welche die beiden äussern Drittel der vordern Fläche des Condylushalses einnimmt, an dem vordern Rande des Meniscus und an der Capsula articularis temporo-maxillaris (Fig. 141).

Der Musculus pterygoideus interuns der Quere nach verbreitet, ist schief nach unten hinten und etwas aussen gerichtet rom Processus pterygoideus bis zum Kieferwinkel. Er entsteht in der liossa pterygoidea mit sehnigen Sehlingen mit Muskelbündeln vermengt und an der äussern und untern Fläehe des Tuberculum pyramidale des Gaumenbeins mit einem dicken fibrösen Stiel; unten inserirt er sich mit fibrösen übereinander gelagerten Schlingen und mit Fleischbündeln an der rauhen dreieckigen Oberfläche, welche die innere Fläche des untern Kieferwinkels einnimmt (Fig. 141).

Die innere Fläche des Pterygoideus internus entspricht der lateralen Wand des Pharynx, von welcher sie durch einen prismatischen, mit der Spitze nach abwärts gerichteten Raum geschieden ist, das Spatium pterygo-pharyngeum, das mit Fett ausgefüllt ist. In diesem Raume verbreiten sich die latero-pharyngealen Phlegmonen.

Die beiden Pterygoidei und der hintere Rand des Kiefers begrenzen einen dreieckigen Raum, das pterygo-maxillare Dreieck, durch welches zuweilen die Arteria maxillaris interna durchzieht (Fig. 141).

Das Ligamentum spheno-maxillare am untern Rande der Spina des Keilbeins und am Processus vaginalis des Schläfenbeins entstanden, richtet sich nach unten und aussen, verbreitet sich fächerförmig und inserirt sich an der Spina Spixi.

Die Arteria maxillaris interna. Die Carotis externa theilt sich im Nireau des Condjlushalses in 2 Endäste: Art. maxillaris interna und Art. temporalis superficialis.

Die Arteria maxillaris interna durehzieht von vorne nach hinten den pterygomaxillaren Raum, dringt in die Fossa pterygo-maxillaris, zieht in die Nasenöffnungen durch das Foramen spheno-palatinum und vertheilt sich in der Nasenschleimhant als Art. spheno-palatina. Im Spatium pterygo-maxillare folgt sie als Begleiterin des Pterygoideus externus bald der äussern Fläche, bald der innern dieses Muskels, also zwei Abarten bildend.

1. Die äussere $A$ bart. Bei dieser zieht die Art. maxillaris durch das pterygomaxillare Dreieck, umschlingt den untern Rand des Pterygoideus externus, folgt dem Interstitium, welehes diesen Muske! rom Temporalis scheidet und dringt in die Fossa pterygo-maxillaris (Fig. 141).

2. Die innere $A$ bart. Bei dieser zweiten folgt die Art. maxillaris der innern Fläche des Pterygoideus externus, zieht durch die beiden Bündel dieses Muskels und dringt wie bei der ersten Abart in die Fossa pterygo-maxillaris.

Die Art. maxillaris schickt in ihrem Verlaufe eine grosse Anzahl ron Aesten ab: 
a) Die Arteria meningea media dringt in die Schädelhöhle durch das Foramen rotundum minus.

b) Der Truncus temporo-dentalis theilt sich in die Arteria dentalis inferior und in die Arteria temporalis posterior.

Die Arteria dentalis inferior steigt ab an der äussern Fläche des Ligamentum spheno-palatinum gelagert und dringt neben dem Nervus dentalis inferior in den Canalis dentalis.

Die Arteria temporalis profunda posterior umschlingt den untern Rand der Fossa temporalis und verzweigt sich im hintern Theile des Schläfenbeins.

c) Die Arteria masseterica entsteht aus der Art. temporalis posterior oder direct aus der Art. maxillaris, zieht durch die Fossa sygmoidalis und dringt in die tiefe Fläche des Masseter.

d) Die Arteria temporalis profunda media durchfliesst den mittlern Theil des Musculus temporalis.

e) Der Truncus temporo-buccalis theilt sich in die Arteria temporalis profunda anterior und in die Art. buccalis. Die erste durchzieht aufsteigend den vordern Theil des M. temporalis, die zweite verläuft gegen die Wange, in welcher sie endigt (Fig. 141).

Bei der innern Abart der Art. maxillaris interna zieht der Truncus temporo-buccalis zwischen den beiden Bündeln des Pterygoideus externus.

f) Die Arteria supra-alveolaris folgt stark gekrümmt dem Alveolarrande des Oberkiefers oberhalb der Insertionen des M. buccinatorius.

Aus der Arteria maxillaris entstehen noch in der Pterygomaxillargrube 1. Die Art. infraorbitalis, die in den Sulcus infraorbitalis neben dem gleichnamigen Nerv dringt. 2. Die Art. dentalis posterior. 3. Die Art. palatina posterior, die in den Canalis palatinus dringt. 4. Die Art. Vidianá und 5. Die Art. pterygo-palatina.

Diese beiden letzteren, sehr kleinen Arterien verzweigen sich, nachdem sie durch den entsprechenden knöchernen Kanal gezogen sind, im obern Theile des Pharynx.

Der Nervus maxillaris inferior, der hintere Ast des Ganglion Gasseri zieht aus der Schädelhöhle durch das Foramen ovale und 5-6 mm mehr nach unten theilt er sich in 2 Endäste: Nervus lingualis und Nervus dentalis inferior, welche sich, nach unten richtend, im spitzen Winkel von einander entfernen.

1. Der Nervus dentalis inferior richtet sich nach unten und aussen, zieht unter dem untern Rande des Pterygoideus erternus und dringt unter der Spina Spixi in den Canalis dentalis inferior, nachdem er zuerst den Nervus mylo-hyoideus abschickt (Fig. 142).

2. Der Nervus lingualis richtet sich gegen den Boden der Mundhöhle nach unten, aussen und vorne, zieht unter dem untern Rande des Pterygoideus externus, rerläuft am Pterygoideus internus im tiefen Paum, der diesen Muskel rom Kiefer scheidet und gelangt unter die Mucosa buccalis. Dieser Nerv wird von einer kleinen Arterie begleitet, einem Aste der Arteria maxillaris oder der Arteria dentalis (Fig. 142).

In seinem Verlaufe anastomosirt der Nervus lingualis mit der Chorda tympani, welche aus der Paukenhöhle durch den innern Theil des hintern Astes der Fissura Glaseri austritt. Der Nervus maxillaris inferior giebt unmittelbar nach seinem Austritte ans der Schädelhöhle eine grosse Anzahl von Collateralästen ab (Fig. 142).

a) Der Truncus temporo-buccalis richtet sich nach vorne, durchzieht den Pterygoideus externus, dem er Aeste zuschickt und theilt sich in zwei Endäste: 1. Ner vus temporalis profundus anterior, der nahe der gleichnamigen Arterie in den 
M. temporalis eindringt; 2. Nervus buccalis, welcher, von der Arteria buccalis begleitet, vertical gegen die laterale Wand der Mundhöhle verläuft.

b) Der Nervus temporalis medius zieht oberhalb des Pterygoideus externus und dringt in den Temporalis nahe der Arteria temporalis media.

c) Der Truncus temporo-massetericus richtet sich nach aussen, zieht oberhalb des Pterygoideus externus unmittelbar vor dem temporo-maxillaren Gelenke und theilt sich in zwei deste: 1. Der Nervus temporalis profundus posterior dringt, von der gleichnamigen Arterie begleitet, in den hintern Theil des Temporalis; 2. Der Nervus massetericus zieht durch die Fossa sygmoidalis und vertheilt sich im Masseter.

d) Der Nervus pterygoideus internus richtet sich nach hinten, zieht durch das Foramen pterygo-spinosum und dringt in den hintern Rand des Pterygoideus internus.

e) Der Nerrus recurrens dringt nahe der Arteria meningea media in die Schädelhöhle und rertheilt sich in der Dura mater.

f) Der Nervus auriculo-temporalis richtet sich nach aussen, umschlingt knopflochartig die Arteria meningea media, zieht hinter dem Condylus, anastomosirt mit dem Facialis, wird aufsteigend und kreuzt die hintere Wurzel der Jochbrücke, indem er sich in der Haut der Schläfe vertheilt.

Das Ganglion oticum liegt an der hintern Fläche des Nerrus maxillaris inferior zwischen dem Nerv und dem Musculus peristaphyloideus externus. Es hat die Form .einer aschgrauen Masse, etwas grösser als ein Hanf korn.

Der Nervus maxillaris superior durchzieht schief nach aussen den obern Theil der Fossa pterygo-maxillaris, liegt zwischen der Tuberositas des liiefers und dem untern Rande des grossen Keilbeinflügels. An dem untern Theile dieses Nerven, an diesen gelehnt, existirt ein Plexus, das Ganglion spheno-palatinum, Ganglion Meckelii, von dem folgende Nerren entstehen: N. dentales posteriores, N. palatinus posterior, N. spheno-palatinus, N. Vidianus, N. pterygo-palatinus und N. pharyngeus superior.

Die Veuae maxillares internae gehen in eine renöse Confluenz über, die obere Carotisconfluenz, die im Niveau der Bifurcation der Carotis externa gelegen ist. Diese Confluenz conmunicirt durch die Vena carotis externa mit der untern CarotisConfluenz und durch dic Vena jugularis externa mit der grossen retro-clavicularen Confluenz.

Technik z. A. d. (t. Der Nervus dentalis inferior und $\mathbf{x}$. lingualis. Ian macht am hintern Winkel des Unterkiefers eine Incision, löst mit dem Meissel von oben nach unten den Pterygoideus internus vom Kiefer ab und legt einen stumpfen Haken in den hintern Rand des Schnittes ein. Mit der Fingerspitze tastet man die innere Fläche des Kiefers ab, die Fingerbeere fühlt die stechende Spina Spixi. Yit der Spitze einer krummen Nadel am Finger gcleitet, schabt man von innen nach aussen die innere Fläche des Kiefers ab und fasst den Nervus dentalis und die Art. dentalis. Nan sucht meln nach innen am Pterygoideus internus und findet den Nerrus lingualis.

Der Nervus massetericus und die Hassetergefässe. Am hintern Rande des Nasseter macht man eine verticale Incision, die am Tuberculum zygomaticum beginnt und gegen die Nitte des Kieferrandes endigt. Man durchschneidet gleichzeitig Alles bis zum Knochen und löst mit der Sondenspitze die tiefe Fläche des Masseter ab; unter diesem findet man das Packet der Gefässe und des Nerrus massetericus, die aus der Fossa sygmoidalis austreten. 


\section{Regio mentalis.}

Der Musculns triangularis der Lippen bildet ein mit der Spitze nach oben gerichtetes Dreieck, das rom untern Rande des Unterkiefers bis zum Mundwinkel gespannt ist. Er entsteht an der vorden Hälfte des untern Kieferrandes durch Fleischbündel, die mit den Ursprungsbündeln des cervicalen Antheiles des Platysma myoides verwebt sind; die Muskelfasern erheben sich nach oben, die hintern vertical, die vordern schief nach vorne. Einige Fasern inseriren sich an der Commissurhaut, andere gehen in den M. orbicularis der Oberlippe über, andere wieder in die Fasern des Zygomaticus major (Fig. 137).

Technik z. A. d. G. Nan macht ron dem Mundwinkel bis zum Kieferrande eine Incision und findet unmittelbar unter der Haut den Husculus triangularis der Lippen.

Der Mnsculus quadratus menti entsteht am vordern Drittel der Linea obliqua externa des Kiefers unterhalb und vor dem M. triangularis. Die Fleischfasern erheben sich schief nach oben und innen, indem sie eine viereckige Muskelplatte bilden, die sich an der tiefen Fläche der Haut der Unterlippe und des Kinns inserirt mit den Fasern des Orbicularis sich kreuzend.

Techuik z. A. d. G. Man macht eine schief von der Mitte der Unterlippe gegen den untern Rand des Kiefers gerichtete Incision und findet unter der Haut dem Schnitte parallel die blassen Fasern des MI. quadratus des Kinns.

Der Muskel der Kinnleiste, Levator menti, entsteht an der vordern Fläche des Unterkiefers in dem Grübchen, das aussen von der medianen Leiste des Kiefers sich befindet. Die Muskelfasern entfalten sich fächerförmig und inseriren sich an der tiefen Fläche der Haut der Unterlippe und des Kinns, indem sie sich oben mit den Fasern des Orbicularis, unten mit den Fasern des M. quadratus, innen mit seinen gleichnamigen Fasern kreuzen, mit denen sie auch die mediane Raphe bilden.

Technik z. A. d. G. Nahe der Medianebene durchschneidet man vertical die Unterlippe und das Kinn und sieht an den Schnitträndern die rothen fächerförmig vertheilten Fasern des Muskels des Kinnleiste.

Man fasst mit den Fingern die Unterlippe und wendet sie nach aussen, mit der Spitze des Bistouri präparirt man die Schleimhaut an ihrer Insertionslinie an dem Alveolarrande; an jeder Seite der Medianraphe sieht man die Wurzel der Kinnleiste.

Der Nervus dentalis inferior tritt aus dem gleichnamigen Kanale durch das vordere oder Foramen mentale dieses Kanales, wird hier als Nerrus mentalis bezeichnet, richtet sich nach oben und innen und theilt sich in eine grosse Anzahl ron Aesten. Die meisten dieser Aeste durchziehen den M. orbicnlaris der Unterlippe und vertheilen sich in der Mucosa labialis; andere endigen in der Haut der Lippe und des Kinns.

Bevor der Tervus dentalis inferior aus seinem Kanale austritt, giebt er einen Ast, den Ramus incisivus ab.

Der Nervus mentalis wird von der Arteria mentalis, dem Endaste der Arteria dentalis inferior, begleitet. Der Tervus incisirus, der tiefe Ast des Dentalis inferior, durchzieht den gleichnamigen Kanal und endigt in der Wurzel der beiden entsprechenden Incisivi inferiores. 
Technik \%. A. 1. (\%. Das vordere Foramen des Canalis dentalis findet man 2 Finger ror der Medianlinie, an jener verticalen Linie, die zwischen den kleinen Molares und etwas näher dem untern Kieferrande sich befmdet. Zwei Finger ror der Medianlinie macht man eine sehief nach innen gerichtete Incision rom untern Rande des Kiefers bis nahe dem Lippenrande. Man schneidet die Haut und schichtenweise die Muskelsehichte dureh; oft begegnet man irgend einem Iste des Nervus mentalis.

Mit der Sondenspitze sucht man am Skelette das Foramen mentale des Canalis dentalis auf und sielst aus demselben den Nervus mentalis austreten, der sich sofort in ein Büschel ron Aesten theilt (Fig. 140).

Man führt am vordern Theile des untern Kieferrandes einen horizontalen Hautschnitt, löst mit dem Meissel die Insertionen des M. triangularis und des II. quadratus des Kinns ab; unter dem obern Schnittrande sieht man in der 'Tiefe aus dem Foramen mentale austretend den Nervenstamm.

Es besteht noch ein selir eleganter Torgang, den Nerv von der Mundhöhle aus aufzufinden. Zu diesem Zwecke zieht man mit den hakenförmig gekrümmten Fingerspitzen die Lippencommissur nach unten und aussen; im Niveau der beiden kleinen Holares und des $\mathrm{M}$. eaninus schneidet man die Mucosa im Grunde des Sulcus bneco-gingivalis cin und löst mit der Sondenspitze das Gewebe, der änssern Fläche des Kiefers folgend, ab; in cinem gegebenen Augenblicke sieht man den Fächer, der von den Aesten des Nervus mentalis gebildet wird.

\section{Die Mundhöhle.}

Die Mundhöhle, Cavitas buccalis, ist oben und hinten von dem harten Gaumen (Palatum durum) und rom Gaumensegel begrenzt, welche sie von den Nasenöffnungen und rom obern 'Theile des Pharynx, rom Fornix pharyngis, scheidet, an den Seitentheilen und rorne von einer musculo-membranösen Wand, ron den Wangen, die vertical rom Oberkiefer zum Unterkiefer gespannt sind.

Diese Wand ist rorne von einem horizontalen Spalt, dem Munde, perforirt, der von zwei an Muskelgeweben reichen Falten, Lippen, begrenzt ist. Unten ist die Mundhöhle von einer dicken Wand begrenzt, rom Boden der Mundhöhle, an welcher die Zunge entsteht; binten communicirt die IIundhöhle durch ein breites ovales Orficium, die Schlundenge, mit dem Pharynx.

Die rordere laterale Wand der Mundhöhle wird ron den Alveolo-dentalbögen durch zwei tiefe Jurchen, Sulci gingivobuccales, eine obere und eine untere, getheilt. Wenn die Mundhöhle geschlossen ist, so vereinigen sich die Zähne, indem die obere und untere Alreolarfurche sich berühren und communiciren an jeder Seite mit der Cavitas buccalis durch ein Orificium, das hinter den letzten Molares gelegen ist.

Die laterale Wand der. Mundhöhle; das Orificium des Ductus Stenonianus. Mit der hakenförmig gekrümmten Fingerspitze zicht man die laterale Wand der Mundhöhle nach aussen und untersucht aufmerksam ibre innere Fläche. In ihrer hintern Hälfte, einen Finger unter dem Sulcus gingivalis superior sieht man das kleine Orificium des Ductus Stenonianus wie eine llötenspitze geschnitten. Findet man dasselbe nicht, 
so reinigt man die Wand vom Speichel und drückt in der Gegend der Ohrspeicheldrüse; ein Schleimtropfen erscheint und zeigt die Oeffnung des Drüsenkanals an.

Findet man die Oeffnung, so kann man mit einer dünnen Sonde den Ductus Stenonianus catheterisiren.

Die untere Wand der Mundhöhle oder der Boden ist oben von der Mundschleimhaut, welche vom Zungenstiele bis zum Alveolarrande gespannt ist, unten von der Haut begrenzt. Er hat die Form eines hufeisenförmigen Raumes, in dem an jeder Seite der Medianlinie die Submaxillar- und Sublingualdrüse liegen.

Digitaluntersuchung. Man tastet den Boden der Mundhöhle zwischen den an die Haut des Unterkiefers angelegten Fingerbeeren der linken Hand und dem Zeigefinger der rechten Hand, der in die Mundhöhle eingeführt wird, ab. Wenn die Region normal ist, so berïhrt der Finger, der in der Mundhöhle sich befindet, die Finger, die am Unterkiefer angelegt sind, und bleiben durch eine dünne Gewebsschichte getrennt; im pathologischen Zustande, wern ein Tumor im sublingualen Raume sich entwickelt, bleiben die Finger durch einen grössern oder kleinern Abstand getrennt.

Mit einer Schieberpincette hebt man die Zungenspitze nach oben und sieht in der Medianlinie das Frenulum linguae und an jeder Seite desselben eine kleine papillenartige Erhabenheit (Ostium umbilicale), an deren Spitze sich der Ductus Warthonianus öffnet. Am Boden sieht man noch das Relief, das die Sublingualdrüse an jeder Seite bewirkt. Die Erhabenheit der Drüse der rechten Seite vereinigt sich mit der linken durch ein kleines medianes Höckerchen, die Glandula incisiva, indem sie miteinander einen mit der Concavität nach hinten gerichteten Bogen bilden.

Die Nun'sche Drüse, eine kleine längliche Masse, liegt zu beiden Seiten der Medianlinie an der untern Fläche der Zungenspitze unter der Schleimhaut und unter einer feinen Muskelschichte, die vom M. stylo-glossus gebildet wird.

Technik z. A. d. G. Man fasst mit einer Pincette die Zungenspitze und zieht sie nach vorne, nahe dem Frenulum an der untern Fläche schneidet man die Schleimhaut und eine dünne Schichte von Muskelfasern ein; man findet eine kleine Drüsenmasse, die Nun'sche Drüse.

Die Glandulae sublinguales liegen, in transversaler Richtung verbreitet, im vordern Theile des Bodens der Mundhöhle an jeder Seite der Zungenwurzel.

Der Raum, der die Sublingualdrüse enthält, wird begrenzt: aussen vom vordern Theile der innern Fläche des Unterkiefers im Niveau der Fossa sublingualis, innen von der inncrn Fläche des M. genio-glossus, oben von der MIundschleimhaut, die horizontal vom Zungenstiele bis zum Alveolarrande des Kiefers gespannt ist.

Unten ist der Raum der Sublingualdrïse vom M. mylo-hyoideus abgeschlossen, der vom vordern Kopfe des Biventer und von der Haut bedeckt ist.

Die innere Fläche der Sublingualdrüse steht mit der vordern Hälfte des Ductus Warthonianus in Beziehung, der im Winkel, den die Drüse mit der Mundschleimhaut bildet, gelagert ist.

Technik z. A. d. G. Man öffnet weit die Mundhöhle, fasst die Zungenspitze und hebt sie nach oben und sucht am Boden die Erhabenheit des obern Randes der Sublingualdrüse auf. Man schneidet die Schleimhaut am innern Theile dieser Erhabenheit ein und legt die innere Fläche der Sublingualdrüse frei. An diese gelöthet findet man den Ductus Warthonianus. 


\section{Regio parotidea.}

Digitaluntersuchumg. Man tastet unter dem Ohre die Depressio parotidea $a b$ und lühlt rorne den hinteren Rand des Unterkiefers, hinten den Processus mastoideus.

Die Depressio parotidea entspricht der Fossa retro-maxillaris, die, ron ihrem Inhalte befreit, eine tiefe pyramidenförmige Grube mit drei Wänden bildet.

1. Die hintere Wand wird ron aussen nach innen gebildet: auf einer mehr ober1lichlichen Ebene von der vordern Fläche des Processus mastoideus und dem vordern Rande des Sternocleidomastoideus; auf einer zweiten Ebene von dem vordern Rande des hintern Biventerkopfes, rom Processus styloides, rom M. stylo-hyoideus und rom Ligamentum stylo-maxillare.

2. Die vordere Wand wird rom hintern Rande des Unterkiefers, der von den Insertionen des Masseter und von dem äussern Drittel der innern Fläehe des Pterygoideus internus und externus bedeclit ist, gebildet.

3. Die obere Wand wird ron der untern Fläehe der Ohrmuschel und dem membranösen Theil des äussern Gehörganges gebildet. Unten gegen den Kieferwinkel vereinigt sich die hintere Wand in einer Furche mit der vordern und von der Faseia sternomastoidea entsteht eine Expansion, die sich am Kieferwinkel und am Ligamentum stylomaxillare inserirt.

Innen ist die Retro-maxillargrube blindsaclförmig durch ein zellig-fibröses Blättchen geschlossen, das rom Processus styloides abgeht, sich nach aussen biegt, mit der Faseie der Pterygoidei verbindet und am hintern Kieferrande sieh inserirt.

Die Retromaxillargrube, von der Drïse ausgefüllt, wird von der Carotis externa, ron zahlreichen Venen und dem N. facialis durehzogen.

I) Carotis exterma durchdringt den Parotisraum im Niveau des Unterkiefers durch ein ovales Orificium, das innen rom Ligamentum stylo-maxillare und aussen rom M. stylohyoideus begrenzt ist.

Sie erhebt sich rertical nach oben an der innern Fläche des hintern Kieferrandes gelagert und theilt sich an der innern Fläche des Condylushalses in die Arteria temporalis superficialis, die gegen die Fossa temporalis zieht und in die Art. maxillaris interna, welehe in das Spatium pterygo-maxillare dringt.

Aus der Pars parotidea der Carotis externa geht die Arteria auricularis posterior ab. Diese erhebt sich an der hintern Wand der Parotisgrube, umschlingt die vordere Fläche des Processus mastoideus, dringt in das Spatium auriculo-mastoideum und endigt in der Olirmuschel und in der Schläfenhaut.

Im Nireau der Bifureation der Carotis externa existirt ein renöser Zusammenfluss, die obere äussere Carotisconfluenz, die durch Vereinigung der Venae maxillares internae, der Venae temporales und des Plexus renosus, welcher den Condylushals umgiebt, gebildet wird. Von dieser Confluenz geht eine oder zwei Venen ab, welehe die Carotis externa begleiten und in die Tena jugularis interna oder in den Truncus thyro-linguo-facialis sich ergiessen und die Vena jugularis externa, die in die renöse retro-clariculare Confluenz mündet.

Der Nerrus facialis tritt aus der Schädelhöhle durch seinen knöchernen líanal - Canalis facialis - durch das Foramen stylo-nastoideum aus, richtet sich nach vorne, unten und aussen und theilt sich in 2 Aeste: 
1. Der Ramus superior oder temporo-facialis kreuzt die äussere Fläche des Condylushalses und theilt sich in zahlreiche Aeste, die sich nach oben gegen die Schläfe und nach vorne gegen das Ohr und die Nase richten.

2. Der Ramus inferior oder cervico-facialis richtet sich nach unten und vorne, umschlingt den Kieferwinkel und theilt sich in Cervicaläste, für das Platysma myoides bestimmt und in Facialäste. Diese letzteren umschlingen den untern Rand des Kiefers und richten sich gegen den Mundwinkel und die Oberlippe.

Die beiden Aeste des Facialisstammes anastomosiren gewöhnlich durch einen Bogen, aus dessen Convexität zahlreiche Endäste entstehen. Die Endäste des obern Facialis liegen

Fig. 143.

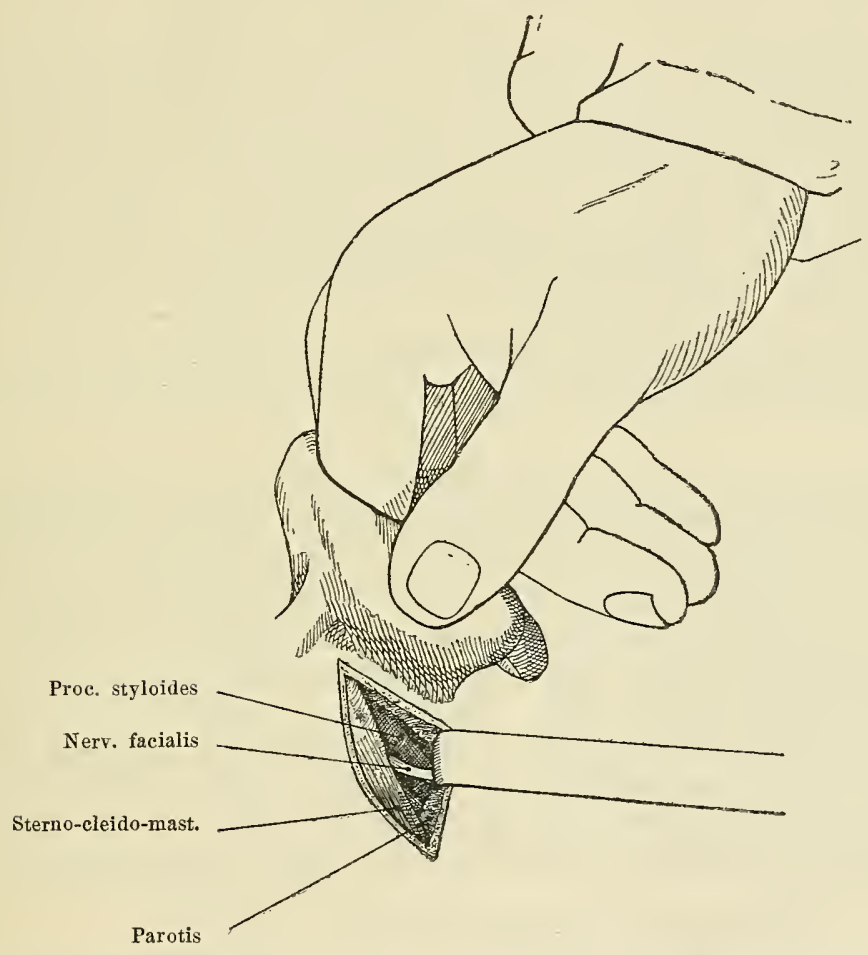

Das Freilegen des Facialis; rechte Seite; ein stumpfer Haken zieht die Parotis nach vorne.

zuerst in der Parotis, in der sie gesucht werden müssen, treten aus der Drüse aus an ihrem vordern und untern Rande; sie anastomosiren unter einander, ein wahres nervöses Netz bildend (Fig. 138).

In der Parotis erhält jeder Facialisast eine Anastomose rom Nervus auriculo-temporalis; am Gesicht anastomosirt der Facialis mit verschiedenen Endästen des Trigeminus.

Die Gebilde, die in der Parotisgrube enthalten sind, lagern sich übereinander von der Haut zur Tiefe in vier Schichten; die erste Schichte wird ron der Wurzel des Ductus 
Stenoniamus gebildet, die zweite rom Nervus facialis, die dritte von den Venen und die vierte ron der Carotis oxterna.

Techuik z. A. des Truncus facialis. Indem ein Assistent das Ohr nach rorne zicht, macht man an der vorderen Flïche des Processus mastoideus und am oberen Theile des Sternomastoideus eine verticale Incision.

Man löst dic Parotis vom Proc. mastoideus ab und von den Muskeln und legt einen stumpfen Haken ein, der sie nach vorne zieht; mit der Spitze der Sonde sucht man im Grunde des Schnittes den Processus styloides auf und findet hinter diesem den Facialis, den man isolirt (Fig. 141).

Ramus cervico-facialis. Man macht eine Incision, welche den hintern Kieferwinkel umschlingt, durehsehneidet die Haut, das Platysma myoides und präparirt das oberfï̈hliche Blättchen der Fascie. Man sucht sorgfältig den Tervenfaden aus dem untern Ende der Parotis austretend. Diese feine Auffindung wird immer gelingen, wenn man aufmerksam vorgelit.

Ramus temporo-facialis. Mlan masht rom Tuberculum condyloideum externum beginnend am hintern Rande des Lnterkiefers eine rerticale Incision. IFan durchschneidet die Haut, die subcutane Fettschichte und schichtenweise die Parotis, indem man mit der Spitze des Bistouri die Schnittränder der Drüse erweitert; in einem gegebenen Augenblicke kann man im Niveau des Condylushalses in der Drüse den Nervus temporo-facialis sehen.

Das Ligamentum stylo-maxillare, schief nach unten, aussen undinnen gerichtet, ist ron der Spitze und äussern Fläche des Processus styloides bis zum hintern Kiefer winkel gespannt.

Techulik z. A. d. G. Man macht von der Spitze des Warzenfortsatzes zum Kieferwinkel eine schicfe Incision, durchschneidet die Haut, die Parotis und Vena jugularis exterma, löst dann mit der Sonde in der Tiefe die Drüse ab und legt einen stumpfen Haken ein, der sie nach oben und innen zieht. Man sucht den Griffelfortsatz auf und findet auf demselben entstehend eine fibröse Schlinge, welche ihn mit dem Kieferwinkel verbindet - das Ligamentum stylo-maxillare.

Im vorderen Winkel des Schnittes am Ligamentum stylo-maxillare gebogen findlet man die Art. carotis. Am äusseren Theile des Griffelfortsatzes unter einem aponeurotischen Blättchen sucht man den dünnen Körper des M. stylo-hyoideus und mehr nach aussen den hinteren Biventerkopf auf.

\section{Regio mastoidea.}

Der Musculus amricularis posterior, M. retrahens auric., entsteht an der äussern Fläche des Os temporale oberhalb der Linea obliqua superior, richtet sich nach rorme und inserirt sich mit kurzen sehnigen Fasern an der hintern Fläche der Ohrmuschel.

Techmik z. A. d. G. Nan zieht das Ohr nach rorne und sieht, dass der Sulcus retro-auricularis durch eine horizontale Erhabenheit der Haut in zwei Theile getheilt ist; auf dieser Erhabenheit macht man eine Incision, schneidet die Haut und die genug dicke Fascie durch und gelangt an dic Fasern des M. auricularis posterior. 
Die Crista supra-meatica. Am obern und hintern Theile des Orificium des äussern Gehörganges existirt eine kleine knöcherne Erhebung, die Spina supra-meatica, an welcher sich die fibröse Wand der Pars membranacea des äussern Gehörganges inserirt. Hinter der Spina findet man eine kleine dreieckige Vertiefung von kleinen Löchern durchlocht, die Foss a supra-meatica. Die Spina und die Depressio suprameatica entsprechen in der Tiefe dem Antrum petrosum.

Antrum petrosum auch Antrum mastoideum. Es ist eine knöcherne Höhle, in der sich die Zellen des Warzenfortsatzes begegnen und die sich vorne in das Cavum tympani öffnet. Diese Höhle muss bei der Trepanation des Proc. mastoideus wegen Eiterung desselben oder des Cavum tympani weit eröffnet werden.

Die äussere Fläche der Regio mastoidea ist oben durch eine hohe krumme Leiste mit der Convexität nach unten begrenzt, die Crista supra-mastoidea; sie setzt sich vorne in die hintere Wurzel der Jochbbrücke fort.

Technik z. A. d. G. Mit der Fingerbeere des Daumens tastet man im Sulcus auriculo-mastoideus die äussere und vordere Fläche des Warzenfortsatzes ab; man fühlt oben die Crista supra-mastoidea.

Man ersucht einen Assistenten, das Ohr nach vorne zu ziehen und macht in dem Grunde des so eröffneten Sulcus auriculo-mastoideus vor oberhalb der Crista bis zur Spitze des Warzenfortsatzes eine verticale Incision. Man schneidet gleichzeitig bis zum Knochen durch, löst dann mit dem Meissel das Periost ab und sucht die Spina und Depressio supra-meatica auf; mit dem Meissel trepanirt man in der Depressio supra-meatica und gelangt in das Antrum petrosum.

Die Glandula lymphatica prae-mastoidea liegt unter der Haut an der Spitze des Warzenfortsatzes, erhält die Lymphgefässe der Kopfhaut und der hintern Fläche der Ohrmuschel. Hypertrophisch bei Syphilis wird sie bei der Diagnose dieser Krankheit als Symptom betrachtet.

Technik z. A. d. G. Man sucht die Spitze des Processus mastoideus auf und fühlt unter der Haut einen kleinen verbreiteten Körper gleiten, die Glandula lymphatica prae-mastoidea. Eine kleine verticale Incision legt diese frei.

\section{Regio submastoideo-occipitalis.}

Der Nervus spinalis (Accessorius Willisii) theilt sich, kaum aus der Schädelhöhle durch den äussern Theil der mittlern Partie der hintern Lücke, Foramen jugulare, ausgetreten, in zwei Aeste: a) der Ramus internus haftet am Vagus, b) der Ramus externus richtet sich schief nach unten, aussen und hinten, zieht an der hintern Wand der Vena jugularis interna unter den hintern Biventerkopf und unter die Arteria occipitalis, umschlingt die Erhabenheit, die der Processus transversus des Atlas bildet, durchzieht das tiefe Bündel des Sterno-mastoideus, zieht durch den mittleren Theil des supra-clavicularen Dreiecks, gelangt unter den Trapezius, an dessen hinterer Fläche er einen Finger vom Spinalrande des Schulterblattes verläuft und endigt in diesem Muskel gegen den untern Winkel dieses Knochens.

Techuik z. A. d. G. Unter dem Processus mastoideus sucht man 
durch Palpation dic Erhabenheit des Processus transversus des Atlas auf. Man macht am vordern Rande des Sterno-mastoideus von der Spitze des Warzenfortsatzes bis gegen den Kieferwinkel eine lncision. Mlan schneidet dic Haut und die Fascie durch, löst den vorderen und tiefen Rand des Sterno-mastoideus ab, den man in einen stumpfen Haken legt. Im obern Winkel des Schnities sucht man unter dem Proc. mastoideus die Erhabenheit des Proc. transversus des Atlas auf; auf dieser unter einem aponeurotischen Blättehen findet man den Nervus spinalis, den man isolirt. Man

Fig. 144 .

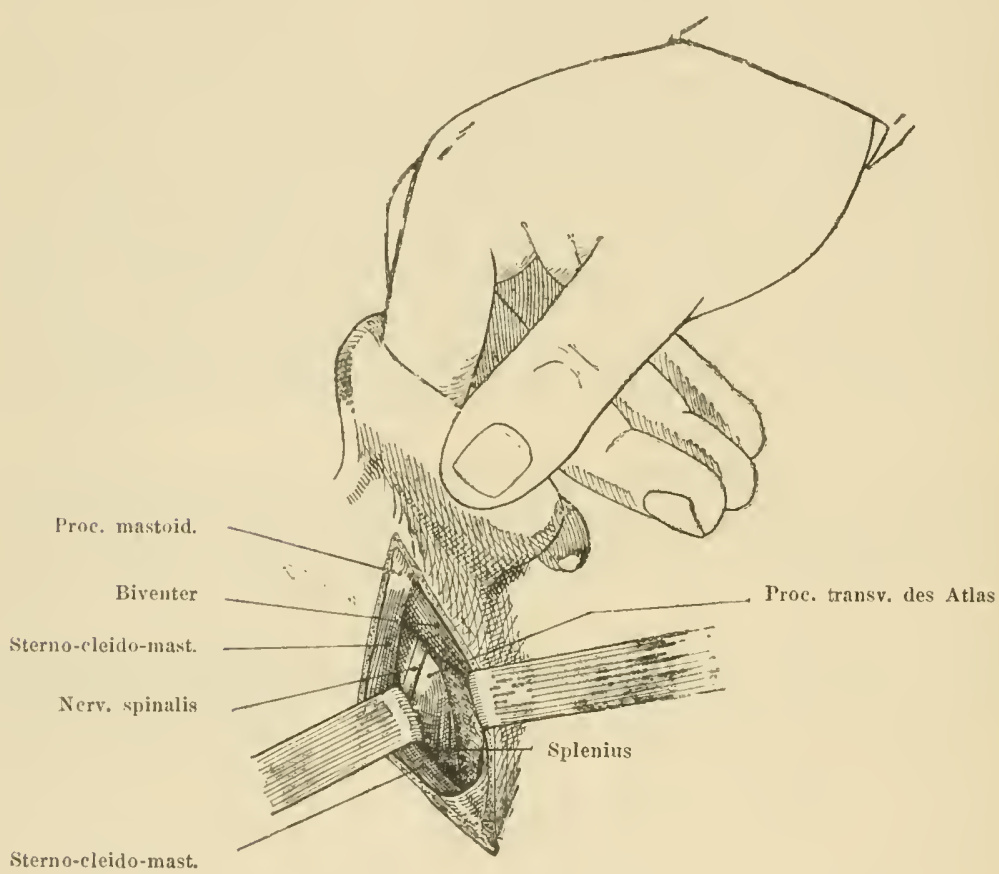

Das Auffinden des rechten Nervus spinalis. Ein stumpfer Haken zieht den Sterno-cleidomastoideus nach hinten, ein anderer Haken zieht die Parotis nach vorne.

folgt dem Nerv, er dringt nach oben unter den Biventer, nach abwärts durchzieht or den Sterno-cleido-mastoideus (Fig. 144).

Die Arteria orcipitalis entsteht aus der Carotis externa im Niveau des Unterkieferwinkels. Sie erhebt sich schief nach oben und hinten, der innern Fläche des hintern Birenterkopfes folgend, zieht dann oberhalb des Proc. transversus des Atlas, welchen sie umschlingt, in einem mit der Concavität nach unten gerichteten Bogen und dringt unter den 1.. occipitalis in das Interstitium, welches den Birenter rom Rectus major superior des Halses scheidet; sie schlängelt sich dann am Complexus major und umschlingt den hintern Rand des M. splenius. Sie wird aufsteigend und tritt unter den Muskeln nahe dem 
Nervus occipitalis durch eine Oeffnung, die oben von einer fibrösen Schlinge begrenzt ist, an der sich die Fasern des Trapezius inseriren (Fig. 145).

Den Austrittspunkt der Arterie findet man an der Vereinigung des innern Drittels mit den beiden äussern Dritteln des Abstandes, der die Spitze des Warzenfortsatzes von der Protuberantia occipitale externa scheidet.

Oberhalb des Trapezbogens theilt sich die Arteria occipitalis in mehrere gebogene Aeste, von denen die meisten sich nach oben und vorne richten und im hintern Theile der Kopfhaut sich vertheilen. Die Arteria occipitalis stellt in ihrem Verlaufe zwei Partien dar, die sich im Niveau des Proc. mastoideus vereinigen; eine Pars ascendens submastoidea, die Begleiterin des Biventer und eine Pars horizontalis sub-occipitalis.

Fig. 145.

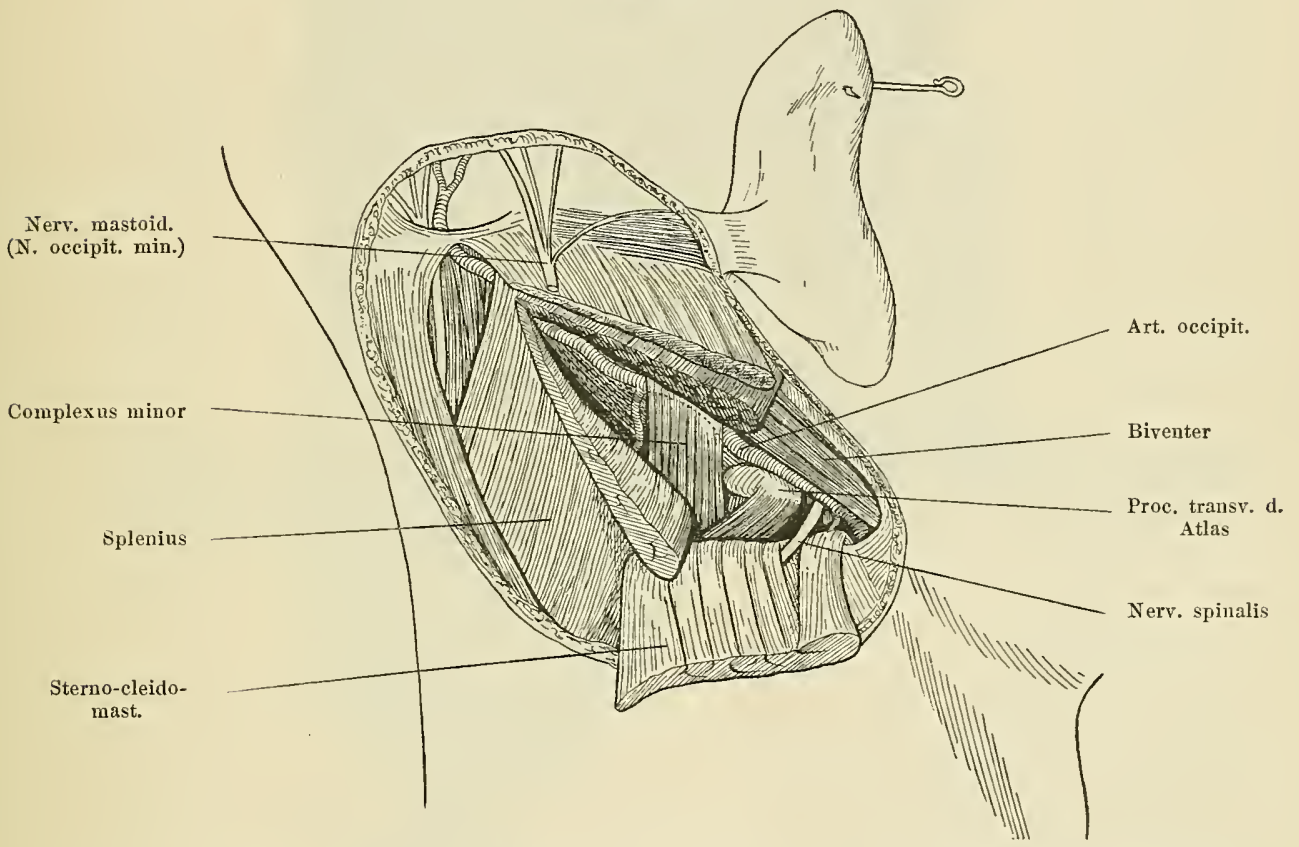

Regio suboccipitalis dextra; der Musculus sterno-cleido-mastoideus und Splenius sind durchschnitten und deren untere Enden nach abwärts gezogen, um die Arteria occipitalis freizulegen. Die Arterie zieht gewöhnlich unter den Complexus minor.

Im Niveau des Warzenfortsatzes ist die Arteria occipitalis von vier Schichten bedeckt: a) von der Haut, b) dem Sternocleido-mastoideus, c) dem M. splenius und d) Complexus minor. Hinter dem Proc. mastoideus sind nur drei Schichten, weil der Complexus minor fehlt.

Technik z. A. d. G. Man sucht die Spitze und den hintern Rand des Proc. mastoideus auf und macht unter demselben eine nach oben wenig schiefe Incision, die an der Spitze des Proc. mastoideus beginnt und drei Finger dahinter endigt. Man schneidet die Haut, die subcutane Schichte, 


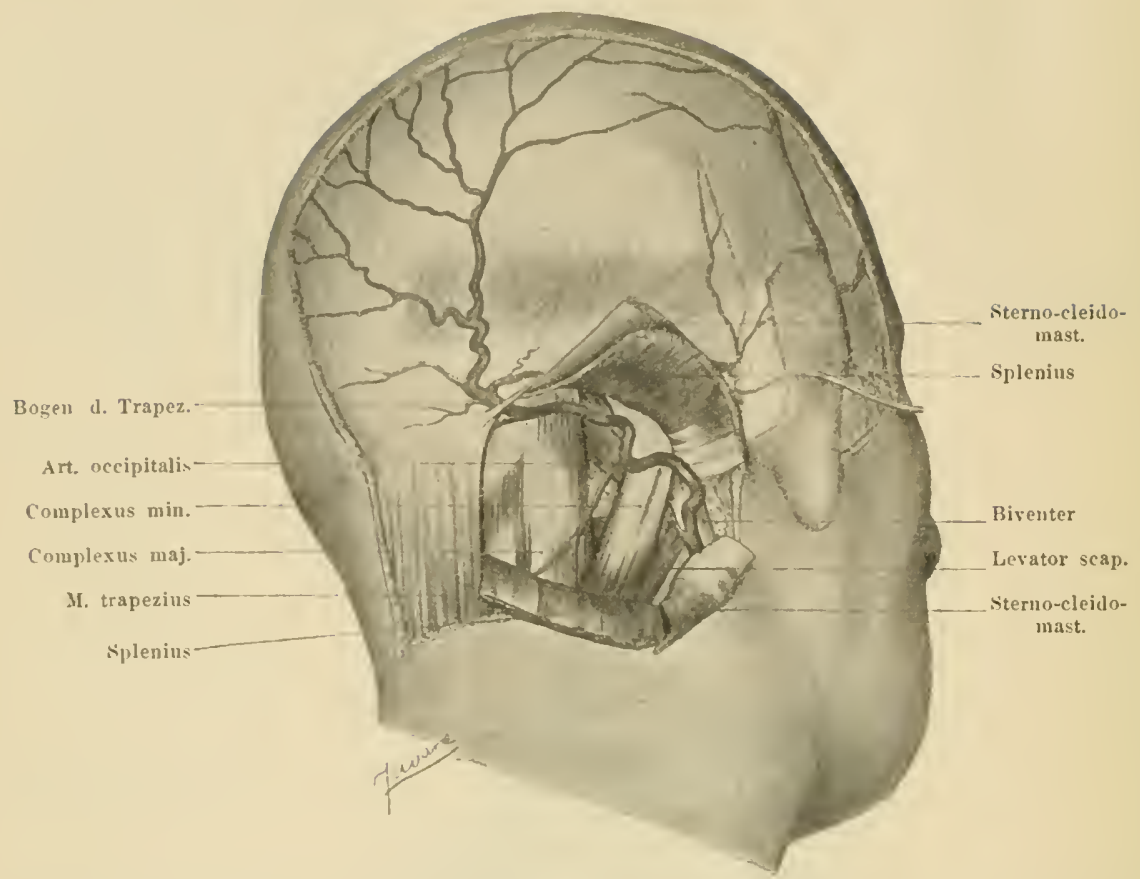

Regio suboccipito-mastoidea. Der Sterno-cleido-mastoideus und Splenius wurden abgejüst und durchschnitten und legen die Art. occipitalis frei. In diesem Falle zieht die Art. occipitalis an der äusseren Fläche des Complexus minor, statt unter demselben.

Fig. 147.

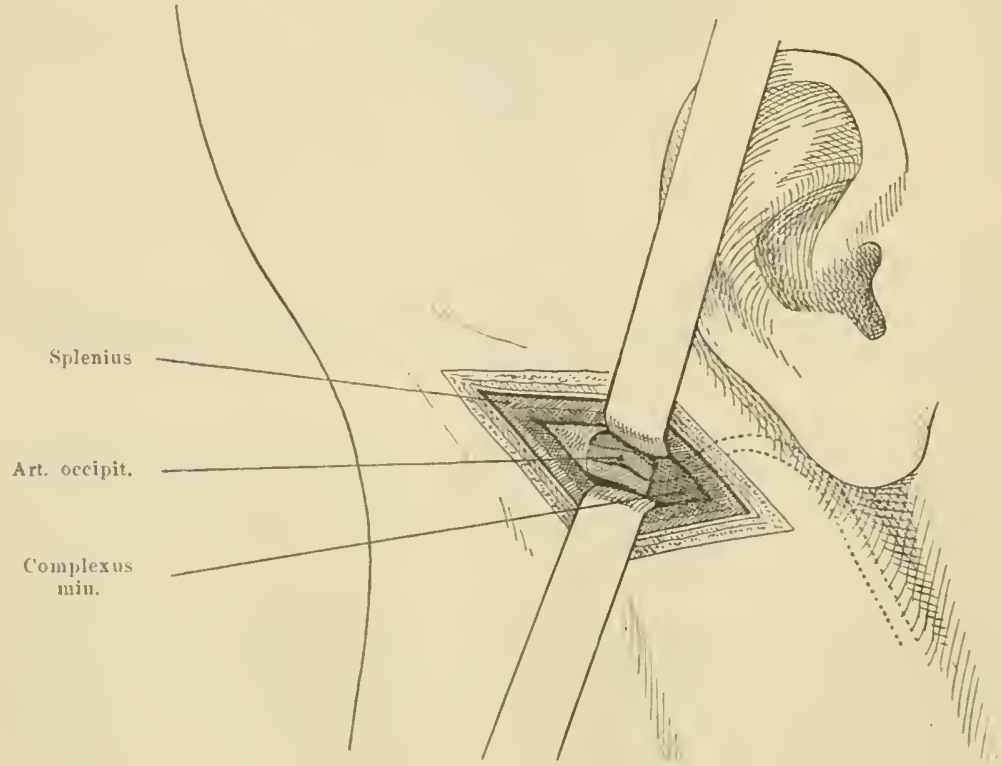

Das Auffinden der Arteria occipitalis; rechte Seite. 
die lamellenförmige Sehne des Sterno-mastoideus und den M. splenius durch, dessen Fasern schief nach unten und hinten gerichtet sind (Fig. 147).

Man legt in die Sehnittränder stumpfe Haken ein und sieht im vordern Winkel des Schnittes, ron der Fascie bedeckt, den Complexus minor. Am hinteren Rande dieses Muskels zerreisst man mit der Sondenspitze die dicke und feste Fascie und findet etwas unter dem Occipitalis die Art. occipitalis, welche im rechten Winkel den hintern Rand des Complezus minor kreuzt. Sie wird ron einer oder zwei zuweilen sehr grossen und dünnwandigen

Fig. 148 .

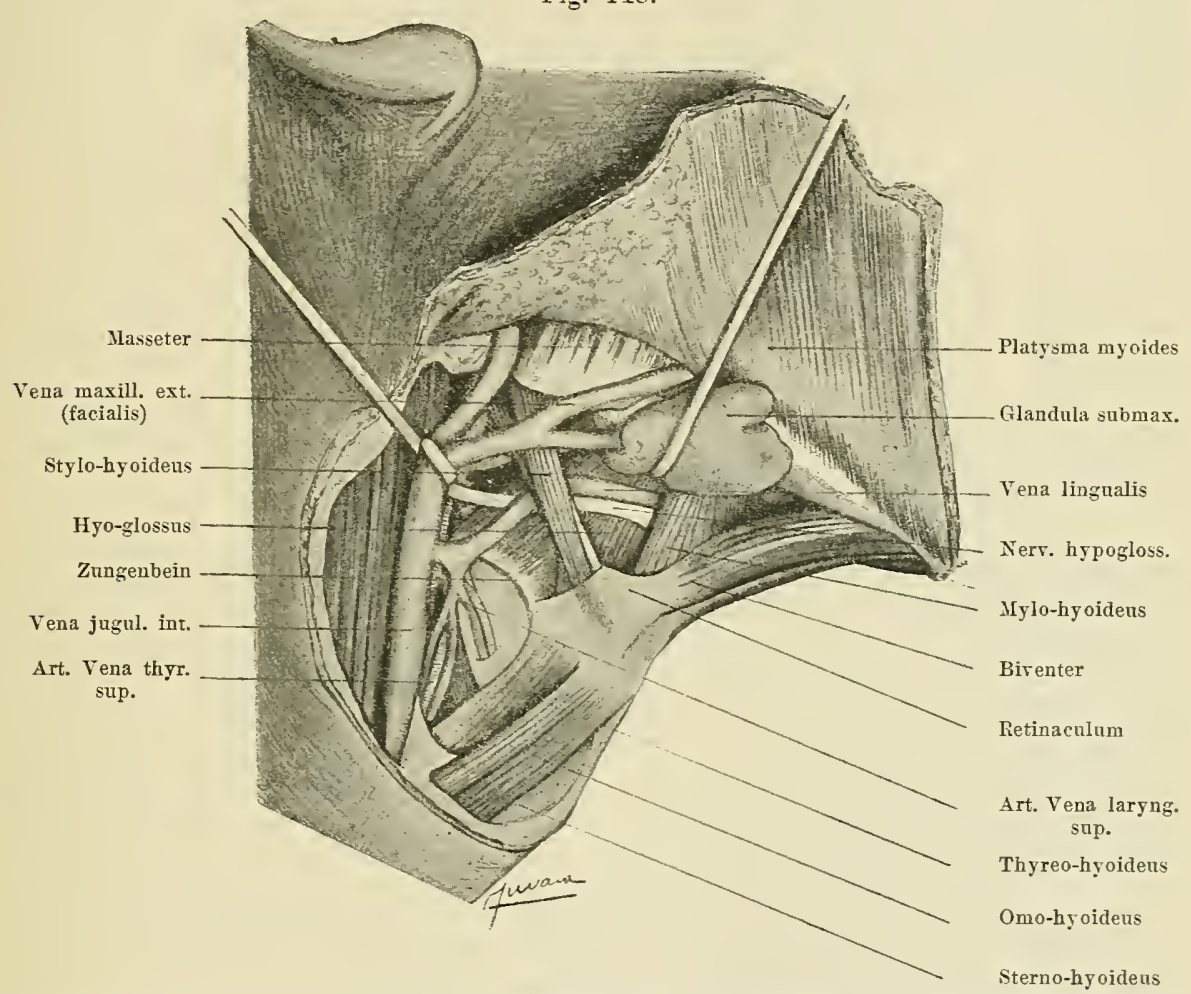

Regio submaxillaris dextra. An der tiefen Fläche des Hautlappens, der durchschnitten und abgehoben wurde, um die Region freizulegen, sieht man die Fasern des Platysma myoides. Ein stumpfer Haken zieht die Submaxillardrüse nach oben, die auf diese Weise das Dreieck der Arteria lingualis bedecken würde.

Venen begleitet; die Arterie und die sie begleitenden Venen sind in einer zellig-fibrösen resistenten Scheide enthalten.

Mitunter zieht die Arterie nicht unter dem Complexus minor, sondern an seiner äusseren Fläche zwischen dieser und dem M. splenius; desshalb sucht man, wenn man die Arteria occipitalis nicht am hinteren Rande des Complexus minor findet, mehr oberflächlich an der äusseren Fläche dieses Muskels (Fig. 146).

Der Nervus occipitalis, der hintere Ast des 2. Cerricalnerren, beschreibt einen 
Bogen nit vorderer Concavität, zieht unter den Obliquus major cervicalis, durchdringt den Complexus major, steigt rortical zwischen diesem und dem Trapezius auf, tritt unter den Bogen dieses Muskels, an den innern Theil der Art. occipitalis angelöthet und theilt sich in ein Büschel von Aesten, dic sich im hintern Theile der Kopfhaut verlieren. Er anastomosirt mit dem Nerrus mastoideus.

Techuik z. A. d. G. Man sucht im obern Theile der suboecipitalen Vertiefung die Protuberantia occipitalis externa auf und nacht 2 Finger nach aussen rou derselben an der hintern Fläche des Nackens eine verticale Ineision. Nan schneidet die Haut, den Trapezius und die Faseic durch und gelangt an die verticalen Fasern des Complexus major, auf welchem man, der Reihe nach unter den beiden Schnitträndern suchend, den sehr dicken Nervus oceipitalis findet; man folgt demselben nach oben in die Kopfhaut und nach unten gegen scinen Ursprung.

\section{Regio submaxillaris.}

Die Submaxillarregion hat die Form eines prismatischen Raumes mit vier Wänden (Fig. 148).

I. Die äussere dreieckige Wand wird von jenem Theile der innern gehöhlten Fläche des Unterkiefers gebildet, welche unter der Crista mylo-hyoidea liegt und hinten ron den Insertionen des Pterygoideus internus bedeckt ist.

2. Die innore Wand wird gebildet: auf einer tiefen Ebene rom Hyoglossus, der rertical rom Rande der Zunge bis zum Schafte und zum grossen Horn des Zungenbeins gespannt ist, oberhalb des Hyoglossus sieht man die antero-posterioren Fasern des Styloglossus; auf einer oberflächlichen Ebene von Mylo-hyoideus, der schief nach unten und rorne ron der Crista nylo-hyoidea bis zum Schafte des Zungenbeins und zur medianen Raphe gespannt ist. Der hintere Rand dieses Muskels ist schief nach unten, vorne und innen gerichtet.

Zwischen Mylo-hyoideus und Hyoglossus existirt ein prismatischer Raun, der oben von der Mundschleimhaut geschlossen ist; in diese dringt die vordere Verlängerung der Submaxillardrïse und deren Ausführungsgang.

Der Biventer beschreibt an der innern Wand der Submaxillarregion eine Curve mit der Concavität nach oben. Diese Curve ist mit dem Körper des Zungenbeins durch einen fibrösen Ring und mit fibrösen Auskreitungen rerbunden.

3. Die untere Wand wird ron der Oberfläche zur Tiefe a) von der Haut, b) vom Platysma myoides und c) ron der Fascia cervicalis superficialis gebildet, die ron unter dem Zungenbeine bis zum untern Rande des Kiefers und vom vordern Biventerkopfe bis zu dem Sterno-mastoideus gespannt ist.

4. Die hintere Wand wird von einem zellig-fibrösen Blättchen gebildet, das transrersal rom Blatte, das den Ilyoglossus bedeckt, zum hintern Kieferwinkel gespannt ist; sie enthält in ihrer Duplicatur den Biventer und Stylo-hyoideus, die von der hintern Wand auf die innere übergehen. Oben ist die Submaxillargrube von der Mundschleimhaut abgeschlossen.

Die Submaxillardriise theilt sich am hintern Rande des Mylo-hyoideus in zwei Partien: a) Die äussere Partie liegt an der äussern Fläche des Mylo-hyoideus und b) Dic innere Partie liegt innen vom Mylo-hyoideus. 
Die Arteria facialis (maxillaris externa) durchzieht den Submaxillarraum. Aus der Carotis externa, etwas oberhalb der Art. lingualis entstanden, dringt sie in das Spatium submaxillare durch ein innen vom Biventer und Stylo-hyoideus gelagertes Orificium; sie umgiebt mit einem Bogen die hintere obere Fläche der Drüse, in die sie einen wahren Kanal bohrt, umschlingt mit einer andern Krümmung mit der Concavität nach oben den untern Rand des Kiefers und tritt ans dem Drïsenraume durch ein Orificium der Fascia superficialis. In diesem Verlaufe giebt sie Drüsenäste und die Arteria mylo-hyoidea ab, welche der innern Fläche des untern Kieferrandes folgt.

Die Vena facialis oder maxillaris externa, zuerst hinter der Arterie gelegen, entfernt sich dann von derselben, verläuft an der äussern Fläche der Drüse und vereinigt sich unter derselben mit den Venae linguales und Thyreoideae inferiores, indem sie den Truncus thyro-linguo-facialis oder die untere äussere Carotisconfluenz bilden, welche in die Vena jugularis interna sich ergiesst. Hinter der Submaxillardrüse anastomosirt die Vena facialis mit der Jugularis externa durch einen Kanal, der in der Fascio liegt.

Der Nervus lingualis folgt dem obern Rande der Submaxillardrüse.

Der Nervis mylo-hyoideus, ein Ast des Nervus dentalis inferior, folgt der gleichnamigen Arterie und verzweigt sich im Mylo-hyoideus und im vordern Biventerkopfe.

Der Nervus hypoglossus beschreibt an der äussern Fläche des Hyoglossus eine Curve, dringt unter den Mylo-hyoideus und verliert sich mit zahlreichen Aesten in den Zungenmuskeln.

Zahlreiche Lymphdrüsen sind längs des untern Randes des Kiefers neben der Arteria mylo-hyoidea vorhanden; die hinterste dieser Drüsenkette, die Glandula subangularis, ist gewöhnlich zuerst beim Lymphadenom des Halses ergriffen.

Techuik z. A. d. G. Man bringt den Kopf in Extensionsstellung und sucht durch Palpation den untern Rand des Kiefers und das Zungenbein auf, zwischen diesen beiden Knochen sieht man die runde Erhabenheit, welche die Drüse bildet. Nan macht unter dem Kiefer eine horizontale Incision, schneidet die Haut, das Platysma myoides und die Fascie durch und gelangt an die Submaxillardrüse, die man ablöst und aus der Nische, welche sie enthält, herauszieht. Man bemerkt, dass sie auf dem hintern Rande des Mylo-hyoideus reitet; ihre äussere Partie bedeckt diesen Muskel, die innere legt sich unter denselben. Man sucht längs des Kiefers die Lymphdrüsen in Form kleiner runder Körper.

In der Rinne, welche den Kiefer vom Mylo-hyoideus scheidet, findet man die Arterie und den Nervus mylo-hyoideus.

Die Arteria lingnalis entsteht aus der Carotis externa etwas oberhalb des hintern Endes des grossen Zungenbeinhorns, beschreibt zuerst an der Pharynxwand eine Curve mit der Concavität nach oben, dringt dann in die Pharynxwand in das Interstitium, das den Hyoglossus vom Constrictor medius trennt, richtet sich nach vorne $2-3 \mathrm{~mm}$ oberhalb des Zungenbeins gelegen. In der Richtung des kleinen Horns wird die Arterie aufsteigend, schlängelt sich stark gekrümmt im Interstitium, das den Genioglossus rom Hyoglossus scheidet und endigt an der Zungenspitze als Arteria ranina.

Die Arteria lingualis giebt zwei Aeste ab: die Art. dorsalis der Zunge entsteht etwas hinter dem kleinen Horn, erhebt sich nach oben und verzweigt sich an der Basis der Zunge und am hintern Theile ihres Randes; b) die Art. sublingualis richtet sich nach vorne, giebt der Sublingualdrüse Aeste, zieht unter derselben, durchzieht den Mylohyoideus und anastomosirt mit der Arteria mylo-hyoidea. 
Techulik z. A. d. (A. Man bringt den Kop in Extensionsstellung und innere Rotation und sucht durch Palpation unter dem Kiefer das Zungenbein auf.

Fingerbreit oberhalb desselben macht man diesem parallel eine horizontale Incision bis zur Erhabenheit des vordern Randes des Sterno-mastoideus; man durchschneidet die Haut, das Platysma myoides und die Fascie und gelangt an die Submaxillardrüse, welche mit der Sonde abgelöst und in einen stumpfen Haken gegeben wird, der sie nach oben zieht. Man sucht am Grunde des Schnittes an der innern Wand der Submaxillargrube schief nach vorne und unten gegen das Zungenbein gerichtet die weisse und glänzende Schne des Biventer auf, die an ihrer vordern Fläche vom dümnen Muskelkörper des Stylo-hyoideus umfasst wird.

Oberhalb des Biventer existirt ein kleines Dreieck, das Dreieck der Art. lingualis, unten ron der Biventersehne, rorn vom hintern Rande des Mylo-hyoideus und oben vom Nervis hypoglossus major begrenzt, der an seinem untern Theile von der Vena lingualis begleitet ist. Der Boden dieses Dreiecks wird ron den verticalen Fasern

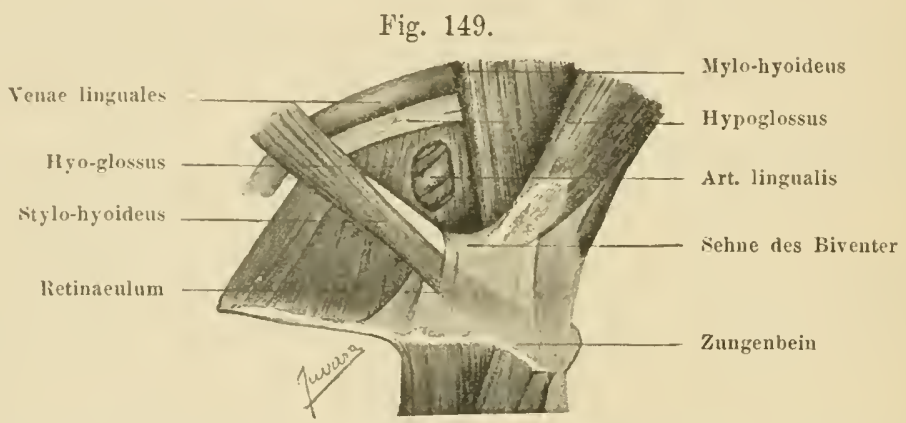

Das Dreieck der Arteria lingualis; eine Lücke wurde im Musculus hyo-glossus ausgeschnitten, durch welche man die Arteria lingualis, unmittelbar unter derselben gelagert, sieht.

des Hyoglossus gebildet, der von einem zellig-fibrösen Blättchen bedeckt ist, welches oben den Nervus hypoglossus einhüllt (Fig. 149).

Im Bereiche dieses Dreiecks durchschneidet man vertical mit Sorgfalt das zellige Blättchen und eröffnet mit der Sondenspitze eines der Interstitien des Hyoglossus; unter demselben findet man in Form eines weisslichen Bandes die Arteria lingualis von einer Bindegewebsschichte umgeben, welche auf den schiefen Fasern des Genioglossus gelagert ist (Fig. 150).

Unter der Biventersehne existirt ein spitzer Winkel mit der Spitze nach vorn gerichtet, der oben vom Biventer, unten rom grossen Zungenbeinhorn begrenzt ist. In diesem Winkel fasst man unmittelbar unter dem Nervus hypoglossus mit der Spitze der Pincette die horizontalen Fasern des Hyoglossus und durchschneidet dieselben. Nan gelangt an die Arteria lingualis auf einem rothen Polster gelagert, welches von den Fasern des M. constrictor medius gebildet wird.

Man muss sorgfältig arbeiten, da man sonst in den Pharynx eindringen kann. 
Der Nervus hypoglossus tritt aus der Schädelhöhle durch das Foramen supracondyloideum, richtet sich schief nach unten gegen das Zungenbein, zieht unter der Schädelbasis hinter den Vagus, Glosso-pharyngeus und N. spinalis und vor der Vena jugularis interna, kreuzt dann die Carotis interna, umschlingt den Ursprung der Art. occipitalis und Carotis externa und bildet einen Haken mit der Convexität nach unten. Er wird dann aufsteigend, zieht oberhalb des Zungenbeins an die äussere Fläche des Hyoglossus angelöthet und dringt unter den Mylo-hyoideus in ein Büschel von Aesten sich auflösend, die für die Zungenmuskeln bestimmt sind.

Von dem Bogen des Hypoglossus entsteht ein dünner Ast, der an der vordern Fläche der Jugularis interna verläuft, und mit einem Aste, der vom Plexus cervicalis superficialis

Fig. 150 .

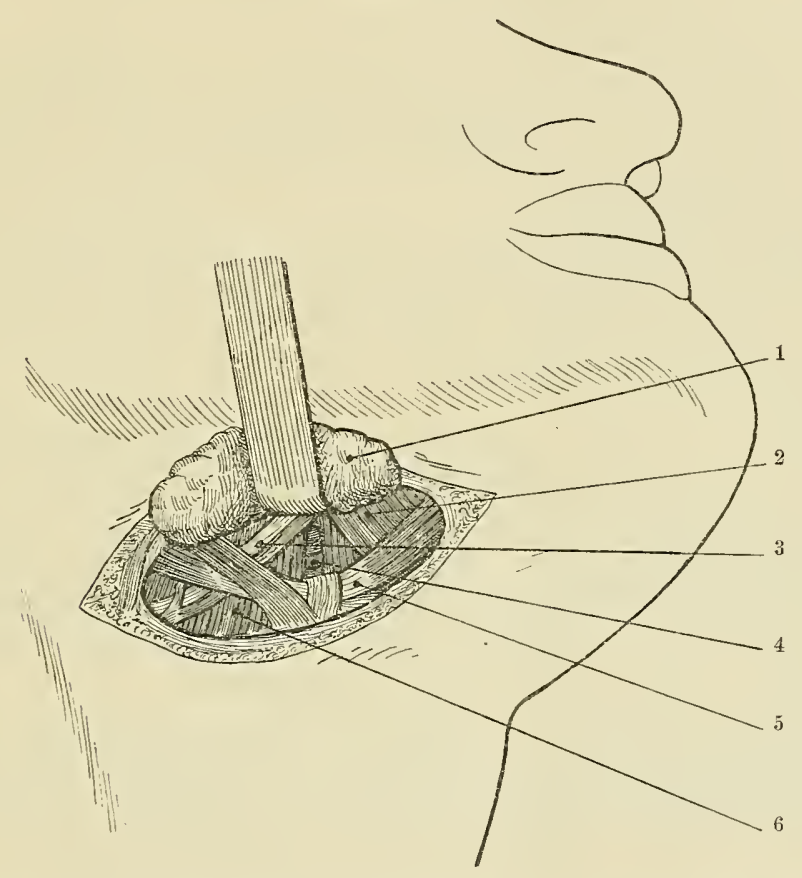

Das Auffinden der Arteria lingualis; rechte Seite. Ein stumpfer Haken zieht die Submaxillardrüse nach oben. 1. Gland. submaxill., 2. Mylo-hyoideus, 3. Nerv. hypogl. Vena lingualis, 4. Art. lingualis, 5. Biventer, 6. Hyo-glossus.

kommt, anastomosirt, die Ansa hypoglossi bildend. Von der Convexität dieser Ansa, von einem wahren Plexus, gehen Nerven ab, für die Musculi subhyoidei bestimmt. Oberhalb des Zungenbeins giebt er den Nerv für den M. thyro-hyoideus ab.

Technik z. A. d. G. Man macht dieselbe Incision wie für die Art. lingualis. An der äusseren Fläche des Hyoglossus unter einem zellig-fibrösen Blättchen findet man den Nervus hypoglossus mit der Sehne des Biventer in einem $X$ sich kreuzend. Man präparirt denselben und folgt ihm nach hinten und oben bis zur Basis des Schädeldaches, nach vorn zur Zunge. 


\section{Regio suprahyoidea.}

Die Regio suprahyoidea hat die Form eines gestutzten Dreicclis, das unten rom liörper des Zungenbeins, oben rom vordern Kieferwinkel und an den Seitentheilen von den innern liändern der rordern Birenterköpfe begrenzt wird.

Der Grund dieses Dreiccks wird ron lirummen Fasern der Mylohyoidei gebildet, dio sich an der Medianlinie verweben, eine Raphe bildend, welche vom Kieferwinkel zur Mitte des Zungenbeinkörpers gespannt ist.

Die Glandulat lymphaticae suprahyoideae. Oberhalb des Zungenbeins unter dem Platysma in einer Fettschichte findet man ein Packet ron 2-3 Drüsen, welche lymphatische Kanäle der Unterlippe erhalten; diese Drüsengruppe ist fast immer bei cinem Kirebse dieser Lippe ergriffen.

T'echuik z. A. d. (4. Man macht eine mediane Incision vom Zungenbeine bis zum Kiefer, durchschneidet die Haut und das Platysma myoides, dessen Fasern sich in der Medianlinie kreuzen; an der Fascie in einer Fettschichte findet man zwei oder drei kleine runde Körper, die Glandulae lymphaticae supra-hyoideae.

Der vordere Kopf des Biventer entsteht mit sehnigen kurzen Fasern und mit Fleischfasem am untern Rande des rordern Winkels des Unterkiefers an jener ranhen Oberfläche, die "Weg des Biventer" genannt wird; hinten gehen die Fleischfasern in das vordere Ende der mittleren Sehne dieses Muskels über und mit einem fibrösen Blatte in den Zungenbeinkörper.

Technik z. A. d. (4. Einen Finger ausserhalb der Medianlinie macht man eine Incision, durchsehneidet die Haut, das Platysma myoides und dic Fascie und gelangt an den Biventer.

Die Genio-hyoidei, an jeder Seite der Medianebene gelegen, entstehen mit kurzen fibrösen Bündeln an den untern Kinnhöckern. Die prismatischen und dreieckigen Fleischkörper inseriren sich hinten an der obern Fläche des Zungenbeinkörpers mit zwei Bündeln, zwischen welche die vordern Bündel der Hyoglossi dringen.

Terhnik z. A. d. (t). Man bringt den Kopf in Extensionsstellung und macht in der Nedianlinie eine Incision vom Kiefer bis zum Zungenbeine. Man durchschneidet die Haut, die Fasern des Platysma myoides und die Raphe der Iylo-hyoidei und gelangt an die longitudinalen Fasern der Geniohyoidei.

Nit der Sonde scheidet man diese Muskeln von den Mylo-hyoidei und legt je einen stumpfen Haken in jedem Schnittrande ein; in der Medianlinie sieht man die Muskelmasse der Genio-hyoidei und an jeder Seite dersclben den untern Rand der Sublingualdrüsen.

Man isolirt und dnrehschneidet transversal die Genio-hyoidei und gelangt an don untern Rand der Genio-glossi: mit der Hohlsonde eröffnet man das tiefe Interstitium, welches diese beiden Mnskeln scheidet und findet zwischen diesen eine kJeine Fettschichte. Mit einer Pincette fasst man den untern Rand der Sublingualdrüse und entfernt diese von der äussern Fläche des Genio-glossus; man sieht im Grunde auf der Schleimhaut an die innere Fläche der Drüse gelöthet den Ductus Warthonianus von der Form eines weissen und dïnmen Stranges; mehr innen findet man an der Zunge liegend den Faden des Nervus lingualis. 


\section{Der Hals.}

\section{Vordere Fläche.}

Digitaluntersuchumg. Die vordere Fläche des Halses hat die Form einer halbeylindrischen und dreieckigen, mit der Spitze nach unten gerichteten Erhabenheit, die an jeder Seite von den Erhebungen der vordern Ränder der Sterno-cleido-mastoidei begrenzt wird.

Die vordere Fläche des Halses abtastend findet man in der Medianlinie von oben nach unten:

1. den vordern Winkel des Unterkiefers,

2. den Körper und die grossen Hörner des Zungenbeins, zwei Finger hinter und etwas unterhalb des Unterkiefers gelegen,

3. eine Tertiefung, welche der Membrana thyreoidea entspricht,

4. den Winkel der Thyreoidea, den Adamsapfel, durch Vereinigung der oberen Ränder mit dem vordern Rande des Schildknorpels gebildet,

5. den vordern Rand der Thyreoidea 1-2 cm lang, gegen dessen Mitte findet man mit der Nagelspitze eine kleine transversale Grube, welche der Insertion der untern Stimmbänder entspricht,

6. eine wenig tiefe Grube, die der Membrana crico-thyreoidea entspricht,

7. das Tuberculum anticum des Ringknorpels,

8. die vordere Fläche der Trachea,

9. die Sternalgrube.

Man wiederhole oft diese Digitaluntersuchung der vorderen Fläche des Halses; man übe die Finger mit dem Erkennen dieser zahlreichen und wichtigen Anhaltspunkte und bevor man in diese Region schneidet, versichere man sich, nochmals das Resultat der ersten Untersuchung prüfend, durch eine zweite und zwar von unten nach oben ausgeführte. Diese Digitaluntersuchung des Halses, die an zarten Individuen so leicht scheint, wird sehr schwer und zuweilen unmöglich an fetten Individuen; oftmals habe ich gesehen, dass meine alten Chefs, berühmte Chirurgen, sich geirrt haben.

An den Seitentheilen des Halses unter dem hinteren Rande des Sternomastoideus fühlt man eine Reihe von Erhabenheiten, die Processus transversi der Halswirbel; von diesen ist der Letzte der höchste und entspricht dem Proc. transversus des VI. Halswirbels, dem Tuberculum Chas- 
saigniaei. L'nter demselben und oberhalb der Clavicula gelangen dir Fingerspitzen in eine Ebone, welche dem scaleno-rertebralen Dreieck entspricht, die Ebene, in welcher sich die Arteria vertebralis erhebt.

Fig. 151.

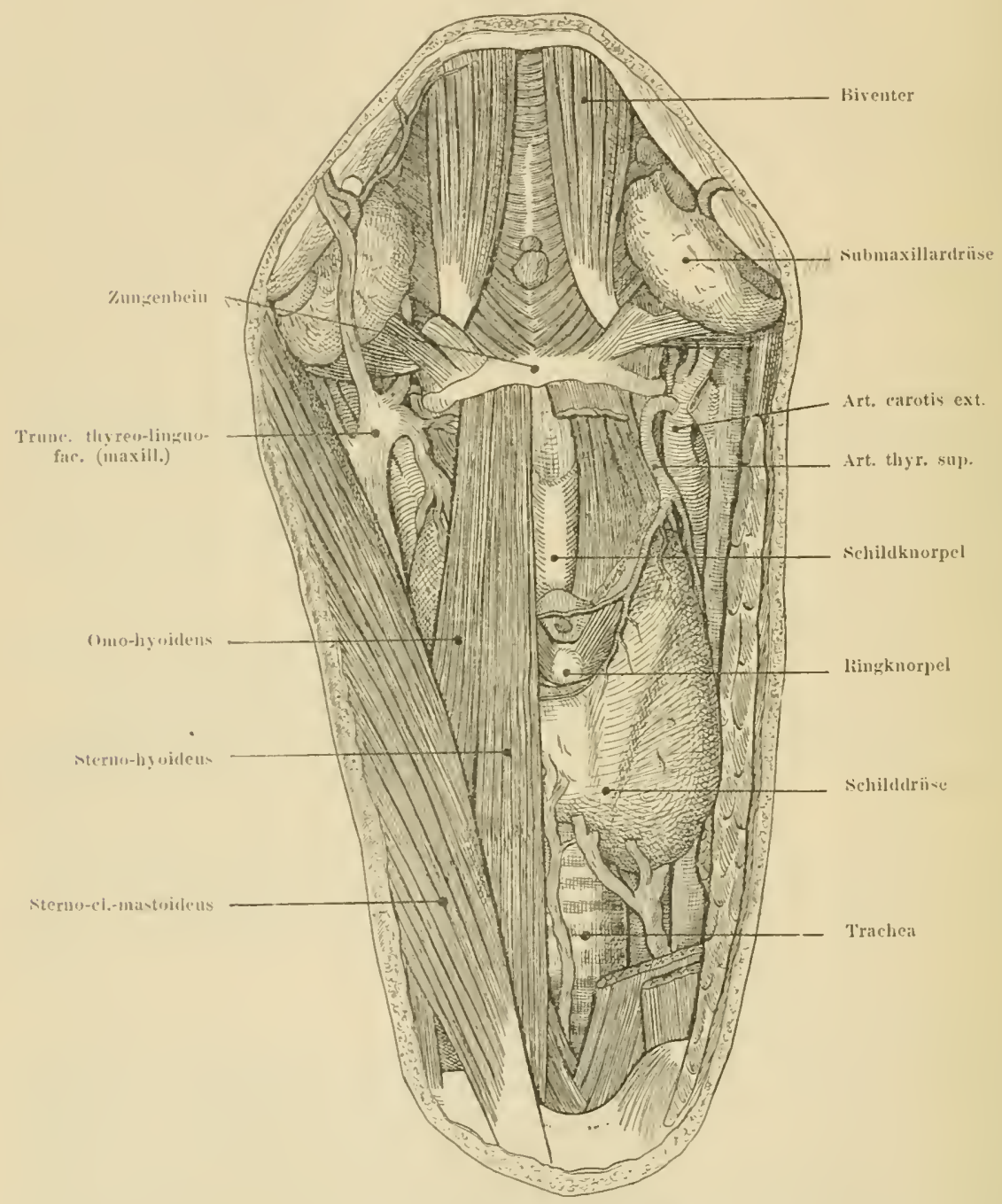

Dit vordere Fläche des Halses. Links wurden die Mruskeln durchschnitten, um die Schilddrüse freizulegen.

An der hintern Fläche des Halses, in der Medianlinie, fühlt und sieht man die Serie der Processus spinosi der letzten 6 Halswirbel; der letztc, der jrominirendste entspricht dem Proc. spinosus des 7. Halswirbels.

Der hintere Bogen des Itlas ist nicht $\iota$ berühren, weil er unter einer 
dicken Muskelmasse verborgen liegt und zwischen Hinterhaupt und dem stark entwickelten Proc. spinosus des Epistropheus eingegraben ist.

Die Membrana hyo-thyreoidea, elastisch und von gelblicher Farbe, ist vertical vom obern Rande des Zungenbeins zum obern Rande des Schildknorpels gespannt.

Dick und resistent im medianen Theile ist sie vom obern Winkel des Schildknorpels zum Zungenbeinkörper gespannt, Ligamentum hyo-thyreoideum medianum; sie verstärkt sich an den hintern Rändern in Form eines kleinen Stranges, der rom Höcker des grossen Zungenbeinhorns zur Spitze des grossen Schildknorpelhornes gespannt ist, Ligamentum hyo-thyreoideum posticum. Oft findet man einen knorpligen Knoten in diesem Ligamente.

Die Membrana hyo-thyreoidea stellt an ihren lateralen Theilen ein oder zwei Orificien dar, durch welche die Gefässe und der Nervus laryngeus superior durchziehen.

Technik z. A. d. G. Man bringt den Hals in Extensionsstellung und sucht das Zungenbein und den obern Rand des Schildknorpels auf; sie sind durch eine verticale Vertiefung getrennt, welche der Nembrana hyo-thyreoidea entspricht. Unter dem Zungenbeine macht man einen horizontalen Hautschnitt von der Medianlinie bis hinter den vordern Rand des Sterno-mastoideus; man durchschneidet cine erste Nuskelschichte vom Sterno-hyoideus und Omohyoideus and eine zweite Schicht, vom Hyo-thyreoideus gebildet, und gelangt an die Membrana hyo-thyreoidea; man präparirt dieselbe und sucht ihre Verstärkungen, das Ligamentum anticum und Lig. posticum auf.

In der Medianlinie eröffnet man bei dieser Operation die Bursa serosa praethyreo-hyoidea.

Arteria thyreoidea superior. Nervis und Arteria laryngea superior. Unter dem grossen Zungenbeinhorn existirt ein kleines Dreieck mit der Spitze nach unten gerichtet, Triangulus subhyoideus, das oben rom hintern Drittel des grossen Horns, vorne vom hintern Rande des M. thyreo-hyoideus, unten und hinten vom vordern Rande des Constrictor inferior, welcher sich liümmt, indem er sich nach innen richtet, am grossen Horne des Schildknorpels und am Ligamentum hyo-thyreoideum posticum begrenzt wird. Der Grund dieses Dreiecks wird von der Mlembrana thyreo-hyoidea gebildet; durch dieselbe dringt in den Larynx die Arteria and der Nervus laryngeus superior.

Der Nervus laryngelts superior entsteht aus dem Vagus, steigt auf die innere Fläche der Carotis interna herab, zieht hinter und unter dem grossen Znngenbeinhorne, durchzieht die Nembrana hyo-thyreoidea im subhyoiden Dreieck und theilt sich in eine grosse Anzahl von Aesten, welche sich in der Schleimhaut des Larynx und der Basis der Zunge vertheilen.

Die Arteria laryngea superior entsteht aus der Arteria thyreoidea superior und dringt in den Larynx neben dem Nerv.

Die Arteria thyreoidea superior entsteht aus der Carotis externa unmittelbar unter dem grossen Zungenbeinhorne, beschreibt im Niveau des subhyoiden Dreiecks einen mit der Convexität nach oben gerichteten Bogen, giebt die Laryngea superior ab und theilt sich am obern Ende des Lappens der Schilddrüse in drei Aeste: einen vordern, einen innern und einen hintern.

Der vordere Ast steigt an dem vordern Rande des Schilddrüsenlappens herab und anastomosirt oberhalb des Isthmus durch einen doppelten Bogen mit der gleichnamigen Arterie der gegenüberliegenden Seite. Ein anderer arterieller Bogen, Arcus prae-cricothyreoidens, vor der Membrana crico-thyreoidea gelegen, vereinigt die vordern Aeste der Arteriae thyreoideae superiores (Fig. 151). 
Tecllnik z. A. I. (1. Man bringt den Hals in Extensionsstellung und sucht das Zungenbein auf; im Nireau des grossen Horns macht man am vordern Rande des Sterno-mastoideus eine verticale Incision. Man löst den Sterno-mastoideus ab und legt einen stumpfen Haken ein, dann arbeitet man vorsichtig mit Pincette und Hohlsonde; unter dem Zungenbeine findet man den Bogen der Art. thyreoidea superior. Unterhalb derselben an der Membrana thrreoidea haftend sucht man den Nervus laryngeus superior; man bemerkt, dass die V'enae thyreoideae superiores sich mit den Lingualvenen und mit der Vena facialis zu einem gemeinsamen Stamme vereinigen, 'Truneus thyro-linguo-facialis oder die untere äussere Carotisconfluenz, die in die Jugularis interna sich ergiesst.

Dic Venae laryngae superiores und Venae pharyngeae mediae gehören der Tena thyreoidea superior an.

Musculi subhyoidei. An jeder Seite der Medianlinie sind die Muskeln in zwei Schichten gelagert.

A. Die oberflächliche Schichte besteht aus dem Sterno-hyoideus und dem Omohyoideus (Fig. 151).

1. Der Sterno-hyoideus hat die Form eines Muskelbandes, das sich ron oben nach unten verbreitert. Er entsteht neben der Ifedanlinie am innern Theile des untern Randes des '/ungenbeinlörpers; unten inserirt er sich an der hintern Fläche des Manubriuun sterni, am obern Rande des I. Rippenlinorpels und an der hintern Fläche des inneren Claricularendes.

2. Der Onı-hyoideus entsteht am Zungenbeinkörper neben und ror dem Sternohyoideus; er richtet sich nach unten, umschlingt die Basis des Halses, zieht hinter die Claricula und inserirt sich mit einem sehnigen Blatte am obern Rande des Schulterblattes neben der Fossa sub-coracoidea. Er besteht aus zwei Muskelbändern, die durch ein fibröses Band vereinigt sind und wird vom äussern Rande des Sterno-hyoideus durch einen spitzen, mit der Basis nach unten gerichteten Winkel getrennt.

B. Die tiefe Schichte wird ron oben nach unten aus dem Thyreo-hyoideus und Sterno-thyreoideus gebildet.

1. Der Thyreo-hyoideus entsteht am untern Rande und an der innern Fläche der z̈ussern Partie des Zungenbeinkörpers und an den beiden vordern DritteIn des untern Randes des grossen IIorns; unten inserirt er sich am untern Höcker und an der Crista obliqua externa des Schildlinorpels.

2. Der Sterno-thyreoideus, breit und dünn, entsteht am untern Höcker, an der Crista obliqua und am obern Höcker des Schildknorpels; von hier richtet er sich nach unten und etwas innen, umhüllt die vordere äussere Fläche des Schilddrüsenlappens und inserirt sich an der hintern Fläche des Nanubrium sterni und am II. Rippenknorpel. Etwas oberhalb des Sternums in der Medianlinie verweben sich die Fasern des Sternothyreoideus der rechten Seite mit jenen der linken Seite.

Im Nivean der Crista thyreoidea tauscht der Sterno-thyreoideus mit dem Hyo-thyreoideus und dem Constrictor inferior Fasern aus; zuweilen entsteht er auch mit einigen Fasern an der fibrösen Kapsel der Schilddrüse.

Terlunik z. A. d. G. Man macht an der vordern Fläche des Halses eine lange Tncision rom Zungenbeinkörper bis zum untern Ende der Clavicula, schneidet die Haut, dic subcutane Schichte und die Fascie durch und gelangt an den Köper des Sterno-hyoideus.

Ilan präparirt den äussern Rand des Schnittes; neben dem Sterno- 
hyoideus findet man den Omo-hyoideus. Durchschneidet man transversal diese oberflächliche Muskelebene, so gelangt man unter derselben an eine zweite Ebene, in welcher man oben den Thyreo-hyoideus, unten den Sternothyreoideus unterscheidet.

Man isolirt und durchschneidet transversal den letzteren Muskel und gelangt an die Schilddrüse.

Membrana crico-thyreoidea. Musculus crico-thyreoideus und Nervus laryıgeus exter'uls. Die Nembrana-crico-thyreoidea, elastisch und von gelblicher Farbe, inserirt sich oben am mittleren Theile des untern Randes des Schildknorpels, unten am obern Rande des vordern Bogens des Ringknorpels. Sie wird von elastischen Bündeln gebildet, die von dem Schildknorpel zum Ringknorpel divergiren; an den Seitentheilen wird sie von den Musculi crico-thyreoidei umrahmt (Fig. 151). An ihrer vordern convexen Fläche, die von kleinen Orificien durchlocht ist, ruht eine kleine Lymphdrüse, die Glandula prae-cricoidea und der Arcus arteriosus prae-crico-thyreoidens, welcher die beiden Thyreoideae superiores verbindet.

Techuik z. A. d. G. Nan bringt den Hals in Extensionsstellung; unter dem Schildknorpel gelangt die Fingerbeere in eine kleine wenig tiefe Vertiefung, die unten vom vordern Bogen des Ringknorpels begrenzt ist. In diesem Niveau macht man in der Medianlinie eine zwei fingerbreit lange Incision, unter der Haut entfernt man die Vena jugularis anterior media, wenn sie vorhanden ist, durchschneidet die Fascie im Interstitium der Sterno-hyoidei und legt an jedem Schnittrande je einen stumpfen Haken ein. Im Grunde des Schnittes sieht man ron oben nach unten: den vordern Rand des Schildknorpels, die Nembrana crico-thyreoidea und den Ringknorpel, der von den IIusculi crico-thyreoidei bedeckt ist.

Vor der Membran sucht man die Lymphdrüse und den Arcus arteriosus prae-crico-thyreoideus auf; mit der Spitze des Bistouri durchsticht man kreuzförmig die Membrana crico-thyreoidea; man macht auf diese Weise eine Tracheotomia inter-crico-thyreoidea und kann eine Canüle einführen.

Der Musculus crico-thyreoideus, klein und dreieckig, inserirt sich oben an dem Schildknorpel an dem untern Theile seiner innern Fläche, an der äussern Hälfte seines untern Randes und an dem kleinen Horne; unten inserirt er sich an der vordern Fläche des Ringknorpels.

Er besteht aus drei Bündeln: ein inneres verticales lamellenförmiges, ein mittleres schiefes nnd ein unteres fiederförmiges horizontales Bündel.

Der Nervus laryngeus externus, ein sehr dünner Ast des Laryngeus superior, richtet sich nach unten und etwas vorne. Er liegt unter der Schilddrüse an der äussern Fläche des Constrictor inferior, dringt mehr unten zwischen die Fasern dieses Muskels unter eine fibröse Schlinge, an der er sich zwischen Ring- und Schildknorpel inserirt und endigt im Muskelkörper des Thyro-cricoideus anterior.

Technik z. A. d. G. Bei in Extensionsstellung befindlichem Halse macht man eine schief nach unten und vorne gerichtete Incision, vom obern Rande des Schildknorpels gegen die vordere Fläche der Trachea. Nan durchschneidet schichtenweise die Musculi subhyoidei und gelangt an den vordern Rand der Schilddrüse. Mit Pincette und Sonde löst man die Schilddrüse vom Constrictor inferior ab und legt einen stumpfen Haken 
ein: mall sucht nun sorgfältig am röthlichen Consirictor einen weissen Faden, den Nerrus laryngeus externus.

Man fasst ihn mit der Pincette und folgt ihm im Constrictor, man gelangt an den oberen Rand des Crico-thyreoideus, in welchen er cindringt.

I)ie Schilddritse, Glandula thyreoidea, ist am IIalse gelagert an jeder Seite der Iaryngo-trachealröhro.

Sie besteht aus zwei Lappen, die miteinander in der Medianlinie durch cine enge Partie; Isthmus, rerbunden sind. Jeder Lappen, ron der Form einer dreieckigen Pyranide, mit der Basis nach unten gerichtet, bietet drei Flächen, drei Ränder und zwei Enden dar (Fig. 151).

1. Die vordere oder musculöse Fläche steht von der Oberfläche zur Tiefe mit drei Muskelschichten in Bezielıung. a) Sterno-mastoideus. b) Sterno-hyoideus nnd c) Sterno-thyreoideus.

2. Die innere oder Tracheo-laryngealfläche ist durch eine horizontale Leiste in zwei Partien getrennt. Die untere concave Partie entspricht der lateralen Flïche der Trachea, mit welcher sie durch feste fibröse Stränge, Ligamentum thyreoideum, verbunden ist; die obere Partie, in Form einer Furche, entspricht dem Ringknorpel und dem hintern Drittel der lateralen Fläche des Schildknorpels, von der sie durch Fasern des Constrictor inferior geschieden ist.

3. Die hintere äussere oder vasculäre Fläche steht innen mit der Wirbelsäule, in der Mitte mit der Carotis communis und aussen mit der Vena jugularis interna in lieziehung.

Der vordere Rand, schief nach unten und innen, geht in den obern Rand des lsthmus über und entspricht der obern Insertion des Sterno-thyreoideus.

Der äussere Rand, convex und dick, entspricht der Vena jugularis interna.

Der hintere Rand, dünn, biegt am hintern Rande des Larynx ab, zwischen Constrictor inferior und Wirbelsäule eindringend.

Das obere Ende, zugespitzt, entspricht der Wurzel des grossen Horns des Schildknorpels, an diesem enfalten sich die Aeste der Thyreoidea superior.

$\Lambda \mathrm{n}$ dem untern abgerundeten und unregelmässigen Ende vertheilen sich die Aeste der Thyreoidea inferior.

1) er Isthmus, von vorne nach hinten verbreitert, liegt an der vordern Fläche der Trachea, deren erste drei bis vier Ringe' er bedeclit; an den Seiten verliert er sich im innern Theile der Lappen; sein oberer Rand entspricht dem Ringknorpel.

Vom obern Rande des Isthmus oder rom Winkel, den er mit einem der Lappen bildet, entsteht eine Verlängerung der Schilddrüse, die Pyramide La lo uette; gewöhnlich links ron der Medianlinie gelagert, ist ihr oberes Ende mit dem Zungenbeinlï̈rper durch einen zellig-fibrösen Tractus verbunden.

Die Pyramide Lalouette kann fehlen oder zu kleinen Drüsenknötchen reducirt sein. Jeder Lappen der Schilddrüse erhält zwei Arterien:

a) Die Arteria thyreoidea superior entsteht aus der Carotis externa.

b) Die Arteria thyreoidea inferior entsteht aus der Arteria subclavia aus einem gemeinsamen Stamme mit den Halsartcrien der Scapularis superior und dem Truncus thyreo-bicervico-scapularis.

Die Arteria thyreoidea media ist nicht constant zu finden und entstelit, wenn sic vorhanden ist, ans dem Aortenbogen und vertheilt sich im Isthmus.

Die Arteria thyreoidea superior und inferior anastomosiren mit einander; zu gleicher Zeit anastomosiren die Arterien des rechten Lappens mit denen des linken durch drei 
bis vier Schleifen, am obern und untern Rande des Isthmus gelegen und durch den Arcus prae-crico-thyreoideus.

Die Venen bilden vier Gruppen:

a) Die Gruppe der Thyreoideae inferiores entsteht am untern Ende der Schilddrüse und mündet in die venöse retro-claviculare Confluenz ein.

b) Die Gruppe der Thyreoideae superiores, die Satelliten der gleichnamigen Arterien gehen in die Vena jugularis interna durch den Truncus thyro-linguo-facialis, nachdem sie während des Verlaufes die Venae laryngeae superiores und pharyngeae mediae aufgenommen haben.

c) Die Gruppe der Thyreoideac mediae entsteht von der Mitte des Lappens, geht in die Jugularis interna über, vor der Carotis ziehend.

Die Venae thyreoideae medianae entstehen am untern Rande und an der vordern Fläche des Isthmus, ziehen vor der Trachea und gehen in den Truncus brachiocephalicus sinister oder sie theilen sich nach rechts und links, mit den Venae thyreoideae inferiores sich verbindend.

Die Schilddrüse ist von einer fibrösen Kapsel umkleidet, die aussen in die Scheide der Halsgefässe übergeht, hinten und innen in die Fascie des Pharynx, vorne in die Fascia muscularis. An der Medianlinie erhebt sie sich vor dem Schildknorpel in Form eines Blättchens bis zum Zungenbeine, an dem sie inserirt und ein wahres Ligamentum suspensorium bildet.

Technik z. A. d. G. Man macht am mittleren Theile des vorderen Randes des Sterno-mastoideus eine verticale Incision, schneidet die Haut und die Fasern des Platysma myoides durch; oft gelangt man an die Vena jugularis anterior lateralis, die Begleiterin des vordern Randes des Sterno-mastoidens. Man durchschneidet die Fascie, löst den Sterno-mastoideus ab und legt ihn in einen stumpfen Haken; man erkennt und eröffnet das Interstitium, welches der Crico-hyoideus vom Stermo-hyoideus tremnt, unter diesem gelangt man an den Lappen der Schilddrüse.

Man macht in der Medianlinie eine Incision vom Zungenbeine bis 2-3 Finger unter dem Ringknorpel. Man durchschneidet die Haut und die Fascie im Interstitium der Sterno-hyoidei und legt stumpfe Haken ein; unter dem Ringknorpel an die Trachea geheftet findet man den Isthmus und von ihm abgehend die Pyramide Lalouette.

Der Nervus laryngens inferior oder recurrens ist ein Ast des Vagus.

Der rechte Recurrens entsteht hinter der Clavicula im scaleno-vertebralen Dreieck, umschlingt die untera Fläche der Art. subclavia und richtet sich nach oben hinter die Carotis communis ziehend, er dringt dann unter die Schilddrüse, zieht zwischen den Rami thyreoidei inferiores und dringt in den Larynx unter dem untern Rande des Constrictor inferior.

Im Larynx liegt er unter der Schleimhaut, hinter der Articulatio crico-thyreoidea in der tiefen Furche, welche der Ringknorpel mit dem Schildknorpel bildet.

Der linke Recurrens entsteht aus dem Vagus im Thorax im Niveau der vordern Fläche des Aortenbogens, welchen er hakenförmig mit der Concavität nach oben umschlingt, zieht dann hinter die Art. subclavia, erhebt sich auf der vordern Fläche des linken Randes des Oesophagus in der Furche, welche dieser mit der linken lateralen Fläche der Trachea kildet und dringt, wie der rechte, unter dem Constrictor inferior in den Larynx ein.

Die Nervi recurrentes sind motorische Nerven für alle Muskeln des Larynx bis auf den Crico-thyreoideus anterior, der vom Nervus laryngeus externus innervirt wird. 


\section{Regio carotidea.}

Der Musculus stemo-releido-mastoideus ist an der lateralen Seite des Halses ron Os temporale und Os occipitale einerseits zum Sternum und zur Clavicula andererseits gespannt. Drei Finger breit ist er in einer fibrösen Scheide enthalten, die durch Duplicatur der Fascia superfieialis des IIalses gebildet wird (Fig. 152).

Err besteht aus zwei Schichten:

1. Die oberflächliche Schichte besteht aus zwei Bündeln:

Fig. 152.

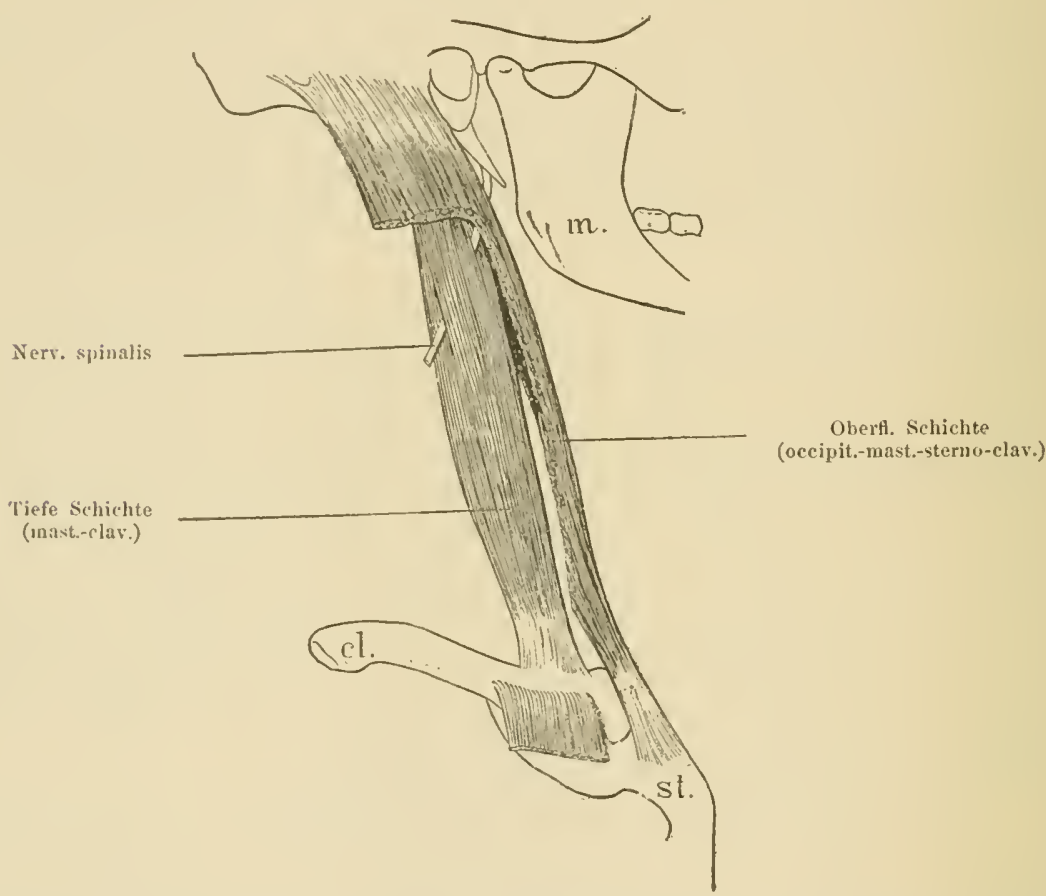

Der Sterno-cleido-mastoideus; rechte Seite. Die oberflächliche Schichte wurde durchsehnitten, um die rom Nervus spinalis durchzogene tiefe Schichte zu sehen.

a) Das vordere oder Sterno-mastoideusbündel entsteht mit einem sehnigen Blatte am rorderu Rande und an der äussern Fläche des Proc. mastoideus und an der obern Lefze der Linea obliqua mastoidea-occipitalis superior.

Sein breiter und dreieckiger Fleischkörper geht unten in eine feste Endsehne über, welche an der rordern Fläche des Sterno-claviculargelenkes gleitet und inserirt sich an der rordern Fläche des Manubrium sterni an einer rauhen Oberfläche, welche etwas oberhalb des Gelenlies sich befindet.

b) Das hintere oder Occipito-clavicularbündel hat die Form eines Dreiecks mit der Basis nach unten gerichtet. Sehr dünn entsteht dasselbe hinter dem vor- 
hergehenden am Os occipitale an der Linea obliqua superior; unten inserirt es sich am innern Drittel der obern Fläche der Clavicula, etwas nach aussen vom innern Ende. Diese beiden Bündel, oben vereinigt, sind unten durch ein dreieckiges, mit der Basis nach unten gerichtetes Interstitium getrennt.

2. Die tiefliegende Schichte wird von einem Bündel gebildet, welches vertical vom Proc. mastoideus zur Clavicula gespannt ist, das Mastoideo-clavicularbündel.

Es entsteht am. Proc mastoideus mit fibrösen Bündeln, die sich mit den Ursprungsbündeln des H. splenius kreuzen. Der dicke Fleischkörper verbreitet sich von oben nach

Fig. 153.

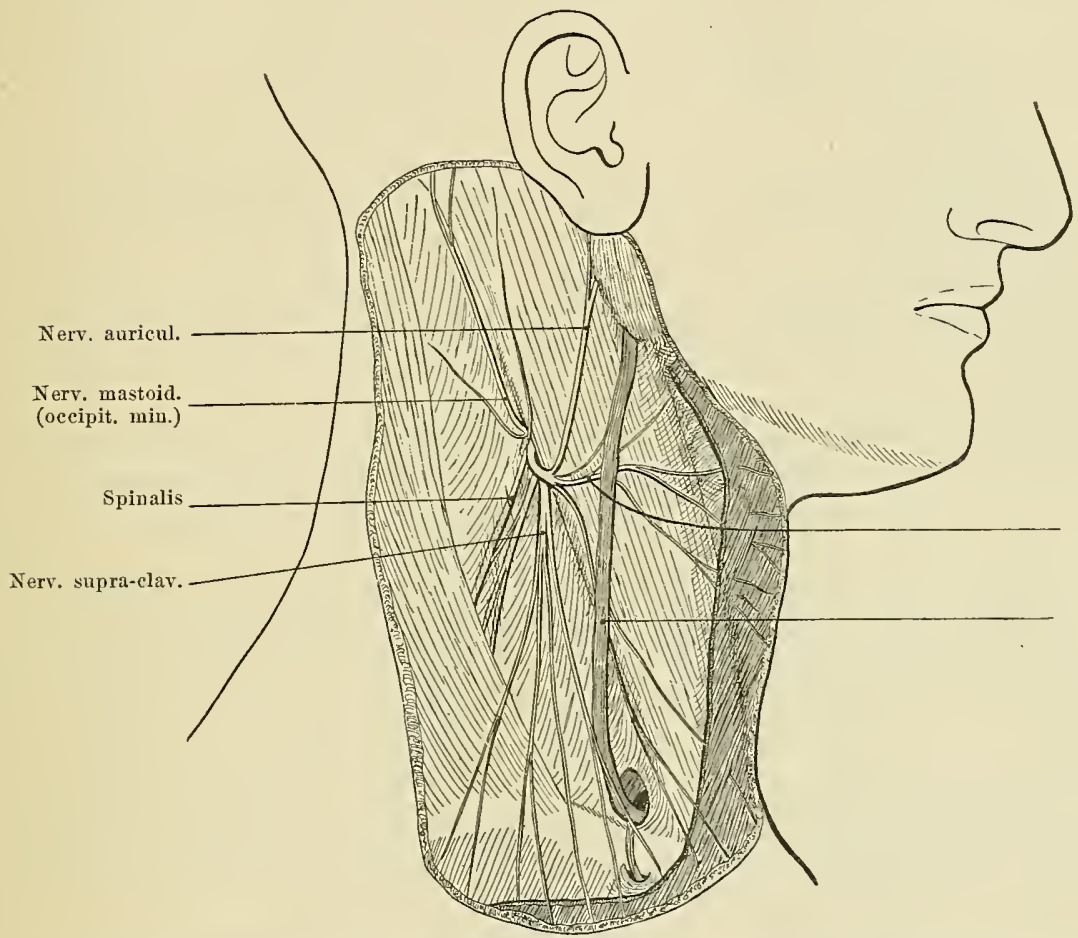

N. cervic. transt. (sube. coll. med.)

Vena jugul. ext.

Die rechte Fläche des Halses; das supraclaviculare Dreieck, die Haut und das Platysma myoides wurden präparirt; auf der Fascie sieht man die Aeste des Plexus cervicalis superficialis und die Vena jugularis externa.

unten und inserirt sich mit aponeurotischen Bündelchen an der Leiste, die am innern Drittel der obern Fläche der Clavicula sich befindet.

Dieses Bündel wird oft rom Nervus spinalis durchzogen; oft zieht der Nerv unter denselben, niemals aber zieht er zwischen den beiden Schichten des Muskels.

Technik z. A. d. G. Man bringt den Kopf in Rotationsstellung; der Sterno-mastoideus spannt sich an und sein vorderer Rand tritt in Form einer Erhabenheit hervor, die am Manubrium sterni endigt. Man macht eine lange Incision vom Proc. mastoideus bis zum innern Ende der Clavicula, man durchschneidet die Haut, die Fasern des Platysma myoides und trifft 
unter demsolben dic Tena jugularis cxterna, den Nervus auricularis und Nervus transversus des Halses, die man durchschneidet.

Ilan durehschneidet dic Faseie und gelangt an die rothen Fasern des Stemo-mastoideus: mit Pincette und Sonde löst man denselben von der Fascic ab, die ihn bedeckt. Etwas oberhalb der Clavicnla durchschneidet man transversal schichtenweise dic oberflächliche Schichte und findet unter derselben unter einem zellig-fibrösen Blättchen das tiefe Cleido-mastoideusbiindel.

Ilan lüst das oberflächliche Bünelel rom tiefen liündel ab und sieht, dass die beiden Selichten oben adhäriren und dass der vordere Rand des Sterno-clavicularbündels sich zur Furclie am vorderen Rande des Cleido-mastoidensbündels biegt. Man sueht die Nerven des Sterno-mastoideus auf, sir gehen vom ämssem Aste des Nerrus spinalis und vom Plexus cervicalis superficialis ab.

Dic beiden Stermo-mastoidei begrenzen miteinander ein mit der Spitze mach muten gerichtetes 1)reicek, in wolchen ohen die mittlere Partic des Halses ein Relicf bitlot.

Der l'lexus cervicalis superficialis wird durch die Anastomose der rordern Leste der vier ersten cervicalen spinaläste gebildet. Er liegt unter dem hintern Rande des Sterno-mastoideus an den Insertionen des M. splenius, des M. angularis und der Scaleni (Fig. 153).

Ans dem Plexus cerricalis superficialis entstehen kleine Muskeläste, die für die tiefen Mnskeln des IFalses bestimmt sind und fünf Hautäste, welche in einen Fächer divergiren, dic ron einem P'unkte, an der Mitte des hintern Randes des Sterno-mastoidens gelegen, ansgehen.

1. Der Nervus mastoideus erhebt sich am hintern Raude des Sterno-mastoideus in der Regio mastoidea, indem er sich in Aeste, die für die Kopfhaut bestimmt sind, theilt, und in andere Aeste, welche sich nach rorue richten, Bogen beschreiben und in der Haut, die die innere Fläche der Ohrmuschel bedeckt, endigen.

Technik $\boldsymbol{z}$. A. I. G. Man macht an der obern Hälfte des hintem Randes des Sterno-mastoideus eine Incision und findet minter der Haut längs dieses Randes in der Duplicatur der dicken und resistenten Fascie einen kleinen Tervenfaden, den Terrus mastoideus. Man fasst ihn mit einer Pincette und folgt ihm nach oben.

2. Der Nervus anricularis richtet sich nach oben und rorne gegen das Ohrläppchen. Hinter dem Kieferwinkel dringt er in die Parotis ein und theilt sich in ein Büschel ron Aesten für das Läppchen und die Ohrmuschel und für die Haut der liegio parotidea. Einige kleine Aeste rerlieren sich in der Parotis, andere anastomosiren mit dem Facialis.

Techuik z. A. d. (4. Man macht eine verticale Incision von der Mitte des hintem Randes des Stemo-mastoideus zum Ohrläppchen, durchschneidet dic Haut und dic Fasern des Platysma myoides und findet anf der Fascie de'n) Nervus auricularis.

3. Der Nerrns cervicalis transversus richtet sich nach rome, zieht unter die Vena jugnlaris externa und theilt sich in zwei Aeste: einen Ramus supra-hyoideus und einen Ramus sub-hyoideus. Jeder dieser Aeste theilt sich in zahlreiche Füden, die durch die Interstitien des Platysma myoides ziehen und sich in der Haut der vordern F]äche des Ilalses vertheilen. 
Technik z. A. d. G. Man macht eine transversale Incision von der Mitte des hintern Randes des Stermo-mastoideus zur Mitte des Schildknorpels.

Man durchschneidet die Haut und die Fasern des Platysma myoides, sucht auf der Fascie der Reihe nach unter jedem einzelnen Schnittrande und findet dem Schnitte parallel einen dünnen Nervenfaden, den Nervus cervicalis transversus. Man isolirt diesen und hebt ihn auf die Sonde.

4. Der Nervus supra-acromialis richtet sich nach unten und hinten, in der Duplicatur der Fascia superficialis enthalten, durchzieht schief das supra-claviculare Dreieck und theilt sich in zahlreiche Aeste, welche sich in der Haut der Schulter vertheilen. Einige Nervenäste durchdringen den M. trapezius.

5. Der Nervus supra-clavicularis richtet sich nach unten, löst sich in ein Büschel von Aesten auf, die sich in einen spitzen Winkel theilen und die Clavicula, unter der sie in der Haut endigen, kreuzen.

Techunik z. A. d. G. Am mittlern Drittel des hintern Randes des Sterno-mastoideus macht man eine verticale Incision, durchschneidet die Haut und die Fasern des Platysma myoides, legt stumple Haken ein und sucht mit der Sonde hinter dem Sterno-mastoideus; unter der Fascie findet man zwei Nervenäste. IIan fasst und zieht mit der Pincette an dem vordern, er erhebt sich und bezeichnet unter der Haut seine Verzweigungen, die vor der Clavicula ziehen, es ist der Nervus supraclavicularis; man zieht am hintern Aste, er spannt die Haut der Schultern an, es ist der Nervus supra-acromialis.

Die Veua jugularis externa entsteht in der Parotisgrube hinter dem Kieferfortsatze aus der Vena temporalis und aus der oberen äusseren Carotisconfluenz gebildet. Sie durchzieht die ganze Länge der Parotis und erhält hinten die Vena supramastoidea, vorne unter dem Kieferwinkel den venösen Kanal, der sie mit der Vena facialis verbindet, verläuft dann vertical an der äussern Fläche des Sterno-mastoideus auf der Fascie und rom Platysma myoides bedeckt.

Etwas oberhalb der Clavicula umschlingt sie den hintern Rand des Sterno-mastoidéus, die Fascie durch ein kreisförmiges Orificium durchziehend, richtet sich nach vorne unter dem Sterno-mastoideus, zieht unter den Omo-hyoideus und mündet in die retroclaviculare Confluenz ein, nachdem sie sich vorher mit mehreren Halsvenen und mit der Vena retro-claricularis vereinigt hat.

Technik z. A. d. G. An zarten Individuen sieht man die Vena jugularis externa zuweilen sehr dick oder doppelt. Man macht vom Kieferwinkel gegen die Mitte der Clavicula eine Incision, schneidet die Haut und das Platysma myoides durch und findet unter demselben auf der Fascie fast immer im Grunde des Schnittes die Vena jugularis externa. Man folgt derselben nach oben in die Parotis, nach unten unter den Sterno-mastoidens, in welchen man ein stumpfen Haken einlegt, bis zu ihrer Einmündung in die venöse Confluenz; man sieht, dass sie oben von einem Aste des Nervus auricularis, unten von einem Aste des Nervus transversus cervicalis begleitet ist.

Die Vena jugnlaris anterior lateralis entsteht in der Regio submaxillaris, steigt am vordern Rande des Sterno-mastoideus herab, durchzieht die Fascie in die Tiefe dringend und geht in die venöse retro-claviculare Conflnenz neben der Vena jugularis externa über. 
Eine bogenförmige Anastomose verbindet sie mit der Vena jugularis externa, andere ticfo Anastomosen verbinden sie mit den Venae thyreoideae superiores.

Terhnik z. A. d. (G. Man macht am vordern Rande des Sternomastoidens eine Incision und findet in einer Duplicatur der Fascie die Vena jugrularis antero-lateralis. Man arbeite sorgfältig, weil die Vene an der Oberfläche liegt.

Das Gefäss- und Nervenpacket des Halses ist in einem prismatischen, dreieckigen Kanale enthalten, der begrenzt wird: hinten von den Processus transversi der

Fig. 154 .

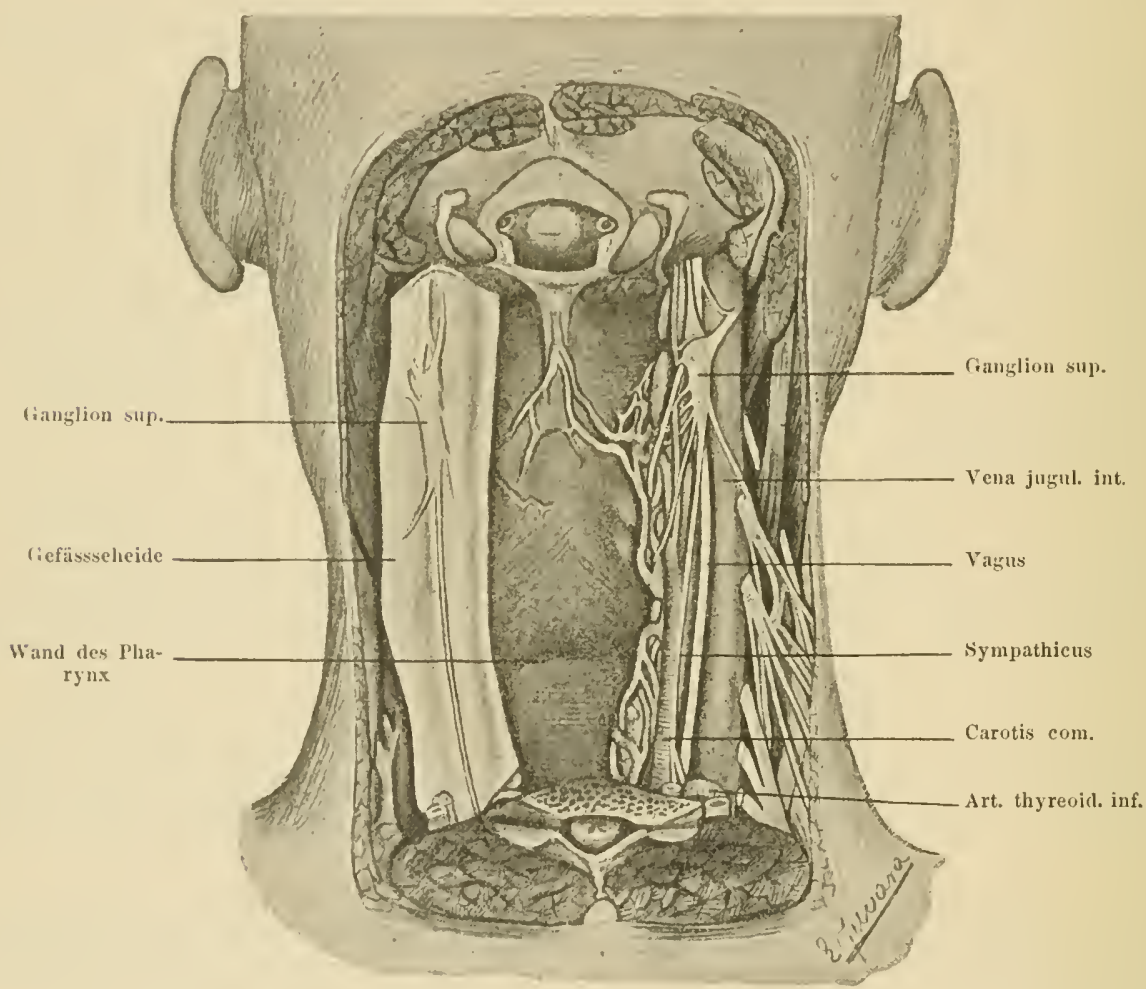

Die Regio carotidea, von der hinteren Seite gesehen, nachdem die Wirbelsäule vom Hinterhaupte bis zum siebenten Halswirbel resecirt wurde. Auf der linken Seite wurde das

hintere Blättchen der Gefässscheide längs des Sympathicus, den es enthält, eröffnet.

Ilalswirbel, die von dem Musculus rectus anterior und ll. longus colli bekleidet sind; jnnen von oben mach unten ron der lateralen Wand des Pharynx, ron der Schilddrïse und von der Trachea; vorne und aussen vom Sterno-mastoideus und den Musculi subhyoidei.

Im Innenraume dieses Kanales ist das Gefäss- und Nervenpacket von einer zelligfibrösen Seheide umkleidet, welehe innen in die Fascienbelkleidung des Pharynx, vorne und aussen in die Aponeurosis muscularis ïbergeht. 
Die Arteria carotis communis dextra entsteht hinter dem Sterno-clavienlarGelenke an der vordern und äussern rechten Fläche der Trachea aus dem Trurcus brachio-cephalicus. Sie richtet sich nach oben und etwas aussen gegen den Höcker des 6. Halswirbels, wird dann vertical und theilt sich zwischen Schildknorpel und Zungenbein in zwei Aeste: der vordere und innere Ast, die Carotis externa, richtet sich nach oben und vorne gegen den Kieferwinkel, der hintere und äussere Ast, die Oarotis in terna, erhebt sich nach oben, den Weg der Carotis communis fortseizend und dringt in die Schädelhöhle durch den Canalis caroticus, der im Felsenbeine des Os temporale gehöhlt ist.

Die Arteria carotis communis sinistra entsteht im Thorax vom mittleren Theile der horizontalen Partie des Aortenbogens zwischen der Wurzel des Truncus brachio-cephalicus, der mehr vorne entsteht und der Subclavia, die mehr hinten und etwas nach aussen entsteht.

Fig. 155.

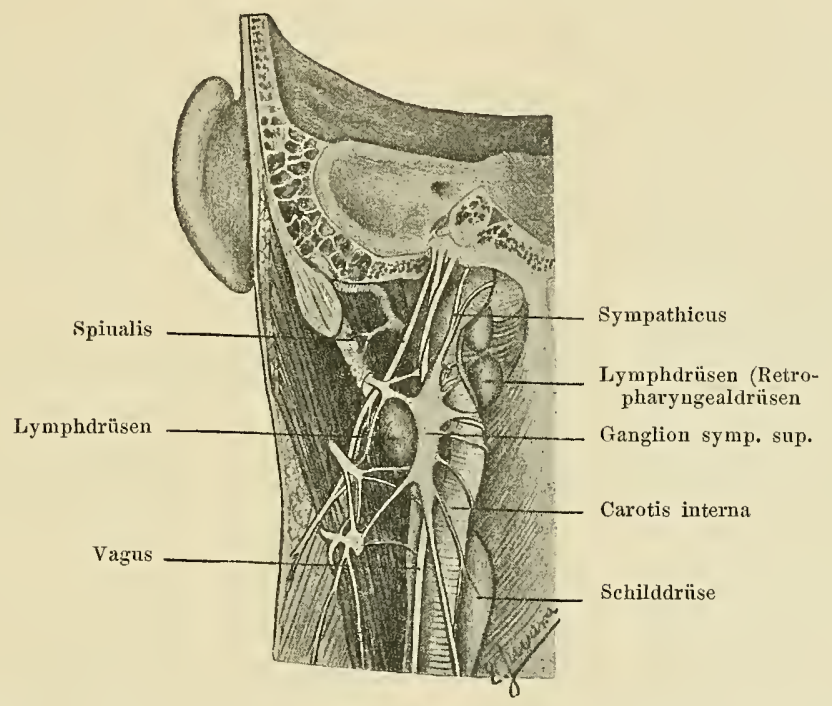

Die Regio carotidea sinistra superior, von der hinteren Seite gesehen. Man sieht die Beziehungen des Ganglion sympathici cervicale superius und die Aeste, die es von den drei ersten Wurzeln des Plexus cervicalis erhält.

In ihrer ersten Partie, Pars thoracica, erhebt sich die Arteria carotis communis sinistra an der lateralen linken Fläche der Trachea, indem hinten die Arteria subclavia sinistra liegt und wird an ihrer äussern und vordern Fläche von einem parietalen Blättchen der Pleura bedeckt.

Oberhalb der Clavicula vèrhält sich die Arteria carotis communis sinistra in derselben Weise wie die rechte.

Die Vena jug ularis interna entsteht unter der Schädelbasis aus dem Sinus jugnlaris, steigt am äussern Theile der Carotis interna und der Carotis communis herab, indem sie im Niveau des grossen Zungenbeinhorns den Truncus thyro-linguo-facialis aufnimmt; zieht vor der innern Partie der Arteria subclavia und vereinigt sich hinter dem innern Ende der Clavicula mit der Vena subclavia, die retr o-clavicular e Confluenz bildend. 
Unter der Schädelbasis liegt die Vena jugularis interna, aussen und hinten von der Arteria carotis interna; oberhalb der Claricula entfernt sie sich etwas ron der Carotis comuunis, von welcher sie durch ein dreieckiges Interstitium, nit der Basis nach unten grerichtet, geschieden ist, in welchem der Vagus erscheint. Unmiltelbar unter der Schädelbasis nimmt die Tena jugularis an ilırer inneren Fläche den Sinus petrosus inferior auf, welcher aus der Schädelhöhle durch den innersten Theil des Faramen jugulare austritt.

Der Nervus vagus (Pneumo-gastricus) tritt aus der Schädelhöhle, aussen vom Nervus spinalis (Accessorius), innen vom Glosso pharyngeus begleitet durch den mittlern Theil des Foramen jugulare, anastomosirt mit dem innem Aste des N. spinalis, steigt in die Furche herab, die aussen von der Jugularis, innen von der Carotis communis interna begrenzt ist, erscheint in dem Interstitium, das die Vena jugularis von der Carotis communis scheidet, zieht ror der Subclaria und dringt in den Thorax ein.

Etwas unterhalb der Schädelbasis giebt er den Nervus laryngeus superior ab, der die innere Fläche der Carotis interna umschlingt und unter dem Zungenbeine in den Larynx eindringt.

Der Nervus glosso-pharyngens theilt sich in zwei Aeste: einem innern und einem äussern Ast.

Der innere Ast, für den Pharynx bestimmt, zieht hinten und innen von der Carotis interna; der äussere Ast, für die Zunge bestimmt, umschlingt die Carotis externa, steigt an der äussern Fläche des M. styla-pharyngeus und unter dem Styloglassus herab, dringt in die Zunge ein und vertheilt sich in der Schleimhaut seiner dorsalen Fläche. Diese beiden Aeste anastomosiren miteinander, rings um die Carotis interna einen Ring bildend.

Der Tervus spiualis (Accessorius) theilt sich in einen innern Ast, der sich am Vagus heftet und in einen äussern Ast, der sich nach unten und aussen richtet und im Sterno-cleidomastoideus und im Trapezius endigt.

Der Nervus lypoglossus tritt aus der Schädelhöhle durch das Foramen supra conlyloideum, richtet sich nach unten, zieht hinter den Glosso-pharyngeus und Vagus und umgreift hakenförmig mit der Concavität nach innen die Arteria carotis communis und Carotis externa.

Die Ansa lyypoglossi, von der plexusartigen Anastomose des absteigenden $\Lambda$ stes des Hypoglossus nit einem Aste des Plexus cervicalis gebildet, liegt gegen die Mitte der vordern Fläche der Vena jugularis; von ihr gehen Aeste für die Musculi subhyoidei ab.

Terhnik z. A. d. G. Man legt einen Holzkeil quer unter die Schultern eines Cadavers; der Hals spannt sich und man erkennt die Erhabenheit des vordern Randes des gespannten Sterno-cleido-mastoideus.

An der untern Hälfte dieses Randes macht man eine Incision, die im Niveau des Schildknorpels beginnt und etwas unterhalb des Sterno-claviculargelenkes endigt.

Man durchschneidet die Fasern des Platysma myoides, präparirt die Fascic län@्s des Randes des Sterno-mastoidens, löst mit der Sonde diesen Nuskel ab und legt jhn in einen stumpfen Haken. Im Winkel, den der Omo-hyoideus mit dem Sterno-hyoideus bildet, zerreisst man mit der Hohlsonde die mittlere Fascie und gelangt unmittelbar darnnter an das Crefässund Nervenpacket (Fig. 156).

Ilan löst aussen sorgfältig die sehr dicke und dïmnwandige Vena jugularis interna und die Adhärenzen an der Gefässscheide ab und findet 
unmittelbar an der Innenseite der Tene die Arteria carotis communis. Der Vagus liegt auf einer hintern Ebene im Interstitium, welches die Vene von der Arterie trennt.

An der vorder Fläche der Jugularis sieht man einen Nervenbógen, die Ansa hypoglossi; von ihrer Convexität, aus einem Plexus, gehen 3 oder 4 Fäden ab, die für die Musculi hyoidei bestimmt sind.

Man macht an der obern Hälfte des vordern Randes des Sternomastoideus einen Hautschnitt bis gegen den Kieferwinkel, schneidet die Fasern des Platysma myoides durch, entfernt die Jugularis externa und schmeidet die Fascie ein. Man löst den Sterno-mastoideus ab und legt ihn in einen stumpfen Haken, der ihn nach aussen zieht. Einen zweiten stumpten Haken legt man in den vordern Rand und sieht im Grunde des

Fig. 156.

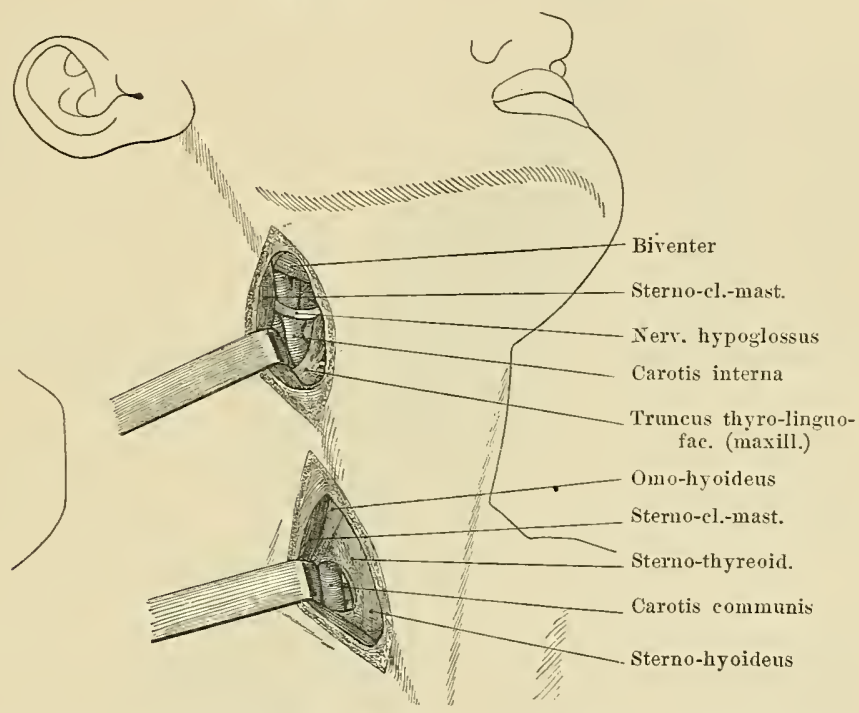

Die laterale rechte Fläche des Halses; das Auffinden der Carotisgefässe. Ein stumpfer Haken zieht den Sterno-cleido-mastoideus nach hinten und legt das Gefäss- und Nervenpacket frei.

Schnittes das Gefäss- und Nervenpacket. Mit der Pincette und Hohlsonde legt man die Gebilde frei, welche das Packet zusammensetzen: die Arteria carotis externa ist mehr nach vorn gelegen und giebt Aeste ab; die Arteria carotis interna, mehr nach hinten gelagert, folgt der Richtung der Carotis communis.

Diese beiden Arterien sind vom Nervus hypoglossus umarmt; der absteigende Ast des Hypoglossus liegt zuerst an der Carotis interna, dann an der Carotis communis.

Die Vena jugularis interna nimmt den äussern Theil des Gefäss- und Nervenpacketes ein, sie nimmt etwas unterhalb der Bifurcationsstelle der Carotis den Truncus thyro-linguo-facialis oder die untere äussere Carotisconfluenz auf. Man sucht tiefer in der Furche, welche die Vene von der 
Arterie scheidet, und findet den Vagus an die Arterie geheftet. In dieser an Gefïssen sehr reichen liegion muss man sorgfältig und aufmerksam arbeiten, indem man sich der Hohlsonde und Pincette bedient; man hüte

Fig. 157.

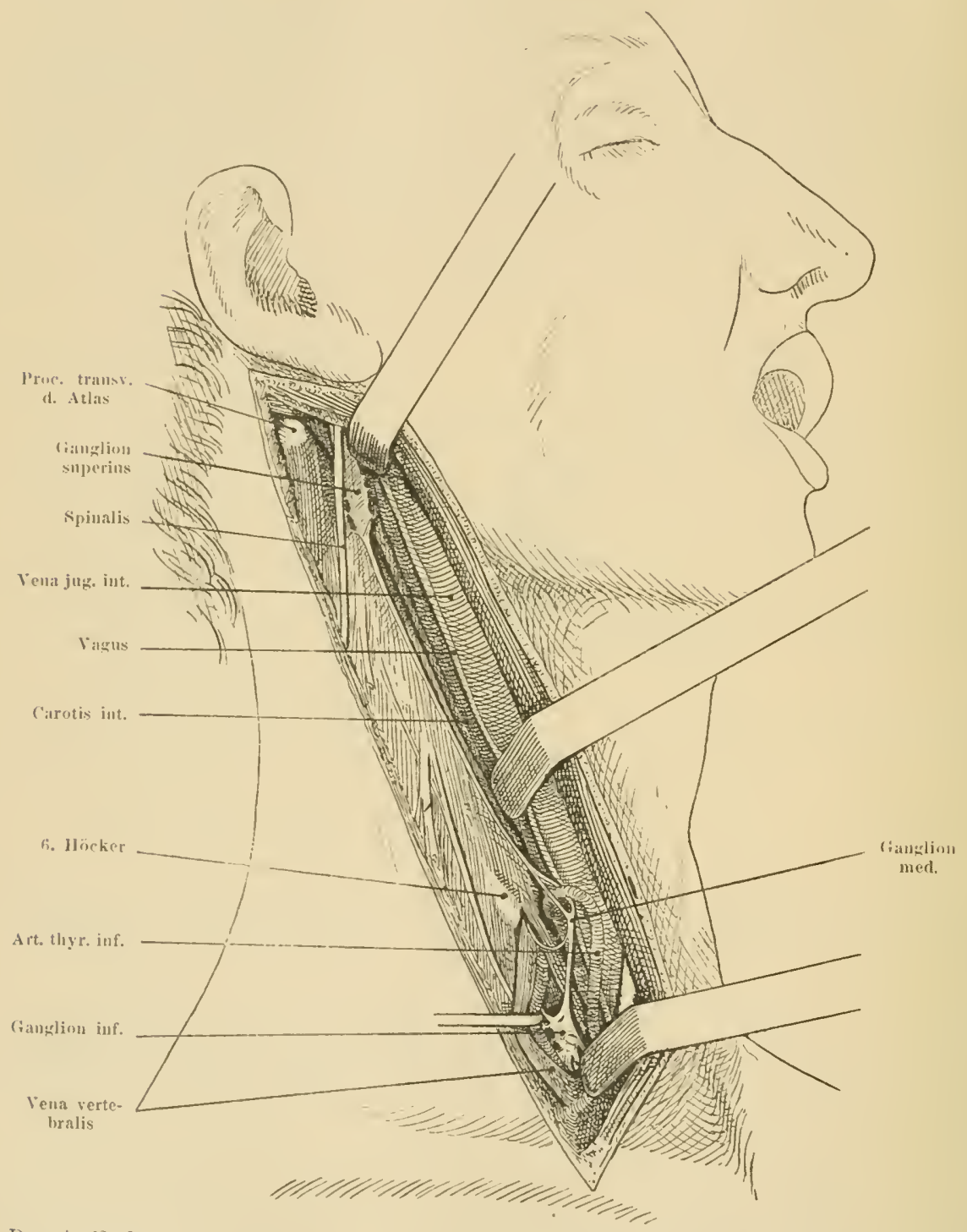

Das Auffuden des Sympathicus und der drei Halsganglien an der rechten Seite; drei stumpfe Haken ziehen das Gefässpacket nach vorne und schützen es.

sich, irgend eine I' ene durch eine brüske Bewegung zu zerreissen, weil das Blut sofort das Operationsfeld überschwemmt und die Ciebilde verbirgt. 
Der Nervus sympathicus cervicalis liegt an der vordern Fläche des Husculus rectus major anterior und $\mathrm{M}$. longus colli in einem lamellenförmigen Bindegewebsblättchen, welches die Fascie der Musculi praevertebrales bedeckt; er folgt von oben nach unten der Carotis interı hủnd Carotis communis (Fig. 154, 155).

In seinem Verlaufe stellt der Sympathicus cervicalis drei Ganglien oder Centren dar.

Das obere Ganglion (Fig. 155) hat die Form einer von vorne nach hinten verbreiterten, $4-5 \mathrm{~cm}$ oder mehr noch langen Spindel. Es beginnt etwas unterhalb der Schädelbasis und endigt im Niveau des Proc. transversus des 3. Halswirbels. Aussen bekommmt es die Wurzeln der ersten 4 Cervicalnerven, innen giebt es eine grosse Zahl von feinen Aesten, welche netzförmig anastomosiren, für den Pharynx und für die Carotis interna ab.

Das mittlere Ganglion, von der Grösse eines Weizenkorns, liegt am innern Rande des Scalenus anticus in der Concavität der äussern Curve der Thyreoideae inferiores einen Finger breit unter dem Höcker des Proc. transversus des 6. Halswirbels.

Das untere Ganglion liegt im Grunde des scaleno-vertebralen Dreiecks in der Grube, welche der Kopf mit dem Halse der ersten Rippe bildet (Fig. 163, 164). Dieses Ganglion, von der Grösse einer Fisole, schickt nach oben in den Canalis vertebralis den Nervus recurrens vertebralis, nach unten und innen zahlreiche Aeste für den Plexus cardio-pulmonalis. Oben und aussen erhält es Wurzeln, die rom 8. Cervical- und 1. Dorsalnerven kommen, unten geht es in das 1. Ganglion dorsale über, mit dem es zuweilen eine gemeinsame Masse bildet, das Ganglion Neubaueri.

Technik z. A. d. G. Nan macht an der lateralen Fläche des in Extensionsstellung befindlichen Halses eine lange Incision, die einen Finger hinter der Spitze des Proc. mastoideus beginnt und an der Clavicula an der Vereinigung seines innern Drittels mit dem mittlern endigt.

Man schneidet oben den Sterno-mastoideus durch, unten folgt man seinem hintern Rande. Die rordern Aeste des Plexus cervicalis superior soll man durchschneiden, kann aber den Nervus spinalis schonen. Uit der Sonde und Fingerspitze löst man vorsichtig von oben nach unten den Sterno-mastoideus und die Gefässscheide mit ihrem Inhalte ab, man legt drei stumpfe Haken ein, welche das Gefässpacket und den Sterno-mastoideus nach vorn ziehen. Auf diese Weise schafft man einen Gang, der vorn von der hintern Fläche des Gefässpacketes und hinten ron der vordern Fläche der Wirbelsäule begrenzt ist, die von den Insertionen der II. praevertebrales bedeckt ist. Etwas innen ron den Höckern der Processus transversi am rothen Felde vom Körper des M. longus colli gebildet, findet man einen dünnen Nervenstrang, den Sympathicus. Yan folgt dem Strange nach oben, er führt an das Ganglion superius; man isolirt dieses Ganglion so hoch als möglich, indem man es von der Carotis und rom Vagus ablöst; man gehe vorsichtig vor, indem man die Vena jugularis mit dem stumpfen Haken niederdrückt. Man folgt dem Strange nach unten, er führt an den Bogen der Art. thyreoida, unter welcher man das Ganglion medium finden kann. Nit einem stumpfen Haken zieht man die Arterie, die Vena vertebralis und den vorderen Rand des Scalenus anticus nach aussen; in der Tiefe am Halse der ersten Rippe findet man das Ganglion inferius (Fig. 157).

Nervi recurrentes. Man macht dieselbe Incision wie für die Arteria carotis communis; man findet die Arterie, in welche man einen stumpfen Haken legt, um sie nach aussen zu ziehen, und löst sie ab. 
Rechts unter derselben in einer Bindegewebsschichte findet man einen Nervenfaden schief nach oben und innen gerichtet, den Nervus recurrens. Mim sieht, dass er vor der Art. thyreoidea zieht und dass er mehr nach oben an dem äussem Rande des Oesophagus liegt.

Jinks sueht man den Nervis recurrens an der Innenseite der Art. carotis in der Furche, die ron der lateralen linken Flïehe der Trachea mit dem Rande des Oesophagus begrenzt wird; man sieht ihn als einen wrissen Strang am rothen Grunde gelagert, der rom Oesophagus gebildet wird. Ilan folgt ilmm nach oben lind sicht ihn unter die Schilddrïse zichen, zwischen den Rami thyreoidei inferiores. Rings um den Nerv befindet sich eine Kette ron kleinen Lymphdrüsen.

\section{Regio supra-clavicularis.}

An untern Theile der lateralen Flïche des Halses existirt eine Grube, die unten von der horizontalen Erhabenheit der Claricula begrenzt ist, die Fossa supraclaricularis. An mageren Individuen ist diese Grube sehr tief, an fetten und besonders bei Frauen ist diese Region mit Fett ansgefiillt.

Wenn man die Regio supraclavicularis abtastet, so sieht man, dass die Tiefe ron oben nach unten zunimmt und wenn die halienförmig gekrümmiten Fingerspitzen oberhalb der Clavicula vordringen, so erreichen sie hinter derselben die Ebene der ersten Rippe. Unter der Ilaut fühlt min oft kleine runde Kürper unter den lingern gleiten, die Lymphdrüsen.

Die liegio-supra-elaricularis hat die Form eines Dreiceks mit der Basis nach unten gerichtet, rorne rom hintern Rande des Sterno-mastoideus, linten rom vordern Rande des Trapezius und unten ron der obern Fläche der Claricula begrenzt.

Die Fascia superficialis iles ILalses, rom Sterno-mastoidens zum Trapezins gespannt, inserirt sich unten an der obern Fläche der Claricula; sie wird oberhalb der Clavicula ron einem Orificium perforirt, durch welches die Vena jugularis externa dringt und von andern kleinen Orificien, aus welchen der Nerrus supraclavicularis und Nervus supraacronialis anstreten (Fig. 158).

Der Grund dieses Dreiccls wird ron oben nach unten rom Splenius, vom Angularis und von den Scaleni gebildet, die von den Proc. transrersi der Halswirbel zur ersten and zweiten Rippe gespannt sind.

Der Sralenus anticus, prismatisch und dreieckig, entsteht an den vordern und untern Hückern der P'roc. transtersi des 3., 4., 5. und 6. Halswirbels.

Dicse Insertionen geschehen mit sehnigen Bündeln an dem 3., 4., 5., mit dicken Fleischfasern an dem fi. Höcker. Der Fleischkörper endigt mit eincr verbreiterten Endsehne, die sich am Tuberculum Lisfranci inserirt am Hlïgel, der sich am Rande und obern Fläche der ersten Rippe befindet (Fig. 159).

Der Scalemus medius, breit und dreieckig, entsteht mit sehnigen Fasern und Fleischbündeln an den l'roe. transrersi der letzten 6 Halswirbel, an den hintern untern Iröckern und an den Rändern der knöchernen Furchen, welche aussen die Löcher für die Vertebralarterien begrenzen. Unten inserirt sich der Flcischkörper nit sehnigen Bündeln und mit Muskielfasern ail der obern Fläche der ersten Rippe, an der rauhen Oberfläche, 
welche das hintere Drittel dieser Fläche einnimmt vom Tuberculum costale zur Furche der Art. subclavia (Fig. 159).

Die innersten sehr kurzen Fasern des Scalenus medius sind von der untern Fläche des 7. Proc. transversus bis zur obern Fläche des Rippenhalses gespannt.

Der Scalenus posticus in Form eines gedrehten Blattes, entsteht mit sehnigen Bündeln am hintern Höcker des 4., 5. und 6. Proc. transversus cervicalis, steigt an der hintern Fläche des Scalenus medius herab, gleitet an der 1. Rippe und inserirt sich am obern Rande und an der äussern Fläche der mittlern Partie der II. Rippe. Diese beiden letzteren Scaleni sind gewöhnlich gemeinschaftlich unter dem Namen Scalenus posticus beschrieben.

Das interscalene Dreieck. Der Scalenus anticus und medius sind durch einen dreieckigen Raum, das interscalene Dreieck, geschieden, der vorne von der hintern Fläche

Fig. 158 .

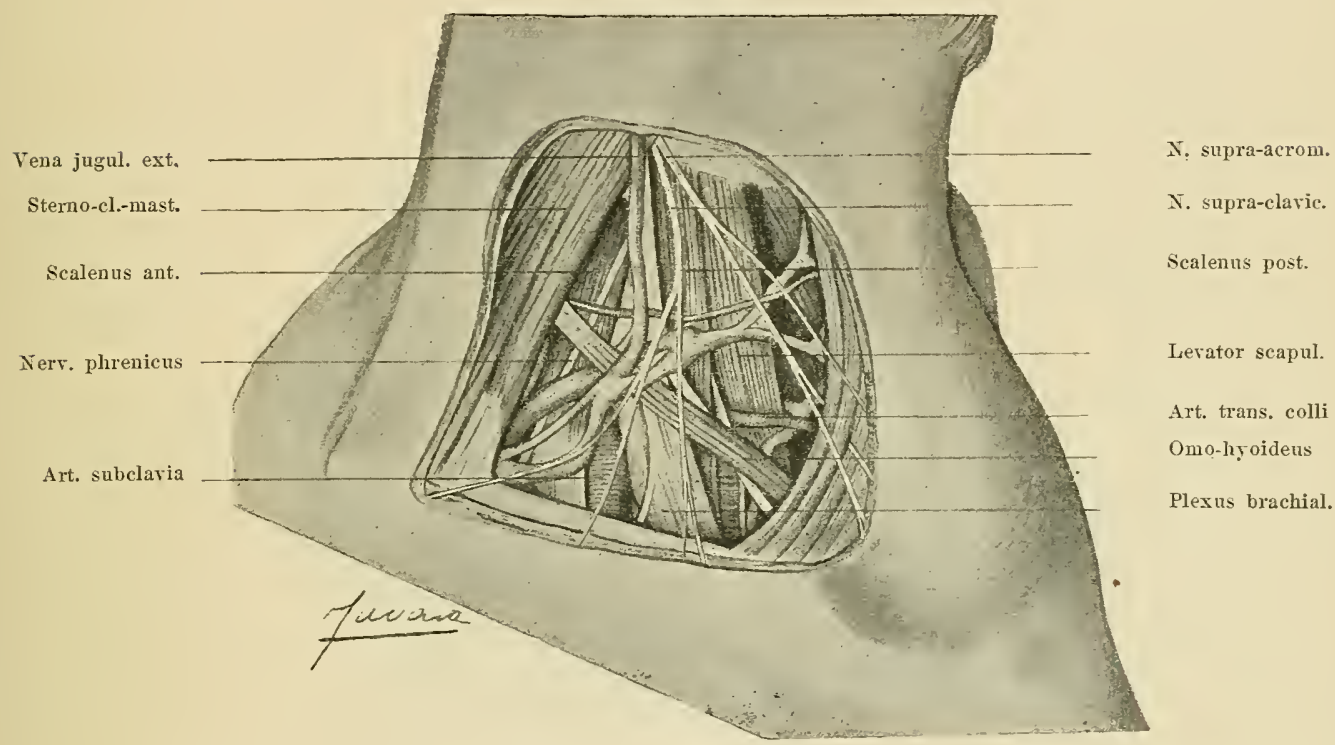

Regio supraclavicularis sinjstra.

des Scalenus anticus, hinten von der vordern Fläche des Scalenus medius und nnten ron der obern leicht in eine Rinne gehöhlten Fläche der 1. Rippe, die Rinne der Art. subclavia, begrenzt ist.

In diesem prismatischen, dreieckig’en, nach aussen geöffneten Raume, findet man die Wurzeln des Plexns brachialis und die Arteria subclaria.

Der Plexus brachialis wird durch Anastomose der vier letzten Cervicalwurzeln und der ersten dorsalen gebildet. Die Wurzeln des Plexus brachialis, schief nach unten und aussen gerichtet, bilden zusammen ein mit der Spitze nach unten gerichtetes Dreieck, das ron einem zellig-fibrösen Blatte bedeckt ist und am Scalenus medius gelagert ist.

Die V. Cerricalwurzel erhält einen Ast der IV. nnd anastomosirt mit der TI., mit der sie einen gemeinsamen Stamm bildet, den Truncus $5+6+4$. Dieser Stamm theilt sich in 2 Aeste, einen vordern und einen hintern. 
Die VII. Wurzel theilt sich in zwei Aeste. Der rordere Ast anastomosirt mit dem vordern Aste des Truncus $5+6$, mit dem er den Truncus $5+6+7$ oder Truneus medio-cutaneus bildet, weil er sich in den Musculo-cutaneus und in die äussere Wurzel des Medianus theilt. Der hintere Ast vereinigt sich mit dem hintern Aste des Truncus $5+6$, mit dem er einen geneinsamen Stamm bildet aus dem Truncus $5+6+7$ zusammengesetzt oder Truncus radio-circumflexus, der sich in den sehr dicken Radialis und Circumhlexus theilt.

Die VIII. Cervicalwurzel anastomosirt mit der 1. Dorsalwurzel. mit der sie einen

Fig. 159.

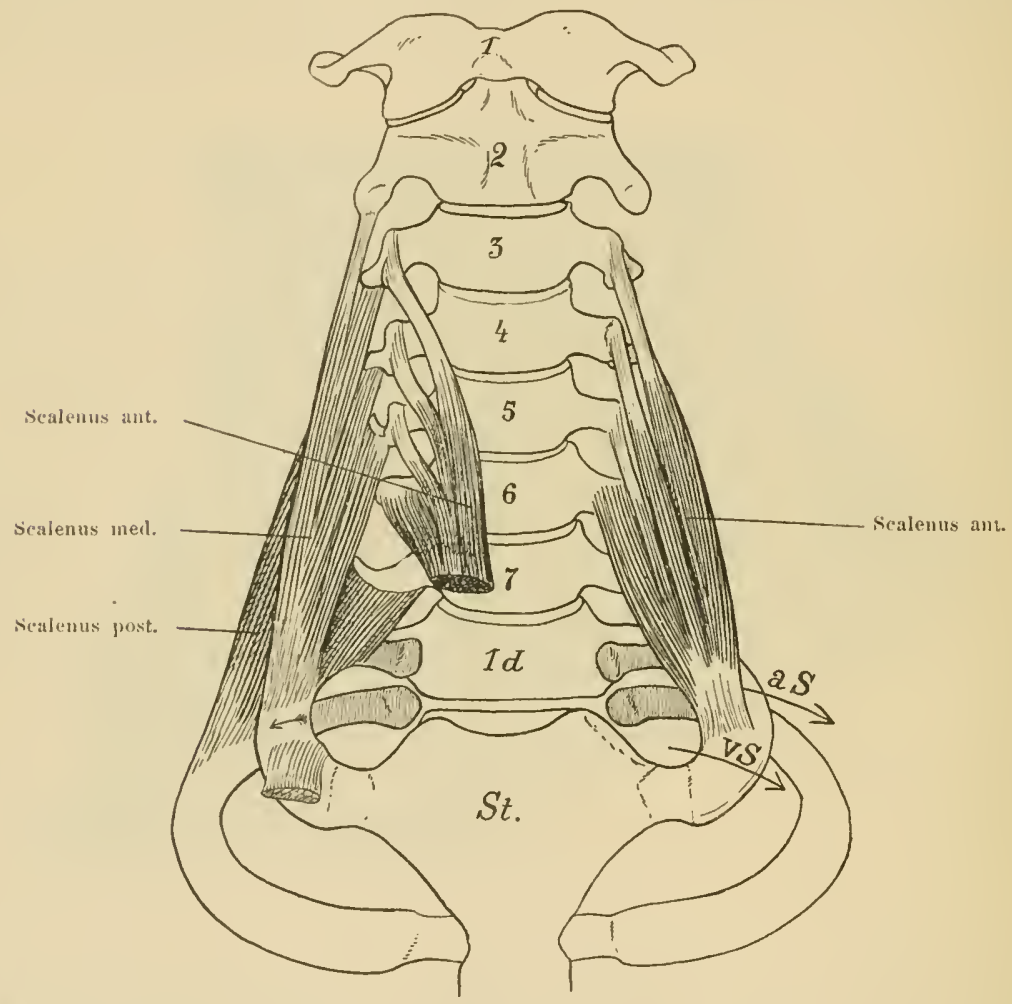

Die Museuli sealeni; reehts ist der Scalenus anticus durehschnitten und nach vorne gezogen, um den Scalenus posticus besser zeigen za können. Die beiden Pfeile zeigen die Richtnog der Art. und Vena subclavia.

gemeinsamen Stamm, 'Truncus $8+1$, bildet, der sich in zwei Aeste theilt. Der vordere dickere Ast oder Truncus medio-cubitalis theilt sich in den Brachii cutaneus internus, Cubitalis und in die innere Wurzel des Medianus. Der hintere dünne Ast vereinigt sich mit dem Truncus circumflexo-radjalis.

Der Nervus Charles Belli (Nervus thoracieus longus) oder der Nerv des Serratus magnus entsteht mit 3 Wurzeln an der hintern Fläehe des Plexus brachialis aus der 5., 6. und 7. Wurzel, llurehzieht den Scalenus postieus und steigt unter der 1. Rippe 
auf die äussere Wand der Achselhöhle herab, indem er sich im Serratus magnus vertheilt.

Der Nervus phrenicus entsteht mit drei Wurzeln ans dem 3., 4. und 5. Cervicalnerven. Zuerst am äussern Rande des Longus colli gelagert, steigt er dann vertical auf die vordere Fläche und anf den innern Rand des Scalenus anticus herab, zieht dann an der Concavität der Art. mammaria interna hinter der venösen retro-clavicularen Confluenz, umschlingt den Ursprung des venösen Trunens brachio-cephalicus und erhebt sich nnter der Pleura mediastina gegen das Diaphragma, in welchem er endigt.

Rechts folgt der Phrenicus der Vena cava superior, zieht vor dem Lungenstielo und steigt an der rechten Fläche des rechten Aurikels und der Vena cava inferior herab. Im Winkel, den das Diaphragma mit dem Herzen bildet, erhebt er eine kleine Plica pleuralis von dreieckiger Form, die Plica Phrenici, welche hinten eine kleine Fossula begrenzt.

Fig. 160.

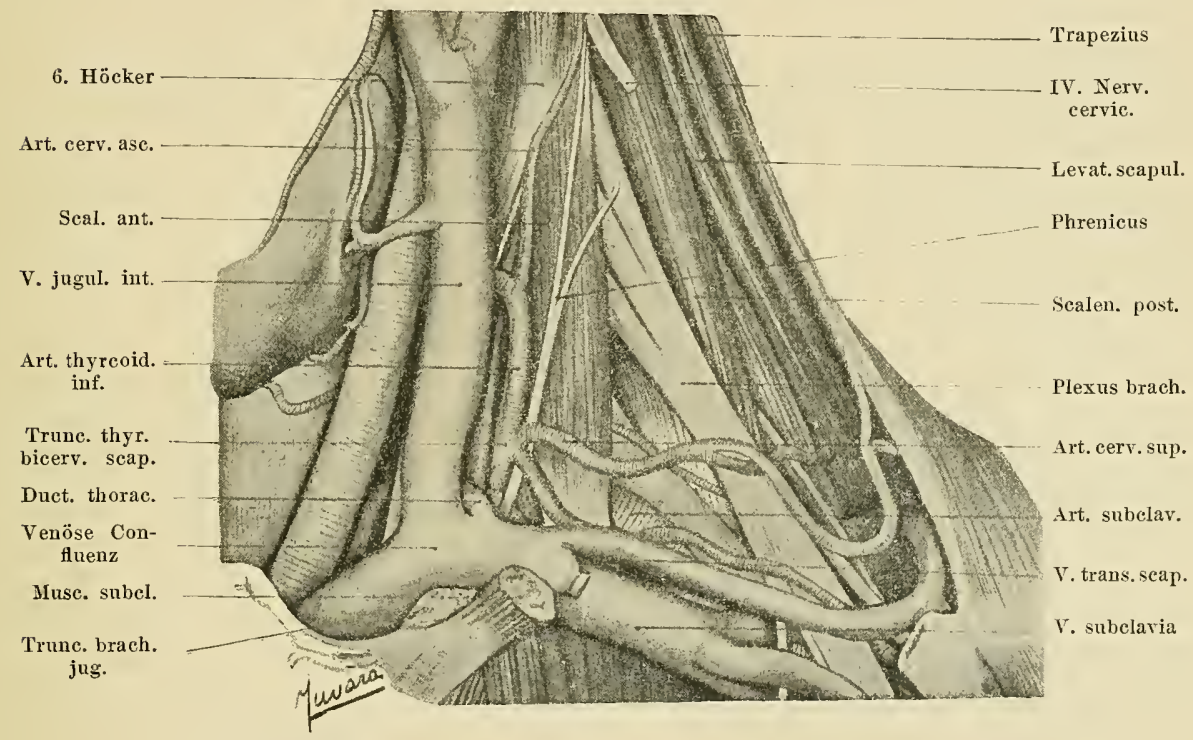

Regio subclavicularis sinistra; tiefe Schichte.

Links kreuzt sich der Phrenicus mit dem Vagus in X, zieht am Aortenbogen etwas vor dem Lungenstiel, umschlingt die hintere Fläche des linken Ventrikels und dringt in das Diaphragma etwas hinter der Herzspitze. In diesem Niveau erhebt er, wie der rechte, eine dreieckige Pleuralfalte, die linke Plica phrenici, welche hinter und unter ihr eine kleine Grube begrenzt.

Der Phrenicus anastomosirt mit dem N. subclavius durch einen dïnnen Faden, welcher bogenförmig die venöse retro-claviculare Confluenz umschlingt.

Der Nervas pectoralis major entsteht mit 2 Wurzeln, eine vom vordern Aste des Truncus $5+6$ und eine vom vordern Aste des 7 . Stammes und steigt vertical hinter der Clavicula ab, wo wir seine Beziehungen zur Art. subclavia bereits kennen. Er ist ein Anhaltspunkt für das Auffinden der Arterie.

Der Nervus suprascapularis entsteht ans dem Truncus $5+6$, richtet sich schief 
nach unten, aussen und hinten gegen die Fossa supra-spinata, in welche er dureh das Orificium sub-coracoideum cindringt.

Die Arteria subclavia dextra entsteht aus der Bifurcation des Truncus brachiocephalicus ein Finger hinter dem Sterno-claviculargelenke, richtet sich nach oben und aussen, cinen Bogen mit der Concavität nach unten beschreibend, zieht oberhalb der I. Rippe in die Basis des intersealenen Dreiecks und endigt im Nireau des untern Randes dieser Rippe in die Art. axillaris iibergehend.

In diesem Verlauf stellt sie drei Partien dar.

a) Die Pars interna oder interscalenica liegt an der Innenseite des Scalenus anticus im scaleno-rertebralen Dreieck, einer kleinen anatomischen Region, die wir später beschreiben werden. In diesem Theile steht die Arterie in Beziehung: rorne mit der venösen retro-claricularen Confluenz, mit der Wurzel der Jugularis interna und mit dem Vagus, der auf dicselbe abbiegt; innen mit dem Ursprunge der Carotis communis unil an einer mehr innen gelegenen Ebene mit derTrachea; unten und hinten mit ler Plenrakuppel (Fig. 161).

b) Die Pars media oder scalenica entspricht rorne dem Scalenus anticus, hinten dem Scalenus posticus und dem Nerrenstamme, der aus der Anastomose des S. Cerrical-mit dem I. Dorsalnerven gebildet wird.

c) Die Pars externa oder extra-scalenica ruht hinten am Scalenus posticus und an den Strängen des Plexus brachialis, unten an der obern Fläche der ersten Rippe, die sie zur Rinne anshöhlt. Vorne entspricht sie der Vena subclavia, ron welcher sic durch einen kleinen dreieckigen mit der Basis nach innen gerichteten, mit Fett gefüllten Raum getheilt wird.

Die Leste der Art. subclavia entstehen fast Alle ans der Pars interna.

1. Der Truncus costo-cervicalis richtet sich nach oben und innen und theilt sich am Halse der 1. Rippe in 2 deste: in die Art. intercostal is für den 1. Intercostalraum bestimmt und in die Art. cerricalis ascendens profunda. Diese Letztere zieht oberhalb des 1 . Rippenhalses, erhebt sich rertical hinter den Proc. transrersi und anastomosirt unter der Schädelbasis mit einem Aste der Art. vertebralis.

2. Die Art. vertebralis entsteht an der obern Fläche der Art. subclavia einen Finger ungefähr innen vom Scalenus anticus, erhebt sich und dringt unter dem Prac. transrersus des 6. Cervicalwirbels in den osteo-muskulösen Kanal, der von den Löchern der Proc. transversi und den Musculi intertransversi anteriores und posteriores begrenzt ist.

3. Die Art. mammaria interna entsteht an einem gegenïberliegenden Punkte der Art. rertebralis, zieht nach unten an das untere Drittel des innern Randes des Scalenus anticus, zieht hinter der 1. Rippe bogenförmig mit der Concavität nach innen gerichtet, die venöse Confluenz und den Phrenicus umgreifend.

4. Der Truncus thyreo-bicervico-scapularis entsteht im Nireau des innern Randes des Scalenus antiens etwas aussen und unter dem Ursprunge der Art. rertebralis, richtet sich nach oben und theilt sich am Rande des Scalenus:

a) Dic Art. scapularis superior, welche zuerst auf die vordere Fläche des Scalenus anticus herab zieht, biegt dann nach aussen ab, der hintern Fläche der Clavicula folgend, zieht vor dem Plexus brachialis und ror der Art. subclaria und dringt in die Fossa supra-spinata oberhalb des Ligamentum subcoracoideum, das sie rom Nerrus scapularis superior scheidet.

b) Dic Art. cervicalis transversa superficialis, gewöhnlich dün, richtet sich nach aussen unter die hintere Fläche des Trapezius dringend, in der sie endigt.

c) Die Art. cervicalis ascendens anterior, die Begleiterin des Phrenicus, 
erhebt sich mehr nach aussen ron der Reihe der vordern Höcker der Proc. transversi und ist auf den Insertionen des Scalenus anticus und posticus gelagert.

d) Die Art. thyreoidea inferior erhebt sich an der vordern Fläche des Scalenus, beschreibt eine Curre mit der Concarität nach unten, einen Finger unter dem herrortretenden Höcker des 6. Proc. transversus cervicalis gelagert, zieht hinter die Carotis communis, biegt auf die laterale Fläche der Trachea ab, eine Curve mit der Concavität nach oben beschreibend und rerzweigt sich am untern Ende des Sckilddrüsenlappens.

Einen Finger unter dem vordern Höcker des 6. Proc. transversus, Tuberculum Chassaigniaci, sticht eine von rorne nach hinten in die Spitze des scaleno-vertebralen Dreiẹcks eingeführte Nadel drei Arterien ein: eine vordere, die Carotis communis, eine mittlere, die Art. thyreoidea inferior und eine tiefe hintere, die Art. vertebralis.

Die Arteria scapularis interna oder cervicalis transversa profunda entsteht aus der Pars scalenica der Subclavia, zieht zwischen den Wurzeln des Ylexus brachialis gewöhnlich oberhalb des 7. Cervicalnerren, umschlingt den Scalenus posticus, biegt ab und steigt längs des innern Randes des Schulterblattes unter der tiefen Fläche des M. rhomboideus herab.

Die Art. subclavia sinistra entsteht an der obern Fläche der horizontalen anteroposterioren Partie des Aortenbogens hinter und etwas aussen ron der Carotis communis sinistra. Sie erhebt sich rertical; an ihre innere Fläche lehnt sich der linke Rand des Oesophagus, rorne befindet sich die Carotis communis mit dem linken Nervus recurrens und hinten die Wirbelsäule; aussen ist sie ron dem parietalen Blatte der Pleura bedeckt, unter dem sie ein Relief bildet.

Hinten und aussen von dem Sterno-claviculargelenke biegt sie nach aussen ab, indem sie sich ebenso wie die rechte verhält.

Die Tena subclavia liegt auf der hintern Fläche der innern Partie der Clavicula in der Mulde, welche die erste Rippe mit der Clavicula und dem Ligamentum costoclaviculare bildet.

Sie entspricht hinten der äussern Partie der Art. subclavia und dem Scalenus anticus, welcher sie ron dem mittlern Theile der Arteria scheidet; innen rereinigt sie sich mit der Jugularis interna, die retro-claviculare Confluenz bildend.

\section{Regio scaleno-vertebralis.}

Ein Raum von Pyramidenform mit der Basis nach unten gerichtet, der begrenzt wird: aussen rom innern Rande des Scalenus anticas, innen rom 7. Cerrical- und 1. Dorsalwirbel, die von den Insertionen des Longus colli bedeclit sind; hinten rom Proc. transversus des 7. Cervicalwirbels, vom Halse der 1. Rippe und den Fasern des Scalenus posticus, der vom Proc. transrersus zur Rippe gespannt ist.

Die Basis des scaleno-vertebralen Dreiecks wird von der Kuppel gebildet, die das parietale Blättchen der Pleura macht. Die Spitze entspricht dem Höcker des Proc. transrersus des VI. Wirbels, unter welchem die Insertionen des Scalenus anticus mit denen des Longus colli sich kreuzen (Fig. 161).

Diese Region, die ein wahres Zusammentreffen ron Gefässen und Nerren darstellt, enthält:

A. Auf einer oberflächlichen Ebene die Pars interna der Art. subclaria mit 
den vier innern Aesten, die auf derselben entstehen; die Art. vertebralis durchzieht die Region ron unten nach oben und dringt an der Spitze in den Kanal, welchen die Proc. transwersi bilden.

Die Vena vertebralis, sehr dick mul dünnwandig, steigt an der vordern und iinssern Fläche der Art. vertebralis herab, zieht gewöhnlich ror der Art. subclaria und nündet neben den andern Halsvenen in die retro-clariculare Confluenz ein.

Der Nerus lagus kreuzt die vordere Fläche der Art. subchavia, weil er etwas innen rou Ursprunge der $\lambda$ rt. vertebralis und der Art. mammaria interna gelagert ist. Der rechte Nerrus recurrens unschlingt die Art. subclaria, zieht hinter derselben und richtet sich nach oben gegen den Larynx.

Fig. 161.

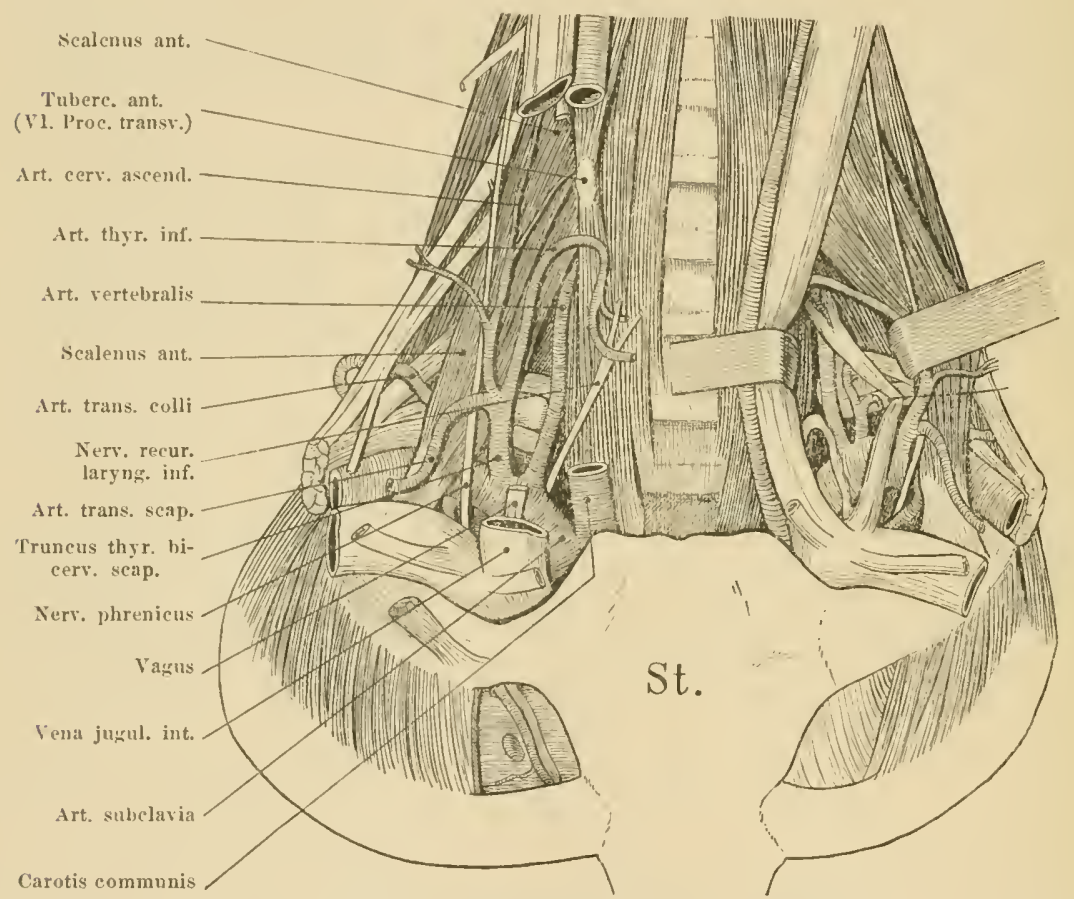

Die scaleno-vertebralen Regionen; links ist ein stumpfer Haken in die Jugularis interna und in die Carotis eingelegt, ein anderer zieht den Scalenus anticus nach aussen, um die im sealeno-vertebralen Dreiecke versteckten Gebilde freizulegen.

DieVena jugularis posterior, V. cervio-costalis, entsteht hinter den Proc. transversi, zieht unter dem Proc. transversus des 7 . Wirbels, erhält die Venae intercostales des ersten Raumes und mündet in die retro-clavieulare Conlluenz hinter der Art. subclavia ziehend. Die Art. subelavia ist oft ron einem venösen Haken umarmt, der vorne ron der Vena vertebralis und hinten von der Vena cervico-costalis gebildet wird.

B. Auf einer tiefen Fläche findet man den IIals der 1. Rippe umgreifend in einem innen offenen Winkel die beiden letzten Wurzeln des Plexus brachialis; der 8. Cervicalnerv liegt an der obern Fläche der Rippe; der erste dorsale unter derselben. Der Sympathicus cervicalis dringt unter dem Höcker des 6. Wirbels in das 
Fig. 162.

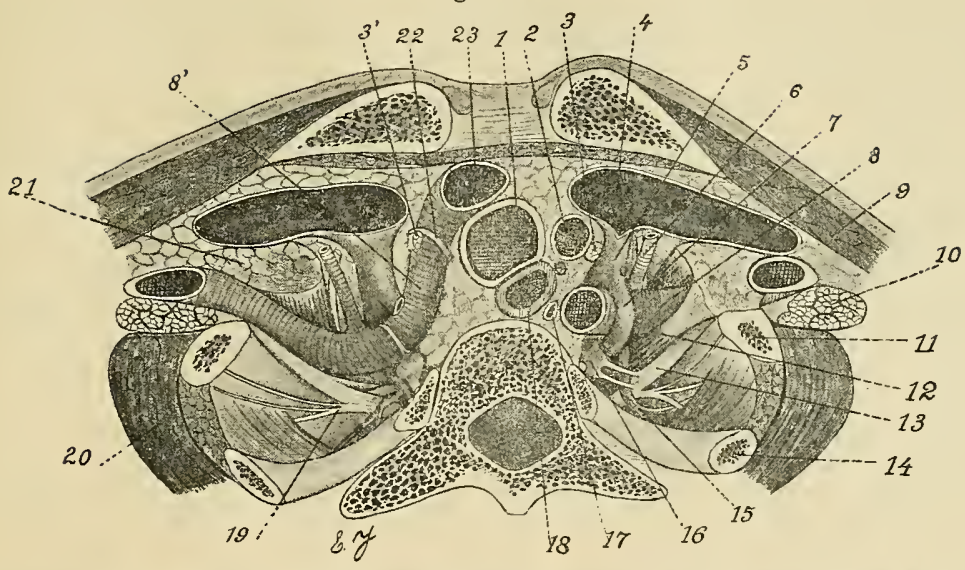

Ein Querschnitt durch die Spitze des Thorax, unmittelbar oberhalb des Manubriums. Man sieht nach Abtragung der Pleurablätter die verschiedenen Organe an der Spitze des Thorax gelagert. 1. Trachea, 2. Carotis communis sinistra, 3. und 3' Vagus, 4. Confluens retro-clavicularis, 5. Stamm, durch Vereinigung der Vena vertebralis mit der Jugularis posterior gebildet, 6. Mammaria interna, 7. Vena jugularis posterior, 8. Arteria subclavia sinistra, 9. Pectoralis major, 10. Plexus brachialis, 11. Erste Rippe, 12. Scalenus accessorius transverso-costalis, 13. I. Nervus dorsalis, 14. Zweite Rippe, 15. Arteria cervico-costalis, 16. Ganglion inferius des Halssympathicus, 17. Ductus thoracicus, 18. Oesophagus, 19. I. Nervus intercostalis, 20. Serratus magnus, 21. Sealenus anticus, 22. Nervus recurrens dexter, die Art, subclavia hakenförmig umschlingend, 23. Truncus brachiocephalicus.

Fig. 163.

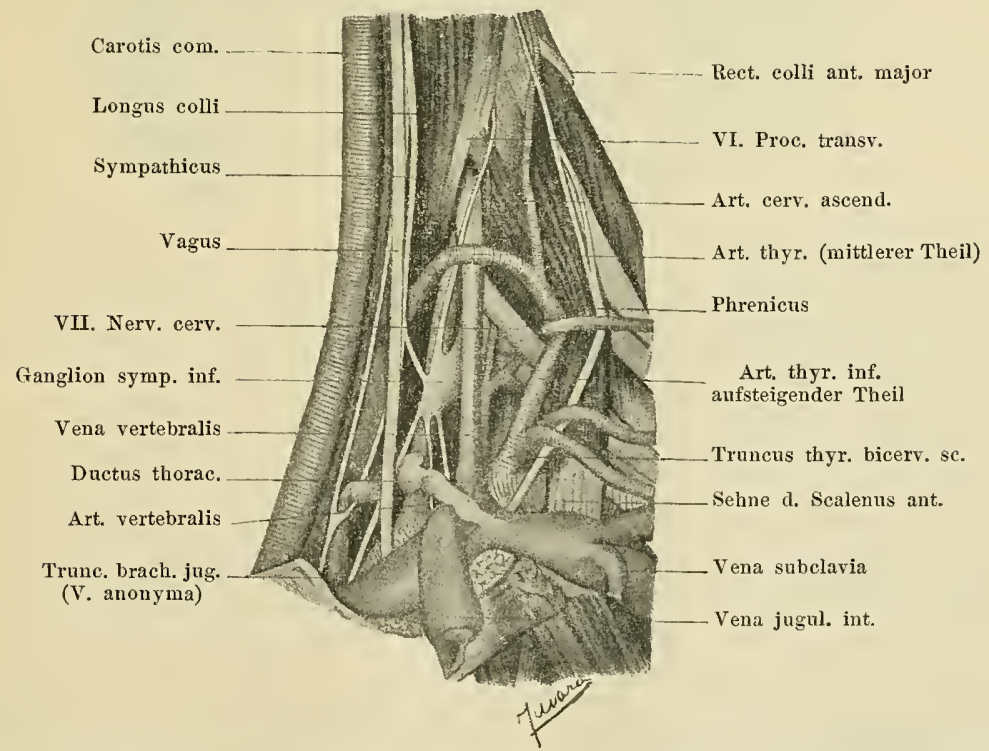

Die Region des scaleno-vertebralen Dreiecks der linken Seite. Die Beziehungen des Ganglion sympathici cervicale inferius. Ein Haken zieht die Art. thyreoidea inf. und den inneren Rand des Scalenus anticus nach aussen. 
scaleno-vertebrale Dreieck. Sein unteres Ganglion liegt in der Concarität des Rippenhalses im Winkel, der ron den beiden Nervenwurzeln hinten und innen ron den Vertebralgefissen gebildet wird.

Die Art. cervicalis theilt sich am Halse der Rippe in die beiden Endäste (Fig. 163).

Trohnik z. A. d. G. Art. subclavia. Man legt einen Holzkeil der länge nach unter den Rücken des Cadarers und drängt die Schulter nach unten und hinten; das Schlüsselbein nähert sich der 1. Rippe und legt ihren äussern Theil frei. Man bezeichnet mit der Nagelspitze an der Clavicula den Vereinigungspunkt ihres inneren Drittels mit dem mittleren Drittel, diescr Punkt entsprieht in der Tiefe dem äussern Rande des Sealenus anticus.

Etwas oberhalb der Clavienla macht man eine Incision, die 2 Finger vom innern Ende der Clavicula beginnt und nach aussen 3-4 Finger breit sich erstreckt. Man durchschneidet die Haut, die Fasern des Platysma

Fig. 164 .

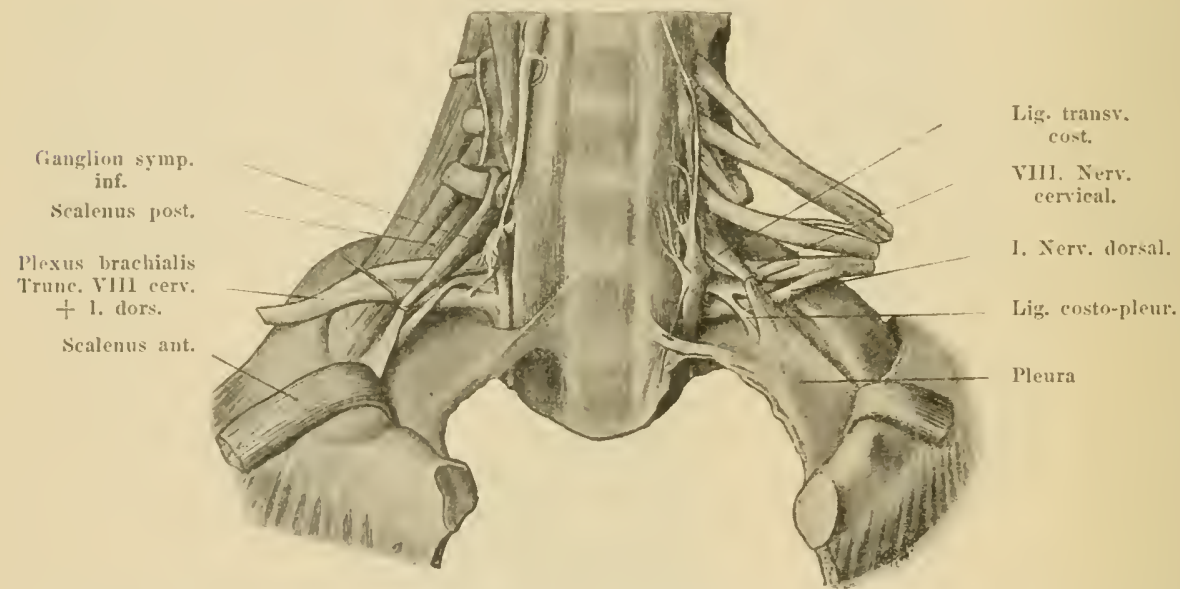

Die Region des scaleno-vertebralen Dreiecks, tiefe Schichte. Die Beziehungen des Ganglion cervicale sympathici inferius mit dem ersten Rippenhalse, mit den beiden letzten Wiurzeln des Plexus brachialis und mit der Pleurakuppel. Diese Figur zeigt den kleinen Musculus transverso-costalis (Scalenus minor), der oben am Proc. transversus des 7. Halswirbels entsteht und sich unten mit einer fächerförmig verbreiterten Sehne an der Bindegewebsschichte, die die Pleura bedeckt, und am concaven Rande der ersten Rippe inserirt. Dieser Muskel, der zuweilen in ein fibröses Band umgebildet ist, wurde von Sebilot als Ligamentum transverso-costale beschrieben. Hinter dem genannten Muskel, an der linken Seite der Figur, sieht man eine kleine fibröse Fascie, das Ligamentum costo-pleurale nach Sebilot. Diese inserirt sich hinten am ersten Rippenhalse, vorne und aussen an der Fascia subpleuralis. Das Lig. costo-pleurale begrenzt mit der Rippe ein kreisförmiges Orificium, durch welches der I. Nervus dorsalis zieht. Die Pleura begrenzt, wie man sieht, mit dem Rippenhalse und der Wirbelsäule eine Grube, die Fossa pleuro-costalis, in welcher man das Ende des Ganglion cervicale inferius findet.

myoides und die Fascie - man schone die Partie des Sterno-mastoideus, die im Sehnitte herrortritt - man legt cinen oder zwei stumpfe Haken in den obern Schnittrand ein, der nach oben und aussen mit der Tena jugularis externa gezogen wird, die man im äussern Winkel des Schnities 
findet (Fig. 165). Mit der Spitze der Hohlsonde und Pincette drückt man gegen den Punkt, den man an der Haut bezeichnet hat, nach unten hinter die Clavicula und nach oben das Fett und Bindegewebe nieder, es erscheint die weisse und glänzende vertical verlaufende Sehne des Scalenus anticus.

Man sucht, indem man sich das Operationsfeld genügend klar legt, im Winkel, den die Sehne des Scalenus mit der obern Fläche der 1. Rippe bildet, und findet die Arteria subclavia, hinten und oberhalb derselben die Stränge des Plexus brachialis, die man mit ihr nicht verwechseln darf. An der Innenseite der Arterie und an der Clavicula haftend findet man die Vena subclavia, die man sorgfältig ablöst, weil sie sehr dünne Wände hat, auch Adhärenzen der Fascien besitzt.

Fig. 165.

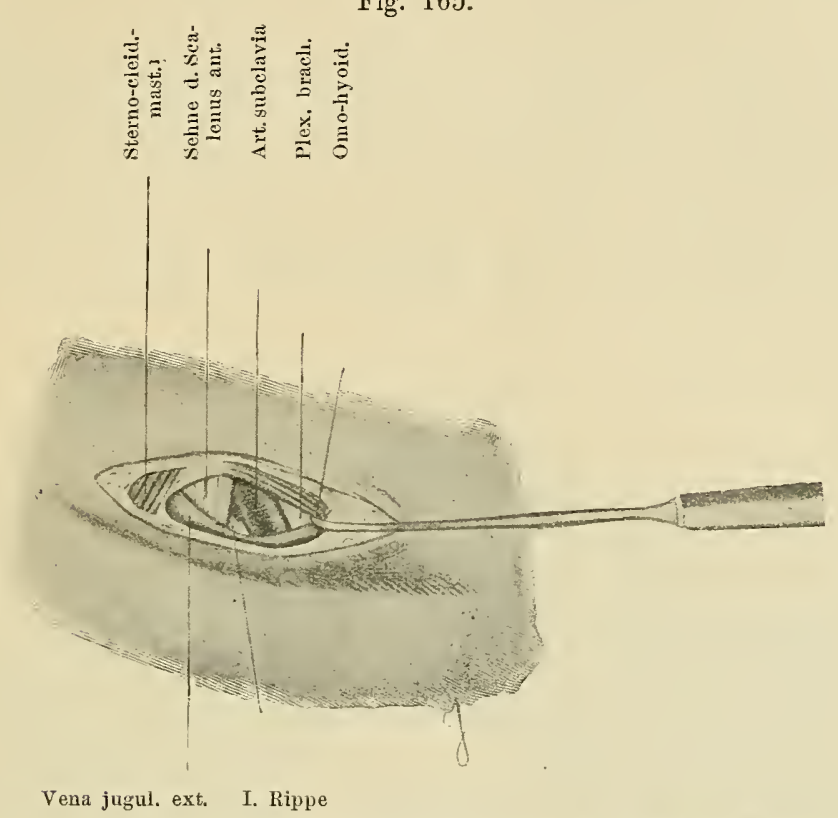

Das Aufsuchen der Arteria subclavia der linken Seite. Ein Haken zieht den Bogen der Vena jugularis externa nach aussen.

Man sucht am innern Rande des Scalenus und sieht den weissen Strang des Phrenicus, den Truncus thyro-bicervico-facialis und die Art. mammaria hinter die Clavicula dringend.

Plexus brachialis und Nervus phrenicus. Oberhalb der Clavicula macht man eine verticale Incision, welche etwas vor der Mitte der Clavicula beginnt und handbreit oberhalb derselben endigt. Man schneidet die Fasern des Platysma und die Fascie durch, mit der Hohlsonde entfernt man das Fett und legt stumpfe Haken ein; man sieht unter dem äussern Rande des Scalenus anticus hervortretend die Wurzeln des Plexus brachialis, die man isolirt und der Reihe nach studirt.

Man sucht an der vordern Fläche des Scalenus und sieht einen weissen 
Strang am rothen Körper des Nuskels gelagert, den Nervus phrenieus; an seiner lnnenseite findet man die Art. cervicalis ascendens.

Dic Art. thyreoidea inferior. Art. und Vena vertebralis. Ilan macht cine verticale Incision am untern Drittel des hintern Randes des Sterno mastoideus von der Clacienla bis etwas oberhalb rom Höcker des 6. Proc. transversus, den man aufzusuchen weiss. Man löst den hintern Rand des Muskels ab und legt ihn in einen stumpfen Haken; im Grunde des Schnittes, ron der Fascie bedeckt, sieht man den Scalcnus anticus. Nlit den Fingern sucht man im oberen Theile des Schnittes den prominenten Höcker des 6. Wirbels auf, $1 \mathrm{~cm}$ unter demselben findet man den Bogen der Art. thyreoidea inferior, unter ihr das Ganglion cervicale medium des Sympathicus. Man sucht am innern Rande des Scalenus anticus die Tena vertebralis auf, löst sie mit Torsicht ab und zieht diese mit einer Cooper'schen Nadel nach aussen; unter der Vene und etwas tiefer findet man die Art. vertebralis in Form eines weisslichen Bandes. Man fasst an der Spitze des scaleno-vertebralen Dreiceks mit einer Pincette den Sympathicusstrang und folgt ihm nach unten in das scaleno-vertebrale Dreicck, er führt an das Ganglion inferius, das man mit Pincette und Hohlsonde rom Rippenhalse ablöst. Weil das Ganglion vertical unter den Gefässen liegt, muss man das Arbeitsfeld klarlegen, indem man mit einer krummen Nadel die Vena vertebralis nach aussen zicht.

\section{Regio sterno-clavicularis.}

I)igitaluntersucluum. Folgt man dem Körper des Schlüsselbeines von aussin nach innen, so fühlt man, dass derselbe gegen sein inneres Ende sich verdickt. Nahe der Medianlinie gelangen die die obere Fläche der Clavieula abtastenden Finger in dic Sternal-Grube. - Entspannt man den Stemo-cleido-mastoideus durch eine Bengung und eine entsprechende Rotation des Kopfes, so fühlen die Finger, welche die vordere Fläche des Gelenkes exploriren, eine verticale Furche, die noch mehr hervortritt, sobald die Schulter nach rïckwärts gedrängt wird. Diese Furche entspricht rler Gelenklinic.

Sterno-claviculat-fielenk. Das innere Ende des Schlïsselbeins ist mit dem Rande der Sterno-chondral-frube durch eine rollständige fibröse Kapsel verbunden. Diese liapsel ist rorne und oben lurch ein Ligamentum antero-superius, rückwärts durch ein Ligamentum posierius verstärkt. Ein mehrfach durchlöcherter fibröser Meniscus scheidet die Gelenkhöhle in zwei Räume. Eine fibröse Schlinge, Ligamentum interclaviculare, verbindet die inneren Enden beider Schlüsselbeine (Fig. 166).

Vorne steht die Gelenklinie zu dem sternalen Antheile der Sehne des Sterno-cleidomastoideus in Bezielung; hinten entspricht sie einem ans zwei Schichten bestehenden Muskelfelde. Die rordere Schichte wird rom Musculus sterno-cleido-hyoideus, die hintere rom II usculus sterno-chondro-thyreoideus rebildet. Links und in der Tiefe entspricht der Sterno-clavicular-Linie die Arteria carotis sinistra; hinten und aussen ron dieser liegt die Arteria subclavia sinistra. 
Fig. 166.

Lig. interclav. Lig. sterno-clav, ant.

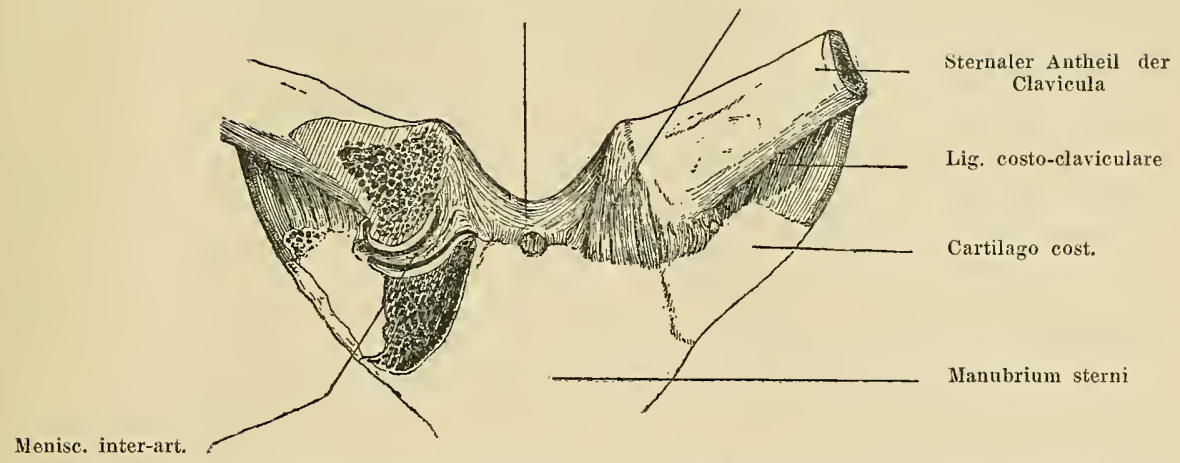

Vordere Fläche des Sterno-claviculargelenkes. Links zeigt das erhobene Schlüsselbein das Ligamentum costo-claviculare, rechts sieht man bei vertical durchsägtem Gelenke die Bandscheibe und die beiden Gelenkräume.

Fig. 167 .

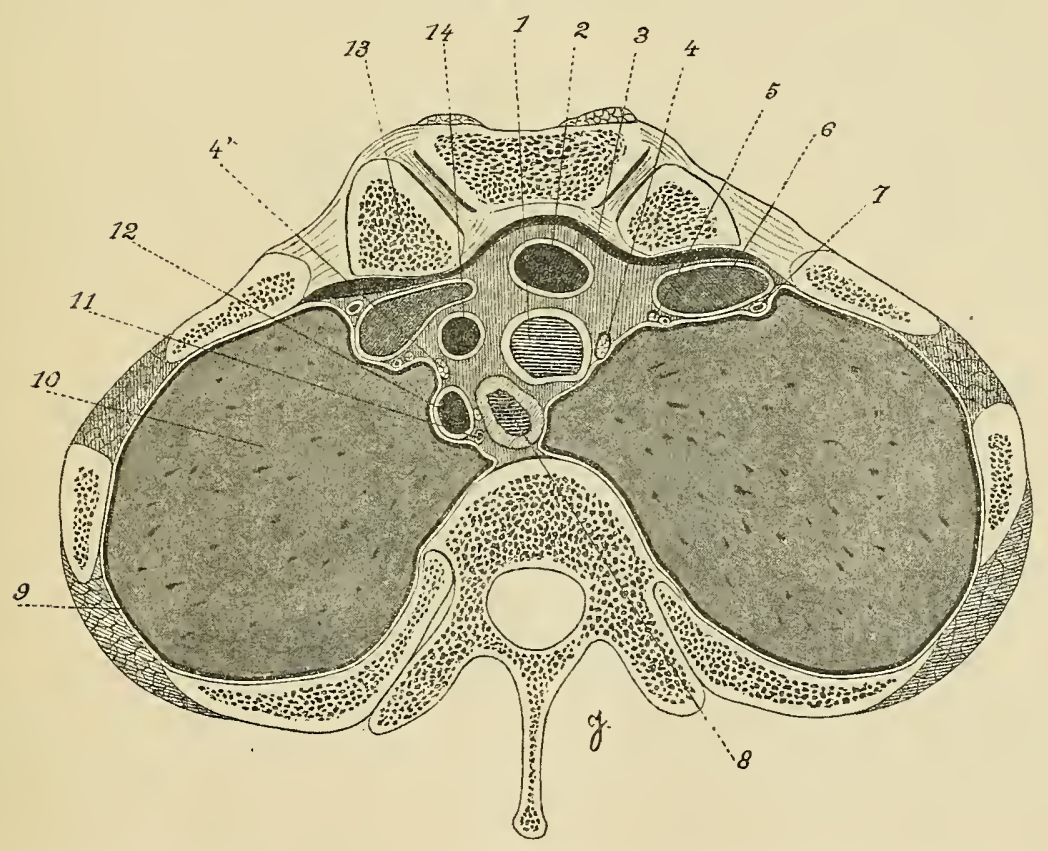

Ein schematischer Querschnitt im Niveau der Sterno-claviculargelenke zeigt die Anordnung der Organe im Mediastinum, welches mit von vorne nach hinten laufenden Linien bezeichnet ist. 1. Trachea, leicht nach rechts von der Medianebene gelagert, 2. Truncus brachio-cepbalicus, 3. Muskelschichte des Sterno-cleido-byoideus, 4. und 4' Vagus, 5. Phrenicus, 6. Confluens brachio-cephalica, 7. Mammaria interna, 8. Oesnphagus, leicht nach links gelagert, 9. Pleurahöhle, 10. Lunge, 11. Ductus thoracicus, 12. Arteria subclavia sinistra, 13. Caput claviculae, 14. Carotis communis sinistra. 
Rechts entspricht die Gelenklinie in einem oberflächlicheren Nivean dem Stamme der Arteria brachio-cephalica.

Der Vagus verläuft sowohl auf der rechten als auch auf der linken Scite ror der Arteria subclavia, etwas nach aussen ron der Ebene der Gelenklinie.

Der Phrenicus und die Arteria mammaria interna entsprechen dem inneren Ende des Schlüsselbeines, nicht aber der Gelenklinie.

Die renöse Confluenz, die Vereingungsstelle der Vena jugularis interua mit ler Vena subclavia liegt auf der hiutern Fläche des innern Schlüsselbeinendes, unnittelbar ausserhalb der Gelenlilinie.

Un ein Messer in die Gelenlinie einstechen zu lïnnen, muss die Schulter nach hinten gedrängt werden, es erölinet sich die Zwischenlinie und in diese wird die Klinge eingeführt, indem dieselbe nach inmen und hinten gerichtet wird.

Der steruale Antheil der Sehne des Sterno-cleido-mastoideus, welehe sich von vorne nach binten verbreitert, inserirt sich an der vordern Fläche des Manubrium sterni, auf einer rauhen Oberfläche, zuweilen sogar auf einem wirklichen Höcker.

Schief nach innen gerichtet liegt diẹ Sehne im Sulcus prae-articularis, welcher aussen durch den vordern Rand des innern Schlüsselbeinendes, hinten durch die Gelenkkapsel begrenzt ist. Ein weiches Bindegewebe, mitunter ein wahrer Schleimbeutel, trennt diese rom Gelenkt.

Techuik z. A. d. G. Durch eine entsprechende Rotation des Kopfes wird der Sterno-cleido-mastoideus gespannt. Man sieht und fühlt dann vor dem Sterno-clavicular-Gelenke den hervortretenden Strang des sternalen Antheiles der Sehne. I or diesem Strange wird hierauf die Haut durchschnitten, beide Ränder werden stumpf mit der Spitze der Sonde freigelegt und die Sehne wird auf der Hohlsonde quer durchschnitten. Man präparirt dann die tiefe Lage des untern Fragmentes und sieht das weiche Bindegewebe oder den Schleimbeutel, welcher die Schne von der Gelenkkapsel scheidet. 


\section{Der Thorax.}

\section{Die vordere Wand.}

Die Arteria mammaria interna entsteht aus der Pars interscalenica der Art. subclavia.

In ihrer ersten Partie richtet sie sich nach innen und etwas vorne, bogenförmig den Phrenicus und die venöse retro-claviculare Confluenz umgreifend.

Fig. 168.

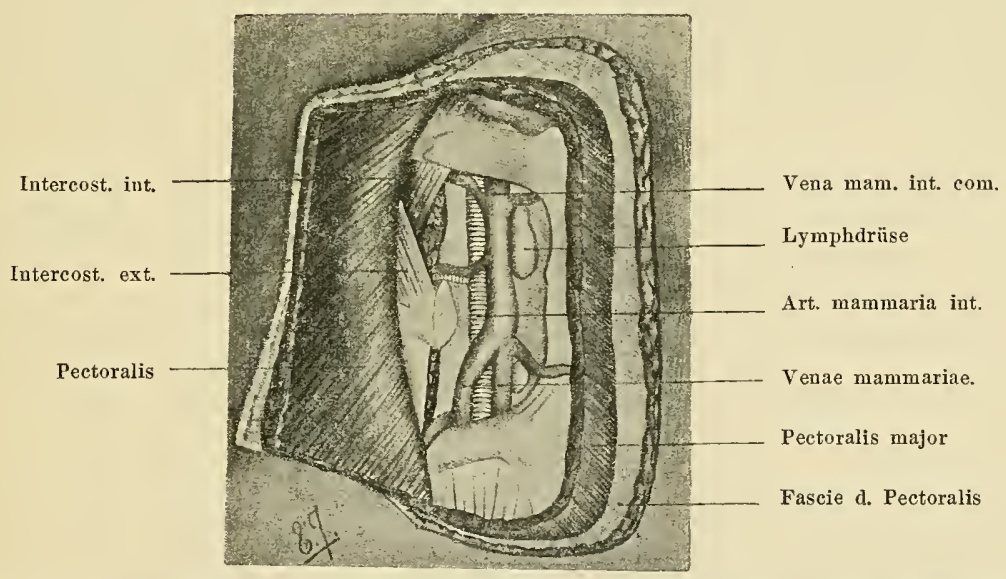

Die Region der Arteria mammaria interna. Diese Figur zeigt die Uebereinanderlage der Schichten, die man durchschneiden muss, um die Arterie zu erreichen. Die erste Schichte wird von der Haut und dem Pectoralis major gebildet, der durchschnitten und in Form eines Lappens zurückgeschlagen wurde; die zweite Schichte, die von den Rippen und Musculi intercostales gebildet wird, wurde an einer kleinen Partie resecirt.

In der zweiten Partie, die am untern Rande der 1. Rippe beginnt, steigt sie vertical auf die hintere Fläche der vordern Thoraxwand herab, einen Finger aussen vom Rande des Sternums gelagert; kreuzt die Rippenknorpel und verläuft unter dem 7. Knorpel auf der hinteren Fläche der Rectus anterior, hinter welchem sie mit der Arteria epigastrica anastomosirt. 
()ben an der Pleura gelagert wird sie gegen den 4. Rippenknorpel ron dieser durch den M. triangularis des Sternums getrennt (Fig. 167, 168).

Die Arteria mammaria interna giebt in der Richtung jedes einzelnen Intercostalraumes äussere lntercostaläste und innere Sternaläste ab; gegen den 1. Kinorpel giebt sie die Art. diaphragmatica superior ab, am 7 . Knorpel entsendet sie einen langen Ast, der sich nach aussen richtet und den Costalinsertionen des Diaphragma folgt.

Die Art. mammaria interna wird zuerst von 2 Venen begleitet, die sich nach oben zu einer einzigen Vene, an der Innenseite der Arterie gelegen, vereinigen und der retroclavicularen Confluenz, angelıören.

Gegen jeden einzelnen Intercostalraum lindet man rings um die Arterie kleine Lymphdrïsen, die ron einer Fettschichte umgeben sind.

Terhnik z. 1. d. G. Man macht am 2. oder 3. Intercostalraume einen horizontalen Hautschnitt, der am Sternum beginnt und drei Finger nach aussen endigt. Ilan schneidet den Pectoralis major durch und legt je einen stumpfen Haken an jedem Schnittrande ein; man sieht an seinem Grunde aussen den Intercostalis externus, dessen Fasern schief nach unten und imnen gerichtet sind und auf einer ummittelbar hintern Ebene, dic nach unten und aussen schiefen Fasern des Intercostalis internus, denn man weiss, dass der Intercostalis externus etwas nach aussen vom Rande des Sternums endigt.

Mit der Spitze des Bistouri schneidet man sorgfältig die Fasern der Intercostales durch und findet mnter denselben an der Pleura gelagert und von einer oder zwei Lymphdrüsen begleitet die Art. mammaria, an ihrer Innenseite die begleitende T'ene; man löst sie ab, indem man sich hütet, dic Pleura durch eine brïske Bewegung der Sondenspitze zu zerreissen. 


\section{Das Abdomen.}

\section{Die vordere Wand.}

Der Nabelring befindet sich nahe der Mitte der Linea alba (der medianen Raphe). Seine hintere Wand ist vom Peritoneum bedeckt, welches sehr adhärent und von narbigem Aussehen ist. Im Niveau des Nabels endigt: nnten der Urachus und die Stränge der Nabelarterien, oben das untere Ende des Ligamentum suspensorium hepatis.

In der Tiefe entspricht der Nabel dem untern Drittel des Körpers des 4. Lendenwirbels; ein Messer, von vorne nach hinten durch den Nabel eingeführt, sticht sich, nachdem es das Abdomen durchzogen hat, am Körper dieses Wirbels auf, nacbdem es zuerst die Bifurcation der Aorta in die beiden Art. iliacae communes durchschnitten hat.

Die Linea alba oder mediane Raphe ist vertical von der Spitze des Processus xiphoides zur Symphyse des Schambeins gespannt. Durch Verwebung der sehnigen Fasern des Obliquus major, Obliquus minor und Transversus abdominis gebildet, hat sie oberhalb des Nabels die Form eines mit der Basis nach oben gerichteten Dreiecks; unterhalb desselben verengt sie sich an der Grenze, die sich dem Schambeine nähert, oberhalb welchem sie zu einer einfachen antero-posterioren Wand reducirt ist.

Wenn man die vordere Fläche des Abdcmens untersucht, so sieht man in der Medianlinie eine verticale wenig tiefe Rinne; sie entspricht der Linea alba.

An Frauen ist die Linea alba durch eine pigmentirte Linie angezeigt, besonders von der Schoossfuge bis zum Nabel.

Der Rectus anterior (Rectus abdominis), nahe der Linea alba gelegen, hat die Form eines dreieckigen Muskelbandes, das vertical vom vordern Theile der Thoraxwand zur Symphyse des Schambeins gaspannt ist. Im obern Theile, 4-5 Finger breit, verschmälert er sich von oben nach unten und ist oberhalb der Symphyse nicht mehr als 2 Finger breit (Fig. 169).

Er entsteht von oben nach unten und von aussen nach innen mit 4 Muskelstreifen: an der untern Fläche der V. Rippe und ihres Knorpels; an der vordern Fläche des Knorpels der VI. und VII. Rippe; an dem äussern und hintern Rande der vordern Fläche des Proc. xiphoides und mit einigen Fasern an der hintern Fläche der Fascie des Pectoralis major.

Der Fleischkörper des Muskels besitzt transversal 3 oder 4 aponeurotische Intersectionen, Inscriptiones tendineae.

Unten inserirt er sich mit einer breiten und festen Sehne am obern Rande des 
Schambeinkörpers ron der Spina pubica bis zur Medianlinie. Einige Mnskelbündel gehen am innern Rande des Fleischliörpers ab und inseriren sich an der Linea alba und an der Symphyse des Schambeins.

Die Recti sind an jeder Seite der Medianlinie in einer fibrösen, von vorne uach linten rerbreiterten Scheide enthalten, die von Insertionsfascien der Muskeln, Obliquus major, Obliquus minor und Transversus gebildet werden. Die rordere Wand dieser Scheide ist continuirlich ron oben nach unten; die hintere. Wand ist unvollständig, weil sie etwas unterhalb des Nabels in einem concaven sichelförmigen Rand endigt, Arcus semicircularis Douglasii. Unterhalb dieses Bogens fehlt die hintere Wand rollständig oder ist zu cinem dünnen fibrösen Blättchen reducirt.

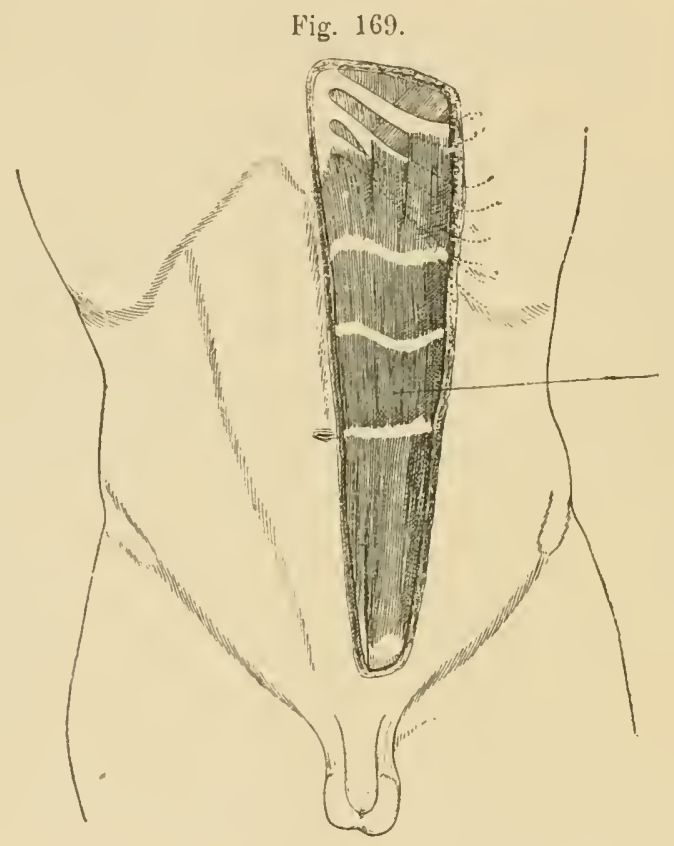

Rectus anterior

Der Rectus anterior (Rectus abdominis) der linken Seite.

Der Musculus pyriformis abdominis liegt oberhalb der Symphyse und hat die Form eines mit der Spitze nach oben gerichteten Dreiecks. Er entsteht am untern Theile der Linea alba mit aponeurotischen kurzen Fasern und inserirt sich unten am obern Rande des Schambeins und an der Symphyse, unmittelbar vor der Insertion des Rectus anterior.

An der vordern Fläche des Rectus gelegen ist er von diesem durch ein fibröses Blatt getrennt, das der liascie des Obliquus minor angehört.

Technik z. A. d. G. Zwei Finger nach aussen von der Medianlinie macht man einen langen Hautschnitt, welcher etwas oberhalb vom untern Rande des Thorax beginnt und am Schambeine endigt. Man durchschneidet die Faseie und gelangt an den Fleischkörper des Rectus anterior und unmittelbar oberhalb des Schambeins an den Körper des Pyriformis. Mit den Fingern löst man ihn aussen und innen von der rordern Wand seiner 
aponeurotischen Scheide ab und bemerkt, dass er im Niveau seiner fibrösen Interstitien mit diesem adhaerirt. Man isolirt ihn vollständig von oben nach unten, sucht an seiner hintern Fläche den Gefässbogen, der dje Hammaria interna mit der Epigastrica verbindet, auf, durchschneidet ihn dann transversal und studirt seine untere Insertion und die hintere Wand seiner fibrösen Scheide.

Man macht etwas aussen von der Medjanlinie eine Incision, die 3 Finger oberhalb der Symphyse beginnt und am Schambeine endigt; unter der Fascie gelangt man an den kleinen dreieckigen und dünnen Körper des Pyriformis.

\section{Regio canalis inguinalis.}

Die Ingninalgegend hat eine dreieckige Form und wird unten von dem Poupart'schen Bande, oben von einer horizontalen Linie begrenzt, welche durch die beiden Spinae iliacae anteriores superiores zieht, innen von einer verticalon Linie, die von der Spina pubica gezogen wird.

Die Schichten, welche in dieser Region über einander liegen sind von der Oberfläche nach der Tiefe hin folgende:

a) Die Haut, an der innern Seite zart und beweglich, mit Haaren bekleidet.

b) Eine subcutane Fettschichte, in welcher die Art. subcutanea abdominis sich schlängelt.

c) Die fest gefügte Fascia superficialis, welche sich innen gegen das Schambein verstärkt, adhärirt am Arcus cruralis.

d) Eine neue Fettschichte.

e) Die Insertionsaponeurose des Obliquus major, welche aus schief nach abwärts und innen gerichteten Bändchen gebildet wird.

f) Der Obliquus minor, welcher aus schief nach oben und innen gerichteten Muskelbündeln gebildet wird.

g) Der Transversus, welcher von transversal gerichteten Muskelbündelchen gebildet wird.

h) Die Fascia transversalis, ein zellig-fibröses Blatt.

i) Das subperitoneale Blatt mit dem subperitonealen Fett.

j) Das Peritoneum.

Man gewöhne sich, diese verschiedenen Schichten zu erkennen, um sich nicht bei einer Laparotomie zu verirren.

Canalis ing'ninalis. Der Leistonkanal oder besser Leistenrinne ist ein begrenzter Zwischenraum, der von den Muskeln der Abdominalwand gebildet wird. Er liegt unmittelbar oberhalb des Poupart'schen Bandes, welches ihm als Boden dient, und ist schief nach abwärts und innen gerichtet. Er hat eine Länge von $5-6 \mathrm{~cm}$, beginnt etwas nach aussen von der Mitte des Poupart'schen Bandes und endigt im Niveau der Spina pubica. Durch diesen zieht beim Manne der Samenstrang, beim Weibe das Ligamentum rotundum.

A. Die vordere Wand des Leistenkanals wird von der Sehne des Obliquus major und vom untern Bündel des Fleischkörpers des Obliquns minor gebildet.

Der Obliquus major schickt ein dreieckiges fibröses, mit der Spitze nach innen gerichtetes Blatt, der vordere untere Pfeiler des Inguinalkanals. Die Fasern dieses 
Bandes arehen leicht tredreht ohne Grenze in das Cruralband über und inseriren sich innen an der Spitze der Spina pubica und an dem fibrösen, sehr dicken und resistenten Gewebe, welches die rordere Fläche des Schambeinliörpers bedeckt.

Das untere Bündel des Obliquus minor oder internus entsteht mit kurzen Sehnenfasern am äussern Drittel des l'oupart'schen Bandes; hinter dem vordern untern Pfeiler gelegen, bedeckt es zuerst den Samenstrang, zieht dann über demselben und indem es eine mit der Concavität nach unten gerichtete Curve beschreibt, geht es mit einem Sehnenblatte auf die hintere Wand des Inguinalcanals über (Fig. 170).

B. Die hintere $\mathrm{W}$ and wird innen und in einer je nach dem Indiriduum rerschieden grossen Ausdehnung von einer fibrösen Fläche dargestellt, welche durch Vereinigung einiger fibrösen Blätter gebildet wird, welche den Muskeln: Transversus und Obliquus minor ron derselben Seite und Transversus, Obliquus minor und major ron der entgegengesetzten Seite angehören.

Fig. 170.

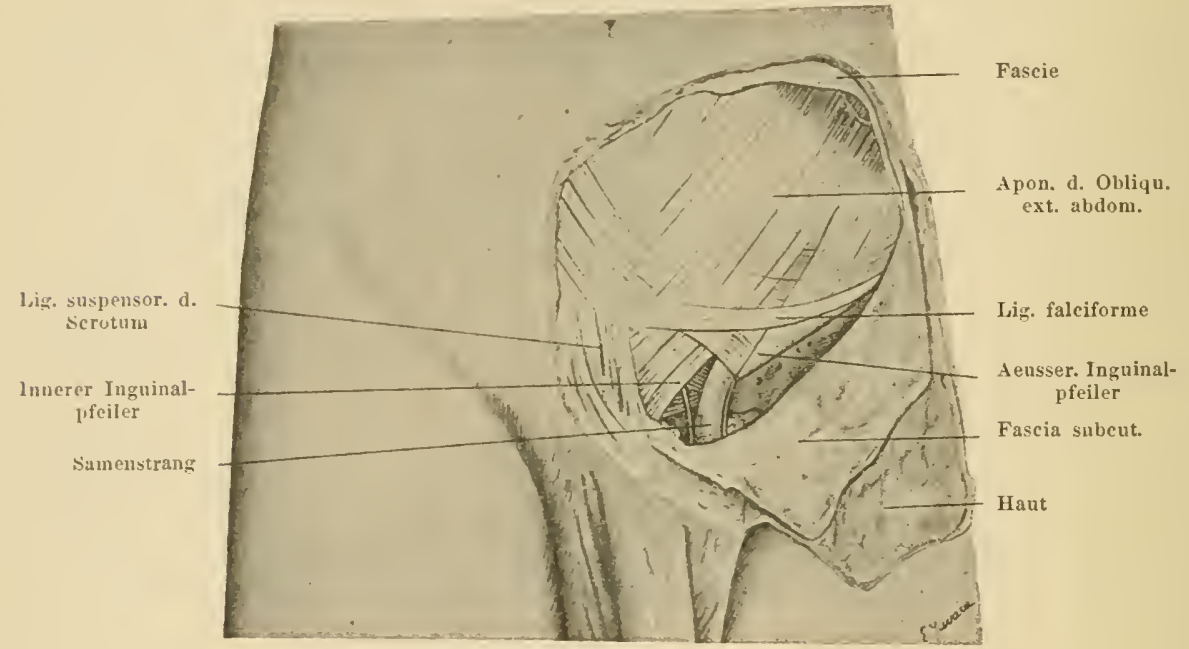

Regio inguinalis sinistra. Die vordere Wand und das Orificium cutaneum des Inguinalkanales.

Diese Fläche, deren zusanmengesetzte Structur selbst durch die feinste Präparirung sehr schwer zu studiren ist, führt den Namen: "Vereinigte Sehne" (Fig. 171).

Nach abwärt inserirt sich "die rereinigte Sehne" an der Crista pectinea, wo sie mit dem Poupart'schen Bande und mit dem Lig. Cooperi sich rerwebt. Hinten und innen ron "der rereinigten Sehne" findet man die sehr feste Sehne des Rectus anterior. Die hintere Inguinalwand ist aussen von "der rereinigten Sehne" sehr dünn, sie wird zu einem einfachen zelliğ-fibrösen Blättchen, durch welches man die Arteria epigastrica mit den sie begleitenden Venen sieht.

Dieser äussere Theil der hintern Inguinalwand wurde von Blaisse nschwache Partie" genannt, weil durch diese Stelle die directen Hernien sich bilden. - Nach abwärts vereinigt sich die rordere Wand mit der hintern längs des Arcus cruralis und bildet eine tiefe Furche, in deren Grund auch das äussere Bündel des Cremaster entsteht und liegt. 
Das hintere oder tiefe Orificium des Inguinalkanals, sehr oft schlecht begrenzt, hat eine orale Form. An der innern Seite dieses Orificiums findet man die Art. epigastrica, an deren Aussenseite das sehr dünne und wenig adhärente Peritoneum in Blindsackform eingestülpt ist, die Fovea inguinalis externa, durch welche die meistentheils angeborene Hernia inguinalis obliqua externa sich bildet.

Das oberflächliche oder Orificium cutaneum des Inguinalkanals liegt oberhalb und aussen von der Spina pubica. Es ist von ovaler Form und wird ron zwei divergirenden Bändern der Aponemrose des Obliquus nıajor gebildet, die Inguinalpfeiler.

Der vordere, unterere oder äussere Inguinalpfeiler bildet die vordere Wand des Inguinalkanals.

Der vordere, obere oder innere Inguinalpfeiler wird von einem rechtwinkligen, 2-3 cm breiten Bande der Sehne des Obliquus major gebildet, ist nach unten

Fig. 171.

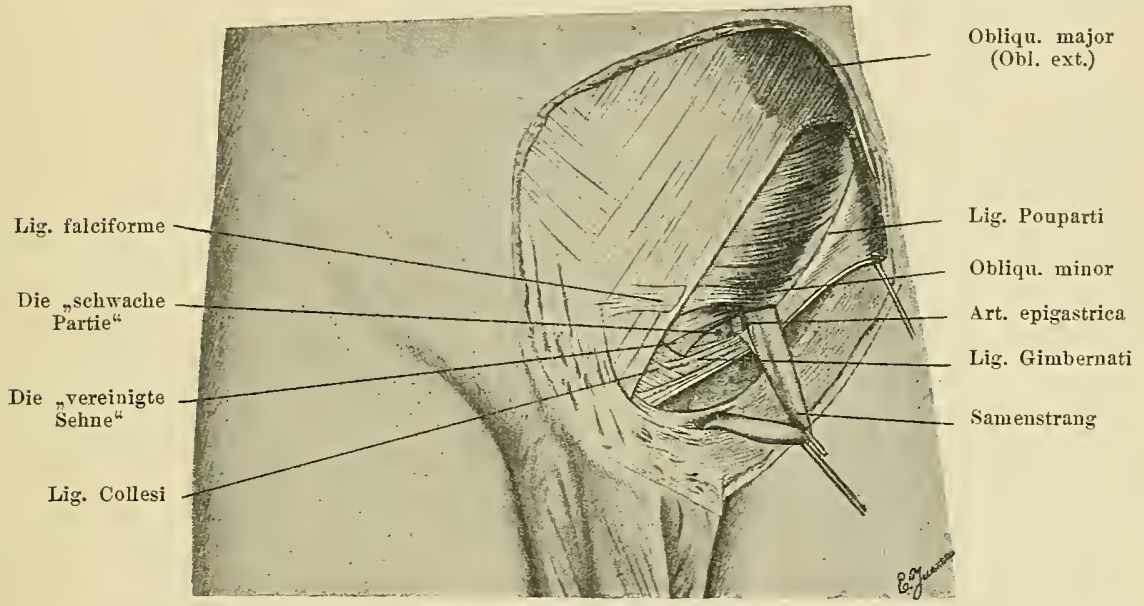

Der Inguinalkanal ist eröffnet, indem die vordere Wand vertical durchschnitten und nach unten geschlagen wurde. Der Samenstrang ist mit einem Haken abgezogen, um den Ort der Arteria epigastrica und denjenigen Theil der hinteren Wand, welcher, schwache Partie" genannt wird, zu sehen.

und innen gerichtet und an der Medianlinie, vor der Symphyse verwebt er sich mit demjenigen der andern Seite. Seine oberflächlichen Fasern gehen in das vor der Schoossfuge befindliche fibröse Gewebe über; die tiefen Fasern oder der hintere Inguinalpfeiler, Lig amentum Collesi, überschreiten die Medianlinie und inseriren sich auf der entgegengesetzten Seite an der obern Fläche der Spina pubici and an der Crista pectinea, indem sie sich mit dem Poupart'schen Bande und mit der "vereinigten Sehne", in welche sie übergehen, verweben.

Nach aussen sind die beiden äussern Pfeiler durch das Ligamentum falciforme oder Fibrae intercrurales vereinigt (Fig. 171).

Es ist dies ein fibröser Fächer, welcher an dem untern Rande des äussern Antheils des Arcus cruralis entsteht; seine Fassrn verlaufen nach oben und rertheilen sich an der vordern Fläche der Sehne des Obliquus major. 
Oft entsteht ein anderer fibröser Fächer an der Spina pubica, umschlingt den untern Pfeiler und seine Fasern vertheilen sich nach aussen.

Vorne entspricht der Inguinalkanal der Iaut, rou welcher cr durch eine mehr oder weniger dicke Fettschicht geschieden ist, in welcher die Arteria abdominis subcutanea sich schlängelt.

In der Tiefe entspricht der Inguinalkanal der Abdominalhöhle und seine hintere Fläche wird rom Peritoneum ausgekleidet.

Wir haben gesehen, dass die Art. epigastrica am innern Rande des tiefen Inguinalorificium sich befindet und müssen uns deshalb hüten, diese anzuscheiden, wenn wir den Ring eines Sackes bei einer eingeklemmten Hernie durchschneiden.

Nach unten entspricht der Inguinalkanal ron imnen nach aussen dem Cruralring, in welchem die Vena und Art. femor. sich befinden.

Seine Beziehung zu dem Schenkelring wird bei der Operation einer Schenkelhernie, die inguinal ausgeführt wird, berücksichtigt. - Die Beziehung zur Vena femoralis ist äusserst wichtig und nicht einmal war diese Vene bei der Radicaloperation der Inguinalhernien angeschnitten worden.

Technik z. A. des Orificium cutaneum. Man sucht die Spina pubica auf und unmittelbar oberhalb und nach aussen von derselben fühlt der Finger an einem mageren Individuum den Leistencanal und kann auch in denselben dringen. An einem fetten Individunm ist das Auffinden des Orificium inguinale pubicum sehr schwer oder sogar unmöglich. Han drückt mit dem Zeigefinger das Scrotum cin, so dass der Finger wie mit einem Handschuhfinger von der Haut des Scrotum bedeckt wird. Drückt man tief, dem subcutanen Bindegewebe folgend, so fühlt man die Spina pubica und oberhalb derselben dringt man in das Orificium inguinale, welches man abtasten und die Festigkeit der Pfeiler auch prüfen kann. Man wiederhole oft diese leichte Untersuchung und übe die Finger, um mit Leichtigkeit eine Hernia inguinalis zu erkennen. Indem man den Zustand des Orificium inguinale studirt, kann man die Indicationen zu den nöthigen Operationen stellen. Man macht fingerbreit oberhalb des Arcus an der Spina pubica beginnend einen Schnitt, durchschneidet das subcutane Fettgewebe und gelangt an die Aponeurose des Obliquus major, welche mit Pincette und Hohlsonde freigelegt wird. Auf diese Weise findet man die beiden äussern Inguinalpfeiler und Commissurfasern, welehe sie mit einander verbinden.

Man führt eine Sonde in den Leistencanal ein und durchschneidet auf derselben seine vordere Wand, man gelangt an den Obliquus minor und an den Samenstrang. - Der Strang wird abgelöst und mit einem stumpfen Haken abgezogen; es wird die hintere Inguinalwand mit der "vereinigten Schne" und mit der "schwachen Partie" freigelegt.

Der hintere Pfeiler oder das Ligamentum Collesi. Man macht gegen das Orificium inguinale cutancum cinen Schnitt, präparirt den Samenstrang mit Hohlsonde und Pincette ab, legt ihn frei und zieht ihn mit einem stumpfen Haken nach aussen; man sieht dam hinter demselben und an der Spina pubica sich inserirend die fibröse Fläche, welche das Ligamentum Collesi darstellt.

Die Arteria epigastrica, rom Endstïcke der Ilinca externa etwas oberhalb des Poupart'schen Bandes entstanden, richtet sich nach oben und innen, zieht unter und innen rom Samenstrange am innern Rande des Orificium inguinale externum und unter 
dem Arcus Douglasii dringt sie in die Scheide des Rectrus anterior, indem sie mit der Mammaria interna anastomosirt.

Im Niveau des Orificiums des Inguinalkanales beschreibt die Art. epigastrica eine Curve mit der Concavität nach oben und aussen, in welcher das Vas deferens beim Manne und das Ligamentum rotundum beim Weibe zieht, in diesem Theile giebt sie die Art. funicularis ab, die für den Samenstrang bestimmt ist.

Die Art. epigastrica ist von ihrem Ursprunge bis unterhalb der Douglas'schen Falte vom Peritoneum bedeckt, unter welchem sie hervortritt.

Die Venae epigastricae, zuerst doppelt, vereinigen sich dann zu einem gemeinsamen Stamme, der am innern Theile der Arterie liegt und in die Vena iliaca externa einmündet.

Fig. 172 .

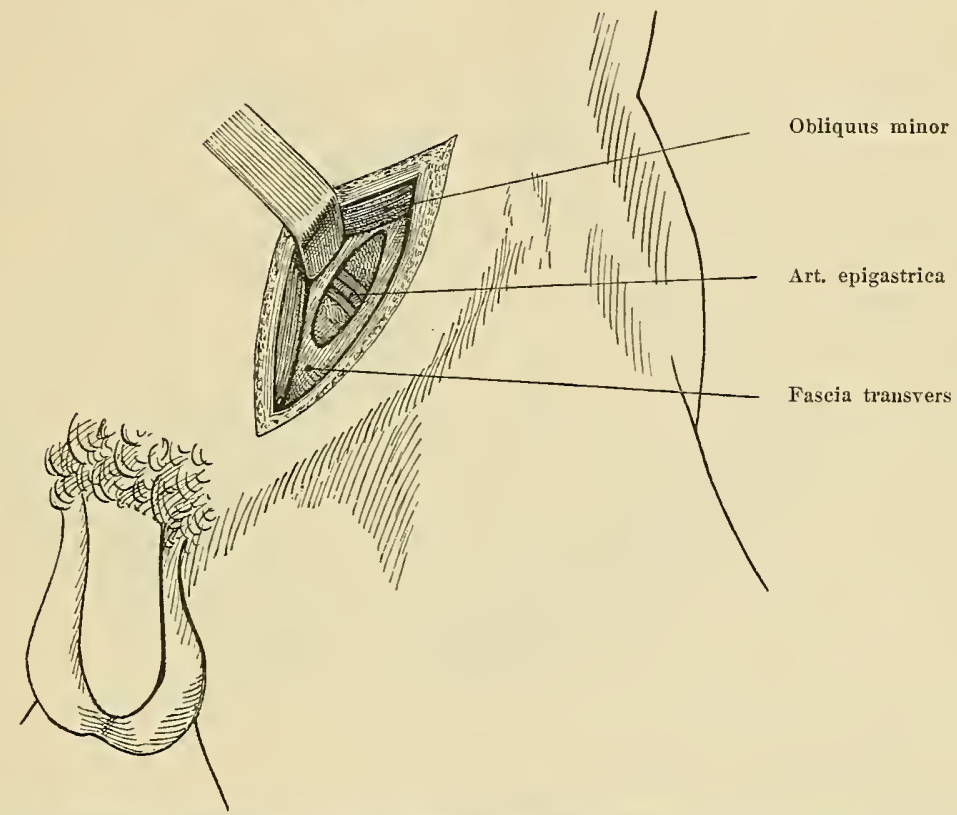

Das Freilegen der Arteria epigastrica. Ein stumpfer Haken zieht den Obliquus minor nach oben.

Technik z. A. d. G. Man sucht das Poupart'sche Band auf und bezeichnet seine Mitte; eine gute Handbreite nach innen findet man in der Tiefe die Art. epigastrica.

Man macht einen Finger oberhalb des Bandes an seinem mittleren Drittel eine Incision, durchschneidet die Haut und die subcutane Schichte, löst die Fascie des Obliquus major ab und gelangt an die Fasern des Obliquus minor. Mit der Hohlsonde löst man den untern Rand dieses Muskels ab und legt je einen stumpfen Haken an jedem Schnittrande ein. Der Grund des Schnittes wird von der Fascie des Transversus gebildet, durch welche man die Arterie durchscheinen sieht. Man zerreisst mit Pincette und Hohlsonde diese Fascie und findet die Art. epigastrica in einer zelligfibrösen Bindegewebsschichte; man legt sie frei, hebt sie auf die Sonde und findet unter ihr das Peritoneum mit dem subperitonealen Blättchen (Fig: 172). 
Die Arteria iliaca exterma, der äussere Bifurcationsast der Arteria iliaca communis, steigt schief nach unten und etwas aussen herab lïngs des innern Randes des Psoas und endigt unter dem l'oupart'schen Bande, wo sie in die Arteria femoralis iibergeht.

Im Nirean des Poupart'schen Bandes giebt die lliaca externa zwei Aeste ab, einen obern und innern, die Epigastrica, einen äussern, die lliaca circumflexa anterior.

Diese Letztere richtet sich, in einer fibrösen Scheicle enthalten, nach aussen gegen die Spina iliaca anterior superior; sie giebt einen Ramus a nterior für die rordere Wand des Abdomens ab, zieht oberhalb des obern Randes des Darmbeines und endigt im lateralen Theile der Abdominalwand.

Hig. 173.

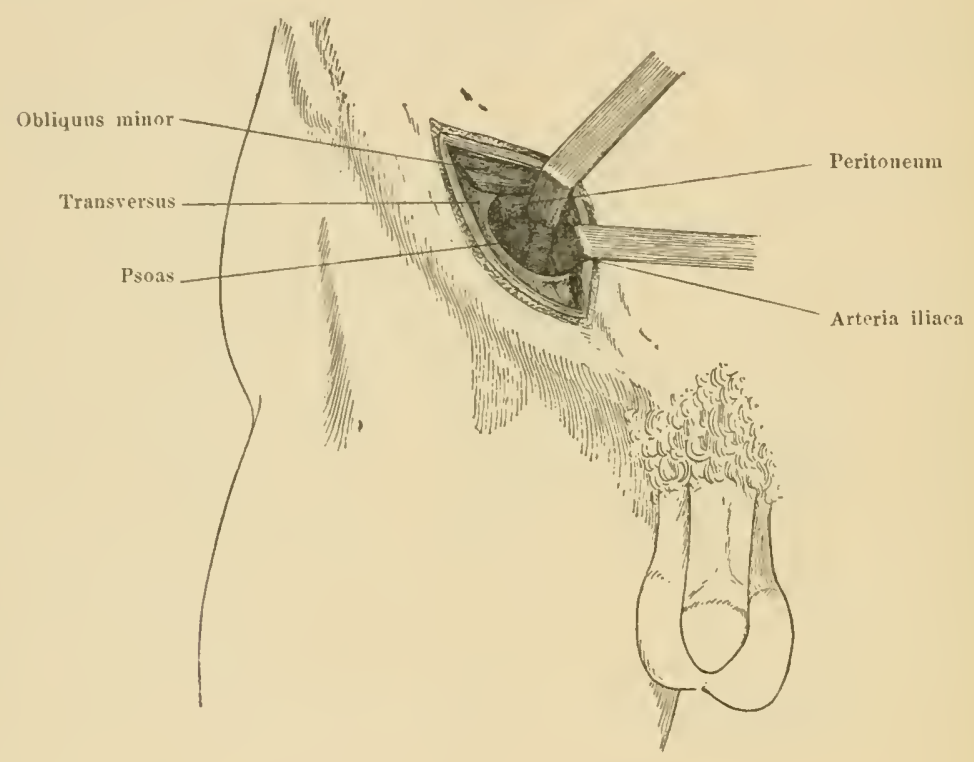

Das Freilegen der Arteria iliaca externa. Zwei stumpfe Haken ziehen den Obliquus major, Obliquus minor und Transversus und die untere Aussackung des Peritoneums nach oben.

Die Vena iliaca externa, ron der Dicke eines Fingers, liegt hinter und etwas innen ron der Arterie; der N. genito-cruralis, zuerst aussen von der Arterie, liommt dann an ihre rordere Seite zu liegen. Die Arterie, Vene und der Nerv, in einer fibrösen Scheide enthalten, werden rom Vas deferens gekireuzt, welches, von der Fossa iliaca in die Beckenhöhle ziehend, auf der Arterie abbiegt.

An den Seitentheilen der Arterie, aussen und innen ron der Furche, welche die Arterie mit der Vene bildet, existirt je eine Kette ron Lymphdrüsen.

Technik z. A. d. G. Man sucht das Poupart'sche Band auf und macht einen Finger oberhalb desselben eine Incision, welche im Nireau der Spina iliaca anterior superior beginnt und 2 Finger nach aussen ron der Medianlinie endigt. Man schneidet die Haut und die subcutane Schichte durch, spaltet die Fascie des Obliquus major, löst den untern Rand des 
Obliquus minor ab, und wenn nöthig durchschneidet man aussen die Fasern dieses Huskels. Man zerreisst mit der Hohlsonde im äussern Theile des Schnittes die Fascie des Transversus, die Venen und Arteria epigastrica schonend, löst das Peritoneum mit der Fingerspitze ab, der Wand in die Fossa iliaca folgend und legt einen oder 2 stumpfe Haken in den obern Schnittrand und im Grunde der peritonealen Aussackung ein. Wir sehen vor uns dann eine trichterförmige Grube, in deren Grund man das Gefässpacket findet.

Mit Vorsicht vorgehend legt man die Arterie frei; an ihrer vordern Fläche sieht man den Nervus genito-cruralis, innen und hinten findet man die Vene, die man sorgfältig ablösen muss, um sie nicht zu zerreissen, weil sie dünne Wände hat (Fig. 173).

Fig. 174 .

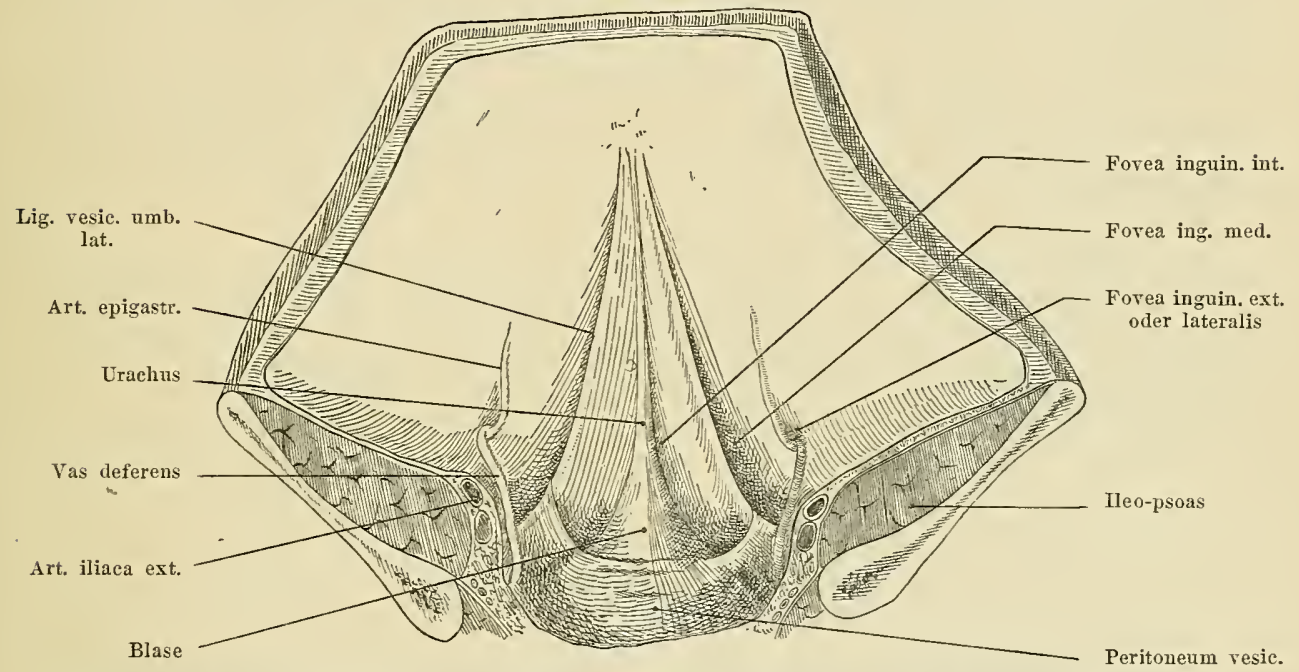

Die hintere Fläche der unteren Partie der vorderen Abdominalwand mit den Peritonealfalten und den Inguinalgrübchen.

Foveae inguimales. An der hintern Fläche des untern Theiles der vordern Abdominalwand existiren 5 Peritonealerhebungen (Fig. 174).

Die mediane Erhabenheit wird vom Urachus gebildet; die mittlern Erhabenheiten von den Strängen der Nabelarterien (Lig. resico-nmbil. later.), die lateralen von den Arteriae epigastricae.

Jeder arterielle Strang ist im freien Rande einer Peritonealfalte in Form eines Halbmonds enthalten, welcher ron den Seiten der Blase bis zum Nabel gespannt ist.

Diese fünf Erhabenheiten begrenzen sechs Grübchen, Foveae, je drei an jeder Seite der Medianlinie.

Diese wenig tiefe Fovea inguimalis interma ist innen rom Urachus, aussen ron der Falte des Nabelstranges, unten von der Erhabenheit des Schambeins begrenzt. Die vordere Wand dieser Grube wird von der Sehne des Rectus abdominis gebildet. D urch diese Grube entsteht die Hernia inguinalis obliqua interna.

Die tiefste Fovea inguimalis media entspricht der hintern Wand des Inguinal- 
kanales. Sie ist innen und hinten von der Falte des Nabelstranges und aussen rom Relief der Art. epigastrica begrenzt. Durch dieselbe entsteht die Hernia inguinalis directa.

Die kleine trichterförmige und wenig tiefe Fovea inguinalis externa wird innen von der Erhabenheit der Art. epigastrica und unten von der Erhabenheit des Vas deferens gebildet.

Das Peritoneum, yon narbigem $\Lambda$ ussehen, mit dem Vas deferens sehr adhärent, stellt kleine trichterförmige Falten dar, welche von kanonede beschrieben wurden. Von der Spitze dieses Grübchens geht ein fibröser Strang ab, der sich auf der andern Seite an der Tunica vaginalis verliert, der obliterirte Strang, der Rest des Canalis peritoneo-vaginalis. Dicser Kanal persistirt oft, durch diesen entsteht die Hernia inguinalis congenitalis.

Zuweilen verstopft er sich zum Theile, meistentheils in seinem peritonealen oder äusseren Theile persistirend; in diesen Fällen nimmt die tiefe Fovea inguinalis externa eine verlängerte Trichterform an, indem sie eine Praedispositionsstelle für einen Iterniensack bildet.

Die Fovea inguinalis externa entspricht dem tiefen Orificium des Leistenkanals; durch diesen entsteht die Hernia inguinalis externa, die häufigste von allen und meistentheils angeboren. Bei Fraueı hat die äussere Inguinalgrube zuweilen die Form eines tiefen Trichters, Canalis Nuci.

Technik z. A. d. (t). Man durchschneidet transversal unter dem Nabel die Abdominalwand und ergänzt mit zwei verticalen lateralen Schnitten einen grossen vordern Lappen. An seiner tiefen Fläche sucht man zuerst die fünf peritonealen Erhabenheiten und zwischen denselben die Foveae inguinales auf.

\section{Regio hypogastrica.}

Der Urachlis, Lig. umbilicale medium, ist ein Strang in der Medianlinie unter dem Peritoneum, welcher ron der Spitze der Blase bis zum Nabel gespannt ist. Er stellt den Rest des Kanales dar, durch welchen am Anfange beim Embryo die Blase mit der Allantois communicirte.

Technik z. A. d. G. Man schneidet in der Medianlinie die Abdominalwand vom Nabel bis zum Schambeine ein. Man legt stumpfe Haken in die Schnittränder ein und zerreisst mit den Fingern das subperitoneale zellig-fibröse Blättchen; hinter der Symphyse findet man die Blase, von deren Spitze man einen Strang abgehen sieht, der sich gegen den Nabel in mehrere Ausläufer theilt, es ist der Urachus, der von einer Fettschicht ungeben und am Peritoneum gelagert ist.

IDie Harıblase liegt im vordern Theile der Beckenhöhle oberhalb der Prostata vor dem Rectum und dem Colon pelvinum. Beim Weibe liegt die Blase an der vordern Wand der Vagina, rom Uteruskörper durch eine peritoneale resico-uterine Aussackung getrennt.

Ihre vordere untere Fläche steht mit der Symphyse des Schambeins in Beziehung; wenn die Blase gespannt ist, verbreitert sich clie vordere Fläche und steht in grösserem 
oder geringerem Masse zur Abdominalwand in Beziehung, von welcher sie durch den praevesicalen Blindsack des Peritoneums getrennt bleibt.

Die lateralen Wände stehen mit den lateralen Wänden der Beckenhöhle in Beziehung.

Technik z. A. d. G. Man macht an der Symphyse des Schambeines beginnend einen Bauchschnitt, der bis 3 oder 4 Finger oberhalb derselben reicht, legt stumpfe Haken ein und führt die hakenförmig gekrümmte Fingerspitze hinter die Symphyse ein, welche das zellige, fette, praevesicale Gewebe nach oben drückt. Man fasst mit den Fingern das, was unmittelbar hinter der Symphyse sich befindet; man fühlt zwischen den Fingern eine dicke Falte von eigenartiger Consistenz, auf welcher man dicke plexusartige Venen sieht, es sind die Venae vesicales, weil die Falte, die zwischen den Fingern sich befindet, die vordere Wand der Blase ist. Man fasst diese mit zwei Schieberpincetten und durchschneidet sie schichtenweise in der Medianlinie, man macht eine Cystotomie. Indem man den Finger in die Blase einführt, tastet man ihre innere Fläche $a b$; unten und vorne fühlt die Fingerbeere eine kreisförmige Grube, den Hals der Blase, wo der Canalis urethralis beginnt.

\section{Regio scrotalis.}

Der Samenstrang und das Vas deferens. Der Samenstrang beginnt am Orificium peritoneale des Leistenkanals und endigt am obern Rande des Testikels. - Er ist $15-16 \mathrm{~cm}$ lang und durchdringt von oben nach unten den Leistenkanal, die Inguinal partie und das Scrotum, die Scrotalpartie. - Beim Austritte aus dem Leistenkanale bildet der Strang einen stumpfen Winkel an der Spina pubica und am Ende des vordern untern Inguinalpfeilers. Der fingerdicke Samenstrang wird von einer zellig-fibrösen Scheide umgeben, welche sich auf den Testikel fortsetzt, indem sie die zellig-fibröse Tunica communis bildet. Im Niveau des Orificium inguinale profundum setzt sich die zelligfibröse Scheide in die Fascia subperitonealis fort und rings um dieses Orificium adhärirt sie an der Fascia transversa. - Die äussere inguinale Peritonealaussackung dringt in den Innenraum der Scheide dieses Stranges. -

An der oberflächlichen Lage des Samenstranges verläuft das äussere Bündel des Cremaster.

Im Innenraum der Scheide des Stranges findet man seine Gebilde in zwei Gruppen getheilt.

a) Die hintere Gruppe wird vom Vas deferens gebildet, welches von der Arteria deferens begleitet wird, von zahlreichen Nervenfäden und von einem Venencomplex umgeben ist.

b) Die vordere Gruppe wird von der Arteria spermatica, in deren Umkreise man einen reichen Venenplexus und zahlreiche Nervenfäden findet, gebildet. - Diese Gebilde sind von einer gelblichen Fettschicht umgeben. Die Venen der vordern Gruppe sind es, welche gewöhnlich bei der Varicocele hypertrophiren.

Bei einem Neugeborenen oder Fötus enthält der Samenstrang noch den Canalis peritoneo-vaginalis, welcher normaler Weise kurze Zeit nach der Geburt obliterirt und an seiner Stelle bleibt ein fibröser Tractus zurück, welcher vom peritonealen Blindsack zum 
oberen vaginalen Blindsack gespannt ist. Anormaler Weise kann der Peritonealkanal in seiner Gesammtheit oder nur partiell persistiren.

Das Vas deferens ist eine membranös-musculöse Tube von der Dicke cines dünnen Bleistiftes, welche ron dem Schweife der Epididymis, in welchen es übergeht, bis oberhalb des hintern obern Randes der Prostata gespannt ist, wo es mit dem Halse der Vesica seminalis sich vereint und den Ductus ejaculatorius bildet.

Letzterer dringt in das Prostatagewebe und öfinet sich in der Uretra prostatica an den lateralen Seiten der Schleimlautfalte, bekannt unter dem Namen Ver u montanum.

Längs seines Verlaufes stellt das Vas deferens bogenförmig den Ramus pubicus des Os ilium umschlingend mehrere Partien dar.

In der ersten Partie oder Portio testicularis ist das Vas deferens in einer Furche gelagert, die ron der innern Fläche der Epididymis und rom hintern Rande des Testikels begrenzt ist.

In dieser Region besitzt das Vas deferens zahlreiche Falten und wird immer dünner je näher es dem Schweife der Enididymis kommt.

In der zweiten Partie oder Portio funicularis folgt es der Tasehe, welche, wie wir gesehen haben, im Strange liegt.

Im Nireau des Orificium inguinale bildet es einen stumpfen Winkel, gleitet an der oberen Fläche der Spina pubica und dringt in den Canalis inguinalis, Portio inguinalis. -

Durch das Orificium inguinale peritoneale dringt das Vas deferens in die Abdominalhöhle; in diesem Nivean beschreibt es eine mit der Concavität nach abwärts und innen gerichtete Falte nnd umsehlingt die Art. epigastrica, indem es sich an die Wand der Fossa iliaca lagert, Portio iliaca. Mehr nach innen kreuzt es sich in $\mathrm{X}$ mit den Iliaealgefässen und mit dem Nervus genito-eruralis, biegt von neuem ab und dringt immer tiefer in die Beckenhöhle, die Portio pelviea. Auf der lateralen Wand der Beckenhöhle gelagert, kreuzt es die Vena iliaca, den Strang der Arteria umbilicalis, das Packet der Gefässe und des Nervus obturatorius; in dem zelligen vesico-rectalen Raume angelangt, richtet es sich nach innen und dringt durch diesen Raum, indem es an dem obern innern Rande der Tesica seminalis haftet, mit dessen IIals es sich wenig oberhalb der Prostata vereinigt.

Längs der Vesica seminalis rerdickt es sich und nahe der Medianlinie haftet es an dem Vas deferens der Gegenseite. Vom Orificium inguinale peritoneale und bis zu den Seitentheilen der Blase liegt das Vas deferens unmittelbar unter dem Peritoneum in einer Theilung des sub-peritonealen Blättehens.

In der Nähe des Orificium inguinale adhärirt das Peritoneum, welches die Forea inguinalis externa bildet, innig mit dem Vas deferens. Das ist die Gegend, wo das Vas deferens sehr schwer zu isoliren ist von dem Halse eines Herniensackes und hier entzündet sich das Peritoneum bei einer gonorrhoischen Entzündung des Tas deferens.

Technik z. A. d. (H. Man tastet die vordere Fläche der Spina pubica ab, wenn man mit der Fingerbeere leicht drückt; an der knöchernen Fläche fühlt man den Samenstrang gleiten, in dessen Innenraume dic Finger ein voluminöses und eonsistentes Organ muterseheiden, das Tas deferens.

Man nimmt und reibt zwischen den Fingern den Stiel des Hodensacks und trennt auf diese Treise die Gebilde des Samenstranges, zwisehen welchen man den Strang des T as deferens fühlt. Nachdem man den Strang erkannt hat, macht man über den Stiel des Hodensacks einen Schnitt, isolirt mit dem Finger und der Hohlsonde den Strang und hebt ihn auf einen stumpfen 
Haken. Mit Pincette und Sonde wird die gemeinsame zellig-fibröse Scheide zerrissen und die Gebilde des Stranges auseinander genommen; man wird sofort das Tas deferens erkennen und auf die Hohlsonde heben (Fig. 175).

Mit der Scheere wird ein Theil dieses Vas resecirt, eine Operation, welche man an einem an Prostatahypertrophie Leidenden macht.

Die Epididymis hat die Form eines prismatischen und dreieckigen Horns, das 3-4 cm lang ist und mit seiner Concavität das obere Drittel der äussern Fläche des Testikels fasst. Sie wird von einer langen Tube gebildet, welche zahllos gewunden und geflochten ist.

Die Epididymis stellt drei Partien dar:

a) Die vordere Partie oder der Kopf ist kugelig und adhärirt am obern vordern Pol des Testikels.

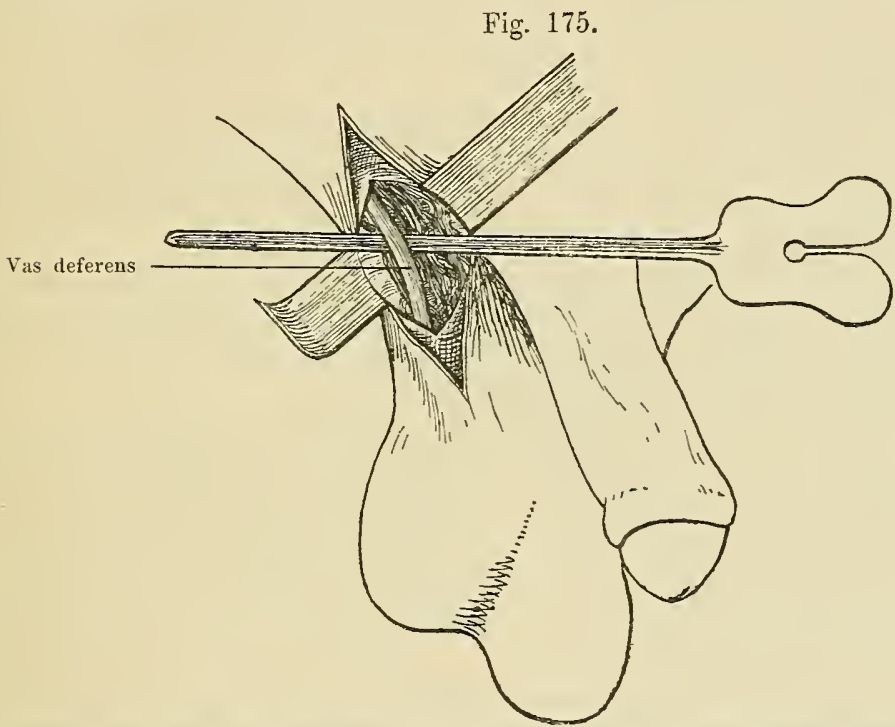

Das Aufsuchen des Vas deferens. Der Samenstrang ist auf einen stumpfen Haken gehoben und das Vas deferens auf eine Hohlsonde.

b) Die mittlere Partie oder der Körper ist etwas dünner und vom Testikel durch die unter der Epididymis befindliche Aussackung der Scheide getrennt.

c) Die hintere Partie oder der Schweif, weniger kugelig als der Kopf, adhärirt wie dieser an dem Testikel.

Der Testikel und die Epididymis sind zum grössten Theile von einer geschlossenen serösen Höhle, der Cavitas vaginalis, umgeben, welche zuerst ein Divertikel der Peritonealhöhle darstellt, mit der sie auch durch den Canalis peritoneo-vaginalis rerbunden war. In dieser Höhle sammelt sich Flüssigkeit bei einer Hydrocele oder bei einem Hämatom der Scheide. Das viscerale Blättchen der Testikelscheide geht im Niveau des Kopfes und des Schweifes der Epididymis direct vom Testikel auf die Epididymis über; im Niveau des Kopfes dringt es in den Blindsack zwischen Epididymis und Testikel, indem es den sub-epididymalen Blindsack bildet.

Technik z. A. d. G. Nan soll mit der grössten Leiçhtigkeit im Grundo 
des Hodensackes den Testikel in Form eines eiförmigen Körpers erkennen, der schr beweglich und schmerzhaft ist, wenn er $\mathrm{zu}$ fest gedrückt wird.

Wir kennen alle den characteristischen Schmerz des Testikels, weshalb wir bei einer Hydrocele seine Lage bestimmen können.

Man nimmt und tastet den Testikel zwischen den Fingern, man fühlt oberhalb desselben seinen hintern obern Rand deckend einen consistenten nicht schmerzhaften Körper, der ron dem 'T'estikel durch eine Furche geschieden ist, es ist dies die Epididymis, an welcher man vorne den Kopf, in der Mitte den Körper und hinten den Schweif unterscheidet. Mit ein wenig Uebung wird man an der innern Fläche der Epididymis in Form eines Stranges die Portio testicularis des Vas deferens erkennen.

Man drïckt und fixirt mit den Fingern den Testikel im Grunde des Scrotum und prïparirt mit dem Bistouri auf seiner Erhebung die auf diese Weise gespannte Haut, es tritt unmittelbar zwischen den Schnitträndern der Testikel heraus, gerade wie der Kern einer Kirsche, wenn man sie zwischen den Fingern drückt.

Man isolirt besser mit dem Finger den Testikel und den untern Theil des Stranges; man bemerkt, dass der untere Pol des Testikels mit dem Grunde des Scrotum durch ein zellig-fibröses Blatt, das Ligamentum scrototesticulare, verbunden ist.

Man nimmt den Testikel zwischen die Finger, durchschneidet an seinem convexen Rande die zellig-fibröse Tunica communis und das parietale Blatt der Tunica propria. Der comprimirte Testikel tritt sofort zwischen den Schnitträndern der Tunica wie eine Hernie hervor.

Nan legt den Testikel frei, indem man die Scheide mit dem Boden nach oben kehrt, und sieht an seiner äussern Seite die Epididymis und unter ihm die Forea sub-epididymalis oder digitata; man bemerkt auch, dass das Orificium dieses Blindsackes unten rom Testikel begrenzt wird, oben von dem untern sehr dünnen Rande der Epididymis, vorn und hinten durch zwei sichelförmige Falten der Tunica propria, welche Ligamenta epididymo-testicularia genannt werden.

Nan durchschneidet die Albuginea und die Testikelsubstanz tritt hernienartig in Form einer braunen Masse herror; man bemerkt, dass die Substanz des Testikels sehr leicht von der Albuginea zu trennen ist und nur durch cinen breiten antero-posterioren Stiel am unteren Rande des Corpus Highmori angeheftet bleibt.

\section{Cavitas abdominalis.}

Die Gallenblase ist ein birnförmiges Säckchen und liegt auf der untern Fäche der Leber in einer Furche, welche innen vom Lobulus quadratus und aussen vom Lobulus rectus begrenzt ist. Ihre Achse ist schief nach oben innen und von rechts nach links gerichtet.

Der Grund der Gallenblase ïberschreitet fingerbreit den vorderen Rand der Leber und setzt sich mit der Abdominalwand in Contact; ihr oberes Ende geht mit einer speciellen trichterförmigen Partie, der Blasenhals, in den Ductus cysticus über, der sich mit dem Duc tus hepaticus vereinigt um den Ductus cho led och us zu bilden (Fig.176). 
Die untere Fläche und die lateralen Theile der Gallenblase sind vom Peritoneum umkleidet, welches an jeder Seite auf die Leber übergeht; die obere Fläche ist direct mit der Leber in Contact. Oft liegt die Gallenblase nicht an der Leber, sondern hängt an derselben mit einer Peritonealfalte, einem Cystomeso, die durch Znsammenkleben zweier Peritonealblättchen gebildet wird. Der Grund der Blase ist von allen Seiten vom Peritoneum bedeckt.

Der Ductus choledochus von der Dicke eines Brieftaschenbleistiftes entsteht durch Vereinigung des Ductus cysticus mit dem Ductus hepaticus, steigt nach unten herab, zieht hinter der aufsteigenden Partie des Duodenum, löthet sich an die innere Wand der absteigenden Partie dieses Organs, in dem er sich in die Duodenalhöhle durch ein kleines Orificium, das an der Spitze einer Erhabenheit, des grossen Carunculus Santorini gelagert ist, öffnet.

Der Ductus choledochus durchzieht sehr schief die Duodenalwand zwischen zwei

Fig. 176.

Art. hepatica

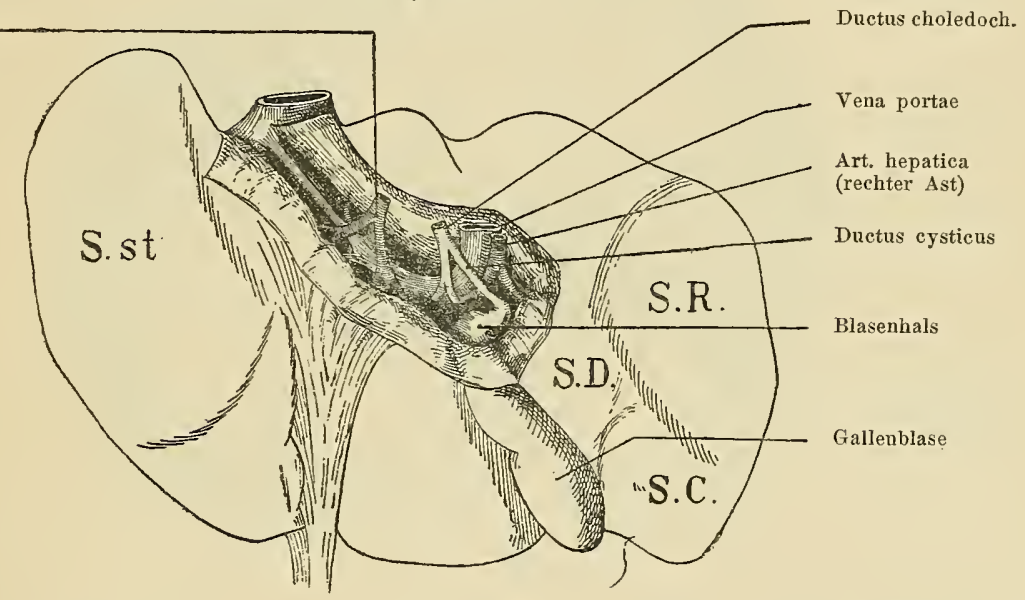

Die hintere untere Fläche der Leber, ihr vorderer Rand befindet sich unten. Die Gebilde des Hilus der Leber sind in den beiden Peritonealblättern, welche des kleine Netz bilden, präparirt. S. st. Magen-Oberfläche, S. R. renale Oberfläche (rechts), S. D. duodenale Oberfläche, S. C. Dickdarmoberfläche.

Lagen der kreisförmigen Scheide ziehend; in der Wand vereinigt er sich mit dem Ductus pancreaticus oder Ductus Wirsungii, mit dem er zusammen ein kleines gemeinsames Grübchen bildet, die Ampulle oder Cavitas Vateri (Fig. 176).

In diesem Verlaufe, vom Gesichtspunkte seiner chirurgischen Beziehungen ist der Choledochus in zwei getrennte Partien getheilt.

1. Die Pars superior supra-duodenalis oder auch Portio chirurgica liegt am rechten Rande des kleinen Netzes, zu ihrer linken Seite hat sie die Art. hepatica, linten die Vena portae.

2. Die Pars inferior retro-duodenalis liegt hinter der aufsteigenden Partie des Duodenum im Pancreaskopfe.

In diesem Theile ist der Ductus choledochus von zahlreichen Arterien und Venen gekreuzt, die im Pancreaskopfe gelegen dem Chirurgen wenig zugänglich sind. 
Terhnik z. A. d. (A. Man schneidet handbreit ron der Medianlinie rertical dic Abdominalwand rom Rippenrande bis $4-5$ Finger unterhalb desselben ein. Mlan legt stumpfe llaken ein, sucht den vordern Rand der Leber auf, hebi diese mit den Fingern nach oben und sieht an ibrer untern Fläche die Gallenblase in Form eines ciförmigen Beutels und von gelblicher Farbe an Cadarer. Man fasst sic zwischin den Fingern und folgt ihr ron unten nach oben bis zum Hilus der Leber. Wenn der gemachte Schnitt zu klein und nicht grenügend deutlich ist, rerlängert man denselben oder besser man durchschneidet mit der Scheere dem Rippenrande folgend die Abdominalwand gegen die Medianlinie und richt den dreieckigen Lappen,

Fig. 177 .

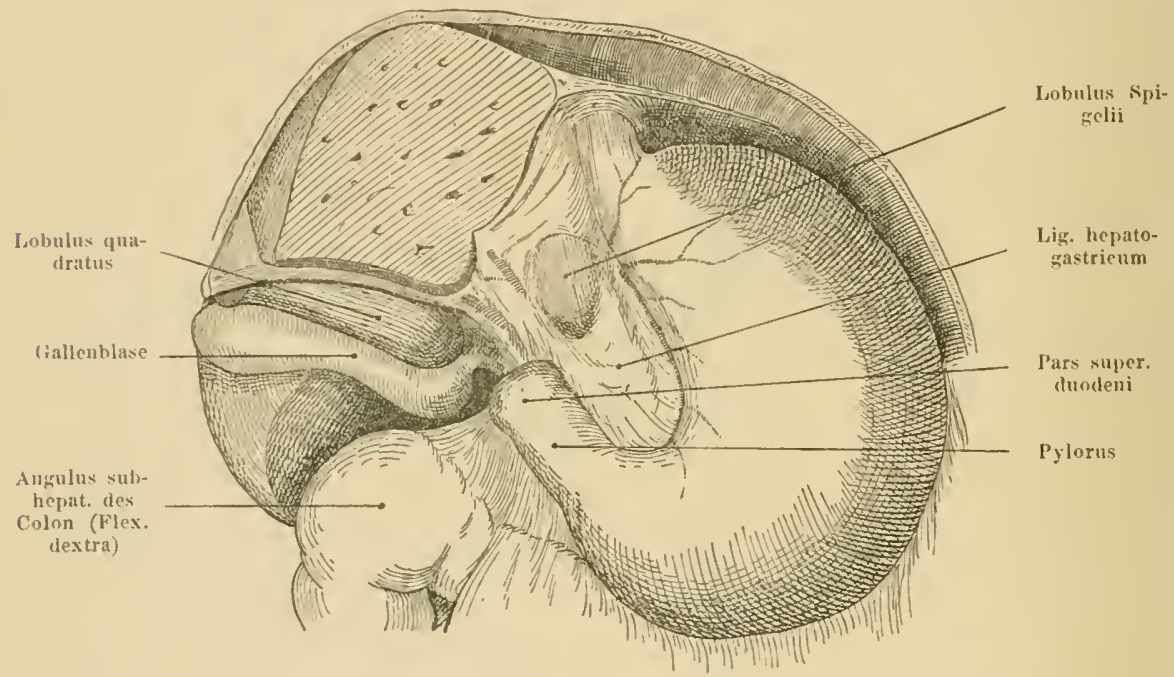

Regio hepato-gastrica. Der linke Leberlappen wurde durchschnitten, um den grössten Theil der vorderen Magenfläche und das kleine Netz (Omentum minus) freizulegen, welches rom Hilus der Leber zum inneren Rande des Oesophagus und des Magens, und zum oberen Rande des Pylorus und des Zwölffingerdarms gespannt ist. Diese im mittleren Theile sehr dünne Falte des Peritoneums ist vorgewölbt, und lässt durchscheinend das abgerundete Ende des Lobulus Spigelii sehen.

den man so gebildet hat, nach unten herab. Man ersucht einen Assistenten, dass er die abgehobene Leber gegen das Diaphragma drücke; man sucht den obern Winkel, den subhepatischen des Duodenum auf, zicht ihn nach unten und sieht dann zwischen Duodenum und Leber sich anspannend die Pars hepato-duodenalis des kleinen Netzes. Mlit Pincette und Hohlsonde zerreisst man vorsichtig nahe dem freien Rande des kleinen Netzes das vordere peritoneale Blättchen dieser Falte und gelangt an einen weisslichen verbreiterten Strang, an den Ductus choledochus; man isolirt diesen, fasst ihn mit cinem Haken, schneidet dann seine vordere Wand ein und tastet, eine Sonde cinführend, seine Höhle ab.

Der Hiatus Winslowii ist eine nnter der Leber gelagerte Lücke, durch welche 
die hinter dem Magen befindliche Höhle des Peritoneum mit der grossen Peritonealhöhle communicirt. Dieses Foramen ist ron vorne nach hinten verbreitert, $1-2 \mathrm{~cm}$ lang und besitzt 4 Wände.

1. Die vordere Wand wird von der hepato-duodenalen Partie des kleinen Netzes gebildet, welche die Gebilde des Leberhilus enthält. Diese Gebilde sind: auf einer hinteren Fläche die Vena portae, auf einer mehr vordern der Ductus choledochus und an dessen'Innenseite die Arteria hepatica (Fig. 177).

2. Die obere Wand wird von der Leber gebildet, durch jenen Anhang oder Falte, die an der Spitze und an der rechten Seite des Lobulns Spigelii entsteht and im Lobulus rectus sich verliert.

Fig. 178.

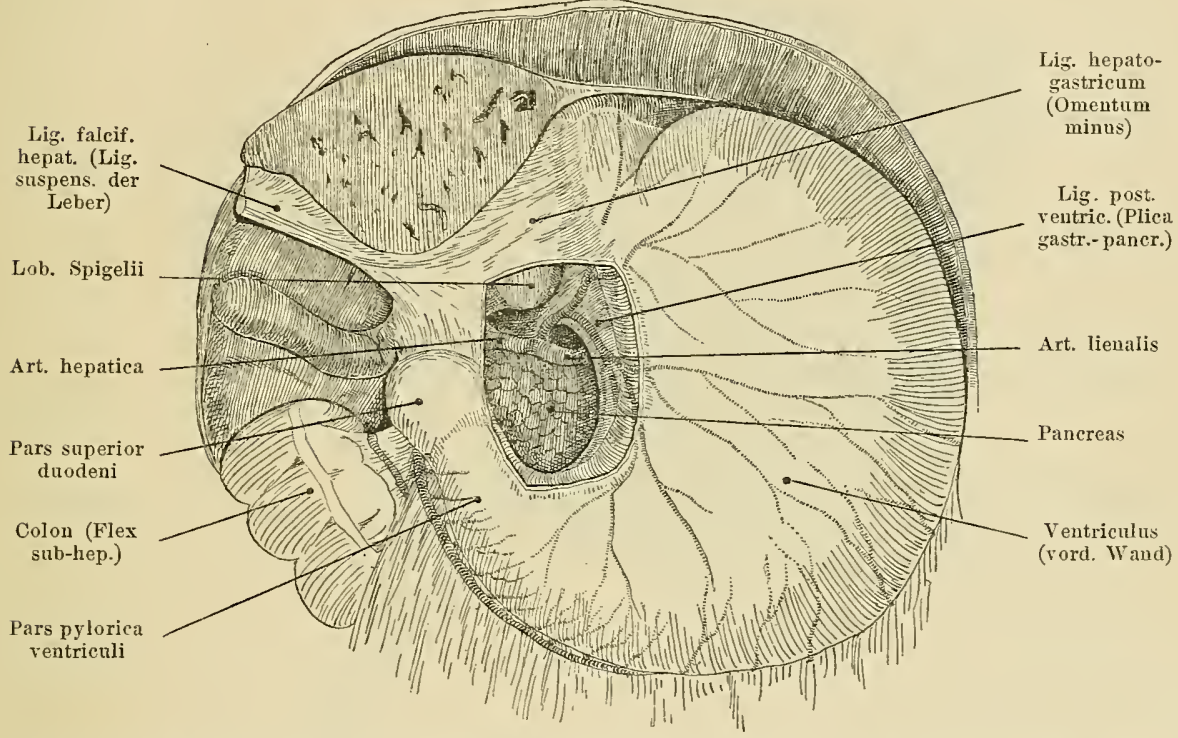

Regio hepato-gastrica. Der linke Leberlappen wurde resecirt; im kleinen Netze wurde eine Lücke ausgeschnitten, um hinter demselben folgende Gebilde sehen zu können: das Pancreas, an seinem oberen Rande links die Arteria lienalis und rechts die Arteria hepatica; die Art. coronaria des Magens, die am freien Rande einer sichelförmigen Falte, Ligamentum posterius des Magens, enthalten ist. Die Arteria hepatica, Arteria lienalis und Art. coronaria entstehen aus demselben Stamme, dem Truncus coeliacus, einem Aste der Aorta.

3. Die hintere Wand wird von der Erhabenheit der Vena cava, die vom Peritoneum bedeckt ist, gebildet.

4. Die untere Wand wird rom Zwölffingerdarm und von der Peritonealfalte gebildet, die von der vorderen Fläche der Vena cava abgeht und an der hintern Fläche der beweglichen Partie des Duodenum sich verliert.

Technik z. A. d. G. Man macht wie für das Auffinden der Gallenblase einen langen lateralen Bauchschnitt. Indem ein Assistent die Leber nach oben zieht, sucht man die Gallenblase auf und folgt mit dem Zeigefinger der linken Hand ihrem rechten Theile; im Grunde dringt die haken- 
förmig gekrïmmte Fingerspitze in ein Foramen ein, in den Hiatus Winslowii. Oberhalb fïhlt und umkreist die l'ingerbeere eine freie oroide Erhabenheit, die beim Berühren ein analoges Gefühl giebt wie der Hals der Urethra, es ist die Spitze des Lobulus Spigelii.

Man wendet die Fingerbeere nach hinten und fühlt cine andere weiche unteritückbare Érbabenheit, die I' ena cava inferior. Man wendet den Finger nach rorne und hebt auf demsetben die vordere Wand, dic rom kleinen Netze gebildet ist; am Finger prïparirt man mit Pincette diese Peritonealfalte und findet vorne und aussen den Duetus choledochus, vorn

Fig. 179 .

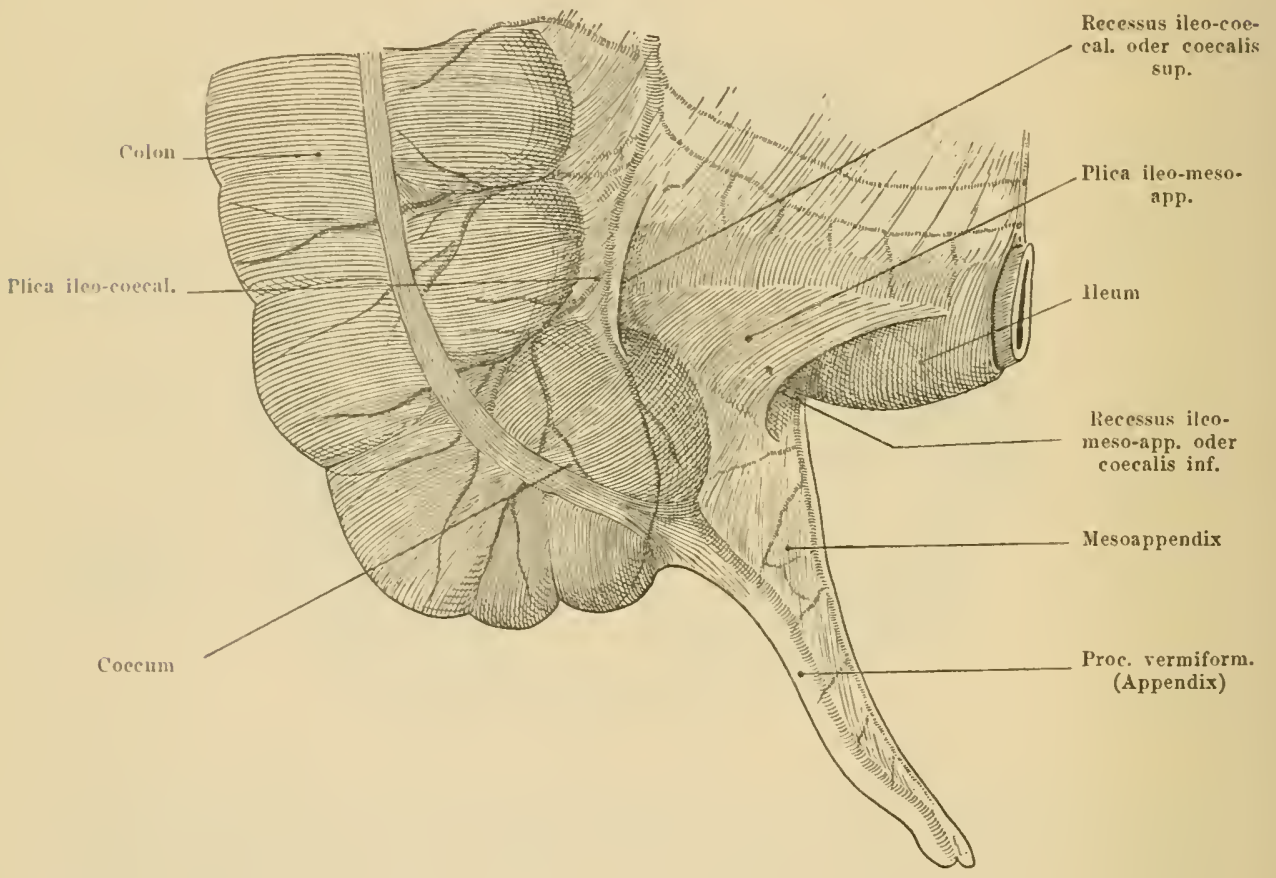

Die vordere Fläche des Coecum mit den pericoecalen Peritonealfalten und den Recessus coecales.

und mehr imnen die Arteria hepatica und hinter diesen Gebilden die Tena portae. Zahlreiche Nervenfïden und einige Lrmphdrüsen findet man rings um diese Arei Gebilde. Ein Ifesser, das im Nireau des Hiatus Winslowii eingeführt würde, müsste rorn den Dnetus choledochus, die Arteria hepatica und Vena portac, hinten die Vena cava inferior durchschneiden.

Die Regio pylorica umfasst zwei Partien; eine rechte Partie Pylorus proprius genannt und eine linke trichterförmige dilatirte Partie Vestibulum pyloricum, welche in den Magen übergeht.

Der Pylorus hat die Form einer dickwandigen Röhre und ist 2 Finger lang; seine lchse ist schief nach oben, innen und hinten gerichtet. Oben geht er in 
die aufsteigende Partie des Duodenums über, von der er durch einen erhobenen leicht zu tastenden Rand getrennt ist (Fig. 178).

Der obere Rand des Pylorus hängt an der Leber durch das kleine Netz; die vordere Fläche steht mit der untern Fläche der Leber und mit der vorderen Abdominalwand in Beziehung, die hintere Fläche entspricht dem Pancreas, ron dem sie durch eine peritoneale Aussackung, durch die Pars pylorica der hinter dem Magen befindlichen Höhle getrennt ist.

Technik z. A. d. G. Man macht rom Processus xiphoides bis 4 Finger oberhalb des Nabels einen medianen Bauchschnitt. Im obern Theile des Schnittes sieht man die Leber; man führt in das Abdomen zwei Finger ein und fasst, der untern Fläche der Leber folgend, wie mit einer Pincette das, was man unter der Leber findet und zieht es nach aussen, es ist der Magen. Man folgt demselben von links nach rechts und sieht in einem gewissen Momente, dass er die Form einer dicken Röhre annimmt, es ist der Pylorus, der in ein breiteres Gebilde mit dünnern ITänden übergeht, in die erste Partie des Duodenum.

Das Coecrum oder die Initialpartie des Dickdarms liegt im obern Theile der Fossa iliaca dextra.

Beim kinde hat das Coecum die Form eines regelmässigen Kegels, ron dessen Spitze der Processus vermiformis abgeht.

Beim Erwachsenen hat das aufgeblasene Coecum die Form eines unregelmässigen höckerigen Kegels, welcher durch drei verticale Furchen, die den drei rerticalen Mnskelstreifen entsprechen, in drei Segmente getheilt ist.

Diese Streifen vereinigen sich miteinander am untern und innern Theile, an der Spitze des Coecum rings um die Wurzel des Processus rermiformis. Oben geht das Coecum in das Colon ascendens über, mit welchem es einen spitzen Winkel bildet, in dem das Ileum durch ein knopflochartiges Orificium sich öffnet, welches ron zwei membranös-musculösen Falten, Valvulae ileo-coecales, begrenzt ist.

Das Coecum ist ron allen Seiten rom Peritoneum belileidet.

Der Processus vermiformis ist mit der hintern Fläche des Mesenterium durch eine dreieckige peritoneale Falte, dem Mesoappendix, verbunden, in dem man die Arteria und Vena appendicularis findet.

Zwei peritoneale Grübchen findet man rings um das Coecum.

1. Der Recessus ilio-coecalis superior, wenig tief, ist vorne ron einer halbmondförmigen peritonealen Falte, Plica arteriae coecalis anterioris begrenzt. Diese Falte entsteht oben oberhalb des Ileum an der vorderen Fläche des Mesenterium und verliert sich unten und aussen am Colon und am Coecum; sie enthält am freien Rande die Arteria und Vena coecalis anterior und neben denselben ein oder zwei Lymphdrüsen.

Hinten ist der Recessus ilio-coecalis superior von der vorderen Fläche des Ileum begrenzt.

2. Der Recessus ilio-meso-appendicularis hat die Form einer Pyramidengrube mit der Spitze nach aussen gerichtet, die Basis nach innen geöffnet. Er wird begrenzt: hinten vom obern Theile des Meso-appendix, oben von der untern Fläche des Ileum und vorne von einer Falte oder der Plica ilio-meso-appendicularis. Diese Falte inserirt sich: oben an der vorderen Fläche des Ileum, aussen am Coecum, unten am Mesoappendex; ihr vorderer Rand ist frei. Diese Falte enthält glatte, vom Coecum zum Lleum gespannte Muskelfasern (Fig. 179).

Techuik z. A. d. G. Man macht an der rechten Seite 3 Finger ober- 
halb des Poupart'schen Bandes und diesem parallel einen Bauchschnitt. Han legt stumpfe Haken ein und entfernt die Darmschlingen; man sieht sie in der Fossa iliaca das Coecum gelagert. Min zicht es nach aussen und bemerkt, dass es von allen Seiten vom Peritoneum bekleidet ist. Ilan sucht die Recessus peri-coecales auf. Zuweilen findet man hinter dem Coecum einen anderen Recessus retro-coecalis.

Das Duodenum und die Recessus duodenales. Das Duodenum, die erste Partie des Dünndarms, beginnt rechts rom Pylorus nnd endigt links unter dem Magen, wo es in das Jejunum mit ciner Schlinge, Flexura duodeno-jejunalis, ïbergeht.

Dem übrigen Dünndarme entgegen, ler sich dureh seine grosse Beweglichkeit characterisirt, ist das Duodenum vor der Wirbelsiule fixirt, weshalb es auch "fixe Schlinge" des Dënndarms genannt wird.

Das Duodenum beschreibt ror den ersten 3 Lendenwirbeln einen Bogen, der die IFurzel des Mesenterium umgreift.

Fig. 180.

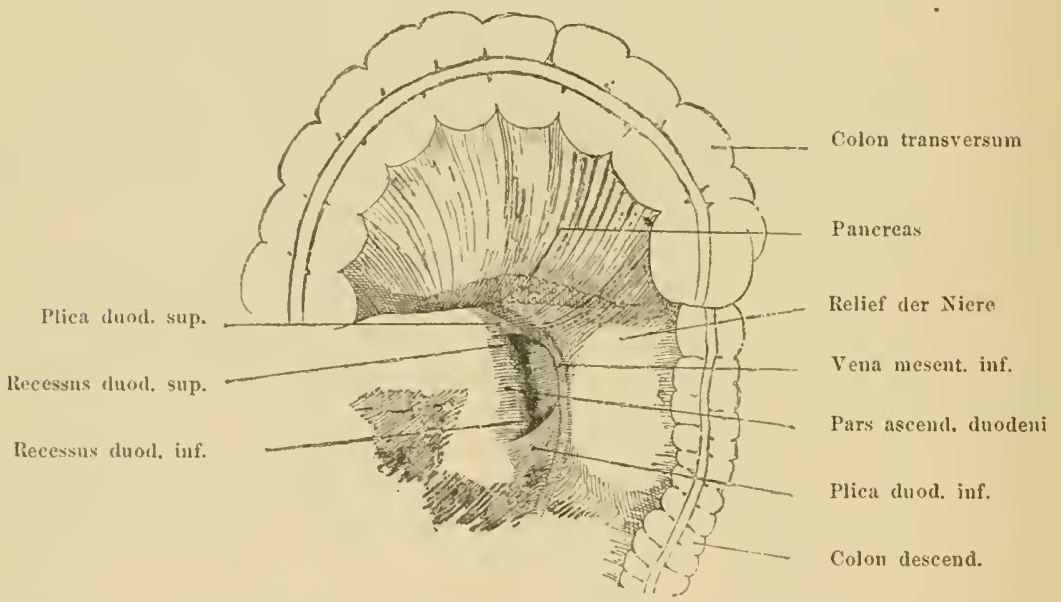

Pars ascendens duodeni. Das Colon transversum ist nach oben gehoben. Man sieht die Duodenalfalten und die Recessus, welche sie begrenzen.

Gewöhnlich hat das Duodenum bei Erwachsenen die Form eines V und stellt drei Partien dar: eine Pars ascendens oder subhepatica, eine Pars descendens oder prae-renalis und eine Pars ascendens oder prae-aortica.

1. Die l'ars ascendens beginnt am Pylorus, richtet sich nach oben und aussen und endigt unter der Leber, wo sie mit einem Winkel, $\Lambda$ ngulus subhepaticus, in die Pars descendens ïbergeht.

Oben ist sie mit dem Hilus der Leber durch die reehte hepato-duodenale Partie des kileinen Netzes verbunden.

2. Die Pars descendens steigt vertical vor der inneren Partie der vordern Fläche der rechten Niere und Vena cava herunter.

Innen ist diese Partie mit dem Pancreaskopfe und dem Ductus choledochus in Beziehung; der Stiel des Meso-colon transrersum theilt sie in 2 Partien; cine obere Portiosupra-meso-colica und eine untere Portiosub-meso-colica. 
3. Die Pars ascendeus prae-aortica beginnt vor dem Körper des IV.Lendenwirbels, wo sie mit einer Aussackung in die Pars descendens übergeht; sie erhebt sich dann sehr wenig schief nach links und endigt hinter dem Magen und unter dem Pancreaskopfe im Niveau des ersten Lendenwirbels.

In diesem Niveau gebt das Duodenum in das Jejunum durch die Duodeno-jejunalSchlinge über, welche vor der Wirbelsäule und den Diaphragmapfeilern durch ein Muskelbündel mit glatten Fasern, Musculus Treitzi, befestigt ist.

Zuweilen hat das Duodenum die Form eines Huteisens mit dem sogenannten U-Typus und an jene drei Partien reilit sich noch eine vierte, die Pars transversa. Andere Male hat es die Form eines Ringes, Typus annularis, der bei líindern normal ist.

Die Beziehungen mit dem Peritoneum sind nach den verschiedenen Partien des Duodenum rerschieden.

Die Pars subhepatica ist fast rollständig rom Peritoneum bedeckt, weshalb sie nur relativ beweglich ist; wir haben bereits gezeigt, dass diese am Hilus der Leber durch das kleine Netz hängt. Unten steht sie mit dem obern Blättchen des Meso-colon transversum in Beziehung, hinten entspricht sie dem Hiatus Winslowii.

Die Pars descendens und ascendens sind rom Peritoneum nur an ihren vordern Flächen bedeckt. Nahe der Pars ascendens bildet das Peritoneum zwei Falten, welche mit den Duodenalwänden zwei Grübchen begrenzen.

Die Plica duodenalis superior peritonei hat die Form eines Halbmonds. Sie inserirt sich innen an der rordern Fläche der Flexura duodeno-jejunalis, aussen und hinten unter dem Mleso-colon an dem peritonealen Blättchen, das die vordere und linke Fläche der Wirbelsäule bedeckt.

Der vordere Rand dieser Falte ist frei; die Curve der Vena mesenterica inferior zieht in dieser Falte, bevor sie mit ihrer Conrexität die Duodeno-jejunal-Schlinge umgreift.

Der Recessus duodenalis superior, wenig tief, schaut nach unten.

Die Plica duodenalis inferior peritonei, um vieles stärker entwickelt, hat die Form eines mit der Spitze nach oben gerichteten Dreiecks. Sie inserirt sich: innen an der lateralen linken Wand der Pars ascendens dnodeni, aussen und hinten am peritonealen Blatte, das die Aorta abdominis bedeclit; ihr oberer Rand ist frei.

Oft vereinigt sich der obere änssere Winkel der Plica duodenalis inferior durch eine Falte mit dem untern änsserm Winkel der obern Falte, auf diese Weise ein breites ovales Orificium bildend, in welches sich die beiden Recessus duodenales öffnen (Fig. 180).

Technik z. A. d. G. Mlan macht an der Linea alba einen Banchschnitt, der 3 Finger unter dem Processus xiphoides beginnt und etwas unter dem Nabelringe endigt. Man sucht den Pylorus auf, folgt diesem von unten nach oben unter der Leber und fühlt in einem gegebenen Augenblicke in Form eines dicken Ringes den Pylorusrand, oberhalb desselben ist die Wand des Darms düm, die Pars prima duodeni.

Man legt stumpfe Haken ein und drückt die Dünndarmschlingen nach rechts und das Colon transversum nach oben unter die Leber; man sieht vom Peritoneum bedeckt die Pars descendens duodeni durchscheinen. Man sucht im obern Winkel des Schnittes das Colon transversum auf, zieht und drückt das grosse Netz nach oben. Mit dem Nittel- und Zeigefinger der rechten Hand folgt man der untern Fläche des Meso-colon, indem man 
sich segen dic Wirbclsäule richtet; ror dieser und unter dem Ifeso-colon fasst man mit den Fingern die Darmsehlinge, die man in den Schnitt bringt; es ist dies die Flexura duodeno-jejunalis oder besser die Pars prima jejuni. IIan folgt dieser Darmsehlinge, sie führt an die Pars ascendens duodeni; man entfernt die Dünndarmschlinge und studirt an der linken Wand der P'ar's aseendens die Recessus und Plicac peritoneales. Unmittelbar links von der Wirbelsäule sicht und fühlt man das Relief der linken Niere, welche an der lintern IVand des Abdomen gelagert ist; unter derselben gelangen clie Finger in die subrenale Aussackung, die unten ron der Erhabenheit der Crista jliaca begrenzt ist.

Das Colon iliacum liegt in der obern Ifälfte der linkien Fossa iliaca, beginnt im Niveau der Crista iliaca, wo cs in das Colon descendens übergeht und endigt am inneren Rande des Psoas, wo es in das Colon pelvinum übergeht.

Das Colon iliacum, eine IIandbreit lang, gewöhnlich von Faecalmassen frei, besitzt gewöhnlich die Form einer Röhre, die dicker als der Daumen ist. Es ist mit dem P'eritonenm, das die Fossa iliaca bedeckt, durch eine kurze Peritonealfalte, einem Mesocolon, rerbunden, welche gewöhnlich mehr als ein Finger hoch ist.

Technik z. A. d. G. Wenn man die vordere Wand des Abdomen niederdrïckt. palpirt man aufmerksam die linke Fossa iliaca; man fühlt rin consistentes und längliches Gebilde unter dem Finger gleiten, das Colon iliacum, das man sehr oft für einen Tumor halten kann. Zwei Finger oberhalh des Poupart'schen Bandes und diesem parallel sclıneidet man in cincr Länge ron 3-4 Fingern die Abdominalwand cin; man führt 2 Finger ein und folgt der hintern Wand der Fossa iliaca. In einem gegebenen Augenblicke begegnet man einer fixen Darmschlinge, die man in die Schnittwunde zicht, es ist das Colon iliacum und die Pars prima des Colon pelvinum. Ilan hat als Beleg die Appendices epiploicae, die an einer Dünndarmschlinge fehlen.

Ian macht am Colon iliacum den sogenannten Anus praeter-naturalis, indem man den Darm eröffnet, nachdem man ihn zuerst an den Sehnitträndern angenäht hat. Zieht man das, was innen rom Colon iliacum folgt, nach aussen, so nimmt man eine sehr lange mitunter enorme Darmschlinge, das Colon pelvinum heraus.

Das Colon pelvinum rom Professor Jonnesco, nach dessen Lage in der Beckenhühle so genannt, entspricht der Sygmoidal- oder Omegaschlinge oder noch dem S iliacum der alten Anatomen.

Es stellt jenen beweglichen Theil des Dickdarms dar, der oben und links am innern Rande des Psoas beginnt, wo er in das Colon iliacum übergeht und unten an der Medianlinie im Nireau des 3. Kreuzwirbels endigt, wo er in das Rectum sich fortsetzt. Die Länge des Colon pelvinum beträgt im Durchschnitt $30-40 \mathrm{~cm}$, übersteigt oft $50 \mathrm{~cm}$ und sehr oft habe ich das Colon $70-80 \mathrm{~cm}$ lang gesehen.

Das Colon pelvinum ist durch eine lange peritoneale Falte, Meso-colon pelvinum, festgchalten, welches wie ein Zelt oberhalb der Beckenhöhle gespannt ist. Die Insertion des Colon pelvinum geschieht längs des innern Randes des Psoas bis zum Niveau des IT. Lendenwirbels und von dort an einer Linie, die an der linken Seite des Y. Lendenwirbels herabsteigt; es kreuzt die Symphysis sacro-iliaca, verläuft in der Mitte der vordern Fläche des Kreuzbeins und endigt am III. Sacralwirbel. Diese Insertion geschicht in einer Linie in Form eines mit der Spitze nach oben gerichteten V. 
Im Insertionswinlel des Meso-colon existirt ein hornförmiges peritoneales Grübchen, der Recessus sygmoidalis, dessen Oeffnung unten und hinten von einer sichelförmigen Falte, andere Male durch ein wahres Diaphragma begrenzt ist.

Technik z. A. d. G. Man macht in der Medianlinie unter dem Nabel einen Bauchschnitt und führt die Hand in die Beckenhöhle ein; in der Douglas'schen Aussackung an der vorderen Fläche des Sackes findet man eine Darmschlinge mit dicken Wänden, die man nach aussen zieht, es ist das Colon pelvinum.

Zahlreiche Appendices epiploicae entstehen in zwei Reihen an jeder Seite der äussern Fläche des Darmes.

Man studirt das Colon pelvinum und sieht wie lang und dick es ist; unter seiner tiefen Fläche sucht man den Recessus sygmoidalis.

Fig. 181.

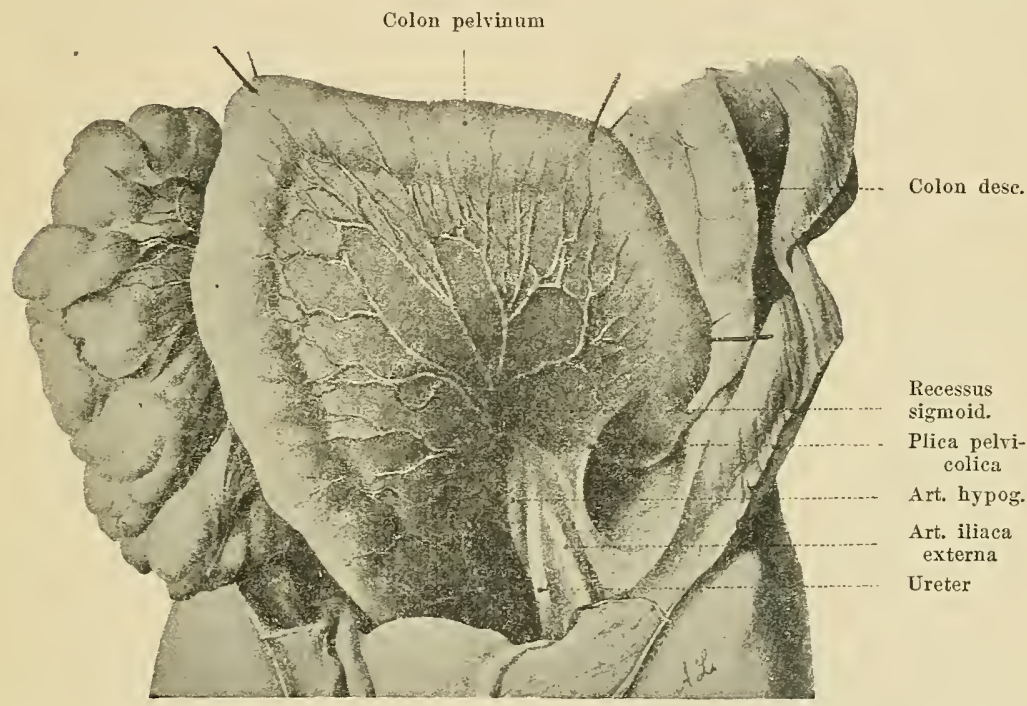

Das von Prof. Jonnesco benannte Colon pelvinum (S romanum oder Sigmoidalschlinge). Das Colon pelvinum wird von drei Haken nach oben gezugen.

Die Nieren, Renes, liegen an jeder Seite der Erhabenheit der Wirbelsäule an der hintern Wand des Thorax und des Abdomen. Ein peritoneales Blättchen zieht vor denselben, ihre vordere Fläche bedeckend; sie sind daher subperitoneale oder extraperitoneale Gebilde.

Das Skelet der Nierenregion wird von den beiden letzten Brustwirbeln mit der XI. nnd XII. Rippe und vom Körper und Proc. transversus der drei ersten Lendenwirbel gebildet. Unter den Rippen vervollständigen die Ligamenta costo-transversa und Ligamenta costiformia das Skelet.

Jede Niere liegt auf einem Muskelpolster, welches oben rom Diaphragma und von innen nach aussen rom Psoas, vom M. quadratus lumborum und ron der Fascie des Transversus gebildet wird:

Der letzte Intercostalnerv mit der begleitenden Arterie folgen dem untern Rande 
der letzten Rippe; der Plexus lumbalis liegt unter dem l'soas, zwischen diesem und der vordern Fläche des M. quadratus femoris.

Der kleine und grosse Nerrus genito-abdominalis richten sich mit den Arteriae lumbales, die sie begleiten, nach unten und aussen unter dem äussern Rande der Niere und dringen in die Abrominalwand ein; der Genito-cruralis zieht auf dem rordern Rand des Psoas nach abwïrts.

Für die rechte Niere entspricht das obere linde dem untern Rande der NI. Rippe und das untere Ende dem III. Proc. transversus lumbalis.

Die linke Nicre ist etwas melı gehoben, ihr oberes Ende entspricht dem obern liande der XI. Ripje und las untere Ende dem obern Rande des III. Proc. transversus lumbalis. Die Beziehungen der vordern Fläche sind verschieden links und rechts.

Rechts ist die vordere liäche der Niere lurch einen Ilügel, der schief vom obern Ende gegen den mittlern Theil des äussern Randes gerichtet ist, getheilt. Die obere regelmässige convexe I'artie steht mit der hintern Flächo des Lobulus rectus hepatis in Beziehung, der sie auch eine Rinne, die Fossula renalis, cingräbt und ron welcher sie durch einen peritonealen Blindsack getrennt ist, weil das peritoneale Blätțchen, nachdem es die Niere bedeckt hat, sich abliegt und die Leber bedeckt.

Oft ist eine peritoneale Falte zwischen Leber und Niere gespannt, das Ligamentum hepato-renale, eine Fossula hepato-renalis begrenzend.

Die untere Partie ist durch die Insertion des Meso-colon ascendens in zwei Theile getheilt.

Die beiden äussern Drittel stehen mit der Plica sub-hepatica des Colon ascendens in Bezichung; das innere Drittel mit der Pars descendens luodeni, welche ror dem Hilus der Niere zwischen diesem und der Vena cava inferior gelagert ist.

Links theilt die Insertion des Meso-colon transversum die vordere Fläche der Niere in zwei Partien: 1. Die obere Partie, Portio supra-meso-colica, ist ron einem peritonealen Blättchen bedeckt, welches die hintere Wand der hinter dem Magen befindlichen Höhle bildet. Diese Partic steht aussen mit der Milz, ron welcher sie durch eine peritoneale Aussackung getrennt ist, in Beziehung, denn das Peritoneum bildet cine Falte, nachdem es die Niere bedeckt hat und bekleidet dic hintere Fläche der Milz. Innen steht die rordere Fläche der Niere mit der hintern Wand des Hagens und unten mit dem Pankreaskopfe in Beziehung, oberhalb dessen man die Arteria und Vena lienalis findet; 2. Die untere Partie oder Portio sub-meso-colica hänt, rom Peritonem bedeckt, frei in der Abdominalhöhle, sie steht mit den Dünndarmschlingen in Beziehung, welche nach rechts gedrüclit werden müssen, um die Niere freizulegen.

Die Pars ascendens dnodeni liegt an der vordern und linken Fläche der Wirbelsïule und ist ron der Niere durch eine Art verticale Mulde, welche dem Ililus der Niere entspricht, getrennt.

Der Angulus sublienalis des Colon transversum und Colon descendens liegen in der Furche, die der äussere liand der Niere mit der Abdominalwand bilden; das Colon descendens ist in dieser Lage durch ein sehr kurzes Meso festgrehalten.

Die Arteria colica superior sinistra kreuzt die vordere Fläche der Niere, vor welcher sie sich in cinen liamus ascendens und einen Ramus descenilens theilt.

Die Richtungen der pleuralen Aussackungen sind rechts und links durch eine linie angezeigt, welche den obern Theil des I. Lendenwirbels mit einem Punkte der XII. Rippe verbindet, der handbreit von der Medianlinie gelagert ist.

Die obern Enden der Nicre sind wie mit einer llaube ron der Basis der Nebennieren bedeckt, dic theilweise auf die vordern Flächęn und ihren innern Rändern herabsteigen. Der obere Theil des innern liandes der rechten Nicre steht nit der Vena cava in- 
ferior in Beziehung, oder besser mit dem Winkel, den diese mit der Vena renalis bildet, mit dem Winkel, welcher der Niere eine Rinne eingräbt.

Unter dem Hilus steht der innere Rand der Niere mit dem Halse des Nierenbeckens und mit der ersten Partie des Ureters in Beziehung. Die Nieren sind jede einzelne in einem zellig-fibrösen Beutel, der Capsula fibrosa, enthalten, die durch Theilung des subperitonealen Blattes entsteht. Eine Fettschichte befindet sich zwischen Niere und Capsula fibrosa, die Capsula adiposa.

Technik z. A. d. G. Man legt den Cadaver auf eine Seite und tastet die Regio lumbalis ab; man sucht oben die beiden letzten Rippen, unten die Crista iliaca und innen die Proc. transversi auf. Man macht der letzten Rippe parallel eine Incision, welche 4 Finger vor der Medianlinie etwas unterhalb der Rippe beginnt und an der Crista iliaca endigt. Man schneidet die Haut, den Latissimus dorsi durch und schneidet transversal am äussern Rande der gemeinsamen Muskelmasse ein; man ge-

Fig. 182.

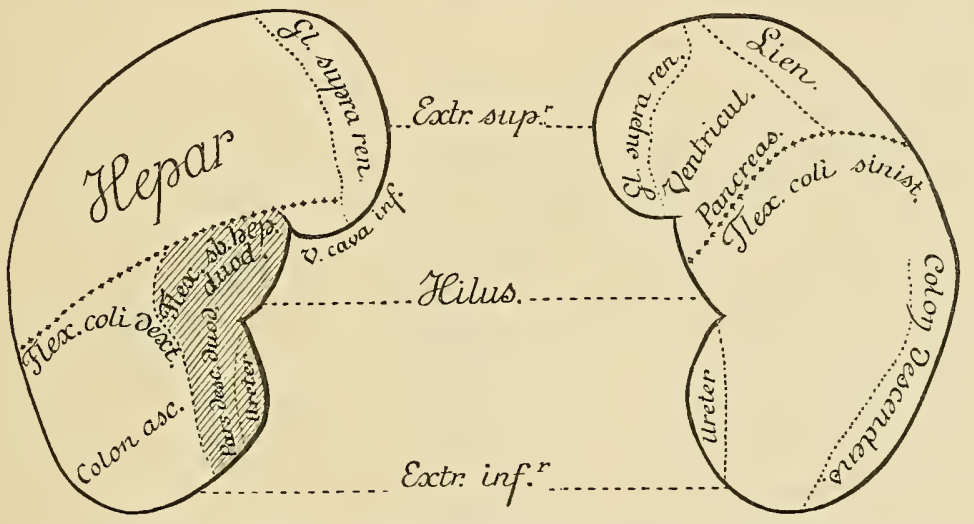

Die Figur zeigt in schematischer Weise die Beziehungen der Nieren. Die gestreifte Partie der vorderen Kläche der rechten Niere entspricht dem Zwölffingerdarme.

langt an den schief nach unten gerichteten äussern Rand des Quadratus lumborum, unter welchem der grosse und kleine Nervus genito-abdominalis austreten, die man durchschneidet.

Man tastet den Grund des Schnittes mit den Fingern ab und fühlt einen verlängerten halbkugelförmigen Körper von einer eigenartigen Consistenz, die Niere, die man noch besser fühlt, wenn ein Assistent sie in den Schnitt drückt, indem er mit der Hand die vordere Wand des Abdomen niederdrückt. Mit den Fingern und Pincette löst man die Niere von der Fettschichte, die sie umgiebt, ab und zieht sie nach aussen aus dem Schnitte, man sieht, dass sie nur an den Gebilden ihres Hilus hängt. Mlan fasst den Hilus zwischen den Fingern und die Niere in der Palma haltend, schneidet man vertical ein, indem man sie in zwei Hälften theilt; man tastet das Nierenbecken ab und mit einer dünnen Sonde catheterisirt man den Ureter. 
Wenn man ein Messer in den letzten Zwischenrippenraum drei Finger von der Medianlinie einsticht, so durehzicht es von der Oberfläche zur Tiefe: die Thoraxwand, den Pleuralsack, das Diaphragma und dringt damn in den obern Rand der Niere ein.

\section{Der Uterus.}

Die Gebärmutter nimmt den mittlern Theil der Beckenhöhle ein zwischen der unten und vorne liegenden Blase und zwischen dem liectum, welches oben und hinten sich befindet. Nach unten setat sich dieselbe in dio Scheide fort, welche lireisförnig rings um diese sich inserirt. In jeder Seite ist sie mit den lateralen Wänden des Beckens durch je eine Peritonealfalte - die Ligamenta lata -.- rerbunden.

Der Uterus stellt zwei getrennte Partien, sowohl rom anatomischen, pathologischen, als auch chirurgischen Gesichtspunkte aus dar: eine obere Partie, den Körper, und eine untere, den lIals, welche durch eine intermediäre verengte Partie, den Isthmus, rereinigt sind.

Der Hals ist durch die Insertion der Scheide in drei Partien getheilt: eine freie in den Grund der Scheide vortretende Partie, Portio raginalis, eine mittlere, an welcher die Scheide sich inserirt und endlich eine obere Partie oder Portio supra-raginalis. Im normalen Zustande bildet der Förper mit dem Halse einen nach unten und vorne otlenen Winkel.

Das Peritoneum schlägt sich, nachdem es die hintere Fläche der Blase bedeckt hat, blindsackförmig, als utero-vesicale Aussacliung, auf die vordere Fläche des Uterusliörpers zurück, gelangt dann, nachdenı es den Grund bedeckt hat, auf seine hintere Fläche, geht etwas auf die Scheide über und schlägt sich dann nach oben auf das Rectum, indem es eine tiefe Aussackung - die retro-raginale Aussackung oder den Douglas'schen Raum bildet. Es folgt daraus, dass das Peritoneum die vordere und hintere Fläche der Gebärmutter ungleichmässig bekleidet; während das Peritoneum vorne nur die vordere Fläche des Körpers bedeckt, bekleidet es hinten sowohl den Körper als auch die Portio supra-raginalis des Halses, unmittelbar nachdem es auf die Scheide übergeht.

Die Ligamenta lata sind zwei Peritonealfalten, welehe an jeder Seite des Uterus gespannt sind. Jedes Band hat die Form eines Quadrates. Der innere Rand inserirt sich am lateralen Rande đer Gebärmutter, wo die beiden Peritonealblättchen, welche es zusammensetzen, sich fortsetzen, das eine auf die vordere Fläche, das andere auf die lintere Fläche d̉erselben.

Der äussere und untere Rand geht in das Peritoneum über, welches das Beclien auskleidet. Der obere Rand ist am Strange, den das runde Mutterband bildet, gespannt.

Das Ligamentum rotundum ist ein muskulöser Strang, der zwischen dem Uterushörper und dem Fettgewebe der grossen Lefze gespannt ist, wo er sich verliert. Es stellt drei Partien dar: eine abdominale, welche zwischen dem Uterusliörper und dem Orificium peritoneale des Leistenkanales sich befindet, ferner eine interstitielle, die im Leistenkanale enthalten ist und endlich die dritte oder labiale Partie. Das runde Mutterband wird ron einer kleinen Arterie, ron mehreren Venen und einem Lymplkanale beglcitet.

Von der hintern Fläche des breiten IIutterbandes entstehen zwei secundäre Falten: die obere, dünne, dreiseitige, das Meso-metron, enthält in ihrem freien Rande einen runden, 
starken, musculös-membranösen, consistenten Kanal, die True. Diese setzt sich nach innen in den Uteruskörper fort, aussen endigt dieselbe durch eine gerunzelte Partie mit knospenartigen Faltungen, die Ampulle. Unter dem Meso-metron entsteht die zweite Falte, das Mesovarium. Letzteres inserirt sich hinten am obern Rande des Eierstucks, aussen verliert es sich am Peritoneum des Beckens durch eine Fortsetzung, in welcher die Ovarialgefässe enthalten sind: die Arteria ovarica, die zahlreichen plexusartig mit einander anastomosirenden Venen und Lymphgefässe.

Die Arteria ovarica entsteht aus der Aorta unterhalb der Nierenarterien. Links adhärirt das Mesorarium mit dem Mesocolon pelvinum mittelst einer Falte, welche Liga-

Fig. 183.

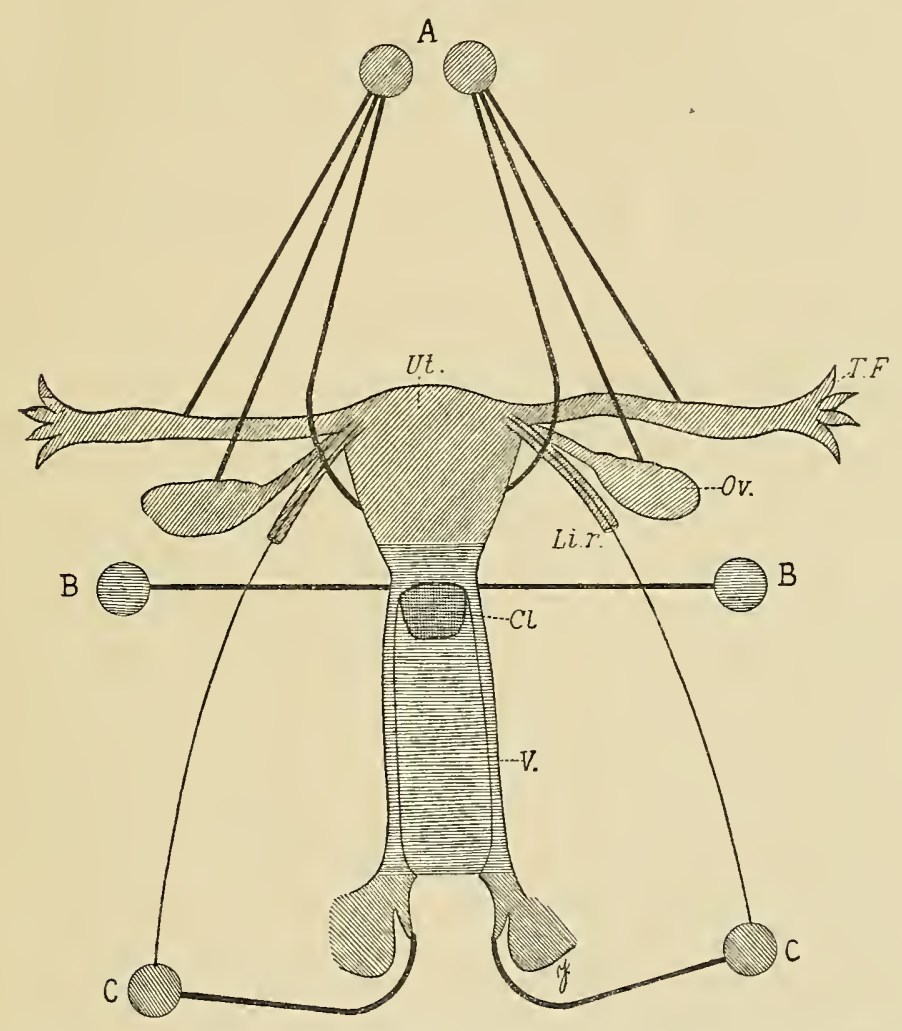

Die schematische Figur zeigt die Vertheilung der Lymphgefässe der weiblichen Geschlechtsorgane. A die lumbalen Lymphdrüsen, welche die Ljmphcanäle aus dem Uteruskörper Ut., aus dem Ovarium Ov. und aus der Tube T. F. aufnehmen. Die Lymphgefässe des Uterushalses Cl. gehen in die Glandulae hypogastrieae B, die der Vulva in die innere Gruppe $\mathrm{C}$ der Inguinaldrüsen ein, welche gleichzeitig einen lymphatischen Kanal längs des runden Mutterbandes von den Hörnern des Uteruskürpers aufnehmen.

mentum ovario-colicum genannt wird. Die Lymphgefässe gehen in die Lymphdrüsen ein, welche die vordere Fläche der Wirbelsäule zwischen den unteren Enden der Nieren einnehmen, Glandulae lumbales. Diese Lymphdrüsen werden bei Krebs des Gebärmutterkörpers ergriffen, während bei Krebs des Cervix uteri die ersten inficirten Drüsen die 
flandulae lymphaticae hypogastricae sind, welche zwischen den Aesten der gleichnamigen Arterie gelagert sind.

Den untern Rand des breiten Mutterbandes nehmen die Arterie und die Venen der Gebärmutter und der Ureter ein. Diese Partie hat eine besondere Bedentung für den Chirurgen, wenn man die Exstirpation der Gebärmutter von der Scheide oder dem Abdomen aus rornehmen will.

Die Arteria uterina entsteht ans der Mrteria hypogastrica und richtet sich nach unten, vorne und innen, inden sie zunächst dem untern Rande des breiten llutterbandes, dann dem Uterusrande folgt. Sie stellt drei getrennte Partien dar: eine untere Partie, die im untern Rande des breiten Mutterbandes in einer zellig-fibrösen Scheide, aus der Taeca hypogastrica stanmend, enthalten ist, eine mittlere, hakenförmig gebogene, welche der seitlichen Aussackung der Scheide entspricht, endlich eine bewegliche Endpartie, die Begleiterin des Randes des Uteruskörpers. Diese Partie giebt zahlreiche $\Lambda$ este ab, welche an zwei Reihen, wie die Zähne eines liammes entstehen. Die mittlere Partie giebt überdies Aeste für die Scheide, für die Wand derselben und Cervicaläste für den IIals des Uterus ab.

Der Ureter zieht unter der Arteria uterina $2-21 / 2 \mathrm{~cm}$ ungefähr ron der Gebärmutter entfernt.

Technik zum Freilegen der Gebärmutter. Nan eröffnet das $\Lambda$ bdomen in der Medianlinie rom Nabel bis zum Schambeine. Man erweitert die Schnittränder, indem man zwei breite stumpfe Haken einlegt. Man drückt den Dünndarm mit einem Schwamm nach oben und sieht dann den Uteruskörper auf der Blase gelagert und bemerkt auch, dass die Gebärmutter sehr verschieblich ist und sehr leicht nach vorne, hinten und seitwärts bewegt werden kann. Mit einer Pincette fasst man die Gebärmutter am Grunde und zieht diese so weit als möglich nach aussen rom Becken. In jeder Seite spannen sich zwei Peritonealfalten an, die breiten Mutterbänder. Man bemerkt, dass die breiten Mutterbänder und die Gebärmutter eine transversale Wand bilden, welche das Becken in zwei Räume scheidet: der eine vortere vesicale enthält die Blase, der andere hintere tiefere und breitere enthält das Rectum und das Colon pelvinum (Flexura sigmoidalis). Vorne ist der resico-uterine Zwischenraum blindsackförmig durch das Peritoneum geschlossen, welches von der Blase auf die Gebärmutter sich zurückschlägt. Lässt man die Fingerbeere des Zeigefingers von oben nach unten auf der hintern Fläche der Gebärmutter gleiten, so gelangt dann der Finger, indem er über die resistente Fläche der Gebärmutter zieht, in der Tiefe an eine weiche Fläche, an die Scheide. In diesem Niveau macht man mit der Scheere einen Querschnitt, eröffnet auf diese Weise den hintern Blindsack der Scheide und fühlt mit der eingeführten Fingerspitze den Gebärmutterhals.

Man sucht am obern Rande des breiten Mutterbandes das runde Mutterband auf, las gleichsam wie ein Strang sich anfühlt.

Hebt man von der hintern Fläche des breiten Mutterbandes die Tube ab, so sieht man, dass sie von einer dreieckigen Falte, dem Mesometron festgehalten wird. Unter der Tube sieht man in der Form eines oblongen Körpers ron warzenartigem Aussehen das Orarium. Man sieht, dass dieses von einer Falte aufrecht gehalten wird, ron dem Mesovarium, und einem peritonealen Grübchen entspricht, das wir Fossula orarica nennen. 
Um die Gebärmutter sorgfältiger studiren zu können, muss man sie gleichzeitig mit den breiten Mutterbändern herausnehmen. Man spannt deshalb das rechte breite Mutterband, bringt an den Gefässstiel des Eierstocks eine Pincette an und durchschneidet mit der Scheere oberhalb derselben; man schneidet dann das rechte IIutterband durch. Dann nimmt man das breite Mutterband zwischen die Finger und durchschneidet es schief gegen den Rand des Gebärmutterhalses. Nahe an der Gebärmatter sieht man die Arteria uterina und die sie begleitenden Venen. Man durchschneidet diese oberhalb einer Pincette, zieht kräftig die Gebärmutter hervor und eröffnet, indem man vertical an ihrem Rande schneidet, die Scheide, welche man rings um den Hals schneidet. Man fasst dann den Hals mit einer gezähnten Pincette und zieht ihn nach oben. Man sucht und findet auch auf der entgegengesetzten Seite des Halses die Arteria uterina sinistra, welche oberhalb einer Pincette durchschnitten wird, und durchschneidet dann von innen nach aussen das breite Nutterband. Am Stiele des Eierstocks angelangt, legt man eine Pincette an und durchschneidet oberhalb derselben. $\mathrm{Zu}$ bemerken ist, dass man die Gebärmutter in ihrer Gesammtheit exstirpiren konnte bei Gebrauch von nur vier Pincetten, weil die Gebärmutter und ihre Anhänge in der That jederseits von zwei Arterien versorgt werden, von der Arteria ovarica und Arteria uterina.

Man eröffnet die Gebärmutterhöhle und bemerkt, dass die Höhle des Körpers von vorne nach hinten verbreitert und von einer glatten Schleimhaut bedeckt ist, während die Scheimhaut des Cervix wie ein Federbart gefaltet ist, der Lebensbaum. Man spannt das Mesotron und untersucht es im durchfallenden Lichte; man sieht, dass es von einem eigenen Organe eingenommen wird, welches aus einer kammförmigen Röhre gebildet wird, das Rosenmüller'sche Organ.

Das rmde Mntterband in Leistenkanale. Man sucht das Schambein auf und macht von diesem beginnend an der vorderen Wand des Leistenkanals eine 3 Finger breite Incision. Nan durchschneidet die Haut und die subcutane Schichte und gelangt an die weissen und glänzenden Fasern der Fascie des Obliquus major. Mlan sucht nun das Orificium subcutaneum oder pubicum des Leistenkanals auf, führt durch dasselbe eine Hohlsonde ein und durchtrennt auf derselben die Fascie des Obliquus; man findet darunter von Fett umgeben einen mehr oder weniger dicken Strang, der zuweilen in mehrere Bündel aufgelöst ist, es ist das runde Mutterband. Es wird mit einer Pincette gefasst. Man eröffnet das Abdomen oberhalb des Schambeins und fasst den Gebärmutterkörper zwischen den Fingern. Zieht man nun die Pincette, welche das runde Nutterband fasst, so sieht man Letzteres sich verlängern und aus der Bauchhöhle austreten zur selben Zeit, wenn auch die Gebärmutter herausgehoben wird, nach vorne gebogen und der $\mathrm{Ab}$ dominalwand genähert ist.

Die danernde Verkürzung der runden Iutterbänder rom Leistenkanale aus als Behandlung der Retroflexion des Uterus führt den Namen der Alexander'schen Operation.

Arteria uterina. Man macht einen medianen Bauchschnitt oberhalb des Schambeins und legt im untern Winkel des Schnittes einen stumpfen Haken ein. Man fasst dann mit den Fingern die Gebärmutter und zieht sie nach aussen. An den Rändern der Gebärmutter sieht man die Arteria 
uterina durclischeinen und wenn man den Rand des breiten Iutterbandes \%wischen den Fingern gleiten lïsst, fühlt man die Arterie in Form eines Stranges.

Jlan sehneidet das l'eritoneum an der vordern Fläehe der Gebärmutter nahe der utero-resicalen Aussackung cin, indem man den Schnitt $1-2 \mathrm{~cm}$ rom Gebärmutterrande verlängert. Ilit dem Finger drückt man den untern Rand des Peritonealschnittes nach unten, legt die rordere Fläche der Gebärmutter frei und sieht an jeder Scite ihres Randes die weissen Streifen der Arteria uterina; man legt sie mit der Sonde frei und führt unter dieselbe die Conper'sche Nadel. Man kam auch die Arterie bei ihrem Alogange aus der Hypogastrica freilegen. Zu diesem Zwecke hebt man den Eierstock aus seiner Lage heraus und schneidet das Peritoneum etwas hinten von dem hintern Rande des Ureters ein; man gelangt an die Hypogastrica. Ton ihr abgehend findet man die Arteria uterina, wolche sich nach rome gegen den Rand der Gebärmutter richtet, indem sie oberhalb des Ureters zicht. Man bemerkt, dass die Arteria uterina zuweilen direct aus der Hypogastrica entsteht, andere Male mit der Arteria umbilicalis mittelst eines gemeinsamen Stammes.

Ilan kann die Arteria uterina mit der Arteria obturatoria nicht verwechseln, weil Letztere an der Wand des Beckens ummittelbar unter dem Nervus obturatorius angelöthet bleibt.

Arteria iliaca rommunis. Die Aorta abdominis theilt sich im Nireau der untern Partie des dritten Lendenwirbels oder auch im Nireau des Meniscus, welcher diesen W'irbel mit dem rierten rereinigt, in zwei Endäste, Arteriae iliacae communes. Diese richten sich schief nach unten und aussen, indem sie sich unter einem spitzen Winkel ron einander entfernen. Nach einem Yerlaufe ron $4-5 \mathrm{~cm}$ theilt sich wieder jede Arterie in zwei Aeste: in einen vordern, Arteria iliaca externa und in einen tiefen Ast. Arteria profunda oder hypogastrica.

Das Nirean, in dem die Theilung der beiden Iliacae communes geschieht, wechselt mit der Höhe des 5. Lendenwirbelkörpers. Die Theilung geschieht bald ror dem Meniscus, welcher den 4. Lendenwirbel rom 5. scheidet, bald ror demjenigen, der den 5. Lendenwirbel rom Kreuzbeine trennt.

Die Arteria iliaca externa folgt dem innern Rande des Psoas, indem sie die Richtung der Arteria iliaca communis gegen das Poupart'sche Band fortsetzt. Die Arteria bypogastrica dringt in das Becken. Torne sind die Iliacae communes rom Peritoneum bedeckt. An der äussern und etwas an der hintern Fläche der Iliaca communis dextra angelöthet findet man die gleichnamige Vene. Die Vena iliaca communis sinistra kreuzt schief die hintere Fläche ihrer Arterie, gelangt an die innere Fläche, zieht unterhab der fliaca communis dextra und rereinigt sich mit der Vene dieser Seite, indem beide die Tena cava inferior bilden.

Im Winkel, der an jeder Seite ron der Iliaca communis begrenzt wird, siebt man oben unter dem Theilungswinkel der Aorta am Lendenwirbelkörper gelagert die Vena iliaca externa sinistra ron der Dicke des Daumens. In der Nedianlinie und die Wirbelkörper kreuzend steigt die Arteria sacralis media, die aus dem Endstïcke der Aorta entsteht, herab und zieht unter der Vena jliaca communis sinistra.

Technik z. A. d. G. Wie bereits erwähnt, bezeichnet der Nabel an der Haut dasjenige Nircau, in dem die Aorta in die beiden Iliacae com- 
munes sich theilt. Ian eröffnet die Bauchhöhle durch einen Schnitt, der fingerbreit oberhalb des Nabels beginnt und 3 Finger ungefähr unter demselben endigt. Nlan entfernt den Darm ron der Medianlinie, indem man diesen nach oben und seitwärts abzieht. Durch das Peritonealblatt sieht man das weissliche Relief, welches die Arterien bilden. Sieht man einer zu reichlichen Fettschicht megen die Arterien nicht, so tastet man mit den Eingern an jeder Seite der Medianlinie die rordere Fläche der Wirbelsäule ab und man fühlt dann fast immer die Arterien in Form dicker elastischer Stränge. Yit einer gezähnten Pincette hebt man das Peritonealblatt in Form einer Falte ab, die mit der Scheere durchtrennt wird. Man folgt mit der Sondenspitze dem Peritonealschnitte nach oben und unten. Man sucht der Reihe nach unter jedem peritonealen Schnittrande und findet dann die beiden Arterien, die man mit der Sondenspitze freilegt. Ian gehe vorsichtig vor, damit dic sehr dicken Tenen, die sie begleiten, nicht zerrissen oder angeschnitten werden. In der Medianlinie am 5. Wirbelkörper findet man die Arteria sacralis media, die ron zwei Tenen begleitet wird. Wenn der Cadarer sehr fett ist, so verlängert man den Bauchschnitt oder besser noch man öffnet weit das Abdomen, indem man einen Kreuzschnitt macht.

Arteria iliaca interna oder hypogastrica. Wie wir gesehen haben, theilt sich die Iliaca communis in die Arteria iliaca externa, die gegen die nntere Extremität sich richtet und in die Art. hypogastrica, die in die Beckenhöhle herabzieht. Die Arteria hypogastrica rerläuft fast vertical und ist ron der Arteria iliaca exierna durch einen nach unten offenen spitzen Winkel getrennt. Tach einem $1-2 \mathrm{~cm}$ langen Verlaufe theiIt sie sich gewöhnlich in zwei Stämme. Der hintere und äussere Stamm, Truncus lumbo-glutaeus, löst sich in die Arteria lumbo-iliaca und Arteria glutaea auf. Die Arteria lumbo-iliaca rertheilt sich mit dem Ramus iliacus in der obern Partie der Fossa iliaca und mit dem Ramus lumbalis durchdringt sie den Zwischenranm, der rom Processus transrersns des 5 . Lendenwirbels und der Crista iliaca begrenzt ist, nnd rertheilt sich in den Rïckenmuslieln.

Ans dem Truncus ileo-Iumbalis entsteht sehr oft die Arteria gIntaea lateralis, welche auf der concaren Fläche des Kreuzbeins längs der Kreuzbeinlöcher herabsteigt, in deren Niveau sie auch Aeste abgiebt. Diese Arterie kann auch aus der Arteria glutaea entstehen.

Die Arteria glutaea dringt in den Ninkel, der rom Nerrus sacro-lumbalis und dem ersten Sacralnerven begrenzt wird, tritt aus dem Becken aus, indem sie den oberu Rand des Foramen sacro-iliacum kreuzt, zieht oberhalb der fibrösen Schlinge, an welcher sich die Fasern des Prriformis inseriren, und rertheilt sich in den Gesässmnskeln.

Der rordere und innere Zweig theilt sich sofort in ein Büschel ron Aesten, ron denen sich einige in den Organen des Kleinen Beckens (die Arteria resicalis, Art. uterina. Irt. haemorhoidalis) rertheilen, andere wieder treten nach einem mehr oder weniger langen Terlanfe aus dem Beclen aus (Art.obturatoria, Art.pudenda int. und Art.ischiadica).

Der erste Ast, der ron oben nach unten entsteht, ist die Arteria umbilicalis: die beim Foetus und Errachsenen eine rerschiedene Bedeutung hat. Beim Foetus ist diese Arterie bedeutend, beim Errachsenen obliterirt sie zum grössten Theile, indem sie in einen fibrösen Strang umgebildet wird, welcher das Ligamentum Iaterale der Blase bedingt. - Tom hintern Theile der Arteria umbilicalis, der durchgängig geblieben ist, entsteht die Arteria vesicalis posterior. 


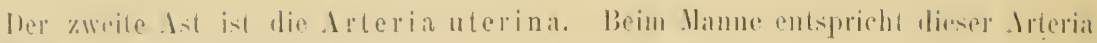
lie Arteria prostatica seminalis.

Den dritten Ast bihlet die Arteria obturatoria, welche sich gegen den C'analis subpubiens richtet und diesen durcharingt, un sich in lem 11 obturator ext. und ()bt. int. und im oberen 'lheile der Ahluetoren zon vertheilen. Diese anastonosirt mit den oheren Jesten der Arteria femoralis profunda.

Es entstehen fermer die Irteriae hiemorrhoidales meiliae und andere kine deste, welele für das fiewehe les Beckens bestimm sind. Dip letzten Leste des vordern und immern Stanmes der Arteria hypogastrica sim die Arteria pudenda interna und lie Irteria ischiarlica. Die erstere anch vordere durehdringt den untern Theil des Foramen sacro-ischialicum, zieht üher die innere liäche der spitze des Plexus sacralis, umsehlingt die Spina ischiadia, dringt dureh das Foramen sacro-ischiddienm minus und richtet sich nach rorne, indem sie der inmern l, fze des untern Randes des Ramus ischio-pubicus les Dambeines bolgt: sie ist in einer aponemotischen frlecile enthalten, welche die nittlere Fascie des l'erinem billet. Die zweite, lie Ireria ischiatica, durchzicht lis Foranen sacro-ischialicum etwas hinter der Irteria pulenda. verläuft hinter dem Plexus sacralis oder zwischen den Wureln desselben und steigt längs des Nervo ischia„licus herab, nachdem sie vorher einige \%weige für den Glutacus maximus und für die Regio sacro-coreygra abgegeben hat. - Die Arteria hypogastrica ist an der Wand iler Beclienhöhle gelagerl, ron der sie zuerst dureh die Vella iliaca externa geschichlen ist, welche an der lnssenseite lep Arterie zirht. mu sich hinter lerselben mit der Venat

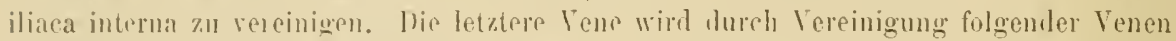
gebildet: I. resicalis, I. uterina beim Weile, I. prostatiea-seminalis beim Manne, I.

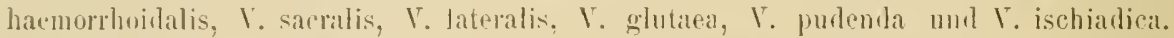
Innen sinul sowohl die Arteria als auch lie lena hypogatstrica rom l'eritonem bedeclit, welches aus der Fossa iliaca anstritt und wie anf einem strange lings der Arteria iliara communis umb externa sich filtet.

Der Ureter ist unmittelhar unter den P'eritonem uplagert, steigt etwas immen vom ler Arterie herah. Beim lleilie lefindet sioh ror der Arteria bypogastrica mol dem

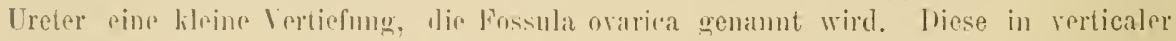
Richtung ohlonge Verlicfurg wird nach oben um hinten von der Arteria lypogastrica und rom limer, nach unten uml rorne ron der Insertion des ligamentum latmm, vorne von den lielief der Arteria ilian communis hegrenzt. Unter lem Peritoneum, welches diese Vertiefung auslileiclet, linlet man ron rorne nach hinten die Vena iliaca externa, den Tervus mol die Arteria obturatoria.

Terhnik \%. A. A. (x. Jan sehneilet das Mbdomen in der Medianlinic zwei Finger unler dem Nahel begimnend bis zum Schambeine ungefähr ein. Ian entleert die Beckinhö̈l]e ihrer Dünndarmschlingen, welehe man mit cincr oder zwei in das Abrlomen gebrachten sevietten nach oben festhält Man sucht unter dem l'ritoneum an Rande der lieckenhöhle einen weisslichen Strang, der in das Becken dringt, auf, es ist der Lreter. Sehr oft ist der l'reter sichtbar. Gicht man diesen nicht, so kann man ihn fühlen, inden man den innern Rand des Beckens leicht abtastet oder besser noch, wenn man das Peritoneum in Form einer Falte zwisehen den Fingern fasst: im Innenranm fïhlt man einen festen Strang. Der Ureter ist der Ausangspunkt für dic Auftindung iler Arteria hypogastrica, demn man findet liese unmittelbar unter jenem. Man schneidet das Peritoneum dem hintern Rande des Ureter parallel ein in der Weise, dass 
man mit einer Pincette eine Peritonealfalte abhebt und diese mit einer Scheere durchtrennt, damit die Spitze des Messers zu tief eingeführt die Arterie nicht verletzen soll. Man folgt nun dem Peritonealschnitte, indem man mit der Sondenspitze nach oben und unten durchreisst. Unmittelbar unter dem Peritoneum sieht man den weisslichen Streifen der Arterie. Man löst diese sorgfältig ah, weil sie ja ron dicken Tenen umgeben ist, und führt dann unter diese einen Haken ein. Um auch sicher überzeugt zu sein, dass man die Arteria hypogastrica und nieht die Arteria iliaca externa aufgefunden hat, so suche man etwas oberhalb und mehr innen, wo man die Iliaca externa finten würde. Man folgt der Arteria hypogastrica nach unten, indem man mit der Sondenspitze das sie umgebende Gewebe entfernt, und man sieht, dass sie sich in Aeste auflöst; es ist dies ein weiterer Berreis, dass die aufgefundene Arterie nur die Hypogastrica sein kann.

Wenn man auf der linken Seite die Aufsuchung ausführt, damn wird man einige Schwierigkeiten haben wegen des Colon pelrinum (Sigmoidalschlinge). Van hebt diese Darmschlinge heraus und drückt sie in die Fossa iliaca, wo sie mit ciner Serriette festgehalten wird. Man sucht wie früber den Treter anf. Wem man an einem weiblichen Cadaver operirt, muss man das Orarium nach rorne oberhalb des Ligamentum latum bringen. Ian untersucht dann die Fossula ovarica und sucht am obern und hintern Rande derselben den weisslichen Strang des Ureter auf. Tenn das Mesocolon pelvinum zn kurz ist oder wenn seine Insertion zu sehr absteigt und auf diese Weise den Ursprung der Art. hypogastrica verdeckt, so kann man dann diese Arterie, durch das Mesocolon suchend, auffinden.

Nan wiederhole ofi das Aufsuchen der Hypogastrica, es ist dies eine Operation, der man sich zuweilen bei chirurgischen Eingriffen wird bedienen kömmen, wenn man z. B. eine temporäre Unterbindung ausführen will im Falle einer Exstirpation rom Abdomen aus des mit Krebs infiltrirten Rectum oder auch wenn man eine Atrophie eines Uterusfibroms herbeiführen will, das man sonst unmöglich exstirpiren kanı oder auch um den reichlichen Blutverlust zu verhindern, weleher bei ausgedehnten Krebsen des Uterushalses eintritt. 
$\therefore$ (2)

Gedruckt bei L. Schumacher in Berlin.

ब) त्र 



COLUMBIA UNIVERSITY LIBRARIES

This book is due on the date indicated below, or at the expiration of a definite period after the date of borrowing, as provided by the rules of the Library or by special arrangement with the Librarian in charge.

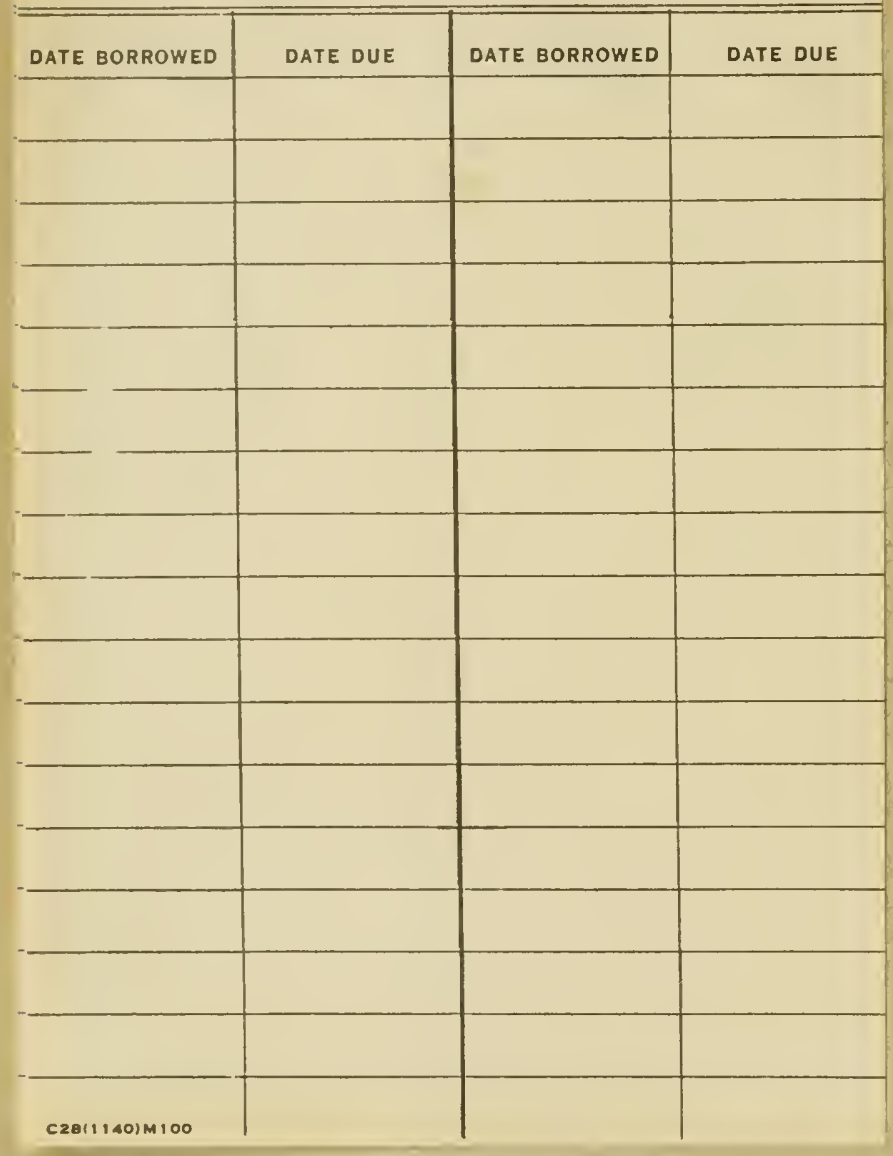


QM531

Juvara

$J 98$ 
